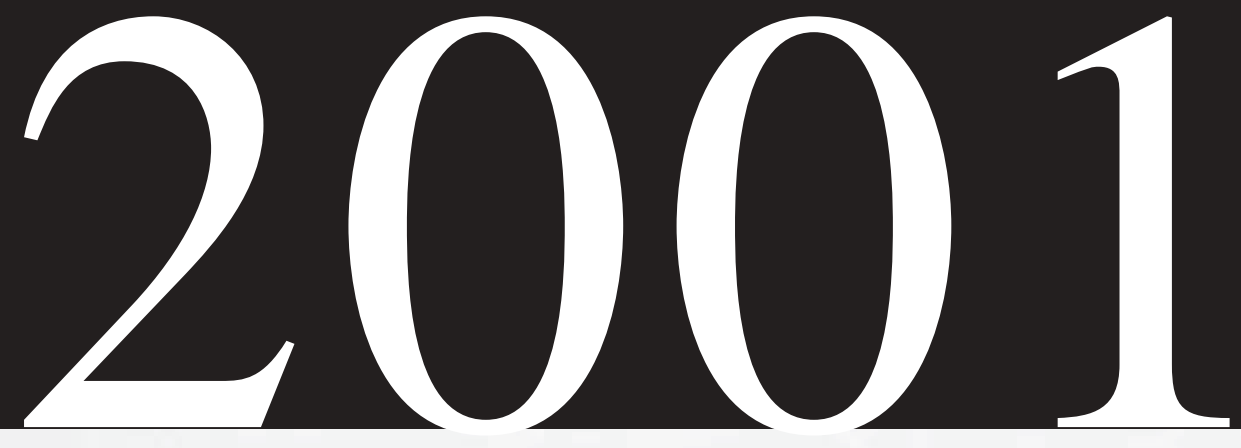

\title{
SITE ENVIRONMENTAL REPORT
}

Nature's perfect balance,

we cannot throw away,

taking care of her is the chal lenge,

hel ping her each day.

Maybe one day we will listen,

to what stories she has to tell,

in the rush of the ocean,

in the whispers of a seashell.

- Brian A. Morales -

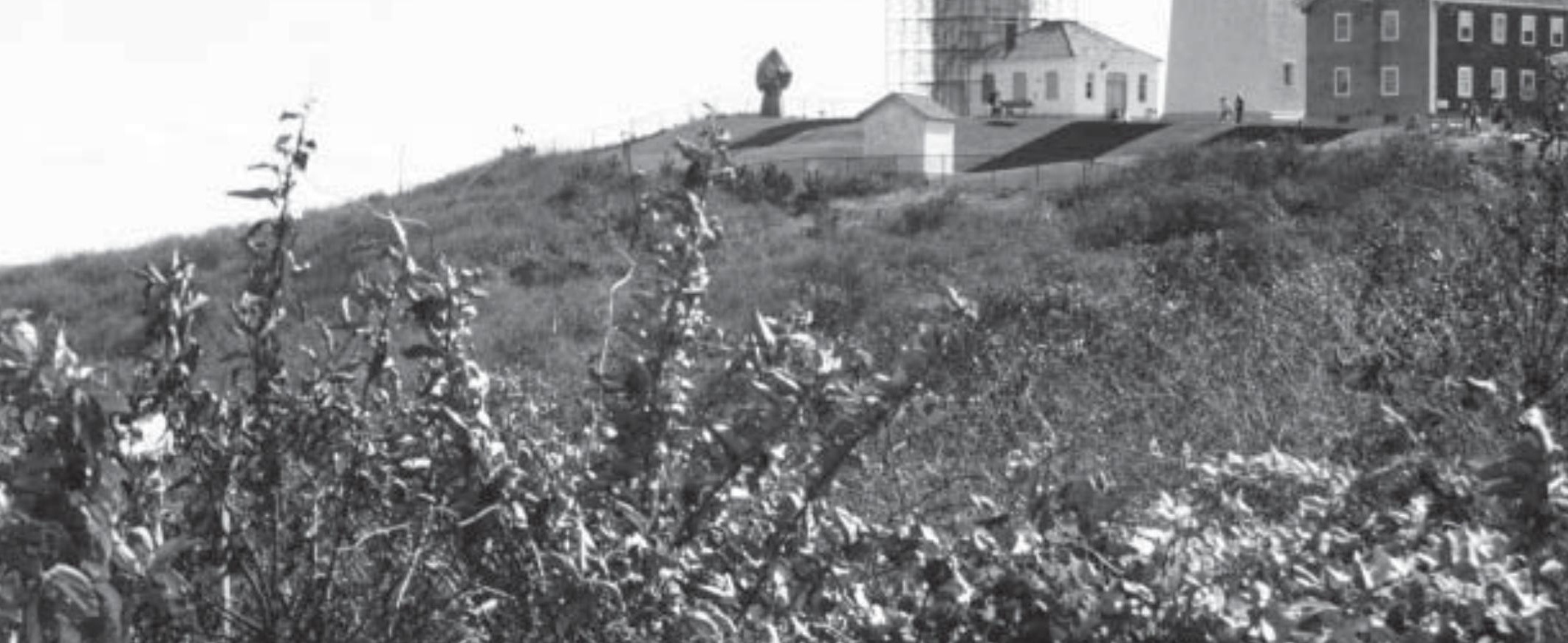




\section{About the Cover and Interior Artwork}

In celebration of the $32^{\text {nd }}$ anniversary of Earth Day, students in grades $\mathrm{K}-12$ from local schools, as well as children of BNL employees, were invited to participate in Brookhaven $\mathrm{N}$ ational Laboratory's third annual Site Environmental Report "Your Environment" Art Contest. The goal of the contest was to raise students' awareness about environmental stewardship, pollution prevention, and waste minimization, and to challenge them to develop artwork that focused on cleaning up and protecting our environment for the future. A panel of BNL staff was asked to choose artwork to represent this year's cover and the chapters of the report. The winning artists received U.S. Savings Bonds and all the students who participated received Certificates of Appreciation.

The Laboratory thanks all of the students and their teachers, principals, and parents for their commitment to preserving the environment. Listed below are the names of the students, their school, grade level, and teacher, and the chapter for which their artwork was chosen.

Brian A. Morales, Patchogue-M edford High School, Grade 11, Ms. Johnson, Cover Photo and poem Michael Lanuto, Ridge Elementary School, Grade 4, Ms. Cohen, Executive Summary Alexander Sneddon, Patchogue-M edford High School, Grade 11, M s. Johnson, Chapter 1 Channon Greenfield, Miller Place High School, Grade 10, Ms. Meier, Chapter 2 Steven Manfro, Ridge Elementary School, Grade 3, M s. Cohen, Chapter 3 Kathleen Carey, Miller Place High School, Grade 9, Ms. Meier, Chapter 4 Julissa N unez, Coram Elementary School, Grade 4, Ms. Kelly, Chapter 5 Maria Sigalas, Coram Elementary School, Grade 4, M s. Kelly, Chapter 6 John L. Knudsen, Ridge Elementary School, Grade 3, Ms. Cohen, Chapter 7 Mariah E. Beltran, Coram Elementary School, Grade 4, Ms. Kelly, Chapter 8 Erik Kahl, Ridge Elementary School, Grade 3, Ms. Cohen, Chapter 9

The 2001 Site Environmental Report is available for public distribution. A summary booklet with a CD ROM version of the entire report is also available. To obtain your free copy, please write or call:

Brookhaven $\mathrm{N}$ ational Laboratory

Environmental Services Division

Attention: SER Project Manager

Building 120

P.O. Box 5000

Upton, NY 11973-5000

(631) 344-3711

The report can also be accessed on the Internet at http://ww w.bnl.gov/esd/ser.htm. 
EXPL RING EARTH'S MYSTERIES PROTECTING ITS FUTURE

\section{Site Environmental Report}

September 2002

Prepared by

Brookhaven Science Associates, LLC

For the U.S. Department of Energy

Under Contract No. DE-AC02-98CH10886

Brookhaven National Laboratory

Brookhaven Science Associates, LLC

P.O. Box 5000

Upton, NY 11973-5000 


\section{DISCLAIMER}

This report was prepared as an account of work sponsored by an agency of the United States Government. Neither the United States Government nor any agency thereof, nor any of their employees, nor any of their contractors, subcontractors, or their employees, makes any warranty, express or implied, or assumes any legal liability or responsibility for the accuracy, completeness, or usefulness of any information, apparatus, product, or process disclosed, or represents that its use would not infringe privately owned rights. Reference herein to any specific commercial product, process, or service by trade name, trademark, manufacturer, or otherwise, does not necessarily constitute or imply its endorsement, recommendation, or favoring by the United States Government or any agency, contractor or subcontractor thereof. The views and opinions of authors expressed herein do not necessarily state or reflect those of the United States Government or any agency, contractor or subcontractor thereof.

Printed in the United States of America

$$
\text { Available from }
$$

National Technical Information Service

U.S. Department of Commerce

5285 Port Royal Road

Springfield, VA22161

\section{$\because$}

PRINTED ON POST-CONSUMER RECYCLED PAPER 


\section{A Message}

from the Interim Laboratory Director

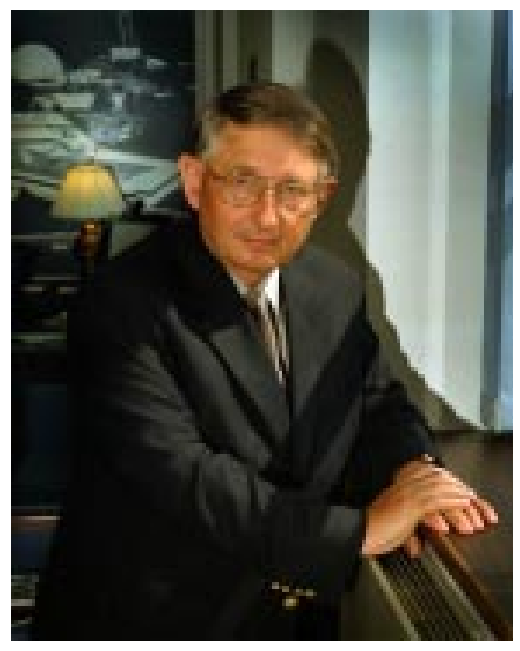

Since taking over as the Interim Director of Brookhaven National Laboratory in October 2001, I have been and remain fully committed to excellence in environmental performance and protecting our environment. As a first-rate scientific laboratory, BNL made significant progress in environmental remediation and communications under Dr. Marburger's leadership. I take our environmental stewardship responsibilities very seriously and I expect all of our employees and visitors to do the same.

This year, BNL demonstrated environmental leadership by becoming fully ISO 14001 registered. BNL is the first Office of Science national laboratory and the first Long Island-based organization to obtain third-party registration to this globally recognized environmental management standard. BNL has made major commitments to the protection of the environment and we are realizing some of these benefits. In 2001, BNL received two Pollution Prevention awards from DOE. Pollution prevention projects saved nearly $\$ 1.4$ million and resulted in the reduction or reuse of more than one and one-half million pounds of industrial, sanitary, radioactive, and hazardous waste. From 1993 to 2001, BNL reduced annual routine hazardous waste generation by 87 percent, mixed hazardous/radioactive waste by 81 percent, and radioactive waste by 72 percent. We have made continual improvements in our compliance record and a significant reduction in our environmental vulnerabilities. We have a groundwater protection program that focuses on the restoration of groundwater quality and preventing future impacts. BNL continues to address historical issues and made significant progress in 2001 in decommissioning the research reactors on site. Additionally, we are supporting ecological research and habitat enhancement at the 530-acre Upton Ecological and Research Reserve. I am committed to an expedited cleanup of our site as well as stewardship of our natural resources.

Communication with our stakeholders - neighbors, regulators, employees, and others - on environmental issues and progress has now become an integral part of how we do business at BNL. In 2001, BNL was named the "Organization of the Year" by the International Association for Public Participation for our success at integrating public participation into our operations, and ensuring that stakeholders are kept informed and have a voice in decisions and issues that affect them. We continue to deliver on our commitments and have made tremendous effort to set in place a permanent environmental stewardship strategy for the Laboratory. As we continue to forge onward with innovative research while improving our environmental operations, we are able to achieve the balance that is in our motto, "Exploring Earth's Mysteries...Protecting Its Future."

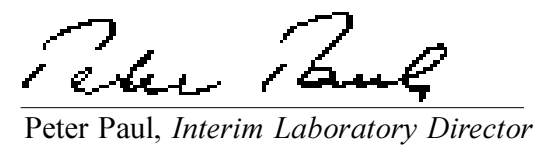

Dr. Peter Paul, formerly Brookhaven's Deputy Director for Science and Technology, was appointed as Interim Director on October 26, 2001, when Dr. John H. Marburger was confirmed by the U.S. Senate as Director, Office of Science and Technology Policy. 


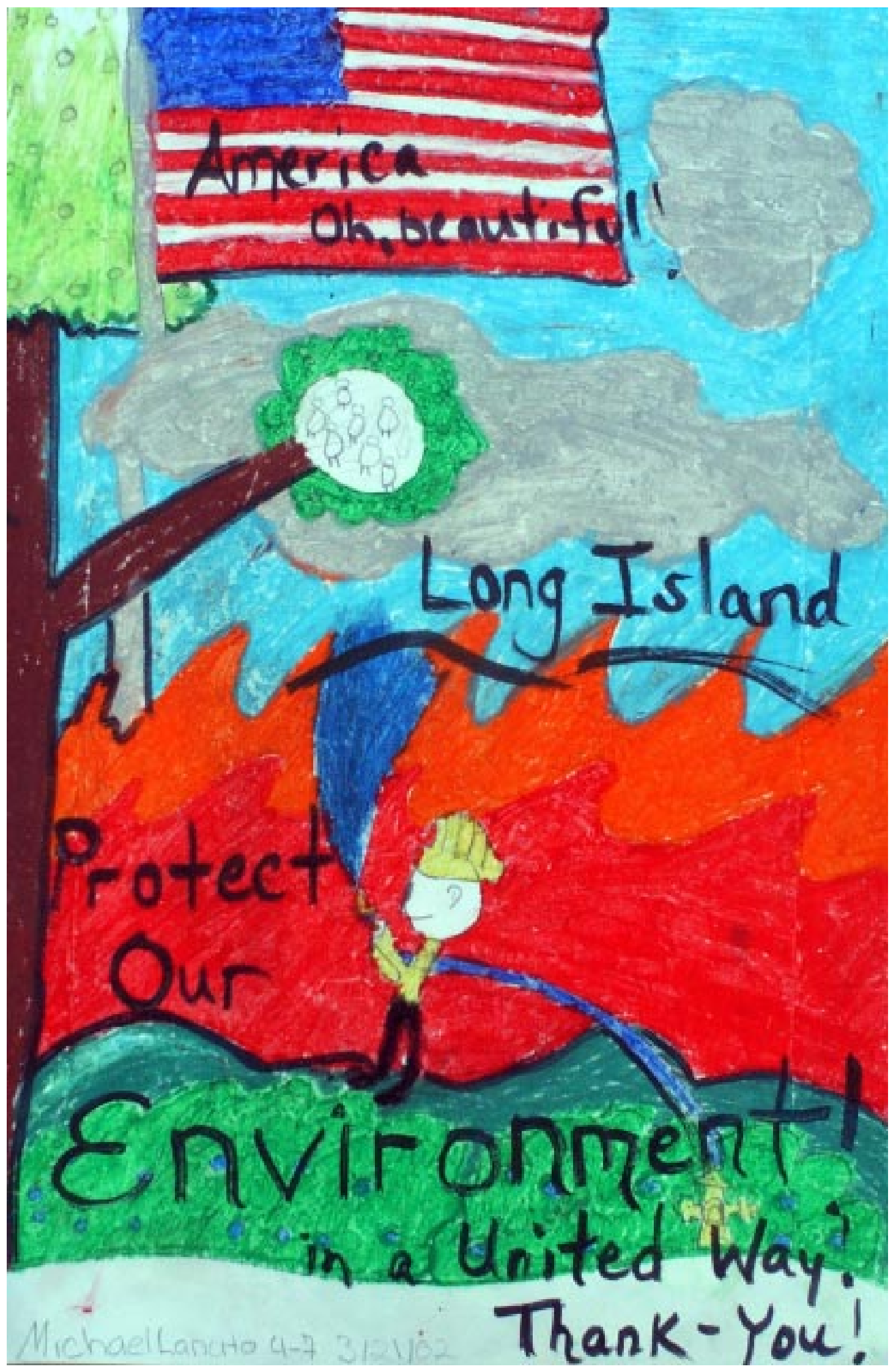

$\underset{\text { RATIONAL LABORATORY }}{\text { BROKEN }} 2001$ SITE ENVIRONMENTAL REPORT iv 


\section{BROOKHAVEN NATIONAL LABORATORY 2001 SITE ENVIRONMENTAL REPORT}

\section{Executive Summary}

The year 2001 marked a major milestone of environmental accomplishments for Brookhaven National Laboratory (BNL), when it became the first U.S. Department of Energy (DOE) Office of Science Laboratory to obtain third-party registration to the International Organization for Standardization's (ISO) 14001 Standard. An ISO 14001-certified environmental management system (EMS) is an internationally recognized framework for implementing a strategic approach to achieve environmental objectives and control environmental impacts. Using this EMS, Brookhaven National Lab strives to fully integrate compliance assurance, pollution prevention, and community outreach into the planning, decision making, and implementation phases of all site activities.

Operated by Brookhaven Science Associates (BSA), for the Department of Energy, BNL manages its world-class scientific research with particular sensitivity to environmental and community issues. BNL's motto, "Exploring Earth's Mysteries...Protecting its Future," reflects a management philosophy to fully integrate environmental stewardship into all facets of its mission, with a healthy balance between science and the environment.

The 2001 Site Environmental Report (SER) summarizes the status of BNL's environmental programs and performance, compliance performance, and restoration, as well the impacts that BNL operations, past and present, have had on the environment.

\section{ENVIRONMENTAL PROGRAMS}

BNL's Environmental Management Program consists of several Labwide environmental programs. Programs such as the ISO 14001certified EMS were implemented to ensure that BNL is managed in an environmentally responsible manner that protects the ecosystem and human health, and improves environmental quality. The cornerstone of BNL's environmental programs is its Environmental Stewardship Policy, which states intentions and principles regarding overall environmental management and provides a framework for planning and action.

The stewardship policy is posted throughout the Laboratory and on the BNL website and is included in all new employee training programs.

The Laboratory's Pollution Prevention/ Waste Minimization Program ("P2") is an essential facet of the EMS that represents a continuous effort to make pollution prevention and waste minimization an integral part of the BNL operating philosophy. In 2001, BNL won two national DOE Pollution Prevention Awards for innovative projects, the "Process Evaluation Project" and the "Environmental Management System Principles Leading Change." A third project, "Preparing for High Flux Beam Reactor Facility Stabilization," was selected as a runnerup. Brookhaven National Laboratory's P2 Program focuses on eliminating or reducing waste, effluents, and emissions at their source, conserving natural resources, reusing materials, recycling, and procuring environmentally preferable products. Pollution prevention is integrated into all planning and decision making at the Laboratory.

A newly formed advisory group for the 530acre Upton Ecological and Research Reserve began developing a natural resource management plan and awarded two research grants to be used to investigate local ecological issues. The reserve permanently preserves a portion of the Central Pine Barrens, a unique ecosystem of forests and wetlands on Long Island that provides habitat for approximately 27 species that are endangered, threatened, or of special concern.

BNL also moved forward with its Cultural Resources Management Program and established a schedule for developing a cultural resources management plan. This plan will be used to guide 
the management of all of BNL's cultural resources. In 2001, a survey was completed to determine the potential historic value of BNL's buildings in accordance with the National Historic Preservation Act, and it was determined that the former High Flux Beam Reactor was eligible for listing on the National Register of Historic Places.

The Facility Review Project ranks, schedules, and dispositions environmental issues identified during the 1997 review of all facilities at BNL. By 2001, 68 percent of all issues were dispositioned and 76 percent of the high-priority issues were resolved.

The goal of BNL's Environmental Restoration Project is to complete on-site and off-site cleanup activities of contamination from past disposal practices. In 2001, approximately 1 billion gallons of groundwater were treated and 600 pounds of volatile organic chemicals were removed from the aquifer. Further highlights are discussed under Environmental Restoration.

\section{COMPLIANCE WITH ENVIRONMENTAL REGULATIONS}

BNL is subject to more than 50 sets of federal, state, and local environmental regulations; 65 site-specific permits; 8 equivalency permits for operation of groundwater remediation systems; as well as other binding agreements. The Laboratory is committed to achieving and maintaining full compliance with these environmental requirements and agreements.

Results for 2001 in air emissions monitoring of nitrogen oxides, carbon monoxide, and sulfur dioxide were all within permit limits; monitoring of the BNL potable water system met all regulatory requirements; and groundwater monitoring at the Major Petroleum Facility continues to demonstrate that current oil storage and transfer operations are not affecting groundwater quality. Liquid effluents discharged to surface water and groundwater met New York State Pollutant Discharge Elimination System permit requirements with the exception of six excursions at the Sewage Treatment Plant and six excursions at other outfalls. Ten petroleum product spills, most of them of one gallon or less, and three spills of regulated materials (ethylene glycol and heat exchange fluid) were reportable.
All spills were cleaned up to the satisfaction of the New York State Department of

Environmental Conservation.

External regulatory agencies conducted 13 environmental audits at BNL in 2001. These audits included reviews of petroleum and chemical storage, hazardous waste operations, and air emissions from the Central Steam Facility, as well as inspections of the Sewage Treatment Plant, outfalls and recharge basins, and the potable water system. Of the 1,200 New York State hazardous waste compliance requirements, BNL met all but two, receiving a notice of violation for administrative deficiencies. Corrective actions were identified and immediate actions were taken to address these issues.

\section{ENVIRONMENTAL MONITORING}

BNL maintains a comprehensive sitewide Environmental Monitoring Program that identifies potential pathways for exposure to the public and the environment, evaluates any impacts BNL activities may have on the environment, and ensures compliance with environmental permit requirements.

Compliance monitoring is conducted to ensure that wastewater effluents, air emissions, and groundwater monitoring data comply with regulatory and permit limits issued under the federal Clean Air Act, Clean Water Act, Oil Pollution Act, Safe Drinking Water Act, and the New York State equivalents. Restoration monitoring is used to determine the overall impacts of past operations, to delineate contamination, and to ensure that removal actions are effective and remediation systems are performing as designed. Surveillance monitoring is used to assess potential environmental impacts resulting from routine facility operations.

In 2001, there were a total of 5,578 sampling events, which included collection of groundwater, potable water, precipitation, air, flora and fauna, soil, sediment, and wastewater discharges. This does not include samples taken to characterize wastes for disposal purposes or nonroutine samples collected in support of restoration characterization activities. Groundwater plumes were tracked, evaluated, and remediated as necessary. Of note, there was a significant 
reduction in the inventory of tritium at the HFBR due to continued decommissioning efforts.

Deer and fish sampling results were consistent with previous years, and vegetables grown in the BNL garden plot continue to support historical analyses that there are no Laboratory-generated radionuclides in farm produce.

Recent characterization work at the Brookhaven Graphite Research Reactor (BGRR) detected higher than expected levels of strontium-90 (Sr-90) in the shallow groundwater beneath the reactor's below-ground ducts, which will be addressed through the legacy

contamination cleanup program.

BNL's Landtrek Project, an innovative computer program that BNL continues to work on, is an extension of the BNL Environmental Information Management System and provides environmental monitoring data to the public and BNL staff over the Internet.

\section{ENVIRONMENTAL RESTORATION}

The Environmental Restoration Program made significant progress in its ongoing efforts to manage on-site and off-site cleanup activities resulting from past disposal practices and accidental spills. Some highlights of the major cleanup activities in 2001 include:

- Installing and operating two additional ground water treatment systems, bringing the total number of installed treatment systems to eight

- Receiving regulatory agency approval for the shutdown of the Operable Unit IV air sparge and soil vapor extraction system

- Receiving a signed Record of Decision for the Operable Unit V Sewage Treatment Plant and the Operable Unit VI EDB Plume (the last decision document for groundwater)

- Pre-design characterization activities for six planned off-site groundwater treatment systems, which involved drilling additional temporary and permanent monitoring wells in portions of East Yaphank and Manorville to refine the location for the treatment systems

- Completion of the remediation and restoration of the Operable Unit I Landscape Soils Project
- Significant progress in decommissioning the BGRR, including the removal of a belowground duct cooler, removal of an aboveground duct, and the development of an Engineering Evaluation and Cost Analysis for the BGRR Canal.

\section{RADIOLOGICAL DOSE ASSESSMENT}

An evaluation of radiological dose impact above natural background levels to the members of the public and the environment determined that impact from BNL operations was minimal and well below regulatory limits. The environmental pathways evaluated include air inhalation, immersion, and ingestion of local deer and fish, as well as direct gamma exposure. Radiological dose to aquatic and terrestrial biota was also assessed and was found to be insignificant and comparable to natural background radiation levels. Sixteen remediation projects were assessed for potential radiological air emissions, and the dose impact from all the projects was determined to be only minimally above natural background radiation.

The U.S. Environmental Protection Agency regulates the airborne emissions from $\mathrm{DOE}$ facilities and includes compliance monitoring and reporting requirements for radiation doses to members of the public. Under these regulations, BNL is required to submit an annual National Emissions Standard for Hazardous Air Pollutants (NESHAPs) report describing air emissions from all sources, and stationary point sources. Due to extra beam irradiation time in 2001, the Brookhaven Linac Isotope Producer facility exceeded 1 percent of the NESHAPs standard, thereby requiring continuous monitoring for air emissions. The effective dose equivalent was estimated to be 0.14 mrem ( $1.4 \mathrm{mSv})$ per year from the short-lived gases oxygen-15 and carbon11. Discussions with the Environmental Protection Agency were initiated to determine cost-effective controls and acceptable monitoring methods.

\section{QUALITY ASSURANCE}

BNL uses its on-site Analytical Services Laboratory and four off-site, contract laboratories to analyze its environmental samples. All the labs are certified by New York State and are subject 
to oversight that includes state and national performance evaluation testing, review of quality assurance programs, and audits.

In 2001, BNL received a combined score of 96 percent "overall satisfactory" for the 593 radiological and nonradiological performance evaluation tests carried out, which is considered excellent. The two primary laboratories used to report radiological analytical data scored 92 percent and 100 percent satisfactory results in state and federal performance evaluation programs, an improvement from last year's overall score of 89 percent and 95 percent. BNL received a satisfactory rating of 96.9 percent in nonradiological performance evaluation testing under the New York State Environmental Laboratory Approval Program, and the three off-site, contract laboratories for nonradiological work scored between 93.3 percent and 94.8 percent.

Quality control is maintained through daily instrument calibration, efficiency and background checks, and testing for precision and accuracy. These controls ensure that all analytical data reported for the 2001 Site Environmental Report are reliable and of high quality.

\section{COMMUNICATION, OUTREACH, AND INVOLVEMENT}

BNL conducted a number of outreach activities in 2001, including presentations and meetings with key stakeholder groups and the public to keep them informed and to gather feedback; regular communications with the local, state, and federal regulators and elected officials; and interactions with the business and educational community. In 2001, more than 25,000 visitors participated in educational and public outreach activities conducted on site.

BNL also celebrated the thirty-first anniversary of Earth Day with a variety of activities involving BNL staff and the community. These activities included awards for employees who had demonstrated an outstanding effort in pollution prevention and waste minimization; a student art contest, with the winning artwork selected for inclusion in the 2001 Site Environmental Report; and an on-site 4-mile race through the Pine Barrens for children and adults. BNL was also selected as the "Organization of the Year" by the International Association for Public Participation, for integrating public participation into its operations and ensuring that stakeholders are kept informed and have a voice in decisions and issues that may affect them.

\section{CONCLUSION}

Overall, Brookhaven National Laboratory continues its progress toward integrating environmental stewardship into all its scientific endeavors and routine site operations. In 2001, the Laboratory reached its three-year goal of certified environmental management and will continue to improve operations in the future. 


\section{Acknowledgments}

The production of the BNL 2001 Site Environmental Report (SER) requires the knowledge, skill, experience, and cooperation of many people and organizations at the Laboratory. Responsibility for producing the SER is with the Environmental Services Division, which is managed by Lori Cunniff. The lead authors, co-authors, and other contributing staff and organizations involved in this year's SER are listed below.

\section{Lead Chapter Authors}

EXECUTIVE SUMMARY

Karen Ratel, Environmental Services Division

CHAPTER 1

Lori Cunniff, Environmental Services Division

CHAPTER 2

Lori Cunniff, Environmental Services Division

CHAPTER 3

Robert Lee, Environmental Services Division

CHAPTER 4

Jeffrey Williams, Environmental Services Division

CHAPTER 5

Robert Lee, Environmental Services Division

CHAPTER 6

Timothy Green, Environmental Services Division

CHAPTER 7

Douglas Paquette, Environmental Services Division

William Dorsch, Environmental Services Division

CHAPTER 8

Balwan Hooda, Environmental Services Division

CHAPTER 9

Salvatore Scarpitta, Radiological Control Division

SUMMARY BOOKLET

Peter Genzer, Community, Education, Government and Public Affairs
Co-authors and Key Contributors

Marcia Allocco, Environmental Services Division

Drew Bennett, Environmental Services Division

Jill Engel-Cox, Battelle Memorial Institute

John Burke, Environmental Services Division

Arland Carsten, Environmental Services Division, Consultant

Jeanne D'Ascoli, Community, Education, Government and Public Affairs

Mary Daum, Environmental Services Division

Mark Davis, Environmental Services Division

George Goode, Environmental Services Division

Peter Heotis, Radiological Control Division

Jennifer Higbie, Environmental Services Division

Robert Howe, Environmental Restoration

Keith Klaus, Environmental Services Division

Barbara Pierce, Plant Engineering

Jason Remien, Environmental Services Division

Charles Schaefer, Radiological Control Division

Richard Setlow, Biology Department

Glen Todzia, Waste Management Division

Mark Toscano, Plant Engineering

SER PROJECT MANAGER

Karen Ratel, Environmental Services Division

EDITOR

Kathleen Robinson, Information Services Division

DESIGNER

Patricia Yalden, Information Services Division

The Environmental Services Division Manager, Lori Cunniff, and the SER Production Team, consisting of those above, would like to thank the staff and management from the following organizations who assisted in the report preparation, provided technical peer review and comments, collected samples and data, prepared maps and diagrams, and provided the analytical services and other support necessary to make this year's report possible:

Community, Education, Government and Public Affairs Directorate

Environment, Safety, Health and Quality Directorate

Environmental Services Division
Environmental Restoration

Information Services Division

Radiological Control Division

Waste Management Division 
Results presented in the 2001 SER are from samples collected, analyzed, and organized by the staff of the Environmental Services Division and the Radiological Control Division. A special word of thanks is extended to those staff, who include:

Kathryn Clifford, Radiological Control Division

Robert Gaschott, Radiological Control Division

Elizabeth Ginty, Radiological Control Division

Philip Hayde, Radiological Control Division
Eric Klug, Radiological Control Division

Richard Lagattolla, Environmental Services Division

Lawrence Lettieri, Environmental Services Division

Anette Meier, Radiological Control Division

\section{SITE ENVIRONMENTAL REPORT TEAM}

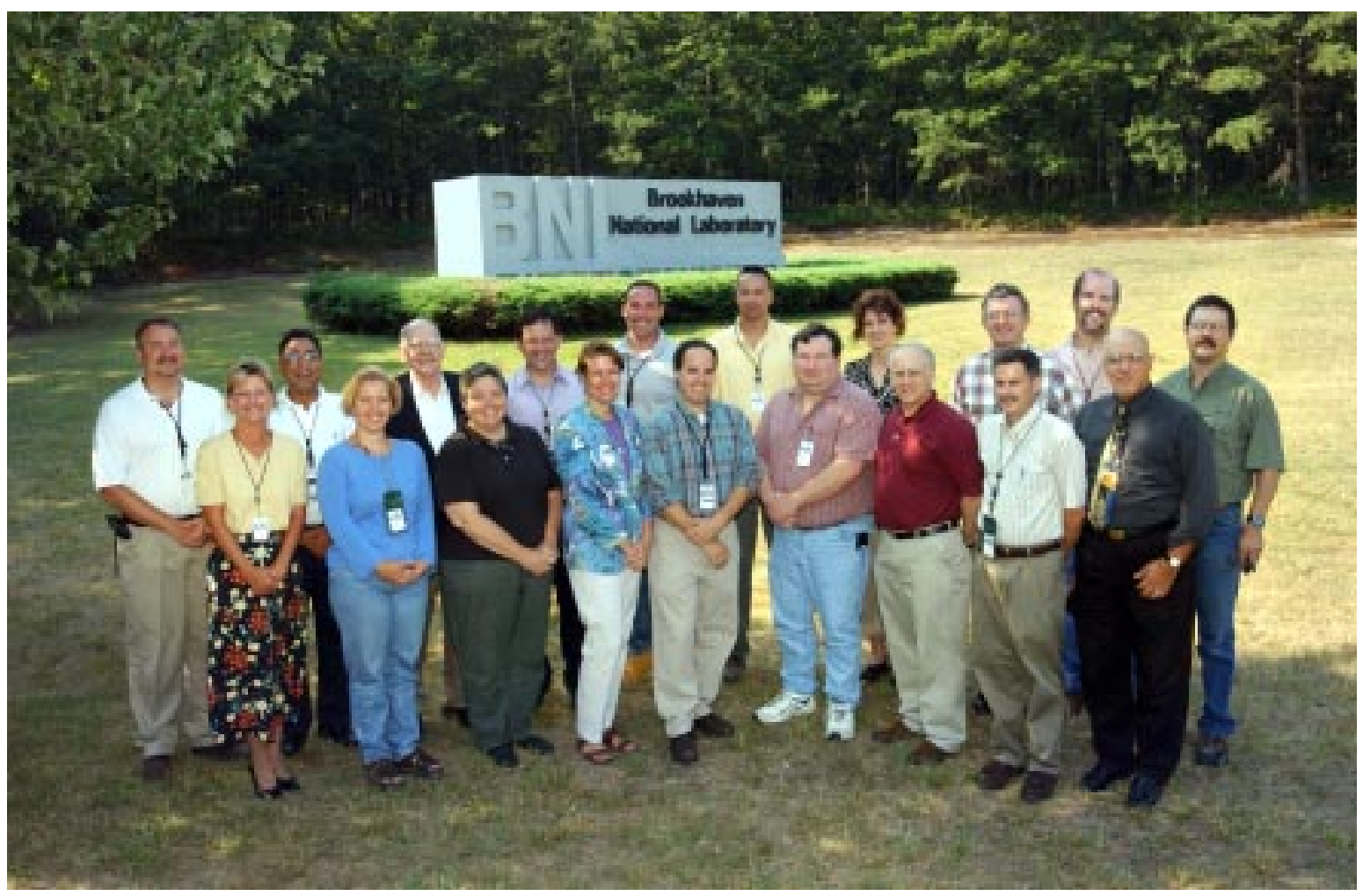

\section{Authors and contributors to the Site Environmental Report:}

(Back row from left to right) George Goode, Balwan Hooda, Arland Carsten, Robert Lee, Jason Remien, William Dorsch, Patricia Yalden, Douglas Paquette, Glen Todzia and Timothy Green.

(Front row from left to right) Karen Ratel, Marcia Allocco, Kathleen Robinson, Lori Cunniff,

Peter Genzer, John Burke, Peter Heotis, Jeffrey Williams and Salvatore Scarpitta. 
Robert Metz, Environmental Services Division

Lisa Muench, Radiological Control Division

Jean Odin-McCabe, Radiological Control Division
Carlee Ogeka, Environmental Services Division

William Rizzitello, Environmental Services Division

Ruilang Wang, Radiological Control Division

The SER Production Team realizes that many other employees contributed to this report and thanks all contributors for their efforts.
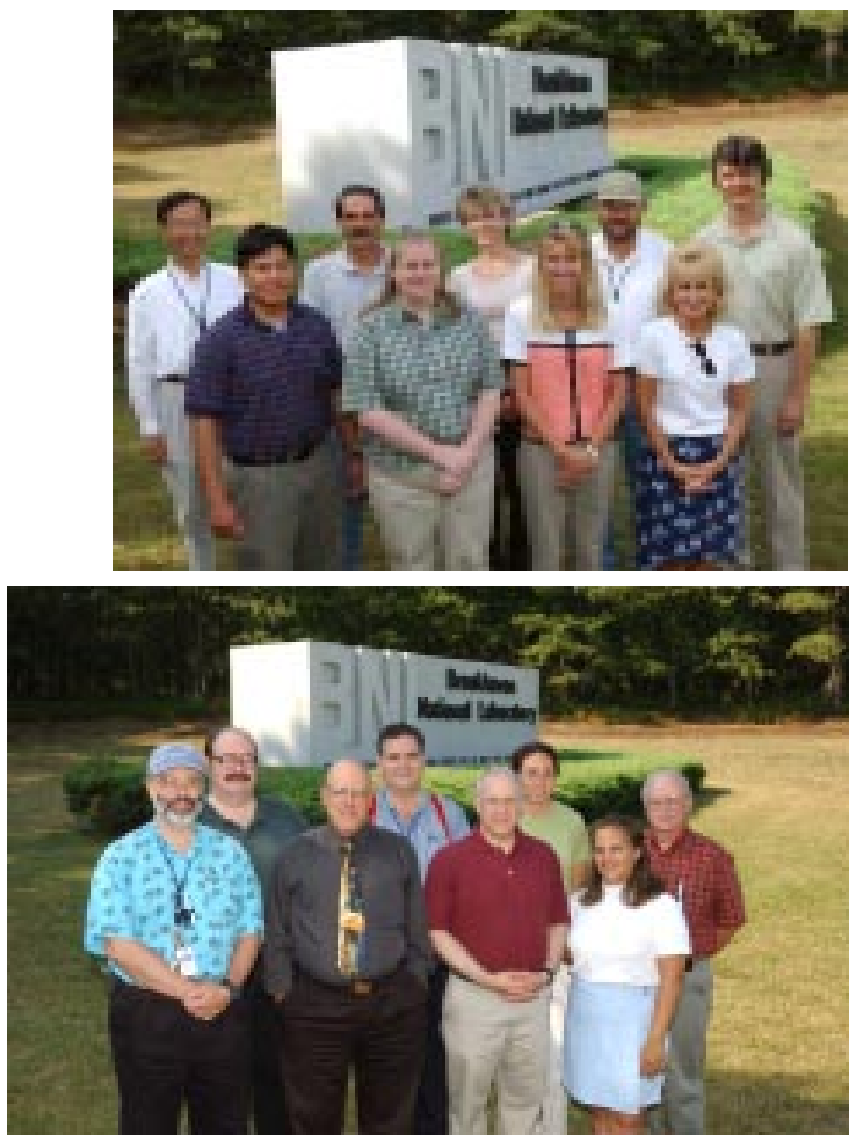

The Analytical Services Laboratory team:

(Back row from left to right) Philip Hayde, Vincent Lettieri, Lisa Muench and Eric Klug.

(Front row from left to right)

Robert Gaschott, Salvatore Scarpitta, Peter Heotis, and Jean Odin-McCabe.

\section{The Data Management Group:}

(Back row from left to right) Daqi Li,

Francis Tramontano, Mary Daum, Richard Pietrzak, and Michael DePhillips,

(Front row from left to right) Alain Domingo, Jennifer Higbie, Amy Ramsdell, and Susan Young.

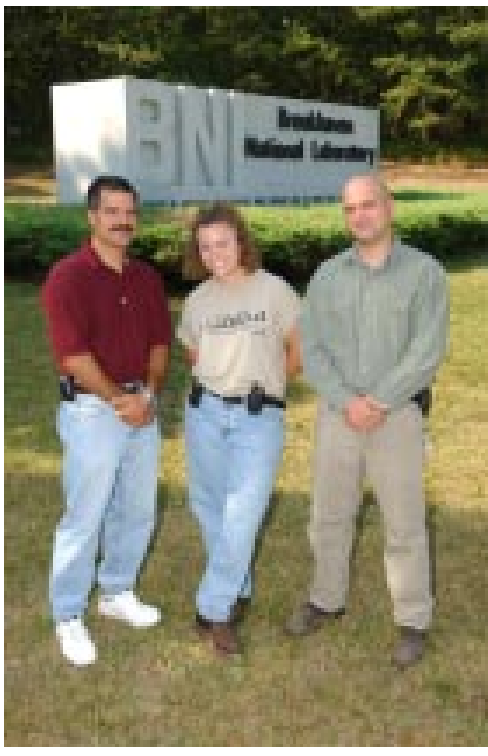

The Environmental Services field sampling team:

(pictured from left to right) Lawrence Lettieri, Carlee Beecher and Robert Metz.

(Richard Lagattolla not pictured) 


\section{A Note from the Editor}

Throughout the Site Environmental Report, there are many references to Brookhaven National Laboratory (BNL), the U.S. Department of Energy (DOE), and the U.S. Environmental Protection Agency (EPA). These acronyms, and others that are explained at the point of first use in each chapter, are used interchangeably with their spelled-out forms as an aid to readers. Also, Appendix A opens with a list of acronyms and their meanings. 


\section{Table of Contents}

A MESSAGE FROM THE LABORATORY DIRECTOR
EXECUTIVE SUMMARY
ACKNOWLEDGEMENTS
TABLE OF CONTENTS
LIST OF FIGURES
LIST OF TABLES

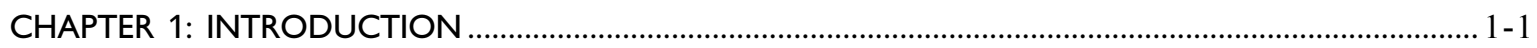

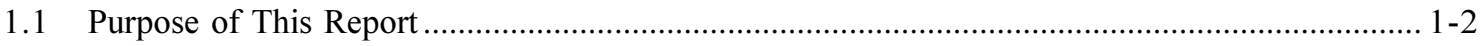

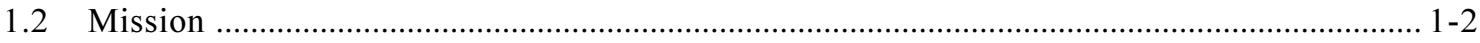

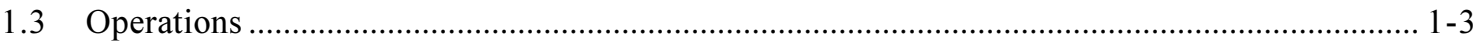

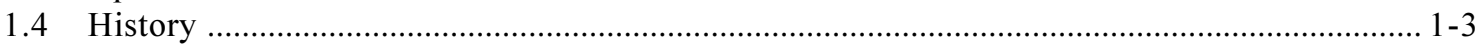

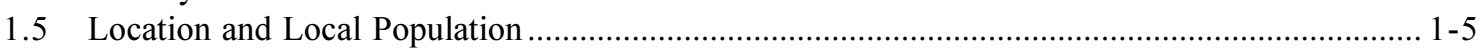

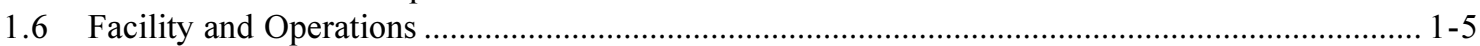

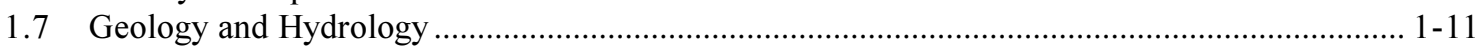

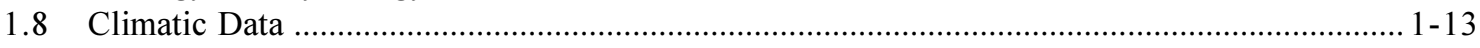

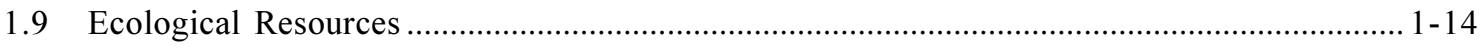

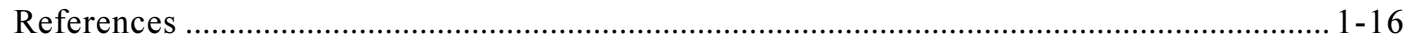

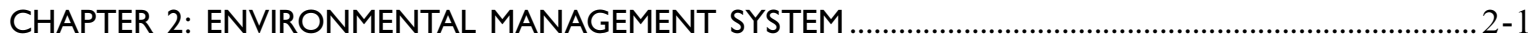

2.1 Stewardship under Brookhaven Science Associates ....................................................................... 2-2

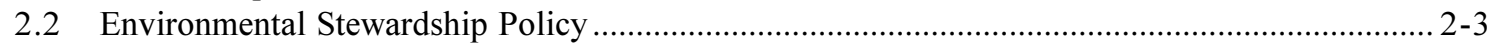

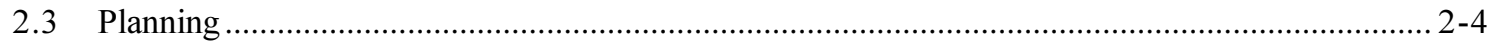

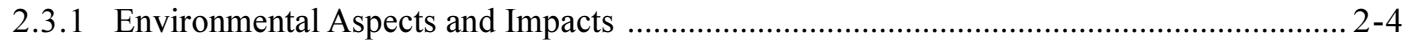

2.3.2 Requirements Management ................................................................................... 2-4

2.3.3 Performance Objectives and Measures ……….......................................................... 2-6

2.3.4 Environmental Management Program …….............................................................. 2-8

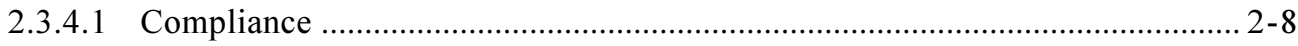

2.3.4.2 Groundwater Protection ………………….................................................... 2-8

2.3.4.3 Waste Management …………....................................................................... 2-9

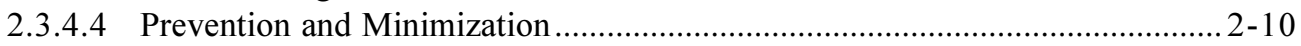

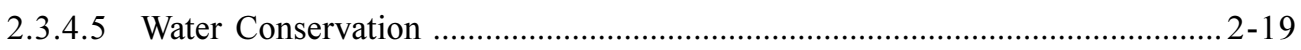

2.3.4.6 Energy Management and Conservation ...........................................................22-20

2.3.4.7 Natural and Cultural Resource Management ..................................................2-2 21

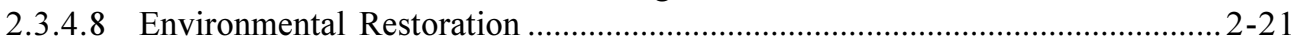

2.3.4.9 The Facility Review Project ……………............................................... 2-23

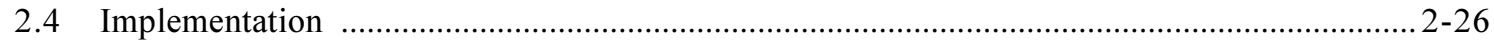

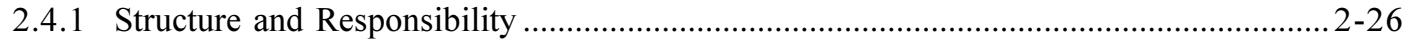

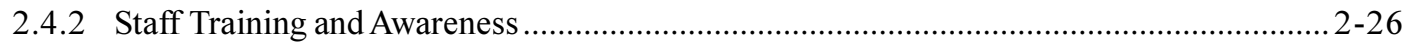

2.4.3 Communication and Community Involvement ……................................................... 2-2 27

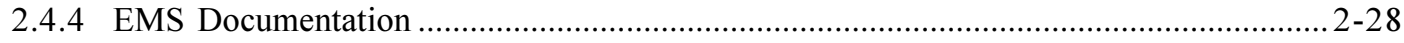

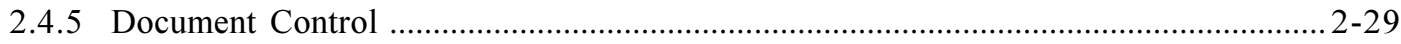

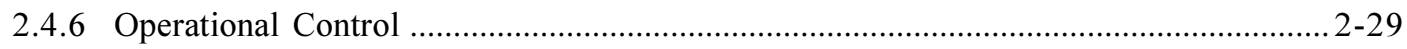




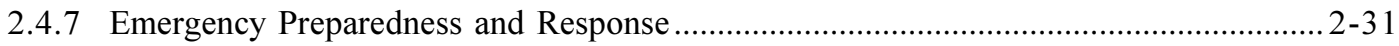

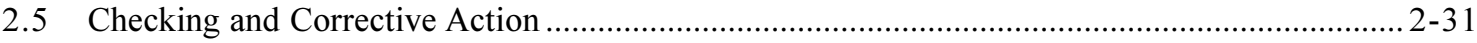

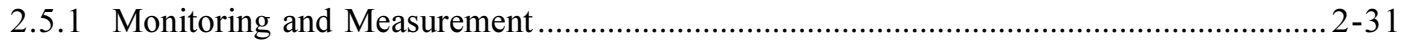

2.5.1.1 Compliance Monitoring ……………………................................................ 2-33

2.5.1.2 Restoration Monitoring. …………………….............................................2-33

2.5.1.3 Surveillance Monitoring. ............................................................................. 2-33

2.5.2 Nonconformance, Corrective, and Preventive Action ................................................ 2-34

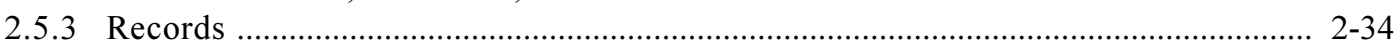

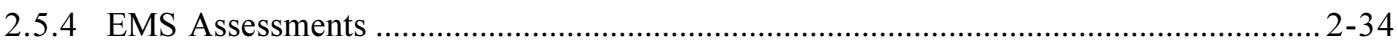

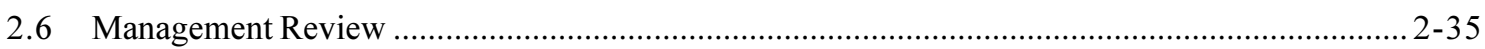

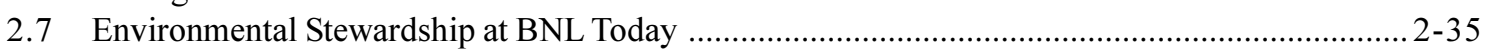

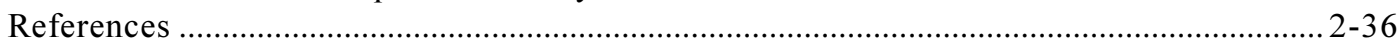

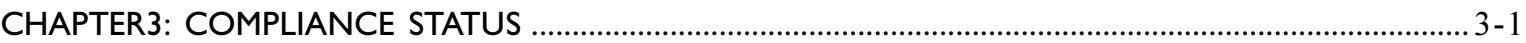

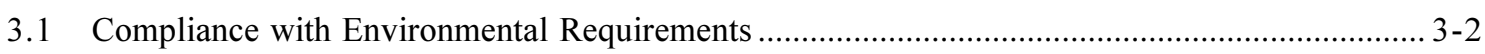

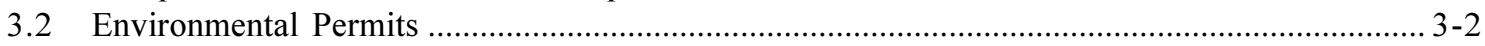

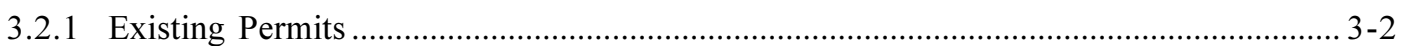

3.2.2 New or Modified Permits and Requests ...................................................................... 3-2

3.2.2.1 State Pollutant Discharge Permits ................................................................ 3-2

3.2.2.2 Air Emissions Permits ................................................................................ 3-2

3.2.2.3 Underground Injection Control Permit ....................................................... 3-7

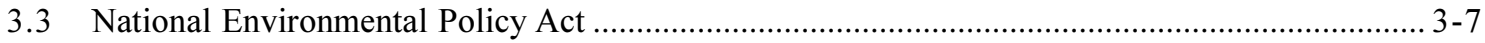

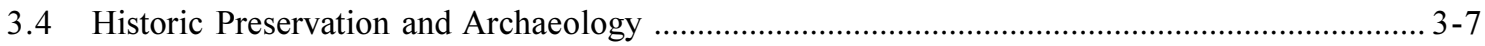

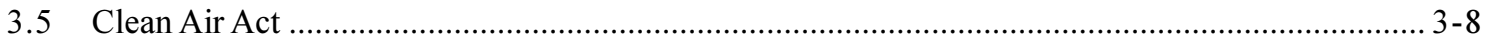

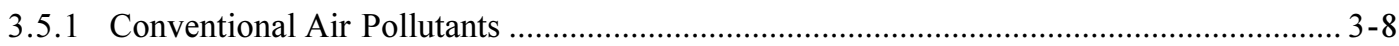

3.5.1.1 Boiler Emissions …………………………............................................... 3-8

3.5.1.2 Ozone-Depleting Substances .................................................................... 3-8

3.5.2 Hazardous Air Pollutants ........................................................................................... 3-9

3.5.2.1 Maximum Available Control Technology ........................................................... 3-9

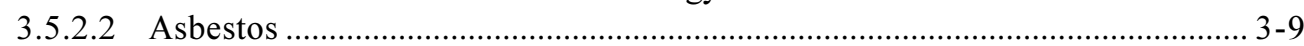

3.5.2.3 Radioactive Airborne Emissions .................................................................... 3-9

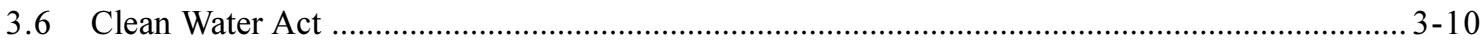

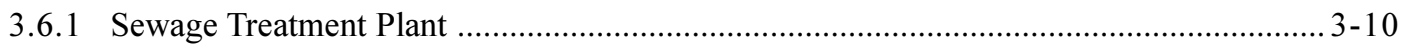

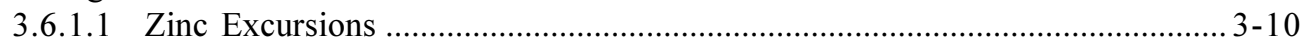

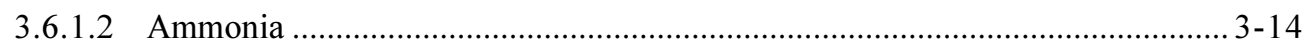

3.6.1.3 Heat Exchange Fluid Loss ....................................................................... 3-14

3.6.1.4 Chronic Toxicity Testing ………………................................................. 3-14

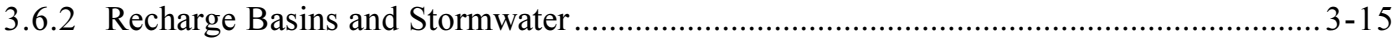

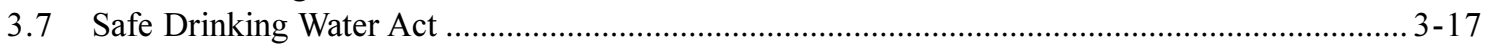

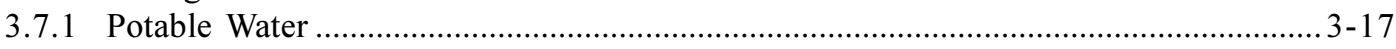

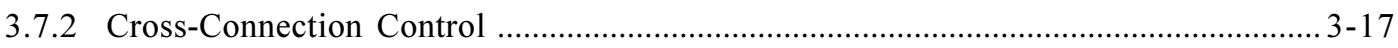

3.7.3 Underground Injection Control ......................................................................... 3-17

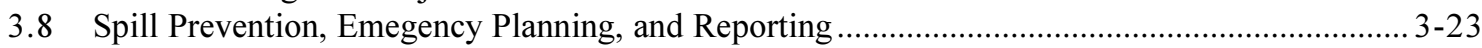

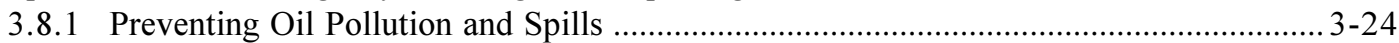

3.8.2 Local and State Reporting Requirements .............................................................. 3-24

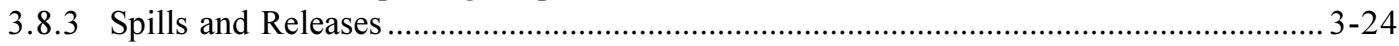

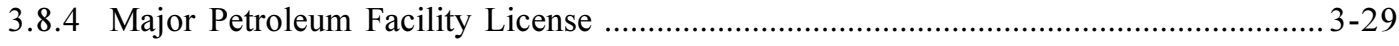

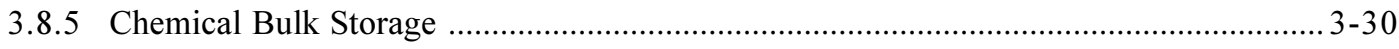

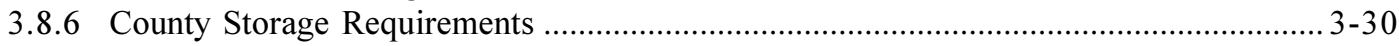

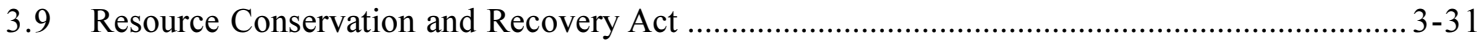

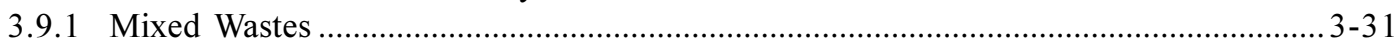

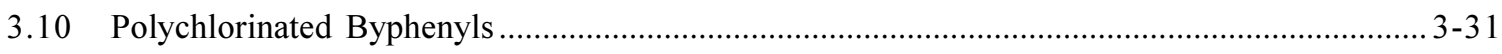

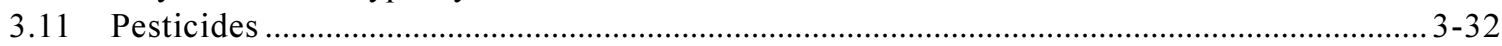




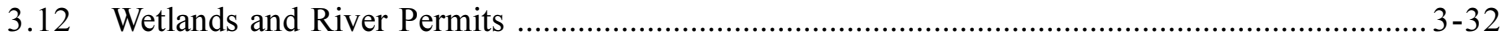

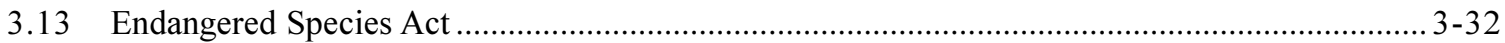

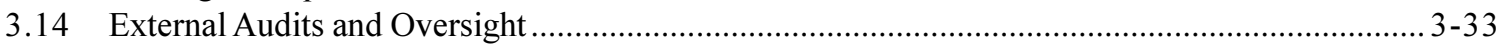

3.14.1 Inspections by Regulatory Agencies ....................................................................... 3-33

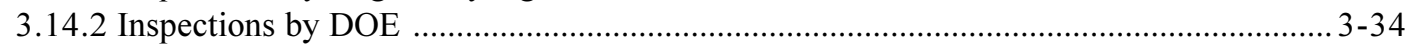

3.14.2.1 Cross-Connection Control Assessment ………..........................................3-34

3.14.2.2 NEPA Program Assessment ......................................................................... 3-34

3.14.3 Enforcement Actions and Memos ………......................................................... 3-36

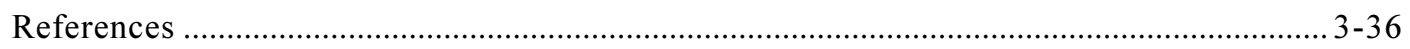

CHAPTER 4: AIR QUALITY ......................................................................................................... 4-1

4.1 Radiological Airborne Emissions ...................................................................................... 4-2

4.1.1 Brookhaven Medical Research Reactor ……............................................................ 4-2

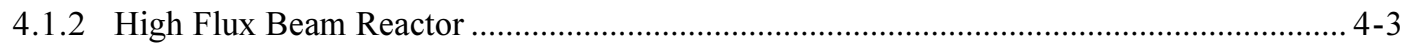

4.1.3 Brookhaven Linac Isotope Producer ………............................................................... 4-3

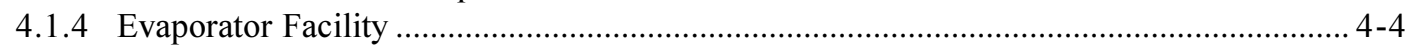

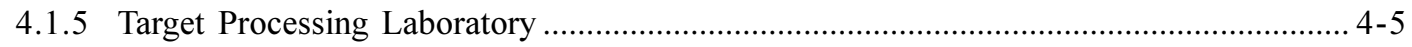

4.1.6 Additional Minor Sources .................................................................................................... 4-5

4.1.7 Uncharacterized Radiological Emission Sources Evaluated in 2001 ............................... 4-5

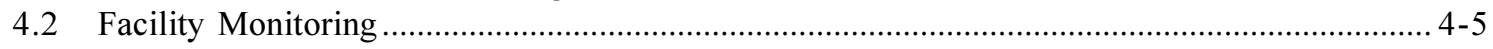

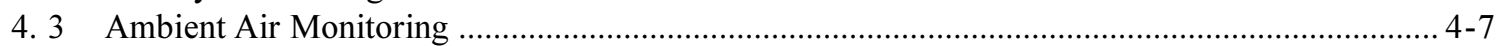

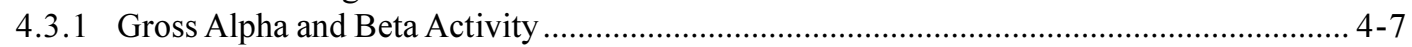

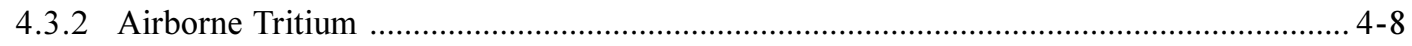

4.3.2.1 Removal Action V Recharge Basin .............................................................. 4-9

4.4 Nonradiological Airborne Emissions ………..................................................................... 4-10

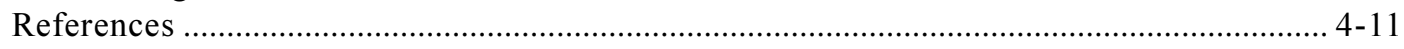

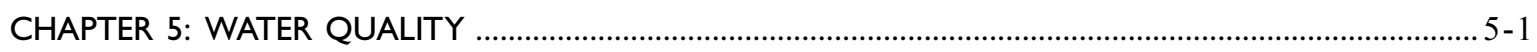

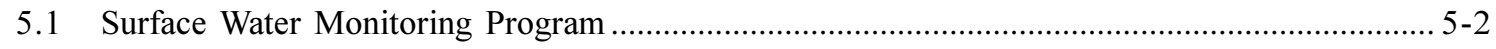

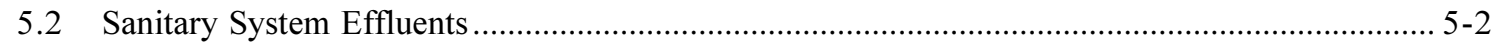

5.2.1 Sanitary System Effluent - Radiological Analyses ........................................................ 5-4

5.2.2 Sanitary System Effluent - Nonradiological Analyses …………............................... 5-8

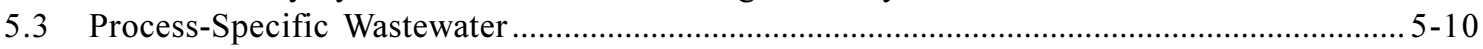

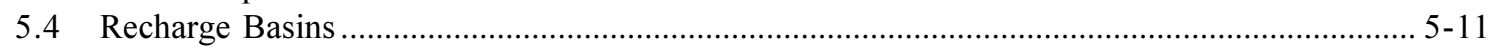

5.4.1 Recharge Basins - Radiological Analyses ……….................................................. 5-12

5.4.2 Recharge Basins - Nonradiological Analyses .......................................................... 5-13

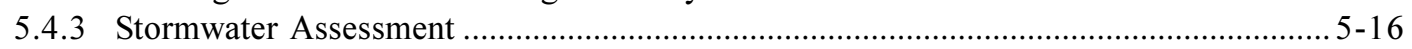

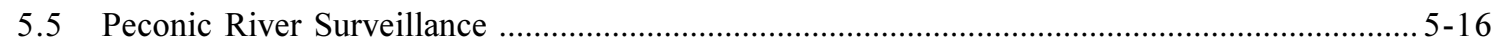

5.5.1 Peconic River - Radiological Analyses ………..................................................... 5-16

5.5.2 Peconic River - Nonradiological Analyses …………......................................... 5-18

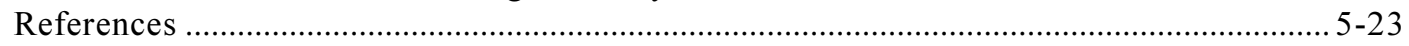

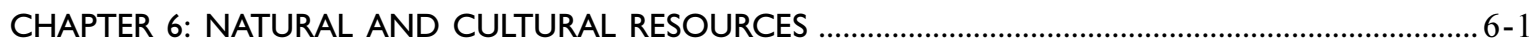

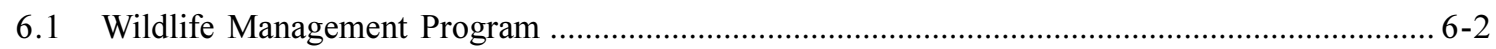

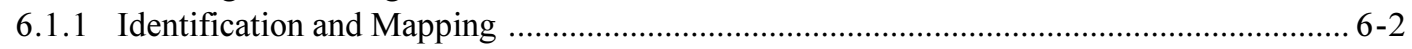

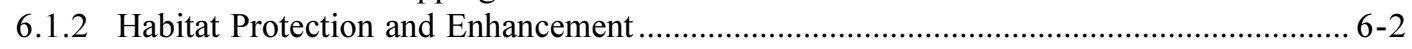

6.1.2.1 Tiger Salamander Efforts ........................................................................... 6-3

6.1.2.2 Other Species ............................................................................................ 6-4

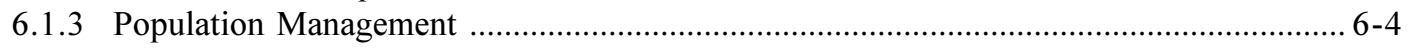

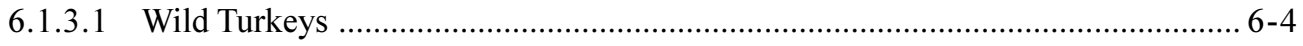

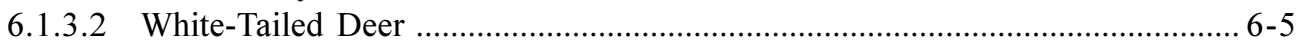

6.1.4 Compliance Assurance and Potential Impact Assessment ................................................ 6-5 


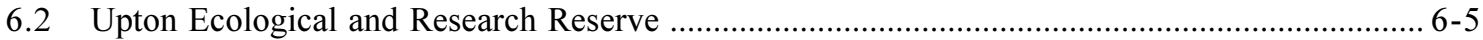

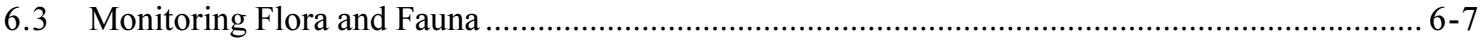

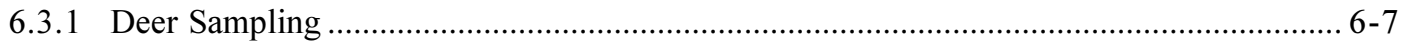

6.3.1.1 Cesium-137 in Deer Meat and Liver ............................................................... 6-7

6.3.1.2 Strontium-90 in Deer Bone …………..................................................... 6-8

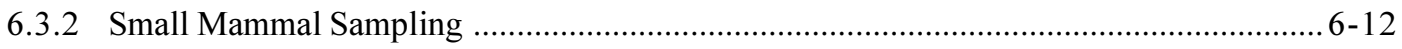

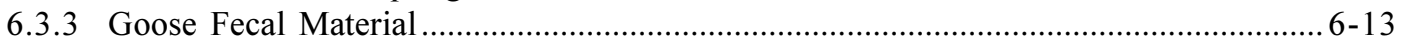

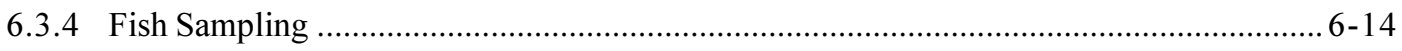

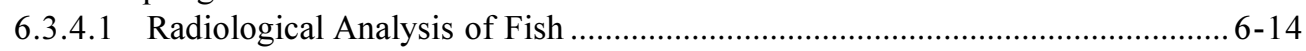

6.3.4.2 Fish Population Assessment ....................................................................... 6-17

6.3.4.3 Nonradiological Analysis of Fish and Shellfish ............................................. 6-17

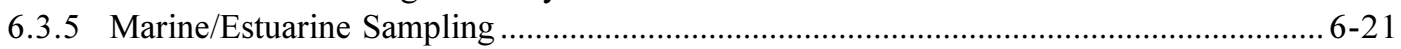

6.3.6 Metals and Pesticides in Aquatic Samples .............................................................. 6-22

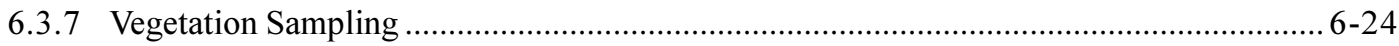

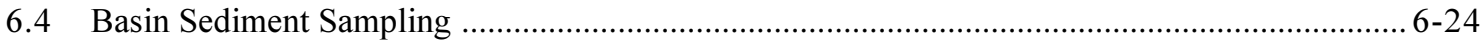

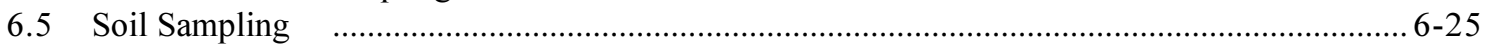

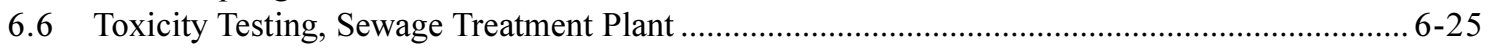

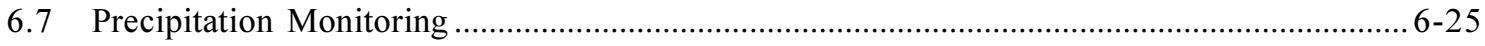

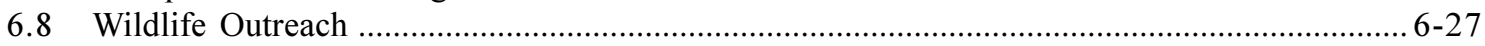

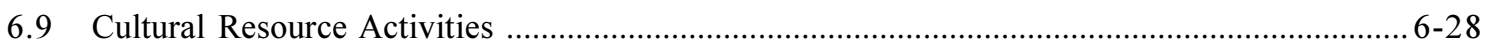

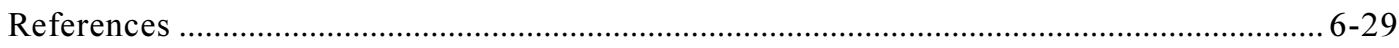

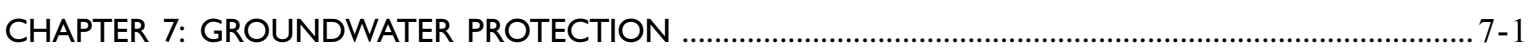

7.1 The BNL Groundwater Protection Management Program …….................................................... 7-2

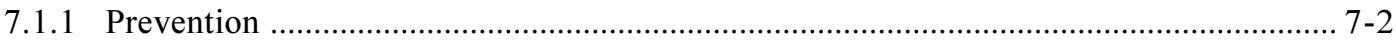

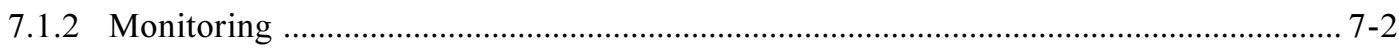

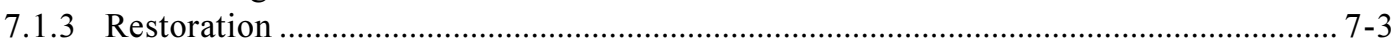

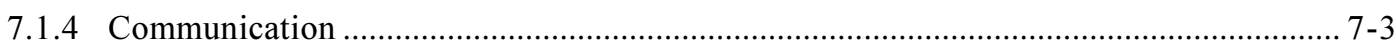

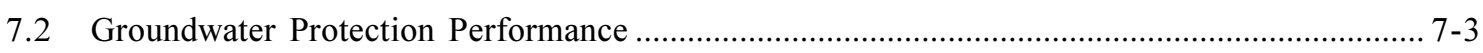

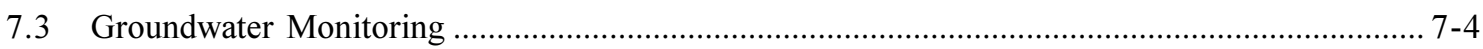

7.4 Supplemental Monitoring of Potable and Process Supply Wells .................................................. 7-5

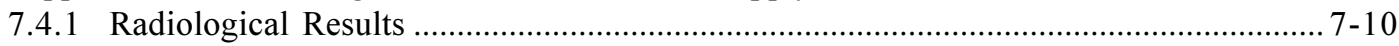

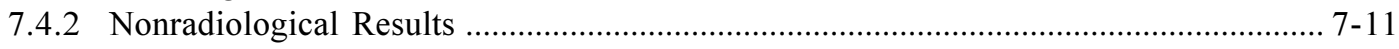

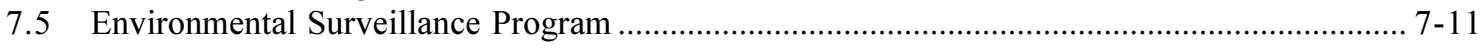

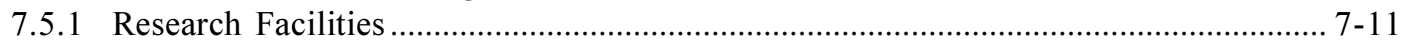

7.5.1.1 Alternating Gradient Synchrotron Complex ................................................. 7-11

7.5.1.2 Brookhaven Linac Isotope Producer (BLIP) ……........................................ 7-14

7.5.1.3 Relativistic Heavy Ion Collider ............................................................. $7-15$

7.5.1.4 Brookhaven Medical Research Reactor ......................................................... 7-15

7.5.2 Surveillance Monitoring of Support Facilities ............................................................... 7-15

7.5.2.1 Sewage Treatment Plant Area ………………............................................

7.5.2.2 Water Treatment Plant ................................................................................ 7-16

7.5.2.3 Motor Pool Facility ..................................................................... 7-17

7.5.2.4 Upton Service Station .................................................................................

7.5.2.5 Major Petroleum Facility …………………….......................................... $7-18$

7.5.2.6 Waste Management Facility ………………...................................................

7.5.2.7 Biology Department Greenhouse Area ……….......................................... 7-19

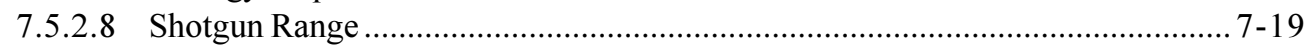

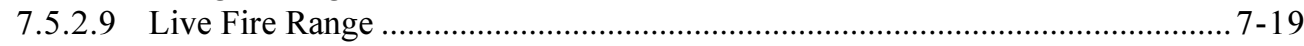

7.5.2.10 Building 830 ....................................................................................... $7-19$

7.6 Environmental Restoration Groundwater Monitoring Program ................................................ 7-20

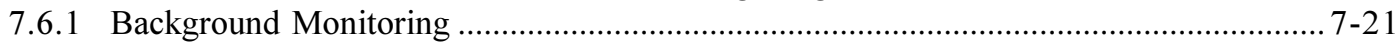

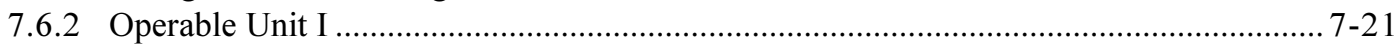


7.6.2.1 Former Landfill, Animal/Chemical Pits, and Glass Holes ............................... 7-21

7.6.2.2 Current Landfill ..........................................................................................

7.6.2.3 Current Landfill/HWMF Plume ……………............................................... 7-25

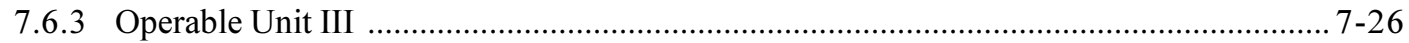

7.6.3.1 OU III Volatile Organic Compound Plumes ………………………............... 7-28

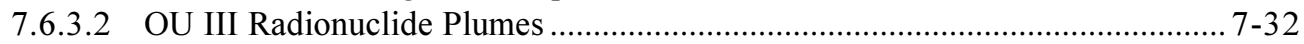

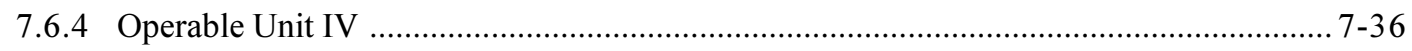

7.6.4.1 1977 Oil-Solvent Spill Site ......................................................................... 7-36

7.6.4.2 Building 650 and 650 Sump Outfall Areas (AOC 6) ……………………...... 7-36

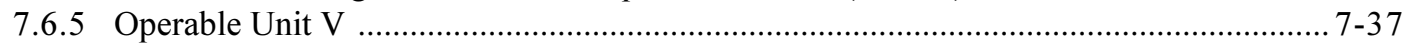

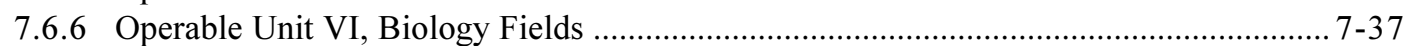

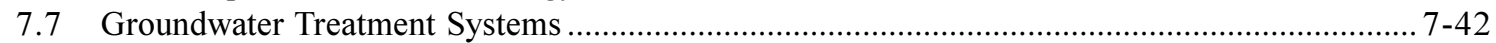

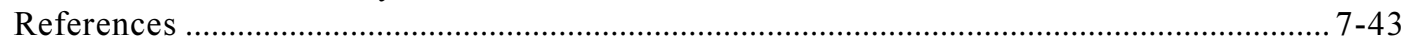

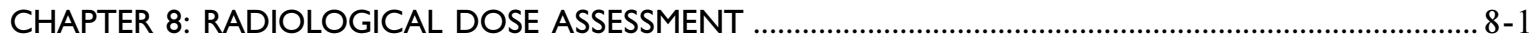

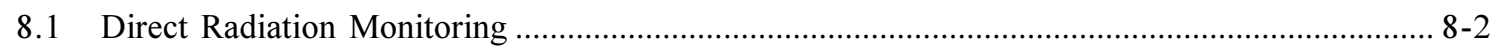

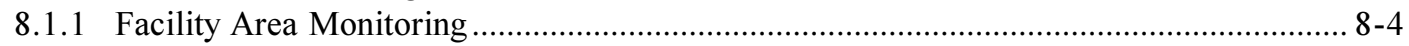

8.1.2 Building 650 Sump Outfall Monitoring ………....................................................... 8-6

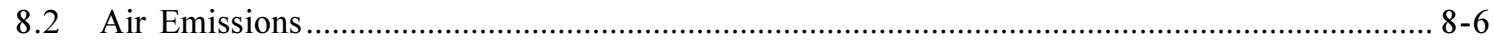

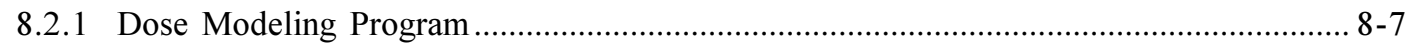

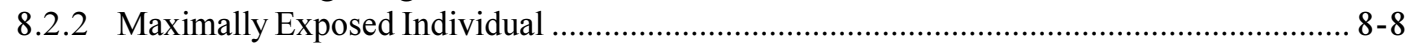

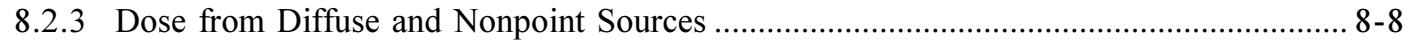

8.2.3.1 Insulating Gas in the TVDG Accelerator ........................................................ 8-8

8.2.3.2 Brookhaven Graphite Research Reactor - Below Ground Duct Filters /

Coolers Removal .................................................................................... 8-8

8.2.3.3 Brookhaven Graphite Research Reactor - Water Treatment House,

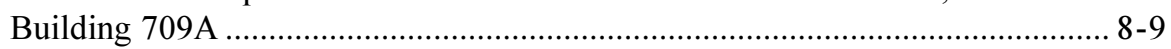

8.2.3.4 Brookhaven Graphite Research Reactor - Lower Canal and Water Treatment House Removal ............................................................................... 8-9

8.2.3.5 Brookhaven Graphite Research Reactor - Temporary HEPA Filtered Hood ..... 8-9

8.2.3.6 Building 830 Vault, B-25s, and Drums ………........................................ 8-9

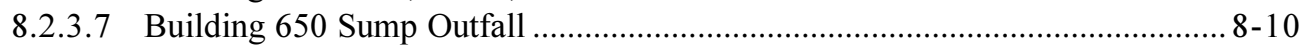

8.2.3.8 Building 811, Underground Storage Tanks ……........................................ 8-10

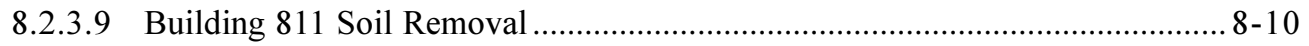

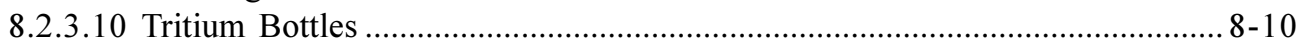

8.2.3.11 Plasma Torch Cutting Project .................................................................... 8-11

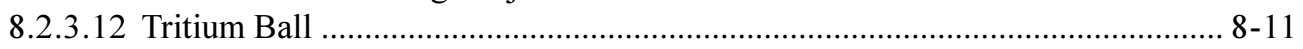

8.2.3.13 Proposed Booster Applications Facility ....................................................... 8-11

8.2.3.14 The V - Target Area, Building 919 ................................................................ 8-11

8.2.3.15 Special Experimental Magnets System Cooling Towers ………………......... 8-11

8.2.3.16 Liquid Effluent Storage Tankers …………..................................................... 8-11

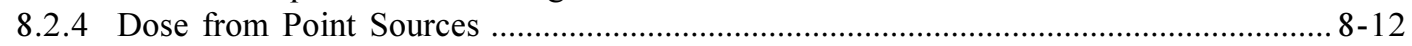

8.2.4.1 Building 931: The Brookhaven Linac Isotope Producer .................................. 8-12

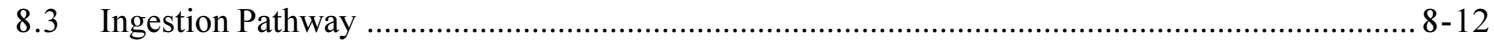

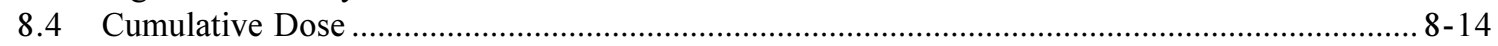

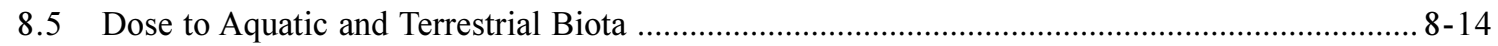

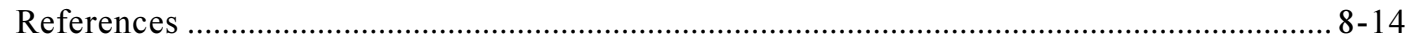

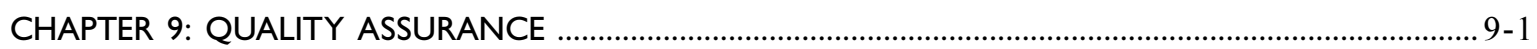

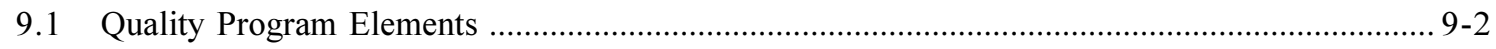

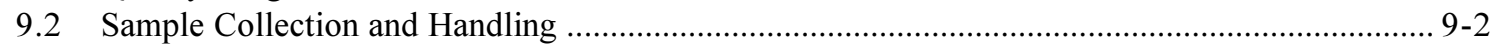

9.2.1 Field Sample Handling ......................................................................................... 9-4

9.2.1.1 Custody and Documentation .......................................................................... 9-4 


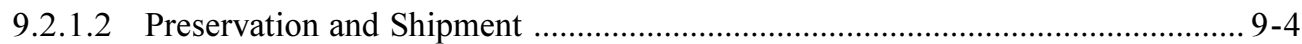

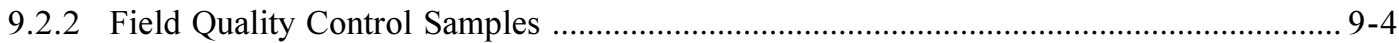

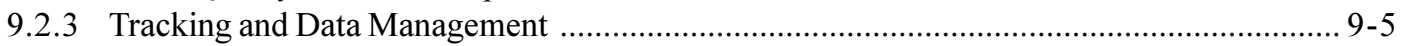

9.2.3.1 Sample Tracking …………..................................................................... 9-5

9.2.3.2 Data Management ......................................................................................... 9-5

9.2.3.3 Distribution of Analytical Data …………..................................................... 9-6

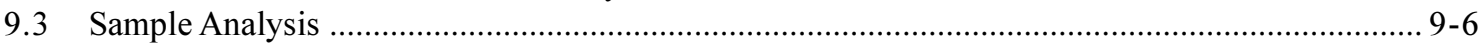

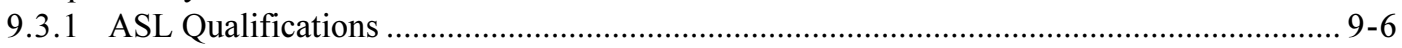

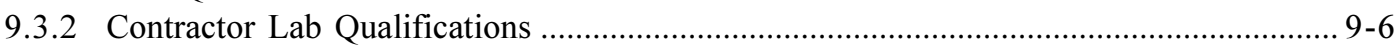

9.4 Verification and Validation of Analytical Results ........................................................................... 9-6

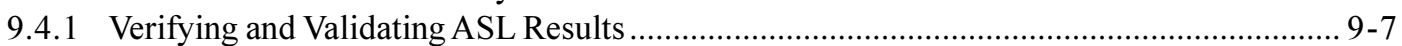

9.4.2 Verifying and Validating Off-Site Results ...................................................................... 9-7

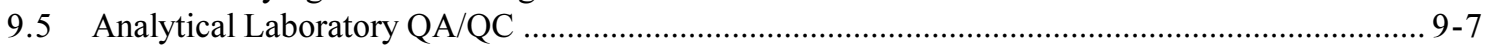

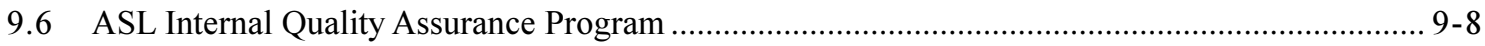

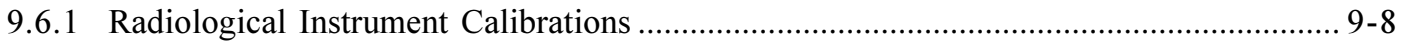

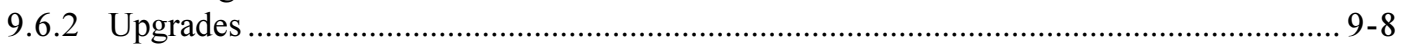

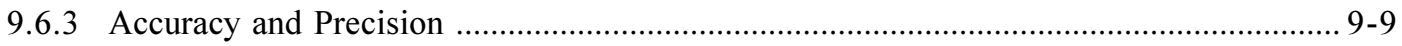

9.6.3.1 Gross Alpha/Beta ………...................................................................... 9-9

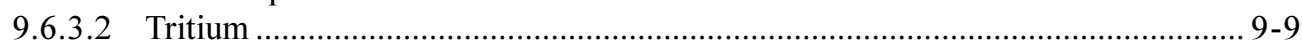

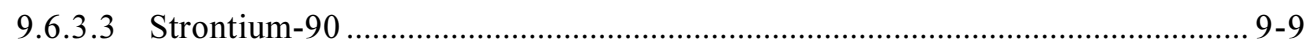

9.6.4 Nonradiological Organic and Inorganic Analyses ......................................................... 9-9

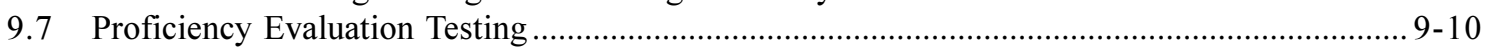

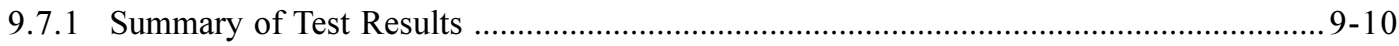

9.7.2 Radiological Assessments _....................................................................................... 9-10

9.7.2.1 Table F-2: EML Radiological Results ........................................................ 9-10

9.7.2.2 Table F-3: ELAP Radiological Results ………........................................... 9-12

9.7.2.3 Table F-4: ERA Radiological Results …….................................................... 9-12

9.7.3 Nonradiological Assessments ................................................................................. $9-12$

9.7.3.1 Table F-5: ELAP Nonpotable Water Results ................................................... 9-12

9.7.3.2 Table F-6: ELAP Solid and Hazardous Waste Chemistry ……………............... 9-12

9.7.3.3 Table F-7: ELAP Potable Water Results .......................................................... 9-12

9.7.3.4 Table F-8: Voluntary ERA PE Studies ....................................................... 9-12

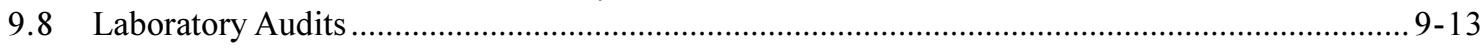

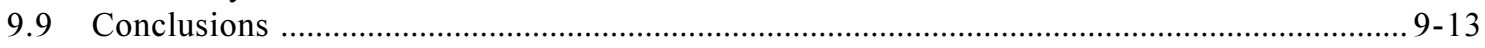

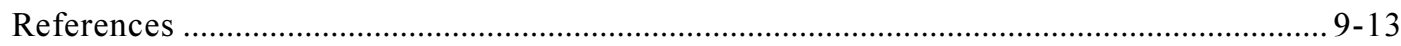

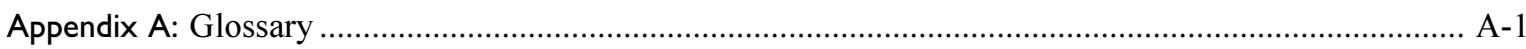

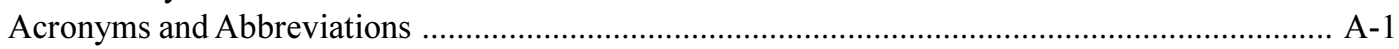

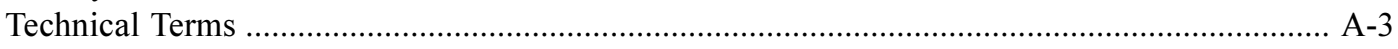

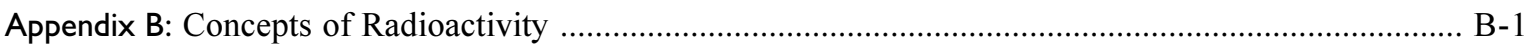

Appendix C: Radiological Data Methodologies .................................................................................. C-1

Appendix D: Instrumentation and Analytical Methods ......................................................................... D-1

Appendix E: Groundwater Monitoring Wells List for 2001 ..................................................................... E-1

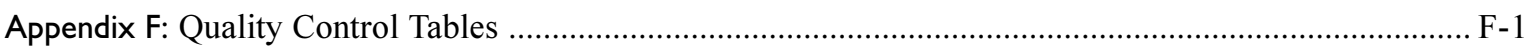

Back Cover: Helpful Information on Units of Measure and Conversions 


\section{List of Figures}

Figure 1-1. Collision Event Recorded by the PHOBOS Detector on July 18, 2001.................................................. 1-4

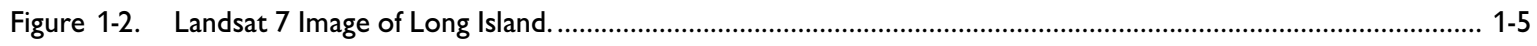

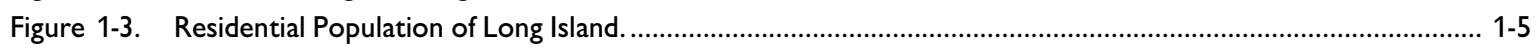

Figure 1-4. Number of BNL Employees Residing in Nearby Towns. .......................................................................... 1-6

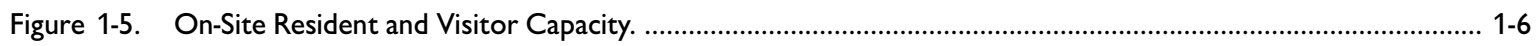

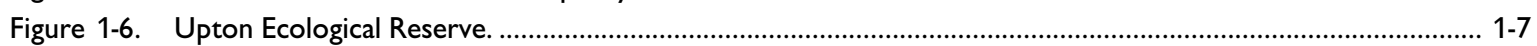

Figure 1-7. Major Scientific Facilities at Brookhaven National Laboratory. ....................................................................... 1-9

Figure 1-8. Major Brookhaven Support and Service Facilities. ............................................................................... 1-10

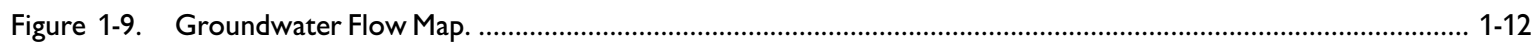

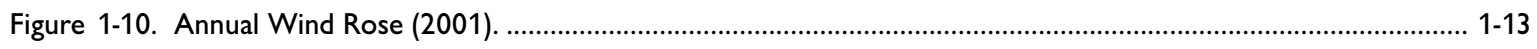

Figure 1-11. 2001 Monthly Precipitation versus 53-Year Monthly Average. ..................................................................... 1-14

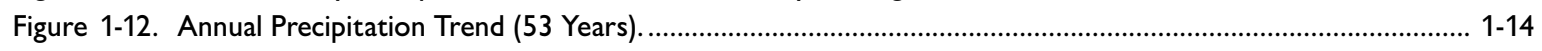

Figure 1-13. 2001 Monthly Mean Temperature versus 53-Year Monthly Average. ........................................................ 1-15

Figure 1-14. Annual Mean Temperature Trend (53 Years) . .................................................................................. 1-15

Figure 2-1. BNL ISO 14001 Registration Certificate and Environmental Stewardship Policy. ......................................... 2-2

Figure 2-2. Key Elements of the BNL EMS and their Relationship to Each Other. ...................................................... 2-3

Figure 2-3. Environmental Management System and Supporting Subject Areas in the Standards Based Management System........................................................................................... 2-7

Figure 2-4. Hierarchy of Environmental Objectives at BNL - an Example for Operational Excellence. ............................. 2-7

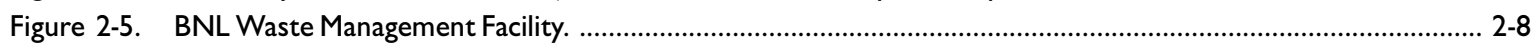

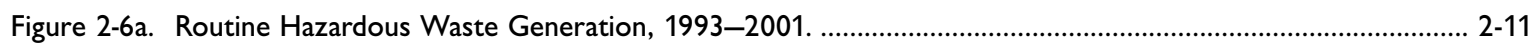

Figure 2-6b. Routine Mixed Waste Generation, 1993-2001...................................................................................... 2-11

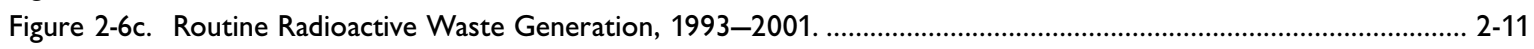

Figure 2-6d. ER and Nonroutine Hazardous Waste Generation 1997-2001.............................................................. 2-12

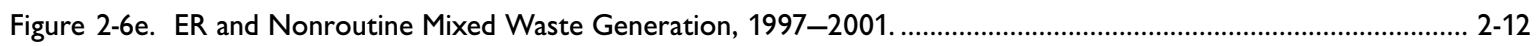

Figure 2-6f. ER and Nonroutine Radioactive Waste Generation, 1997-2001......................................................... 2-12

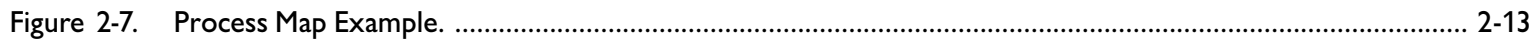

Figure 2-8. Water Consumption Trend............................................................................................................... 2-20

Figure 2-9. Building Energy Performance Since 1985 ......................................................................................... 2-21

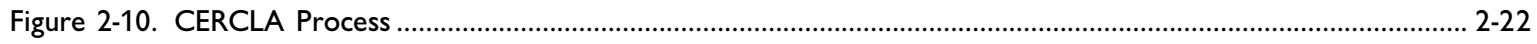

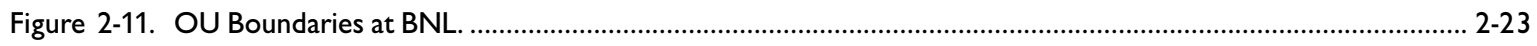

Figure 2-12. Environmental Restoration Actions Taken during 2001. ...................................................................... 2-25

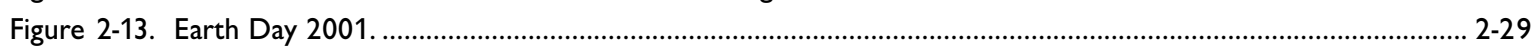

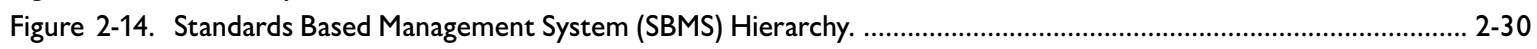

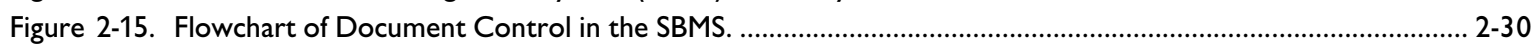

Figure 2-16. Gunnite Cap Installed Over g-2 Area Prevents Rainwater from Reaching the Activated Soils and Potentially Contaminating the Groundwater. ........................................................................................ 2-31

Figure 3-1. Maximum Concentration of Copper Discharged from the BNL Sewage Treatment Plant, 1997-2001. ....... 3-12

Figure 3-2. Maximum Concentration of Iron Discharged from the BNL Sewage Treatment Plant, 1997-2001. ............ 3-12

Figure 3-3. Maximum Concentration of Lead Discharged from the BNL Sewage Treatment Plant, 1997-2001. ........... 3-12

Figure 3-4. Maximum Concentration of Silver Discharged from the BNL Sewage Treatment Plant, 1997-2001.......... 3-13

Figure 3-5. Maximum Concentration of Nickel Discharged from the BNL Sewage Treatment Plant, 1997-2001. ........ 3-13

Figure 3-6. Maximum Concentration of Zinc Discharged from the BNL Sewage Treatment Plant, 1997-2001............ 3-13

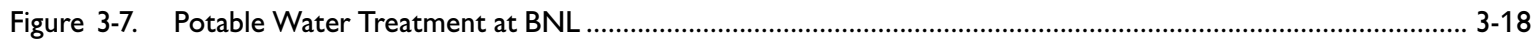

Figure 4-1. Air Emission Release Points Subject to Continuous Monitoring. .............................................................. 4-2 
Figure 4-2. High Flux Beam Reactor Tritium Emissions, Ten-Year Trend (1992-2001). ................................................ 4-4

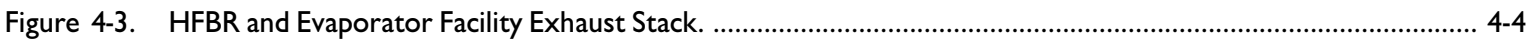

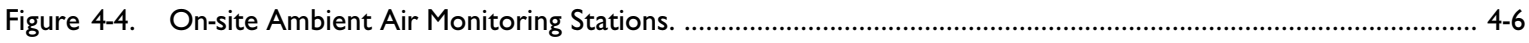

Figure 4-5. Airborne Gross Beta Concentration Trend Recorded at Station P7. .......................................................... 4-8

Figure 5-1. Photo of Peconic River West of Monitoring Station HMn........................................................................ 5-2

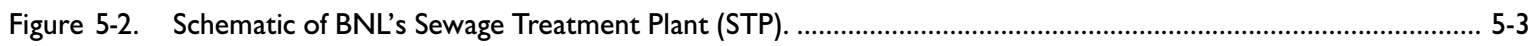

Figure 5-3. Tritium Concentrations in Effluent from the Sewage Treatment Plant (CY 2001)....................................... 5-6

Figure 5-4. Average Tritium Concentrations at BNL's Sewage Treatment Plant,

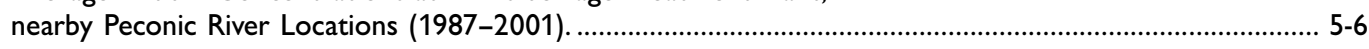

Figure 5-5. Tritium Released to the Peconic River, 15-Year Trend (1987-2001). ........................................................ 5-6

Figure 5-6. Cesium-137 in the Sewage Treatment Plant Influent and Effluent (1990-2001)........................................... 5-8

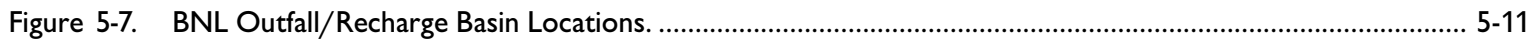

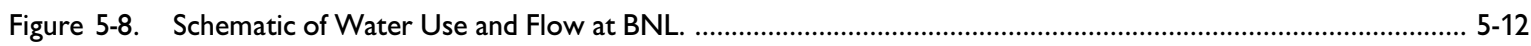

Figure 5-9. Sampling Stations for Surface Water, Fish, and Shellfish...................................................................... 5-17

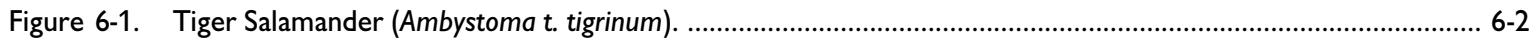

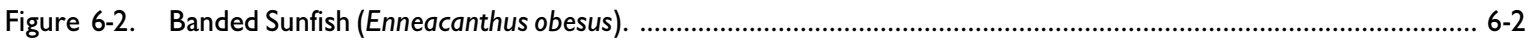

Figure 6-3. Swamp Darter (Etheostoma fusiforme). ....................................................................................................... 6-2

Figure 6-4. BNL Site Map Indicating the Boundary of the Upton Ecological and Research Reserve. ................................ 6-6

Figure 6-5. Distribution of Samples across Concentration Ranges of CS-137

in Deer Meat Samples Taken 1996-2001................................................................................................... 6-12

Figure 6-6. Five Year Trend of Cesium-137 Average Concentrations in Meat Taken

from On-Site and Off-Site Deer (1997-2001) ............................................................................................ 6-12

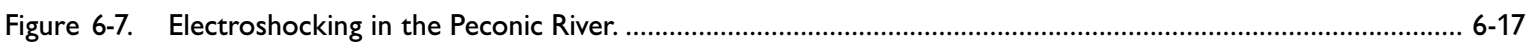

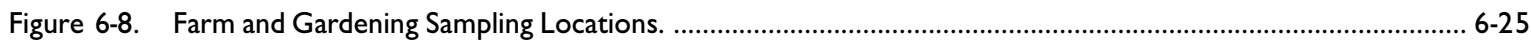

Figure 6-9. Summer Intern Working on Tiger Salamander Ecology. ……..................................................................... 6-28

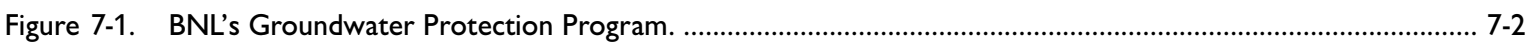

Figure 7-2. Groundwater Protection Performance during 2001. ................................................................................. 7-4

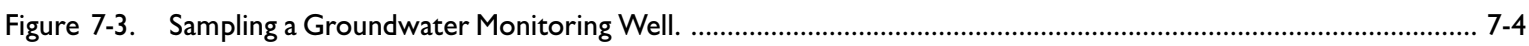

Figure 7-4 Locations of BNL Groundwater Monitoring Wells. .................................................................................. 7-6

Figure 7-5. Groundwater Flow and Water Table Elevation (June 2001) . .......................................................................... 7-7

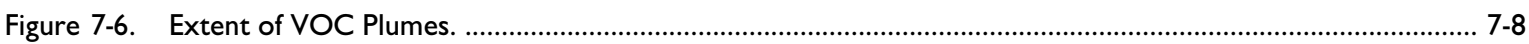

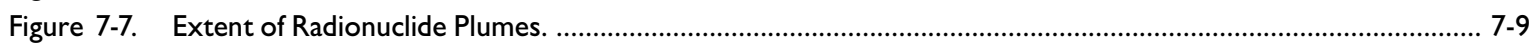

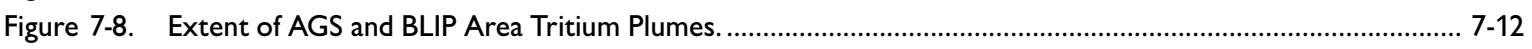

Figure 7-9. Operable Unit I TVOC Plume Comparisons - 1997 and 2001. ................................................................ 7-22

Figure 7-10. Former Landfill, Animal/Chemical Pits and Glass Holes Strontium-90 Plume Map. ...................................... 7-24

Figure 7-11. Former Hazardous Waste Management Facility Strontium-90 Plume. ........................................................... 7-27

Figure 7-12. Operable Unit III TVOC Plume Comparisons - 1997 and 2001. ................................................................ 7-29

Figure 7-13. High Flux Beam Reactor Tritium Plume Comparisons - 1997 and 2001................................................. 7-34

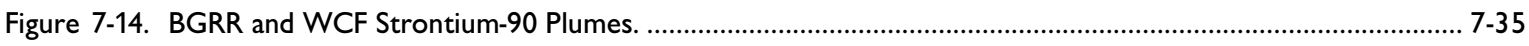

Figure 7-15. Operable Unit IV, Area of Concern 6, Strontium-90 Plume. ................................................................... 7-38

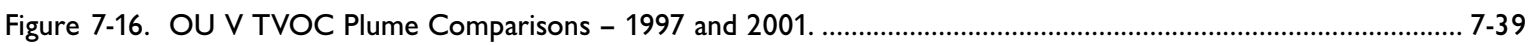

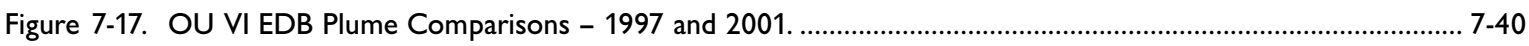

Figure 7-18. Locations of BNL Groundwater Remediation Systems. .......................................................................... 7-41

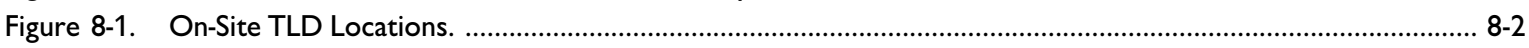

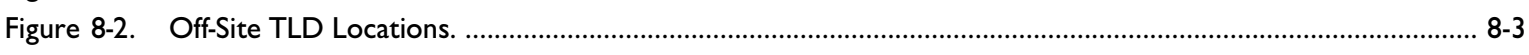

Figure 9-1. Flow of Environmental Monitoring QA/QC Program Elements .................................................................. 9-3

Figure 9-2. Radiological Results Summarized: Labs' Scores in US DOE/EML, NYSDOH ELAP,

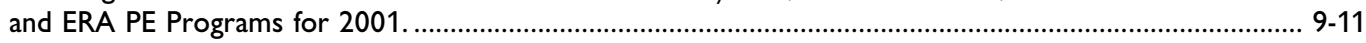

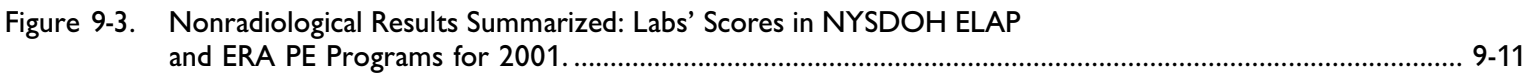

Figure B-1. Typical Annual Radiation Doses from Natural and Man-Made Sources (mrem). ........................................... B-2 


\section{List of Tables}

Table 2-1. BNL's Criteria for Significant Environmental Aspects. ................................................................................... 2-5

Table 2-2. BNL Pollution Prevention, Waste Reduction, and Recycling Projects. ......................................................... 2-15

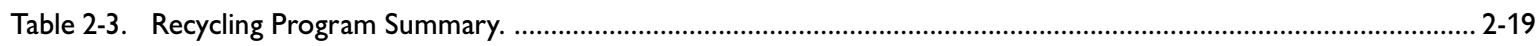

Table 2-4. Hierarchy of Environmental Objectives at BNL. ........................................................................................... 2-24

Table 2-5. Category, Risk Rank, Number, and Status of Issues Identified in the Facility Review Project,

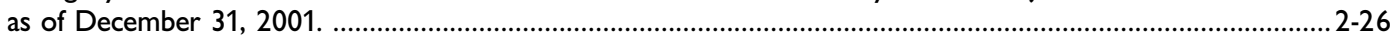

Table 2-6. Summary of BNL Sampling Program Sorted by Media. ................................................................................. 2-32

Table 3-1. Federal, State, and Local Environmental Statutes and Regulations Applicable to BNL. ...................................... 3-3

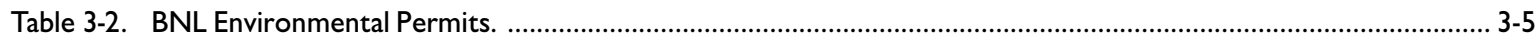

Table 3-3. Analytical Results for Wastewater Discharges to Sewage Treatment Plant Outfall 001. ................................ 3-11

Table 3-4. Analytical Results for Wastewater Discharges to Sewage Treatment Plant Outfalls 002-008 and 010. ......... 3-15

Table 3-5. Potable Water Wells and Potable Distribution System: Bacteriological, Inorganic Chemical, and Radiological Analytical Results (Maximum Concentration, Minimum pH Value). .......................................... 3-20

Table 3-6. Potable Water Wells: Analytical Results for Principal Organic Compounds, Synthetic Organic Chemicals, Pesticides, and Micro-Extractables. ....................................................................... 3-21

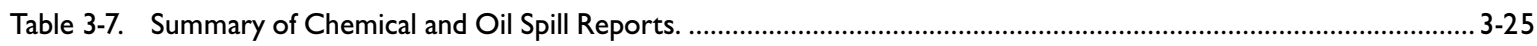

Table 3-8. Summary of Other Environmental Occurrence Reports. ............................................................................... 3-27

Table 3-9. Existing Agreements and Enforcement Actions Issued to BNL, with Status. .................................................... 3-35

Table 4-1. Airborne Radionuclide Releases from Monitored Facilities. ............................................................................ 4-3

Table 4-2. Gross Activity Detected in Facility Air Particulate Filters. ................................................................................. 4-7

Table 4-3. Gross Activity Detected in Air Particulate Filters ........................................................................................... 4-7

Table 4-4. Ambient Airborne Tritium Measurements. ............................................................................................................. 4-9

Table 4-5. Ambient Tritium Monitoring Results at RA V Recharge Basin. ......................................................................... 4-10

Table 4-6. Central Steam Facility Fuel Use and Emissions (1996-2001). ........................................................................... 4-11

Table 5-1. Tritium and Gross Activity in Water at the Sewage Treatment Plant. ............................................................... 5-5

Table 5-2. Gamma-Emitting Radionuclides and Strontium-90 in Water at the Sewage Treatment Plant. .............................. 5-7

Table 5-3. Average Water Quality and Analysis of Metals in Water at the Sewage Treatment Plant. ................................. 5-9

Table 5-4. Radiological Analysis of Samples from On-Site Recharge Basins. ...................................................................... 5-13

Table 5-5. Water Quality Data for Samples from On-Site Recharge Basins. .................................................................... 5-14

Table 5-6. Analysis of Metals in Samples from On-Site Recharge Basins. ........................................................................ 5-15

Table 5-7. Radiological Results for Surface Water Samples Collected along the Peconic and Carmans Rivers. ................. 5-19

Table 5-8. Water Quality Data for Surface Water Samples Collected along the Peconic and Carmans Rivers. .................. 5-20

Table 5-9. Analysis of Metals in Surface Water Samples Collected along the Peconic and Carmans Rivers. ....................... 5-21

Table 6-1. New York State Threatened, Endangered, and Species of Special Concern. .................................................... 6-3

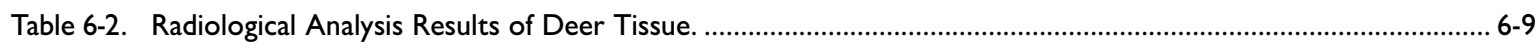

Table 6-3. Radiological Analysis of Small Mammals (Squirrels). .....................................................................................13

Table 6-4. Radiological Analysis of Goose Fecal Material, Associated Grass Clippings, and Soil. ...................................... 6-14

Table 6-5. Radiological Analysis of Fish from the Peconic River System and Control Location. ........................................ 6-16

Table 6-6. BNL Peconic River (STP to HMn) Population Survey Results. ............................................................................. 6-17

Table 6-7. Metals Analysis of Fish and Shellfish from the Peconic River System and Control Locations. ............................. 6-18

Table 6-8. Pesticide and PCB Analysis in Fish and Shellfish from the Peconic River System and Control Locations. .......... 6-20

Table 6-9. Radiological Analysis Results for Shellfish, Aquatic Vegetation, Water, and Sediment. ....................................... 6-22

Table 6-10. Metals Analysis in Aquatic Vegetation, Water, and Sediments from the Peconic River System, Bays, and Control Locations.

Table 6-11. Pesticide and PCB Analysis of Aquatic Vegetation, Water, and Sediments from the Peconic River System, Bays, and Control Locations. 


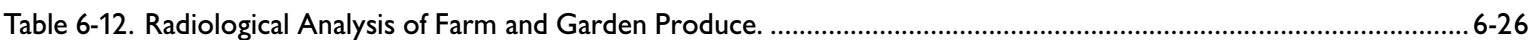

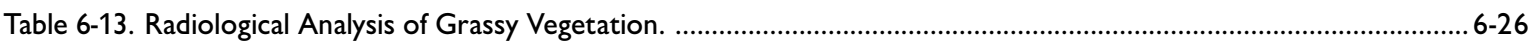

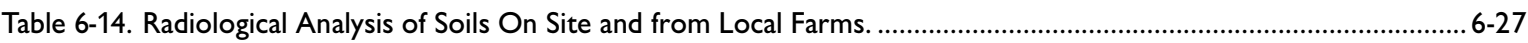

Table 7-1. Potable and Process Well Radiological Analytical Results. .............................................................................. 7-10

Table 7-2. Groundwater Remediation Systems Treatment Summary for 1997 - 2001. .................................................... 7-42

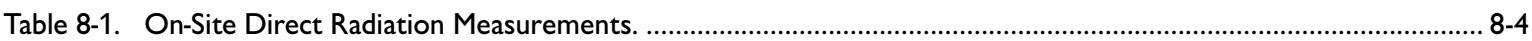

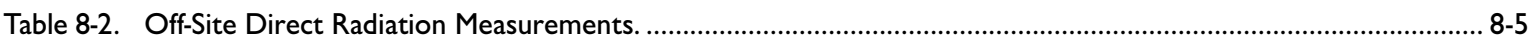

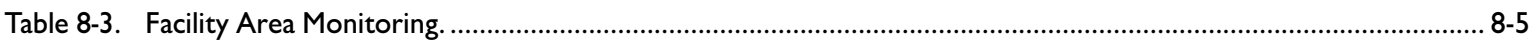

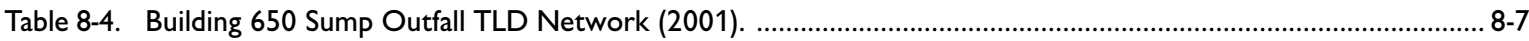

Table 8-5. Effective Dose Equivalent from Airborne Emissions. .................................................................................. 8-13

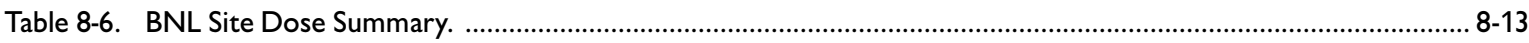

Table C-1. Typical Minimum Detection Limits for Gross Activity and Tritium Concentrations in Water.............................. C-2

Table C-2. Typical Minimum Detection Limits for Gamma Spectroscopy Analysis. ................................................................. C-2

Table C-3. Typical Minimum Detection Limits for Chemical Analyses by BNL Analytical Services Lab

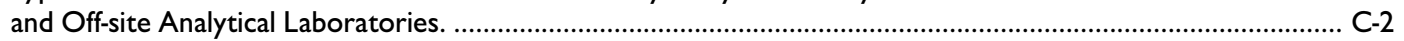

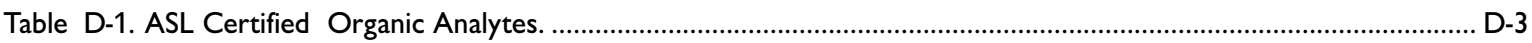

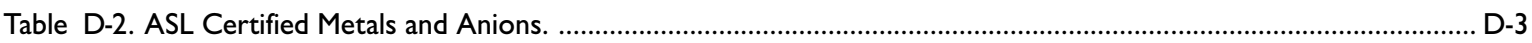

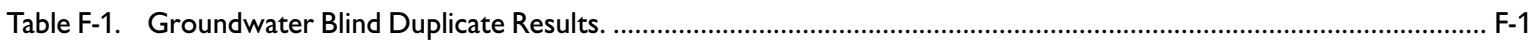

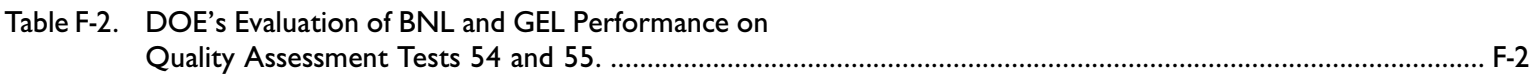

Table F-3. NYSDOH's Evaluation of the Potable Water Radiochemistry Testing Done by BNL and Two Contract Labs. ............................................................................................. F-3

Table F-4. Results for BNL and GEL on the InterLab RadCheM Proficiency Test Conducted by Environmental Resource Associates. ..................................................................................... F-3

Table F-5. NYSDOH's Evaluation of the Nonpotable Water Testing Performed by BNL and Contract Labs.

Table F-6. NYSDOH's Evaluation of BNL Performance on Proficiency Tests 240 and 245 (Solid and Hazardous Waste Chemistry).

Table F-7. NYSDOH's Evaluation of the Potable Water Testing Performed by BNL and Contract Labs.

Table F-8. Independent Company's Evaluation of Water Supply and Pollution Studies Performed by BNL and Contract Lab. 
B ROOKHAVEN

NATIONAL

LABORATORY

2001 SITE ENVIRONMENTAL REPORT

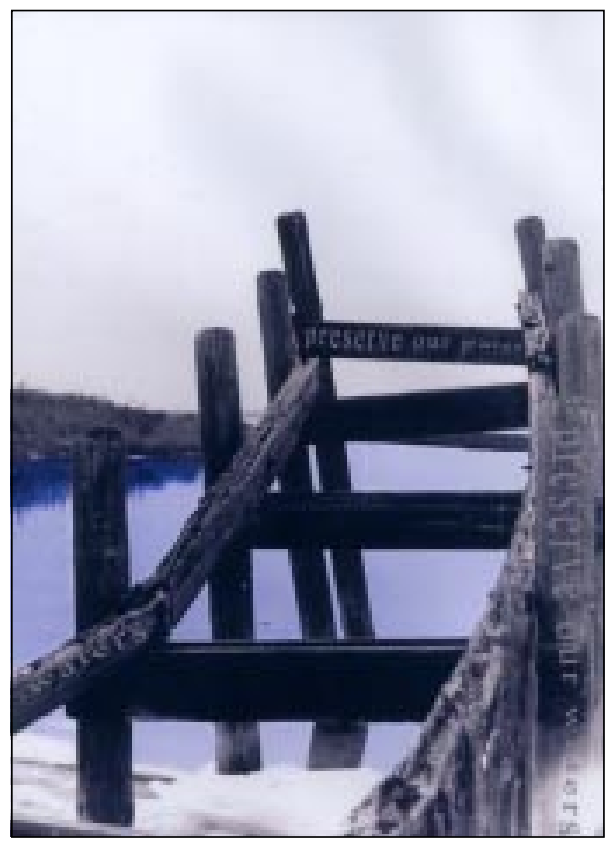

Chapter 1

\section{Introduction}

Brookhaven National Laboratory, a U.S. Department of Energy national laboratory, received the International Organization for Standardization (ISO) 14001 Certification in 2001 and is the first Office of Science national laboratory to obtain third-party registration to this globally recognized environmental management standard. Located in the center of the unique pine barrens ecosystem of Long Island, New York, Brookhaven National Laoratory is committed to conducting its mission of research and education in a safe and environmentally responsible manner. The Laboratory prepares this Site Environmental Report annually to summarize the status of its environmental programs and performance. This report also describes impacts, both past and present, that Laboratory operations have had on the environment. Chapter 1 describes the site's facilities, ecological resources, demographics, and history. Chapter 1 also discusses local characteristics in terms of geology, hydrology, and climate, providing background material for the technical information in the chapters that follow. 


\subsection{PURPOSE OF THIS REPORT}

The U.S. Department of Energy (DOE) requires its facilities, including Brookhaven National Laboratory (BNL), to establish environmental programs and report annually on environmental performance. The Site Environmental Report (SER) is prepared in accordance with DOE Order 231.1, "Environment, Safety and Health Reporting," and confirms compliance with DOE Order 5400.5, "Radiation Protection of the Public and Environment." Additionally, DOE Order 5400.1, "General Environmental Protection Program," establishes the requirement for environmental protection programs. SERs inform BNL staff, DOE, regulators, and the public and provide an historical record of the environmental condition of the site.

The 2001 SER describes the status and results of BNL's environmental protection programs for calendar year 2001. BNL has been preparing annual SERs continuously since 1968 . In June 2001, BNL published Radiological Emissions and Environmental Monitoring for Brookhaven National Laboratory, 1947-1961 (Meinhold and Meinhold 2001). Combined with Radiological Environmental Monitoring Report for Brookhaven National Laboratory 1967-1970 (Meinhold and Hull 1998) and individual reports for the years 1962 through 1966, BNL has now recorded and compiled nearly all of its environmental history since the Laboratory's inception in 1947.

This chapter provides background material to support the technical information in the chapters that follow. Chapter 2 describes BNL's environmental management system and programs, including pollution prevention and environmental restoration. Chapter 3 summarizes BNL's compliance with the wide variety of environmental regulations and permits that govern site operations. Chapters 4 through 7 discuss specific programs and data by environmental media, including air (Chapter 4), water (Chapter 5), natural and cultural resources (Chapter 6), and groundwater (Chapter 7). Chapter 8 provides information on radiological dose to individuals and fauna. Chapter 9 describes how BNL ensures that the data used to monitor environmental impact are of high quality and accuracy. The appendices provide definitions of technical terms, an explanation of the concepts of radioactivity, radiological data methodologies, analytical methods and instrumentation used, identification of the groundwater monitoring wells, and the quality control tables associated with quality assurance.

The SER is available as a downloadable file on the BNL web page, and as a condensed version in a separate Summary Booklet, along with a $C D$ version of this report (see inside front cover for ordering information). This information is available in several formats to provide easily accessible environmental information to BNL's stakeholders. The Summary Booklet provides information to visitors, students, and members of the public in support of BNL's educational and community outreach program.

\subsection{MISSION}

BNL's role for DOE is to produce excellent science and advanced technology in a safe, environmentally responsible manner with the cooperation, support, and appropriate involvement of the scientific and local communities. The four key DOE missions are Energy Resources, Science and Technology, Environmental Quality, and National Security. The elements of BNL's mission that support these key DOE missions are the following:

- To conceive, design, construct, and operate complex, leading-edge, user-oriented facilities in a safe, environmentally benign manner that is responsive to DOE and the needs of the international community of users.

- To carry out basic and applied research in long-term programs at the frontier of physical, chemical, life, and environmental sciences in support of DOE's missions.

- To develop advanced technologies that address national needs and to transfer them to other organizations and to the commercial sector.

- To disseminate technical knowledge, to educate new generations of scientists and engineers, to maintain technical capabilities in the nation's workforce, and to encourage scientific awareness in the general public. BNL's policy is to integrate environmental 
stewardship into all facets of the Laboratory's mission and operations. Figure 2-1 (in Chapter 2) shows BNL's Environmental Stewardship Policy, which represents the highest level of commitment to conducting research and operational activities in a manner that protects the ecosystem and the health of employees and the public.

\subsection{OPERATIONS}

Brookhaven National Laboratory conducts research in physics, biomedical, and environmental sciences, as well as in energy technologies. BNL also builds and operates major facilities available to university, industrial, and government scientists. BNL is operated for DOE by Brookhaven Science Associates (BSA), a notfor-profit partnership between Battelle Memorial Institute and the Research Foundation of the State University of New York on behalf of the State University of New York at Stony Brook. BSA began operating the Laboratory on March 1, 1998 under DOE Contract No. DEAC02-98CH10886.

BNL, home to many world-class research facilities and scientific departments, attracts resident and visiting scientists in many fields. Approximately 3,000 resident scientists, engineers, technicians, and support staff work at BNL. More than 4,000 academic and industrial researchers from all over the world visit the site each year to participate in scientific collaborations. Just a few of the scientific discoveries at BNL include promising cocaine addiction treatment, discovery of new subatomic particles, Ldopa used for medical treatments for Parkinson's disease, advances in biotechnology for cleaning up pollution, asbestos-digesting foam, advanced energy technology studies, the quiet jackhammer, and a patent for long-life rechargeable batteries. In 2001, BNL was ranked among the top five major institutions worldwide in terms of the impact of its environmental research, and DOE recognized BNL with three Energy 100 Awards for scientific and technological achievements that have contributed to society by helping consumers save money and improve their quality of life. The three areas of research recoginized were studies of drug addiction and drug action using the imaging technique called positron emission tomography (PET), the invention of the Flame Quality Indicator (a device that measures flame brightness in oil burners), and the development of techniques for preventing and diagnosing Lyme disease.

BNL's annual budget is approximately $\$ 450$ million. Most of this budget directly supports the local economy through wages and purchases of materials and services. BNL is the largest employer in eastern Long Island. In fiscal year 2001, BNL purchased more than \$24 million worth of supplies and services from Long Island businesses. Employee salaries, wages, and fringe benefits accounted for 57 percent, or $\$ 258$ million, of BNL's total budget. Additionally, most of the 3,000 BNL employees live and shop locally in Suffolk County and throughout Long Island (see Section 1.5). An independent Suffolk County Planning Commission report concluded that BNL's spending for operations, procurement, payroll, construction, medical benefits, and technology transfer spreads throughout Long Island's economy, making BNL vital to Long Island's economic health (Kamer 1995).

\subsection{HISTORY}

BNL was founded in 1947 by the Atomic Energy Commission. The objective was to build a regional laboratory that could provide researchers with powerful tools too costly for their home institutions to build and maintain. Although BNL no longer operates any research reactors, the Laboratory's first major scientific facility was the Brookhaven Graphite Research Reactor (BGRR), which began operations in 1950. The BGRR was used for peaceful scientific exploration in the fields of medicine, biology, chemistry, physics, and nuclear engineering. The BGRR operated until 1969 and is now being decommissioned. Its capacity was replaced and surpassed in 1965 by the High Flux Beam Reactor (HFBR), which provided neutrons to researchers of all disciplines, from solid state physics to art history. During a scheduled maintenance shutdown in 1997, a leak in the HFBR's spent fuel storage pool was discovered. In November 1999, the Secretary of Energy made a decision to permanently close the HFBR. 
Medical research at BNL began in 1950 with the opening of one of the first hospitals devoted to nuclear medicine. It was followed by the Medical Research Center in 1958, the Brookhaven Medical Research Reactor (BMRR) in 1959, and the Brookhaven Linac Isotope Producer (BLIP) in 1973. Chemists and physicians could view the inner workings of the brain in 1977 with the advent of positron emission tomography cameras. Two more imaging techniques were added to the PET research efforts to form the Center for Imaging and Neuroscience in 1996. Except for the BMRR, all of these medical facilities are currently operating. Due to a reduction of research funding, the BMRR conducted its last run on December 28, 2000. Since then, actions to place that facility in a safe, stabilized condition have been ongoing, and plans have been made to ship its spent fuel to DOE's Savannah River Site in the fall of 2002.

High-energy particle physics research at BNL began in 1952 with the Cosmotron, the first particle physics accelerator to achieve billionelectron-volt energies. Work at the Cosmotron resulted in a Nobel Prize-winning discovery in physics in 1957. In 1960, the Alternating Gradient Synchrotron (AGS), a much larger accelerator that surpassed the Cosmotron's capabilities, became operational. It has yielded many discoveries on new particles and phenomena, for which BNL researchers were awarded three additional Nobel Prizes in physics in 1976, 1980, and 1988. The AGS continues to operate. Another accelerator, the Tandem Van de Graaff, began operating in 1970 and continues operating to the present. In 1982, the National Synchrotron Light Source (NSLS) began operation. The NSLS guides charged particles in an orbit. As the electrons spin inside a hollow donut-shaped tube called an electron storage ring, they give off light called synchrotron light. This synchrotron light, which can be detected by specialized instruments, has many uses in both the physical and biological research sciences.

BNL's newest accelerator facility, the Relativistic Heavy Ion Collider (RHIC), began operation in 2000. This two-ringed particle accelerator has a circumference of 2.4 miles and has four detectors that are now recording full- energy collisions. The RHIC is expected to produce data that will give a clearer picture of what happens when gold ions collide at nearly the speed of light (Figure 1-1). The goal of this research is to recreate (on a microscopic scale) the hot, dense conditions that are thought to have existed when the universe first formed, so scientists can study the basic components of matter as they existed in its earliest form.

The RHIC is an example of BNL's commitment to fully integrate today's world-class science with world-class protection of the environment. In August 1999, the RHIC became the first facility at BNL and the first on Long Island to receive International Organization for Standardization (ISO) 14001 Environmental Management System certification (see Chapter 2 for details). In 2001, the entire BNL facility became ISO 14001 registered, becoming the first Office of Science national laboratory to obtain third-party registration to this globally recognized environmental standard.

It is unfortunate that historical operations and waste management practices at BNL led to releases of chemicals and radioactive materials that resulted in soil and groundwater contamination. In 1989, BNL was added to the federal Comprehensive Environmental Response, Compensation \& Liability Act (CERCLA) National Priorities List of environmentally contaminated sites identified for priority cleanup. In the past four years, BNL has made significant progress toward improving environmental

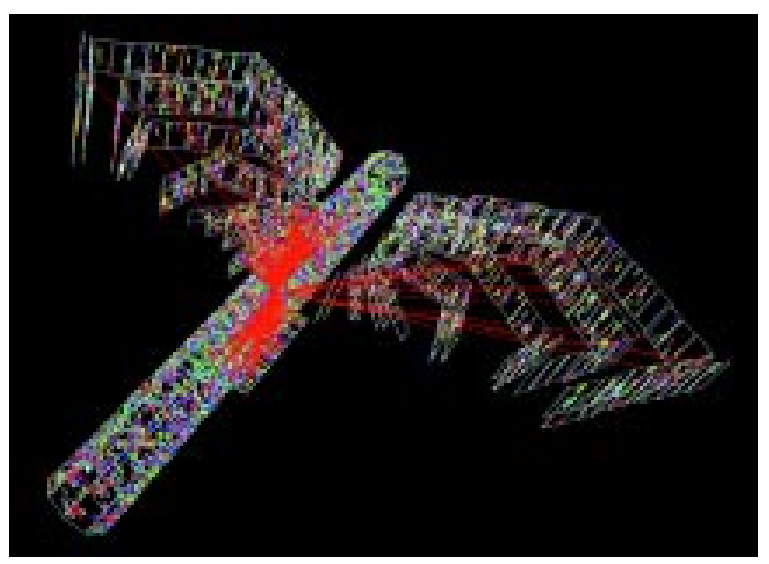

Figure 1-1. Collision Event Recorded by the PHOBOS Detector on July 18, 2001. 
operations and remediating past contamination (see Chapter 2 for details). In 2001, BNL received an "Excellent" performance rating from DOE for its environmental, health, and safety operational performance, and BNL's Environmental Management System was rated "Outstanding," which is the highest possible ranking.

\subsection{LOCATION AND LOCAL POPULATION}

$\mathrm{BNL}$ is located near the geographical center of Suffolk County, Long Island, New York. BNL is in Brookhaven Township, about 60 miles east of New York City (Figure 1-2). Nearly one-third of the 1.43 million people who reside in Suffolk County live in Brookhaven Township (LIPA 2001). Figure 1-3 shows the population distribution on parts of Long Island. As with all townships on Long Island, there has been an increase in residential housing in Brookhaven Township in recent years, a trend that is expected to continue. More than 75 percent of BNL's approximately 3,000 employees live within a 15-mile radius of the Laboratory (Figure 1-4).

Approximately 150 people reside long-term in the apartments and cottages on site, and many of the 4,000 scientists who visit each year stay short-term in on-site housing. Figure 1-5 shows the housing capacity for on-site residents and visitors. In addition to the resident staff and visiting scientists, more than 25,000 visitors participated in educational and public outreach activities conducted on site during 2001.

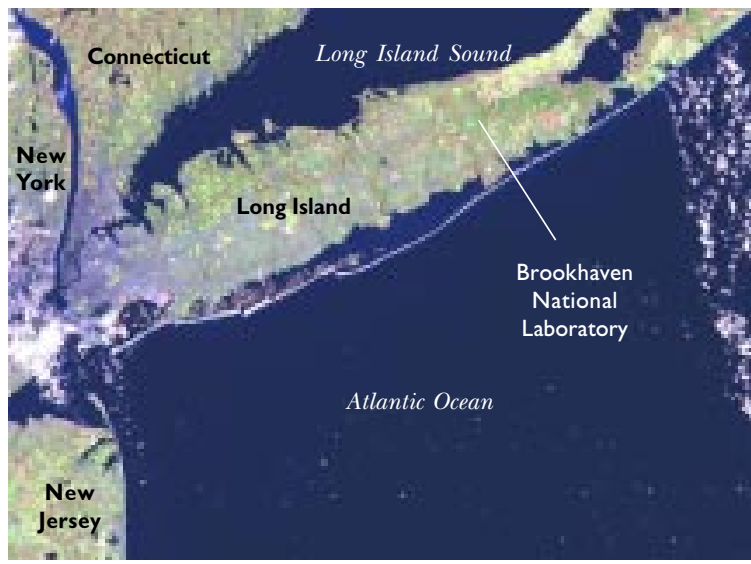

Figure 1-2. Landsat 7 Image of Long Island (courtesy of NASA).

\subsection{FACILITY AND OPERATIONS}

Most of BNL's principal facilities are located near the center of the 5,265-acre site. The developed area is approximately 1,650 acres, consisting of approximately

- 500 acres originally developed by the Army (as part of Camp Upton) and still used for offices and other operational buildings

- 200 acres occupied by large, specialized research facilities

- 550 acres occupied by outlying facilities, such as the Sewage Treatment Plant, research agricultural fields, housing facilities, and fire breaks

- 400 acres of roads, parking lots, and connecting areas.

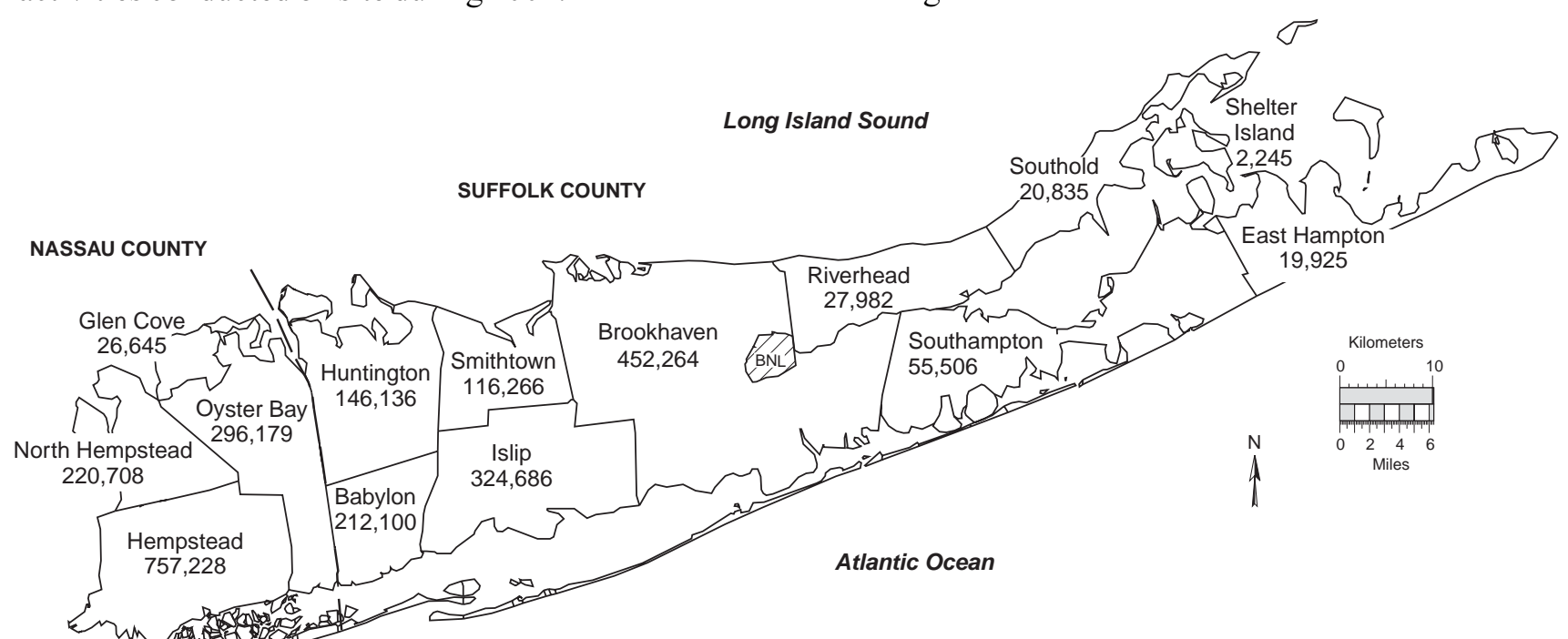

Figure 1-3. Residential Population of Long Island (source: LIPA 2001). 

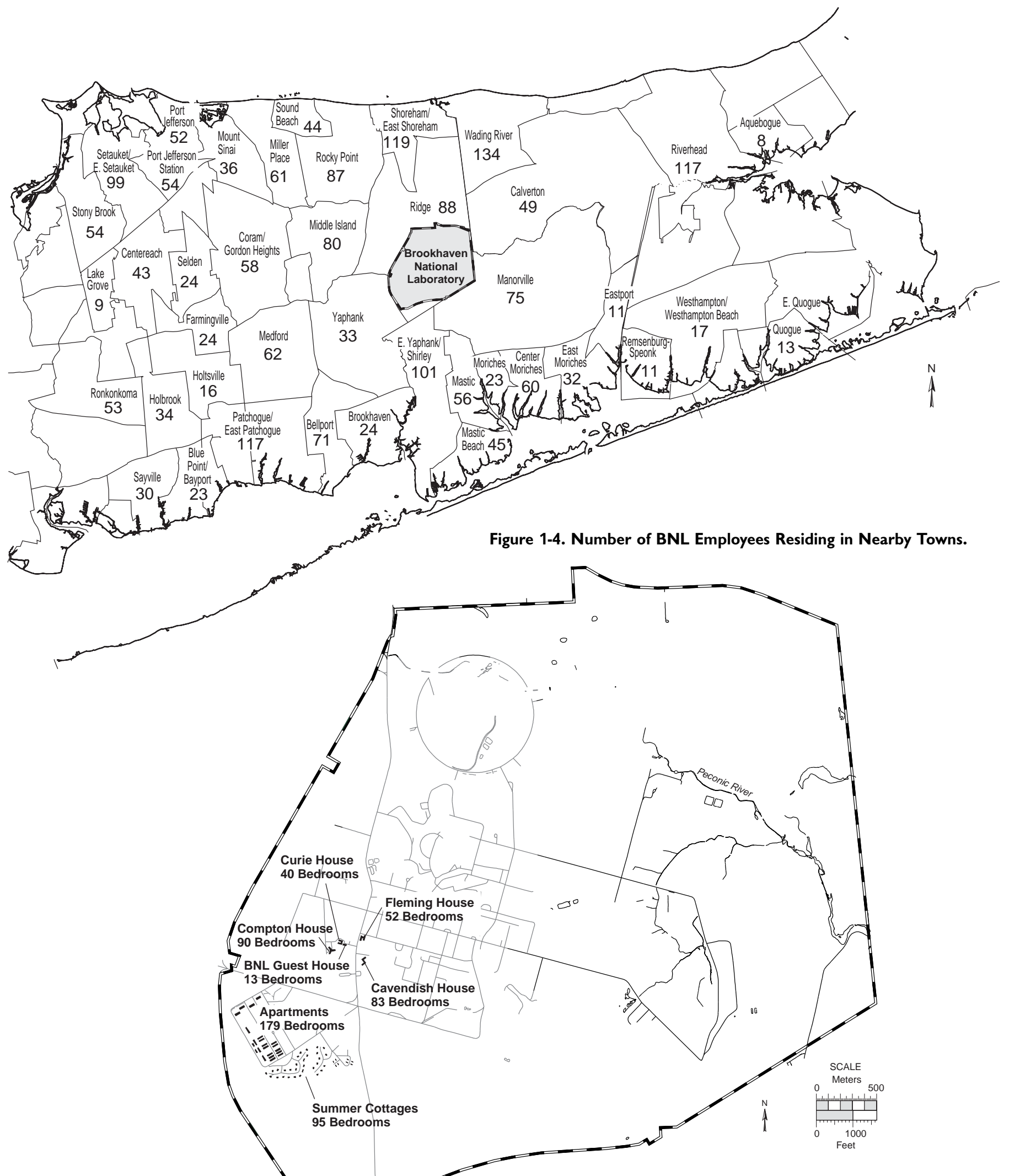

Figure 1-5. On-Site Resident and Visitor Capacity. 


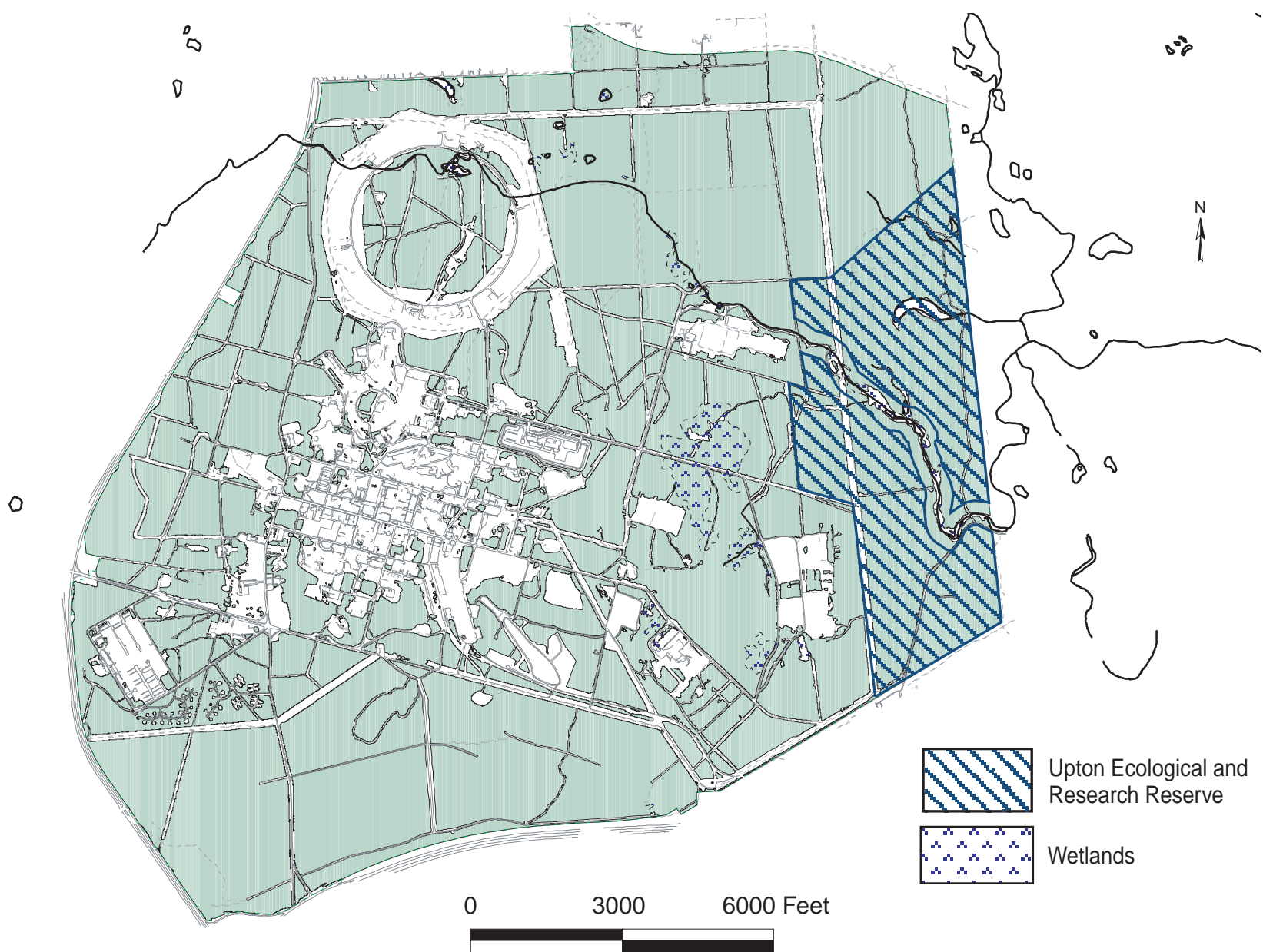

Figure 1-6. Upton Ecological Reserve.

The balance of the site, approximately 3,600 acres, is mostly wooded and represents native pine barrens ecology. In November 2000, DOE and the U.S. Fish and Wildlife Service (FWS) set aside 530 acres of the undeveloped land at BNL as the Upton Ecological and Research Reserve (Figure 1-6). More information about on-site natural resources, the reserve, and the plants and animals it protects can be found in Section 1.9 and in Chapter 6.

The major scientific facilities at BNL are shown and briefly described in Figure 1-7. As noted earlier, the three research reactors (the BGRR, the HFBR, and the BMRR) are no longer operational. In addition to the scientific facilities, numerous other facilities support BNL's science and technology mission by providing basic utility and environmental services (Figure 1-8):
- Water Treatment Plant. The potable water treatment facility has a capacity of 5 million gallons per day. (Actual 2001 usage averaged 2.13 million gallons per day; see Chapter 2 for more information.) Potable water is obtained from six on-site wells. Three wells located along the western boundary of the site, are treated with a lime-softening process to remove naturally occurring iron and are air-stripped to ensure that volatile organic compounds (VOCs) are at or below New York State drinking water standards. Three wells located along the eastern section of the developed site are treated with carbon to ensure VOCs meet or exceed the standards.

- Central Chilled Water Plant. This facility provides chilled water sitewide for air conditioning and process refrigeration via a network of underground piping. The plant 


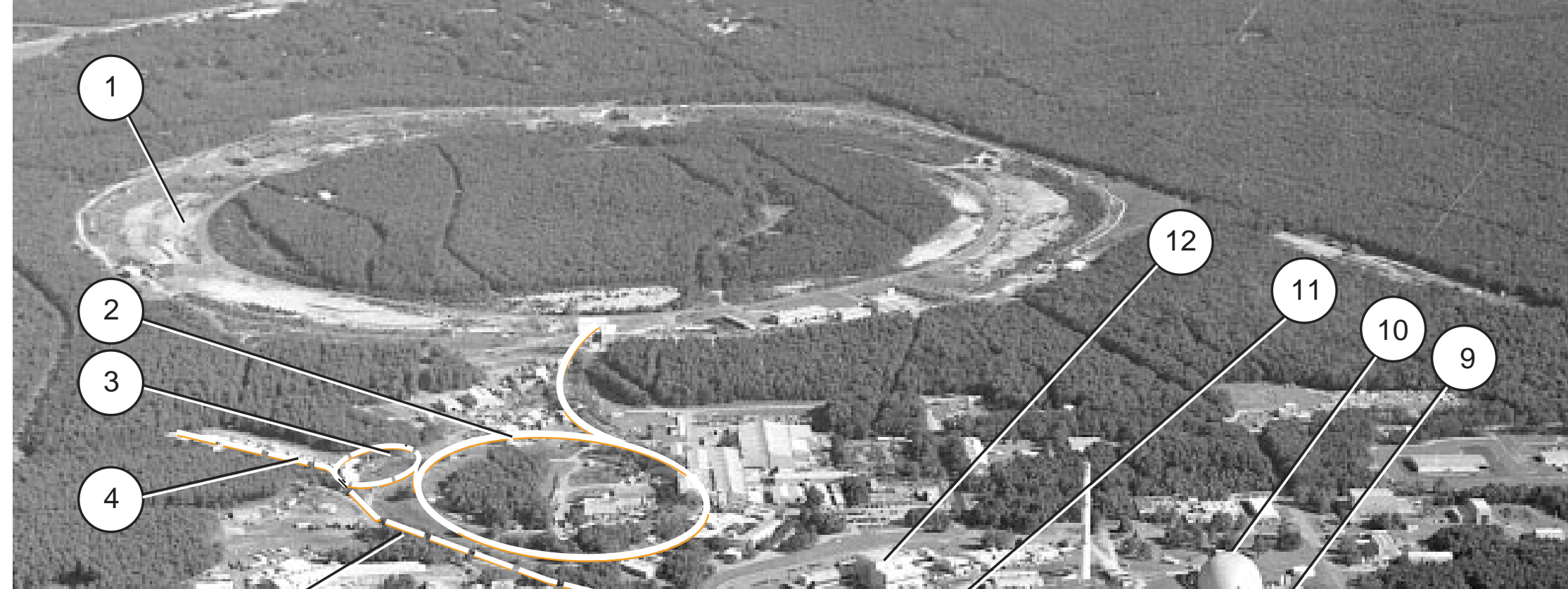

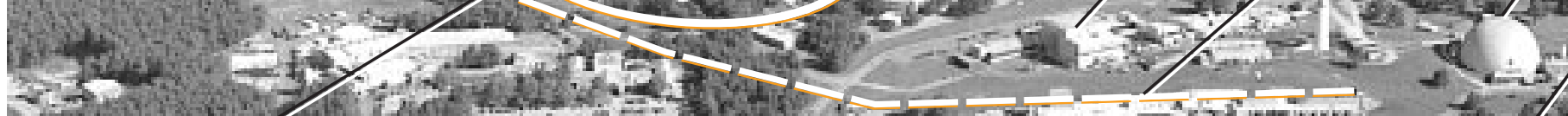

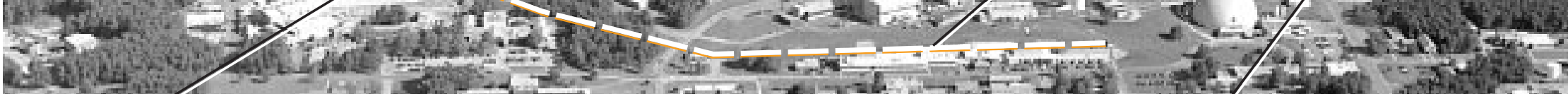

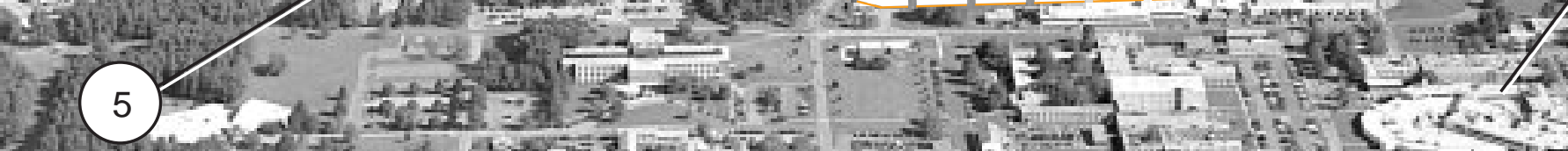

and 0 . $\sin$

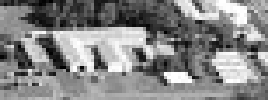

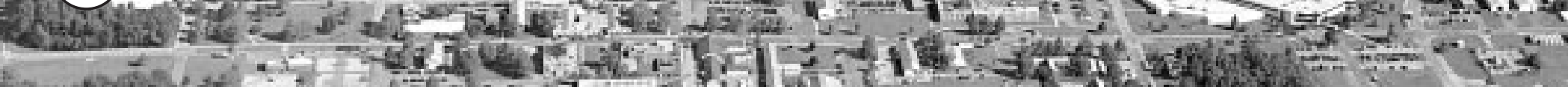

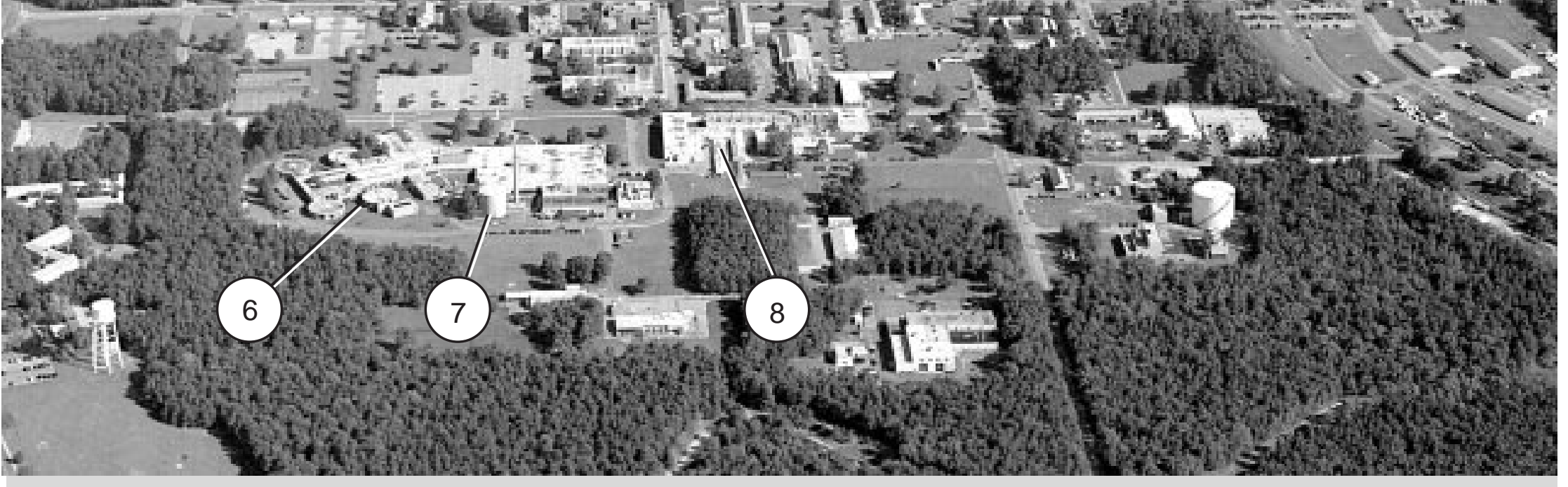




\section{RELATIVISTIC HEAVY ION COLLIDER (RHIC)}

RHIC is one of the world's largest and most powerful accelerators. RHIC's main physics mission is to study particles smaller than atoms.

\section{ALTERNATING GRADIENT SYNCHROTRON (AGS)}

The AGS is used for high-energy physics research and accelerates protons to energies up to $30 \mathrm{GeV}$, and heavy-ion beams to $15 \mathrm{GeV}$. A $200 \mathrm{MeV}$ Linear Accelerator, described below, serves as a proton injector for the AGS and also supplies a continuous beam of protons for radionuclide production by spallation reactions in the Brookhaven Linac Isotope Producer facility.

\section{AGS BOOSTER}

The AGS Booster is a circular accelerator, 200 meters in circumference, that receives either a proton beam from the Llinac, or heavy ions from the Tandem Van de Graaff. The Booster accelerates proton particles and heavy ions before injecting them into the AGS ring. This facility became operational in 1992.

\section{LINEAR ACCELERATOR (LINAC) AND BROOKHAVEN LINAC ISOTOPE PRODUCER (BLIP)}

The Llinac provides beams of polarized protons for the AGS and for the Relativistic Heavy lon Collider. BLIP utilizes the excess beam capacity of the Linac to produce radioisotopes used in research and medical imaging. It is one of the key production facilities in the nation for radioisotopes which are crucial to clinical nuclear medicine. It also supports research on new diagnostic and therapeutic radiopharmaceuticals.

\section{HEAVY ION TRANSFER LINE (HITL)}

The HITL connects the Tandem Van de Graaff and the AGS. This interconnection permits ions of intermediate mass to be injected into the AGS where they can be accelerated to an energy of $15 \mathrm{GeV} / \mathrm{amu}$. These ions then are extracted and sent to the AGS experimental area for physics research.

\section{RADIATION THERAPY FACILITY (RTF)}

Part of the Medical Research Center, the RTF is a high-energy dual x-ray mode linear accelerator for radiation therapy of cancer patients. This accelerator delivers therapeutically useful beams of $x$-rays and electrons for conventional and advanced medical radiotherapy techniques.

\section{BROOKHAVEN MEDICAL RESEARCH REACTOR (BMRR)}

The BMRR was the world's first nuclear reactor built exclusively for medical research applications. It produced neutrons in an optimal energy range for experimental treatment of a type of brain cancer known as glioblastoma multiforme. This reactor stopped operating in December 2000.

\section{SCANNING TRANSMISSION ELECTRON MICROSCOPE (STEM)}

This facility includes two microscopes, STEM 1 and STEM 3, used for biological research. Both devices allow scientists to see the intricate details of living things, from bacteria to human tissue.

\section{NATIONAL SYNCHROTRON LIGHT SOURCE (NSLS)}

The NSLS utilizes a linear accelerator and booster synchrotron as an injection system for two electron storage rings which operate at energies of 750 $\mathrm{MeV}$ vacuum ultraviolet (VUV), and $2.5 \mathrm{GeV}$ (x-ray). The synchrotron radiation produced by the stored electrons is used for VUV spectroscopy and x-ray diffraction studies.

\section{HIGH FLUX BEAM REACTOR (HFBR)}

The HFBR was one of the premier neutron physics research facilities in the world. Neutron beams produced at the HFBR were used to investigate the molecular structure of materials, which aided in pharmaceutical design and materials development as well as expanded the knowledge base of physics, chemistry and biology. A leak in the fuel storage pool was discovered in 1997. Since that time the HFBR has not been in operation and was permanently shut down in November 1999.

\section{TANDEM VAN DE GRAAFF AND CYCLOTRON}

These two facilities are used in medium-energy physics investigations, and for producing special nuclides. The heavy ions from the Tandem Van de Graaff also can be injected into the AGS for physics experiments.

\section{BROOKHAVEN GRAPHITE RESEARCH REACTOR (BGRR)}

No longer in operation, the BGRR was used for scientific exploration in the field of medicine, biology, chemistry, physics, and nuclear engineering.

Figure 1-7. Major Scientific Facilities at Brookhaven National Laboratory. 


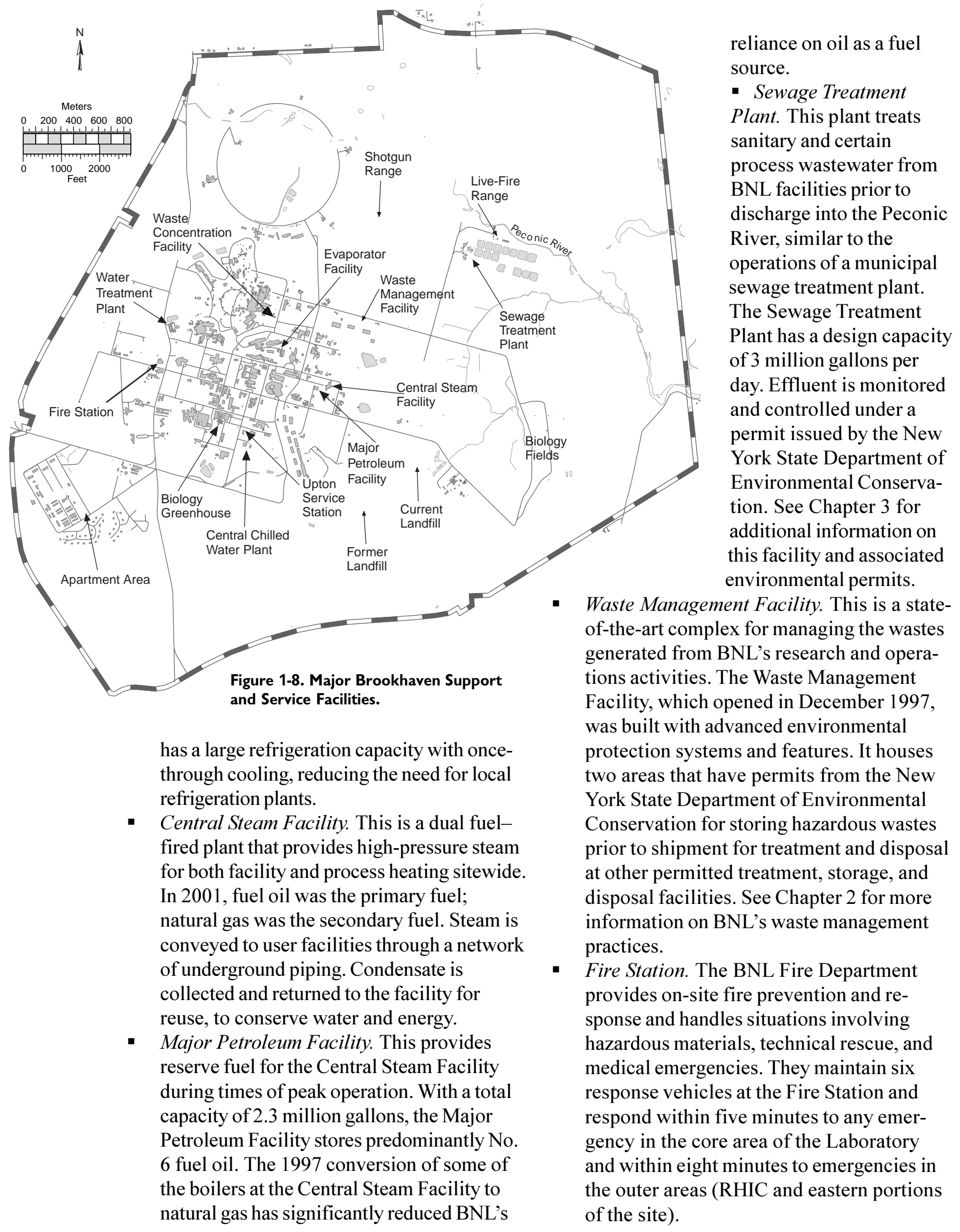




\subsection{GEOLOGY AND HYDROLOGY}

BNL lies on the western rim of the shallow Peconic River watershed. The marshy areas in the northern and eastern sections of the site are part of the headwaters of that river. Depending on the height of the water table relative to the base of the riverbed, the Peconic River both recharges to, and receives water from, the sole source aquifer system beneath Long Island. In times of sustained drought, the river water typically recharges to groundwater; with normal to above-normal precipitation, the river receives water from the aquifer. In general, the terrain of the BNL site is gently rolling, with elevations varying between 44 and 120 feet above sea level. Depth to groundwater from the surface of the land ranges from 5 feet near the Peconic River to about 80 feet in the higher elevation areas in the central and western portions of the site.

The hydrology of this area is very well defined. Studies of Long Island hydrology and geology in the vicinity of the Laboratory indicate that the uppermost Pleistocene deposits, composed of highly permeable glacial sands and gravel, are between 120 and 250 feet thick (Warren et al. 1968, Scorca et al. 1999). Water penetrates these deposits readily and there is little direct runoff into surface streams unless precipitation is intense. These sandy deposits store large quantities of water called the Upper Glacial aquifer. On average, about half of the annual precipitation is lost to the atmosphere through evapotranspiration and the other half percolates through the soil to recharge the groundwater (Koppelman 1978). The area has a high recharge rate (22 inches per year) that varies seasonally.

The Long Island Regional Planning Board and Suffolk County have identified the BNL site as overlying a deep-flow recharge zone for Long Island groundwater (Koppelman 1978, SCDHS 1987). Precipitation and surface water that recharge within this zone have the potential to replenish the deep Magothy and Lloyd aquifer systems lying below the Upper Glacial aquifer. It is estimated that up to two-fifths of the recharge from rainfall moves into the deeper aquifers. The extent to which groundwater at the BNL site contributes to deep flow recharge has been confirmed through the use of an extensive network of shallow and deep wells installed at BNL and surrounding areas

(Geraghty and Miller 1996).

This groundwater system is the primary source of drinking water for both on- and offsite private and public supply wells and, as such, has been designated a sole source aquifer system by the U.S. Environmental Protection Agency. BNL uses approximately 2.13 million gallons of groundwater per day to meet potable water needs and heating and cooling requirements. Approximately 74 percent of the water pumped from BNL supply wells is returned to the aquifer through on-site recharge basins.

About 19 percent is discharged into the Peconic River. Human consumption, evaporation (cooling tower and wind losses), and sewer line losses account for the remaining 7 percent. An additional 2.74 million gallons of groundwater are pumped each day from remediation wells for treatment and then returned to the aquifer by way of recharge basins.

Groundwater flow direction across the BNL site is influenced by natural drainage systems moving eastward along the Peconic River, southeast toward the Forge River, and south toward the Carmans River (Figure 1-9). Pumping from on-site water supply wells also affects the direction and speed of groundwater flow, especially in the central, developed areas of the site. Two natural groundwater divides have been identified near BNL (Scorca et al. 1999). One divide is located approximately one-half mile north of BNL and a second divide transects portions of the site when the water table is high and the aquifer flows into the stream bed of the Peconic River. These divides define the boundaries of the area that contributes groundwater to the Peconic watershed.

In most areas at BNL, the horizontal velocity of groundwater is approximately 0.75 to 1.2 feet per day (Geraghty and Miller 1996). In general terms, this means that it takes approximately 20 to 22 years for groundwater to travel from the central, developed area of the site to the BNL southern boundary. Chapter 7 provides details on BNL's comprehensive Groundwater Protection Management Program. 


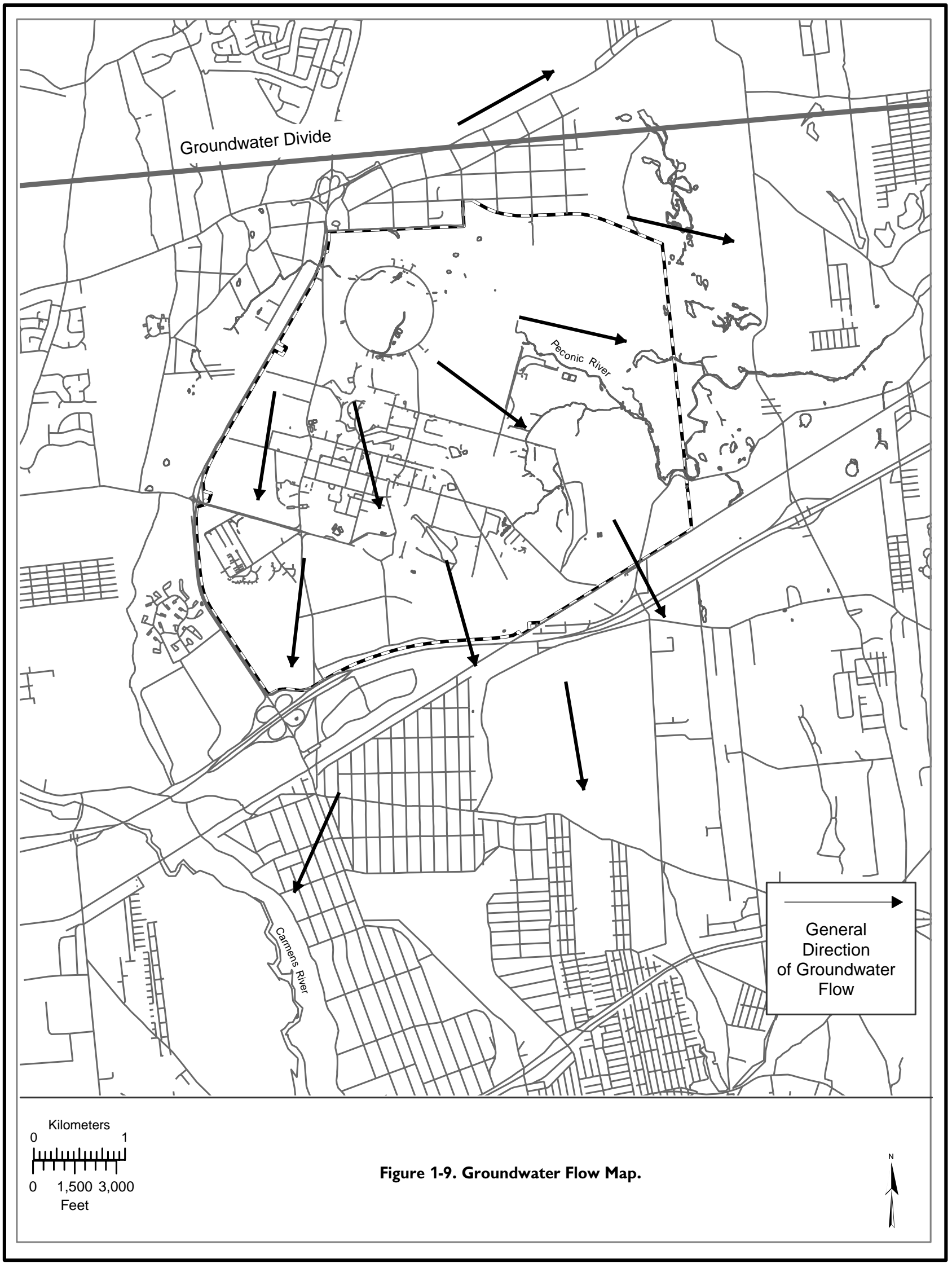




\subsection{CLIMATIC DATA}

The Meteorological Group at BNL has collected meteorological data on site since 1949. The prevailing ground-level winds at BNL are from the southwest during the summer, from the northwest during the winter, and about equally from these two directions during the spring and fall (Nagle 1975, Nagle 1978). Figure 1-10 shows the 2001 annual wind rose for BNL, which depicts the annual frequency distribution of wind speed and direction, measured at an on-site meteorological tower at heights of 33 and 300 feet.

Year 2001 brought 51.2 inches of snow, 21.6 inches more than normal for the period. The sole blizzard of the year produced 15 inches of snow on March 5 and 6. The March total of 19 inches of snowfall was three times the average for the month.

The total precipitation for 2001 was 45.55 inches. Most of the precipitation occurred from March through September. The 10.37 inches of precipitation in March made it the wettest March recorded (the closest was the March 1953 total of 10.36 inches). April was drier than normal (2.03 inches, compared to the average 4.22 inches), and the late fall and winter months were drier than average. Overall, 2001 was slightly drier than average; the precipitation was 2.87 inches below the 53-year annual average of 48.42 inches, about 5.9 percent drier than average. Figures 1-11 and 1-12 present the 2001 monthly and the 53-year annual precipitation data.

The monthly mean temperature in 2001 was $52.3^{\circ} \mathrm{F}$, ranging from a monthly mean low temperature of $29.4^{\circ} \mathrm{F}$ in January to a monthly mean high temperature of $74.3^{\circ} \mathrm{F}$ in August.

The year 2001 was slightly warmer than average, $2.3^{\circ} \mathrm{F}$ above the 53 -year annual average of $50.0^{\circ} \mathrm{F}$; it was the fifth warmest year since BNL started recording weather statistics in 1949. In general, using a linear average, temperatures at $\mathrm{BNL}$ have increased $2.05^{\circ} \mathrm{F}$ over the past 53 years, compared to a worldwide average surface temperature increase of $0.5^{\circ} \mathrm{F}$ $\left(0.3^{\circ} \mathrm{C}\right)$ over approximately the same time period (Jones et al. 1999). Figures 1-13 and 1-14 show the 2001 temperatures and the historical annual mean temperatures.

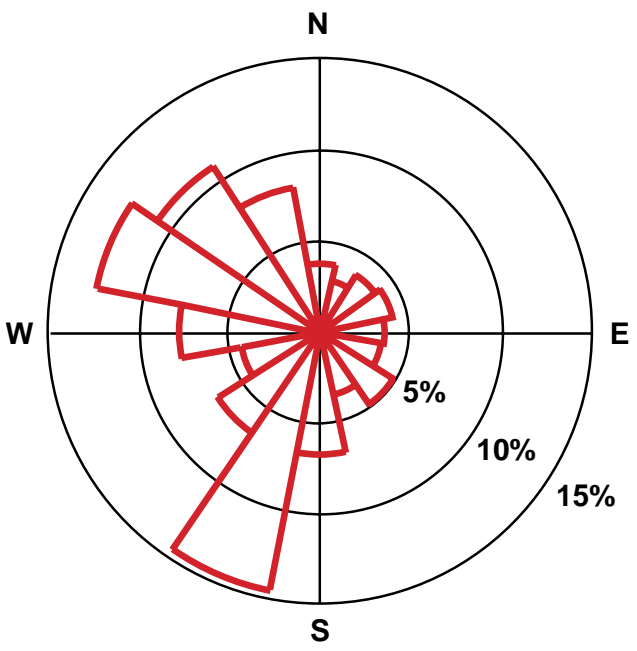

10-m level Calm $(<0.5 \mathrm{~m} / \mathrm{s}): 16.7 \%$

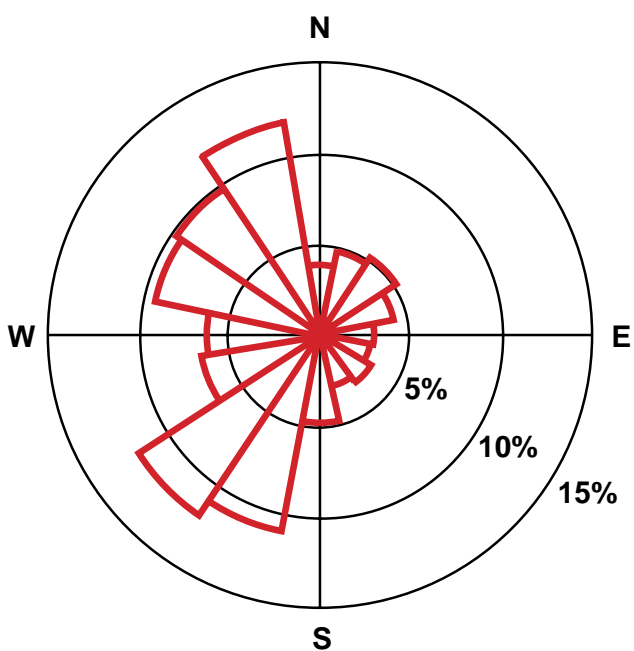

90-m level Calm $(<0.5 \mathrm{~m} / \mathrm{s}): 0.2 \%$

Explanation: The arrows formed by the wedges indicate wind direction. Each concentric circle represents a $5 \%$ frequency, that is, how often the wind is coming from that direction. The wind direction was measured at heights of 33 and 300 feet (10 and 90 meters). For example, this diagram indicates that the predominant wind direction at 33 feet (10 meters) was from the south-southwest.

Figure 1-10. Annual Wind Rose (2001). 


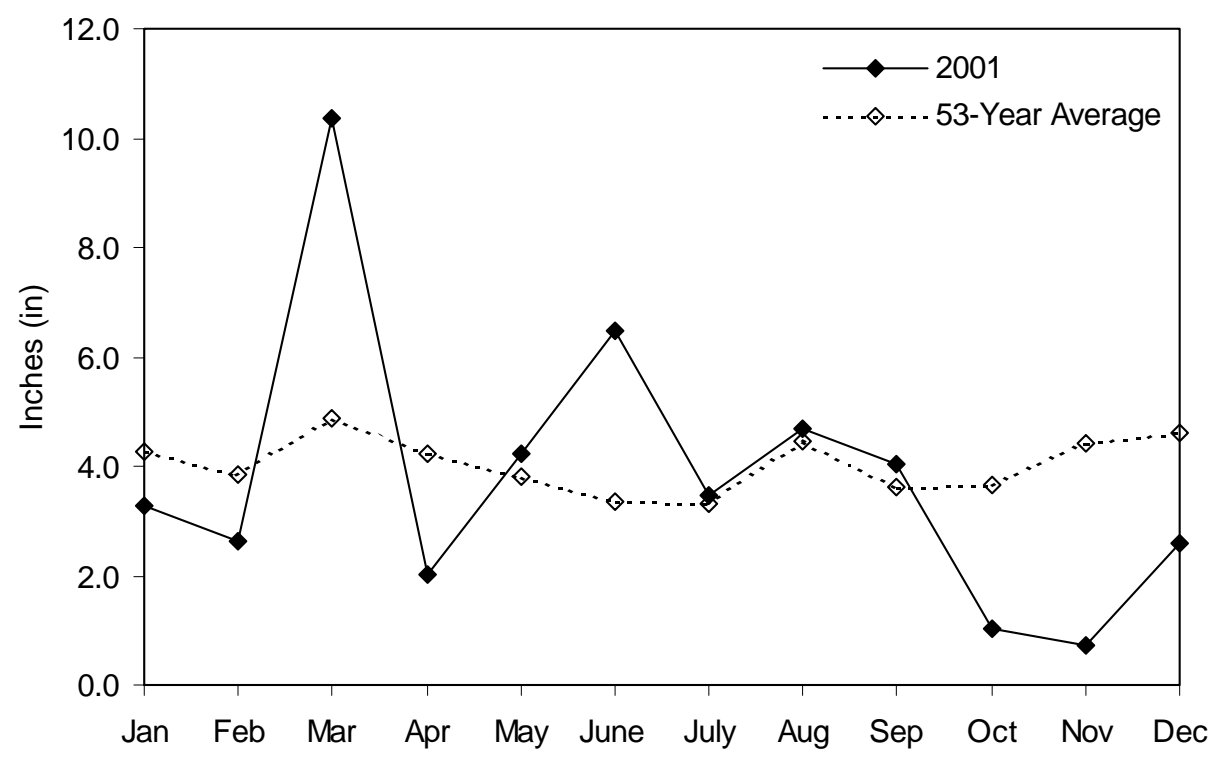

Figure 1-11. 2001 Monthly Precipitation versus 53-Year Monthly Average.

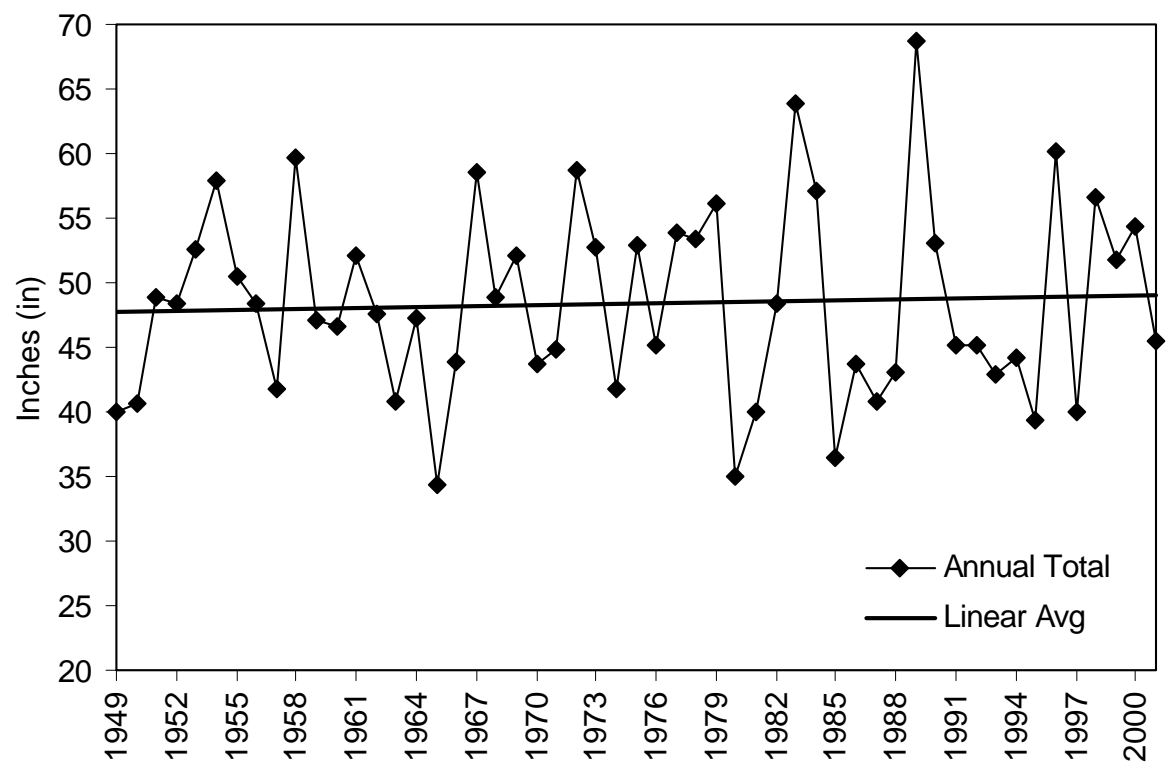

Figure 1-12. Annual Precipitation Trend (53 Years).

\subsection{ECOLOGICAL RESOURCES}

$\mathrm{BNL}$ is located in the oak/chestnut forest region of the Coastal Plain. BNL property constitutes about 5 percent of the 100,000-acre New York State-designated region known as the Central Pine Barrens. Additionally, part of the Peconic River running through BNL was desig- nated "scenic" by the New York State Wild, Scenic, and Recreational River System Act (New York State 1972). As noted before, because of the general topography and porous soil, the land is very well drained and generally there is little surface runoff or open standing water. However, depressions form small, pocket wetlands with 


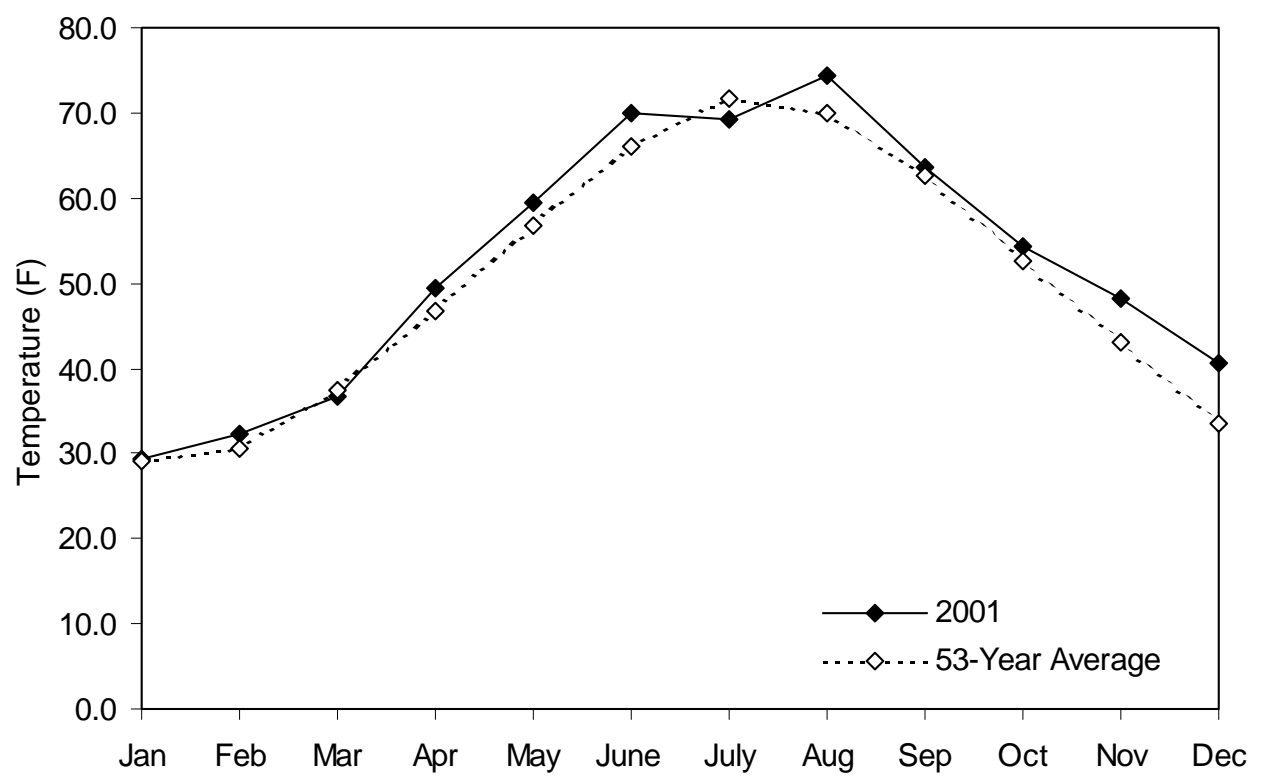

Figure 1-13. 2001 Monthly Mean Temperature versus 53-Year Monthly Average.

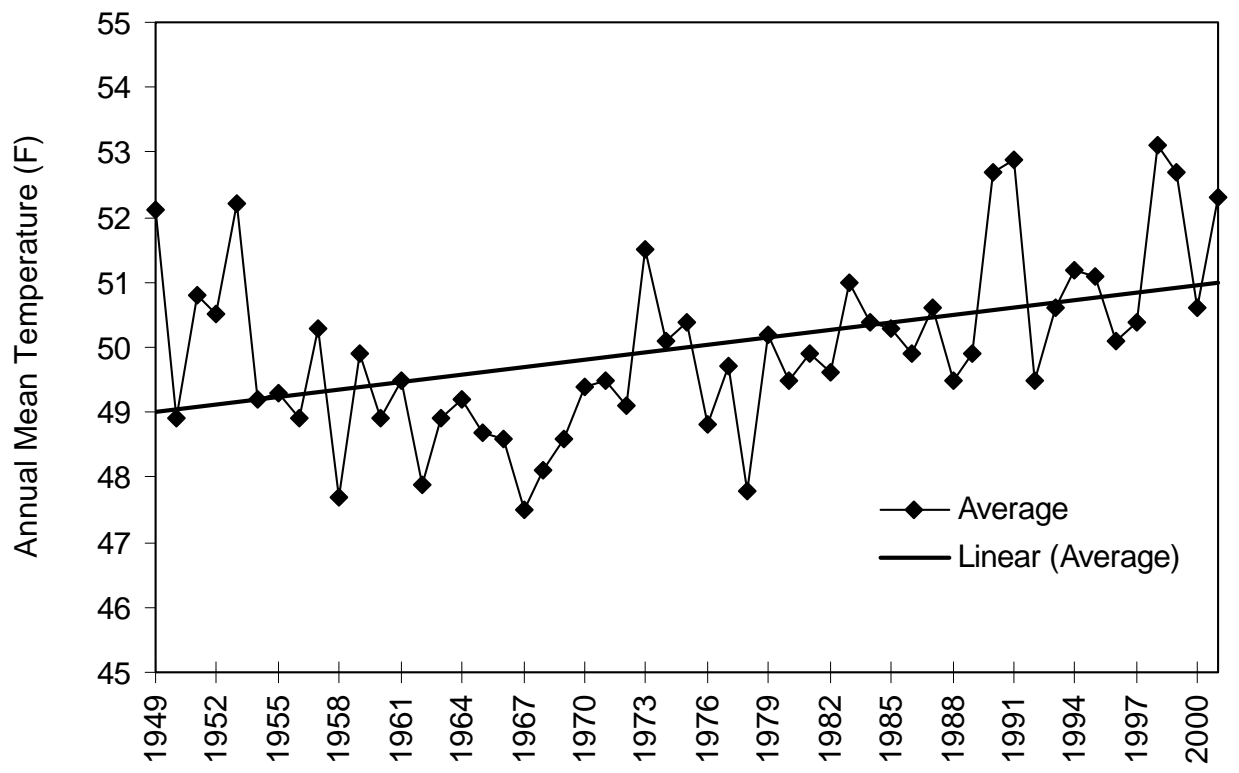

Figure 1-14. Annual Mean Temperature Trend (53 Years).

standing water on a seasonal basis (vernal pools), and there are six significant, regulated wetlands on site. Thus, a mosaic of wet and dry areas on the site correlates with variations in topography and depth to the water table.

Vegetation on site is in various stages of succession, which reflects a history of distur- bances to the area. For example, when Camp Upton was constructed in 1917, the site was entirely cleared of its native pines and oaks; it was cleared again in 1940 when Camp Upton was reactivated. Other past disturbances include fire, local flooding, and draining. Current operations minimize disturbances to the more natural 
areas of the site. More than 230 plant species have been identified on site.

The 15 mammal species at BNL include species common to mixed hardwood forests and open grassland habitats. The white-tailed deer density is currently estimated at 140 per square mile. There were 85 per square mile estimated in 1992 (Thomlinson 1993) and 236 per square mile in 2000 (BNL 2001). The notable reduction in deer population between 2000 and 2001 is largely due to a combination of overpopulation, lack of acorns (a primary winter food), and significant snowfall in February and March of 2000.

At least 85 species of birds are known to nest at BNL, and an additional 130 species have been documented as "visiting" the site. These numbers are due to BNL's location in the Atlantic Flyway and the scrub/shrub habitats that offer food and rest to migratory songbirds. Open fields bordered by hardwood forests at the recreation complex are excellent hunting areas for hawks.

Permanently flooded retention basins and other watercourses support amphibians and aquatic reptiles. Nine amphibian and ten reptile species have been identified, as well as nine species of fish. Ecological studies at the BNL site have confirmed 15 breeding sites for the New York State endangered eastern tiger salamander (Ambystoma t. tigrinum) in vernal pools and some recharge basins. The New York State Department of Environmental Conservation listed the banded sunfish (Eanneacanthus obesus) as a threatened species in 1999. It lives solely within the Peconic River system, including backwater areas of the river on site (Scheibel 1990). In 2000, the New York State threatened swamp darter fish (Etheostoma fusiforme) was positively identified on site in one of the larger ponds associated with the Peconic River.

A state threatened insect, the frosted elfin butterfly (Callophrys irus), was added to BNL's list of protected species due to the potential that the appropriate habitat exists at the Laboratory. This small butterfly lays its eggs near lupine, where the caterpillars feed. Confirmation of this butterfly's presence will be attempted during its breeding season in 2002.

Other wildlife species of interest that inhabit this area include the wild turkey, red fox, eastern box turtle, and the red-tailed hawk. One New York State threatened plant is found on site: the stiff goldenrod (Solidago rigida). A discussion of the Laboratory's wildlife protection strategy can be found in Chapter 6 .

In November 2000, DOE joined with the U.S. Fish and Wildlife Service to establish the Upton Ecological and Research Reserve. This action set aside 10 percent of BNL property for conservation and ecological research. The reserve permanently preserves a portion of the Central Pine Barrens, a unique ecosystem of forests and wetlands on Long Island. This area provides habitat for approximately 27 species that are endangered, threatened, or of special concern. DOE has committed to providing the FWS with $\$ 200,000$ a year, over a five-year period, for land management activities and research in the Upton Ecological and Research Reserve. The partnership and funding created by DOE and FWS resulted in educational programs carried out jointly by the Laboratory, Suffolk County Community College, and FWS. A Technical Advisory Group, made up of local land management agencies, was formed in 2000. This committee assists BNL and FWS by providing technical expertise and input to the development of a Natural Resource Management Plan for the Laboratory. The Upton Reserve funded two research proposals submitted in 2001. More information about the reserve, natural resource management, plants, and animals can be found in Chapter 6.

\footnotetext{
REFERENCES

BNL. 2001. Site Environmental Report 2000. Brookhaven National Laboratory, Upton, NY.

DOE Order 231.1. 1995. Environment, Safety and Health Reporting. U.S. Department of Energy, Washington, D.C. Change 1: 11-07-96.

DOE Order 5400.1. 1988. General Environmental Protection Program. U.S. Department of Energy, Washington, D.C. Change 1: 6-29-90.

DOE Order 5400.5. 1990. Radiation Protection of the Public and Environment. U.S. Department of Energy, Washington, D.C. Change 2: 1-7-93.

Geraghty and Miller, Inc. 1996. Regional Groundwater Model, Brookhaven National Laboratory, Upton, N.Y. A report to Brookhaven National Laboratory. November 1996.

Jones, P.D., M. New, D.E. Parker, S. Martin, and I.G. Rigor. 1999.

"Surface air temperature and its changes over the past 150 years." Reviews of Geophysics, May 1999, 37(2):173-179.
} 
Kamer, Pearl. 1995. The Impact of Brookhaven National Laboratory on the Long Island Economy. Suffolk County Planning Commission, Suffolk County Department of Planning. June 1995.

Koppelman, L.E. 1978. The Long Island Comprehensive Waste Treatment Management Plan (Long Island 208 Study), Volumes I and II. Long Island Regional Planning Board, Hauppauge, N.Y. July 1978.

LIPA. 2001. Long Island Population Survey 2001: Population Estimates for Nassau and Suffolk Counties and the Rockaway Peninsula. Long Island Power Authority. Uniondale, N.Y. December 2001. Available at <http://www.lipower.org/pdfs/ community/popsurvey2001.pdf>.

Meinhold, C.B. and A.P. Hull. 1998. Radiological Environmental Monitoring Report for Brookhaven National Laboratory 1967-1970. DOE Contract No. DE-AC02-98CH10866. Brookhaven National Laboratory, Upton, N.Y. October 1998.

Meinhold, C.B. and A.F. Meinhold. 2001. Radiological Emissions and Environmental Monitoring for Brookhaven National Laboratory, 1947-1961. DOE Contract No. DE-AC02-98CH10866. Brookhaven National Laboratory, Upton, N.Y. May 2001.

Nagle, C. M. 1975. Climatology of Brookhaven National Laboratory: 1949-1973. BNL-50466. Brookhaven National Laboratory, Upton, N.Y. November 1975
Nagle, C.M. 1978. Climatology of Brookhaven National Laboratory: 1974 through 1977. BNL-50857. Brookhaven National Laboratory, Upton, N.Y. May 1978.

New York State. 1972. Wild, Scenic and Recreational River System Act. Environmental Conservation Law, Title 27, Article 15, and subsequent updates.

SCDHS. 1987. Suffolk County Comprehensive Water Resources Management Plan. Volumes I and II. Division of Environmental Quality, Suffolk County Department of Health Services, Hauppauge, N.Y. January 1987.

Scheibel, M.S. 1990. "Review of New York State endangered species potentially impacted by construction of the RHIC at Brookhaven National Laboratory." Letter to Gerald C. Kinne, September 24, 1990.

Scorca, M.P., W.R. Dorsch, and D. E. Paquette. 1999. Stratigraphy and Hydrologic Conditions at the Brookhaven National Laboratory and Vicinity, Suffolk County, New York, 1994-97. U.S. Geological Survey Water Resources Investigations Report 99-4086. 55 p. Thomlinson, W. 1993. Deer Population Estimate for the BNL Site. Summer Project Report. Brookhaven National Laboratory, Upton, N.Y. March 1993.

Warren, M.A., W. deLaguna, and N.J. Lusczynski. 1968. Hydrology of Brookhaven National Laboratory and Vicinity, Suffolk County, New York. U.S. Geological Survey Bulletin, 1156-C. 
Intentionally Left Blank 
B ROOKHAVEN

NATIONAL

L A B ORATORY

\section{SITE ENVIRONMENTAL REPORT}

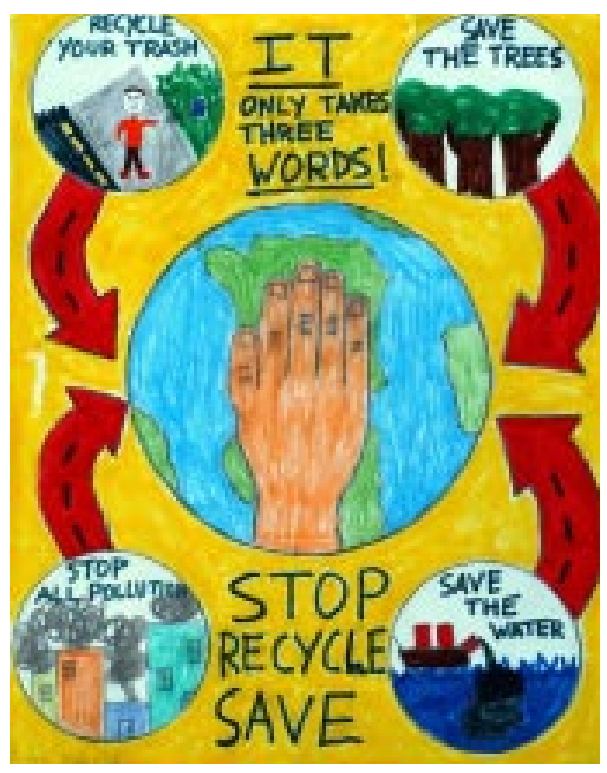

Chapter 2

\section{Environmental Management System}

In 2001, BNL became officially registered to the globally recognized environmental management standard, ISO 14001, affirming the Laboratory's leadership position as the first Long Island-based operation and the first DOE Office of Science facility to achieve this accreditation. The Laboratory's Environmental Management System has an emphasis on compliance assurance, pollution prevention, and community outreach. Under the Environmental Management System, compliance and other environmental considerations are fully integrated into the planning, decision making, and implementation phases of all site activities. Existing industrial and experimental processes on site are regularly evaluated for regulatory compliance and pollution prevention opportunities. In 2001, BNL was recognized with two Pollution Prevention awards from DOE. Pollution prevention projects saved more than $\$ 1,385,000$ and resulted in the reduction or reuse of approximately $1,955,000$ pounds of waste. The Laboratory continues to address legacy issues under the Facility Review Project and the Environmental Restoration Program. A comprehensive program to monitor environmental quality is in place and a Technical Advisory Group was formed in 2001 to address natural resource management issues in the Upton Ecological and Research Reserve. The Laboratory is openly communicating with neighbors, regulators, employees, and other interested parties on environmental issues and progress. 


\subsection{STEWARDSHIP UNDER BROOKHAVEN SCIENCE ASSOCIATES}

During the summer of 2001, under the leadership of Brookhaven Science Associates (BSA), Brookhaven National Laboratory became officially registered to the globally recognized environmental management system, ISO 14001. BNL's registration certificate and the Environmental Stewardship Policy are shown in Figure 2-1. An Environmental Management System (EMS) is a methodology for managing the environmental aspects of an organization's operation in order to:

- Identify how operations can potentially impact the environment

- Define and prioritize what needs protection and how to do it

- Monitor, measure, and communicate what is done and how it is done
- Continually improve environmental protection programs.

An EMS includes planning; establishing responsibilities; instituting procedures, practices, and processes; and dedicating resources to develop, implement, and achieve environmental commitments. The purpose of an EMS is to ensure that programs are managed in an environmentally responsible manner that protects the ecosystem and human health. The ultimate goal is to improve environmental performance and environmental quality.

BNL's EMS is modeled on the International Organization for Standardization (ISO) 14001 Standard, Environmental Management SystemSpecification with Guidance for Use (ISO 1996). ISO 14001 is a consensus standard developed by an international consortium of industry, government, and environmental

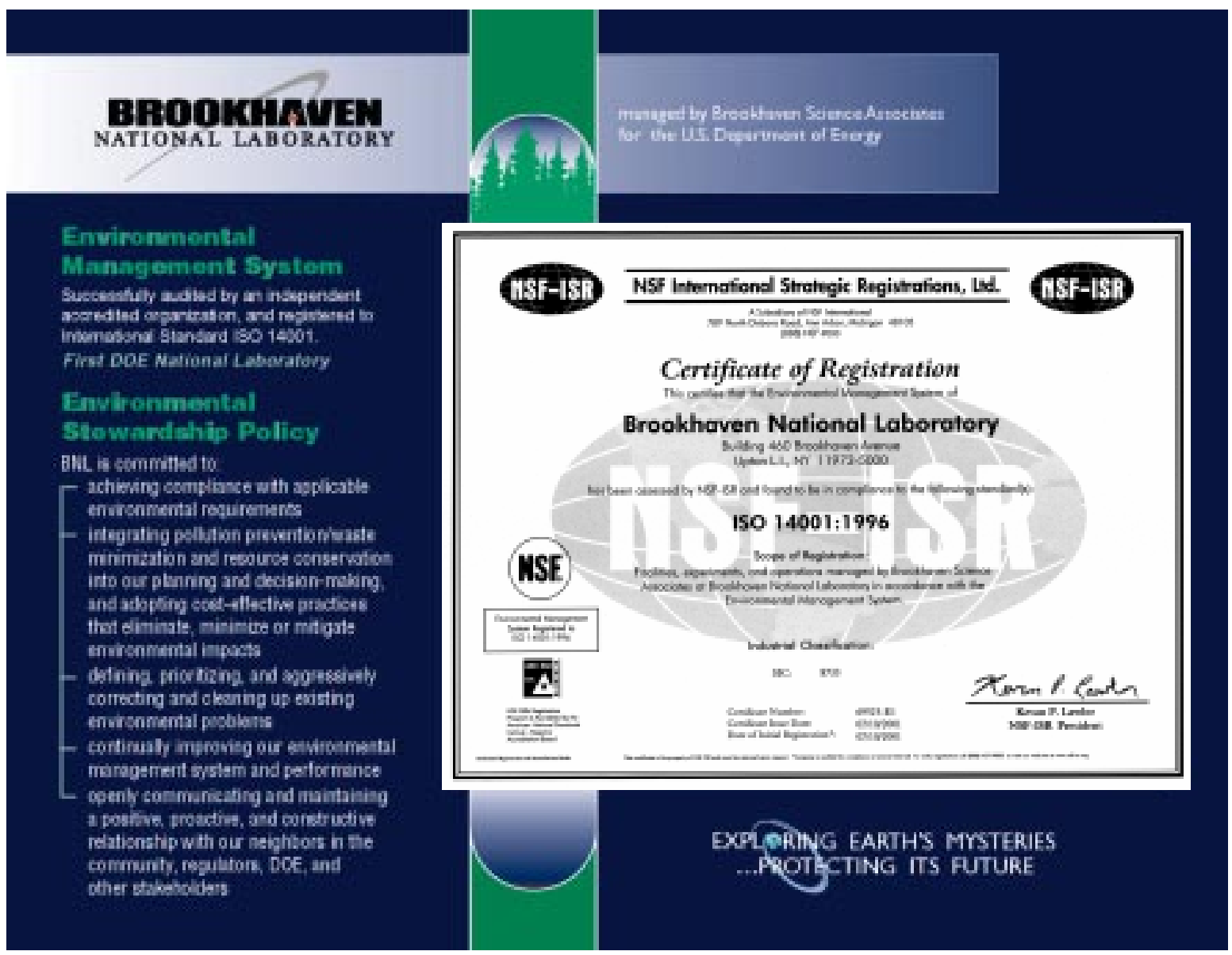

Figure 2-1. BNL ISO 14001 Registration Certificate and Environmental Stewardship Policy. 
groups. This system has been adopted by notfor-profit organizations such as BNL, as well as by the private sector at companies such as Lucent Technologies, IBM, and Motorola. BNL refers to its EMS as an ISO 14001 "Plus" system, since it has enhanced emphasis on compliance, pollution prevention, and community outreach. BNL's EMS is built on the "Plan, Do, Check, Act" model, and focuses on continual improvement. The EMS can be categorized in the following manner:

Environmental Policy, Planning, Implementation, Checking and Corrective Action, and Management Review. These categories cover the 17 elements of the ISO 14001 model. Figure 2-2 shows the relationships among the program elements. This chapter discusses the 17 elements of BNL's EMS and summarizes how BNL implements the requirements of each one. The EMS is integrated with the BNL's other management systems, such as training and emergency preparedness, and is part of the sitewide Integrated Safety Management System.

\subsection{ENVIRONMENTAL STEWARDSHIP POLICY}

The cornerstone of an EMS is a commitment to environmental protection at the highest levels of the organization. The Environmental Stewardship Policy, issued and signed by the Laboratory Director, is a statement of BNL's intentions and principles regarding overall environmental performance. It provides a framework for planning and action and is included in training programs. The Environmental Stewardship Policy is posted throughout the Laboratory and on the BNL website.

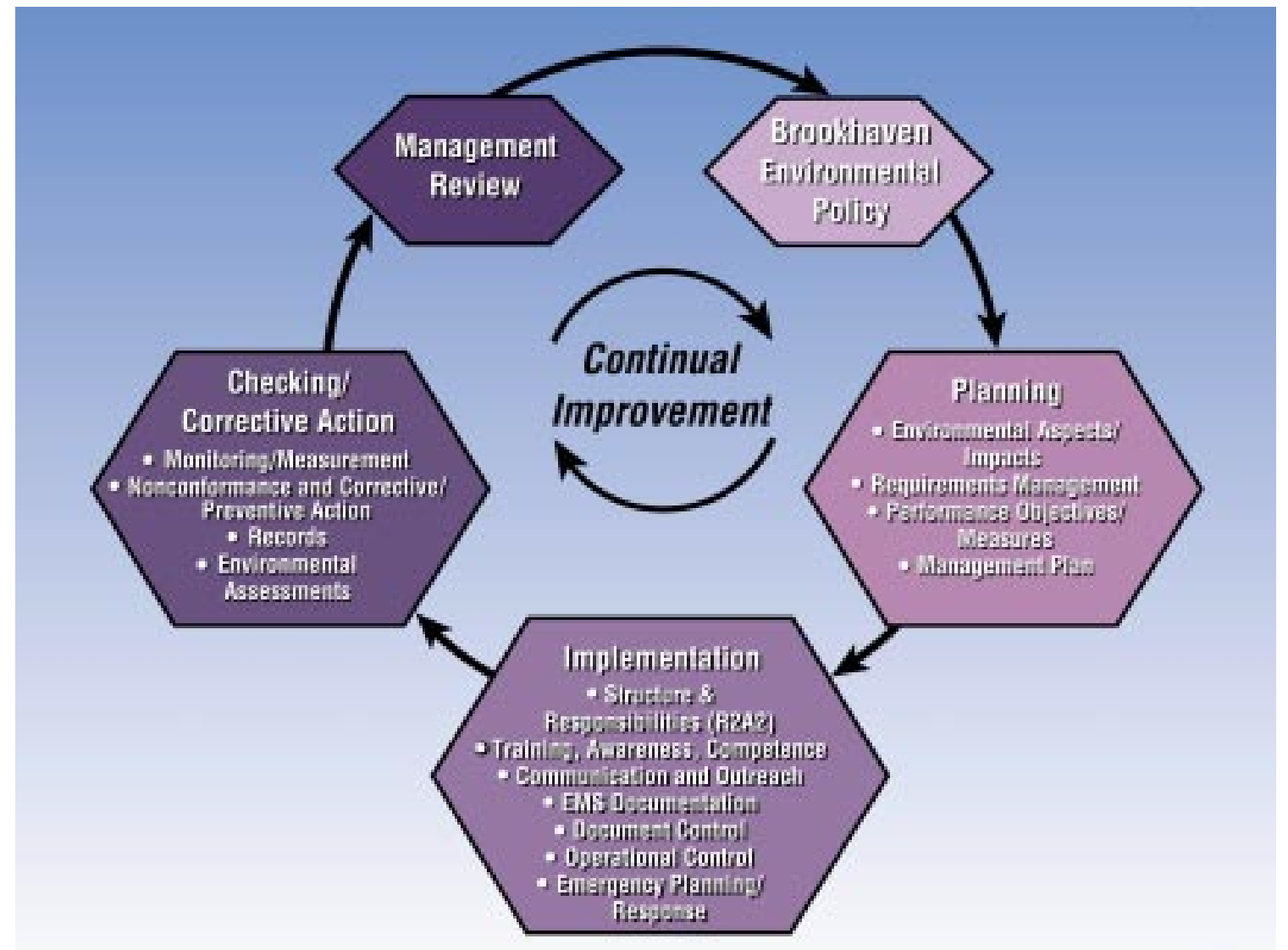

Figure 2-2. Key Elements of the BNL EMS and their Relationship to Each Other. 
The Environmental Stewardship Policy contains the following goals and commitments, focusing on compliance, pollution prevention, cleanup, community outreach, and continual improvement:

- Achieve and maintain compliance with applicable environmental requirements. These requirements include over 50 sets of local, state, and federal laws and regulations; 13 DOE Directives; eight Executive Orders; and approximately 65 operating permits (see Chapter 3).

- Integrate pollution prevention/waste minimization, resource conservation, and compliance into BNL activities during planning and decision making. Adopt costeffective practices that eliminate, minimize, or mitigate environmental impacts. This includes conserving natural resources and ensuring that environmental emissions, effluents, and waste generation are As Low As Reasonably Achievable (a concept known as "Environmental-ALARA," or "EALARA," discussed in Chapter 5).

- Define, prioritize, and aggressively correct and clean up existing environmental problems. This commitment encompasses removal or treatment of contamination caused by historical practices. It also includes strengthening the environmental monitoring program to ensure that controls designed to protect the environment are working, and to provide early detection of a potential threat to the environment (see Section 2.5.1).

- Maintain a positive, proactive, and constructive relationship with neighbors in the community, regulators, DOE, and other stakeholders. Openly communicate with stakeholders about program progress and performance (see Section 2.4.3).

- Continually improve the environmental management system and performance. Establish appropriate environmental objectives and performance indicators to guide these efforts and measure our progress. To maintain certification, BNL will employ proactive measures to prevent problems. When problems do occur, the approach is to investigate the root cause and take corrective actions as appropriate.

\subsection{PLANNING}

\subsubsection{Environmental Aspects and Impacts}

An environmental aspect is any element of an organization's activities, products, or services that can interact with the environment. As required by the ISO 14001 Standard, BNL evaluates its operations, identifies the aspects of operations that can impact the environment, and determines which of those impacts are significant. Environmental management programs are used to control and manage significant aspects, to prevent or minimize the impacts. Table 2-1 provides a list of BNL's significant environmental aspects. BNL's criteria for significance are based on both actual and perceived impacts of its operations and regulatory requirements. For example, because the Laboratory is situated over a sole source aquifer that provides drinking water, protection of groundwater is a high priority, and possible impact to it is a significant concern. Because of concerns on the part of the surrounding community, radioactivity in any environmental media (air, water, soil) is also deemed a significant aspect. Impacts are reevaluated as necessary to ensure that the significant aspects and potential impacts continue to reflect the concerns of stakeholders and changes in regulatory requirements, and to incorporate new aspects or impacts that have been identified.

\subsubsection{Requirements Management}

To implement the compliance commitments in the Environmental Stewardship Policy, BNL implemented and continues to improve on a tool called Standards Based Management System (SBMS). SBMS is a web-based system designed to deliver Laboratory-level requirements and guidance to all staff in a userfriendly format. All Labwide procedures reside in this system organized by "Subject Areas."

New or revised requirements (e.g., new regulations) are analyzed to determine their applicability to BNL, and to identify whether actions are required to achieve compliance. This 
Table 2-1. BNL's Criteria for Significant Environmental Aspects.

\begin{tabular}{l|}
\hline Environmental Aspect \\
\hline Regulated Industrial Waste Generation \\
\hline Hazardous Waste Generation \\
\hline Radioactive Waste Generation \\
\hline Mixed Waste Generation \\
\hline Regulated Medical Waste Generation \\
\hline Atmospheric Discharges
\end{tabular}

\section{Criteria for Significant Aspects}

Any amount of regulated industrial waste generation.

Any amount of hazardous waste generation.

Any amount of radioactive waste generation.

Any amount of mixed waste generation.

Any amount of regulated medical waste generation.

a) Any process that requires a point source air permit or inclusion in the Title $V$ permit as an emission unit, or contributes to a regulated emission point.

b) Operations or activities that use engineering controls to reduce hazardous air pollutant or radionuclide emissions.

c) Radioactive emissions that require monitoring (continuous or confirmatory) per $40 \mathrm{CFR} 61$ subpart $\mathrm{H}$ of the National Emission Standards for Hazardous Air Pollutants.

Liquid Discharges

a) Radionuclides that are detectable at the point of discharge from the facility.

b) Discharges of any of the chemicals listed on the BNL State Pollutant Discharge Elimination System Permit.

c) Operations or activities that use engineering controls to reduce the quantity or concentration of pollutant.

d) Existence of underground injection control devices.

Storage or Use of Chemicals
or Radioactive Materials
(potential for accidental
release or contamination)

a) Storage or use of chemicals or radioactive materials requiring engineering controls as specified in BNL procedures.

b) System configuration requires back-flow prevention in accordance with the BNL procedures.

c) Transportation of chemicals or dispersible radioactive materials.

d) Storage or use of PCBs as specified in BNL procedures.

e) Any underground pipes or ducts that contain chemical and/or radioactive material/contamination.

f) Storage or use in quantities capable of resulting in a reportable spill, as defined in BNL procedures.

\section{Water Consumption}

b) Continuous ( $24 \mathrm{hrs} /$ day), permanent (to continue for the foreseeable future) once-through water use greater than 4 gallons per minute (gpm) that discharges to the sanitary sewer system.

c) Daily (8 hrs/day), permanent, once-through water use greater than $10 \mathrm{gpm}$ that discharges to the sanitary sewer system.

d) Continuous use greater than $10 \mathrm{gpm}$, or daily use greater than $15 \mathrm{gpm}$ for a period greater than 60 days that discharge to the sanitary sewer system.

\begin{tabular}{l}
\hline Power Consumption \\
\hline Historical Monuments/ \\
Cultural Resources \\
(groundwater, soil) \\
\hline Sensitive/Endangered Species \\
and Sensitive \\
Habitats (including \\
Pine Barrens)
\end{tabular}

\begin{tabular}{ll}
\hline Environmental Noise & $\begin{array}{l}\text { a) Exceed ordinance levels [7am-10pm: 55 dba; 10pm-7am: } 50 \mathrm{dba} \text { (20 min. average)] at property boundary or } \\
\text { offsite location. }\end{array}$ \\
\hline $\begin{array}{l}\text { Historical Contamination } \\
\text { (groundwater, soil) }\end{array}$ & $\begin{array}{l}\text { a) Pre-existing contamination (radiological or nonradiological) causing remedial activities resulting in costs in } \\
\text { excess of } \$ 50,000 .\end{array}$ \\
\hline Soil Activation & \begin{tabular}{l} 
a) Any soil activation. \\
\hline Transuranic Waste
\end{tabular} \\
\hline $\begin{array}{l}\text { a) Generation or potential to generate any radioactive waste stream classified as transuranic waste (i.e., contains } \\
\text { greater than } 100 \text { nanocuries per gram of trans-uranium isotopes). }\end{array}$ \\
\hline $\begin{array}{l}\text { a) Other compliance requirement specific to an organization or aspect that could impact the environment (e.g., } \\
\text { asbestos research). }\end{array}$ \\
b) Any historical or legacy issue.
\end{tabular}

Source: Identification of Significant Aspects and Impacts Subject Area, SBMS

a) Total organizational power consumption greater than $58 \mathrm{M} \mathrm{KWh/yr}$.

a) Any modification to a historically significant structure (e.g., BGRR, Cosmotron building, and World War I foxholes/trenches).

b) Proposed modification to known archaeologically significant area(s) or discovery of archaeologically significant material (lithic scatter, bone, foundations, etc.)

a) Potential for habitat destruction, harm or harassment within 850 feet of a critical habitat (recharge basins, vernal pools, natural and manmade ponds and waterways).

b) Disturbance within 100 feet of a regulated wetland (that is already not identified as a critical habitat).

c) Disturbance within $1 / 2$ mile of the Peconic River.

d) Activity affecting five or more acres of undeveloped land.

) Exceed ordinance levels [7am-10pm: $55 \mathrm{dba} ; 10 \mathrm{pm}-7 \mathrm{am}: 50 \mathrm{dba}$ (20 min. average)] at property boundary or Pre-existing contamination (radiological or nonradiological) causing remedial activities resulting in costs in

a) Generation or potential to generate any radioactive waste stream classified as transuranic waste (i.e., contains

Other compliance requirement specific to an organization or aspect that could impact the environment (e.g. b) Any historical or legacy issue. 
may involve developing or revising documents, operating procedures, or Subject Areas, or implementing administrative controls, providing training, installing engineered controls, or increasing monitoring.

There are Subject Areas on a variety of environmental topics. They are regularly updated by teams of researchers, technical staff, and environmental protection professionals, with input from regulatory agencies. Existing standards for work and research planning and control have been upgraded to ensure that reviews by qualified environmental, safety, and health professionals occur early in the planning process, and that adequate measures to control hazards and risks are incorporated during the design phase. The information provided in the SBMS focuses on what staff need to know to do their work in an environmentally responsible manner and translates requirements into a format and language that are easily understandable. Figure 2-3 lists the environmental protection and other key subject areas that support the EMS.

\subsubsection{Performance Objectives and Measures}

The Performance Based Management System is designed to develop, align, balance, and implement the Laboratory's strategic objectives, including environmental objectives. The system drives BNL's improvement agenda by establishing a prioritized set of key objectives, called critical outcomes. BNL works with DOE to clearly define expectations and performance measures. Factors for selecting environmental priorities include:

- Significant environmental aspects

- Risk and vulnerability (primarily, threat to the environment)

- Legal requirements (laws, regulations, permits, enforcement actions)

- Commitments (in the Environmental Stewardship Policy, to regulatory agencies, to the public)

- Importance to DOE, the public, and other stakeholders.

Objectives and targets are developed by Fiscal Year (FY). In FY 2001 (October 1, 2000 through September 30, 2001), they included:
- Achieve excellent performance in environmental protection (e.g., minimize permit exceedances and spills and maintain full compliance).

- Complete environmental improvement projects in a timely manner (e.g., EMS, Groundwater, Environmental Restoration, and Environmental Data Management).

- Minimize generation of all wastes.

- Enhance the effectiveness of Laboratory communications and create opportunities for the involvement of stakeholders.

Responsibilities for achieving these expectations are assigned at all relevant levels of the organization, starting with senior management and flowing to the individual level. The following example illustrates this network of responsibilities (also see Figure 2-4).

Under the FY 2001 Operational Excellence critical outcome, BNL had an objective to integrate pollution prevention/waste minimization and resource conservation into all planning and decision making. A related performance objective was to reduce hazardous, mixed, and low-level radioactive routine waste streams. The performance measure was to reduce all three waste streams below FY 2000 levels. At the department level, this could translate into an organizational goal to develop and implement an action plan to reduce waste generation. A staff member might have an individual goal to learn and comply with the Pollution Prevention and Waste Minimization Subject Area requirements, and to purchase environmentally preferable products.

This approach helps employees understand how their work relates to Laboratory-level performance objectives, so they can align their efforts toward achieving BNL missions. It also ensures that BNL operations are conducted in accordance with the expectations established by DOE and BNL management. Through performance-based management, BSA focuses environmental management improvement initiatives on addressing the priorities of DOE, regulatory agencies, and the community. Specifically, in 2001, emphasis was placed on fully implementing the EMS and obtaining sitewide ISO 14001 registration, improving the 
ENVIRONMENTAL PROTECTION SUBJECT AREAS

$$
\text { Drinking Water }
$$

Environmental Assessments

Environmental Evaluation of Industrial Processes and Experimental Research

Environmental Monitoring

Groundwater Protection Contingency Plan

Hazardous Waste Management

Identification of Significant Environmental Aspects and Impacts

Liquid Effluents

Mixed Waste Management

NEPA and Cultural Resource Evaluation

Nonradioactive Airborne Emissions

Oil/PCB Management

Pollution Prevention and Waste Minimization

Radioactive Airborne Emissions

Radioactive Waste Management

Regulated Medical Waste Management

$$
\text { Spill Response }
$$

Storage and Transfer of Hazardous Materials

Underground Injection Control

\section{KEY SUPPORT SUBJECT AREAS}

Calibration

Correspondence and Commitment Tracking

Community Involvement in Laboratory Decision-Making

Facility Use Agreements

Graded Approach for Quality Requirements

Hazard Analysis

Integrated Assessment

Internal Controlled Documents

Investigation of Incidents, Accidents, and Injuries

Lessons Learned

Nonconformance, Corrective and Preventive Action

Operational Readiness Evaluation

Records Management

Requesting SBMS Variances

Requirements Management

Roles, Responsibilities, Accountabilities, and Authorities

Training and Qualification

Emergency Preparedness

Figure 2-3. Environmental Management System and Supporting Subject Areas in the Standards Based Management System. Labwide requirements are contained in SBMS Subject Areas, available online at <https://sbms.bnl.gov>

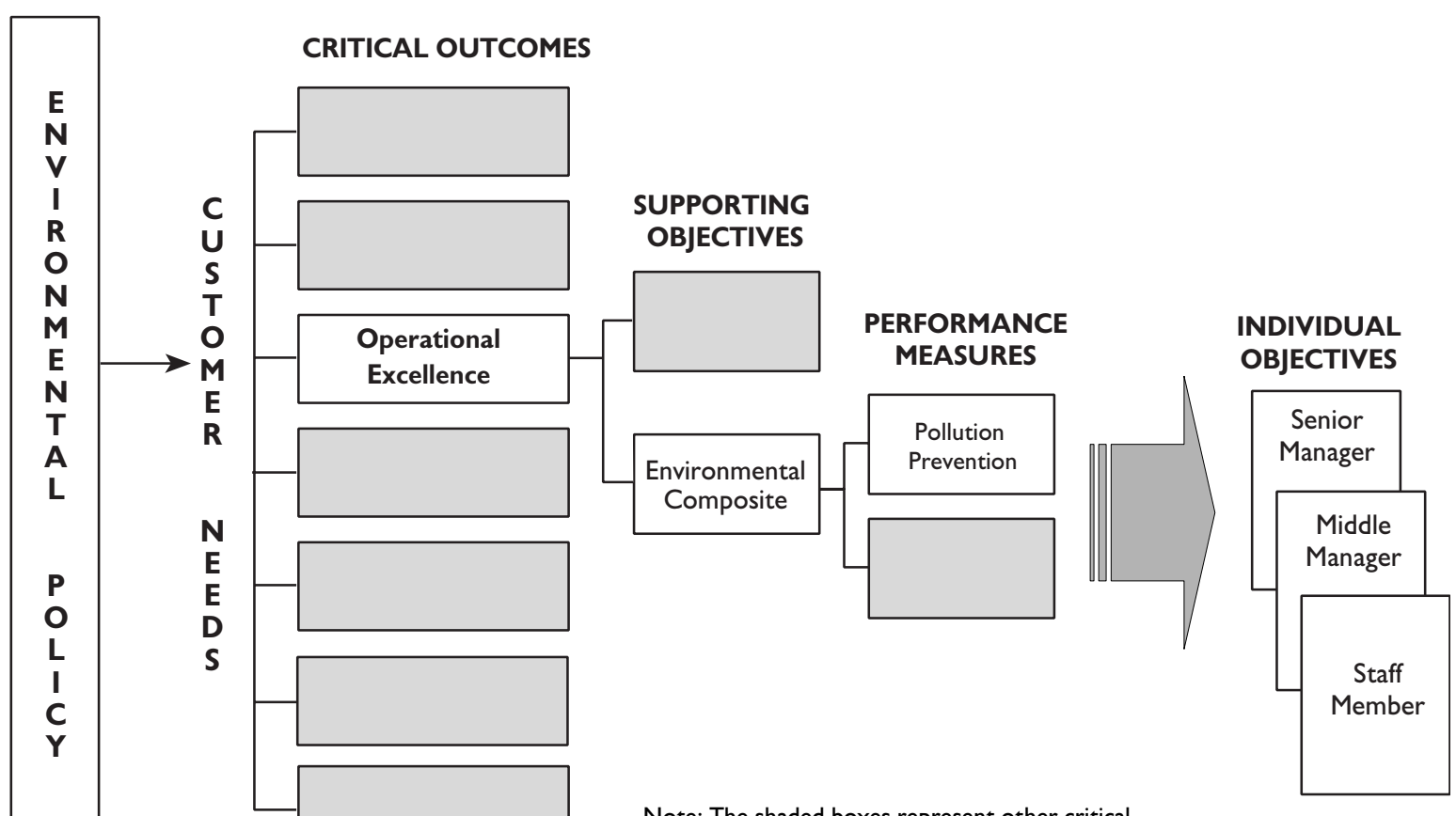

Note: The shaded boxes represent other critical outcomes, objectives and targets.

Figure 2-4. Hierarchy of Environmental Objectives at BNL - an Example for Operational Excellence. 
Laboratory's groundwater protection program, enhancing the pollution prevention programs, achieving and maintaining compliance, and expediting environmental restoration.

\subsubsection{Environmental Management Program}

Organizations within BNL develop action plans detailing how they will achieve their objectives and targets and commit the necessary resources to successfully implement both Labwide and facility-specific programs. BNL has a budgeting system designed to ensure that priorities are balanced, and that resources essential to the implementation and control of the EMS are provided.

BNL has several important Labwide environmental programs developed and funded to further integrate environmental stewardship into all facets of BNL's missions. The key programs are described below.

\subsubsection{Compliance}

BNL has an extensive program to ensure full compliance with all applicable environmental regulatory requirements and permits. Some programs are routine, such as the National Emission Standards for Hazardous Air Pollutants, National Pollutant Discharge Elimination System, and Resource Conservation and Recovery Act compliance programs. Other programs are special projects or initiatives, such as upgrading petroleum and chemical storage tanks facilities, upgrading the sanitary sewer system, closing underground injection control devices, retrofitting or replacing air conditioning equipment refrigerants, and managing legacy waste. See Chapter 3 for a discussion of these programs and their status.

\subsubsection{Groundwater Protection}

BNL's Groundwater Protection Management Program is designed to prevent impacts to groundwater and to restore groundwater quality by integrating pollution prevention efforts, monitoring groundwater restoration projects, and communicating on

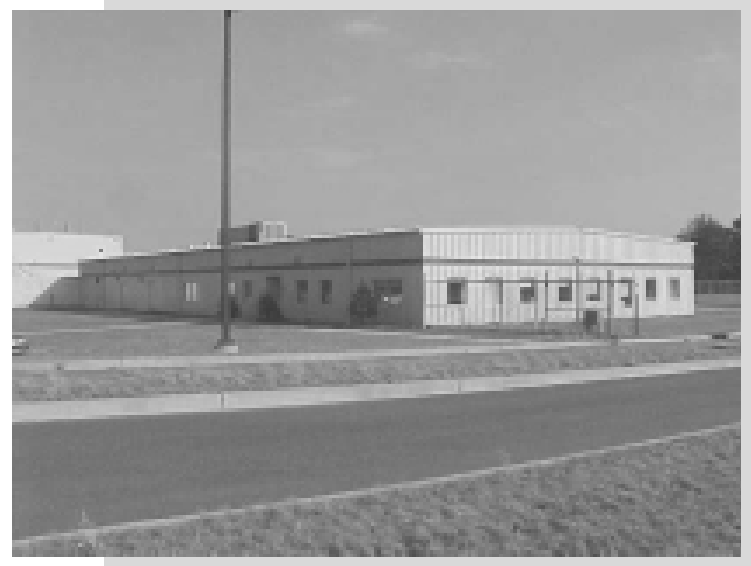

Bldg. 860 contains offices for technical and professional staff. Staff are responsible for providing support to the Laboratory to facilitate pickup, storage, and off-site disposal of hazardous, radioactive, and mixed waste.

\section{Hazardous Waste Management}

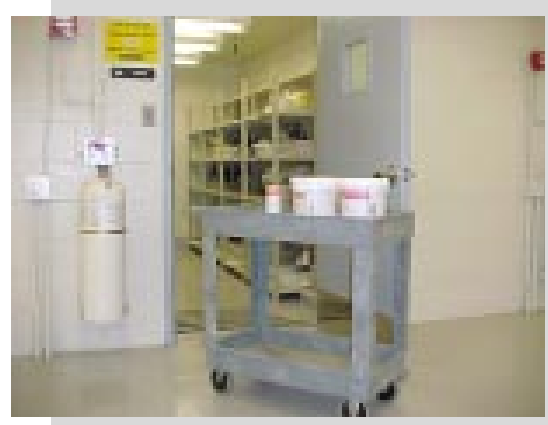

Bldg. 855 is used for the storage of BNL's industrial, hazardous and polychlorinated biphenyl (PCB) solid, liquid, and gaseous wastes. This building was designed and built to provide tertiary containment for stored wastes to prevent environmental contamination should a spill occur. This was accomplished through the use of sealed concrete floors and an impervious liner placed under the building that exceeds regulatory requirements.

Wastes from various research and maintenance activities are typically generated in quantities of five gallons or less. These wastes are stored in containment trays placed on shelves within secondarily contained storage rooms, referred to as lab pack rooms. Wastes stored in these rooms are segregated by hazard class to prevent incompatible materials from reacting.

Some wastes, such as liquid wastes from photographic processing and waste oils, are collected in 55-gallon drums and stored in drum storage bays. These bays provide the space needed to maneuver and inspect larger containers. As in the lab pack rooms, wastes are placed into the drum storage bays by hazard class to segregate incompatible materials. Containment is provided by concrete floors coated with a chemically resistant sealant, which slope toward sealed collection sumps.

Figure 2-5. BNL Waste Management Facility. 


\section{Radioactive Waste Management}

Bldg. 865 is used for the sorting, repackaging, and temporary storage of solid, low-level radioactive wastes generated by BNL research and maintenance activities. Typical radioactive wastes consist of paper, plastic, glass, and metal. Most radioactive wastes are received at the Waste Management Facility in plastic bags. After receipt, most of these bags are consolidated into

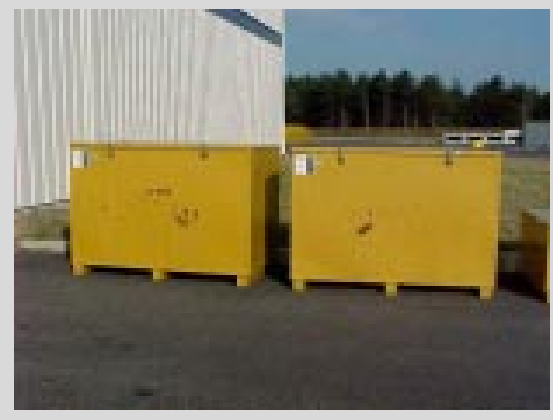
metal bins where they may be

further consolidated through compaction. Metals, glass, and heavy objects that could puncture a bag are sometimes packaged directly into these bins or other appropriate container.

Prior to shipment off-site, bins containing waste are stored in belowgrade concrete vaults. Bins are inserted into and removed from these vaults via an overhead crane. Only solid radioactive wastes are stored in Bldg. 865.

\section{Mixed Waste Management}
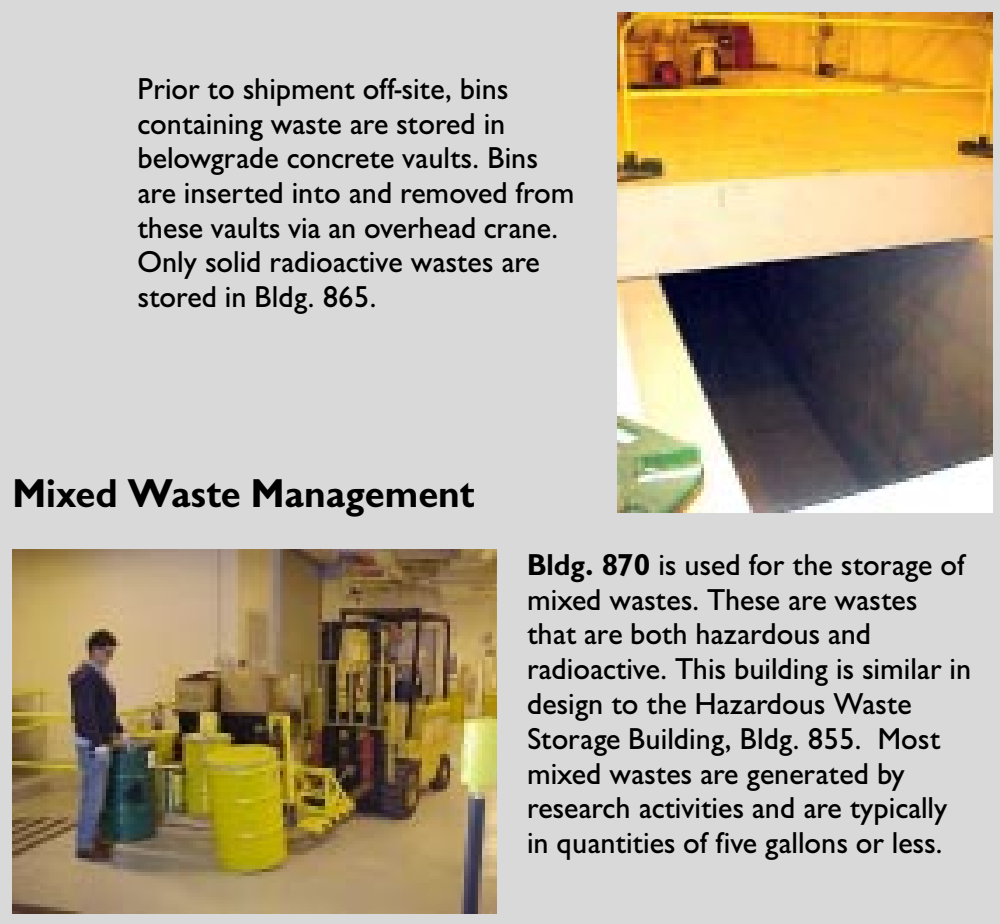

Bldg. 870 is used for the storage of mixed wastes. These are wastes that are both hazardous and radioactive. This building is similar in design to the Hazardous Waste Storage Building, Bldg. 855. Most mixed wastes are generated by research activities and are typically in quantities of five gallons or less.

Bldg. $\mathbf{8 7 0}$ is comprised of storage bays that provide secondary containment. Small waste items are stored within containment trays on shelves in the bays. Typical mixed wastes include radioactively contaminated acids and alcohols, mercury-containing apparatus, and lead used in shielding applications. Mixed wastes are stored in this building prior to off-site treatment and disposal. performance. BNL has also developed a Groundwater Protection Contingency Plan that defines an orderly process for taking corrective actions quickly in response to unexpected monitoring results. Key elements of the groundwater program are the full and timely disclosure of any off-normal circumstances and regular communication on the performance of the program. Chapter 7 provides additional details about the Groundwater Protection Management Program and monitoring results for 2001 .

\subsubsection{Waste Management}

The goal of BNL's Waste Management Program is safe and efficient management of waste, from its generation to off-site disposal. The program emphasizes pollution prevention and waste minimization. It ensures that there is a defined pathway and budget for disposing of any waste generated, and also that BNL complies with applicable regulatory and permit requirements. These include DOE Order 435.1 (1999), Radioactive Waste Management, and the Resource Conservation and Recovery Act (RCRA) regulations that require disposal of all radioactive and hazardous wastes within one year of receipt by the Waste Management Program. This requirement keeps sites from accumulating excess waste.

BNL's Waste Management Facility has a permit from the New York State Department of Environmental Conservation (NYSDEC): Permit No. 1-422-00032/00102-0, consisting of four operations sites: Buildings 855, 860, 865 , and 870 . Figure $2-5$ illustrates and describes the operations in each of these buildings.

Mixed wastes present a special disposal challenge, as they contain both hazardous and radioactive constituents. In 2001, BNL shipped approximately 1,200 cubic feet of mixed waste off site for treatment and disposal. This waste results from both routine and cleanup operations, and much of it had been in storage for years due to the lack of treatment options. During that time, it was monitored by BNL in accordance with the NYSDEC-approved $B N L$ Site Treatment Plan (BNL 1997). 
The Water Processing Facility (Building $810 / 811$ ) is used to manage liquid radioactive wastes. Bulk quantities of radioactive wastewater are stored in tanks at this facility, in permitted tanks for either on-site processing or off-site treatment and disposal.

In addition to the Waste Management and Water Processing Facilities, BNL has nineteen 90-Day Hazardous Waste Accumulation Areas and approximately 200 Hazardous Waste Satellite Accumulation Areas, where small quantities of hazardous waste are managed at or near the point of generation in laboratories and shops. Trained staff, following standard operating procedures, manage these areas.

In 2001, BNL generated the following types and quantities of waste from routine operations:

- Hazardous Waste: 10.1 tons

- Mixed Waste: 55 cubic feet

- Radioactive Waste: 3,488 cubic feet.

These quantities represent significant reductions from previous years, as can be seen in Figures 2-6a through c. These figures represent waste from routine operations only. Routine operations are defined as ongoing industrial and experimental operations. The picture is not complete however, without consideration of wastes generated from "nonroutine" or one-time events and waste generated from environmental restoration activities. Nonroutine waste includes construction and demolition wastes, environmental restoration wastes, legacy waste, lead-painted debris, lead shielding, and PCB waste. Figures 2-6d, 2-6e, and 2-6f show wastes generated under the Environmental Restoration Program. Waste generation from these activities varies significantly from year to year. This is to be expected, based on the progress of the cleanup schedule. As environmental restoration activities move from remedial investigations and feasibility studies to remedial actions, waste generation changes. For example, in 2001, radioactive waste increases can be attributed to soils, debris, and concrete from increased work at the Brookhaven Graphite Research Reactor (BGRR) and the former Hazardous Waste Management Facility. Radioactive waste is expected to continue to significantly exceed mixed and hazardous generation rates, with these waste generation numbers fluctuating from project to project. The purpose of remedial actions is to remove waste or contaminants from the environment. Thus, as the Environmental Restoration Program enters the active cleanup phase, waste volumes from nonroutine operations and remedial actions will continue to rise. The Pollution Prevention Program recognizes this, and will continue to target these waste streams for minimization.

\subsubsection{Prevention and Minimization}

BNL's environmental stewardship policy includes a commitment to integrate pollution prevention and waste minimization into all planning and decision making. Consistent with this commitment and the requirements of Executive Order 13148 (2000), "Greening the Government Through Leadership in Environmental Management," BNL continued to strengthen the Pollution Prevention Program in 2001.

Recognizing BNL's strong commitment to reducing waste and protecting the environment, in 2001 DOE awarded the Laboratory two prestigious national awards for pollution prevention. BNL won these awards for the "Process Evaluation Project" and "Environmental Management Systems Principles Leading Change." The Process Evaluation Project, completed in May 2000, was a systematic environmental assessment of all waste-generating operations and experiments. This assessment utilized specialized tools called process maps. See Figure 2-7 for a sample map. Approximately 145 industrial operations and 1,800 experiments were evaluated and are reevaluated each year. This process identified more than 260 pollution prevention opportunities. Of these, 97 were determined to be technically feasible with a high probability of successful implementation (i.e., "viable"). Seventy-six of these opportunities were determined to have low cost and were implemented by departments. Twenty-one opportunities were determined to be expensive; proposals were generated for 17 (81 percent) of them, seeking funding from the Pollution Prevention program. 


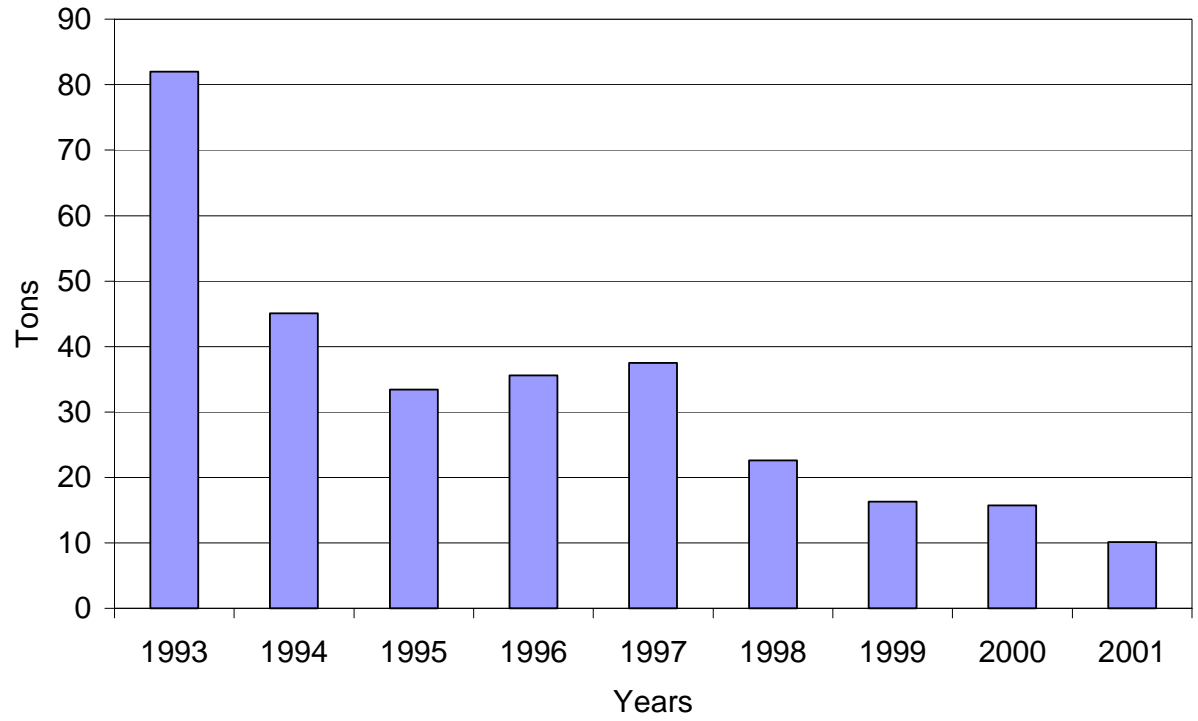

Figure 2-6a. Routine Hazardous Waste Generation, 1993-2001.

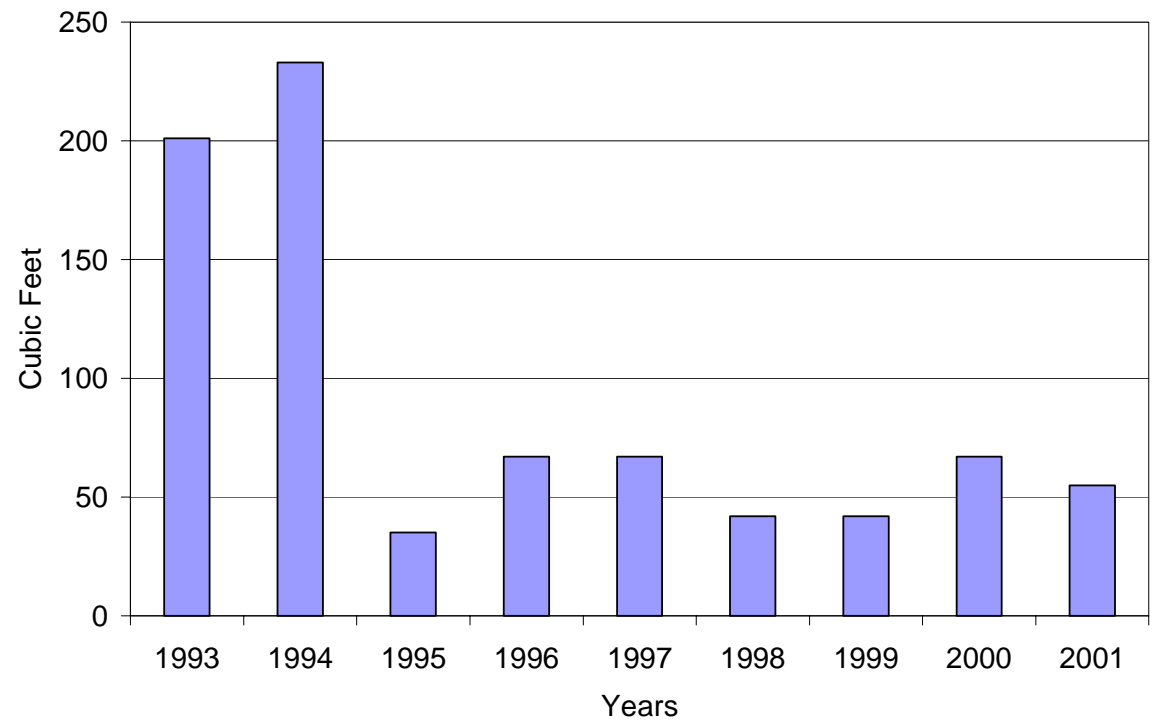

Figure 2-6b. Routine Mixed

Waste Generation, 1993-2001.

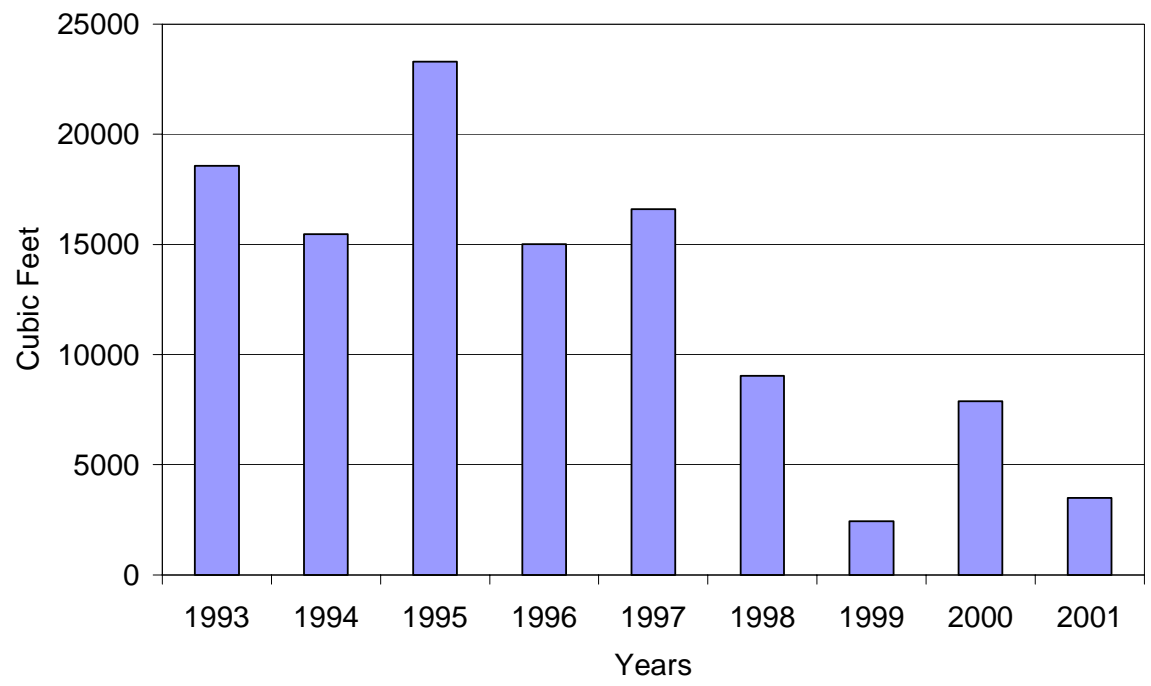

Figure 2-6c. Routine Radioactive Waste Generation, 1993-2001. 
CHAPTER 2: ENVIRONMENTAL MANAGEMENT SYSTEM

Figures 2-6d through 2-6f show the nonroutine waste not included in the totals in Section 2.3.4.3, as well as other hazardous, mixed,

and radioactive wastes generated by the Environmental Restoration (ER) Program.

Figure 2-6d. ER and Nonroutine Hazardous Waste Generation 1997-2001.

Figure 2-6e. ER and Nonroutine Mixed Waste Generation, 1997-2001.

Figure 2-6f. ER and Nonroutine Radioactive Waste Generation, 1997-2001.

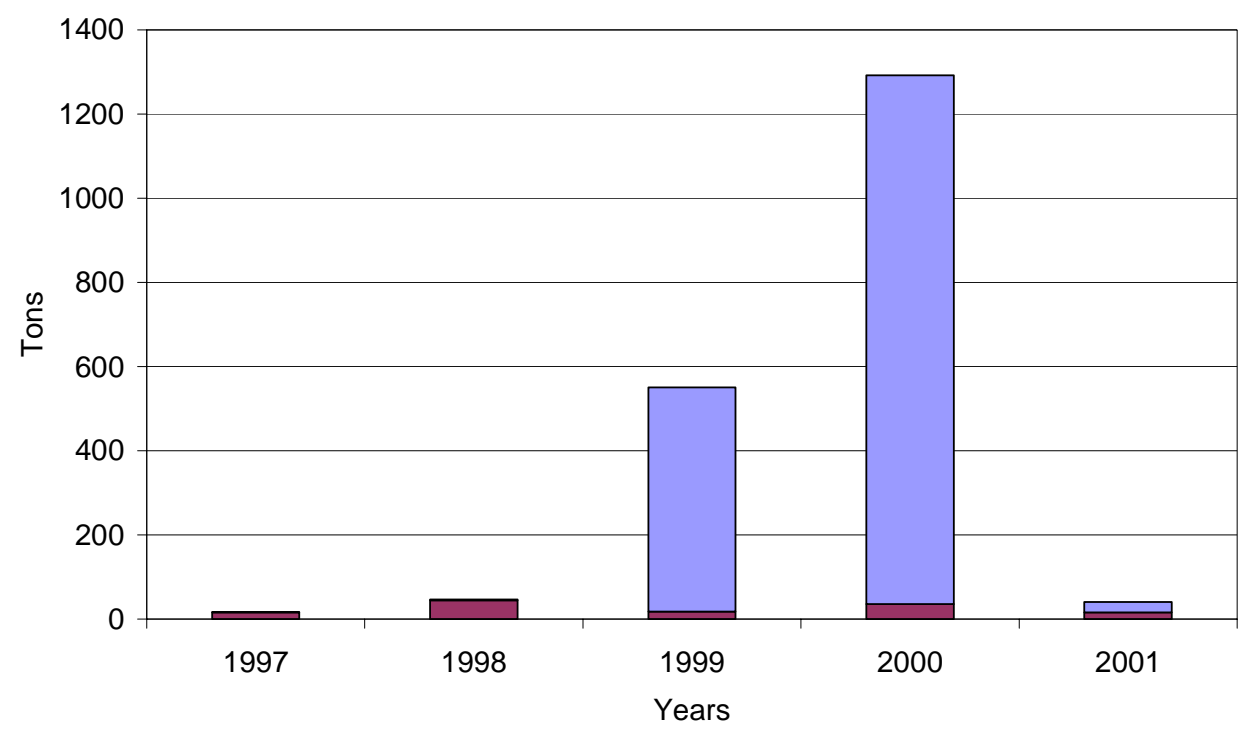

$\square$ Nonroutine Waste $\square$ ER Hazwaste

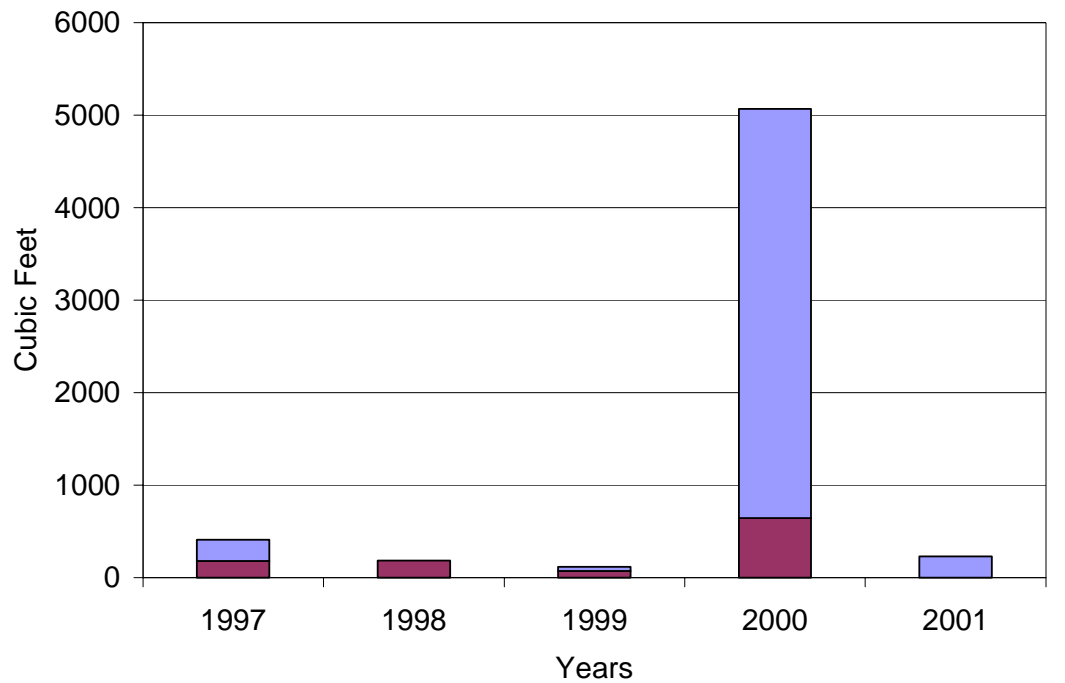

$\square$ Nonroutine Mixed $\square$ ER Mixed

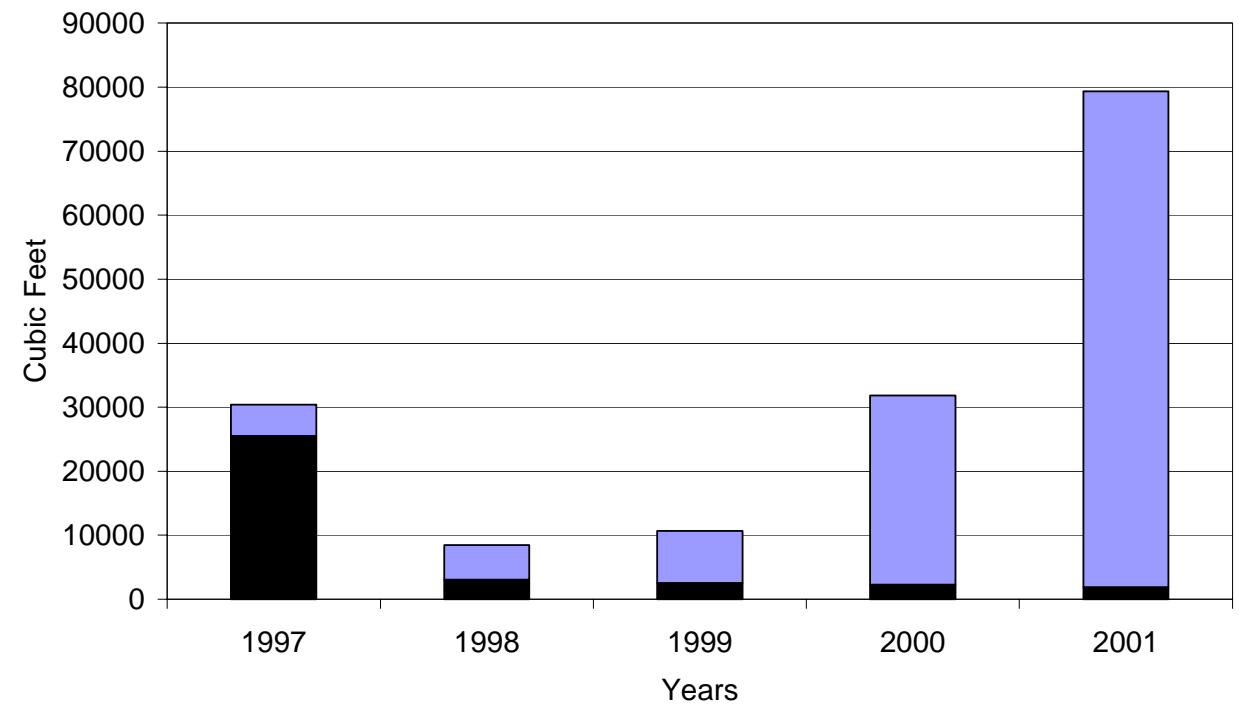

- Nonroutine Radwaste $\square$ ER Radwaste 


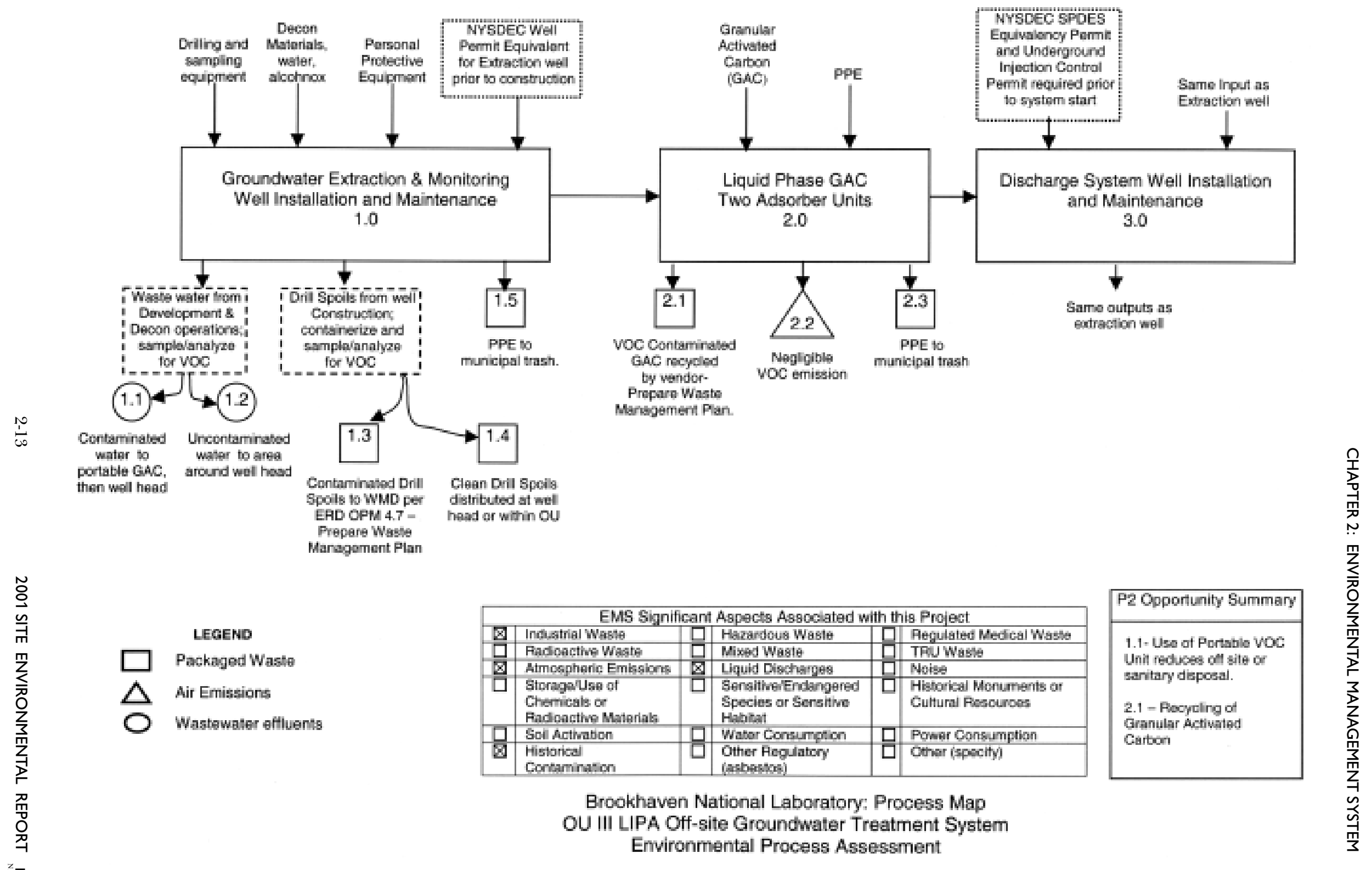

Figure 2-7. Process Map Example.

BNL has evaluated approximately 2,000 industrial and research processes on site and produced process maps like this one showing inputs, outputs, and regulatory requirements.

This project received a DOE Pollution Prevention Award in 2001. 
The EMS Principles Leading Change award was for the ongoing effort to fully integrate environmental stewardship into all facets of BNL's operations. In addition to the DOE awards, EPA Region II also recommended both projects for inclusion in President Clinton's Library of Accomplishments. A third project, "Preparing for High Flux Beam Reactor Facility Stabilization," was selected as a runner-up in the DOE national awards. This project sought alternative uses for equipment and supplies that were once part of the former HFBR; recycling these materials saved the Laboratory more than $\$ 300,000$.

The BNL Pollution Prevention Program reflects national and DOE pollution prevention goals and policies, and represents an ongoing effort to make pollution prevention and waste minimization an integral part of the BNL operating philosophy. Key elements of the Pollution Prevention Program include the following:

- Eliminate or reduce wastes, effluents, and emissions at the source where possible, and ensure that environmental effluents, emissions, and wastes are As Low As Reasonably Achievable (E-ALARA).

- Procure environmentally preferable products (also known as "affirmative procurement").

- Conserve natural resources and energy.

- Reuse and recycle materials.

- Achieve or exceed BNL/DOE waste minimization, pollution prevention, recycling, and affirmative procurement goals.

- Comply with applicable requirements (e.g., New York State Hazardous Waste Reduction Goal, Executive Orders).

- Reduce waste management costs.

- Identify funding mechanisms for evaluating and implementing pollution prevention opportunities.

- Implement pollution prevention projects.

- Improve employee and community outreach and awareness of pollution prevention goals, plans, and progress.

The EMS provides a mechanism for expanded awareness and employee involvement in the Pollution Prevention Program, and for systematically evaluating and implementing value-added pollution prevention opportunities at the Laboratory. In particular, pollution prevention planning has been incorporated into the BNL work planning processes such as the experimental safety reviews, facility design reviews, and routine work planning. This is consistent with the principles of integrated safety management and the approach is beginning to produce excellent results. The increasing number of pollution prevention project proposals submitted by scientific research staff, up nearly 300 percent since 1999, demonstrates the success of this system.

The sustained efforts of the BNL pollution prevention and recycling programs have achieved significant reductions in waste generated by routine operations. From 1993 through 2001, BNL reduced hazardous waste generation by 85 percent, mixed waste by 81 percent, and radioactive waste by 72 percent.

Implementation of pollution prevention opportunities, recycling programs, and conservation initiatives has significantly reduced both waste volumes and management costs. In 2001 alone, these efforts resulted in nearly $\$ 1,386,000$ in cost savings and approximately $1,955,000$ pounds of materials being reduced, recycled, or reused. Table 2-2 describes the projects that were implemented in 2001 and includes the number of pounds of materials reduced, reused, or recycled and the estimated cost benefit of each project.

BNL also has an active and successful solid waste recycling program. The recycling program involves all employees. Office staff collect paper in designated containers in their workspace. Custodial staff collect and consolidate recycled paper to central locations, where it is shipped to the recycling facility. In 2001, BNL collected 246 tons of paper for recycling. In addition to paper, the recycling program collects many other kinds of materials, including cardboard, bottles and cans, construction debris, motor oil, scrap metals, lead, automotive batteries, printer and toner cartridges, fluorescent light bulbs, machine coolant, and antifreeze. In 2001, BNL expanded 
CHAPTER 2: ENVIRONMENTAL MANAGEMENT SYSTEM

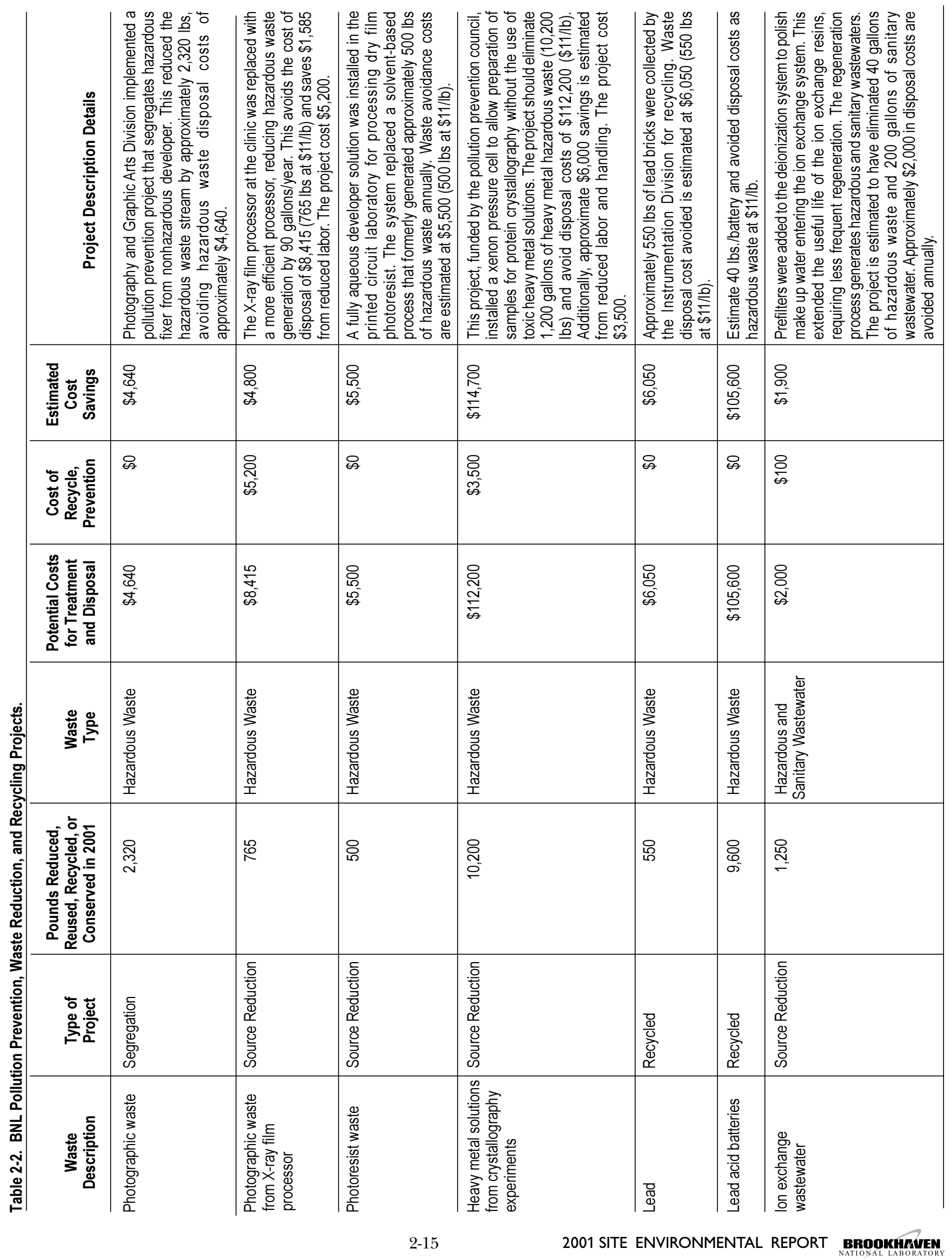




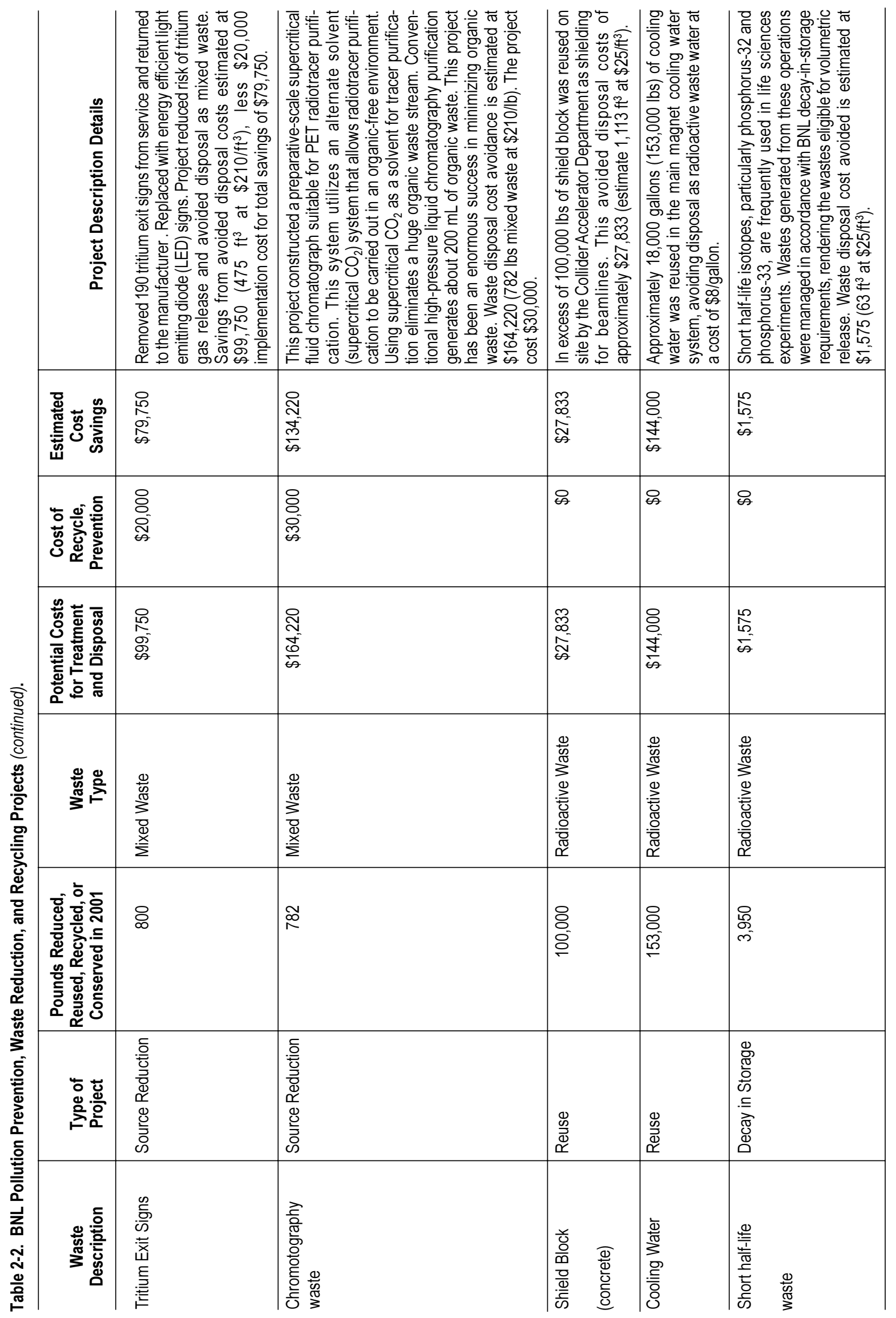


CHAPTER 2: ENVIRONMENTAL MANAGEMENT SYSTEM

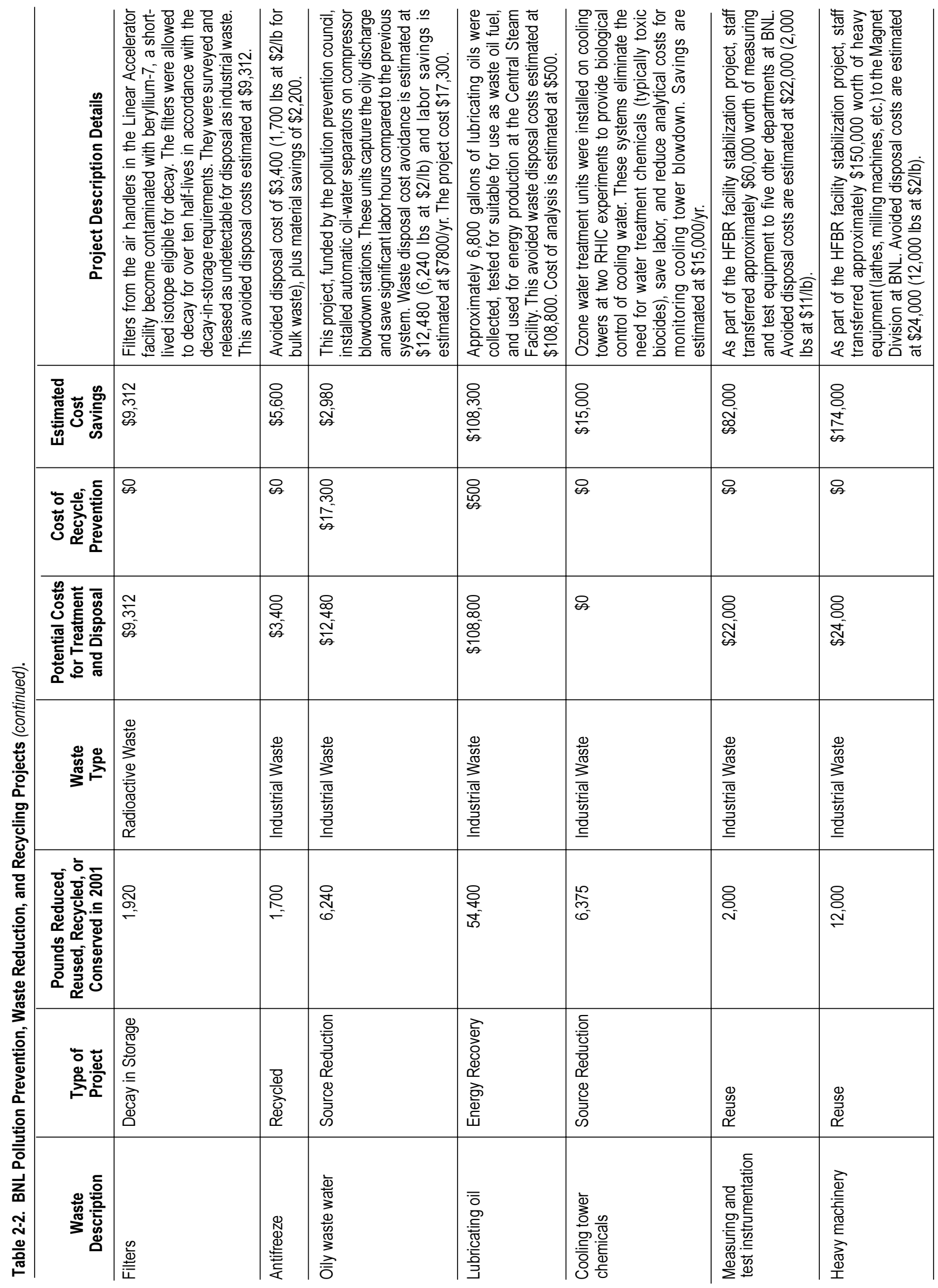


CHAPTER 2: ENVIRONMENTAL MANAGEMENT SYSTEM

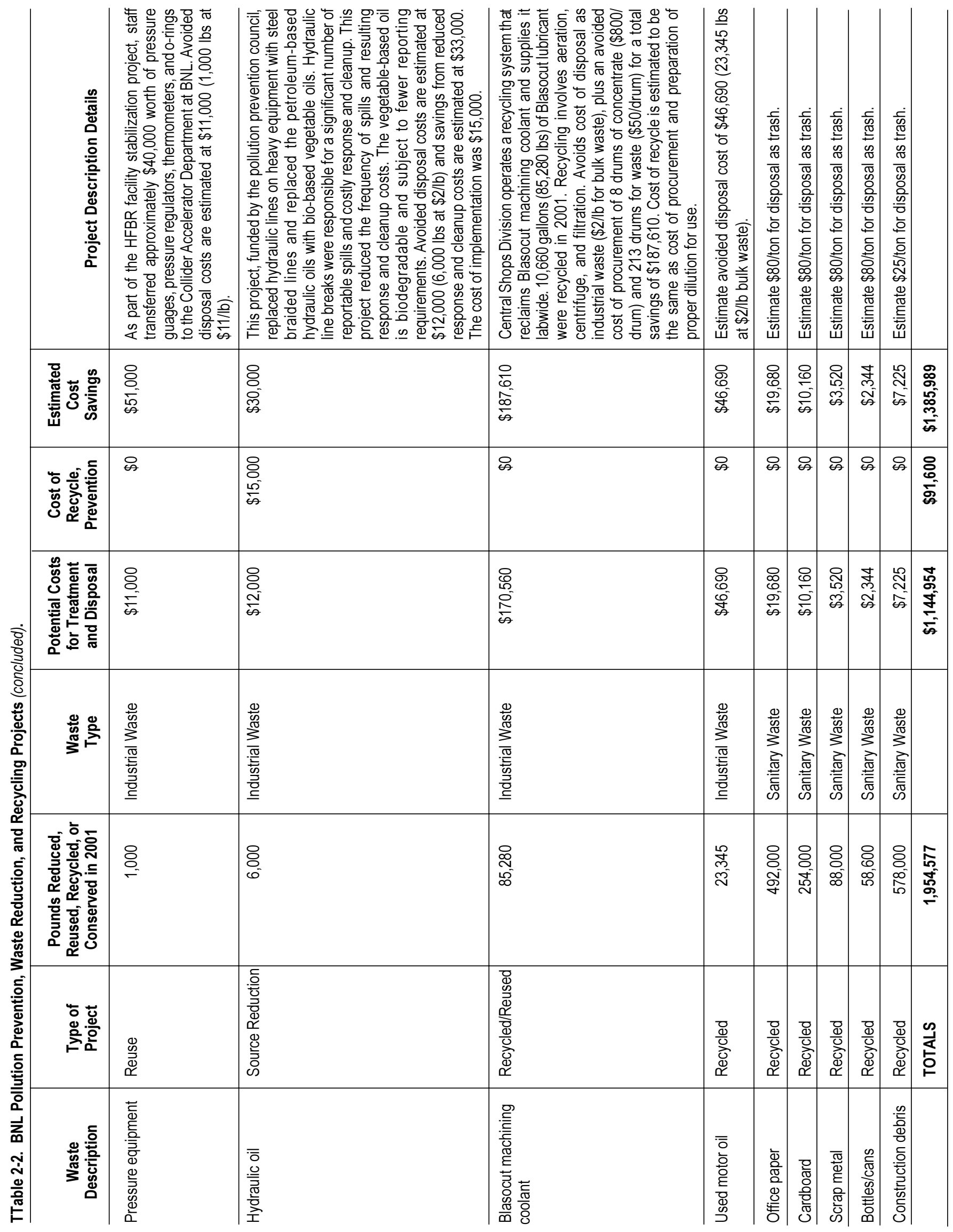




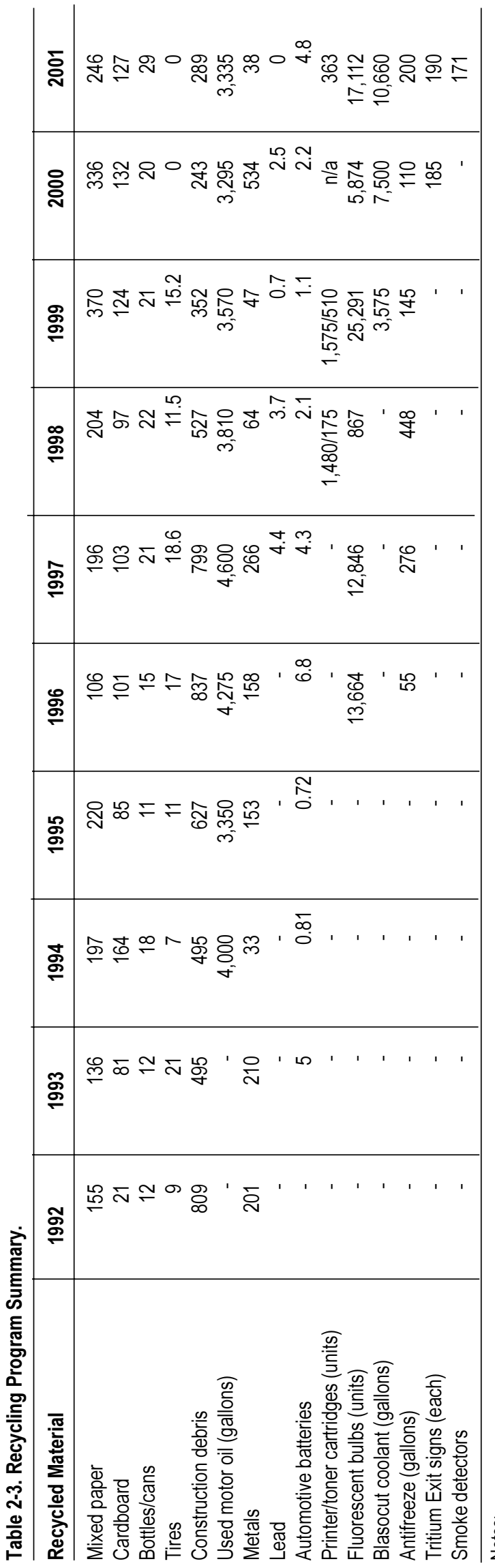

the recycling program to include smoke detectors, which are shipped back to the manufacturer. Table 2-3 shows the total number of tons (or units) of these materials recycled in 2001 and the trends since 1992.

BNL has operated a rideshare program since 1995. BNL is planning on integrating its program with Long Island Transportation Management to provide a larger pool of participants. The Laboratory offers a guaranteed ride service that can be used by program participants. Some BNL groups encourage the use of flexible work schedules with extended hours, which eliminates one to two days of travel every two weeks.

In the summer of 2001, Cornell Cooperative Extension (CCE) of Suffolk County conducted an assessment of BNL's Integrated Pest Management Program (Sanok, 2001). CCE found that the Laboratory's current pest management program constitutes a fully Integrated Pest Management control strategy due to BNL's limited use of chemicals in all areas. CCE commended BNL for taking a proactive approach and agreed to assist with additional training, information on pest management issues, and a written procedure for addressing the many concerns associated with this issue. BNL's environmental stewardship supports these efforts to maintain an attractive and productive facility while minimizing the health and environmental risks. Additionally, with the exception of hydroseeding to reestablish damaged landscape, lawn areas are not watered, fertilized, or treated with pesticides. This reduces the need for mowing, which in turn reduces air emissions from mowers and tractors and the potential for oil spills. When areas other than lawns are identified for revegetation, they are planted with grasses, wildflowers, or trees native to the Northeast, when available and appropriate.

\subsubsection{Water Conservation}

BNL has a strong water conservation program and has achieved dramatic reductions in water usage since the mid 1990s. The Laboratory continuously evaluates water conservation as part of facility upgrades or new 


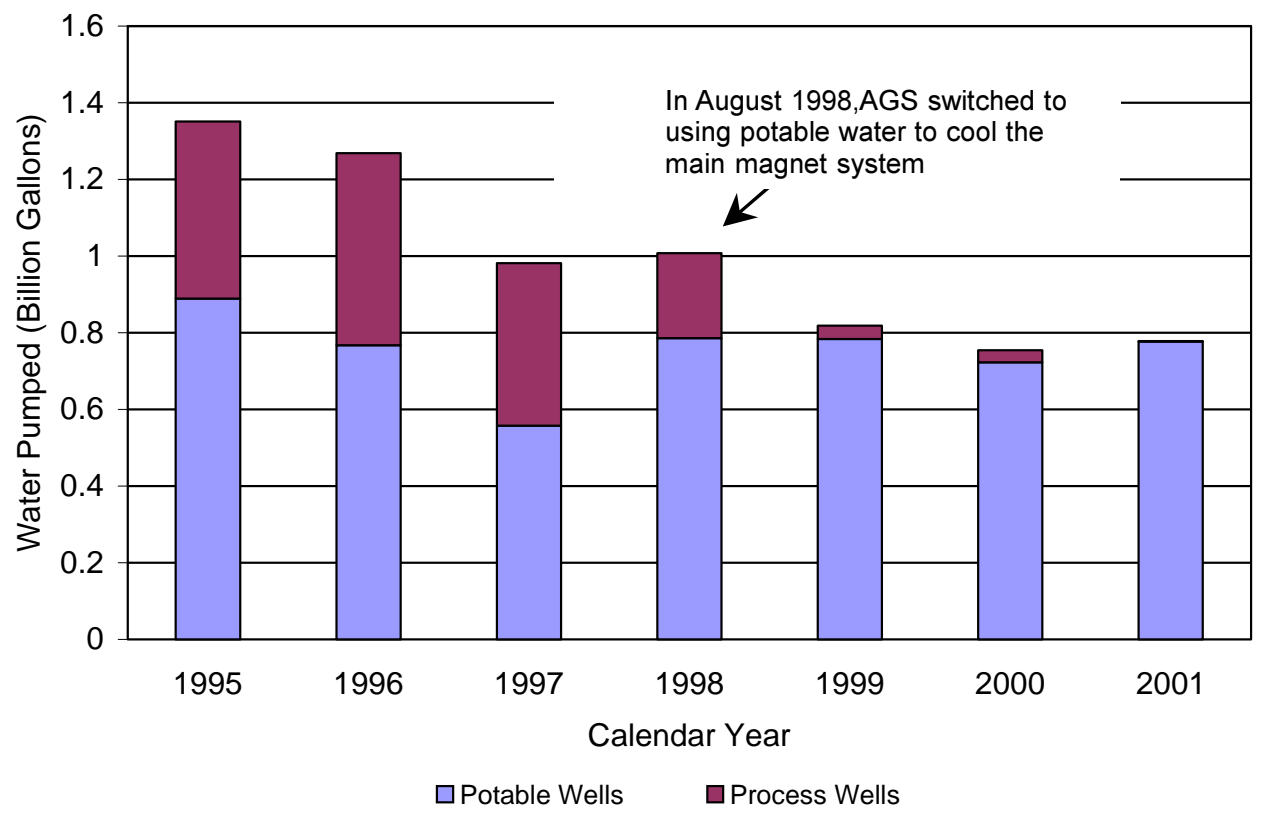

Figure 2-8. Water Consumption Trend.

construction initiatives. These efforts include more efficient and expanded use of chilled water for the heating, ventilation, and air conditioning system, and reuse of once-through cooling water for other systems such as cooling towers. The goal is to reduce the consumption of potable water and reduce the impacts of clean water discharges on Sewage Treatment Plant operations. Figure 2-8 shows the seven-year trend of water consumption. The total annual reduction since 1995 is $600,000,000$ gallons.

\subsubsection{Energy Management and Conservation}

BNL's Energy Management Group has been in place since 1979. This group works to reduce BNL's energy use and costs by identifying costeffective energy efficiency projects, monitoring energy use and utility bills, and assisting in obtaining the least expensive energy sources possible. This group is responsible for the development, implementation, and coordination of BNL's Energy Management Plan.

BNL has more than 4 million square feet of building space. Many BNL scientific experiments use particle beams generated and accelerated by electricity, with the particles controlled and aligned by large electromagnets. Fuel and natural gas are used to produce steam at the Central Steam Facility. In 2001, BNL used 290,806,524 kWh of electricity, 4,104,968 gallons of fuel oil and propane, and 851,300 cubic feet of natural gas. Natural gas use started in FY 1997 and is reducing the need for fuel oil. Use of natural gas (instead of fuel oil) reduced emissions, saved energy, and lowered costs. (See additional information on fuel use in Chapter 4.) BNL is a participant in the Long Island Power Authority's (LIPA) Peak Load Reduction Curtailment Program. The Laboratory has agreed to reduce electrical demand during critical days throughout the summer when LIPA expects customer demand to meet or exceed the company's available supply. In return, BNL receives a rebate for each megawatt reduced for each critical day.

In 2001, several energy-related projects and initiatives were completed. These include completion of a new compressed natural gas vehicle fueling facility for BNL vehicles, completion of a natural gas contract that will save more than $\$ 1.7$ million over three years (more than $\$ 300,000$ was saved in FY2001), fuel purchasing strategies that saved $\$ 592,000$, and the connection of the Chemistry Building to the central chilled water, eliminating the need for two large, out-dated chloroflourocarbon chillers. BNL also received $\$ 940,000$ for new energy conservation projects, ranging from LED 


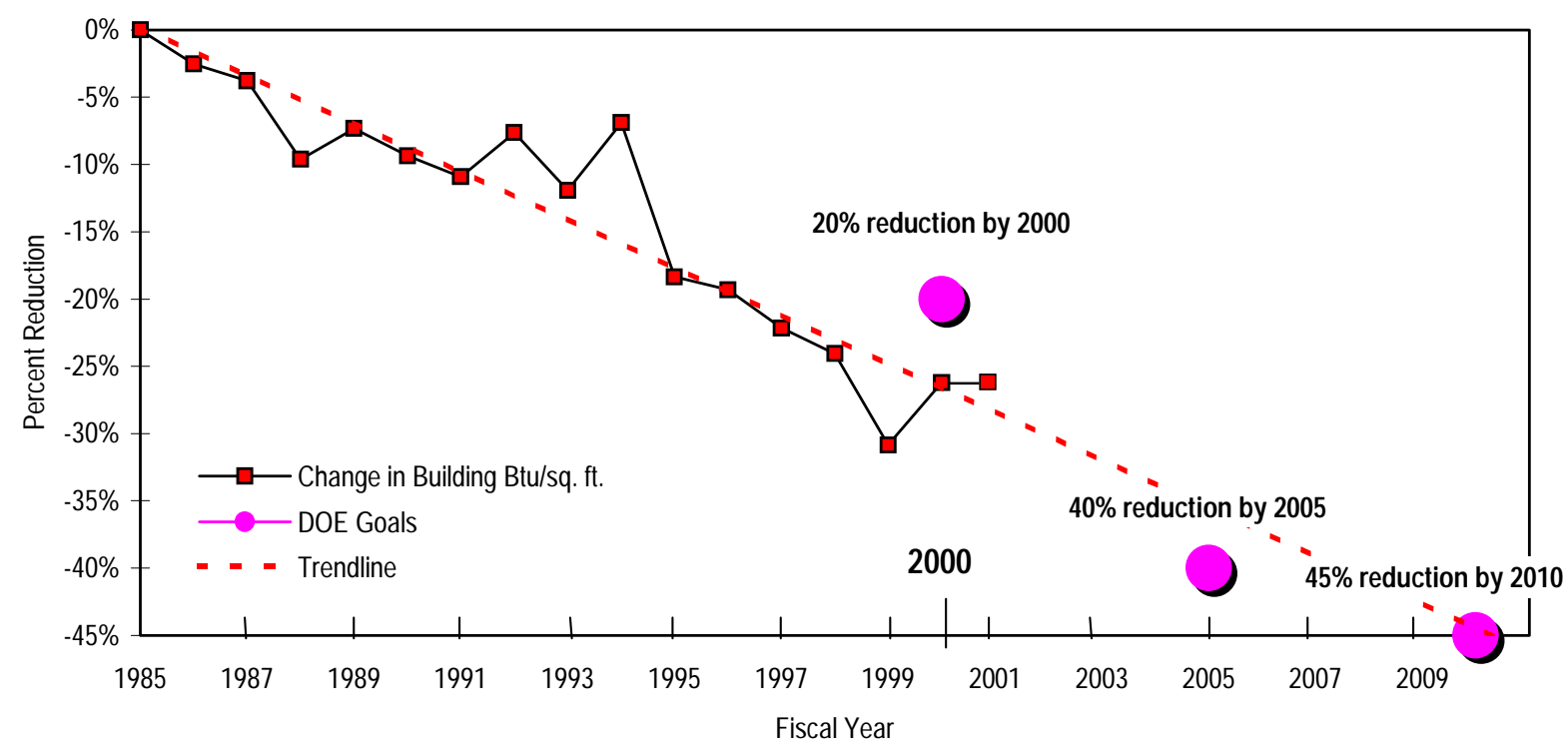

Figure 2-9. Building Energy Performance Since 1985.

lighting to a solar heating system for the swimming pool.

The National Energy Conservation Policy Act, as amended by the Federal Energy Management Improvement Act of 1988 and the Energy Policy Act of 1992, requires federal agencies to apply energy conservation measures and improve federal building design to reduce energy consumption per square foot. Current goals are to reduce energy consumption per square foot, relative to 1985 , by 20 percent in 2000,40 percent by 2005 , and 45 percent by 2010. BNL energy use per square foot in 2001 is 26 percent less than in 1985 (see graph in Figure 2-9). However, it is becoming increasingly difficult to find economically attractive energy projects. Energy use in 2001 was similar to 2000 . The measure of $\mathrm{Btu} / \mathrm{ft}^{2}$ (shown in Figure 2-9) does not take weather into account. When the Btu/ $\mathrm{ft}^{2}$ per degree-day (adjusted for weather) is calculated, there is actually an 8.4 percent drop from 2000 to 2001. BNL's Energy Management Group assisted with a demonstration and test of microturbines at the Laboratory in 2001. In cooperation with Keyspan Energy and the Energy Sciences and Technology Department and with financial assistance from the Federal Energy Management Program, two microturbines were installed at the Laboratory as part of DOE's strategic effort to develop alternatives to large-scale power plants. Overall annual energy savings for FY2001 were $\$ 15,000,000$. BNL continues to seek out alternative energy to meet its future energy needs, support federally required "green" initiatives, and reduce energy costs.

\subsubsection{Natural and Cultural Resource Management}

The Laboratory continues to develop, enhance, and implement its natural resource program, building on a foundation established by the Wildlife Management Plan. Over the past year, BNL has begun to develop a cultural resource program to identify and manage properties that are determined to be eligible or potentially eligible for inclusion on the National Register of Historic Places. For more information about these two programs, refer to Chapter 6.

\subsubsection{Environmental Restoration}

The Comprehensive Environmental Response, Compensation and Liability Act (CERCLA), commonly known as Superfund, was enacted by Congress on December 11, 1980. As part of CERCLA, EPA established the National Priorities List (NPL), which is a list of sites nationwide where cleanup of past 
contamination is required. BNL is listed on the NPL with 32 other Long Island sites (16 in Suffolk County—see http://www.epa.gov/ superfund/sites/npl/ny.htm). Most of the contamination at BNL is associated with past accidental spills and outmoded practices for handling, storing, and disposing of chemical and radiological material.

BNL follows the CERCLA process (Figure 2-10), which includes the following steps:

- Conduct a Preliminary Assessment (review of historical documents, interviews with employees, site reconnaissance).

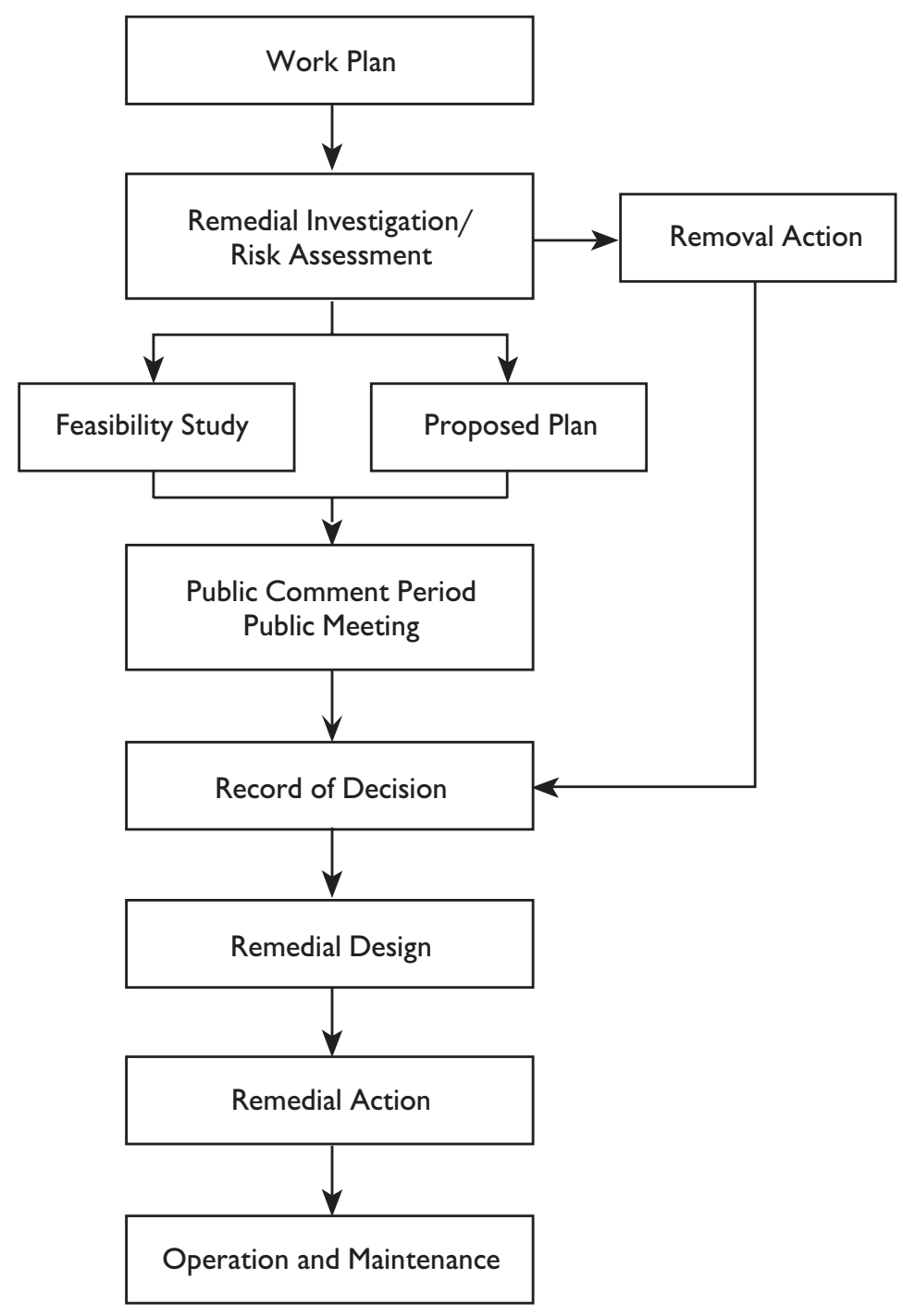

Figure 2-10. CERCLA Process.
- Conduct a Site Inspection, which often includes sampling.

- Conduct a Remedial Investigation to characterize the nature and extent of contamination and assess the associated risks.

- Prepare a Feasibility Study and Proposed Plan to list and evaluate remedial action alternatives and present the proposed alternative.

- Issue a Record of Decision (the remedy/ corrective action agreed to by DOE, EPA, and NYSDEC).

- Perform the Remedial Design/Remedial Action, which includes final design, construction specifications, and carrying out the remedy selected.

At each step, EPA distinguishes between sites that do or do not require further action, based on potential threat to human health and the environment. An expedited cleanup action, called a Removal Action, can also be conducted. This requires an Engineering Evaluation/Cost Analysis, which evaluates and recommends specific cleanup actions. The selected action is then documented in an Action Memorandum, the equivalent of a Record of Decision.

The goal of BNL's Environmental Restoration Program is to complete onsite cleanup activities and install all groundwater treatment systems by 2006 or earlier. The Laboratory has made substantial progress in characterizing and removing sources of contamination (e.g., underground tanks) and in treating or removing the groundwater and soil contamination that are the result of past disposal practices. The Environmental Restoration Program has also worked to advance the decontamination and decommissioning of the former BGRR and the stabilization of the HFBR.

Historical facility records and sampling have been used to determine where contamination might be present on the site today. These areas were geographically grouped into Operable Units (OU). For a fuller description, see Areas of Concern at BNL, Upton, New York-A Reference Handbook (BNL 1998a). A map of 


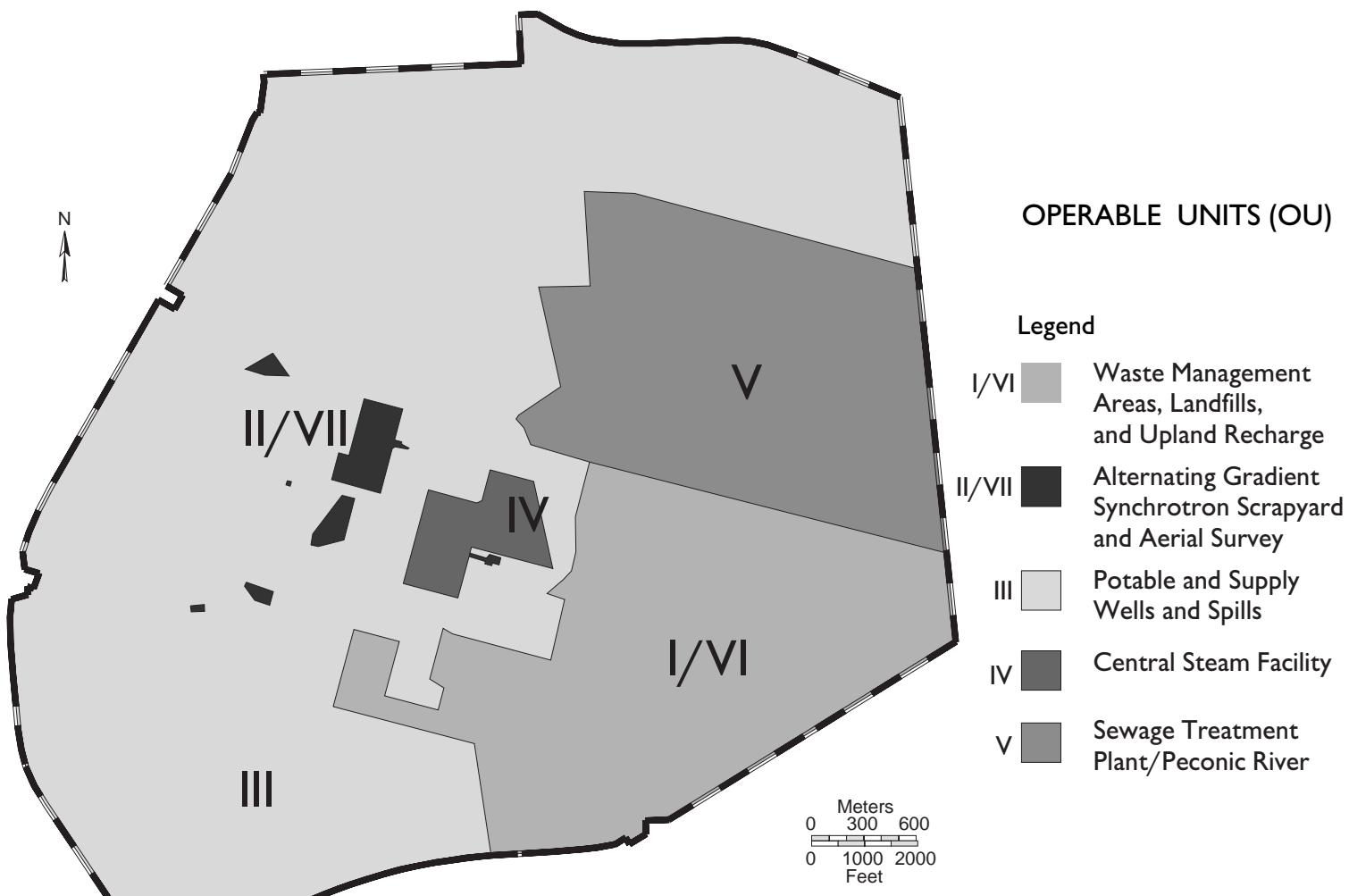

Figure 2-11. OU Boundaries at BNL.

the OUs is shown in Figure 2-11. Table 2-4 provides a description of each OU (I through VII) and a summary of environmental restoration actions taken during 2001 (also see Figures 2-12a through 2-12f). Significant progress was made in environmental restoration in 2001. The cleanup implementation has been organized into four classes of projects: soils, groundwater, Peconic River, and reactors. These are detailed in Table 2-4.

\subsubsection{The Facility Review Project}

The Facility Review Project was a comprehensive examination of all site facilities, existing or demolished, to identify any past or current activities with the potential to degrade the environment. During this project, BNL reviewed the entire operating history of the site and more than 900 systems, facilities, and operations including tanks, pipes, sumps, cesspools, storage areas, historical discharges, and current and past operating practices. Twenty-eight individuals from fifteen other DOE facilities provided highlevel technical and management support during the review. A final report was issued on October 7, 1998 (BNL 1998b).

The report identified 75 issues as having the highest priority, due to their potential to contaminate groundwater above drinking water standards. Seventy-six percent of these issues were dispositioned by December of 2001 . Additionally, more than 1,675 issues that had the potential to impact the environment were identified as needing further evaluation. These were further subdivided into operational and legacy issues. In March 2000 the Facility Review Disposition Project Plan (BNL 2000a) was approved. This three-year project provides the mechanisms needed to rank risk, to schedule, and to resolve the issues identified during the Facility Review Project of 1997. BNL continues to work closely with Suffolk County Department of Health Services on these issues, using a shared database to track progress. See Table 2-5 for a breakdown of the number of issues and their status. Overall, 68 percent of all issues were dispositioned by the end of 2001. The goal is to resolve all of these issues by the end of 2002 . 
Table 2-4. Hierarchy of Environmental Objectives at BNL.

\begin{tabular}{|c|c|c|}
\hline Cleanup Project & Operable Unit/Description & Environmental Restoration Program Actions in 2001 \\
\hline Soil Projects & $\begin{array}{l}\text { OU I } \\
\text { OU II } \\
\text { OUVII }\end{array}$ & $\begin{array}{l}\text { - Boneyard project legacy waste transported to ATG for processing (1.1 million pounds). } \\
\text { - Size reduction of Boneyard project yard components/ debris and subsequent transport to Envirocare } \\
\text { of Utah for disposal( }\left(42,500 \mathrm{ft}^{3}\right) \text {. } \\
\text { - Completed remediation and restoration of the Landscape Soils (AOC 16). . } \\
\text { Approximately } 1,500 \mathrm{yd}^{3} \text { of soil from the Chemical Holes remediation was transported to Envirocare } \\
\text { of Utah for disposal. } \\
\text { - Removal Action Work Plans for the Bldg. } 811 \text { underground storage tanks and soils, and BIdg. } 650 \\
\text { - Pump outfall were submitted to regulators. } \\
\text { - Final design for radiologically contaminated soils was submitted to regulators. }\end{array}$ \\
\hline \multirow[t]{4}{*}{$\begin{array}{l}\text { Groundwater } \\
\text { Projects }\end{array}$} & OU III & $\begin{array}{l}\text { - Completed construction and began routine operations of on-site groundwater treatment system at } \\
\text { - Middle Road for volatile organic compounds (VOCs). } \\
\text { - Coman construction of on-site groundwater treatment system for VOCs at western south boundary. } \\
\text { - evaluation. } \\
\text { - } \quad \text { Continued installation of temporary and permanent monitoring wells for the HFBR tritium plume. } \\
\text { several Geoprobes and monitoring wells. An Engineering Evaluation and Cost Analysis was } \\
\text { prepared for regulator review. (This is not included under any specific OU at this time but it is an } \\
\text { AOC). } \\
\text { - During 2001, 1,032,684,000 gallons of groundwater were treated and } 600 \text { pounds of VOCs were } \\
\text { removed. Since the first groundwater treatment system started operating in December } 1996, \\
\text { approximately } 2,900 \text { pounds of VOCs have been removed from more than } 4 \text { billion gallons of } \\
\text { groundwater. } \\
\text { - Conducted pre-design characterization by installating temporary and permanent monitoring wells } \\
\text { for five planned off-site groundwater treatment systems south of BNL in East Yaphank and } \\
\text { Manorville. } \\
\text { Continued characterization of the Magothy Aquifer. }\end{array}$ \\
\hline & OU IV & $\begin{array}{l}\text { - A petition for system shut-down was submitted and approved by the regulators for the OU IV air } \\
\text { sparge and soil vapor extraction soil and groundwater treatment system. The system was placed } \\
\text { on stand-by in August. } \\
\text { - Continued groundwater monitoring. } \\
\text { - Completed interim remedy monitoring for the Bldg. } 650 \text { Sump and Sump Outfall. }\end{array}$ \\
\hline & OU VI & $\begin{array}{l}\text { - } \quad \text { EPA and DEC approved the Record of Decision. } \\
\text { - Continued monitoring the ethylene dibromide plume. } \\
\text { monitoring wells for the planned off-site groundwater treatment system south of BNL in Manorville. }\end{array}$ \\
\hline & Groundwater Monitoring & $\begin{array}{l}\text { - Completed the BNL } 2000 \text { Groundwater Status Report. } \\
\text { - Collected and analyzed 2,389 groundwater samples from } 594 \text { monitoring wells. } \\
\text { - Completed a comprehensive data quality objective assessment of the groundwater monitoring } \\
\text { program. } \\
\text { - Issued the Environmental Monitoring Plan, } 2001 \text { Update. }\end{array}$ \\
\hline Peconic River & OU V & $\begin{array}{l}\text { - Record of Decision signed for the Sewage Treatment Plant. } \\
\text { - Technology fact sheets distributed and Peconic River fact sheets updated. }\end{array}$ \\
\hline Reactors & BGRR. & $\begin{array}{l}\text { - The Below Ground Duct Cooler was removed. The cooler waste will be sent to Envirocare of Utah } \\
\text { in } 2002 \text {. } \\
\text { - The Above Ground Duct was removed. Sections of concrete duct were size reduced to meet } \\
\text { transportation and disposal site criteria. Shipping of the duct sections to Envirocare of Utah began } \\
\text { in August. The final disposal of duct sections is scheduled to finish during the first quarter of } 2002 \text {. } \\
\text { - An Engineering Evaluation and Cost Analysis (EE/CA) was developed and issued for the BGRR } \\
\text { Canal. Work began on the decontamination, soil remediation, and removal of belowground piping } \\
\text { and equipment associated with the Canal. } \\
\text { - The Below Ground Duct and associated soils were characterized in accordance with an approved } \\
\text { Sampling and Analysis Plan. The characterization data will be analyzed as part of the overall }\end{array}$ \\
\hline
\end{tabular}


Table 2-4. Hierarchy of Environmental Objectives at BNL (concluded).

\begin{tabular}{l|c|c}
\hline Cleanup Project & Operable Unit/Description & Environmental Restoration Program Actions in 2001 \\
\hline Reactors & HFBR & $\begin{array}{l}\text { BGRR risk assessment and end-state determination. } \\
\text { Approximately } 250 \text { tons of oiled sand at the site of the former FA310 Tank, a 250,000- } \\
\text { gallon holdup tank, were removed and sent off site for disposal as industrial waste. } \\
\text { Following demolition of the concrete pits and foundation ring, clean soil was back- } \\
\text { filled, graded and hydro-seeded, returning the area to a grassy, gently rolling slope. } \\
\text { A radiological and hazardous material characterization of the HFBR and ancillary support } \\
\text { buildings was completed. }\end{array}$ \\
& $\begin{array}{l}\text { The Ra-Be source was moved to the HFBR from the basement of Bldg. 703. } \\
\text { A final inspection by Suffolk County of the HFBR facility concluded that the facility is in } \\
\text { full compliance with the provisions of Article 12 of the Sanitary Code. }\end{array}$ \\
\hline
\end{tabular}

a

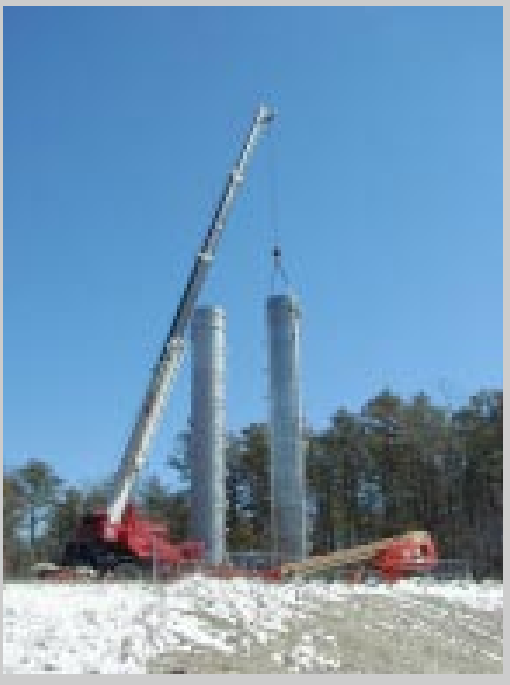

a. Middle Road Groundwater Treatment System began operations in October 2001.

b. OU IV Air Sparge Soil Vapor Extraction System received approval for system "shutdown" from the regulators in January 2001. It pumped on and off during the year and was turned off in August 2001.

c. Removal of the contaminated BGRR Canal north concrete pad area.

d. Plant Engineering rigging personnel loading an Above Ground Duct section onto a truck for transport to a disposal facility.

e. Above Ground Duct section 4-1 cuts are complete and being prepared for separation. Saw House being moved away from saw cut 4-4.

f. Workers remove cooling coils from the Below Ground Duct. b

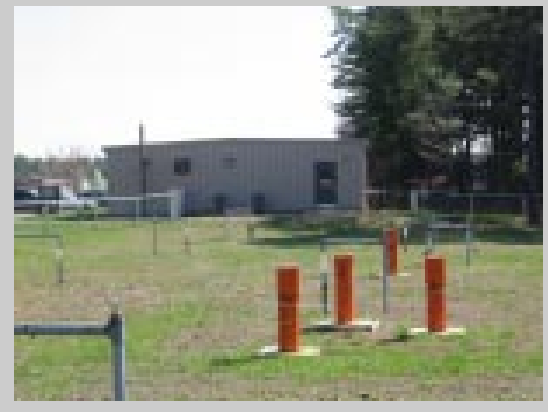

C
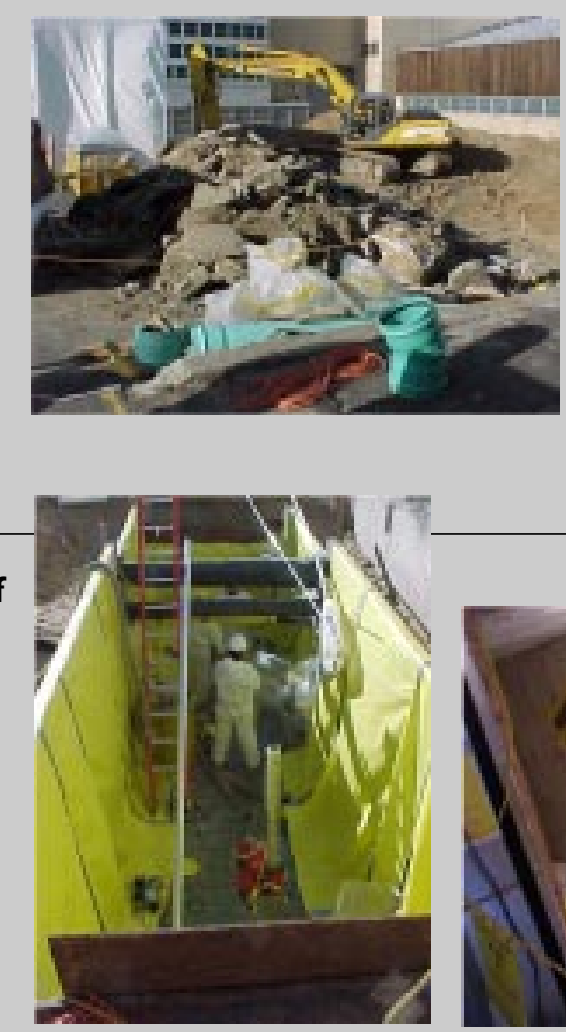

d

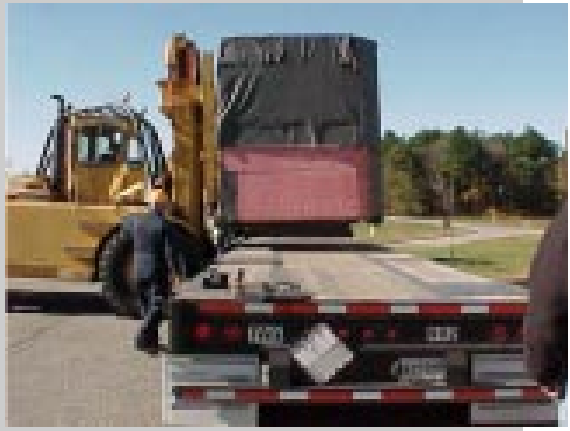

e
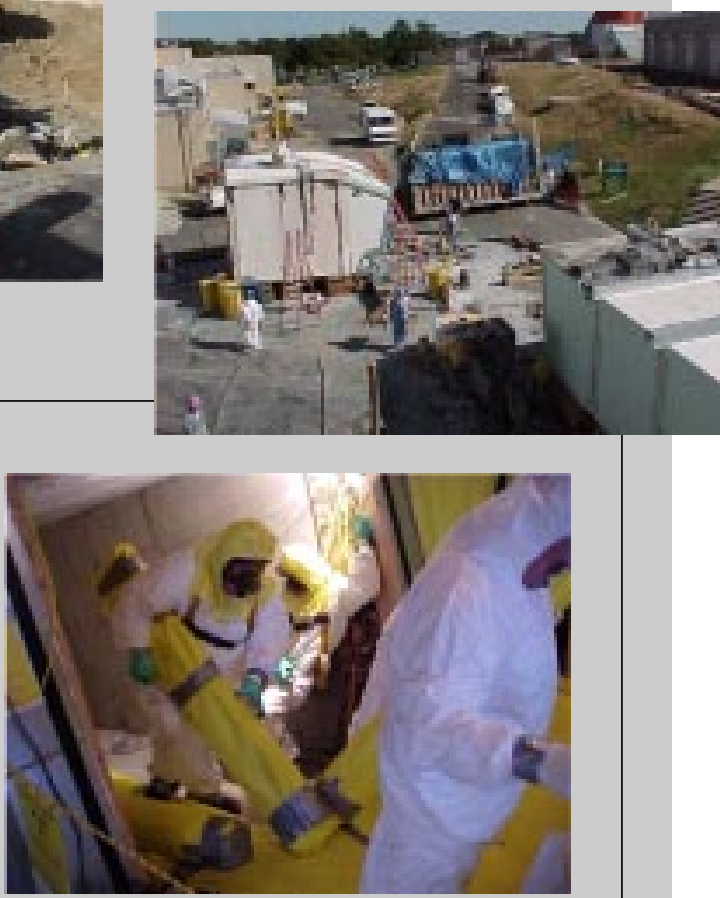

Figure 2-12. Environmental Restoration Actions Taken during 2001. 
Table 2-5. Category, Risk Rank, Number, and Status of Issues Identified in the Facility Review Project, as of December 31, 2001.

\begin{tabular}{|c|c|c|c|c|}
\hline \multirow{2}{*}{$\begin{array}{l}\text { Category } \\
75 \text { High-Priority Issues }\end{array}$} & \multirow{2}{*}{$\begin{array}{l}\text { Rank: Type of Issue } \\
\text { High Priority: Potential to impact groundwater above drinking water standards }\end{array}$} & \multirow{2}{*}{$\frac{\text { Number }}{75}$} & \multicolumn{2}{|c|}{ Dispositioned } \\
\hline & & & 57 & $(76 \%)$ \\
\hline \multirow{2}{*}{$\begin{array}{l}\text { 1,175 Operational } \\
\text { Issues } \\
\text { (responsible organization } \\
\text { still exists) needing } \\
\text { further evaluation }\end{array}$} & Rank 1-3: Potential to impact groundwater, but not above drinking water standards & 176 & 145 & $(82 \%)$ \\
\hline & Rank 4-6: Lower priority, requiring engineering controls or documentation & 999 & 595 & $(60 \%)$ \\
\hline \multirow{2}{*}{$\begin{array}{l}500 \text { Legacy Issues } \\
\text { (responsible organization } \\
\text { does not exist) needing } \\
\text { further evaluation }\end{array}$} & Rank 1-3: Potential to impact groundwater, but not above drinking water standards & 212 & 161 & $(48 \%)$ \\
\hline & Rank 4-6: Lower priority, requiring engineering controls or documentation & 288 & 230 & $(80 \%)$ \\
\hline \multicolumn{2}{|l|}{ Total } & 1,750 & 1,188 & $(68 \%)$ \\
\hline
\end{tabular}

\subsection{IMPLEMENTATION}

\subsubsection{Structure and Responsibility}

All employees at BNL have clearly defined roles and responsibilities in key areas including environmental protection. Every BNL employee is required to develop a Roles, Responsibilities, Accountabilities, and Authorities document signed by the employee, their supervisor, and the supervisor's manager. Specifics on environment, safety, and health performance expectations are included in these documents.

One key to the success of BSA's approach to environmental stewardship has been leadership. At Laboratory meetings and in memorandums, the Director continues to reaffirm his personal commitment to environmental protection and his expectation that all staff participate in this way of doing business. The Deputy Director for Operations manages the Environment, Safety, Health \& Quality Directorate and leads environmental protection efforts. He is responsible for coordinating the EMS within BNL and reporting on performance to senior management, utilizing the staff of the Environmental Services Division to accomplish this task.

BSA also more clearly defined expectations for staff and management. In the past, as is often the case, responsibility for environment, safety, and health had been relegated to support organizations. Now, under the BSA performance based management model, senior management has communicated their expectation that all line managers take full responsibility for environment, safety, and health performance, and that line managers and staff be held accountable. Environmental and waste management technical support personnel assist the line organizations with their environmental responsibilities. The Environmental Compliance Representative program, initiated in 1998, continues to be well received and is an effective means of integrating environmental planning and pollution prevention into the work planning processes of the line organizations. A comprehensive training program for staff, visiting scientists, and contractor personnel is in place (see Section 2.4.2), thus ensuring that all personnel are aware of their environmental responsibilities.

\subsubsection{Staff Training and Awareness}

Extensive training on EMS requirements has been provided to staff whose responsibilities involve environmental protection. In total, approximately 14,000 hours of environmental training were provided between 1998 and 2001.

- All permanent employees and visiting scientists with the potential to impact the environment are required to take a computer-based training course developed by BNL to provide a basic level of environmental awareness. The course discusses the EMS, reviews basic environmental requirements, and describes the impacts of non- 
compliance. Contractors and visiting scientists complete a modified training program covering the key points of BNL's environmental program as part of the required site orientation.

- Staff whose work could directly impact the environment are given job-specific training focused on implementing processes and controls to minimize environmental impacts.

- To support the Laboratory's Assessment Program (see Section 2.5.4), BNL continues to train select individuals to perform EMS internal audits.

\subsubsection{Communication and Community Involvement}

When BSA was awarded the contract to manage BNL in 1998, they made a commitment to establish an effective partnership between DOE, the Laboratory, and a full range of community members to address issues that affect quality of life in the community. At the core of the communication and community involvement programs are the Environmental Stewardship Policy and the Community Involvement Policy and Plan (available at http:// www.bnl.gov/community/).

As discussed in Section 2.2, the Environmental Stewardship Policy contains a commitment to maintain a positive, proactive, and constructive relationship with the community and regulators, and to promote open communication on environmental performance. The Community Involvement Policy and Plan was written with input from both internal and external stakeholders, and documents BSA's efforts to ensure that the public will be kept informed of issues; that the Laboratory will actively seek and consider input from regulators, stakeholders, and the general public; and that opportunities will continue to be provided for an open, two-way exchange of information, knowledge, and perspectives.

The Laboratory continues efforts to improve working relationships with regulatory agencies by sharing information and by working to resolve issues on plans, priorities, and corrective actions of importance to the regulators. The Laboratory meets regularly with regulators from the New York State Department of Environmental Conservation, the U.S. Environmental Protection Agency Region II, and the Suffolk County Department of Health Services. Suffolk County inspectors have a permanent office on site.

Another forum for communication is the Brookhaven Executive Roundtable, which was established by DOE in August 1997. The Roundtable includes staff from the offices of local, state, and federal elected officials, regulatory agencies, and representatives from DOE and the Laboratory.

In addition, the Community Advisory Council was established in September 1998. The Council, which serves in an advisory capacity to the Laboratory Director, consists of representatives from more than 30 varied stakeholder groups, including civic, business, union, health, education, employee, and environmental organizations. At monthly meetings, both the Roundtable and the Council are given frequent updates on Laboratory activities, environmental issues, and progress. Feedback and recommendations are considered in the Laboratory's decision-making processes.

The Council closely followed and gave feedback to the Laboratory on remediation activities, including groundwater issues; the BGRR; and plans for cleaning up portions of the Peconic River, including a recommendation to conduct pilot programs to attempt to minimize impacts to the Peconic River wetlands. A report on the DOE Assessment on Distribution of Cancer Among Former and Current BNL Workers was given by the DOE Office of Health Studies and the Director of the New York State Cancer Registry, which stated that the distribution among the BNL cohort was not substantially different from that which was expected, including no overall excess in radiosensitive solid cancers (Schymura 2001). The Council was also briefed on the Historical Emissions Report 1947-1961 (Meinhold \& Meinhold 2001), the Sewage Treatment Plant discharges, sanitary sewer modifications and upgrades, the Upton Ecological and Research Reserve, the Landtrek Project, and the 2001 Earth Day activities, as well as presentations by Science Chairs and researchers. Finally, the 
Council hosted a series of six forums on "Energy and the Environment" which were open to the public.

Stakeholders are provided with many other opportunities to learn about and provide input on issues of importance to them-from working groups to roundtables to one-on-one interactions with managers and subject matter experts. Input is actively sought to help the Laboratory make better decisions that take the community's values and perspectives into account. Public outreach activities include briefings to local civic and community groups; meetings and presentations to local, state, and federal regulators and elected officials; and regular interactions with the business and educational communities. The Correspondence and Commitment Tracking System is used to track and ensure response to communications from external interested parties. Laboratory Envoys, who are well educated about BNL and its issues, regularly interact with individuals and groups in the community, gathering feedback, and responding to concerns.

In 2001, BNL hosted more than 25,000 visitors, including students and community members who participated in Summer Sunday, open houses, science museum visits, high school, college and community tours. The Laboratory also maintains an informative website, www.bnl.gov; issues press releases; publishes the Brookhaven Bulletin (a weekly employee newsletter), cleanupdate (a periodic newsletter on environmental cleanup), Laboratory Link (a monthly brief on research activities), and e-mail updates to keep the public and employees informed about a wide variety of Laboratory activities and issues, including environmental issues. Section 6.8 in Chapter 6 discusses additional outreach activities associated with the natural resources program.

BNL was selected as the "Organization of the Year" in 2001 by the nonprofit organization, International Association for Public Participation. BNL was recognized for integrating public participation into its operations, ensuring that stakeholders are kept informed and have a voice in decisions and issues that may affect them.
In 2001, BNL celebrated the thirty-first anniversary of Earth Day with a variety of activities involving BNL staff and the community, including environmental awards, an art contest, a four-mile race, environmental displays, and an on-site Office Swap (reuse of office products) (see Figure 2-13). Brookhaven Science Associates, contributed corporate funds in support of these events as part of a commitment to environmental stewardship.

Another innovative program that BNL continues to work on is the LandTrek project, which is an extension of the BNL

Environmental Information Management System. The BNL LandTrek project, developed with support from DOE's Oakland office, provides environmental monitoring data to the public and BNL staff and managers over the Internet. The website was created based on community and staff input and continues to be updated as new data become available. Access is restricted, due to security issues. Password access may be obtained by visiting the website at http://webeims.b459.bnl.gov/website/bnl/ and requesting a password. Additional information about the LandTrek project can be found at http://www.bnl.gov/esd/landtrek.htm. BNL continues to expand the LandTrek website by providing additional data on BNL facilities and environmental media.

\subsubsection{EMS Documentation}

BNL has a comprehensive, up-to-date set of Laboratory-wide environmental documents describing its EMS program. A web-based system, known as the Standards Based Management System (discussed in Section 2.3.2), provides access to regulatory requirements and Laboratory-wide procedures and manuals that tell staff how to control processes and perform work at BNL in a way that protects the environment. SBMS has improved the quality, usability, and communication of Laboratorylevel requirements.

The core elements of the EMS are described and regularly updated in the ISO 14001 Plus Environmental Management System Manual. This document can be found at https:// sbms.bnl.gov/program/pd02/pd02d011.htm. 

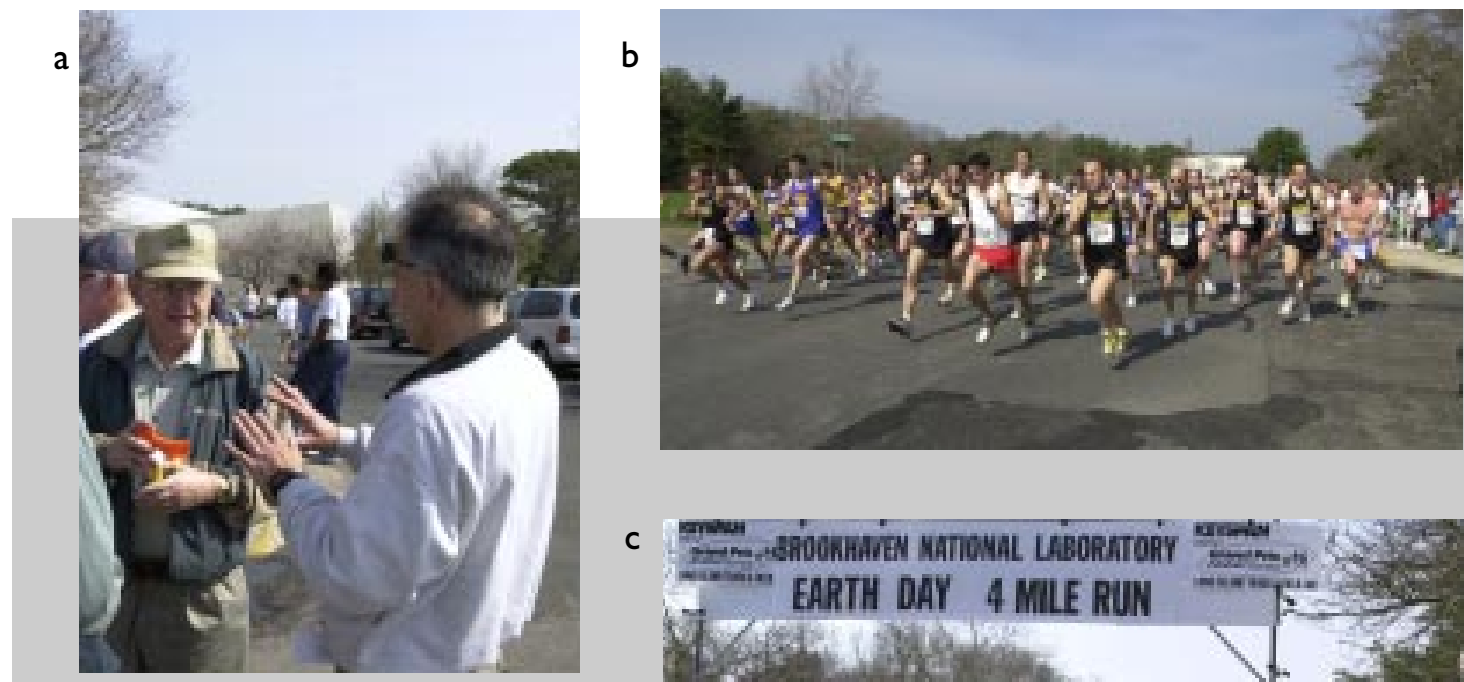

a. Laboratory Director gets ready to start 4-mile Earth Day run through the Long Island Pine Barrens.

b. Runners start 4-mile Earth Day race.

c. Runners reach the finish line after completing the 4-mile Earth Day race.

d. Scientists display environmental research work, such as bio-fuel (a vegetable-based home heating fuel).

e. Kids get ready to begin the half-mile Fun Run for Earth Week.
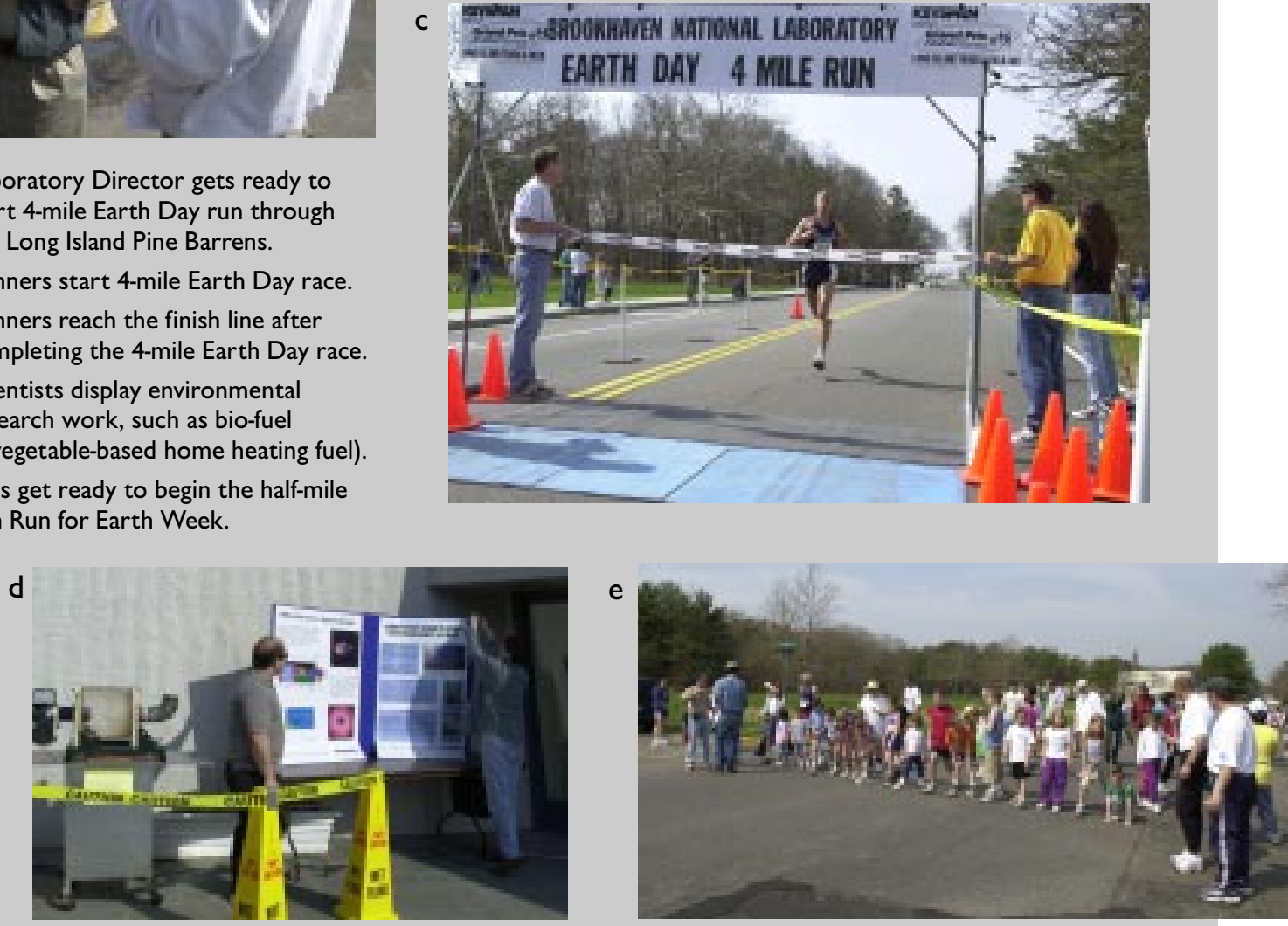

Figure 2-13. Earth Day 2001.

\subsubsection{Document Control}

The SBMS (discussed in Section 2.3.2) contains a comprehensive document control system to ensure effective management of procedures and other system documents. When facilities require additional procedures to control their work, document control protocols are implemented to ensure that workers have access to the current versions of procedures. Figure 2-14 shows the document hierarchy, including document inputs, and Figure 2-15 provides a flowchart of the document control process within SBMS.

\subsubsection{Operational Control}

Operations at the Laboratory are evaluated for the adequacy of current controls to prevent impacts to the environment through the use of Process Evaluations (see Figure 2-7 for an example), work planning and control, and 
REQUIREMENTS

EXPECTATIONS

PRACTICE
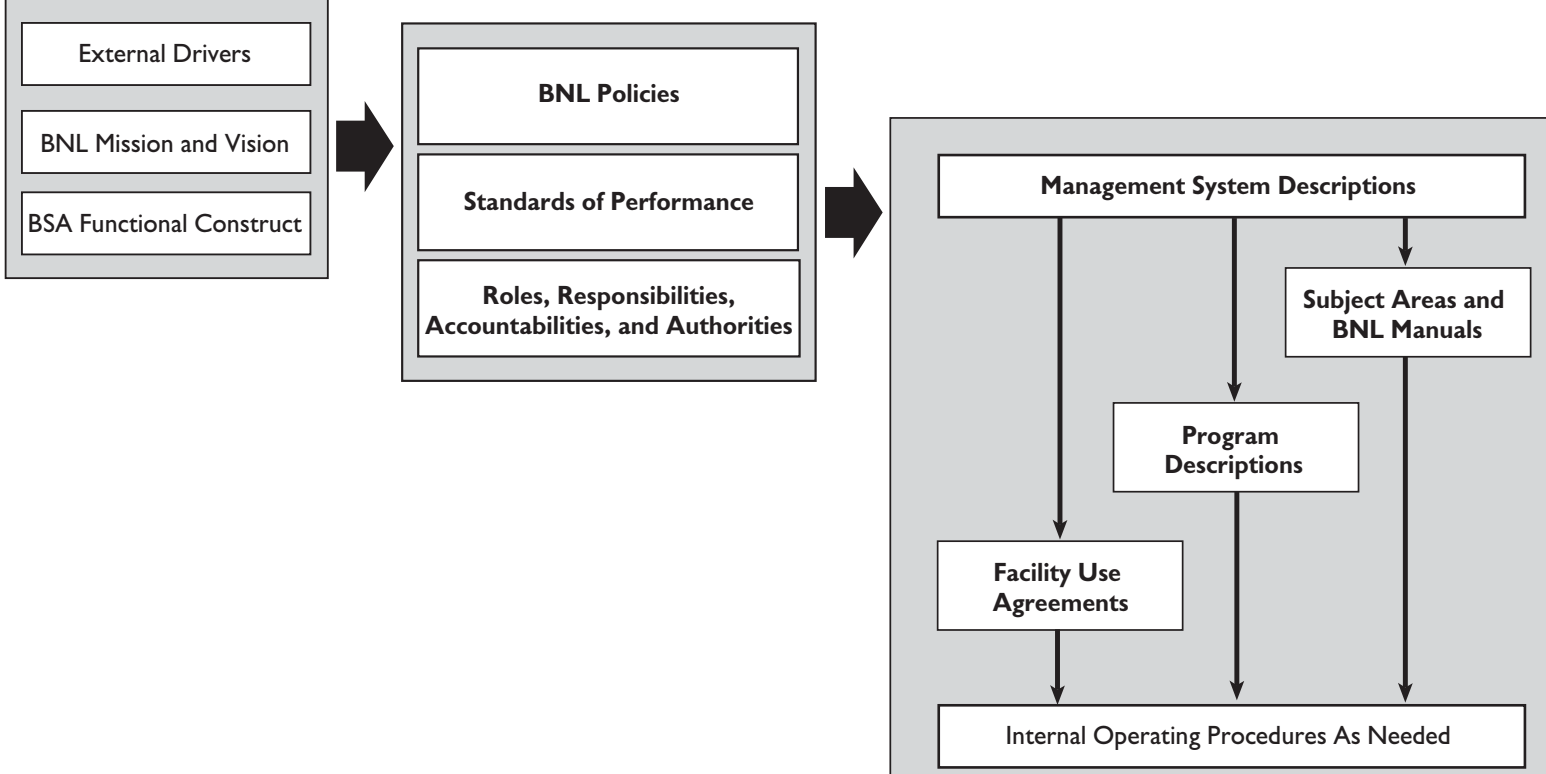

Figure 2-14. Standards Based Management System (SBMS) Hierarchy.

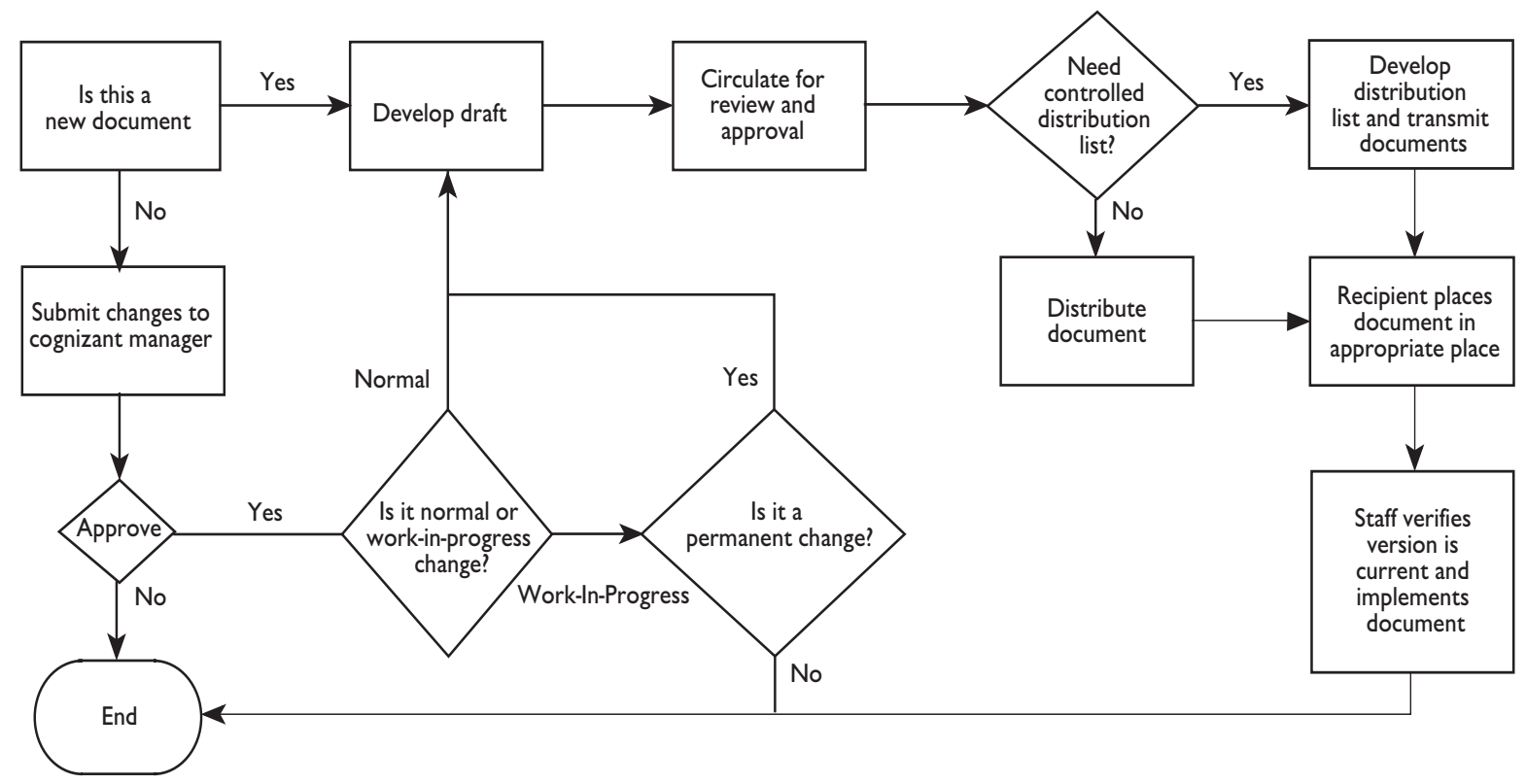

Figure 2-15. Flowchart of Document Control in the SBMS. 
experimental design review. As needed, additional administrative or engineered controls are identified and plans for upgrades and improvements are developed and implemented. An example of an engineered control is the capping of the accelerator beam stops to prevent rainwater from reaching the activated soils and potentially contaminating the groundwater (Figure 2-16). Key operational control procedures are documented either in the SBMS or in facility-specific internal standard operating procedures and work instructions.

\subsubsection{Emergency Preparedness and Response}

BNL has an emergency preparedness and response program and specialized staff to provide timely response to hazardous material spills or other environmental emergencies. This program includes procedures for preventing, as well as responding to, emergencies. For more information on BNL's emergency preparedness, view the webpage http://www.bnl.gov/emergencyservices/.

\subsection{CHECKING AND CORRECTIVE ACTION}

\subsubsection{Monitoring and Measurement}

One key element of BNL's Performance Based Management Program is routine and systematic assessment processes. The Laboratory's Assessment Program was established to monitor progress toward achieving high-priority improvements, as well as routine expectations such as compliance with environmental regulations. Areas for improvement are identified and tracked to completion. See Section 2.5.4 for further details on BNL's assessment programs.

Effluent and emissions monitoring helps ensure the effectiveness of controls, adherence to regulatory requirements, and timely identification and implementation of corrective measures. BNL has a comprehensive, sitewide environmental monitoring program. This program identifies potential pathways for exposure of the public and the environment, as well as evaluating what impact BNL activities may be having on the environment. It also ensures compliance with environmental permit requirements.

The monitoring program is reviewed and revised, as necessary, on an annual basis to reflect changes in permit requirements, changes in facility-specific monitoring activities, or the need to increase or decrease monitoring based on the review of previous analytical results. As required under DOE Order 5400.1 (1988), BNL's Environmental Monitoring Plan, Triennial Update (BNL 2000c) outlines annual sampling goals by specific media and frequency. The 2000 plan also specifies the data quality objectives associated with the monitoring program.

There were a total of 5,578 sampling events of groundwater, potable water, precipitation, air, plants and animals, soil, sediment, and discharges in 2001 under the Environmental Monitoring Program, as shown in Table 2-6. This does not include samples taken to characterize wastes for disposal purposes or nonroutine samples collected in support of restoration characterization activities. Specific sampling programs for the various media are described further in Chapters 3 through 7.

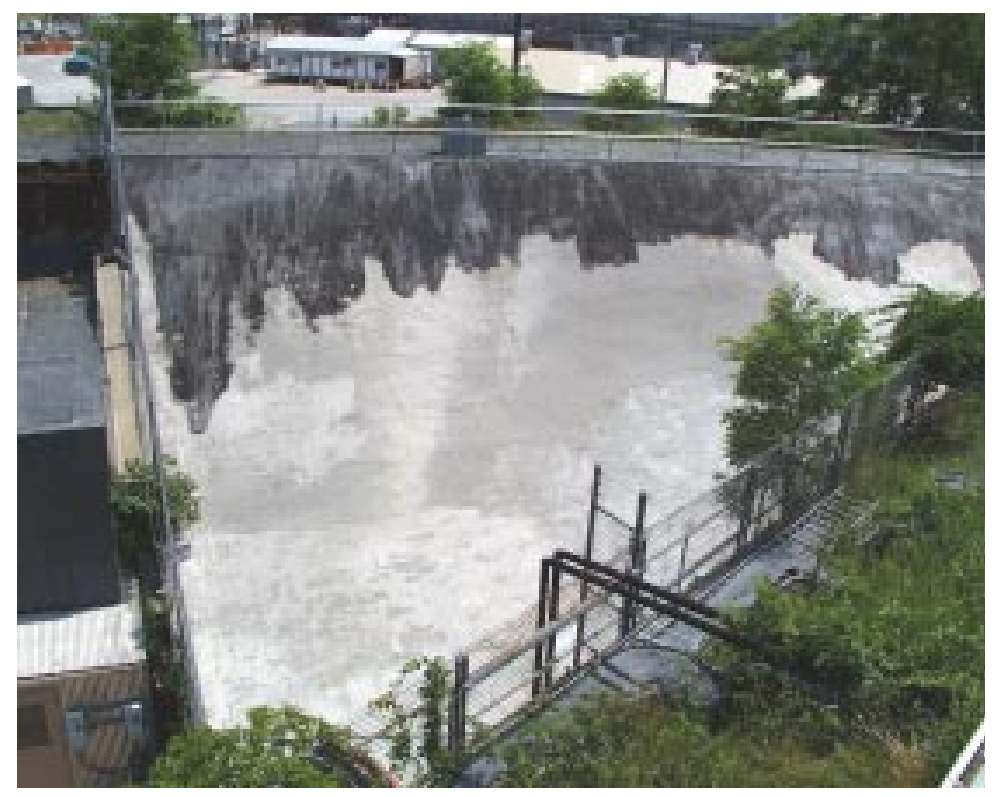

Figure 2-16. Gunnite Cap Installed Over g-2 Area Prevents Rainwater from Reaching the Activated Soils and Potentially Contaminating the Groundwater. 
Table 2-6. Summary of BNL Sampling Program Sorted by Media.

\begin{tabular}{|c|c|c|}
\hline Environmental Media & $\begin{array}{c}\text { Total \# of Sampling } \\
\text { Events* }\end{array}$ & Purpose \\
\hline Groundwater & 2,739 & $\begin{array}{l}\text { To evaluate impacts of past and present operations on groundwater quality, under } \\
\text { the Environmental Restoration, Environmental Surveillance, and Compliance } \\
\text { programs. }\end{array}$ \\
\hline On-site Recharge Basins & 186 & $\begin{array}{l}\text { Recharge basins used for wastewater and stormwater disposal are monitored in } \\
\text { accordance with discharge permit requirements and for environmental } \\
\text { surveillance purposes. }\end{array}$ \\
\hline Potable Water & 136 & $\begin{array}{l}\text { Potable water wells and the BNL distribution system are monitored routinely for } \\
\text { chemical and radiological parameters to ensure compliance with Safe Drinking } \\
\text { Water Act requirements and for environmental surveillance purposes. }\end{array}$ \\
\hline Sewage Treatment Plant & 866 & $\begin{array}{l}\text { The STP influent and effluent and several downstream Peconic River stations } \\
\text { are monitored routinely for organic, inorganic, and radiological parameters to } \\
\text { assess BNL impacts on the estuary. The number of samples taken depends on } \\
\text { flow-e.g., samples are scheduled for collection at Station HQ three times per } \\
\text { week, but if there is no flow, no sample can be collected. See discussion in } \\
\text { Chapters } 3 \text { and } 5 \text {. }\end{array}$ \\
\hline Precipitation & 8 & $\begin{array}{l}\text { Precipitation samples are collected from two locations to determine if radioactive } \\
\text { emissions have impacted rainfall, and to monitor worldwide fallout from nuclear } \\
\text { testing. The data are also used, along with wind speed and direction, temperature, } \\
\text { and atmospheric stability, to help model atmospheric transport and diffusion of } \\
\text { radionuclides. }\end{array}$ \\
\hline Air - Tritium & 373 & $\begin{array}{l}\text { Silica gel cartridges are used to collect atmospheric moisture for subsequent } \\
\text { tritium analysis. These data are used to assess tritium levels downwind of the } \\
\text { reactors. Due to several years of nondetectable measurements, and the shutdown } \\
\text { of the HFBR, monitoring was reduced from weekly to monthly in several areas of } \\
\text { the site in 1999. See discussion in Chapters } 4 \text { and } 8 \text {. }\end{array}$ \\
\hline Air - Particulate & 490 & $\begin{array}{l}\text { Gamma analysis is performed on samples of particulate matter collected from } \\
\text { air samples. The purpose is determine whether there has been impact from } \\
\text { BNL operations. }\end{array}$ \\
\hline Air - Charcoal & 87 & $\begin{array}{l}\text { Charcoal samples are used to assess for radioiodines, which could be released } \\
\text { in reactor emissions. }\end{array}$ \\
\hline Fauna & 98 & $\begin{array}{l}\text { Fish, deer, and small mammals are monitored to assess impacts on wildlife } \\
\text { associated with past (or current) BNL operations. }\end{array}$ \\
\hline Flora & 60 & $\begin{array}{l}\text { Since the primary pathway from soils to fauna is via ingestion, vegetation is } \\
\text { sampled to assess uptake of contaminants by plants and hence to fauna. This } \\
\text { number includes } 33 \text { samples taken of farm produce. }\end{array}$ \\
\hline Soils & 387 & $\begin{array}{l}\text { Soil samples are collected from adjacent farms and other local areas to confirm } \\
\text { that Laboratory emissions have no impact on surrounding areas. Soil samples } \\
\text { are also collected in conjunction with Environmental Restoration investigative } \\
\text { work. }\end{array}$ \\
\hline Miscellaneous & 148 & $\begin{array}{l}\text { Samples are collected periodically from manholes and other locations to assess } \\
\text { compliance with regulatory requirements. This number includes samples taken } \\
\text { by the ESD field sampling team for Plant Engineering (e.g., collected during } \\
\text { sewer line cleanouts). }\end{array}$ \\
\hline $\begin{array}{l}\text { Total Number of Sampling } \\
\text { Events in } 2001\end{array}$ & 5,578 & $\begin{array}{l}\text { This number includes all the samples identified in the EMP (BNL 2000b) plus } \\
\text { samples collected by the ESD field sampling team as special requests. The } \\
\text { number does not include samples collected to monitor Environmental Restoration } \\
\text { air and water treatment system processes, or samples taken by the Waste } \\
\text { Management Division, waste generators or Environmental Compliance } \\
\text { Representatives for waste characterization purposes. }\end{array}$ \\
\hline
\end{tabular}

* In one sampling event, multiple samples may be collected from a single location. For example, a separate sample for tritium, gross alpha and beta, and VOCs may be collected from a groundwater monitoring well during one event. 
There are three components to the Environmental Monitoring Program: compliance, restoration, and surveillance monitoring.

\subsubsection{Compliance Monitoring}

Compliance monitoring is conducted to ensure that wastewater effluents, air emissions, and groundwater monitoring data comply with regulatory and permit limits issued under the federal Clean Air Act, Clean Water Act, Oil Pollution Act, Safe Drinking Water Act, and the New York State equivalents. Included in compliance monitoring are the following:

- Air emissions monitoring is conducted at reactors, accelerators, and other radiological emission sources, as well as the Central Steam Facility. Real-time, continuous emission monitoring equipment is installed and maintained at these facilities or periodically samples are collected and analyzed to ensure compliance with regulatory requirements. Analytical data are routinely reported to the permitting authority. See Section 3.5 of Chapter 3 for details.

- Wastewater discharge monitoring is performed at the point of discharge to ensure that the effluent complies with release limits in BNL's State Pollutant Discharge Elimination System (SPDES) permits. Sixteen point-source discharges are monitored under the BNL program: four under the Environmental Restoration Program and twelve under the State Pollutant Discharge Elimination System permit. As required by permit conditions, samples are collected daily, weekly, monthly, or quarterly and monitored for organics, inorganics, or radiological parameters. Monthly reports that provide analytical results and an assessment of compliance for that reporting period are filed with the permitting agency. See Section 3.6 of Chapter 3 for details.

- Groundwater monitoring is also performed in accordance with permit requirements. Specifically, monitoring of groundwater is required under the Major Petroleum Facility License for the Central Steam Facility, and the Resource Conservation and
Recovery Act permit for the Waste Management Facility. Extensive groundwater monitoring is also conducted under the Environmental Restoration program as required under the Records of Decision for many of the Operable Units or Areas of Concern (see Chapter 7 for details). Additionally, to ensure that the Laboratory maintains a viable potable water supply, groundwater is monitored as required by the New York State Department of Health. See Chapter 3 for details on potable water supply monitoring programs and results.

\subsubsection{Restoration Monitoring}

Restoration monitoring is performed to determine overall impacts of past operations, to delineate the real extent of contamination, and to ensure that removal actions are effective and that remedial systems are performing as designed under CERCLA.

This program typically includes the collection of soil and groundwater samples in order to determine the lateral and vertical extent of the contaminated area. Samples are analyzed for organics, inorganics, and radiological contaminants, and the analytical results are compared with guidance, standards, or background concentrations. Areas where impacts have been confirmed are fully characterized and, if necessary, remediated to mitigate continual impacts. Followup monitoring of groundwater is conducted in accordance with a Record of Decision.

\subsubsection{Surveillance Monitoring}

Surveillance monitoring is conducted to further monitor what impact, if any, BNL operations have on the environment (pursuant to DOE Order 5400.1). The focus of the environmental surveillance program is to assess potential environmental impacts that result from routine facility operations. This program includes the collection of ambient air, surface water, groundwater, flora, fauna, and precipitation samples. Samples are analyzed for radiological, organic, and inorganic contaminants. Additionally, routine reviews of data collected by thermoluminescent dosimeters 
(devices to measure radiation exposure) that are placed on site and off site are performed under this program.

Control samples (also called background or reference samples) are also collected on and off the site to compare BNL results to areas that could not have been impacted by BNL operations.

The monitoring programs can be broken down further by the relevant law or requirement (e.g., Clean Air Act) and even further by specific environmental media and type of analysis. The results of monitoring and the analysis of the monitoring data are the subject of the remainder of this Site Environmental Report. Chapter 3 summarizes environmental requirements and compliance data; Chapters 4 through 8 give details on media-specific monitoring data and analysis; and Chapter 9 provides supporting information for understanding and validating the data shown in this report.

\subsubsection{Nonconformance, Corrective, and Preventive} Action

BNL continues to improve processes to identify and correct problems. This includes implementation of a Lessons Learned program to prevent recurrences, a robust Self-

Assessment Program and an electronic webbased assessment and action tracking system.

\subsubsection{Records}

EMS-related records, including audit and training records, are maintained to ensure integrity, facilitate retrieval, and to protect them from loss. BNL maintains a records retention schedule on the SBMS.

\subsubsection{EMS Assessments}

To periodically verify that the EMS is operating as intended, audits are conducted. These audits are part of the sitewide selfassessment program and are designed to ensure that any nonconformance to the ISO 14001 Standard is identified and addressed. An independent, accredited registrar also conducts the ISO 14001 registration audits annually. In addition, compliance with regulatory requirements is verified through routine inspections, operational evaluations, and focused compliance audits. BNL's Assessment Program consists of several processes.

- Self-assessment is the systematic evaluation of internal processes and performance. The approach for the environmental selfassessment program includes evaluating programs and processes within organizations that have environmental aspects. Conformance to ISO 14001 EMS requirements is verified, progress toward achieving environmental objectives is monitored, operations are inspected to verify compliance with regulatory requirements, and the overall effectiveness of the EMS is evaluated. Environmental experts routinely participate in these assessments. Management also conducts assessments to evaluate Laboratory environmental performance from a programmatic perspective, to determine if there are Labwide issues that require attention, and to facilitate the identification and communication of best management practices used in one part of the Laboratory that could improve performance in other parts. Laboratory management also routinely evaluates progress on key environmental improvement projects. BNL periodically teams with the local DOE office to perform assessments in order to facilitate the efficiency of assessment activities and ensure that the approach to performing the assessments meets DOE expectations.

- Independent assessments are performed by staff who do not have line responsibility for the work processes. These assessments verify the effectiveness and adequacy of management processes (including self-assessment programs) at the division, department, directorate, and Laboratory levels. Special investigations are also conducted to identify the root causes of problems, corrective actions, and lessons learned.

The Laboratory's Assessment Program is augmented by programmatic, external audits conducted by DOE. Staff from the offices of 
Battelle Memorial Institute and BSA

subcontractors also perform periodic independent reviews. As noted above, an independent third party conducts ISO 14001 registration audits of the environmental management system. NSF conducted the ISO 14001 registration for BNL June 18-22, 2001, and found eight minor nonconformances and five opportunities for improvement. Corrective action reports were prepared for each minor nonconformance, and were accepted by the auditor. All corrective actions were completed.

$\mathrm{BNL}$ is also subject to extensive oversight by external regulatory agencies (see Chapter 3 ). Results of all assessment activities related to environmental performance are included, as appropriate, throughout this report.

\subsection{MANAGEMENT REVIEW}

In addition to audits, a management review process has been established to involve top management in the overall assessment of environmental performance, the Environmental Management System, and progress toward achieving environmental goals. This review identifies, as necessary, the need for changes to, and continual improvement of, the EMS.

\subsection{ENVIRONMENTAL STEWARDSHIP AT BNL TODAY}

BNL now has an unprecedented knowledge of its potential environmental vulnerabilities and current operations due to programs such as the Facility Review project, process evaluations, the work planning and control system, groundwater protection, environmental restoration, and information management systems that were designed to improve the Laboratory's environmental systems and performance. Compliance assurance programs are improving BNL's compliance status. Pollution prevention projects have reduced costs, minimized waste generation, and reused and recycled significant quantities of materials.

The Laboratory is openly communicating with neighbors, regulators, employees, and other interested parties on issues and progress. BNL must continue to deliver on commitments and demonstrate real improvements in environmental performance in order to regain and maintain the stakeholders' trust. This annual Site

Environmental Report is an important communication mechanism, as it summarizes BNL's environmental programs and performance for the 2001 calendar year. Additional information about BNL's environmental programs is available on BNL's website at $<$ www.bnl.gov>. Environmental project plans, status reports, procedures, and more are accessible to the general public at http:// www.bnl.gov/esd/. The Laboratory is pursuing other mechanisms to communicate data in a more user friendly, visual, and timely manner, such as the BNL Landtrek project, which is viewed as a model in the DOE complex.

BNL's Environmental Management System includes a commitment to continual improvement. The Laboratory fulfills this commitment by establishing performance goals, developing action plans to achieve these goals, and periodically assessing performance. These processes are implemented within the context of the broader, Labwide efforts to improve the management systems.

The existing BNL Environmental Management System is viewed as exemplary in the DOE complex. BNL is the first Office of Science national laboratory to obtain thirdparty registration to ISO 14001, a globally recognized environmental standard. Due to external recognition of BNL's knowledge and unique experience implementing the ISO 14001 EMS program, several DOE facilities and private universities have invited BNL to extend its outreach activities and share its experiences, lessons learned, and successes. As noted above, BNL's environmental programs and projects have been recognized with regional and national awards.

Audits have consistently observed a high level of management involvement, commitment, and support for environmental protection and the EMS. Audits and EMS management reviews have noted the following improvements made since BSA began managing the Laboratory:

- The EMS has been strengthened, integrated with other BNL management systems, and formalized. 
- Line ownership for environmental stewardship has been established, key roles and responsibilities have been identified and clarified, and expectations have been made explicit.

- A comprehensive environmental training program has been implemented.

- BNL has an improved understanding of environmental aspects, waste streams, and applicable requirements from the process evaluations.

- There is much greater formality with regard to control of EMS documents, manuals, and procedures. Procedures and requirements have been updated, and environmental management programs have been improved.

- BNL has been very successful in achieving environmental goals and Critical Outcomes. There have been successes in ISO 14001 registration, compliance improvements (e.g., facility modifications, implementation of SBMS, enhanced operational controls), and increased environmental knowledge and awareness on the part of management, employees, and visiting scientists.

- Communications on environmental issues have improved, occur at the highest levels of management, and reporting is more formal. Managers are better informed about aspects, issues, and performance.

- Core EMS teams representing many organizations have been formed, and the consensus process used to develop the system has improved buy-in.

- There has been strong penetration of the EMS throughout organizations, and cultural change has been sweeping.

For over 50 years, the unique, leading-edge research facilities at BNL have made many innovative scientific contributions possible. Today, BNL continues its research mission while paying much closer attention to cleaning up and protecting the environment. The Laboratory's environmental motto, which was generated in an employee suggestion contest, is "Exploring Earth's Mysteries ... Protecting Its Future." This reflects BNL's desire to balance world-class research with environmentally responsible operations.

\section{REFERENCES}

BNL. 1997. Brookhaven National Laboratory Site Treatment Plan. Brookhaven National Laboratory, Upton, NY. January 1997.

BNL. 1998a. Areas of Concern at Brookhaven National Laboratory, Upton, New York-A Reference Handbook. Brookhaven National Laboratory, Upton, NY. June 1998.

BNL. 1998b. BNL Facility Review Final Report, Review of Potential Environmental Release Points. Brookhaven National Laboratory, Upton, NY. October 7, 1998.

BNL. 1999. Site Environmental Report for Calendar Year 1997. BNL52553. Brookhaven National Laboratory, Upton, NY. February 1999

BNL. 2000a. Facility Review Disposition Project Plan. Brookhaven National Laboratory, Upton, NY. March 2000.

BNL. 2000b. Final Report, EPA Phase II Process Evaluation Project. Brookhaven National Laboratory, Upton, NY. June 2000.

BNL. 2000c. BNL Environmental Monitoring Plan 2000, Triennial Update. BNL-52584. Brookhaven National Laboratory, Upton, NY. March 31, 2000.

DOE Order 430.2. 1996. In-House Energy Management. U.S. Department of Energy, Washington, D.C. June 13, 1996 (expired June 13, 2000).

DOE Order 435.1. 1999. Radioactive Waste Management. U. S. Department of Energy, Washington, D.C. July 7, 1999.

DOE Order 5400.1. 1988. General Environmental Protection Program. U.S. Department of Energy, Washington, D.C. Change 1: 6-29-90.

EPA/DOE. 1998. Memorandum of Agreement by and between the Environmental Protection Agency and the United States Department of Energy. EPA and DOE. March 23, 1998.

Executive Order 13148. Greening of the Government Through Leadership in Environmental Management. April 22, 2000

ISO. 1996. ISO 14001, Environmental Management Systems Specification with Guidance for Use. First Edition. International Organization for Standardization. Geneva, Switzerland. September 1, 1996

Meinhold, C.B. and A.F. Meinhold. 2001. Radiological Emissions and Environmental Monitoring for Brookhaven National Laboratory, 1947-1961. DOE Contract No. DE-AC02-98CH10866. Brookhaven National Laboratory, Upton, N.Y. May 2001.

Sanok, William J. 2001. "Integrated Pest Management Assessment - Brookhaven National Laboratory." Cornell Cooperative Extension of Suffolk County. August 2001.

Schymura, Maria J., Ph.D. 2001. "Assessing Cancer Risk among Former and Current Brookhaven National Laboratory Workers." New York State Cancer Registry, New York State Department of Health. April, 2001.

\section{EXPLORING EARTH'S MYSTERIES ...PROTECTING ITS FUTURE}


BROOKHAVEN

NATIONAL

LABORATORY

2001 SITE ENVIRONMENTAL REPORT

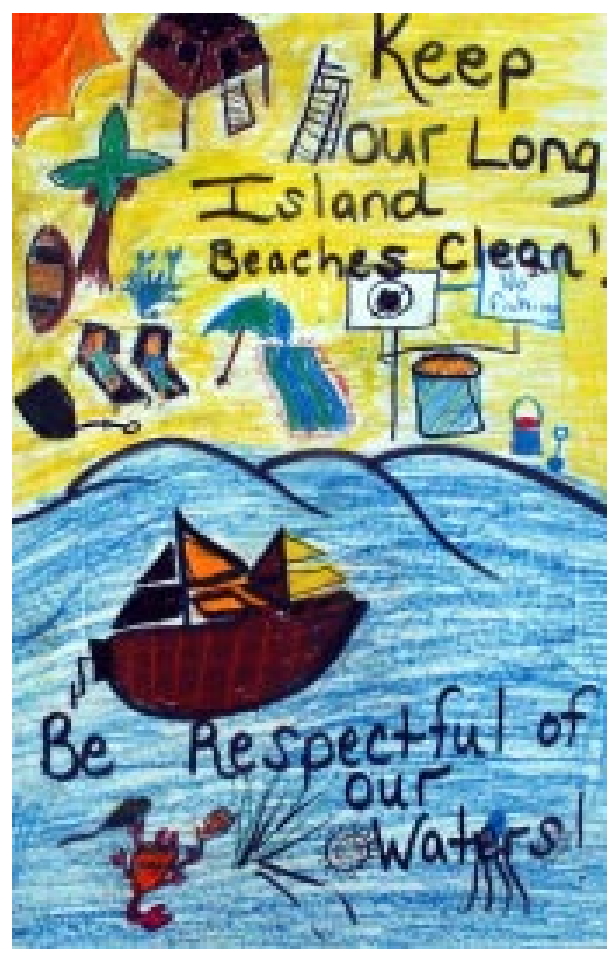

Chapter 3

\section{Compliance Status}

Brookhaven National Laboratory is subject to more than 50 sets of federal, state, and local environmental regulations; 65 site-specific permits; 8 equivalency permits for operation of groundwater remediation systems; and several other binding agreements. In 2001, BNL operated in compliance with the majority of these requirements, and programs are in place to address areas for continued improvement.

Emissions of nitrogen oxides, carbon monoxide, and sulfur dioxide were all within permit limits. Approximately 1,725 pounds of ozone-depleting refrigerants were recovered for recycling. Monitoring of the BNL potable water system showed that the potable water supply met all regulatory requirements. Groundwater monitoring at the Major Petroleum Facility continues to demonstrate that current oil storage and transfer operations are not affecting groundwater quality. During 2001, liquid effluents discharged to surface water and groundwater met all New York State Pollutant Discharge Elimination System permit requirements with the exception of six excursions at the Sewage Treatment Plant and six at other outfalls. The 12 permit excursions were reported to the New York State Department of Environmental Conservation.

Ten reportable spills of petroleum products occurred on site in 2001. The majority were less than one gallon, and all were cleaned up or addressed to the satisfaction of the state. In addition to petroleum spills, one ethylene glycol spill that exceeded New York State limits and two heat exchange fluid spills that were greater than five gallons were reportable to the state and Suffolk County. BNL underwent 13 environmental audits by external regulatory agencies in 2001. These audits included reviews of petroleum and chemical storage, hazardous waste operations, and air emissions from the Central Steam Facility, as well as inspections of the Sewage Treatment Plant, outfalls and recharge basins, and the potable water system. Of the 1,200 New York State hazardous waste compliance requirements, BNL met all but two, receiving a notice of violation for two administrative deficiencies. Immediate corrective actions were taken to address both concerns. The Major Petroleum Facility was found to be in substantial compliance with the license, although several minor issues were identified. Corrective actions were implemented to address these issues. Similarly, minor nonconformances were identified during the Chemical Bulk Storage inspection conducted by the state. Corrective actions have been identified and the Laboratory continues to work with the New York State Department of Environmental Conservation to resolve open items. 


\subsection{COMPLIANCE WITH ENVIRONMENTAL REQUIREMENTS}

Brookhaven National Laboratory is subject to more than 50 sets of federal, state, and local environmental regulations; 65 site-specific permits; 8 equivalency permits for operation of groundwater remediation systems; and several other binding agreements. The federal, state, and local environmental statutes and regulations that BNL operates under are summarized in Table 3-1, along with a discussion of BNL's compliance status with regard to each requirement.

\subsection{ENVIRONMENTAL PERMITS}

\subsubsection{Existing Permits}

Many processes and facilities at BNL operate under permits issued by environmental regulatory agencies. Table 3-2 provides a complete list of the existing permits, which are briefly described below:

- State Pollutant Discharge Elimination System (SPDES) permit

- Major Petroleum Facility (MPF) license

- Resource Conservation and Recovery Act (RCRA) permit for the Waste Management Facility

- Registration certificate from the New York State Department of Environmental Conservation (NYSDEC) for tanks storing bulk quantities of hazardous substances

- Two NYSDEC certificates for registered gasoline vapor recovery systems

- Seven radiological emission authorizations issued under the National Emission Standards for Hazardous Air Pollutants (NESHAPs) by the U.S. Environmental Protection Agency (EPA)

- Forty-seven NYSDEC Certificates to Operate air emission sources

- One NYSDEC permit for asbestos emissions from the Inhalation Toxicology Facility

- Two permits for construction activities within the Peconic River corridor

- An Underground Injection Control (UIC) Area permit for the operation of 90 wells

- A permit for the operation of six domestic water supply wells

- Eight equivalency permits (four air and four SPDES) for the operation of groundwater remediation systems installed under the Interagency Agreement (Federal Facility Agreement under CERCLA 120, Admin. Docket No. II-CERCLA-FFA-00201).

\subsubsection{New or Modified Permits and Requests}

\subsubsection{State Pollutant Discharge Permits}

The State Pollutant Discharge Elimination System permit authorizes discharges from the BNL Sewage Treatment Plant (STP) to the Peconic River, and discharges of cooling water and stormwater to recharge basins, including discharges from RHIC facilities. In November, BNL submitted a request to revise the SPDES permit. These revisions included: deletion of Outfalls 002A and 004, since the operations contributing to these releases either ceased or were redirected to another point source; construction of two new recharge basins for increased drainage capacity to prevent overloading of existing basins; increased monitoring to include metals analyses for three existing discharges (Outfalls 002, 008, and 010); decreased monitoring for Outfall 007, as evaluation of iron releases from the Water Treatment Plant has shown no detrimental impact on the environment; and decreased monitoring for corrosion control chemical residuals for Outfall 003, since cooling tower discharges have ceased. Additionally, in June 2001 NYSDEC approved a request that had been made in late 2000 for the use of new corrosion control chemicals in several cooling tower systems.

\subsubsection{Air Emissions Permits}

Air emissions permits are granted by the New York State Department of Environmental Conservation. Permits are issued either as "equivalency" permits for restoration projects conducted under the Comprehensive Environmental Response, Compensation, and Liability Act (CERCLA), or as changes to the BNL Title $\mathrm{V}$ draft operating permit, which is expected to be issued in final form in January 2002. Permitting activities for 2001 are discussed below.

CERCLA. In July, BNL submitted an equivalency permit application to NYSDEC for a newly constructed air stripping treatment system in Operable Unit III. The treatment 
Table 3-1. Federal, State, and Local Environmental Statutes and Regulations Applicable to BNL.

\begin{tabular}{|c|c|c|c|}
\hline $\begin{array}{l}\text { Regulator: } \\
\text { Codified } \\
\text { Regulation }\end{array}$ & Regulatory Program Description & Compliance Status & $\begin{array}{l}\text { Report } \\
\text { Reference } \\
\text { Sections }\end{array}$ \\
\hline $\begin{array}{l}\text { Advisory Council } \\
\text { on Historic } \\
\text { Preservation: } \\
36 \text { CFR } 60 \\
36 \text { CFR } 63 \\
36 \text { CFR } 79 \\
36 \text { CFR } 800 \\
43 \text { CFR } 7\end{array}$ & $\begin{array}{l}\text { The National Historic Preservation Act identifies, } \\
\text { evaluates, and protects historic properties eligible for } \\
\text { listing in the National Register of Historic Places. Historic } \\
\text { properties can be archeological sites, historic structures, } \\
\text { or historic documents, records, or objects. }\end{array}$ & $\begin{array}{l}\text { The High Flux Beam Reactor, Brookhaven Graphite Research } \\
\text { Reactor (BGRR) complex, and World War I trenches in the area of } \\
\text { the Relativistic Heavy lon Collider project have been determined } \\
\text { to be eligible for inclusion in the National Register of Historic } \\
\text { Places. The former Cosmotron building was identified as being } \\
\text { potentially eligible in an April } 1991 \text { letter from the New York State } \\
\text { Historic Preservation Officer (NYSHPO). Any activities involving } \\
\text { these facilities are identified through the NEPA process and an } \\
\text { evaluation is initiated to determine if the proposed action would } \\
\text { impact the features that extend eligibility to these facilities. Some } \\
\text { activities associated with the decontamination and } \\
\text { decommissioning of the BGRR were determined to impact its } \\
\text { eligibility, and mitigative actions are proceeding according to a } \\
\text { Memorandum of Agreement between DOE and NYSHPO. BNL is } \\
\text { currently developing a Cultural Resource Management Plan to } \\
\text { ensure compliance with applicable cultural resource regulations. }\end{array}$ & 3.4 \\
\hline $\begin{array}{l}\text { EPA: } \\
40 \text { CFR } 50-80 \\
40 \text { CFR } 82 \\
\text { NYSDEC: } \\
6 \text { NYCRR } 200-258 \\
6 \text { NYCRR } 307\end{array}$ & $\begin{array}{l}\text { The Clean Air Act (CAA) and the New York State } \\
\text { Environmental Conservation Laws regulate the release } \\
\text { of air pollutants through the use of permits and air quality } \\
\text { limits. Emissions of radionuclides are regulated by the } \\
\text { EPA, under National Emission Standards for } \\
\text { Hazardous Air Pollutants (NESHAPs) authorizations. }\end{array}$ & $\begin{array}{l}\text { All air emission sources have permits or have been exempted } \\
\text { under the New York State air program. }\end{array}$ & 3.5 \\
\hline $\begin{array}{l}\text { EPA: } \\
40 \text { CFR } 141-149 \\
\text { NYSDOH: } \\
10 \text { NYCRR } 5\end{array}$ & $\begin{array}{l}\text { The Safe Drinking Water Act (SDWA) and New York } \\
\text { State Department of Health standards for public water } \\
\text { supplies establish minimum drinking water standards } \\
\text { and monitoring requirements. SDWA requirements are } \\
\text { enforced by the Suffolk County Department of Health } \\
\text { Services. }\end{array}$ & $\begin{array}{l}\text { BNL maintains a sitewide public water supply. This water supply } \\
\text { meets all primary and secondary drinking water standards as well } \\
\text { as operational and maintenance requirements. }\end{array}$ & 3.7 \\
\hline $\begin{array}{l}\text { EPA: } \\
40 \text { CFR } 112 \\
40 \text { CFR } 328 \\
40 \text { CFR } 355 \\
40 \text { CFR } 370 \\
40 \text { CFR } 372\end{array}$ & $\begin{array}{l}\text { The Oil Pollution Act, Emergency Planning and } \\
\text { Community Right-to-Know Act (EPCRA), and the } \\
\text { Superfund Amendment Reauthorization Act (SARA) } \\
\text { require that facilities storing large quantities of petroleum } \\
\text { products and/or chemicals prepare emergency planning } \\
\text { documents and report the inventory of such chemicals } \\
\text { to EPA, the state, and local emergency planning groups. }\end{array}$ & $\begin{array}{l}\text { Since facilities at BNL store or use chemicals or petroleum in } \\
\text { quantities exceeding threshold planning quantities, BNL is subject } \\
\text { to these requirements. BNL is in full compliance with all } \\
\text { emergency planning requirements. }\end{array}$ & $\begin{array}{l}3.8 .1 \\
3.8 .2 \\
3.8 .3\end{array}$ \\
\hline
\end{tabular}


Table 3-1. Federal, State, and Local Environmental Statutes and Regulations Applicable to BNL (concluded).

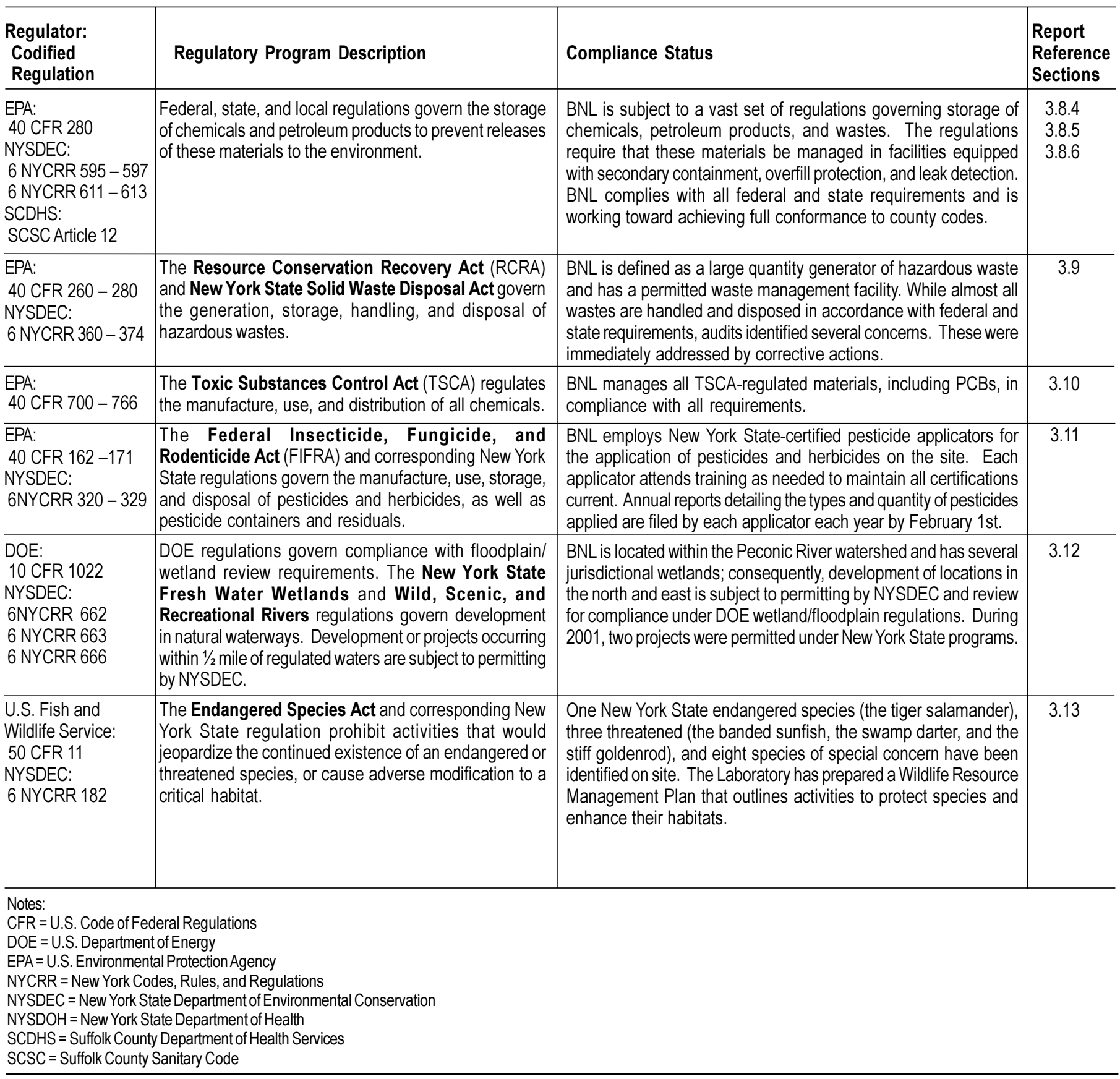

system was designed to remediate groundwater contaminated with volatile organic compounds (VOCs) that flows toward the site's south boundary. The application stated that anticipated airborne emissions associated with the system will be properly controlled in conformance with 6 NYCRR 212 air pollution control requirements. NYSDEC approved the applica- tion in October and the treatment system began operating in November.

Clean Air Act Title $V$. Under the Clean Air Act Amendments of 1990 (CAAA), BNL is defined as a major emission source of criteria pollutants $\left(\mathrm{NO}_{\mathrm{x}}, \mathrm{SO}_{2}\right)$ and is required to obtain a Title $\mathrm{V}$ operating permit. This permit will consolidate all emission sources and all applicable 
Table 3-2. BNL Environmental Permits.

\begin{tabular}{|c|c|c|c|c|}
\hline $\begin{array}{l}\text { Building or } \\
\text { Facility }\end{array}$ & $\begin{array}{l}\text { Process/Equipment } \\
\text { Designation Description }\end{array}$ & $\begin{array}{l}\text { Permitting Agency } \\
\text { and Division }\end{array}$ & $\begin{array}{l}\text { Permit } \\
\text { Number }\end{array}$ & $\begin{array}{l}\text { Expiration } \\
\text { Date }\end{array}$ \\
\hline 197 & welding shop & NYSDEC-Air Quality & 1-472200 349119704 & $04-01-00$ (a) \\
\hline 197 & epoxy coating/curing exhaust & NYSDEC-Air Quality & 1-4722003491 19708 & $06-08-98^{(a)}$ \\
\hline 206 & cyclone G-10 & NYSDEC-Air Quality & $1-472200349120601$ & $04-01-00^{(a)}$ \\
\hline 207 & belt sander & NYSDEC-Air Quality & $1-472200349120701$ & 04-01-00(a) \\
\hline 244 & cyclone collector & NYSDEC-Air Quality & $1-472200349124401$ & $01-28-99$ (a) \\
\hline 422 & cyclone collector & NYSDEC-Air Quality & $1-472200349142202$ & $11-29-96$ (a) \\
\hline 422 & cyclone collector & NYSDEC-Air Quality & $1-472200349142203$ & $11-29-96$ (a) \\
\hline 423 & stage II vapor recovery & NYSDEC-Air Quality & $1-472200$ D365 WG & None ${ }^{(b)}$ \\
\hline 423 & welding hood & NYSDEC-Air Quality & $1-472200349142305$ & $05-15-01$ \\
\hline 458 & paint spray booth & NYSDEC-Air Quality & $1-472200349145801$ & $04-23-97^{(a)}$ \\
\hline 462 & machining, grinding exhaust & NYSDEC-Air Quality & $1-472200349146201$ & $11-29-96^{(a)}$ \\
\hline 462 & machining, grinding exhaust & NYSDEC-Air Quality & $1-472200349146202$ & $11-29-96^{(a)}$ \\
\hline 473 & vapor degreaser \& fume hood & NYSDEC-Air Quality & $1-472200349147301$ & $03-22-96^{(\mathrm{c})}$ \\
\hline 479 & cyclone G-10 & NYSDEC-Air Quality & $1-472200349147905$ & $04-01-00$ (a) \\
\hline 490 & Inhalation Toxicology Facility & NYSDEC-NESHAPS & $1-472200349149001$ & $05-15-01$ \\
\hline 490 & Inhalation Toxicology Facility & NYSDEC-Air Quality & $1-472200349149002$ & $05-15-01^{(d)}$ \\
\hline 490 & lead alloy melting & NYSDEC-Air Quality & $1-472200349149003$ & $05-15-01$ \\
\hline 490 & milling machine/block cutter & NYSDEC-Air Quality & $1-472200349149004$ & $05-15-01$ \\
\hline 510 & metal cutting exhaust & NYSDEC-Air Quality & $1-472200349151002$ & $09-30-98^{(a)}$ \\
\hline 510 & calorimeter enclosure & EPA-NESHAPS & BNL-689-01 & None \\
\hline 526 & polymer mix booth & NYSDEC-Air Quality & $1-472200349152601$ & 04-01-00(a) \\
\hline 526 & polymer weighing & NYSDEC-Air Quality & 1-472200 349152602 & $04-01-00$ (a) \\
\hline $535 B$ & plating tank & NYSDEC-Air Quality & $1-472200349153501$ & $04-01-00^{(a)}$ \\
\hline $535 \mathrm{~B}$ & etching machine & NYSDEC-Air Quality & $1-472200349153502$ & $04-01-00$ (a) \\
\hline $535 B$ & PC board process & NYSDEC-Air Quality & $1-472200349153503$ & $05-15-01$ \\
\hline $535 B$ & welding hood & NYSDEC-Air Quality & $1-472200349153504$ & $09-30-98$ (a) \\
\hline 555 & scrubber & NYSDEC-Air Quality & $1-472200349155501$ & $04-01-00$ (d) \\
\hline 555 & scrubber & NYSDEC-Air Quality & $1-472200349155502$ & $04-01-00^{(d)}$ \\
\hline 610 & combustion unit & NYSDEC-Air Quality & $1-47220034916101 \mathrm{~A}$ & $05-15-01$ \\
\hline 610 & combustion unit & NYSDEC-Air Quality & $1-472200349161005$ & $05-15-01$ \\
\hline 610 & combustion unit & NYSDEC-Air Quality & $1-472200349161006$ & $05-15-01$ \\
\hline 610 & combustion unit & NYSDEC-Air Quality & $1-472200349161007$ & $12-18-02$ \\
\hline 630 & stage II vapor recovery & NYSDEC-Air Quality & 1-472200 D366 WG & None ${ }^{(b)}$ \\
\hline 703 & machining exhaust & NYSDEC-Air Quality & $1-472200349170301$ & 05-15-01 \\
\hline 705 & building ventilation & EPA-NESHAPS & BNL-288-01 & None \\
\hline 820 & accelerator test facility & EPA-NESHAPs & BNL-589-01 & None \\
\hline 865 & lead melting pot & NYSDEC Air Quality & 472200349186501 & 01-14-03 \\
\hline 902 & spray booth exhaust & NYSDEC-Air Quality & 472200349190201 & $09-30-98^{(a)}$ \\
\hline 902 & belt sander & NYSDEC-Air Quality & 472200349190202 & $05-15-01$ \\
\hline 902 & sanding, cutting, drilling & NYSDEC-Air Quality & 472200349190203 & $05-15-01$ \\
\hline 902 & brazing/soldering exhaust & NYSDEC-Air Quality & 472200349190204 & $05-15-01$ \\
\hline 902 & painting/soldering exhaust & NYSDEC-Air Quality & 472200349190205 & $05-15-01$ \\
\hline 903 & cyclone G-10 & NYSDEC-Air Quality & 472200349190302 & $04-01-00$ (a) \\
\hline
\end{tabular}


CHAPTER 3: COMPLIANCE STATUS

Table 3-2. BNL Environmental Permits (concluded).

\begin{tabular}{|c|c|c|c|c|}
\hline $\begin{array}{l}\text { Building or } \\
\text { Facility }\end{array}$ & $\begin{array}{l}\text { Process/Equipment } \\
\text { Designation Description }\end{array}$ & $\begin{array}{l}\text { Permitting Agency } \\
\text { and Division }\end{array}$ & $\begin{array}{l}\text { Permit } \\
\text { Number }\end{array}$ & $\begin{array}{l}\text { Expiration } \\
\text { Date }\end{array}$ \\
\hline $\begin{array}{l}903 \\
905 \\
919 A \\
922 \\
923 \\
924 \\
924 \\
924 \\
930 \\
930 \\
\text { AGS Booster } \\
\text { RHIC }\end{array}$ & $\begin{array}{l}\text { brazing process exhaust } \\
\text { machining exhaust } \\
\text { solder exhaust } \\
\text { cyclone exhaust } \\
\text { electronic equipment cleaning } \\
\text { spray booth exhaust } \\
\text { magnet coil production press } \\
\text { machining exhaust } \\
\text { electroplating/acid etching } \\
\text { bead blaster } \\
\text { accelerator } \\
\text { accelerator }\end{array}$ & $\begin{array}{l}\text { NYSDEC-Air Quality } \\
\text { NYSDEC-Air Quality } \\
\text { NYSDEC-Air Quality } \\
\text { NYSDEC-Air Quality } \\
\text { NYSDEC-Air Quality } \\
\text { NYSDEC-Air Quality } \\
\text { NYSDEC-Air Quality } \\
\text { NYSDEC-Air Quality } \\
\text { NYSDEC-Air Quality } \\
\text { NYSDEC-Air Quality } \\
\text { EPA-NESHAPs } \\
\text { EPA-NESHAPS }\end{array}$ & $\begin{array}{l}472200349190303 \\
472200349190503 \\
472200349191903 \\
472200349192201 \\
\text { submitted 3-93 } \\
472200349192401 \\
472200349192402 \\
472200349192403 \\
472200349193001 \\
472200349193002 \\
\text { BNL-188-01 } \\
\text { BNL-389-01 }\end{array}$ & $\begin{array}{l}09-30-98 \text { (a) } \\
05-15-01 \\
05-15-01 \\
04-01-00 \text { (a) } \\
\text { status pending(e) } \\
09-30-98^{(f)} \\
05-15-01 \\
05-03-98^{(a)} \\
05-15-01^{(f)} \\
05-15-01 \\
\text { None } \\
\text { None }\end{array}$ \\
\hline RTF & & EPA-NESHAPS & BNL-489-01 & None \\
\hline REF/NFB & & EPA-NESHAPS & BNL-789-01 & None \\
\hline CSF & major petroleum facility & NYSDEC-Water Quality & $1-1700$ & 03-31-02 \\
\hline SPDES & sewage plant \& other outfalls & NYSDEC-Water Quality & NY-0005835 & 03-01-05 \\
\hline WMF & waste management & NYSDEC - Hazardous Waste & $1-4722-00032 / 00102-0$ & $07-12-05$ \\
\hline BNL Site & chemical tanks- HSBSRC & NYSDEC - Bulk Storage & $1-000263$ & $7-27-01$ \\
\hline BNL Site & Underground Injection Controls & EPA-Safe & NYU500001 & $02-11-11$ \\
\hline $\mathrm{RHIC}$ & sewer extension & NYSDEC - Nat. Res. & $1-4722-0032 / 00123$ & $07 / 31 / 04$ \\
\hline STP & sewer upgrades & NYSDEC - Nat. Res. & $1-4722-00032 / 00127$ & $06 / 01 / 05$ \\
\hline $\begin{array}{l}\text { Plant Engineering } \\
\text { CERCLA Projects }\end{array}$ & potable water wells & NYSDEC - Nat. Res. & 1-4722-00032100113-0 & 09/13/08 \\
\hline $\begin{array}{l}\text { Ou III; So. Boundary } \\
\text { and Middle Rd.; } \\
\text { Bldg. } 518\end{array}$ & groundwater treatment system & $\begin{array}{l}\text { NYSDEC - SPDES Equiv. } \\
\text { NYSDEC - Air Equiv. }\end{array}$ & $1-51-009$ & $3 / 30 / 02$ \\
\hline Bldg. 868 & groundwater treatment system & NYSDEC - Air Equiv. & NA & NA \\
\hline TR-829 & $\begin{array}{l}\text { carbon tetrachloride } \\
\text { groundwater remediation }\end{array}$ & NYSDEC - SPDES Equiv. & $1-51-009$ & NA \\
\hline OS-1 & $\begin{array}{l}\text { off-site groundwater } \\
\text { treatment system }\end{array}$ & NYSDEC - Operating & NA & NA \\
\hline OU I; Bldg. 598 & groundwater treatment & $\begin{array}{l}\text { NYSDEC - SPDES Equiv. } \\
\text { NYSDEC - Air Equivalency }\end{array}$ & $1-52-009$ & $10 / 06$ \\
\hline Bldg. 598 & $\begin{array}{l}\text { tritium pump } \\
\text { and recharge }\end{array}$ & NYSDEC - SPDES Equiv. & $1-52-009$ & $3 / 30 / 02$ \\
\hline
\end{tabular}

Notes:

AGS = Alternating Gradient Synchrotron

CSF $=$ Central Steam Facility

EPA = U.S. Environmental Protection Agency

HSBSRC $=$ Hazardous Substance Bulk Storage Registration Certificate

NESHAPs = National Emission Standards for Hazardous Air Pollutants

NYSDEC $=$ New York State Department of Environmental Conservation

REF/NFB = Radiation Effects Facility/Neutral Beam Facility

$\mathrm{RHIC}=$ Relativistic Heavy lon Collider

RTF = Radiation Therapy Facility

STP \& RCB = Sewage Treatment Plant and Recharge Basins

WMF $=(\mathrm{New})$ Waste Management Facility

$\mathrm{NA}=$ NotAvailable or NotApplicable

(a) Permits for processes with past due expiration dates have been extended until NYSDEC approves BNL's Title V permit or until the NYSDEC reclassifies the processes as exempt and trivial pursuant to 6 NYCRR Part 201 provisions.

(b) NYSDEC has indicated the process is subject to registration only.

(c) The vapor/sonic degreaser and fume hood shared a common exhaust stack. The degreaser has been removed. The fume hood is still used for aerosol spray coating and wipe cleaning of parts.

(d) Process is not in service.

(e) Response to application never received from the NYSDEC. The process was also included in the BNL Title $V$ permit application.

(f) Process removed from service. 
federal and state regulatory requirements into a single document. The permit application was originally filed in December 1998. After completing an initial quality assurance review of the application, NYSDEC forwarded an Administrative Error Report to BNL in June 1999. The administrative errors in the BNL application were corrected and some minor revisions were made to the application to capture emission sources that were identified during the Process Evaluation Project (see Chapter 2 for a description of this project). An amended permit application was submitted to NYSDEC in February 2000 and a notice of complete application was issued to BNL on August 6, 2001. This notice was subsequently published in local newspapers and the public was given an opportunity to comment on the draft permit through September 21 . During the public comment period, BNL reviewed the draft permit and requested several minor revisions. No other comments were received by NYSDEC, and EPA did not offer any objections to the terms and conditions of the draft permit. During the last week of December, NYSDEC informed BNL that they expected to address BNL's proposed changes to the draft permit and issue a final Title $\mathrm{V}$ operating permit in January 2002.

\subsubsection{Underground Injection Control Permit}

Under the Safe Drinking Water Act, BNL was required to apply for and obtain an Area Permit for Underground Injection Control (UIC) wells (e.g., drywells, cesspools, and leaching pools). The application required the submittal of an Area permit application, a complete inventory of all UICs, and a map depicting their location. An initial application was filed in December 1998 and revised in September 1999. The application was approved in August 2000 with issuance of a draft permit. A final permit was issued in January 2001. This permit authorizes the operation of 90 UICs, including 86 stormwater drywells and 4 small sanitary systems. Several changes to the permit occurred in 2001, essentially due to changes in the reported inventory. During 2001, thirteen UICs were closed and applications were filed for the installation of four new devices.

\subsection{NATIONAL ENVIRONMENTAL POLICY ACT}

The National Environmental Policy Act (NEPA) regulations require federal agencies to evaluate the effects of proposed major federal activities on the environment. The prescribed evaluation process ensures that the proper level of environmental review is performed before an irreversible commitment of resources is made. During 2001, environmental evaluations were completed for 165 proposed projects. Of these, 112 were considered minor actions requiring no additional documentation. The remaining 53 projects were addressed through the submission of Environmental Evaluation Notification Forms to the U.S. Department of Energy. Fifty-two of these evaluations resulted in the determination that they were covered by existing Categorical Exclusions, as defined by 10 CFR 1021. DOE determined that one project, White-tailed Deer Management at BNL, would require an Environmental Assessment (EA). An EA evaluating proposed upgrades to the National Synchrotron Light Source, Accelerator Test Facility, and the Source Development Lab was completed in 2001. Based on the analyses in the EA, DOE issued a Finding of No Significant Impact, determining that the proposed action did not constitute a major federal action significantly affecting the quality of the human environment; therefore, the preparation of an Environmental Impact Statement (EIS) was not required.

\subsection{HISTORIC PRESERVATION AND ARCHAEOLOGY}

$\mathrm{BNL}$ is subject to several cultural resource laws, most notably the National Historic Preservation Act (NHPA) and the Archeological Resource Protection Act (ARPA). These acts require federal agencies to identify, evaluate, and consider the effects of federal actions on historical and archeological sites eligible for listing or inclusion on the National Register of Historic Places. The sites may include historic structures, objects, documents, and Native American Indian lands.

In October 2001, the New York State Historic Preservation Officer concurred with BNL's determination that the High Flux Beam Reactor (HFBR) complex was eligible for listing on the National Register of Historic Places. BNL 
has two additional structures or sites that have been determined to be eligible for listing: the Brookhaven Graphite Research Reactor (BGRR) complex and the World War I training trenches and foxholes associated with Camp Upton. During 2001, additional activities associated with NHPA and ARPA compliance included the following:

- In February 2001, BNL accepted receipt of the Architectural Inventory of the Brookhaven National Laboratory (Bernstein 2001). BNL had contracted with an off-site vendor to perform an architectural survey to identify and evaluate BNL properties for their historic value. Information developed from this document will be used to identify buildings and structures that may be eligible for listing on the National Register of Historic Places.

- BNL continued to develop documentation associated with the "Memorandum of Agreement (MOA) for the Mitigation of the BGRR Decommissioning" (Desmarais 2000). Production of a video documentary detailing the history of the BGRR occurred in 2001.

The contract, which utilized the services of a professional archivist to inventory and appraise BGRR-related records and to develop a BGRR Researcher's Guide, was completed in December 2001.

- The annual Department of Interior questionnaire regarding historic and cultural resources was completed.

- In September 2001, the DOE Brookhaven Area Office issued a Federal Archeological Permit to an off-site contractor to perform an archeological survey before the proposed installation of a natural gas pipeline. The authorized period for fieldwork was September 6, 2001 to October 30, 2001.

Chapter 6 contains additional information related to cultural resource management activities.

\subsection{CLEAN AIR ACT}

The objectives of the Clean Air Act (CAA) that is administered by EPA and NYSDEC are to improve or maintain regional ambient air quality through operational and engineering controls on stationary or mobile sources of air pollution. Both conventional and hazardous air pollutants are regulated under the CAA.

\subsubsection{Conventional Air Pollutants}

BNL has a variety of nonradioactive air emission sources that are subject to federal or state regulations. The following subsections describe the most significant sources and the methods used by BNL to comply with the applicable regulatory requirements.

\subsubsection{Boiler Emissions}

BNL has four boilers (Nos. 1A, 5, 6, and 7) at the Central Steam Facility that are subject to NYSDEC Reasonably Available Control Technology (RACT) requirements. Three of the boilers can burn either residual fuel oil or natural gas; Boiler 1A burns fuel oil only. Natural gas was the predominant fuel burned in Boiler 6, whereas Boilers 5 and 7 burned mostly low nitrogen and sulfur content residual fuel oil.

For boilers with maximum operating heat inputs greater than or equal to $50 \mathrm{MMBtu} / \mathrm{hr}$ (14.6 MW), RACT requirements establish emission standards for oxides of nitrogen $\left(\mathrm{NO}_{\mathrm{x}}\right)$. Boilers with a maximum operating heat input between 50 and $250 \mathrm{MMBtu} / \mathrm{hr}$ (14.6 and 73.2 $\mathrm{MW}$ ) can demonstrate compliance using periodic emissions tests or by using continuous emission monitoring equipment. Emission tests conducted in 1995 confirmed that BNL Boilers 1A and 5, both of which are in this size category, met the $\mathrm{NO}_{\mathrm{x}}$ emission standards when burning low nitrogen and sulfur content residual fuel oil (below 0.3 percent). To ensure continued compliance, an outside contractor laboratory analyzed composite samples of fuel deliveries (collected quarterly) and confirmed that the fuelbound nitrogen and sulfur content met these requirements. Compliance with the $0.30 \mathrm{lbs} /$ MMBtu $\mathrm{NO}_{\mathrm{x}}$ emissions standards for Boilers 6 and 7 was demonstrated by continuous emission monitoring of the flue gas. For the year 2001, $\mathrm{NO}_{\mathrm{x}}$ emissions from Boilers 6 and 7 averaged $0.110 \mathrm{lbs} / \mathrm{MMBtu}$ and $0.245 \mathrm{lbs} / \mathrm{MMBtu}$, respectively, and there were no known exceedances of the $\mathrm{NO}_{x}$ emissions standard for either boiler.

\subsubsection{Ozone-Depleting Substances}

Refrigerants. All refrigerant recovery and recycling equipment used by refrigerant service 
technicians is certified to meet refrigerant evacuation levels specified by 40 CFR 82.158 . Under the preventative maintenance program, refrigeration and air conditioning equipment containing ozone-depleting substances is regularly inspected and maintained. As a matter of standard practice at BNL, if a refrigerant leak is found, technicians will either immediately repair the leak or isolate it and prepare a work order for the needed repairs. This practice exceeds the leak repair provisions of 40 CFR 82.156.

Approximately 600 pounds of R-11, 2 pounds of R-12, 1,119 pounds of R-22, and 5 pounds of R-123 refrigerants were recovered and reclaimed for future use from equipment that was serviced during 2001. Two 650-ton R11 centrifugal chillers were taken out of service when Building 555 was connected to the Central Chilled Water Facility for comfort cooling. The refrigerant in these two chillers will be recovered and sent to a refrigerant reclamation facility in 2002.

Halon. Halon 1211 and 1301 are extremely efficient fire suppressants but are no longer acceptable, due to their effect on the earth's ozone layer. In 1998, BNL purchased equipment to comply with the halon recovery and recycling requirements of the CAA, 40 CFR 82 Subpart H. Halon recovery and recycling devices are used when portable fire extinguishers or fixed systems are removed from service and during periodic hydrostatic testing of halon cylinders. In 2001, the Halon 1211 device was used to recover 120 pounds of Halon 1211 from seven portable fire extinguishers that were taken out of service and replaced with ABC dry chemical extinguishers. The recovered Halon 1211 was transferred to a storage tank and is now included in BNL's static inventory.

\subsubsection{Hazardous Air Pollutants}

In 1970, the Clean Air Act established standards to protect the general public from pollutants that may lead to death or an increase in irreversible or incapacitating illnesses. The National Emissions Standards for Hazardous Air Pollutants, known as NESHAPs, were updated significantly in 1990. EPA developed a program to limit the emissions of 189 toxic air pollutants.
This program includes a list of regulated contaminants; a schedule for implementing control requirements; aggressive, technology-based emission standards; industry-specific requirements, special permitting provisions; and a program to address accidental releases. The following subsections describe BNL's compliance with NESHAPs regulations.

\subsubsection{Maximum Available Control Technology}

During preparation of the BNL Title V Phase II application, BNL reviewed existing state and federal regulations administered under the CAA to determine applicability to BNL activities and operations. Based on this review, it was concluded that no proposed or promulgated Maximum Available Control Technology standards apply to $\mathrm{BNL}$ operations. Additional evaluation conducted in 2001 determined that no Maximum Available Control Technology standards apply to anticipated emissions from proposed activities or operations.

\subsubsection{Asbestos}

As required, BNL provided notice to the EPA Region II office regarding the removal of materials that contained asbestos. During 2001, 335 linear feet of asbestos-containing pipe insulation and 10,966 square feet of asbestos-containing surface material were removed and disposed of in accordance with EPA requirements.

\subsubsection{Radioactive Airborne Emissions}

Emissions of radiological contaminants are evaluated and, if necessary, monitored to ensure that they do not affect the environment. A full description of the monitoring conducted by BNL in 2001 is provided in Chapter 4. BNL transmitted all data pertaining to radioactive air emissions and dose calculations to EPA on schedule, in fulfillment of the June 30 annual reporting requirement. In 2001, the maximum off-site dose due to airborne radioactive emissions from the Laboratory continued to be far below the 10 mrem $(100 \mu \mathrm{Sv})$ annual dose limit specified in 40 CFR 61 Subpart H. (See Chapter 8 for more information on the estimated air dose.) The dose to the maximally exposed individual resulting from airborne emissions, calculated using EPA's CAP88-PC (CAAAssessment Package-2000) 
model, was 0.137 mrem $(1.4 \mu \mathrm{SV}$ ) (see Chapter 8 for more information).

\subsection{CLEAN WATER ACT}

The disposal of wastewater generated by $\mathrm{BNL}$ operations is regulated under the Clean Water Act (CWA), as implemented by NYSDEC and under DOE Order 5400.5 (1990). The goals of the CWA are to achieve a level of water quality that promotes the propagation of fish, shellfish, and wildlife; to provide waters suitable for recreational purposes; and to eliminate the discharge of pollutants into surface waters. New York State was delegated CWA authority in 1975. NYSDEC issues a SPDES permit to regulate wastewater effluents at BNL. This permit establishes release concentration limits and specifies monitoring requirements.

The BNL SPDES permit was renewed in September 1999 with an effective date of March 1, 2000 and an expiration date of March 1, 2005. This permit provides monitoring requirements and specifies effluent limits for 12 of 14 outfalls, as described below:

- Outfall 001 is the discharge of treated effluent from the STP to the Peconic River.

- Outfalls 002, 002A, 002B, 003, 004, 005, 006A, 006B, 008, 010, and 011 are recharge basins used to discharge cooling tower blowdown, once-through cooling water, and/ or stormwater. There was no monitoring of Outfall 002A and very limited monitoring of 002B in 2001 because the RHIC cooling towers operated infrequently. No monitoring requirements are imposed for Outfall 011.

- Outfall 007 receives backwash water from the potable Water Treatment Plant filter building.

- Outfall 009 consists of numerous subsurface and surface wastewater disposal systems that receive predominantly sanitary waste, and steam- and air-compressor condensate discharges. There are no monitoring requirements imposed for this outfall.

See Figures 5-2 and 5-7 in Chapter 5 for the locations of BNL outfalls.

Each month BNL prepares a Discharge Monitoring Report that reports monitoring data, evaluates compliance with permit limitations, and identifies corrective measures taken to address permit excursions. This report is submitted directly to the NYSDEC central and regional offices, and the Suffolk County Department of Health Services.

\subsubsection{Sewage Treatment Plant}

Sanitary and process wastewater generated by BNL operations is conveyed to the Sewage Treatment Plant for processing before being discharged to the Peconic River. The STP provides tertiary treatment of sanitary and process wastewater (i.e., biological reduction of organic matter and reduction of nitrogen). This treatment process became fully functional in 1998. Chapter 5 provides a detailed description of the treatment process. In 2000, BNL initiated an improvement project at the STP that continued into 2001. This project involves replacing or relining 16,000 lineal feet of piping, constructing a new aerobic solids digester, relining holdup ponds used to hold wastewater suspected of containing contaminants at concentrations that could jeopardize the STP effluent quality, and repairing or replacing piping that serves the sand filtration system.

A summary of the nonradiological monitoring results for the STP discharge at Outfall 001 is provided in Table 3-3. The relevant SPDES permit limits are also shown. BNL monitors the STP discharge for more than 100 parameters monthly and well over 200 parameters quarterly. BNL's compliance with effluent limits earned a score of more than 99 percent overall, but there were six reported exceedances of SPDES permit limits in 2001: five for zinc and one for ammonia nitrogen. Figures 3-1 through 3-6 plot five-year trends for the maximum monthly concentrations of iron, lead, mercury, silver, nickel, and zinc in the STP discharge.

\subsubsection{Zinc Excursions}

Excursions for zinc were recorded from January through March. Investigation of these excursions showed that they were attributed to two sources, both of which were a result of sewer line rehabilitation work. The first and most significant source was from the removal of residual sludge from the sewer lines prior to line 
Table 3-3. Analytical Results for Wastewater Discharges to Sewage Treatment Plant Outfall 001.

\begin{tabular}{|c|c|c|c|c|c|c|}
\hline Analyte & Min. & Max. & $\begin{array}{l}\text { Min. Monitoring } \\
\text { Frequency }\end{array}$ & $\begin{array}{l}\text { SPDES } \\
\text { Limit }\end{array}$ & $\begin{array}{c}\text { No. of } \\
\text { Exceedances }\end{array}$ & $\begin{array}{c}\% \\
\text { Compliance }^{*}\end{array}$ \\
\hline Max. Temperature $\left({ }^{\circ} \mathrm{F}\right)$ & 46 & 81 & Daily & 90 & 0 & 100 \\
\hline $\mathrm{pH}(\mathrm{SU})$ & 5.8 & 7.2 & Continuous Recorder & $\begin{array}{l}\text { Min. } 5.8 \\
\text { Max. } 9.0\end{array}$ & 0 & 100 \\
\hline $\begin{array}{l}\text { Avg. 5-Day Biological } \\
\text { Oxygen Demand (BOD) (mg/L) }\end{array}$ & 1 & 7 & Twice Monthly & 10 & 0 & 100 \\
\hline Max. 5-Day BOD (mg/L) & $<2$ & 17 & Twice Monthly & 20 & 0 & 100 \\
\hline$\%$ BOD Removal & $>86$ & $>97$ & Monthly & 85 & 0 & 100 \\
\hline $\begin{array}{l}\text { Avg. Total Suspended } \\
\text { Solids (TSS) (mg/L) }\end{array}$ & $<4$ & 4.5 & Twice Monthly & 10 & 0 & 100 \\
\hline Max. TSS (mg/L) & $<4$ & 5 & Twice Monthly & 20 & 0 & 100 \\
\hline$\%$ TSS Removal & $>89$ & 100 & Monthly & 85 & 0 & 100 \\
\hline Settleable Solids (ml/L) & 0.0 & 0.0 & Daily & 0.1 & 0 & 100 \\
\hline Ammonia Nitrogen (mg/L) & $<0.1$ & 2.9 & Twice Monthly & 2 & $1^{(\mathrm{a})}$ & 96 \\
\hline Total Nitrogen (mg/L) & 5.4 & 10 & Twice Monthly & 10 & 0 & 100 \\
\hline Total Phosphorus (mg/L) & 0.9 & 1.8 & Twice Monthly & NA & 0 & 100 \\
\hline Cyanide ( $\mu \mathrm{g} / \mathrm{L})$ & $<10$ & $<10$ & Twice Monthly & 100 & 0 & 100 \\
\hline Copper (mg/L) & 0.03 & 0.07 & Twice Monthly & 0.15 & 0 & 100 \\
\hline Iron (mg/L) & 0.15 & 0.30 & Twice Monthly & 0.37 & 0 & 100 \\
\hline Lead (mg/L) & $<0.001$ & 0.009 & Twice Monthly & 0.019 & 0 & 100 \\
\hline Nickel (mg/L) & 0.003 & 0.006 & Twice Monthly & 0.11 & 0 & 100 \\
\hline Silver (mg/L) & $<0.001$ & 0.003 & Twice Monthly & 0.015 & 0 & 100 \\
\hline Zinc (mg/L) & 0.02 & 0.21 & Twice Monthly & 0.1 & $5^{(b)}$ & 82 \\
\hline Mercury (mg/L) & $<0.0001$ & 0.0002 & Twice Monthly & 0.0008 & 0 & 100 \\
\hline Toluene $(\mu \mathrm{g} / \mathrm{L})$ & $<1$ & $<1$ & Twice Monthly & 5 & 0 & 100 \\
\hline Methylene Chloride ( $\mu \mathrm{g} / \mathrm{L})$ & $<1$ & 2 & Twice Monthly & 5 & 0 & 100 \\
\hline 1,1,1-Trichloroethane $(\mu \mathrm{g} / \mathrm{L})$ & $<1$ & $<1$ & Twice Monthly & 5 & 0 & 100 \\
\hline 2-Butanone $(\mu \mathrm{g} / \mathrm{L})$ & $<1$ & $<5$ & Twice Monthly & 50 & 0 & 100 \\
\hline PCBs $(\mu \mathrm{g} / \mathrm{L})$ & $<0.065$ & $<0.065$ & Quarterly & NA & 0 & 100 \\
\hline Max. Flow (MGD) & 0.5 & 0.7 & Continuous Recorder & 2.3 & 0 & 100 \\
\hline Avg. Flow (MGD) & 0.4 & 0.6 & Continuous Recorder & $\mathrm{NA}$ & 0 & 100 \\
\hline Avg. Fecal Coliform (MPN/100 ml) & $<2$ & 90 & Twice Monthly & 200 & 0 & 100 \\
\hline Max. Fecal Coliform (MPN/100 ml) & $<2$ & 130 & Twice Monthly & 400 & 0 & 100 \\
\hline
\end{tabular}

Notes:

See Chapter 5, Figure 5-7 for location of Outfall 001.

$*_{\%}$ Compliance $=[($ Total No. Samples - Total No. Exceedances $) /$ Total No. of Samples $] \times 100$

$\mathrm{MGD}=$ Million Gallons per Day

MPN = Most Probable Number

NA $=$ NotApplicable

$\mathrm{SU}=$ Standard Unit

(a) A permit exceedance occurred in October of 2001. The results received from the New York State-certified analytical laboratory exceeded the permit limit, although, BNL process control test results for the same water sample were below the limit. Since routine monitoring of the Sewage Treatment Plant effluent shows ammonia concentrations to be significantly below the permit limit of $2.0 \mathrm{mg} / \mathrm{L}$, the permit exceedance data is questionable.

(b) There were permit exceedances in January, February, and March of 2001. The violations are probably due to sewer upgrades being performed on site during this time. 
Figure 3-1. Maximum

Concentration of Copper Discharged from the BNL Sewage Treatment Plant, 1997-2001.

Figure 3-2. Maximum Concentration of Iron Discharged from the BNL Sewage Treatment Plant, 1997-2001.

Figure 3-3. Maximum Concentration of Lead Discharged from the BNL Sewage Treatment Plant, 1997-2001.
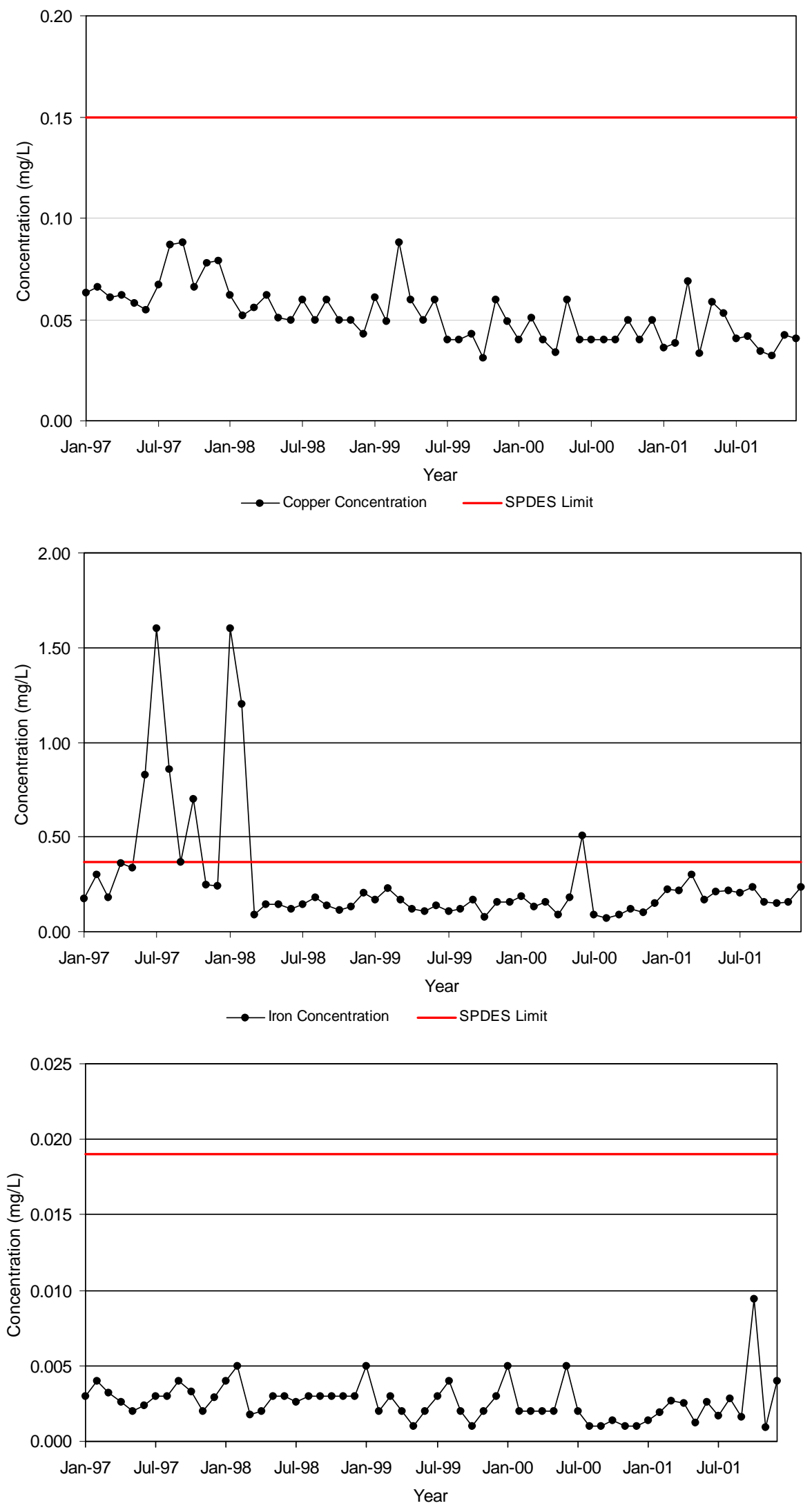

$\longrightarrow$ Lead Concentration $\quad$ SPDES Limit 

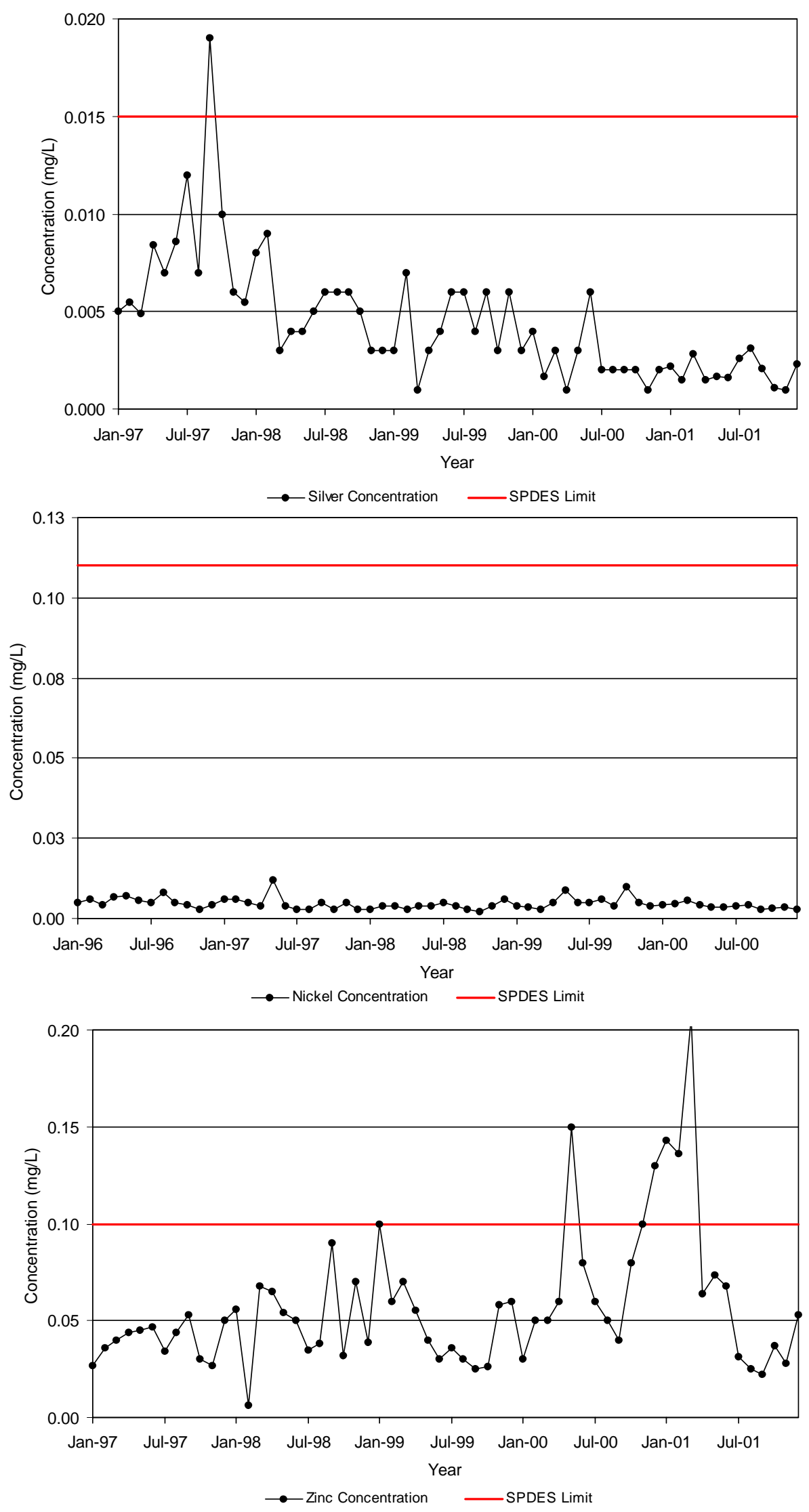

Figure 3-4. Maximum Concentration of Silver Discharged from the BNL Sewage Treatment Plant, 1997-2001.

Figure 3-5. Maximum Concentration of Nickel Discharged from the BNL Sewage Treatment Plant, 1997-2001.

Figure 3-6. Maximum Concentration of Zinc Discharged from the BNL Sewage Treatment Plant, 1997-2001. 
replacement. Analysis of the sludge showed it to contain several parts per million of soluble zinc. It is theorized that the zinc dissolved in the wash water used to clean the sewer lines became trapped in the sludge within the clarifiers at the STP. The zinc was then slowly released over several months in the STP effluent. The second source of soluble zinc was the slip lining materials that were used during the sewer line rehabilitation project. Zinc compounds were used in the fabrication of the liner material to prevent the polyethylene from becoming too rigid. Although this was a minor source, it probably contributed to the zinc load in the influent to the sewer plant. When the sewer project ended, the concentration of zinc in the STP effluent returned to normal levels.

\subsubsection{Ammonia}

A sample of STP effluent collected on October 8, 2001 exhibited an ammonia concentration of $2.94 \mathrm{mg} / \mathrm{L}$. This value exceeded the SPDES permit limit of $2.0 \mathrm{mg} / \mathrm{L}$. However, an aliquot of this sample collected by the BNL STP operators on October 8, 2001, as part of routine in-house process control testing, exhibited an ammonia concentration of $0.02 \mathrm{mg} / \mathrm{L}$, and therefore the excursion was considered suspect. There were no other excursions of ammonia found in subsequent samples.

\subsubsection{Heat Exchange Fluid Loss}

In March, the Environmental Services staff was notified of a loss of heat exchange fluid from the Building 902 cooling tower. Building 902 houses several large compressors used in a helium cryogenic cooling system that is used for testing magnets used in facilities like the RHIC. A heat transfer fluid (UCON LB-170X) is used to cool the compressors. The hot heat exchange fluid is cooled using a "shell and tube" heat exchanger, which is cooled by recirculated cooling water provided by the Building 902 cooling tower. To reduce corrosion potential and minimize the buildup of scale, the conductivity of the water in the cooling tower is monitored. When needed, clean water is automatically added to the tower, causing the displaced water to overflow to the sanitary sewer.
In March of 2001, a tube in the heat exchanger failed, releasing approximately 20 gallons of heat exchange fluid to the cooling tower. The tower was secured to prevent further releases and STP staff were notified of the release. Examination of the STP showed that the fluid was evident in the discharge to the Peconic River as a white, persistent foam. To prevent continued release, the STP was placed in a diversion mode and the discharge was collected in the holdup ponds for evaluation. According to information from the fluid manufacturer, the heat exchange fluid has low aquatic toxicity and naturally degrades in 28 days. Analysis of the material contained in the holdup pond showed no detectable fluid after four weeks. The water was subsequently pumped back to the head of the treatment plant for treatment and release. The incident was reported to NYSDEC, DOE, and other regulatory agencies; it was not classified as a permit exceedance.

\subsubsection{Chronic Toxicity Testing}

BNL's SPDES permit requires that "whole effluent toxicity" tests be conducted to ensure that chemicals present in the STP effluent are not toxic to aquatic organisms. BNL's chronic toxicity testing program began in 1993 and continued through 2001. Samples were collected and tested quarterly. The program consists of performing seven-day chronic toxicity tests on two freshwater organisms: water fleas (Ceriodaphnia dubia) and fathead minnows (Pimephales promelas). Sets of ten organisms are exposed to varying concentrations of the STP effluent (100, 50, 25, 12.5, and 6.25 percent) for seven days in each test. During testing, the size of fish and/or rate of reproduction for the water flea were measured and compared to untreated organisms (i.e., controls). The test results were submitted to NYSDEC for review.

In 2001, two of the four tests for water flea reproduction and one test for minnow survival revealed toxicity. Comparison of chemical data to the toxicity data gave no indication of any single element or compound that would have contributed to these observations. BNL is continuing to work with NYSDEC to evaluate the data and determine the next steps toward monitoring. 


\subsubsection{Recharge Basins and Stormwater}

Outfalls 002 through 008 and Outfall 010 discharge to groundwater, replenishing the underlying aquifer. Monitoring requirements for each of these discharges vary depending on the type of wastewater received and the type of cooling water treatment reagents used. No monitoring requirements were imposed for Outfalls 009 and 011. Due to the infrequent discharge from cooling towers at the RHIC, there was limited monitoring of Outfall 002B in 2001. Additionally, there were no samples collected from Outfall 002A. Outfall 002A was connected to Outfall 002 during 2001 and a request was made to NYSDEC to delete this discharge from the BNL SPDES permit. Table 3-4 summarizes the monitoring requirements and performance results for 2001.

There were six excursions at these outfalls in 2001. Five were for exceedance of effluent limits for hydroxyethylidene-diphosphonic acid, one at each of five outfalls. Since all results occurred during the same monitoring period (October 2001) and the compound was detected in a discharge known to not contain the compound, the results were considered suspect. Followup sampling in December showed all levels to be within limits. The last exceedance was for $\mathrm{pH}$ measured at Outfall 005. Elevated $\mathrm{pH}$ in the BNL domestic water system was the most probable cause of the $\mathrm{pH}$ excursion. To increase the $\mathrm{pH}$ of domestic water and reduce the corrosivity of the water system, hydroxides (either calcium or sodium) were added to the well water. Discharges to Outfall 005 follow an asphalt swale for several hundred yards before intercepting the monitoring station. During dry weather, evaporation results in higher $\mathrm{pH}$ levels in the water when measured at the monitoring station. All measurements taken upstream of the asphalt swale show $\mathrm{pH}$ levels consistent with that of drinking water. The discharge of slightly alkaline wastewater would not have detrimental effects on groundwater, due to the naturally acidic conditions of Long Island's groundwater.

Several changes to the monitoring requirements were proposed for these outfalls in 2001 . These changes include deleting Outfalls 002A and 004, reducing the monitoring at Outfalls 003

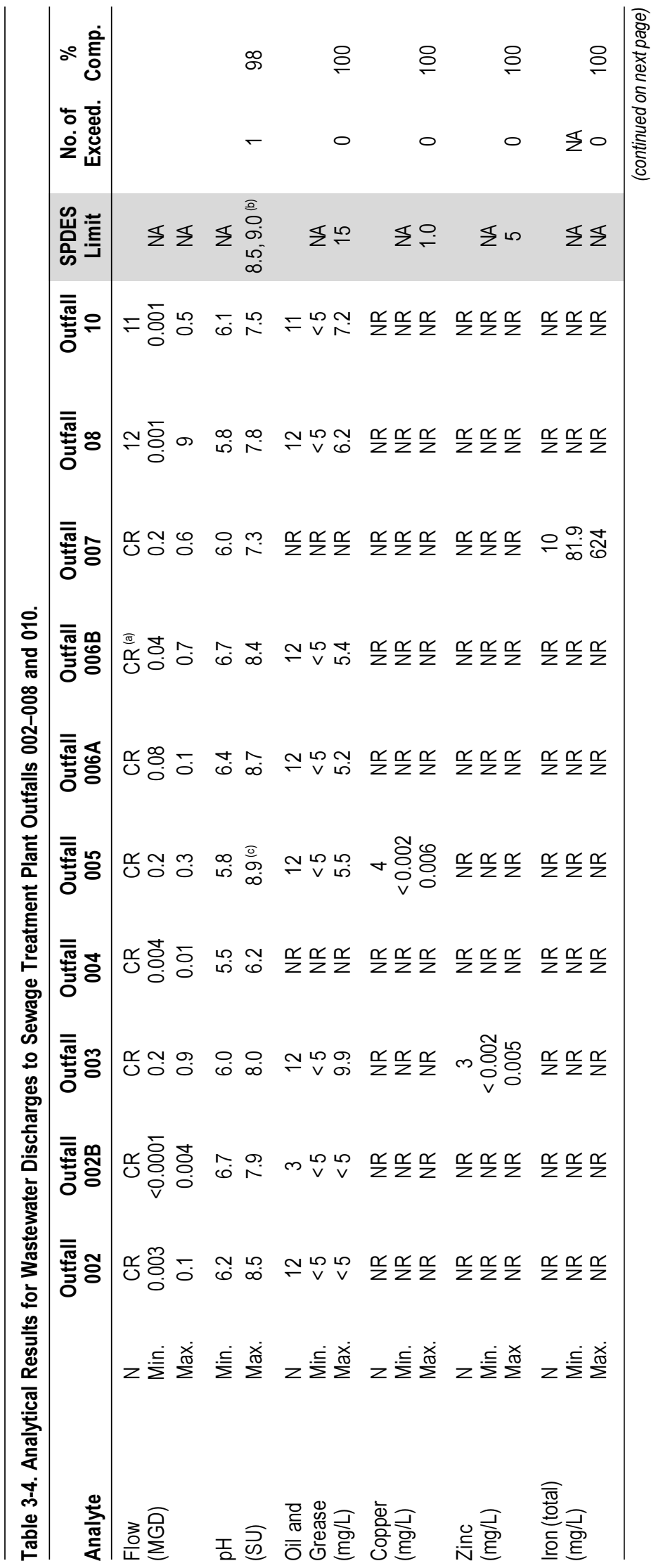


CHAPTER 3: COMPLIANCE STATUS

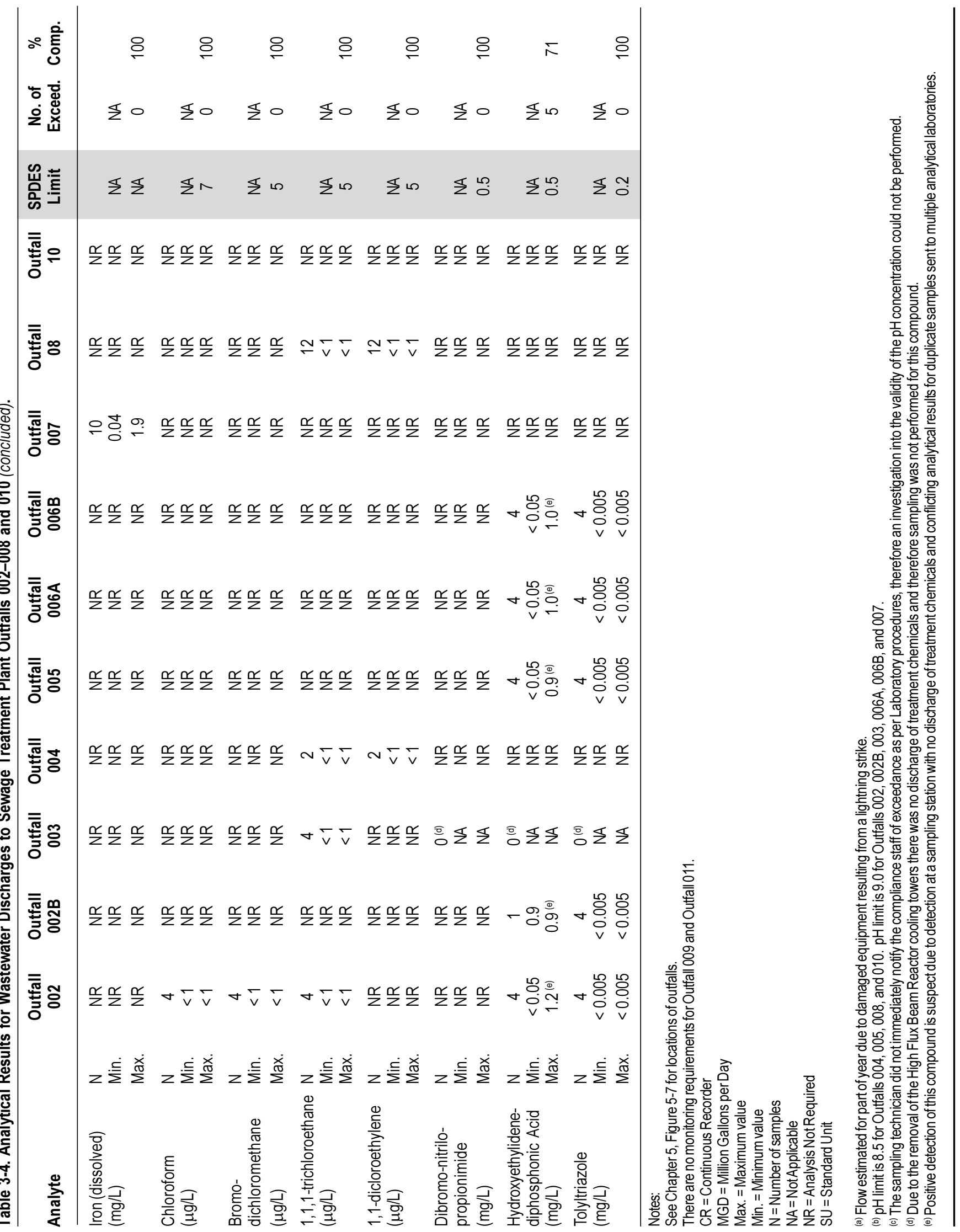


and 007 , and increasing the monitoring at Outfalls 002,008 , and 010 . Additional monitoring has been proposed for these outfalls because inorganics (primarily aluminum and lead) were detected under the BNL Environmental Surveillance Program (See Chapter 5). During 2001, BNL confirmed the presence of a significant area of lead contamination at Outfall 010, attributable to historic operations at the Central Steam Facility. The contaminated area is being investigated and will be addressed once it has been fully delineated.

\subsection{SAFE DRINKING WATER ACT}

The distribution and supply of drinking water is regulated under the federal Safe Drinking Water Act (SDWA). In New York State, implementation of the SDWA is delegated to the New York State Department of Health (NYSDOH) and administered by the Suffolk County Department of Health Services (SCDHS). Because BNL provides potable water to "more than 25 full-time residents," it is subject to the same requirements as a public water supplier. Monitoring requirements are prescribed annually by SCDHS, and a Potable Water Sampling and Analysis Plan (Chaloupka 2001) is prepared to comply with these requirements. The 1996 amendments to the SDWA required preparation of a source water assessment for all sources of public drinking water. In December 2000, the BNL Source Water Assessment for Drinking Water Supply Wells was prepared in satisfaction of this requirement (Bennett et al. 2000). The assessment is designed as a management tool to further protect the sole-source aquifer system underlying the BNL site.

\subsubsection{Potable Water}

BNL maintains six groundwater wells for on-site distribution of potable water. To meet drinking water standards, groundwater is treated with activated carbon or air stripping to remove volatile organic compounds. Groundwater from three of the six wells is also treated to reduce naturally occurring iron. Figure 3-7 shows the treatment process used for removing iron from groundwater.

As required by $\mathrm{NYSDOH}$ regulations, $\mathrm{BNL}$ monitors the potable wells regularly for bacteria, inorganics, organics, and pesticides. BNL also voluntarily monitors drinking water supplies for radiological contaminants. Tables 3-5 and 3-6 provide the potable water supply monitoring data for 2001. Color and iron exceeded drinking water standards in samples collected from three of the wells prior to distribution. Treatment at the Water Treatment Plant effectively reduced these levels to below drinking water standards. At the point of consumption, all drinking water supplies complied with primary drinking water standards during 2001. Chapter 7 provides additional data on environmental surveillance tests performed on potable wells. This additional testing exceeds the minimum SDWA testing requirements.

\subsubsection{Cross-Connection Control}

The SDWA requires that public water suppliers implement practices to protect the public water supply from sanitary hazards. One of the safety requirements is to rigorously prevent connections between the potable water supply and systems containing hazardous substances ("cross-connections"). Cross-connection control is the installation of control devices at the interface between a facility and the domestic water main. Cross-connection control devices are required at all facilities where hazardous materials are used in a manner that could result in their introduction into the domestic water system, especially under low-pressure conditions. In addition, secondary cross-connection controls at the point of use are also recommended to protect users within a specific facility from hazards that might be posed by intrafacility operations.

BNL has installed and maintains more than 150 cross-connection control devices at interfaces to the potable water main, and secondary control devices at the point of use. Approximately 120 cross-connection control units were tested in 2001, including primary and secondary devices. All problems found were corrected, and the devices were retested to ensure proper functioning.

\subsubsection{Underground Injection Control}

Underground injection control wells are regulated under the SDWA. UICs at BNL include drywells, cesspools, septic tanks, and leaching 


\section{How Does BNL Produce Its Drinking Water?}

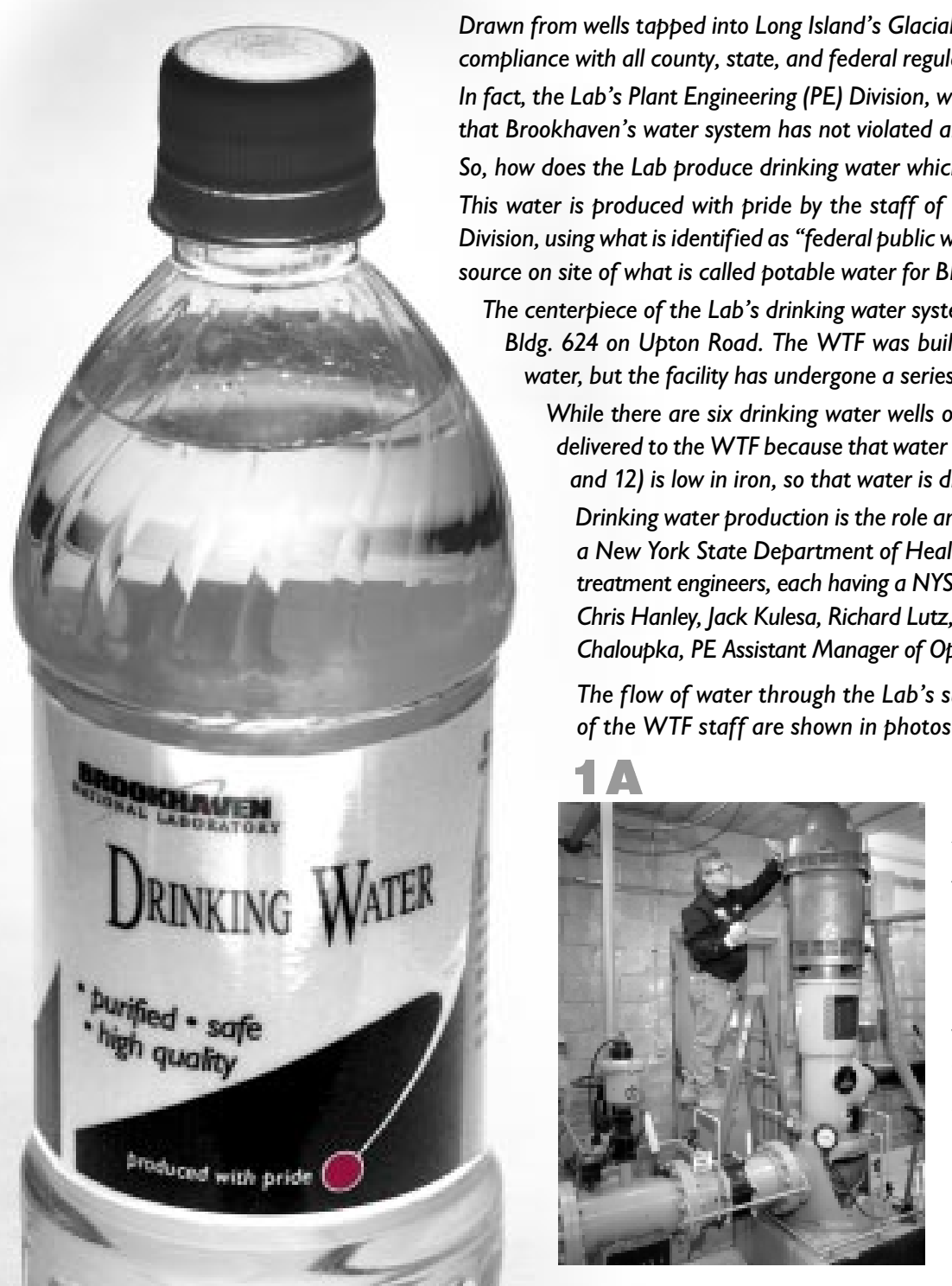

Drawn from wells tapped into Long Island's Glacial Aquifer, BNL's drinking water last year, as in the past, was in full compliance with all county, state, and federal regulations.

In fact, the Lab's Plant Engineering (PE) Division, which is responsible for the Lab's drinking water, is proud to report that Brookhaven's water system has not violated any water quality standard.

So, how does the Lab produce drinking water which is purified, safe, and high quality? And who produces it? source on site of what is called potable water for BNL's transient and resident population of 3,500 people.

The centerpiece of the Lab's drinking water system is the Water Treatment Facility (WTF), located in and around dg. 624 on Upton Road. The WTF was built in 1963 to remove iron and manganese from the Lab's source water, but the facility has undergone a series of upgrades over the years, most recently in 1995-96.

While there are six drinking water wells on site, the water from only three wells (numbered 4, 6, and 7) is

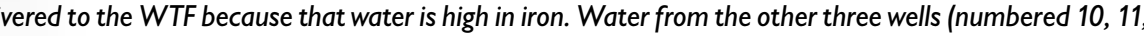
and 12) is low in iron, so that water is distributed directly, after passing through activated carbon filters.

Drinking water production is the role and responsibility of Water System Supervisor Tony Ross, who holds New York State Department of Health (NYSDOH) grade IA certification. He is assisted by seven wate ard Lutz, Phil Pizzo, and Joe Tullo. WTF operations are overseen by William (

The flow of water through the Lab's supply system and the on-the-job performance the WTF staff are shown in photos by Roger Stoutenburgh and described below.

1A. WELLS 4, 6, and 7: provide source water high in iron that is "finished" at BNL's Water Treatment Facility (WTF). At one of these wells, Phil Pizzo performs preventive maintenance on pump motor.

1B. CARBON FILTRATION AT WELLS 10, 11, and 12: removes any volatile organic compounds before the lowiron water from these wells directly enters the drinking water distribution system. Noting the pressure of the carbon filtration system is Richard Lutz.

2. CHLORINATION: of water from Wells 4,6 , and 7 is performed at this point to kill bacteria and oxidize the iron in the water. Iron removal by oxidation and filtration reduces the water's iron concentration from 3 to 4 milligrams per liter $(\mathrm{mg} / \mathrm{l})$ to the "finished" water's 0.03 $\mathrm{mg} / \mathrm{l}$. Inspecting a liquid sodium hypochlorite storage tank is Joe Tullo.

3. AERATION TANK: reduces carbon dioxide gas and aids in the oxidation of iron. At the aeration tank, Steve Barcelo (right) describes the action to Frank Masia.
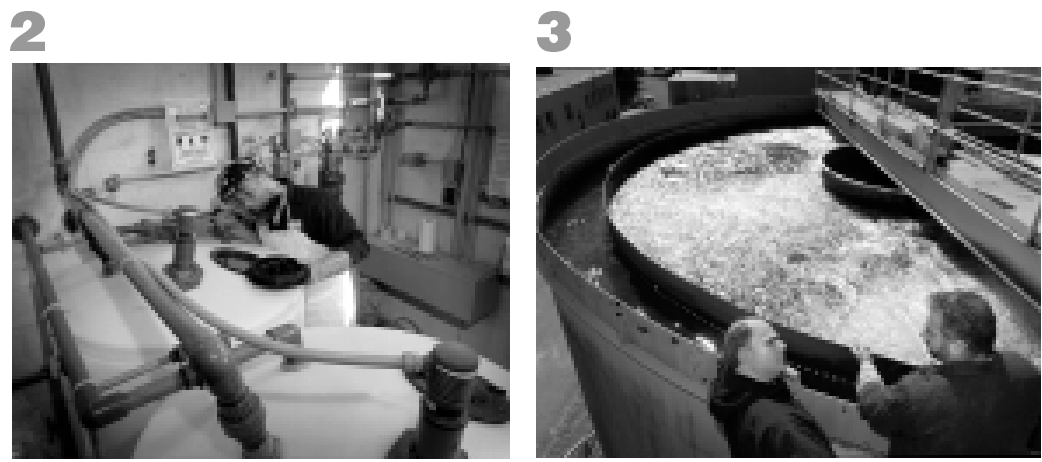

Figure 3-7. Potable Water Treatment at BNL

(Reproduced with permission from The Bulletin [BNL 2001a]). 

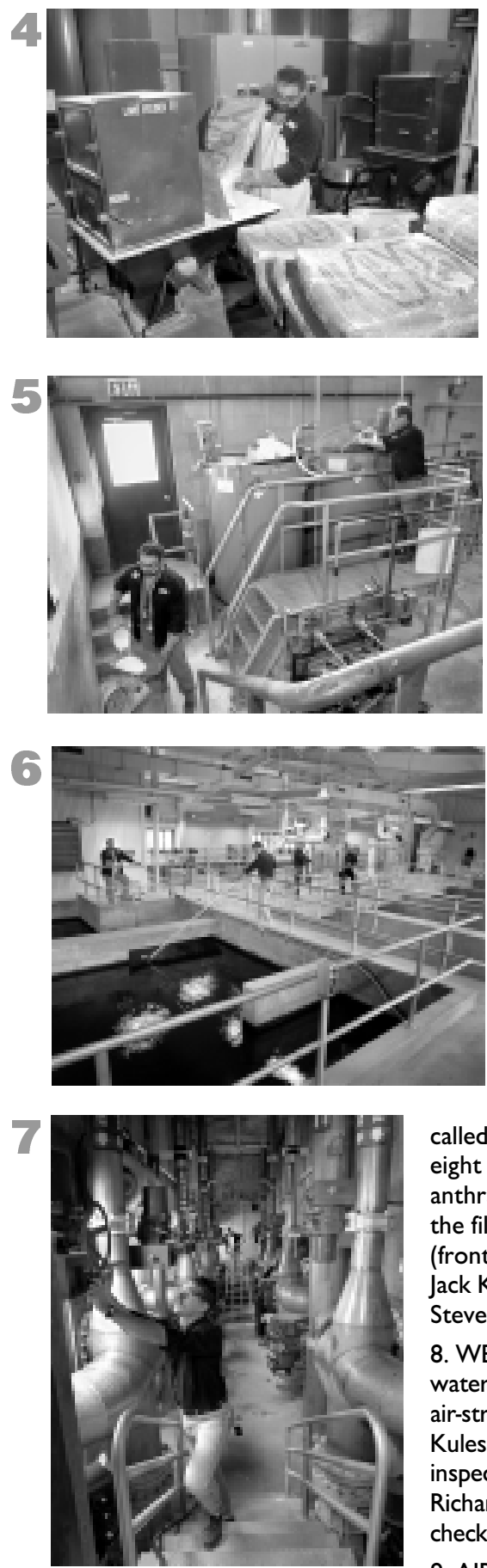

called a rapid sand filter made up of eight filter cells containing sand and anthracite. Inspecting the valves in the filtration valve gallery are: (front to back)

Jack Kulesa, Richard Lutz, and Steve Barcelo.

8. WET WELL: stores the filtered water before it is pumped into the air-stripping towers. While Jack Kulesa (background) is seen inspecting the wet-well pump seals, Richard Lutz works on a check valve.

\section{AIR-STRIPPING TOWERS:}

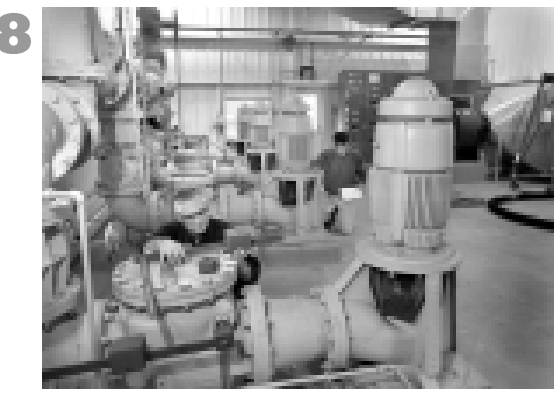

remove any volatile organic compounds (VOCs) from the water undergoing the WTF process by spraying the water down over whiffle ball-like fill while air flows upward through the water spray. Inspecting the towers from the top is Steve Barcelo. Frank Masia looks on from below.

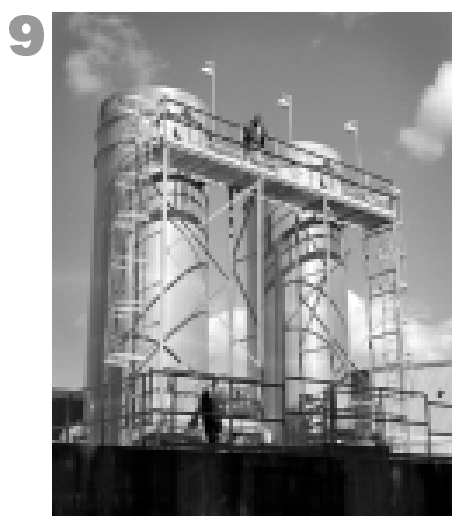

0

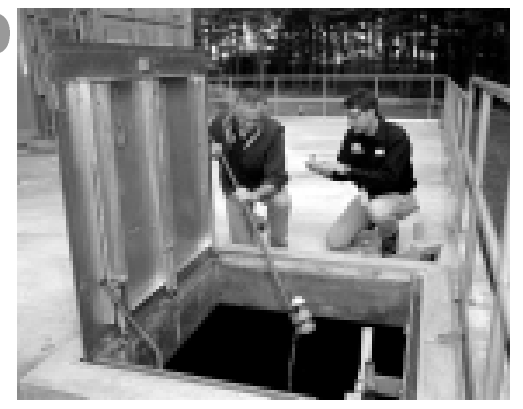

1

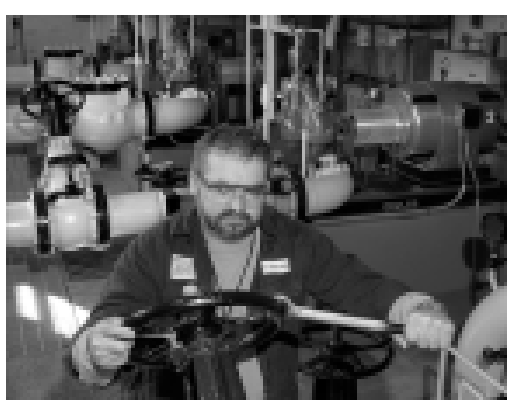

10. CLEAR WELL: stores what is now called "finished" water before its final chlorination and distribution. Seen taking a water sample at the clear well are Jack Kulesa (right) and Richard Lutz (left).

11. HIGH-SERVICE PUMPS: send the finished water from the WTF to the two water towers on site. Adjusting the flow rate of a highservice pump is Steve Barcelo.

12. ONE-MILLION-GALLON WATER STORAGE TOWER:

as viewed from its base, is the larger of the Lab's two water towers. Built in 1985, and located at Cornell and North Sixth Street, this tank is 126 feet above the ground; its bowl is 75.5 feet in diameter. Located next to Police Headquarters, Bldg. 50 , the other water storage tank holds 300,000 gallons and was built for the U.S.

Army in 1941, when the site was Camp Upton. Water from the two towers is delivered on site via 45 miles of distribution pipe, which is a mix of cast iron dating from World War II Camp Upton, transite, plastic, and cement-lined ductile iron. When distribution pipe is added or replaced, cement-line ductile iron is used.

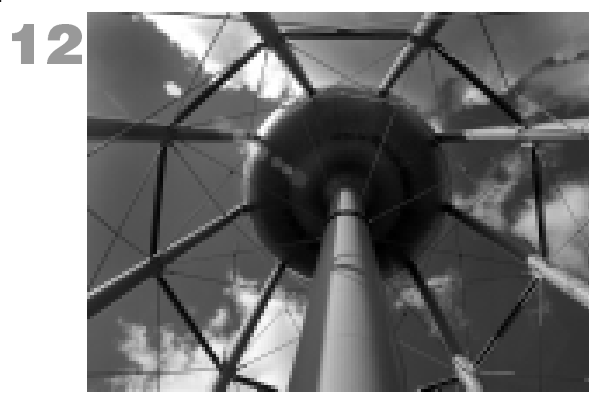

13. TESTING THE QUALITY OF BNL'S DRINKING WATER: at the WTF is Tom Boucher. The Lab's drinking water is tested in various locations weekly, monthly, quarterly, semi-annually, and annually, depending upon the specific test. Test samples are analyzed by certified

laboratories, and results are

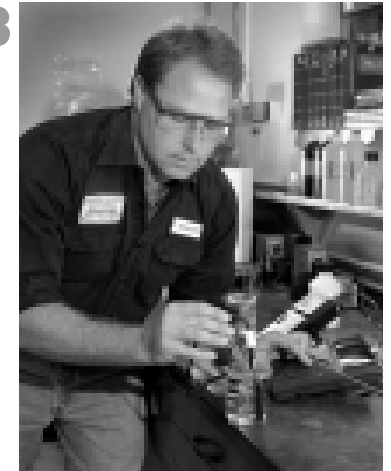
reported to the Suffolk County Department of Health Services, which conducts its own annual tests of all county water systems. In addition, the results are delivered to BNL's Environmental Services Division, which ensures that the Lab's water is in compliance with all applicable regulations. The results are summarized in the Lab's annual Water Quality Consumer Confidence Report (BNL 2001b).

For answers to frequently asked questions about BNL's drinking water quality, go to www.bnl.gov/bnlweb/pubaf/water/waterFAQ.pdf 
Table 3-5. Potable Water Wells and Potable Distribution System: Bacteriological, Inorganic Chemical, and Radiological Analytical Results (Maximum Concentration, Minimum pH Value).

\begin{tabular}{|c|c|c|c|c|c|c|c|c|}
\hline Compound & $\begin{array}{c}\text { Well } \\
\text { No. } 4\end{array}$ & $\begin{array}{l}\text { Well } \\
\text { No. } 6\end{array}$ & $\begin{array}{l}\text { Well } \\
\text { No. } 7\end{array}$ & $\begin{array}{c}\text { Well } \\
\text { No. } 10\end{array}$ & $\begin{array}{c}\text { Well } \\
\text { No. } 11\end{array}$ & $\begin{array}{c}\text { Well } \\
\text { No. } 12\end{array}$ & $\begin{array}{c}\text { Potable } \\
\text { Distribution } \\
\text { Sample }\end{array}$ & $\begin{array}{l}\text { NYS } \\
\text { DWS }\end{array}$ \\
\hline \multicolumn{9}{|l|}{ Water Quality Indicators } \\
\hline Total Coliform & ND & ND & ND & ND & ND & ND & ND & Negative \\
\hline Color (Units) & NA & $40^{*}$ & $30 *$ & $<5$ & $<5$ & $<5$ & $<5$ & 15 \\
\hline Odor (Units) & 0 & 0 & 0 & 0 & 0 & 0 & 0 & 3 \\
\hline Cyanide ( $\mu \mathrm{g} / \mathrm{L})$ & $<10$ & $<10$ & $<10$ & $<10$ & $<10$ & $<10$ & $<10$ & NS \\
\hline Conductivity ( $\mu \mathrm{mhos} / \mathrm{cm})$ & 120 & 125 & 135 & 168 & 255 & 262 & 285 & SNS \\
\hline Chlorides (mg/L) & NA & 14.4 & 22.2 & 19.7 & 27.3 & 14.5 & 26.0 & 250 \\
\hline Sulfates (mg/L) & NA & 8.0 & 8.0 & 8.1 & 8.5 & 8.2 & 7.8 & 250 \\
\hline Nitrates (mg/L) & NA & 0.31 & 0.21 & 0.33 & 0.38 & 0.40 & 0.25 & 10 \\
\hline Nitrites (mg/L) & $<0.10$ & $<0.10$ & $<0.10$ & $<0.10$ & $<0.10$ & $<0.10$ & $<0.10$ & 1.0 \\
\hline Ammonia (mg/L) & $<0.10$ & $<0.10$ & $<0.10$ & $<0.10$ & $<0.10$ & $<0.10$ & $<0.10$ & SNS \\
\hline pH (Standard Units) & 6.1 & 6.1 & 5.9 & 6.1 & 6.0 & 6.0 & 6.3 & SNS \\
\hline MBAS (mg/L) & NA & $<0.08$ & $<0.08$ & $<0.08$ & $<0.08$ & $<0.08$ & $<0.08$ & SNS \\
\hline \multicolumn{9}{|l|}{ Metals } \\
\hline Antimony ( $\mu \mathrm{g} / \mathrm{L})$ & NA & $<5.9$ & $<5.9$ & $<5.9$ & $<5.9$ & $<5.9$ & $<5.9$ & 6.0 \\
\hline Arsenic $(\mu \mathrm{g} / \mathrm{L})$ & NA & $<3.0$ & $<3.0$ & $<3.0$ & $<3.0$ & $<3.0$ & $<3.0$ & 50 \\
\hline Barium (mg/L) & $N A$ & $<0.2$ & $<0.2$ & $<0.2$ & $<0.2$ & $<0.2$ & $<0.2$ & 2.0 \\
\hline Beryllium ( $\mu \mathrm{g} / \mathrm{L})$ & NA & $<3.0$ & $<3.0$ & $<3.0$ & $<3.0$ & $<3.0$ & $<3.0$ & 4.0 \\
\hline Cadmium ( $\mu \mathrm{g} / \mathrm{L})$ & $N A$ & $<5.0$ & $<5.0$ & $<5.0$ & $<5.0$ & $<5.0$ & $<5.0$ & 5.0 \\
\hline Chromium (mg/L) & NA & $<0.01$ & $<0.01$ & $<0.01$ & $<0.01$ & $<0.01$ & $<0.01$ & 0.1 \\
\hline Fluoride (mg/L) & NA & $<0.10$ & $<0.10$ & $<0.10$ & $<0.10$ & $<0.10$ & $<0.10$ & 2.2 \\
\hline Iron (mg/L) & NA & $4.00^{*}$ & $1.62^{*}$ & 0.04 & 0.04 & $<0.02$ & 0.17 & 0.3 \\
\hline Lead ( $\mu \mathrm{g} / \mathrm{L})$ & NA & $<1.0$ & 1.1 & $<1.0$ & $<1.0$ & $<1.0$ & 6.2 & 15 \\
\hline Manganese (mg/L) & NA & 0.07 & 0.05 & $<0.01$ & $<0.01$ & $<0.01$ & 0.12 & 0.3 \\
\hline Mercury ( $\mu \mathrm{g} / \mathrm{L})$ & NA & $<0.2$ & $<0.2$ & $<0.2$ & $<0.2$ & $<0.2$ & $<0.2$ & 2.0 \\
\hline Nickel (mg/L) & $N A$ & $<0.04$ & $<0.04$ & $<0.04$ & $<0.04$ & $<0.04$ & $<0.04$ & 0.1 \\
\hline Selenium ( $\mu \mathrm{g} / \mathrm{L})$ & NA & $<5.0$ & $<5.0$ & $<5.0$ & $<5.0$ & $<5.0$ & $<5.0$ & 50.0 \\
\hline Sodium (mg/L) & NA & 8.9 & 11.6 & 15.6 & 14.0 & 10.8 & 14.0 & SNS \\
\hline Silver ( $\mu \mathrm{g} / \mathrm{L})$ & NA & $<0.01$ & $<0.01$ & $<0.01$ & $<0.01$ & $<0.01$ & $<0.01$ & 100 \\
\hline Thallium ( $\mu \mathrm{g} / \mathrm{L})$ & NA & $<1.9$ & $<1.9$ & $<1.9$ & $<1.9$ & $<1.9$ & $<1.9$ & 2.0 \\
\hline Zinc (mg/L) & NA & $<0.02$ & $<0.02$ & 0.04 & $<0.02$ & $<0.02$ & 0.04 & 5.0 \\
\hline \multicolumn{9}{|l|}{ Radioactivity } \\
\hline Gross Alpha Activity (pCi/L) & $<0.76$ & 1.67 & 1.38 & NA & $<0.83$ & 2.49 & NR & 15.0 \\
\hline Gross BetaActivity (pCi/L) & $<2.15$ & 2.98 & $<2.37$ & NA & $<2.37$ & 3.12 & NR & 50.0 \\
\hline Tritium (pCi/L) & $<315$ & $<315$ & $<315$ & NA & $<315$ & $<315$ & NR & 20,000 \\
\hline Strontium-90 (pCi/L) & $<0.37$ & $<0.37$ & $<0.50$ & NA & 0.7 & $<0.42$ & NR & 8.0 \\
\hline \multicolumn{9}{|l|}{ Other } \\
\hline Asbestos (M. Fibers/L) & NR & NR & $N R$ & NR & NR & NR & $<0.25$ & 7 \\
\hline Calcium (mg/L) & NR & NR & NR & NR & NR & NR & 11.0 & SNS \\
\hline Alkalinity (mg/L) & NR & NR & $N R$ & NR & NR & NR & 39.0 & SNS \\
\hline \multicolumn{9}{|c|}{$\begin{array}{l}\text { Notes: } \\
\text { See Chapter 7, Figure 7-5 for well locations. } \\
\text { MBAS = Methylene Blue Active Substances } \\
\text { NA = NotAnalyzed due to well shutdown } \\
\text { ND = NotDetected } \\
\text { NR = Analysis Not Required } \\
\text { SNS = Drinking Water Standard Not Specified } \\
\text { NYS DWS = New York State Drinking Water Standard } \\
\text { WTP = Water TreatmentPlant }\end{array}$} \\
\hline
\end{tabular}


Table 3-6. Potable Water Wells: Analytical Results for Principal Organic Compounds, Synthetic Organic Chemicals, Pesticides, and Micro-Extractables.

\begin{tabular}{|c|c|c|c|c|c|c|c|c|}
\hline Compound & $\begin{array}{c}\text { WTP } \\
\text { Effluent }\end{array}$ & $\begin{array}{l}\text { Well } \\
\text { No. } 4\end{array}$ & $\begin{array}{l}\text { Well } \\
\text { No. } 6\end{array}$ & $\begin{array}{l}\text { Well } \\
\text { No. } 7\end{array}$ & $\begin{array}{l}\text { Well } \\
\text { No. } 10\end{array}$ & $\begin{array}{l}\text { Well } \\
\text { No. } 11\end{array}$ & $\begin{array}{l}\text { Well } \\
\text { No. } 12\end{array}$ & $\begin{array}{l}\text { NYS } \\
\text { DWS }\end{array}$ \\
\hline Dichlorodifluoromethane & $<M D L$ & $<M D L$ & $<M D L$ & $<M D L$ & $<M D L$ & $<M D L$ & $<M D L$ & 5 \\
\hline Chloromethane & $<\mathrm{MDL}$ & $<M D L$ & $<\mathrm{MDL}$ & $<\mathrm{MDL}$ & $<\mathrm{MDL}$ & $<\mathrm{MDL}$ & $<M D L$ & 5 \\
\hline Vinyl Chloride & $<\mathrm{MDL}$ & $<M D L$ & $<\mathrm{MDL}$ & $<M D L$ & $<\mathrm{MDL}$ & $<M D L$ & $<M D L$ & 2 \\
\hline Bromomethane & $<M D L$ & $<M D L$ & $<M D L$ & $<M D L$ & $<M D L$ & $<M D L$ & $<M D L$ & 5 \\
\hline Chloroethane & $<\mathrm{MDL}$ & $<M D L$ & $<\mathrm{MDL}$ & $<\mathrm{MDL}$ & $<\mathrm{MDL}$ & $<\mathrm{MDL}$ & $<M D L$ & 5 \\
\hline Fluorotrichloromethane & $<\mathrm{MDL}$ & $<M D L$ & $<\mathrm{MDL}$ & $<\mathrm{MDL}$ & $<\mathrm{MDL}$ & $<M D L$ & $<M D L$ & 5 \\
\hline 1,1-dichloroethene & $<\mathrm{MDL}$ & $<M D L$ & $<M D L$ & $<M D L$ & $<M D L$ & $<M D L$ & $<M D L$ & 5 \\
\hline Methylene Chloride & $<\mathrm{MDL}$ & $<M D L$ & $<\mathrm{MDL}$ & $<\mathrm{MDL}$ & $<\mathrm{MDL}$ & $<\mathrm{MDL}$ & $<M D L$ & 5 \\
\hline trans-1,2-dichloroethene & $<\mathrm{MDL}$ & $<M D L$ & $<\mathrm{MDL}$ & $<\mathrm{MDL}$ & $<\mathrm{MDL}$ & $<M D L$ & $<M D L$ & 5 \\
\hline 1,1-dichloroethane & $<\mathrm{MDL}$ & $<M D L$ & $<M D L$ & $<M D L$ & $<\mathrm{MDL}$ & $<\mathrm{MDL}$ & $<M D L$ & 5 \\
\hline cis-1,2-dichloroethene & $<\mathrm{MDL}$ & $<\mathrm{MDL}$ & $<\mathrm{MDL}$ & $<\mathrm{MDL}$ & $<\mathrm{MDL}$ & $<\mathrm{MDL}$ & $<M D L$ & 5 \\
\hline 2,2-dichloropropane & $<\mathrm{MDL}$ & $<M D L$ & $<\mathrm{MDL}$ & $<\mathrm{MDL}$ & $<\mathrm{MDL}$ & $<\mathrm{MDL}$ & $<M D L$ & 5 \\
\hline Bromochloromethane & $<\mathrm{MDL}$ & $<M D L$ & $<\mathrm{MDL}$ & $<\mathrm{MDL}$ & $<\mathrm{MDL}$ & $<M D L$ & $<M D L$ & 5 \\
\hline 1,1,1-trichloroethane & $<M D L$ & $<M D L$ & $<\mathrm{MDL}$ & $<\mathrm{MDL}$ & $<\mathrm{MDL}$ & $<M D L$ & $<M D L$ & 5 \\
\hline Carbon Tetrachloride & $<\mathrm{MDL}$ & $<M D L$ & $<\mathrm{MDL}$ & $<\mathrm{MDL}$ & $<\mathrm{MDL}$ & $<\mathrm{MDL}$ & $<M D L$ & 5 \\
\hline 1,1-dichloropropene & $<\mathrm{MDL}$ & $<M D L$ & $<M D L$ & $<M D L$ & $<M D L$ & $<M D L$ & $<M D L$ & 5 \\
\hline 1,2-dichloroethane & $<\mathrm{MDL}$ & $<M D L$ & $<\mathrm{MDL}$ & $<\mathrm{MDL}$ & $<\mathrm{MDL}$ & $<M D L$ & $<M D L$ & 5 \\
\hline Trichloroethene & $<\mathrm{MDL}$ & $<M D L$ & $<\mathrm{MDL}$ & $<\mathrm{MDL}$ & $<\mathrm{MDL}$ & $<\mathrm{MDL}$ & $<M D L$ & 5 \\
\hline 1,2-dichloropropane & $<\mathrm{MDL}$ & $<M D L$ & $<\mathrm{MDL}$ & $<M D L$ & $<M D L$ & $<\mathrm{MDL}$ & $<M D L$ & 5 \\
\hline Dibromomethane & $<\mathrm{MDL}$ & $<M D L$ & $<\mathrm{MDL}$ & $<M D L$ & $<\mathrm{MDL}$ & $<M D L$ & $<M D L$ & 5 \\
\hline trans-1,3-dichloropropene & $<\mathrm{MDL}$ & $<M D L$ & $<\mathrm{MDL}$ & $<\mathrm{MDL}$ & $<\mathrm{MDL}$ & $<M D L$ & $<M D L$ & 5 \\
\hline cis-1,3-dichloropropene & $<\mathrm{MDL}$ & $<M D L$ & $<\mathrm{MDL}$ & $<M D L$ & $<M D L$ & $<\mathrm{MDL}$ & $<M D L$ & 5 \\
\hline 1,1,2-trichloroethane & $<\mathrm{MDL}$ & $<M D L$ & $<\mathrm{MDL}$ & $<\mathrm{MDL}$ & $<\mathrm{MDL}$ & $<M D L$ & $<M D L$ & 5 \\
\hline Trihalomethanes & 3.7 & 2.4 & $<\mathrm{MDL}$ & 1.5 & $<\mathrm{MDL}$ & 0.6 & 0.7 & 100 \\
\hline 1,3-dichloropropane & $<\mathrm{MDL}$ & $<M D L$ & $<M D L$ & $<M D L$ & $<M D L$ & $<M D L$ & $<M D L$ & 5 \\
\hline Chlorobenzene & $<\mathrm{MDL}$ & $<M D L$ & $<\mathrm{MDL}$ & $<\mathrm{MDL}$ & $<\mathrm{MDL}$ & $<M D L$ & $<M D L$ & 5 \\
\hline 1,1,1,2-tetrachloroethane & $<\mathrm{MDL}$ & $<M D L$ & $<\mathrm{MDL}$ & $<\mathrm{MDL}$ & $<\mathrm{MDL}$ & $<\mathrm{MDL}$ & $<M D L$ & 5 \\
\hline Bromobenzene & $<M D L$ & $<M D L$ & $<\mathrm{MDL}$ & $<\mathrm{MDL}$ & $<M D L$ & $<M D L$ & $<M D L$ & 5 \\
\hline 1,2,3-trichloropropane & $<\mathrm{MDL}$ & $<M D L$ & $<\mathrm{MDL}$ & $<\mathrm{MDL}$ & $<\mathrm{MDL}$ & $<\mathrm{MDL}$ & $<M D L$ & 5 \\
\hline 2-chlorotoluene & $<\mathrm{MDL}$ & $<M D L$ & $<\mathrm{MDL}$ & $<\mathrm{MDL}$ & $<M D L$ & $<M D L$ & $<M D L$ & 5 \\
\hline 4-chlorotoluene & $<M D L$ & $<M D L$ & $<\mathrm{MDL}$ & $<\mathrm{MDL}$ & $<M D L$ & $<M D L$ & $<M D L$ & 5 \\
\hline 1,3-dichlorobenzene & $<\mathrm{MDL}$ & $<M D L$ & $<\mathrm{MDL}$ & $<\mathrm{MDL}$ & $<\mathrm{MDL}$ & $<M D L$ & $<M D L$ & 5 \\
\hline 1,4-dichlorobenzene & $<\mathrm{MDL}$ & $<M D L$ & $<\mathrm{MDL}$ & $<\mathrm{MDL}$ & $<\mathrm{MDL}$ & $<M D L$ & $<M D L$ & 5 \\
\hline 1,2-dichlorobenzene & $<M D L$ & $<M D L$ & $<M D L$ & $<\mathrm{MDL}$ & $<\mathrm{MDL}$ & $<M D L$ & $<M D L$ & 5 \\
\hline 1,2,4-trichlorobenzene & $<\mathrm{MDL}$ & $<M D L$ & $<M D L$ & $<\mathrm{MDL}$ & $<M D L$ & $<M D L$ & $<M D L$ & 5 \\
\hline Hexachlorobutadiene & $<\mathrm{MDL}$ & $<M D L$ & $<\mathrm{MDL}$ & $<\mathrm{MDL}$ & $<\mathrm{MDL}$ & $<\mathrm{MDL}$ & $<M D L$ & 5 \\
\hline 1,2,3-trichlorobenzene & $<\mathrm{MDL}$ & $<M D L$ & $<M D L$ & $<\mathrm{MDL}$ & $<M D L$ & $<M D L$ & $<M D L$ & 5 \\
\hline Benzene & $<\mathrm{MDL}$ & $<M D L$ & $<\mathrm{MDL}$ & $<\mathrm{MDL}$ & $<\mathrm{MDL}$ & $<M D L$ & $<M D L$ & 5 \\
\hline Toluene & $<\mathrm{MDL}$ & $<M D L$ & $<\mathrm{MDL}$ & $<\mathrm{MDL}$ & $<\mathrm{MDL}$ & $<\mathrm{MDL}$ & $<M D L$ & 5 \\
\hline Ethylbenzene & $<\mathrm{MDL}$ & $<M D L$ & $<\mathrm{MDL}$ & $<\mathrm{MDL}$ & $<\mathrm{MDL}$ & $<\mathrm{MDL}$ & $<M D L$ & 5 \\
\hline
\end{tabular}

(continued on next page) 
Table 3-6. Potable Water Wells: Analytical Results for Principal Organic Compounds, Synthetic Organic Chemicals, Pesticides, and Micro-Extractables (continued).

\begin{tabular}{|c|c|c|c|c|c|c|c|c|}
\hline Compound & $\begin{array}{c}\text { WTP } \\
\text { Effluent }\end{array}$ & $\begin{array}{l}\text { Well } \\
\text { No. } 4\end{array}$ & $\begin{array}{l}\text { Well } \\
\text { No. } 6\end{array}$ & $\begin{array}{l}\text { Well } \\
\text { No. } 7\end{array}$ & $\begin{array}{c}\text { Well } \\
\text { No. } 10\end{array}$ & $\begin{array}{l}\text { Well } \\
\text { No. } 11\end{array}$ & $\begin{array}{c}\text { Well } \\
\text { No. } 12\end{array}$ & $\begin{array}{l}\text { NYS } \\
\text { DWS }\end{array}$ \\
\hline Tetrachloroethene & $<M D L$ & $<M D L$ & $<M D L$ & $<\mathrm{MDL}$ & $<\mathrm{MDL}$ & $<\mathrm{MDL}$ & $<M D L$ & $<M D L$ \\
\hline m-xylene & $<M D L$ & $<M D L$ & $<M D L$ & $<M D L$ & $<M D L$ & $<M D L$ & $<\mathrm{MDL}$ & 5 \\
\hline p-xylene & $<M D L$ & $<M D L$ & $<M D L$ & $<M D L$ & $<M D L$ & $<M D L$ & $<M D L$ & 5 \\
\hline o-xylene & $<M D L$ & $<M D L$ & $<M D L$ & $<\mathrm{MDL}$ & $<\mathrm{MDL}$ & $<M D L$ & $<M D L$ & 5 \\
\hline Styrene & $<M D L$ & $<M D L$ & $<M D L$ & $<\mathrm{MDL}$ & $<\mathrm{MDL}$ & $<M D L$ & $<M D L$ & 5 \\
\hline Isopropylbenezene & $<M D L$ & $<M D L$ & $<M D L$ & $<M D L$ & $<M D L$ & $<M D L$ & $<\mathrm{MDL}$ & 5 \\
\hline n-propylbenzene & $<M D L$ & $<M D L$ & $<M D L$ & $<M D L$ & $<M D L$ & $<M D L$ & $<\mathrm{MDL}$ & 5 \\
\hline 1,3,5-trimethylbenzene & $<M D L$ & $<M D L$ & $<M D L$ & $<M D L$ & $<M D L$ & $<M D L$ & $<M D L$ & 5 \\
\hline tert-butylbenzene & $<M D L$ & $<M D L$ & $<M D L$ & $<M D L$ & $<M D L$ & $<M D L$ & $<\mathrm{MDL}$ & 5 \\
\hline 1,2,4-trimethylbenzene & $<M D L$ & $<M D L$ & $<M D L$ & $<M D L$ & $<M D L$ & $<M D L$ & $<M D L$ & 5 \\
\hline sec-butylbenzene & $<M D L$ & $<M D L$ & $<M D L$ & $<M D L$ & $<M D L$ & $<M D L$ & $<\mathrm{MDL}$ & 5 \\
\hline p-isopropyltoluene & $<M D L$ & $<M D L$ & $<M D L$ & $<M D L$ & $<M D L$ & $<M D L$ & $<M D L$ & 5 \\
\hline n-butylbenzene & $<M D L$ & $<M D L$ & $<M D L$ & $<M D L$ & $<M D L$ & $<M D L$ & $<\mathrm{MDL}$ & 5 \\
\hline methyl tert. Butylether & $<M D L$ & $<M D L$ & $<M D L$ & $<M D L$ & $<M D L$ & $<M D L$ & $<M D L$ & 50 \\
\hline Lindane & $<M D L$ & $<M D L$ & $<M D L$ & $<M D L$ & $<M D L$ & $<M D L$ & $<\mathrm{MDL}$ & 0.2 \\
\hline Heptaclor & $<\mathrm{MDL}$ & $<\mathrm{MDL}$ & $<M D L$ & $<\mathrm{MDL}$ & $<\mathrm{MDL}$ & $<M D L$ & $<\mathrm{MDL}$ & 0.4 \\
\hline Aldrin & $<M D L$ & $<\mathrm{MDL}$ & $<M D L$ & $<\mathrm{MDL}$ & $<\mathrm{MDL}$ & $<M D L$ & $<M D L$ & 5 \\
\hline Heptachlor Epoxide & $<\mathrm{MDL}$ & $<\mathrm{MDL}$ & $<\mathrm{MDL}$ & $<\mathrm{MDL}$ & $<\mathrm{MDL}$ & $<M D L$ & $<M D L$ & 0.2 \\
\hline Dieldrin & $<\mathrm{MDL}$ & $<\mathrm{MDL}$ & $<\mathrm{MDL}$ & $<\mathrm{MDL}$ & $<\mathrm{MDL}$ & $<M D L$ & $<M D L$ & 5 \\
\hline Endrin & $<M D L$ & $<\mathrm{MDL}$ & $<\mathrm{MDL}$ & $<\mathrm{MDL}$ & $<\mathrm{MDL}$ & $<M D L$ & $<\mathrm{MDL}$ & 0.2 \\
\hline Methoxychlor & $<\mathrm{MDL}$ & $<\mathrm{MDL}$ & $<\mathrm{MDL}$ & $<\mathrm{MDL}$ & $<\mathrm{MDL}$ & $<\mathrm{MDL}$ & $<\mathrm{MDL}$ & 40 \\
\hline Toxaphene & $<\mathrm{MDL}$ & $<\mathrm{MDL}$ & $<M D L$ & $<\mathrm{MDL}$ & $<\mathrm{MDL}$ & $<M D L$ & $<\mathrm{MDL}$ & 3 \\
\hline Chlordane & $<\mathrm{MDL}$ & $<\mathrm{MDL}$ & $<M D L$ & $<\mathrm{MDL}$ & $<\mathrm{MDL}$ & $<M D L$ & $<\mathrm{MDL}$ & 2 \\
\hline Total PCB's & $<\mathrm{MDL}$ & $<\mathrm{MDL}$ & $<\mathrm{MDL}$ & $<\mathrm{MDL}$ & $<\mathrm{MDL}$ & $<M D L$ & $<\mathrm{MDL}$ & 0.5 \\
\hline 2,4,5,-TP (Silvex) & $<\mathrm{MDL}$ & $<M D L$ & $<\mathrm{MDL}$ & $<\mathrm{MDL}$ & $<\mathrm{MDL}$ & $<M D L$ & $<\mathrm{MDL}$ & 10 \\
\hline Dinoseb & $<\mathrm{MDL}$ & $<\mathrm{MDL}$ & $<M D L$ & $<\mathrm{MDL}$ & $<\mathrm{MDL}$ & $<M D L$ & $<\mathrm{MDL}$ & 50 \\
\hline Dalapon & $<\mathrm{MDL}$ & $<\mathrm{MDL}$ & $<M D L$ & $<\mathrm{MDL}$ & $<M D L$ & $<M D L$ & $<\mathrm{MDL}$ & 50 \\
\hline Pichloram & $<\mathrm{MDL}$ & $<\mathrm{MDL}$ & $<M D L$ & $<\mathrm{MDL}$ & $<\mathrm{MDL}$ & $<M D L$ & $<\mathrm{MDL}$ & 50 \\
\hline Dicamba & $<\mathrm{MDL}$ & $<\mathrm{MDL}$ & $<\mathrm{MDL}$ & $<\mathrm{MDL}$ & $<\mathrm{MDL}$ & $<M D L$ & $<\mathrm{MDL}$ & 50 \\
\hline Pentachlorophenol & $<\mathrm{MDL}$ & $<\mathrm{MDL}$ & $<M D L$ & $<\mathrm{MDL}$ & $<\mathrm{MDL}$ & $<M D L$ & $<\mathrm{MDL}$ & 1 \\
\hline Hexachlorcyclopentadiene & $<M D L$ & $<M D L$ & $<M D L$ & $<M D L$ & $<M D L$ & $<M D L$ & $<M D L$ & 5 \\
\hline Di(2-ethylhexyl)Phthalate & $<\mathrm{MDL}$ & $<M D L$ & $<M D L$ & $<\mathrm{MDL}$ & $<M D L$ & $<M D L$ & $<\mathrm{MDL}$ & 50 \\
\hline Di(2-ethylhexyl)Adipate & $<M D L$ & $<M D L$ & $<M D L$ & $<M D L$ & $<M D L$ & $<M D L$ & $<\mathrm{MDL}$ & 50 \\
\hline Hexachlorobenzene & $<\mathrm{MDL}$ & $<\mathrm{MDL}$ & $<\mathrm{MDL}$ & $<\mathrm{MDL}$ & $<\mathrm{MDL}$ & $<M D L$ & $<\mathrm{MDL}$ & 5 \\
\hline Benzo(A)Pyrene & $<M D L$ & $<M D L$ & $<M D L$ & $<M D L$ & $<M D L$ & $<M D L$ & $<M D L$ & 50 \\
\hline Aldicarb Sulfone & $<M D L$ & $<M D L$ & $<M D L$ & $<\mathrm{MDL}$ & $<\mathrm{MDL}$ & $<M D L$ & $<M D L$ & SNS \\
\hline Aldicarb Sulfoxide & $<M D L$ & $<M D L$ & $<M D L$ & $<M D L$ & $<M D L$ & $<M D L$ & $<M D L$ & SNS \\
\hline Aldicarb & $<M D L$ & $<M D L$ & $<M D L$ & $<M D L$ & $<M D L$ & $<M D L$ & $<\mathrm{MDL}$ & SNS \\
\hline Oxamyl & $<M D L$ & $<M D L$ & $<M D L$ & $<M D L$ & $<M D L$ & $<M D L$ & $<\mathrm{MDL}$ & 50 \\
\hline
\end{tabular}


Table 3-6. Potable Water Wells: Analytical Results for Principal Organic Compounds, Synthetic Organic Chemicals, Pesticides, and Micro-Extractables (concluded).

\begin{tabular}{|c|c|c|c|c|c|c|c|c|}
\hline Compound & $\begin{array}{c}\text { WTP } \\
\text { Effluent }\end{array}$ & $\begin{array}{c}\text { Well } \\
\text { No. } 4\end{array}$ & $\begin{array}{c}\text { Well } \\
\text { No. } 6\end{array}$ & $\begin{array}{c}\text { Well } \\
\text { No. } 7 \\
\mu \mathrm{g} / \mathrm{L}\end{array}$ & $\begin{array}{c}\text { Well } \\
\text { No. } 10\end{array}$ & $\begin{array}{c}\text { Well } \\
\text { No. } 11\end{array}$ & $\begin{array}{c}\text { Well } \\
\text { No. } 12\end{array}$ & $\begin{array}{l}\text { NYS } \\
\text { DWS }\end{array}$ \\
\hline 3-Hydroxycarbofuran & $<M D L$ & $<\mathrm{MDL}$ & $<M D L$ & $<M D L$ & $<M D L$ & $<M D L$ & $<\mathrm{MDL}$ & 50 \\
\hline Carbofuran & $<M D L$ & $<M D L$ & $<M D L$ & $<M D L$ & $<M D L$ & $<M D L$ & $<\mathrm{MDL}$ & 40 \\
\hline Carbaryl & $<M D L$ & $<\mathrm{MDL}$ & $<M D L$ & $<M D L$ & $<M D L$ & $<\mathrm{MDL}$ & $<\mathrm{MDL}$ & 50 \\
\hline Methonmyl & $<M D L$ & $<\mathrm{MDL}$ & $<M D L$ & $<M D L$ & $<M D L$ & $<M D L$ & $<M D L$ & SNS \\
\hline Glyphosate & $<\mathrm{MDL}$ & $<\mathrm{MDL}$ & $<M D L$ & $<M D L$ & $<M D L$ & $<\mathrm{MDL}$ & $<\mathrm{MDL}$ & 50 \\
\hline Diquat & $<M D L$ & $<M D L$ & $<M D L$ & $<M D L$ & $<M D L$ & $<M D L$ & $<\mathrm{MDL}$ & 50 \\
\hline Ethylene Dibromide & $<M D L$ & $<M D L$ & $<M D L$ & $<M D L$ & $<M D L$ & $<M D L$ & $<M D L$ & 0.05 \\
\hline 1,2-dibromo-3-chloropropane & e $<M D L$ & $<M D L$ & $<M D L$ & $<M D L$ & $<M D L$ & $<M D L$ & $<M D L$ & 0.2 \\
\hline $2,4,-D$ & $<M D L$ & $<\mathrm{MDL}$ & $<M D L$ & $<M D L$ & $<M D L$ & $<M D L$ & $<M D L$ & 50 \\
\hline Perchlorate & $<M D L$ & $<M D L$ & $<M D L$ & $<M D L$ & $<M D L$ & $<\mathrm{MDL}$ & $<\mathrm{MDL}$ & SNS \\
\hline Alachor & $<M D L$ & $<M D L$ & $<M D L$ & $<M D L$ & $<M D L$ & $<M D L$ & $<M D L$ & 2 \\
\hline Simazine & $<M D L$ & $<M D L$ & $<M D L$ & $<M D L$ & $<M D L$ & $<\mathrm{MDL}$ & $<\mathrm{MDL}$ & 50 \\
\hline Atrazine & $<M D L$ & $<M D L$ & $<M D L$ & $<M D L$ & $<M D L$ & $<\mathrm{MDL}$ & $<M D L$ & 3 \\
\hline Metolachor & $<M D L$ & $<M D L$ & $<M D L$ & $<M D L$ & $<M D L$ & $<\mathrm{MDL}$ & $<M D L$ & 50 \\
\hline Metribuzin & $<M D L$ & $<M D L$ & $<M D L$ & $<M D L$ & $<M D L$ & $<M D L$ & $<\mathrm{MDL}$ & 50 \\
\hline Butachlor & $<M D L$ & $<M D L$ & $<M D L$ & $<M D L$ & $<M D L$ & $<M D L$ & $<M D L$ & 50 \\
\hline Propachlor & $<M D L$ & $<\mathrm{MDL}$ & $<M D L$ & $<M D L$ & $<M D L$ & $<\mathrm{MDL}$ & $<\mathrm{MDL}$ & 50 \\
\hline
\end{tabular}

Notes:

See Chapter 7, Figure 7-5 for well locations

For compliance determination with New York State Department of Health standards, potable water samples were analyzed quarterly during the year by H2M Labs Inc., a New York State-certified contractor laboratory.

The minimum detection limits for principal organic compound analytes are $0.5 \mu \mathrm{g} / \mathrm{L}$. Minimum detection limits for synthetic organic chemicals and micro-extractables are compound-specific, and in all cases are less than the New York State Department of Health drinking water standards.

$<\mathrm{MDL}=$ Less than the minimum detection limit for the analyte in question

SNS = Drinking Water Standard not specified

NYS DWS = New York State Drinking Water Standard

WTP = Water TreatmentPlant

pools, all of which are classified by EPA as Class $\mathrm{V}$ injection wells. Proper management of UIC devices is vital for protecting underground sources of drinking water. In New York State, the UIC program is implemented through EPA, since NYSDEC did not adopt UIC regulatory requirements (New York regulates discharges of pollutants to cesspools under the SPDES program). Under the EPA's UIC program, all Class $\mathrm{V}$ injection wells must be included in an inventory maintained with the agency.

During 2001, BNL continued the process of closing numerous UICs. These included devices located at Buildings 703 (one device), 901 (one device), 907 (two devices), 908 (two devices), 1005 (three devices), 1006 (two devices), and 1007 (two devices). Additionally, due to the presence of contaminants above Suffolk County Department of Health Services Action Levels, devices located at Buildings 1002, 1010, and 1012 were closed in 2001 by the removal of the septic tanks. Due to the unavailability of storm water management systems, applications were filed to install new UICs at several locations, including Buildings 120 and 908. The UIC inventory on file with EPA will be updated as these devices are installed.

\subsection{SPILL PREVENTION, EMERGENCY PLANNING, AND REPORTING}

Several federal, state, and local regulations address the management of storage facilities containing chemicals, petroleum, and other hazardous materials. These regulations include 
specifications for storage facilities, and requirements for release planning documentation and release reporting. The following subsections describe BNL's compliance with these regulations.

\subsubsection{Preventing Oil Pollution and Spills}

BNL must maintain a Spill Prevention Control and Countermeasures (SPCC) Plan as a condition of its Major Petroleum Facility License and as required by the Oil Pollution Act. This plan is part of BNL's emergency preparedness program and outlines mitigating and remedial actions that would be taken in the event of a major petroleum release. The plan also provides information regarding release prevention measures, the design of storage facilities, and maps detailing their locations. The SPCC Plan is filed with NYSDEC, EPA, and DOE. The plan is updated triennially and was last updated in December 2000 (Chaloupka 2000). BNL remained in full compliance with the SPCC requirements in 2001.

BNL also maintains a facility response plan that outlines emergency response procedures to be implemented in the event of a worst-case discharge of oil. EPA reviewed this plan in 2000 and identified several technical deficiencies and formatting issues. Response to the deficiencies was handled in two phases. Phase I addressed simple changes to the plan, which included revising outdated information and providing cross-references to address the formatting issues. Phase II was a complete plan update that was submitted to EPA in December as part of the SPCC Plan.

\subsubsection{Local and State Reporting Requirements}

The Emergency Planning and Community Right-to-Know Act (EPCRA) (42 USC 11001,

\begin{tabular}{|c|c|c|}
\hline \multicolumn{3}{|c|}{ Applicability of EPCRA to BNL } \\
\hline 302-303: & $\begin{array}{l}\text { Planning } \\
\text { Notification }\end{array}$ & Yes[X] No[ ] Not Required [ ] \\
\hline 304: & $\begin{array}{l}\text { EHS Release } \\
\text { Notification }\end{array}$ & Yes[X] No[ ] Not Required [ ] \\
\hline 311-312: & $\begin{array}{l}\text { MSDS/Chemical } \\
\text { Inventory }\end{array}$ & Yes[X] No[ ] Not Required [ \\
\hline 313: & TRI Reporting & Yes[X] No[ ] Not Required [ ] \\
\hline
\end{tabular}

et seq.) and Title III of the Superfund Amendments and Reauthorization Act (SARA) require that facilities report inventories and releases of certain chemicals that exceed specific storage thresholds to the local emergency planning committee and the state emergency response commission. Community Right to Know requirements are codified under 40 CFR Parts 355,370 , and 372 . BNL fully complied with these requirements in 2001 through the submittal of the required reports under EPCRA Sections 302, 303, 311, and 312. During 2000, the Part 313 Toxic Release Inventory thresholds were significantly lowered from 10,000 pounds to just 10 pounds for mercury and polychlorinated biphenyls (PCBs). Consequently, in 2001, BNL was required to submit reports for these two classes of chemicals. In total, 21 pounds of mercury and 917 pounds of PCBs were reported in the Form R Toxic Release Inventory Report, which was submitted on June 29, 2001. For 2001, the Section 313 reporting threshold for lead was similarly reduced from 10,000 pounds to 1 pound. Reporting for 2002 will therefore include mercury, PCBs, and lead.

There were no releases of extremely hazardous substances reported under Part 304 during 2001 .

\subsubsection{Spills and Releases}

When a spill of hazardous material occurs, BNL personnel are required to immediately notify the on-site Fire Rescue Group, who are trained to respond to such releases. The initial step in spill response is to contain and control any release and to notify additional response personnel (i.e., BNL environmental professionals, industrial hygienists, etc.). Environmental professionals reporting to the scene assess the spill for environmental impact and determine its reportability. Any release of petroleum products to soils or surface water is reportable to EPA, NYSDEC, and SCDHS. In addition, releases of petroleum products greater than five gallons to outdoor impermeable surfaces or containment areas are reported to the SCDHS. Spills of chemicals in quantities greater than CERCLA-reportable quantities are reportable to the National Response Center, NYSDEC, and SCDHS. Remediation of the spill is conducted as 
necessary to restore the site. For example, if a piece of heavy equipment were to rupture a hydraulic line and release hydraulic oil to the soil, immediate actions would be taken to stop the leak. The contaminated soil would then be excavated and containerized for off-site disposal.

During 2001, there were 51 spills, of which only 13 met external agency reporting criteria. The remaining releases were either small-volume releases to containment areas or other impermeable surfaces, or were gaseous releases that did not exceed a reportable quantity. Nine of the 13 reported releases involved very small volumes ( $<10$ gallons) of petroleum or ethylene glycol that reached soils. New York State has a "zero tolerance" level for releases of oils to soil or

Table 3-7. Summary of Chemical and Oil Spill Reports.

\begin{tabular}{|c|c|c|c|c|c|}
\hline $\begin{array}{l}\text { BNL Spill } \\
\text { Number }\end{array}$ & Date & Material & Quantity & ORPS Report* & Source/Cause and Corrective Actions \\
\hline $01-03$ & $1 / 29 / 01$ & $\begin{array}{l}\text { Oil and } \\
\text { antifreeze }\end{array}$ & 2 quarts & No & $\begin{array}{l}\text { A BNL employee discovered an oily substance on the snow and frozen } \\
\text { ground behind Bldg } 50 \text {. BNL employees applied absorbent and container- } \\
\text { ized the spilled material for proper disposal. }\end{array}$ \\
\hline $01-11$ & $3 / 9 / 01$ & Hydraulic fluid & 35 gallons & $\begin{array}{l}\text { Yes } \\
(\mathrm{CH}-\mathrm{BH}- \\
\mathrm{BNL}-\mathrm{PE}- \\
2001-0001)\end{array}$ & $\begin{array}{l}\text { While the hydraulic-powered cable winch of a BNL electrical line truck was } \\
\text { in use, a hydraulic hose failed, releasing oil to the snow and asphalt; this } \\
\text { was worsened by moderate rain. Spill absorbents were used to recover the } \\
\text { spilled material and was containerized for proper disposal. Additional oil } \\
\text { was recovered as the snow melted. }\end{array}$ \\
\hline $01-14$ & $3 / 21 / 01$ & Antifreeze & $<1$ quart & No & $\begin{array}{l}\text { A Caterpillar metal crusher was being used near Bldg. 445, when the } \\
\text { operator noticed coolant leaking from the equipment. A small patch of } \\
\text { contaminated soil was recovered for proper disposal. }\end{array}$ \\
\hline$\overline{01-16}$ & $4 / 18 / 01$ & $\begin{array}{l}\text { UCON Heat } \\
\text { Exchange } \\
\text { Fluid }\end{array}$ & $\begin{array}{l}115-120 \\
\text { gallons }\end{array}$ & No & $\begin{array}{l}\text { The cryogenics control room of RHIC received an alarm indicating that a } \\
\text { compressor had shut down. A failure of a steel nipple and brass fitting on } \\
\text { the sample tap of a redundant compressor pump resulted in a loss of } \\
\text { approximately } 115-120 \text { gallons of UCON LB-170-X lubricating fluid to the } \\
\text { pumping skid below. The recovered fluid and absorbent materials were } \\
\text { disposed of properly. }\end{array}$ \\
\hline $01-17$ & $5 / 16 / 01$ & Hydraulic fluid & $<1$ quart & No & $\begin{array}{l}\text { While land just west of Bldg. } 477 \text { was being graded, a hydraulic line for the } \\
\text { lift on a John Deere pay loader failed, releasing hydraulic fluid to the } \\
\text { ground. BNL employees applied absorbent and containerized the spilled } \\
\text { material for proper disposal. }\end{array}$ \\
\hline$\overline{01-18}$ & $5 / 22 / 01$ & $\begin{array}{l}\text { Transmission } \\
\text { fluid }\end{array}$ & $\sim 3.5$ gallons & No & $\begin{array}{l}\text { A steel hose on the BNL garbage truck failed, releasing } \sim 3.5 \text { gallons of } \\
\text { transmission fluid onto asphalt and gravel surfaces. Due to steady rain, the } \\
\text { material was dispersed. Absorbents were used to recover the fluid for } \\
\text { proper disposal. The storm drains in the vicinity were diked, and inspection } \\
\text { of the associated recharge basin did not reveal any contamination. }\end{array}$ \\
\hline$\overline{01-21}$ & $6 / 19 / 01$ & Transformer oil & $\begin{array}{l}10-20 \\
\text { gallons }\end{array}$ & No & $\begin{array}{l}\text { A transformer at the Bldg. } 930 \text { transformer yard failed, resulting in the } \\
\text { release of } 10-20 \text { gallons to the containment structure and the surrounding } \\
\text { soil. BNL employees recovered the oil and contaminated soil and } \\
\text { containerized it for proper disposal. }\end{array}$ \\
\hline $01-22$ & $6 / 27 / 01$ & Engine oil & $<1$ quart & No & $\begin{array}{l}\text { During an Exit Readiness Evaluation for Building } 820 \mathrm{~A} \text {, a plastic tub filled } \\
\text { with what appeared to be motor oil was discovered on the south side of the } \\
\text { building. Rain caused the oil to overflow the tub and spill onto the soil and } \\
\text { bluestone driveway. The oil and contaminated soil were containerized for } \\
\text { proper disposal. }\end{array}$ \\
\hline$\overline{01-28}$ & $8 / 8 / 01$ & Hydraulic fluid & $<1$ gallon & No & $\begin{array}{l}\text { During transport, a Grove man-lift released hydraulic fluid to the roadway } \\
\text { and grassy surrounding area. The contaminated grass was removed and } \\
\text { containerized with the spill absorbent for proper disposal. }\end{array}$ \\
\hline$\overline{01-30}$ & $8 / 11 / 01$ & $\begin{array}{l}\text { UCON Heat } \\
\text { Exchange } \\
\text { Fluid }\end{array}$ & $\sim 20$ gallons & No & $\begin{array}{l}\text { A cryogenics group technician inadvertently removed the plate from a } \\
\text { solenoid valve assembly while the system was pressured. This resulted in a } \\
\text { release of approximately } 20 \text { gallons of atomized fluid to the air and } \\
\text { pumping skid below. The lubricant was recovered with absorbent material } \\
\text { and containerized for proper disposal. }\end{array}$ \\
\hline
\end{tabular}


Table 3-7. Summary of Chemical and Oil Spill Reports (concluded).

\begin{tabular}{l|l|l|l|l|l}
\hline $\begin{array}{l}\text { BNL Spill } \\
\text { Number }\end{array}$ & Date & Material & Quantity & ORPS Report* & Source/Cause and Corrective Actions \\
\hline $01-41$ & $10 / 3 / 01$ & Hydraulic fluid & $5-10$ gallons & No & $\begin{array}{l}\text { The operator of the on-site service station alerted BNL employees to a } \\
\text { problem with a lift at the service station. A service technician was called to } \\
\text { inspect the lift and discovered there had been a release of } ~ \\
\text { of hydraulic fluid since the last inspection in July of 2001. The lift was } \\
\text { drained and removed from service. In calendar year 2002, the lift will be } \\
\text { replaced by an aboveground lift, and any impacted soils will be } \\
\text { remediated and properly disposed. }\end{array}$ \\
\hline $01-43$ & $10 / 12 / 01$ & Hydraulic fluid & $\sim 2$ quarts & No & $\begin{array}{l}\text { A hydraulic fitting on a front-end loader broke while loading scrap wood } \\
\text { into a dumpster for off-site disposal. Oil sprayed onto a portion of the wood } \\
\text { and the ground adjacent to the dumpster. The contaminated wood was } \\
\text { removed and containerized with spill absorbent for proper disposal. }\end{array}$ \\
\hline $01-47$ & $11 / 1 / 01$ & Hydraulic fluid & $\sim 1$ gallon & No & $\begin{array}{l}\text { As radiologically contaminated waste was being moved within the railcar } \\
\text { loading area, a leak in the hydraulic system of the front-end loader was } \\
\text { discovered. A pan was subsequently placed beneath the loader to capture } \\
\text { any dripping fluid. Since the spill occurred within a posted radioactive } \\
\text { material controlled area, contaminated soil was treated as mixed waste. } \\
\text { BNL employees excavated the contaminated soil and transferred it to the } \\
\text { railcar for proper disposal. }\end{array}$
\end{tabular}

*ORPS Report: Release is reportable to the U.S. Department of Energy under the requirements of DOE Order 232.1A, Occurrence Reporting and Processing of Operations Information.

water; consequently, spills of any amount to soil are reportable.

Table 3-7 provides information on the reportable spills, including the date of the spill, material involved, and quantity released. It also includes a summary of the cause and corrective actions taken, and notes whether the spill was reportable to DOE through the Occurrence Reporting and Processing System (ORPS).

Five of the nine reported small-volume releases resulted from failed hydraulics on heavy equipment. During 2001, a pollution prevention project was initiated to replace petroleum-based oils with vegetable-based oils in several of the BNL lawn mowers and to replace standard hydraulic hoses with braided stainless steel hoses. There were no reported releases in 2001 from BNL lawn mowers. The program will be expanded in 2002 to include hydraulic lift mechanisms and other heavy equipment, (e.g., the BNL garbage truck). The four remaining smallvolume spills were associated with motor vehicle operations or accidents.

There were four larger spills reported during 2001 that exceeded 10 gallons each. These included two releases of heat transfer fluid to the Building $1005 \mathrm{H}$ containment area beneath the pumps used in the RHIC cryogenic system, a release from a transformer, and a hydraulic oil spill from the BNL electrical line truck.

Twelve other environmental incidents were reported to DOE through ORPS as described below and in Table 3-8:

- Historical cesium-137 contamination was discovered in the soil floor of the basement of Building 704.

- Three incidents were related to the handling of radiologically contaminated materials. The first was a shift in load during the lifting of large sections of concrete ductwork that was being removed from the BGRR. The load fell onto the hydraulic controls of the platform trailer, resulting in a release of hydraulic fluid to the pavement. The second incident occurred while a container of dry radioactive waste was being moved at Building 650 . The container fell from the forklift, spilling some contents to the roadway. The last incident involved finding a drum of radiologically contaminated waste in a shipment of nonradiological waste. There was no spread of radiological contamination from any of these incidents.

- One incident involved the overflow of the D- 
Table 3-8. Summary of Other Environmental Occurrence Reports.

\begin{tabular}{|c|c|c|c|}
\hline ORPS* ID & $\begin{array}{l}\text { Date of } \\
\text { Occurrence }\end{array}$ & Occurrence Description & Status \\
\hline CH-BH-BNL-BNL-2001-0002 & $1 / 29 / 01$ & $\begin{array}{l}\text { Phase II of the BGRR Decommissioning Project includes removal of the primary } \\
\text { air-cooling ducts with subsequent disposal. During the critical lift of section No. } 4 \text {, } \\
\text { the } 287,000-\mathrm{lb} \text {. section became unstable and fell onto the hydraulic controls of the } \\
\text { heavy-duty platform trailer that was to be used to transport it. An Internal Review } \\
\text { committee completed an investigation into the cause of the load shift during the } \\
\text { rigging operation. }\end{array}$ & $\begin{array}{l}\text { Closed: All corrective } \\
\text { actions have been } \\
\text { completed. }\end{array}$ \\
\hline CH-BH-BNL-PE-2001-0001 & $3 / 9 / 01$ & $\begin{array}{l}\text { Plant Engineering tower linemen positioned the line truck to unplug nozzles in the } \\
\text { Air Stripping Tower at Bldg. 598. When the vehicle became stuck in the fresh snow, } \\
\text { the on-board hydraulic winch was used to free the truck. During this use, a hydrau- } \\
\text { lic hose failed, resulting in a } 15 \text {-gallon oil spill. Absorbent material was used to } \\
\text { recover the spill material, which was contained by the snow and underlying roadway. }\end{array}$ & $\begin{array}{l}\text { Closed: All corrective } \\
\text { actions have been } \\
\text { completed. }\end{array}$ \\
\hline CH-BH-BNL-BNL-2001-0007 & $3 / 15 / 01$ & $\begin{array}{l}\text { On Monday, 3/12/01, a loss of heat transfer fluid from the primary compressor } \\
\text { system in Bldg. } 902 \text { was noted. The system uses a fluid-to-water heat exchanger } \\
\text { as part of an open loop cooling tower system. During the investigation into the loss, } \\
\text { transfer fluid was detected in the cooling tower basin, which overflows to the STP. } \\
\text { The STP operators were notified and reported a heavier than usual foam at the } \\
\text { plant and effluent to the Peconic River. A decision to divert the STP to the lined } \\
\text { holding ponds was made, even though the material had a low aquatic toxicity and } \\
\text { biodegrades in } 28 \text { days. On 3/14/01, the primary compressor was isolated and the } \\
\text { STP was placed on line. }\end{array}$ & $\begin{array}{l}\text { Closed: All corrective } \\
\text { actions have been } \\
\text { completed. }\end{array}$ \\
\hline CH-BH-BNL-HFBR-2001-0003 & $4 / 25 / 01$ & $\begin{array}{l}\text { Samples of soil that forms the floor of a basement room in Bldg. } 704 \text { were found to } \\
\text { contain } 229 \mathrm{pCi} / \mathrm{g} \text { Cs-137, exceeding the } 23 \mathrm{pCi} / \mathrm{g} \text { remediation goal established by } \\
\text { EPA and NYSDEC. The Fan House Facility (Bldg. 704) is shared by both the HFBR } \\
\text { and BGRR, although the primary design function was to house exhaust fans, } \\
\text { ductwork, and other equipment for the BGRR, which ceased operation in } 1968 \text {. } \\
\text { Normal operations of the HFBR cannot cause an airborne release of Cs-137 and } \\
\text { no physical pathway exists that could cause contamination generated by the HFBR } \\
\text { to be deposited in this location. Therefore, the contamination can only be attrib- } \\
\text { uted to past operation of the BGRR. A Preliminary Assessment/Site Investigation plan } \\
\text { was developed for the soil contamination in accordance with the CERCLA process. }\end{array}$ & $\begin{array}{l}\text { Closed: All corrective } \\
\text { actions have been } \\
\text { completed. }\end{array}$ \\
\hline CH-BH-BNL-BNL-2001-0011 & $5 / 3 / 01$ & $\begin{array}{l}\text { On 5/2/01, the Sensaphone leak detection system within Bldg. } 801 \text { registered two } \\
\text { separate leaks. Upon investigation, the D-waste tank system was not found to be } \\
\text { leaking. Early on } 5 / 3 / 01 \text {, a third alarm was received for a different part of the system. } \\
\text { Upon investigation, radiologically contaminated water was found in the neutraliza- } \\
\text { tion cell. Investigation revealed a partial clog of the D waste pipes, causing a backup } \\
\text { of wastewater into all system pipes. A leak in a joint of one pipe occurred when the } \\
\text { backed-up water reached that location. The joint was subsequently repaired. }\end{array}$ & $\begin{array}{l}\text { Closed: All corrective } \\
\text { actions have been } \\
\text { completed. }\end{array}$ \\
\hline CH-BH-BNL-BNL-2001-0014 & 6/18/01 & $\begin{array}{l}\text { During the movement of a B- } 25 \text { container containing dry radioactive material, the } \\
\text { load shifted. This caused the container to flip over, dislodge its cover, and spill its } \\
\text { contents on the ground. The Emergency Services division was called, as per the } \\
\text { procedures for chemical/oil spills. Referring to the Emergency Action levels, the } \\
\text { event was characterized as an Operational Emergency. This required off-site noti- } \\
\text { fication to the DOE Chicago Office and the Suffolk County Fire, Rescue, and Emer- } \\
\text { gency Services Department. The container was uprighted } 4 \text { hours later, at which } \\
\text { time the operational emergency was terminated. A critique was held to determine } \\
\text { the direct and contributing causes, as well as appropriate corrective actions. }\end{array}$ & $\begin{array}{l}\text { Closed: All corrective } \\
\text { actions have been } \\
\text { completed. }\end{array}$ \\
\hline CH-BH-BNL-BNL-2001-0016 & $7 / 5 / 01$ & $\begin{array}{l}\text { A comprehensive 5-day hazardous waste inspection was conducted by NYSDEC } \\
\text { on June } 6-14,2001 \text {. On July } 5,2001 \text {, a Notice of Violation was received for two } \\
\text { administrative deficiencies noted during the inspection. Approximately } 1,200 \text { com- } \\
\text { pliance points were checked during the in-depth inspection. A critique was com- } \\
\text { pleted to determine the direct and contributing causes of the two administrative } \\
\text { deficiencies. }\end{array}$ & $\begin{array}{l}\text { Closed: All corrective } \\
\text { actions have been } \\
\text { completed. }\end{array}$ \\
\hline
\end{tabular}


Table 3-8. Summary of Other Environmental Occurrence Reports (concluded).

\begin{tabular}{|c|c|c|c|}
\hline ORPS* ID & \begin{tabular}{|l|} 
Date of \\
Occurrence
\end{tabular} & Occurrence Description & Status \\
\hline CH-BH-BNL-BNL-2001-0020 & $7 / 25 / 01$ & $\begin{array}{l}\text { A portion of the waste generated from remediation of the BGRR aboveground ducts } \\
\text { was shipped to a waste processor in Oak Ridge, Tennessee during } 9 / 22-10 / 9 / 00 \text {. } \\
\text { The material was categorized and manifested as radioactive low-specific activity. } \\
\text { When preparing to ship the balance of waste inventory, the Waste Management Divi- } \\
\text { sion (WMD) revised the evaluation of the material and reclassified the waste as bulk } \\
\text { PCB product waste. The analysis and subsequent reclassification of the shipment } \\
\text { was documented in a Waste Management Division Nonconformance Report dated } 6 / \\
18 / 01 \text {. EPA was notified on } 7 / 25 / 01 \text { of the discrepancy in a format other than a routine } \\
\text { report, resulting in an occurrence report. A critique was completed to determine the } \\
\text { direct and contributing causes. }\end{array}$ & $\begin{array}{l}\text { Closed: All } \\
\text { corrective } \\
\text { actions have } \\
\text { been completed. }\end{array}$ \\
\hline CH-BH-BNL-BNL-2001-0022 & $8 / 10 / 01$ & $\begin{array}{l}\text { It was discovered that the federal and New York state reportable quantities for spills of } \\
\text { ethylene glycol differ. The federal reportable quantity is } 5,000 \text { pounds, whereas the state's } \\
\text { reportable quantity is } 1 \text { pound; the federal was increased in 1998. A review of ethylene } \\
\text { glycol spills from } 1998 \text { through } 2001 \text { found five spills of antifreeze which should have } \\
\text { been reported to NYSDEC, as required by } 6 \text { NYCRR } 595.3 \text {, but were not. The ethylene } \\
\text { glycol and other contaminants released during each of the unreported spills was imme- } \\
\text { diately remediated, therefore there were no environmental impacts. The Oil/Chemical } \\
\text { Spill Response procedure was updated and all response team members were trained. }\end{array}$ & $\begin{array}{l}\text { Closed: All } \\
\text { corrective } \\
\text { actions have } \\
\text { been completed. }\end{array}$ \\
\hline CH-BH-BNL-BNL-2001-0025 & 9/19/01 & $\begin{array}{l}\text { A Medical Department researcher had radiologically contaminated shoes and neglected } \\
\text { to detect this contamination during a personal survey after completing work on } 9 / 18 / 01 \text {. } \\
\text { A post work survey on } 9 / 19 / 01 \text { by a health physics technician revealed contamination in } \\
\text { the laboratory, the medical building's hallways, an office, another building on site, and } \\
\text { the researcher's personal vehicle. The researcher's radiological qualifications were } \\
\text { suspended until an extensive retraining program was completed to reinforce the require- } \\
\text { ments and expectations associated with radiological work involving dispersible material. }\end{array}$ & $\begin{array}{l}\text { Closed: All } \\
\text { corrective } \\
\text { actions have } \\
\text { been completed. }\end{array}$ \\
\hline CH-BH-BNL-AGS-2001-0002 & $8 / 10 / 01$ & $\begin{array}{l}\text { A disk in the liquid helium line used to cool the superconducting magnets within the } \\
\text { RHIC complex burst. This resulted in a release to the environment of } 380,000 \text { cubic feet } \\
\text { of helium valued at } \$ 26,600 \text {. An investigation of the event found that elevated system } \\
\text { pressure had occurred due to the shut-off of several compressors in the helium refrigera- } \\
\text { tion system from a remote workstation, not the cryogenic control room. }\end{array}$ & $\begin{array}{l}\text { Open: While the } \\
\text { ORPS report has } \\
\text { been accepted } \\
\text { by DOE, one } \\
\text { corrective action } \\
\text { remains open. It } \\
\text { involves the } \\
\text { retraining of } \\
\text { cryogenic } \\
\text { personnel on } \\
\text { revised operating } \\
\text { procedures, } \\
\text { which were } \\
\text { finalized in May } \\
\text { of } 2002 \text {. }\end{array}$ \\
\hline CH-BH-BNL-BNL-2001-0029 & $11 / 11 / 01$ & $\begin{array}{l}\text { A shipment of low-level radioactive waste from the BGRR project was identified by the } \\
\text { truck driver as being overweight following a tire blowout and subsequent weighing of the } \\
\text { conveyance in transit to final disposal. The tractor, trailer, and load was estimated well } \\
\text { below the } 80,000 \text {-lb. DOT limit, but when weighed, the total weight was found to be } \\
82,400 \text { lbs. }\end{array}$ & $\begin{array}{l}\text { Closed: All } \\
\text { corrective } \\
\text { actions have } \\
\text { been completed. }\end{array}$ \\
\hline CH-BH-BNL-BNL-2001-0034 & $12 / 13 / 01$ & $\begin{array}{l}\text { A truck preparing to transfer nonradioactive waste off site went through the vehicle radio- } \\
\text { logical monitor prior to exiting the site. The monitor detected radiological activity and } \\
\text { alarmed. A survey identified radioactive material in a 55-gallon drum, which was subse- } \\
\text { quently labeled as radioactive waste. }\end{array}$ & $\begin{array}{l}\text { Closed: All } \\
\text { corrective } \\
\text { actions have } \\
\text { been completed. }\end{array}$ \\
\hline
\end{tabular}

${ }^{*}$ Occurrence Report: Release is reportable to the U.S. Department of Energy under the requirements of DOE Order 232.1A, Occurrence Reporting and Processing of Operations Information. 
waste piping system in Building 801. A clog caused a backup of water into the piping system and a release of radiologically contaminated wastewater to the secondary containment.

- One incident involved the release of heat exchange fluid into the Building 902 cooling tower. The tower overflowed into the BNL sanitary sewer. Further information is provided in Section 3.6.

- One incident involved the issuance of a notice of violation by NYSDEC for deficiencies identified during the annual RCRA inspection.

- One incident involved incomplete waste characterization for the shipment of the BGRR concrete duct sections. Upon further evaluation, PCBs were identified in surface paints, thereby making the waste PCB "bulk product waste" in addition to being radioactive.

- One incident involved the release of 380,000 cubic feet of helium gas from the RHIC due to the failure of a rupture disk. Total cost for this loss exceeded $\$ 25,000$.

- One incident involved reporting ethylene glycol releases to NYSDEC. Under NYS requirements, any ethylene glycol spill of greater than 1 pound requires reporting, whereas the reportable quantity under federal rules is 5,000 pounds. Five releases of glycol exceeded the state's deminimus levels, but were well below the federal reporting criteria.

- One incident involved the spread of radioactive material via contamination of a researcher's shoes.

- One incident involved the overweight shipment of nonradiological waste. The vehicle exceeded the maximum load restriction by 2,400 pounds.

All incidents were addressed through the identification and implementation of corrective actions geared toward the root cause. No off-site nor on-site environmental consequences arose from the ORPS incidents.

\subsubsection{Major Petroleum Facility License}

The storage of 2.3 million gallons of petroleum products (principally No. 6 fuel oil) subjects BNL to Major Petroleum Facility licensing by
NYSDEC. BNL maintains an MPF License for storing and transferring oil at the Central Steam Facility. During 2001, BNL remained in full compliance with license requirements, which require $\mathrm{BNL}$ to monitor groundwater in the vicinity of the seven active, aboveground storage tanks that range in size from 60,000 to 600,000 gallons. The license also requires that $\mathrm{BNL}$ inspect storage facilities monthly and test the systems for leak detection, high level monitoring, and secondary containment. Tank integrity is also checked periodically. Groundwater monitoring consists of monthly checks for floating products and twice-yearly tests for semivolatile organic compounds. In 2001, no contaminants or floating products were found in groundwater wells that monitor the MPF. See Chapter 7 for additional information on groundwater monitoring results.

The petroleum facility is inspected annually by NYSDEC. The 2001 annual inspection was conducted in January. The inspection noted two conditions that required immediate corrective actions, and three conditions requiring corrective actions prior to pending operations. The two conditions requiring immediate action were performance testing of the impressed current cathodic protection system, and inspection of "telltales" on Tanks 9 and 10. Tell-tales are access ports installed in the interstitial space of the tank bottoms (these tanks have two bottom layers of steel to prevent leakage to the environment). Both conditions were corrected within 30 days of the date of inspection. Two of the three remaining corrective actions were required before Tanks 5 and 6 could be returned to service. These actions were to repair piping and install color coding at the fill ports. Color coding of the fill ports was completed within seven days of the inspection. Piping upgrades were completed in December.

The third "corrective" action was a reminder that indepth integrity testing of the secondary containment liners was due in June. This testing was performed under contract by a consulting engineering firm. The tests found that four of the six containment areas were in substantial compliance with the secondary containment system requirements. Minor maintenance issues were identified and immediately corrected. The liner in the berm serving Tank 4, a 300,000-gallon storage 
tank of No. 6 fuel oil, was found to be deteriorated in several areas and in need of replacement. This work was completed by November 30 . The last berm, serving Tank 12 (60,000 gallons of No. 2 fuel oil) did not meet state guidance permeability rates of $1 \times 10^{-6} \mathrm{~cm} / \mathrm{sec}$. This issue is under further discussion with NYSDEC.

\subsubsection{Chemical Bulk Storage}

All underground tanks, and all aboveground tanks larger than 185 gallons that store specific chemical substances listed in 6 NYCRR 597, must be registered with NYSDEC. BNL holds a Hazardous Substance Bulk Storage Registration Certificate. In total, BNL has 18 registered tanks: 17 aboveground tanks storing water treatment chemicals (for cooling towers, wastewater, or potable water treatment), and one for storing gallium trichloride used in neutrino experiments. The tanks range in size from 475 to 2,000 gallons. During 2001, three tanks storing cooling water treatment chemicals at the High Flux Beam Reactor were placed into a "permanently out of service" status and will remain that way until they are removed. Additionally, a tank storing water treatment chemicals at Building 600 was replaced with a smaller tank, thereby removing the need to register this facility.

In February, NYSDEC conducted its first inspection of the BNL chemical storage facilities. This inspection revealed four deficiencies in the management of these systems. The deficiencies included an administrative finding on the location of test reports, inadequate secondary containment for chemical transfers, labeling of valve positions, and fire protection for tanks that were subject to melting. All issues have been resolved with the exception of secondary containment for transfers. Construction designs have been submitted to NYSDEC; issues regarding containment for the transfer hoses are still being negotiated.

\subsubsection{County Storage Requirements}

Article 12 of the Suffolk County Sanitary Code, administered by SCDHS, regulates the storage and handling of toxic and hazardous materials in aboveground or underground storage tanks, drum storage facilities, piping systems, and transfer areas. Article 12 specifies design criteria to prevent environmental impacts resulting from spills or leaks. It also specifies administrative requirements, such as identification, registration, and spill reporting procedures. In 1987, BNL entered into a voluntary Memorandum of Agreement with SCDHS, in which DOE and BNL agreed to conform to the environmental requirements of Article 12.

BNL has 478 active and more than 390 inactive storage facilities listed in the Suffolk County Tanks Database. Also included in the county database are another 41 storage facilities associated with environmental restoration activities conducted under the CERCLA program that are not regulated under Article 12. BNL storage facilities listed in the database include those storing fuel (some of which are also regulated under the MPF license), wastewater, and chemicals, as well as those used in support of laboratory research.

At the close of 2001, 147 of the active tanks listed in the Suffolk County database fully conformed with all Article 12 administrative, maintenance, and technical requirements. Approximately 173 active tanks require administrative corrective actions (e.g., corrected registrations, submittal of as-built design plans to SCDHS, proper labeling, etc.) or maintenance (e.g., replacement of light bulbs). Fewer than 15 percent of the active facilities were found to be in technical nonconformance with Article 12 requirements (e.g., no secondary containment, no high-level detection).

BNL has an ongoing program to upgrade or replace existing storage facilities and to meet with representatives of SCDHS regularly to discuss storage issues. In April 2001, BNL initiated a project plan to achieve full conformance with Article 12 requirements. This Article 12 Improvements Project is primarily divided into two major tasks. The first task involves designing and constructing modifications to storage facilities that require technical upgrades to bring them into conformance with Article 12. The second task will involve preparing as-built design plans for many other existing storage facilities on site that already conform to Article 12 standards. Final plans and specifications for tanks that require upgrades were submitted to SCDHS for review 
and approval in December 2001; construction activities were scheduled to begin in February or March of 2002. Overall, the project will provide administrative and technical improvements to approximately 115 active storage facilities. Other upgrades continue to be addressed through labeling and filing of addendums to the BNL tank inventory (i.e., filing tank registrations), which will continue through 2003.

In an effort to continuously improve BNL operations and minimize impacts to the environment, revisions to the Storage and Transfer of Toxic or Hazardous Materials laboratory procedure, which primarily addresses SCDHS Article 12 regulations, were initiated in 2001 . This procedure includes measures for handling groundwater and surfacewater runoff from outdoor storage or work areas (e.g., excess material storage yards, welding areas, shielding storage areas). Design guidelines and requirements for planning, operating, and decommissioning an outdoor storage or work area are included in these revisions.

\subsection{RESOURCE CONSERVATION AND RECOVERY ACT}

The RCRA regulates hazardous wastes that could present risks to human health or the environment if mismanaged. The regulations are designed to ensure that hazardous wastes are managed "from cradle to grave," that is, from the point of generation to final disposal. In New York state, the RCRA program is delegated to NYSDEC by EPA, with EPA retaining an oversight role. BNL is considered a large-quantity generator and has a RCRA permit to store hazardous wastes for one year prior to off-site shipment for treatment and disposal. As noted in Chapter 2, BNL has a number of 90-day storage and satellite accumulation areas.

On June 16, 2001, NYSDEC conducted its annual inspection of the BNL hazardous waste management operations and issued a notice of violation for two administrative deficiencies. One item was corrected during the inspection. The other item involved the location of collection points for managing waste batteries. Documentation was provided confirming that BNL had satisfactorily addressed all the noted deficiencies.

\subsubsection{Mixed Wastes}

Mixed wastes are materials that are both hazardous (under RCRA guidelines) and radioactive. The Federal Facilities Compliance Act (FFCA), issued in 1992, requires that DOE work with local regulators to develop a site treatment plan to manage mixed waste. Development of the plan has two purposes: 1) to identify available treatment technologies and disposal facilities (DOE or commercial) that are able to manage mixed waste produced at federal facilities, and 2) to develop a schedule for treating and disposing of these waste streams.

BNL updates its Site Treatment Plan for Mixed Wastes (BNL 1997) annually and submits it to NYSDEC. The update documents the current mixed waste inventory and describes efforts undertaken to seek new commercial treatment and disposal outlets for various waste streams. Treatment options for most of the mixed waste now in storage have been identified, and most of the current inventory will be shipped off site for treatment and disposal in 2002. BNL will continue to update the treatment plan for wastes that have no identified disposal pathway.

\subsection{POLYCHLORINATED BYPHENYLS}

The storage, handling, and use of PCBs are regulated under the Toxic Substance and Control Act (TSCA). Capacitors manufactured prior to 1970 that are believed to be oil-filled are handled as if they contain PCBs, even when the existence of PCBs cannot be verified through an investigation of manufacturer's records. All equipment containing PCBs must be inventoried, with the exception of capacitors containing less than three pounds of dielectric fluid and items with a concentration of PCB source material of less than 50 parts per million. This inventory is updated by July 1 of each year. All PCB-containing articles or PCB-contaminated equipment must be labeled. BNL responds to any PCB spill in accordance with emergency response procedures. BNL was in compliance with TSCA requirements in 2001.

\subsection{PESTICIDES}

The storage and application of pesticides (insecticides, rodenticides, herbicides, algicides, 
etc.) are regulated under the Federal Insecticide, Fungicide, and Rodenticide Act (FIFRA). Pesticides at BNL are used to control undesirable insects, mice, and rats; to control bacteria in cooling towers; and to maintain certain areas free of vegetation (e.g., around fire hydrants and inside secondary containment berms). Insecticides are also applied to agricultural research fields and in greenhouses on site. Herbicide use is minimized wherever possible (e.g., through spot treatment of weeds). All pesticides are applied by BNL-employed New York State-certified applicators. By February 1, each applicator files an annual report with NYSDEC detailing insecticide and herbicide use for the previous year.

BNL is in full compliance with FIFRA requirements. In 2001, BNL initiated an integrated pest management review of herbicide and insecticide application practices. In cooperation with the Cornell Cooperative Extension Service, the Laboratory evaluated opportunities to further reduce pesticide use. Integrated pest management seeks to minimize the application of pesticides by the use of improved prevention and inspection techniques for pest identification rather than broad application, and by the use of reduced-risk pesticides. The review showed that BNL's current pest management programs constitute a complete integrated pest management control strategy that has resulted in limited use of chemicals in all of the areas that were considered.

\subsection{WETLANDS AND RIVER PERMITS}

As noted in Chapter 1, portions of the BNL site are situated on the Peconic River floodplain. Portions of the Peconic River are listed by NYSDEC as either scenic or recreational under the Wild, Scenic, and Recreational River System Act. BNL also has six areas regulated as wetlands and a number of vernal (seasonal) pools on site. Construction or modification activities performed within these areas require permits from NYSDEC.

Activities that could require review under the natural resource protection program are identified during the NEPA process (see Section 3.3). In the preliminary design stages of a construction project, design details required for the permit application process are specified. These design details ensure that the construction activity will not negatively affect the area, or if it does, that the area will be restored to its original condition. When design is near completion, permit applications are filed. During and after construction, BNL must comply with the permit conditions.

In 2001, two activities that required special permits were initiated and one ongoing activity was continued. The first new project consists of upgrading the Sewage Treatment Plant by constructing a new solids digester, demolishing the existing digester, relining the holdup ponds, and repairing or replacing piping that serves the sand filter beds. This project is expected to continue into the early part of 2002 . The second new project is the construction of a new recharge basin within the RHIC ring, which is expected to start in 2002. The continuation project involved extending the BNL sanitary sewer to the RHIC area of the site. All sewer extension work was completed in June.

\subsection{ENDANGERED SPECIES ACT}

In 1999, NYSDEC revised its list of "endangered," "threatened," and "species of special concern." The tiger salamander (Ambystomat. tigrinum) is the only state endangered species found at BNL. Tiger salamanders are listed in New York State as endangered because populations have declined due to habitat loss through development, road mortality during breeding migration, introduction of predatory fish into breeding sites, historical collection for the bait and pet trade, water level fluctuations, pollution, and general disturbance of breeding sites. BNL has prepared a Wildlife Management Plan (Naidu 1998) that formalizes the strategy and actions needed to protect 14 confirmed tiger salamander breeding locations identified on site. The strategy includes identifying and mapping habitats, monitoring breeding conditions, improving breeding sites, and controlling activities that could negatively affect breeding.

The banded sunfish (Enneacanthus obesus) and swamp darter (Etheostoma fusiforme) are found in the Peconic River drainage areas on site at BNL. Both are listed as threatened species within New York State. The reason for this status is that the only remaining populations of these fish in New York are on eastern Long Island. 
Measures that are being taken by BNL to protect the banded sunfish and swamp darter and their habitat include the following:

- Eliminating, reducing, or controlling pollutant discharges

- Upgrading the STP to reduce nitrogen loading in the Peconic River

- Monitoring populations and water quality

- Maintaining adequate flow in the river to enable the fish to survive drought

- Controlling disturbances to the river and adjacent banks.

The frosted elfin (Callophrys irus) is a small, amber-colored butterfly that depends on lupine. In the past, a population has utilized an area of lupine on BNL grounds. This habitat still exists and it is assumed that the butterfly is still present. Management of this habitat and surveys for this butterfly are being added to BNL's natural resource management program.

BNL also has eight species on site that are listed as "species of special concern." Species of special concern have no protection under the state endangered species laws, but may be protected under other state and federal laws (e.g., Migratory Bird Treaty Act). New York State monitors species of special concern and manages their populations and habitats, where practical, to ensure that they do not become threatened or endangered.

The species of special concern found at BNL include the marbled salamander (Ambystoma opacum), the spotted turtle (Clemmys guttata), the eastern box turtle (Terrapene carolina), the eastern hognosed snake (Heterodon platyrhinos), the horned lark (Eremophila alpestris), the whip-poor-will (Caprimulgus vociferus), the vesper sparrow (Pooecetes gramineus), and the grasshopper sparrow (Ammodramus savannarum). Management efforts taken for the tiger salamander also benefit the marbled salamander. At present, no additional protective measures are planned for the eastern box turtle or spotted turtle, as little activity occurs within their known habitat on site. The eastern hognosed snake has only been seen on site once, in 1994 (LMS 1995). BNL will be evaluating bird populations as part of the management strategy outlined in the Wildlife Management Plan. Data concerning species of special concern will be used appropriately in making management decisions regarding those species. In addition to the bird species mentioned above, 19 other bird species listed as species of special concern and two federally threatened species have been observed on site or flying over the site during spring and fall migrations.

BNL has 17 plant species protected under state law. One is a threatened plant, stiff goldenrod (Solidago rigida), and one is a rare plant, the narrow-leafed bush clover (Lespedeza augustifolia). The other 15 species are considered to be "exploitably vulnerable," which means that they may become threatened or endangered if factors that result in population declines continue. These plants are currently sheltered at BNL due to the large areas of undeveloped pine barrens habitat on site. Locations of these rare plants must be determined, populations estimated, and management requirements established. Management of protected plants will be included in the Natural Resource Management Plan currently under development. See Chapter 6 for more information.

\subsection{EXTERNAL AUDITS AND OVERSIGHT}

BNL was inspected by federal, state, or local regulators on at least 13 occasions in 2001. These inspections are summarized in Section 3.14.1. Since 1998, Suffolk County has had two full-time staff members at BNL to perform inspections. In 2001, this staff was reduced to one full-time and one part-time position, due to decreased activity. In addition to external audits and oversight, BNL has a comprehensive selfassessment program, which includes conducting Labwide compliance reviews. During 2001, BNL conducted a NEPA program review in conjunction with DOE-BAO, and a liquid effluent evaluation.

\subsubsection{Inspections by Regulatory Agencies}

- Hazardous Waste. NYSDEC conducted a RCRA/hazardous waste compliance inspection in June 2001. See Section 3.9 for information regarding this inspection.

- Air Compliance. NYSDEC conducted an annual inspection of the Central Steam 
Facility in March 2001. No issues were identified during this inspection.

- Potable Water. SCDHS conducts annual inspections of the BNL potable water system to collect samples and ensure that facilities are maintained. There were no issues in 2001. All sample results were within drinking water standards, except for iron, which is naturally occurring. As noted in Section 3.7.1, BNL treats the drinking water supply to remove iron prior to consumption.

- Sewage Treatment Plant. SCDHS conducts quarterly inspections of the BNL STP. In 2001, no performance or operational issues were identified during these inspections. Additionally, in July, NYSDEC conducted a routine inspection, during which facility operations were evaluated and effluent samples collected. No issues were identified during this inspection.

- Recharge Basins. As part of SCDHS oversight, three inspections are conducted annually of recharge basins and other SPDES outfalls. In 2001, SCDHS completed their scheduled inspections and collected samples during two of the three assessments. No issues were identified during these inspections.

- Major Petroleum Facility. The MPF is inspected annually by NYSDEC. This inspection was conducted in January 2001 (see Section 3.8.4).

- Chemical Bulk Storage. In February, NYSDEC conducted its first inspection of the storage facilities regulated under the NYS Chemical Bulk Storage Program. The four deficiencies are described in Section 3.8.5.

\subsubsection{Inspections by DOE}

DOE Headquarters (EH-10) conducted an assessment of the Laboratory's Price Anderson Acts Amendment (PAAA) program. Overall, the assessment concluded that the BNL PAAA program is generally established, formalized by procedure, and is in general conformance with DOE expectations. Ten areas for improvement were noted and a corrective action plan was prepared to address the issues. The Chicago Operations Office conducted no assessments during 2001. The DOE Brookhaven Area Office
(BAO) continued to provide oversight of BNL programs during 2001 and conducted compliance assessments on Cross-Connection Control and the NEPA program. The results of each assessment are summarized below.

\subsubsection{Cross-Connection Control Assessment}

The BAO assessment of the BNL CrossConnection Control Program evaluated BNL's compliance to Safe Drinking Water Act requirements, associated State guidance, and adherence to BNL sitewide procedures (i.e., Standards Based Management System Subject Areas). The results of this assessment identified four Concerns, six Findings, six Observations, and one Noteworthy Practice. The four Concerns identified during this assessment included improper design of cross-connection control device replacements; not performing annual testing for devices located in inaccessible areas; errors in completion of the reporting forms; and nonadherence to Labwide procedure requirements. All six of the Findings were attributed to deficiencies in design approvals and design details. The Noteworthy Practice identified the Operational Readiness Review (a walk-through inspection by specialists in safety, environmental, and plant engineering) as a good opportunity to identify cross-connection control deficiencies prior to facility occupancy.

\subsubsection{NEPA Program Assessment}

The NEPA Program assessment was performed in collaboration with BNL and DOE-BAO staff. The purpose of this assessment was to review and evaluate the status of selected projects for agreement with associated NEPA documentation. Two of the projects reviewed had undergone revisions after their initial NEPA reviews, with new environmental aspects being identified. It was determined that neither the BNL NEPA nor DOE-BAO NEPA coordinators had been informed of these revisions. The assessment report stated that both project revisions would likely have been considered to be within the scope of the original NEPA documents, but that qualified NEPA reviewers should have determined that fact. Recommendations for improvement were noted in the report and are being reviewed for implementation. 
Table 3-9. Existing Agreements and Enforcement Actions Issued to BNL, with Status.

\begin{tabular}{|c|c|c|c|c|}
\hline Number & Title & Parties & $\begin{array}{l}\text { Effective } \\
\text { Date }\end{array}$ & Status \\
\hline \multicolumn{5}{|l|}{ Enforcement } \\
\hline Not Applicable & $\begin{array}{l}\text { Notice of Noncompliance- } \\
\text { Toxic Substances } \\
\text { Control Act }\end{array}$ & EPA and DOE & 2/12/98 & $\begin{array}{l}\text { All required information was submitted to EPA on 10/6/98. The Waste Manage- } \\
\text { ment Division implemented a revised Hazardous Waste Control Form in } 1999 . \\
\text { There was no additional activity regarding this Notice in 2001, and efforts have } \\
\text { been taken to close it. Since all actions have been completed, BNL is consid- } \\
\text { ering this Notice of Noncompliance complete. }\end{array}$ \\
\hline $\begin{array}{l}\text { Index } \\
\text { No. 113-98-01 }\end{array}$ & $\begin{array}{l}\text { Compliance Order- } \\
\text { Clean Air Act }\end{array}$ & EPA and DOE & $2 / 24 / 98$ & $\begin{array}{l}\text { BNL, DOE, and EPA met in May } 1998 \text { to review and clarify the issues presented } \\
\text { in this Order. Documentation necessary to support BNL operations was submit- } \\
\text { ted to EPA prior to the issuance of the Order. Since there has been no further } \\
\text { activity since 1998, BNL is considering this Order completed. }\end{array}$ \\
\hline $\begin{array}{l}\text { Docket No. } \\
\text { UIC-AO-98-01 }\end{array}$ & $\begin{array}{l}\text { Administrative Order on } \\
\text { Consent - Safe Drinking } \\
\text { WaterAct }\end{array}$ & EPA and DOE & \begin{tabular}{l|}
$3 / 4 / 98$ \\
(date of \\
receipt by \\
DOE)
\end{tabular} & $\begin{array}{l}\text { The final Underground Injection Control area permit was received by BNL in } \\
\text { January 2001. With the issuance of the permit, the Order on Consent was } \\
\text { terminated. }\end{array}$ \\
\hline Cl-8975-03-99 & Consent Order & $\begin{array}{l}\text { NYSDEC } \\
\text { and } \\
\text { BNL }\end{array}$ & $3 / 24 / 99$ & $\begin{array}{l}\text { NYSDEC cited BNL for two administrative and one technical noncompliance } \\
\text { with hazardous waste regulations. Specifically, late submittal of a closure cer- } \\
\text { tificate for the former Hazardous Waste Management Facility, a missing land } \\
\text { disposal restriction code on a manifest, and the unavailability of a communica- } \\
\text { tion device in a } 90 \text {-day storage area. All deficiencies were corrected and a } \\
\text { penalty of } \$ 2,250 \text { was paid to NYSDEC in } 1999 \text {. A letter from NYSDEC was } \\
\text { received in July } 2001 \text { indicating that BNL was in compliance with the agree- } \\
\text { ment and the issue was resolved. }\end{array}$ \\
\hline Not Applicable & $\begin{array}{l}\text { Notice of Violation- } \\
\text { Resource Conservation } \\
\text { and Recovery Act }\end{array}$ & NYSDEC & 6/16/01 & $\begin{array}{l}\text { A Notice of Violation was issued for deficiencies in hazardous waste manage- } \\
\text { ment practices. These deficiencies were noted during the } 2001 \text { annual haz- } \\
\text { ardous waste compliance inspection conducted by NYSDEC. This Notice was } \\
\text { effectively closed in } 2001 \text {. }\end{array}$ \\
\hline \multicolumn{5}{|l|}{ Agreements } \\
\hline Not Applicable & Suffolk County Agreement & $\begin{array}{l}\text { SCDHS, DOE, } \\
\text { and BNL }\end{array}$ & $\begin{array}{l}\text { Originally } \\
\text { signed on } \\
9 / 23 / 87\end{array}$ & $\begin{array}{l}\text { This Agreement was developed to ensure that the storage and handling of toxic } \\
\text { and hazardous materials at BNL conform with the environmental and technical } \\
\text { requirements of Suffolk County codes. }\end{array}$ \\
\hline Not Applicable & $\begin{array}{l}\text { Federal Facilities } \\
\text { Compliance Agreement } \\
\text { (FFCA) on Mixed Wastes }\end{array}$ & $\begin{array}{l}\text { NYSDEC } \\
\text { and DOE }\end{array}$ & \begin{tabular}{l|}
1992 \\
(Updated \\
Annually)
\end{tabular} & $\begin{array}{l}\text { The FFCA requires that a site treatment plan to manage mixed wastes be } \\
\text { written and updated annually. BNL is in compliance with this requirement. }\end{array}$ \\
\hline $\begin{array}{l}\text { II-CERCLA- } \\
\text { FFA-00201 }\end{array}$ & $\begin{array}{l}\text { Federal Facility Agreement. } \\
\text { under the Comprehensive } \\
\text { Environmental Response, } \\
\text { Compensation and Liability } \\
\text { Act (CERCLA) Section } 120 \\
\text { (also known as the Inter- } \\
\text { agency Agreement or "IAG" } \\
\text { on the Environmental Res- } \\
\text { toration Program) }\end{array}$ & $\begin{array}{l}\text { EPA, DOE, } \\
\text { and NYSDEC }\end{array}$ & 05/26/92 & $\begin{array}{l}\text { Provides the framework, including schedules, for assessing the extent of con- } \\
\text { tamination and conducting the BNL cleanup. Work is performed either as an } \\
\text { Operable Unit or a Removal Action. The IAG integrates the requirements of } \\
\text { CERCLA, RCRA, and the National Environmental Policy Act. All IAG-scheduled } \\
\text { milestones were met in } 2001 \text {. }\end{array}$ \\
\hline Not Applicable & $\begin{array}{l}\text { Memorandum of Agreement } \\
\text { (MOA) by and between the } \\
\text { U.S. Environmental Protec- } \\
\text { tion Agency and the U.S. De- } \\
\text { partment of Energy }\end{array}$ & EPA and DOE & $03 / 23 / 98$ & $\begin{array}{l}\text { BNL is currently in full compliance with the terms of the MOA. See Chapter } 2 \text { for } \\
\text { further discussion. }\end{array}$ \\
\hline \multicolumn{5}{|c|}{$\begin{array}{l}\text { Notes: } \\
\text { EPA = U.S. Environmental Protection Agency } \\
\text { DOE = U.S. Department of Energy } \\
\text { NYSDEC = New York State Department of Conservation } \\
\text { SCDHS = Suffolk County Department of Health Services }\end{array}$} \\
\hline
\end{tabular}




\subsubsection{Enforcement Actions and Memos}

No new consent orders were issued to BNL in 2001. A notice of violation was issued by NYSDEC as a result of the annual RCRA inspection (see discussion in Section 3.9). EPA and DOE signed a voluntary Memorandum of Agreement on March 23, 1998, which is discussed in Chapter 2. During 2001, BNL continued to be in full compliance with the terms of the MOA. All existing enforcement actions and MOAs are listed in Table 3-9, along with a summary of their status. BNL believes that it has fully complied with the terms and conditions listed in these actions and has submitted supporting documentation to the regulatory agencies. The Laboratory continues to work with the regulators to close these actions as expeditiously as possible.

\section{REFERENCES}

Bennett, D., D. Paquette, K. Klaus, W. Dorsch. 2000. Brookhaven National Laboratory Source Water Assessment for Drinking Water Supply Wells. BNL-52608. Brookhaven National Laboratory, Upton, NY. December 2000.

Bernstein, D. 2001. The Architectural Inventory of the Brookhaven National Laboratory. The Institute for Long Island Archaeology, Department of Anthropology, State University of New York at Stony Brook, February 2001.

BNL. 1997. BNL Site Treatment Plan. Brookhaven National Laboratory, Upton, NY. January 1997.
BNL. 2000. Brookhaven National Laboratory Site Master Plan. Brookhaven National Laboratory, Upton, NY. November 2000.

BNL. 2001a. Belford, M., "How Does BNL Produce Its Drinking Water?" The Bulletin. 55 (18):2. May 25, 2001. Brookhaven National Laboratory, Upton, NY.

BNL. 2001b. "2001 BNL Water Quality Consumer Confidence Report." The Bulletin. Special Supplement, May 25, 2001. Brookhaven National Laboratory, Upton, NY.

Chaloupka, W. 2000. Brookhaven National Laboratory Spill Prevention Control and Countermeasure Plan. Brookhaven National Laboratory, Upton, NY. December 15, 2000.

Chaloupka, W. 2001. Brookhaven National Laboratory 2001 Annual Potable Water Sampling Plan. Brookhaven National Laboratory, Upton, NY. January, 2001.

DEAR 970.5204-2. 1997. Integration of Environment, Safety, and Health into Work Planning and Execution. Department of Energy Acquisition Regulation. U.S. Department of Energy, Washington, D.C. June 1997 .

Desmarais, R. 2000. "MOA Between BHG and New York State Historic Preservation Office Concerning Decommissioning Project." DOE Letter to E.A. Zimmerman, BNL. May 3, 2000.

DOE Order 5400.5. 1990. Radiation Protection of the Public and the Environment. U.S. Department of Energy, Washington, D.C. Change 2: 1-7-93.

DOE Policy 450.4. 1996. Safety Management System Policy. U.S. Department of Energy, Washington, D.C. 10-15-96.

EPA. 2000. Federal Facilities Agreement Under CERCLA 120. Administrative Docket Number I-CERCLA-FFA-00201.

LMS (Lawler, Matusky, \& Skelly Engineers). 1995. Phase II Sitewide Biological Inventory Report. Prepared for the Office of Environmental Restoration, Brookhaven National Laboratory, Upton, NY.

Naidu, J. 1998. Brookhaven National Laboratory Wildlife Management Plan. Brookhaven National Laboratory, Upton, NY. December 28, 1998. 


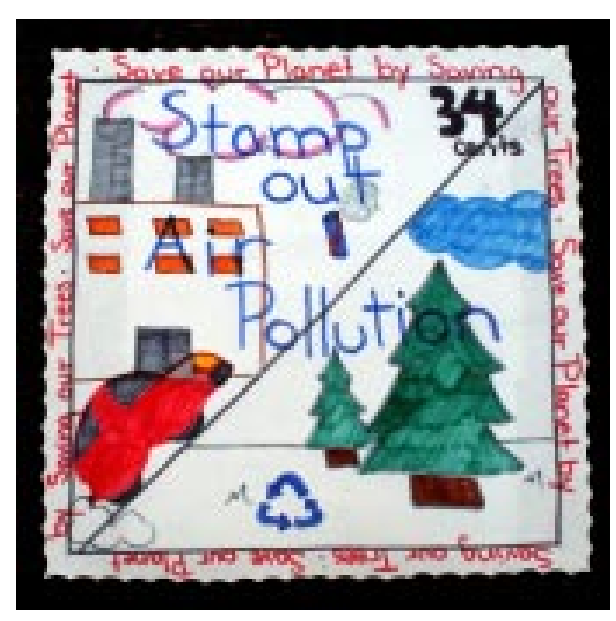

Chapter 4

\section{Air Quality}

Brookhaven National Laboratory performs both radioactive and nonradioactive continuous emissions monitoring at several facilities to ensure compliance with the requirements of the Clean Air Act. In addition to a facility emissions monitoring program, routine environmental air sampling is conducted to verify local air quality and to assess the possible environmental impacts of the Laboratory's operations.

During 2001, BNL facilities released a total of $9,814 \mathrm{Ci}$ of airborne radioactive material. Short-lived gaseous oxygen-15 and carbon-11 released from the Brookhaven Linac Isotope Producer accounted for more than 99.9 percent of the site's radiological air emissions.

Continuing a pattern observed in 2000 , natural gas prices were higher than residual fuel prices through much of 2001, causing the Central Steam Facility to rely more on residual fuel to meet the heating and cooling needs of BNL's major facilities than in 1999. As a result, annual facility emissions of particulate matter, nitrogen oxides, and sulfur dioxide were considerably higher in 2001 than in 1999. 


\subsection{RADIOLOGICAL AIRBORNE EMISSIONS}

Federal air quality laws and DOE regulations governing the release of airborne radioactive material include 40 CFR 61 Subpart H (from the National Emission Standards for Hazardous Air Pollutants, or NESHAPs - part of the Clean Air Act), DOE Order 5400.1 (1990), General Environmental Protection Program, and DOE Order 5400.5 (1993), Radiation Protection of the Public and the Environment. Under

NESHAPs Subpart $\mathrm{H}$, facilities with emissions that have the potential to deliver a radiation dose of greater than $0.1 \mathrm{mrem} / \mathrm{year}(1 \mu \mathrm{Sv} /$ year $)$ to a member of the public must be continuously monitored. BNL has five facilities that fall into this category. Figure 4-1 indicates the location of each of the monitored facilities, and Table 4-1 presents the airborne releases from each of these facilities during 2001. Facilities with potential emissions that fall below this value require only periodic, confirmatory monitoring. Annual emissions from each facility are discussed in the following sections. The associated radiation dose calculations are presented in Chapter 8.

\subsubsection{Brookhaven Medical Research Reactor}

In August 2000, DOE announced that the Brookhaven Medical Research Reactor (BMRR) would be permanently shut down. Until it stopped operating in late December 2000, the BMRR was fueled with enriched uranium, moderated and cooled by light water, and was operated intermittently at power levels up to 3 megawatts (thermal). Air from the interior of the containment building was used to cool the neutron reflector surrounding the core of the

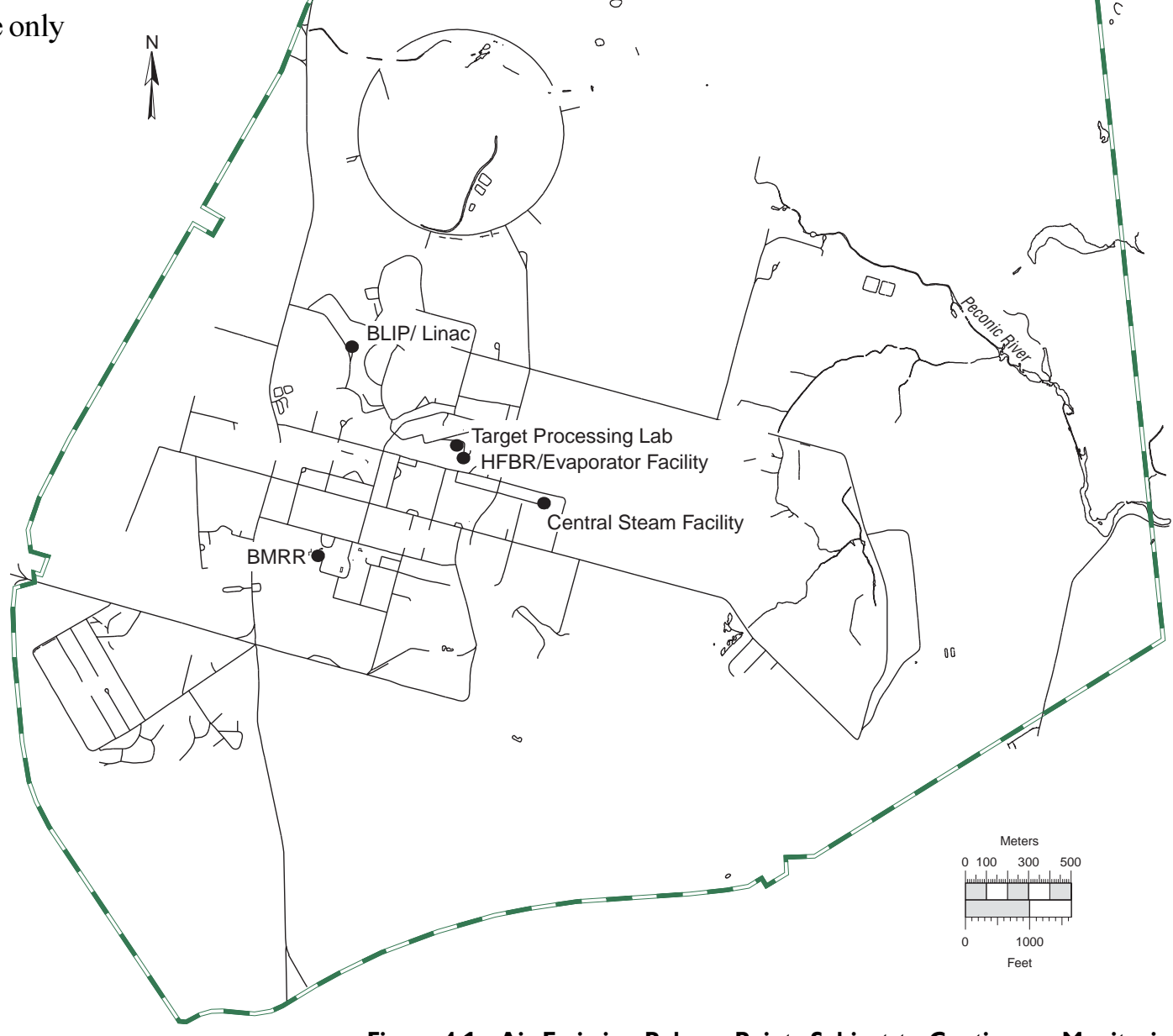

Figure 4-1. Air Emission Release Points Subject to Continuous Monitoring. 
Table 4-1. Airborne Radionuclide Releases from Monitored Facilities.

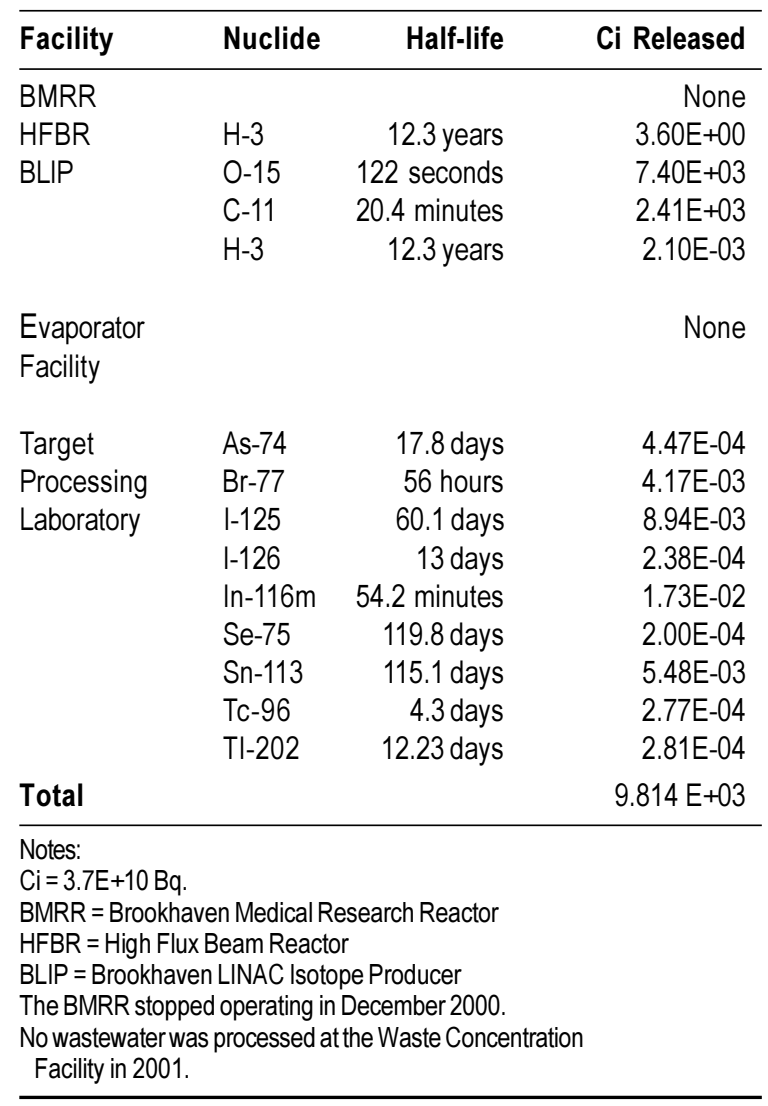

reactor vessel. As air was drawn through the reflector, it was exposed to a neutron field, resulting in activation of the argon fraction of the air and producing argon-41, an inert gas with a short half-life of 1.8 hours. After passage through the reflector, the air was routed through a roughing filter and a high efficiency particulate air (HEPA) filter to remove any particulate matter. Charcoal filters were also used to remove radioiodines produced during the fission process. Following filtration, the air was exhausted to the atmosphere through a 150 -foot stack adjacent to the reactor containment building.

Since the BMRR is no longer operating, the frequency of monitoring was reduced from continuous to semi-annual. January 2001 sampling showed no air emissions at zero power level with building ventilation on and the BMRR core unchanged. Real-time monitoring was used to track argon-41 air emissions, while passive filter media were used to collect and quantify radioiodines and particulate emissions. The monitoring results for the year showed there were no quantifiable emissions of argon- 41 or nonargon radionuclides.

\subsubsection{High Flux Beam Reactor}

Following the discovery of an underground plume of tritiated groundwater emanating from a leak in the spent fuel storage pool, the High Flux Beam Reactor (HFBR) was kept in a standby mode from January 1997 until November 1999, when DOE announced that it would be permanently shut down. The storage pool was drained in December 1997 to prevent additional leakage as well as to facilitate repairs and double lining to conform to Suffolk County Article 12. When the HFBR operated, it used heavy water as a neutron moderator and fuel coolant. Heavy water, or $\mathrm{D}_{2} \mathrm{O}$, is water composed of a nonradioactive isotope of hydrogen known as deuterium. When exposed to the neutron fields generated inside the reactor vessel, the deuterium became activated, producing radioactive tritium (half-life $=12.3$ years). Tritium continues to be released from the HFBR even though the fuel has been removed from the reactor vessel and the heavy water has been drained from the cooling loops; the vessel and associated cooling loops contain residual heavy water. Tritiated water vapor (abbreviated HTO) is released from the vessel and associated piping systems (via diffusion at valve seals and other system penetrations) to building air, where it is routed to the facility's 328-foot stack. Concentrations of HTO in air emissions are assessed using an integrating silica gel absorbent. In 2001, 3.6 Ci of airborne HTO were released from the HFBR. Figure 4-2 illustrates the declining trend of tritium emissions from the HFBR since 1992.

\subsubsection{Brookhaven Linac Isotope Producer}

Protons from the Linear Accelerator are sent via an underground beam tunnel to the Brookhaven Linac Isotope Producer (BLIP), where they strike various target metals. These metals, which become activated by the proton beam, are then transferred to the Target Processing Laboratory (Building 801) for later use in radiopharmaceutical research. During irradiation, the targets are cooled by a continuously recircu- 


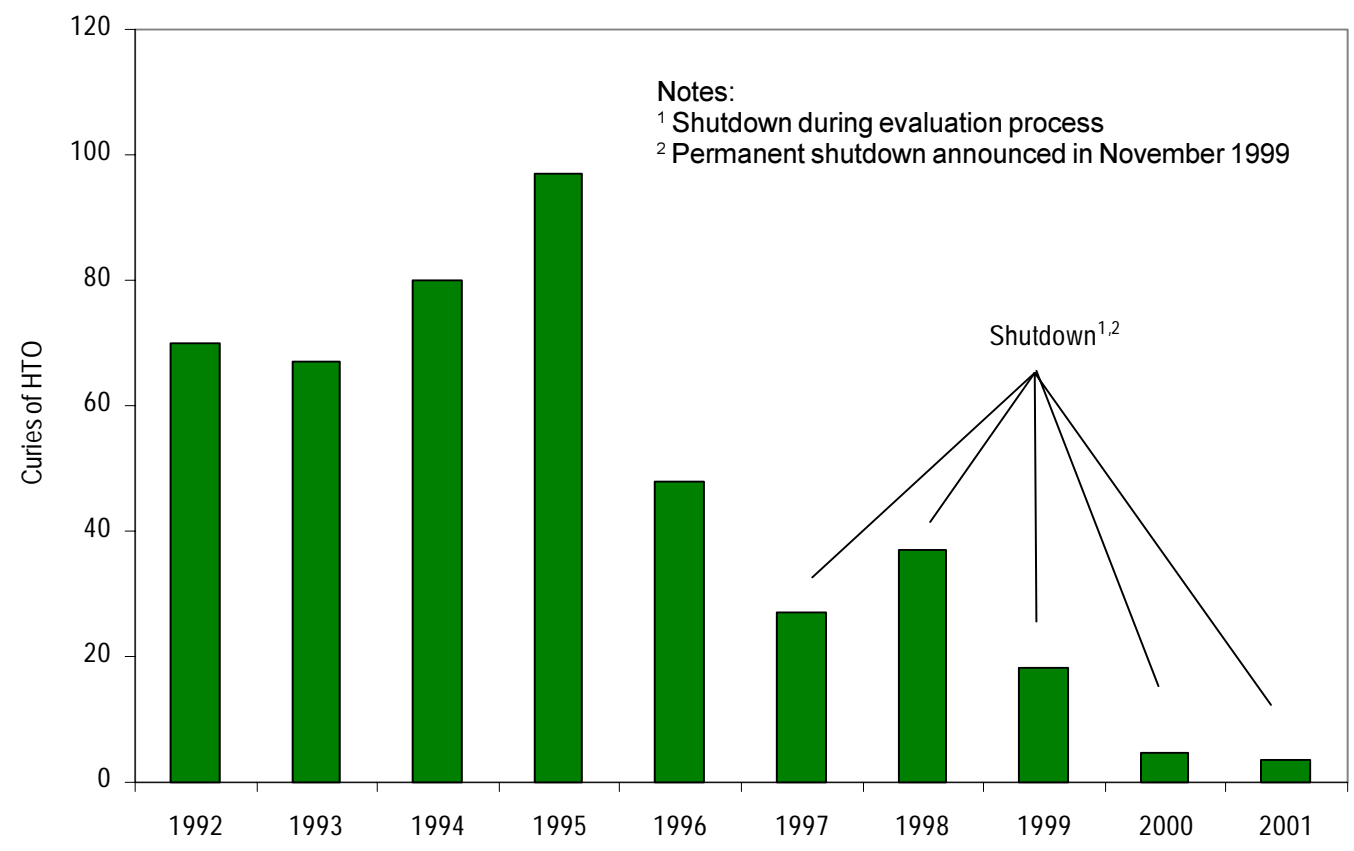

Figure 4-2. High Flux Beam Reactor Tritium Emissions, Ten-Year Trend (1992-2001).

lating water system. Several radioisotopes are produced in the cooling water, the most significant of which are oxygen-15 and carbon-11 (radionuclides with respective short half-lives of 122 seconds and 20.4 minutes). Both of these isotopes are released as gaseous airborne emissions.

In recognition of the fact that carbon-11 was not characterized in prior year samples, collected samples in 2001 were counted for longer intervals to insure the characterization of the carbon11 fraction in BLIP emissions. In 2001, the BLIP operated over a period of 35 weeks. During this period, 2,410 $\mathrm{Ci}$ of carbon-11 and 7,400 $\mathrm{Ci}$ of oxygen-15 were released. Tritium produced from activation of the target cooling water was also released, but in a much smaller quantity. The increase in oxygen - 15 emissions, compared to $2000(1,070 \mathrm{Ci})$ is due partly to an increase in the period of operations ( 13 weeks in 2000 , compared to 35 weeks in 2001) and partly to an increase in the average proton beam intensity ( 56 microamperes in 2000 , compared to 75 microamperes in 2001). See Table 4-1 for a complete listing of the radionuclides released.

\subsubsection{Evaporator Facility}

The Evaporator Facility (Building 802B) was constructed to reduce the total amount of tritiated water released to the Peconic River from BNL operations through the Sewage Treatment Plant (STP). The Evaporator Facility began processing wastewater in 1995.

Liquid waste generated on site that contains residual radioactivity is accumulated at the Waste Concentration Facility (WCF) in Building 811. At the WCF, suspended solids and a high percentage of radionuclides are removed from the liquid using reverse osmosis. However, because tritium is an isotope of hydrogen (a very small molecule), it cannot be removed from the liquid waste. The tritiated water which remains following waste

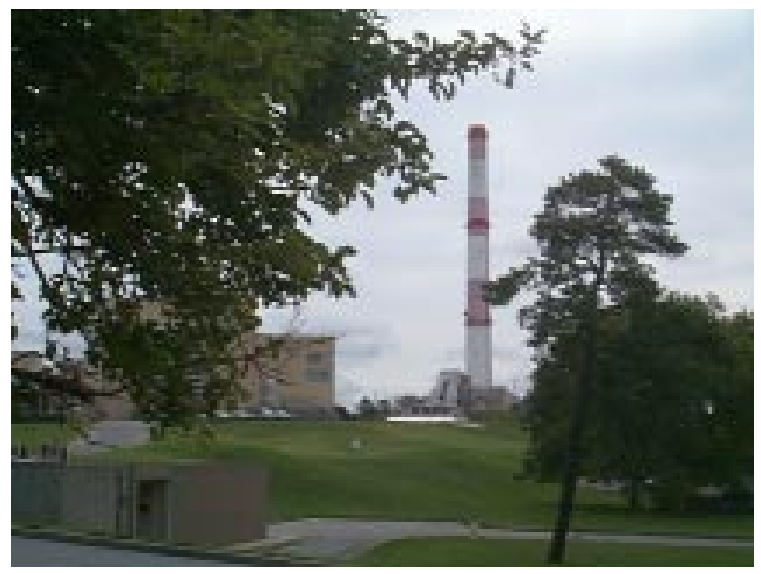

Figure 4-3. HFBR and Evaporator Facility Exhaust Stack. 
concentration is transferred to the Evaporator Facility in Building 802B, where it is converted to steam and released as an airborne emission. The emissions are directed to the same stack used by the HFBR to exhaust building air (see Figure 4-3). This method is preferable to release via surface water because there is virtually no potential to influence groundwater; the potential for this tritium to contribute to an off-site dose is minimized by atmospheric dispersion.

In 2001, no liquid waste was processed at the WCF. As a result, the Evaporator Facility was not used and there were no emissions of tritiated water vapor.

\subsubsection{Target Processing Laboratory}

Target metals irradiated at the BLIP facility are transported to the Target Processing Laboratory (Building 801), where the useful isotopes are chemically extracted for radiopharmaceutical production. Airborne radionuclides released during the extraction process are drawn through multistage HEPA and charcoal filters and then vented to the HFBR stack (see Table 4-1 for isotopes and quantities). Radionuclide quantities released from this facility annually are small, typically in the millicurie range. In 2001, the total release from the Target Processing Laboratory was $0.037 \mathrm{Ci}$.

\subsubsection{Additional Minor Sources}

Several research departments within BNL conduct work that involves very small quantities of radioactive materials (in the microcurie to millicurie range) within designated fume hoods. Transferring material between containers, pipetting, and chemical compound labeling are typical of the work conducted within the hoods. Due to the use of HEPA filters, the nature of the work conducted, and the small quantities involved, these operations have a very low potential for atmospheric releases of any significant quantities of radioactive materials. Compliance with NESHAPs Subpart $\mathrm{H}$ is demonstrated through the use of an inventory system that allows an upper estimate of potential releases to be calculated. Facilities that demonstrate compliance in this way include Buildings $318,463,490,490 \mathrm{~A}, 555,703 \mathrm{~W}$, and 830 , where research is conducted in the fields of biology, chemistry, medicine, applied science, and advanced technology.

\subsubsection{Uncharacterized Radiological Emission Sources Evaluated in 2001}

Within NESHAPs Subpart H, there are established procedures to evaluate the potential impacts to the public of activities that emit or have the potential to release radiological emissions to the atmosphere. Using these procedures and the EPA-approved CAP88-PC dose modeling program, several planned environmental restoration and waste management activities were evaluated in 2001 . These evaluations determined whether NESHAPs permitting and continuous monitoring requirements would be applicable or whether periodic confirmatory sampling would be needed to ensure compliance with Subpart H standards for radionuclide emissions. Chapter 8 discusses the NESHAPs evaluations of the various environmental restoration and waste management activities that were expected to commence in 2001.

One of the environmental restoration activities found to have a significant potential impact was the removal of the pad area that surrounded the canal and water treatment house of the Brookhaven Graphite Research Reactor (a reactor that produced neutrons for scientific research from 1950 to 1969 and is now being decommissioned). Results using the CAP 88-PC computer model conservatively estimated an effective dose equivalent of $1.7 \mathrm{mrem} /$ year (17 $\mu \mathrm{Sv} / \mathrm{yr}$ ) to the maximally exposed individual assumed to be living at the site boundary. This value exceeded the $0.1 \mathrm{mrem} / \mathrm{year}(1 \mu \mathrm{Sv} / \mathrm{yr})$ threshold that triggers the NESHAPs Subpart $\mathrm{H}$ requirements for continuous monitoring. Chapter 8 discusses in detail the continuous monitoring that took place while this project was underway from March to July of 2001.

\subsection{FACILITY MONITORING}

In the past, potential sources of radioactive particulate emissions that have been monitored included the BMRR, the HFBR, the Evaporator Facility, the Target Processing Laboratory (Building 801), and the BLIP. Since the BMRR and HFBR are permanently shut down and the 
Evaporator Facility did not process any liquid wastes in 2001, no particulate sampling was conducted at these facilities.

The samplers in the exhaust duct for the Target Processing Laboratory and the exhaust stack for the BLIP are equipped with glass-fiber filter paper designed to capture airborne particulate matter generated at these facilities (see Figure 4-4 for locations). The filter paper is collected and analyzed on a weekly basis for gross alpha and beta activity. Particulate filter analytical results for gross alpha and beta activity are reported in Table 4-2. Annual average gross alpha and beta airborne activity levels for samples collected from the Target Processing Laboratory were -0.0066 $\mathrm{pCi} / \mathrm{m}^{3}$ and $-0.1130 \mathrm{pCi} / \mathrm{m}^{3}$, respectively. The annual average gross alpha and beta airborne activity levels for samples collected from the BLIP exhaust stack were $-0.0049 \mathrm{pCi} / \mathrm{m}^{3}$ and -0.6640 $\mathrm{pCi} / \mathrm{m}^{3}$, respectively. (For a discussion of negative values associated with radioactivity monitoring, see Appendix B.)

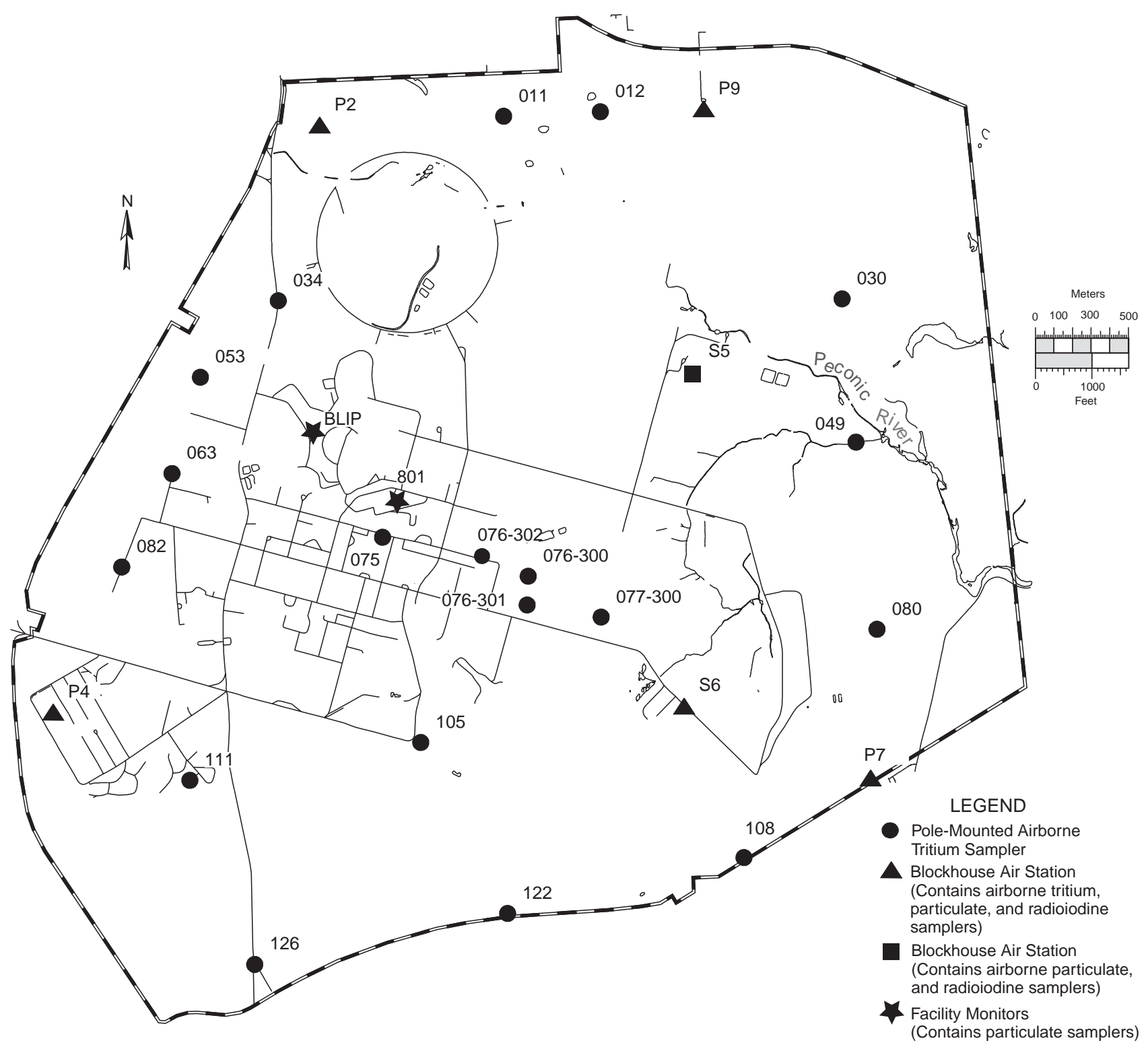

Figure 4-4. On-site Ambient Air Monitoring Stations. 
Table 4-2. Gross Activity Detected in Facility Air Particulate Filters.

\begin{tabular}{llcc}
$\begin{array}{l}\text { Facility } \\
\text { Monitor }\end{array}$ & $\begin{array}{c}\text { Gross Alpha } \\
\left(\mathrm{pCi} / \mathrm{m}^{3}\right)\end{array}$ & $\begin{array}{c}\text { Gross Beta } \\
\left(\mathrm{pCi} / \mathrm{m}^{3}\right)\end{array}$ \\
\hline 801 & $\mathrm{~N}$ & 51 & 50 \\
& Max. & $0.0224 \pm 0.0166$ & $0.2080 \pm 0.0848$ \\
& Avg. & $-0.0066 \pm 0.0035$ & $-0.1130 \pm 0.0051$ \\
& MDL & 0.0621 & 0.1430 \\
BLIP & N & 51 & 51 \\
& Max. & $0.1780 \pm 0.1590$ & $0.4370 \pm 0.4210$ \\
& Avg. & $-0.0049 \pm 0.0172$ & $-0.6440 \pm 0.0260$ \\
& MDL & 0.2430 & 0.7560 \\
\hline Notes: & \multicolumn{3}{c}{} \\
See Figure 4-4 for sample station locations. \\
All values shown with a 95\% confidence interval. \\
SeeAppendix B for discussion of negative values. \\
N= Number of samples collected \\
MDL= Minimum Detection Limit \\
\hline
\end{tabular}

\section{3 AMBIENT AIR MONITORING}

As part of the Environmental Monitoring Program, an array of monitoring stations is in place around the BNL site to collect air samples for determining possible radionuclides in the air. Samplers are housed within six blockhouse stations (see Figure 4-4 for locations). The blockhouses are fenced to control access and to protect costly sampling equipment. In addition to the blockhouses, 19 pole-mounted, batterypowered silica-gel samplers (used for tritium analysis) are located throughout the site, primarily along the site boundary.

At each blockhouse, glass-fiber filter paper captures airborne particulate matter, charcoal cartridges collect any potential radioiodines, and silica-gel absorbent collects water vapor for tritium analysis. (Note that Station S5 does not contain a tritium sampler.) Filter paper is collected weekly and analyzed for gross alpha and beta activity using a gas-flow proportional counter. Charcoal cartridges are collected monthly and analyzed by gamma spectroscopy. Silica-gel samples are collected one week a month for processing by liquid scintillation analysis. Before April 1999, silica-gel samples were collected weekly, but multiple years' worth of results below the minimum detection limit (MDL) were the basis for reducing the sampling frequency.

\subsubsection{Gross Alpha and Beta Activity}

Particulate filter analytical results for gross alpha and beta activity are reported in Table 4-3.
The annual average gross alpha and beta airborne activity levels for the six monitoring stations were $0.0007 \mathrm{pCi} / \mathrm{m}^{3}$ and $0.0118 \mathrm{pCi} / \mathrm{m}^{3}$, respectively. Annual gross beta activity trends recorded at Station P7 are plotted in Figure 4-5. The results at this location are typical for the site. The trend shows seasonal variation in activity within a range that is representative of natural background levels. The gross alpha activity is not plotted because the vast majority of results were below the MDL.

The New York State Department of Health (NYSDOH) received duplicate filter samples that were collected at Station P7, located at the southeast site boundary. These samples were

\begin{tabular}{|c|c|c|c|}
\hline $\begin{array}{l}\text { Sample } \\
\text { Station }\end{array}$ & & $\begin{array}{l}\text { Gross Alpha } \\
\left(\mathrm{pCi} / \mathrm{m}^{3}\right)\end{array}$ & $\begin{array}{c}\text { Gross Beta } \\
\left(\mathrm{pCi} / \mathrm{m}^{3}\right)\end{array}$ \\
\hline P2 & $\begin{array}{l}\text { N } \\
\text { Max. } \\
\text { Avg. } \\
\text { MDL }\end{array}$ & $\begin{array}{c}52 \\
0.0030 \pm 0.0059 \\
0.0006 \pm 0.0002 \\
0.0010\end{array}$ & $\begin{array}{c}52 \\
0.0737 \pm 0.0181 \\
0.0120 \pm 0.0008 \\
0.0031\end{array}$ \\
\hline P4 & $\begin{array}{l}\text { N } \\
\text { Max. } \\
\text { Avg. } \\
\text { MDL }\end{array}$ & $\begin{array}{c}52 \\
0.0028 \pm 0.0056 \\
0.0007 \pm 0.0002 \\
0.0010\end{array}$ & $\begin{array}{c}52 \\
0.0907 \pm 0.0018 \\
0.0138 \pm 0.0006 \\
0.0032\end{array}$ \\
\hline $\mathrm{P} 7$ & $\begin{array}{l}\text { N } \\
\text { Max. } \\
\text { Avg. } \\
\text { MDL }\end{array}$ & $\begin{array}{c}51 \\
0.0029 \pm 0.0041 \\
0.0006 \pm 0.0002 \\
0.0009\end{array}$ & $\begin{array}{c}51 \\
0.0424 \pm 0.0189 \\
0.0102 \pm 0.0007 \\
0.0030\end{array}$ \\
\hline P9 & $\begin{array}{l}\text { N } \\
\text { Max. } \\
\text { Avg. } \\
\text { MDL }\end{array}$ & $\begin{array}{c}52 \\
0.0020 \pm 0.0008 \\
0.0007 \pm 0.0001 \\
0.0008\end{array}$ & $\begin{array}{c}52 \\
0.0424 \pm 0.0024 \\
0.0102 \pm 0.0002 \\
0.0026\end{array}$ \\
\hline S5 & $\begin{array}{l}\text { N } \\
\text { Max. } \\
\text { Avg. } \\
\text { MDL }\end{array}$ & $\begin{array}{c}52 \\
0.0016 \pm 0.0007 \\
0.0007 \pm 0.0001 \\
0.0010\end{array}$ & $\begin{array}{c}52 \\
0.0256 \pm 0.0025 \\
0.0129 \pm 0.0003 \\
0.0031\end{array}$ \\
\hline S6 & $\begin{array}{l}\text { N } \\
\text { Max. } \\
\text { Avg. } \\
\text { MDL }\end{array}$ & $\begin{array}{c}52 \\
0.0024 \pm 0.0008 \\
0.0006 \pm 0.0001 \\
0.0009\end{array}$ & $\begin{array}{c}52 \\
0.0222 \pm 0.0023 \\
0.0117 \pm 0.0002 \\
0.0029\end{array}$ \\
\hline \multicolumn{2}{|l|}{$\begin{array}{l}\text { Grand } \\
\text { Average }\end{array}$} & $0.0007 \pm 0.0001$ & $0.0118 \pm 0.0008$ \\
\hline \multicolumn{4}{|c|}{$\begin{array}{l}\text { Notes: } \\
\text { See Figure } 4-4 \text { for sample station locations. } \\
\text { All values shown with a } 95 \% \text { confidence interval. } \\
\mathrm{N}=\text { Number of samples collected } \\
\mathrm{MDL}=\text { Minimum Detection Limit }\end{array}$} \\
\hline
\end{tabular}




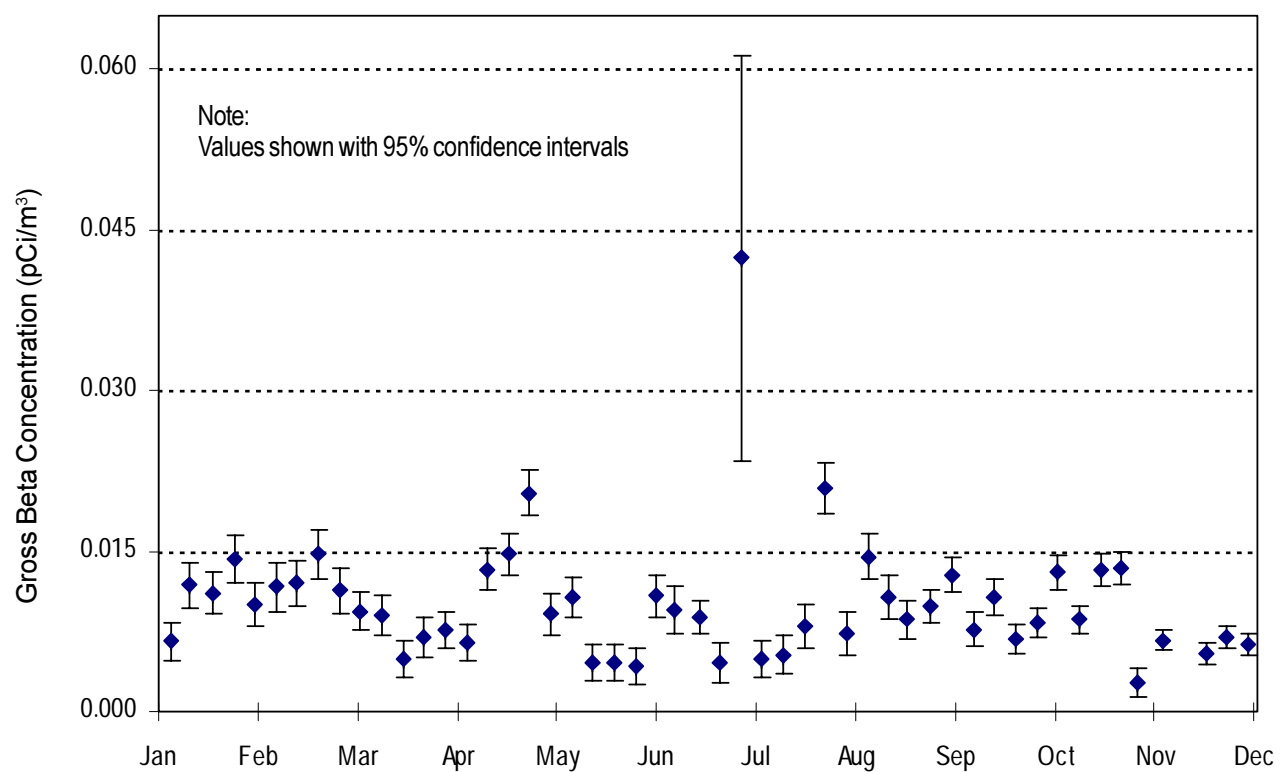

Figure 4-5. Airborne Gross Beta Concentration Trend Recorded at Station P7.

collected weekly and analyzed by the NYSDOH laboratory for gross beta activity. The analytical results received were comparable to the Station P7 samples analyzed by the BNL Analytical Services Laboratory. Analytical results for gross beta activity reported by the NYSDOH laboratory were between 0.003 and $0.028 \mathrm{pCi} / \mathrm{m}^{3}$, whereas the $\mathrm{BNL}$ results ranged from 0.003 to $0.042 \mathrm{pCi} / \mathrm{m}^{3}$.

As part of a statewide monitoring program, NYSDOH also collects air samples in Albany, New York, a control location with no potential to be influenced by nuclear facility emissions. NYSDOH reported in 2001 that airborne gross beta activity at that location varied between 0.00589 and $0.027 \mathrm{pCi} / \mathrm{m}^{3}$. Sample results measured at $\mathrm{BNL}$ generally fall within this range, demonstrating that on-site radiological air quality is consistent with that observed at locations in New York State not located near radiological facilities.

\subsubsection{Airborne Tritium}

Airborne tritium in the form of HTO is monitored throughout the BNL site. In addition to the five blockhouses containing tritium samplers, 16 pole-mounted monitors (not including those which monitor the Removal Action V Recharge Basin (see Section 4.3.2.1) are located at or near the property boundary (see Figure 4-4 for locations). Two additional pole-mounted monitors are centrally located on site. Airborne tritium is collected using a pump that draws air through a column of silica gel, a water-absorbent medium. The absorbed HTO is recovered by distillation and analyzed using liquid scintillation counting techniques.

Table 4-4 lists the number of validated samples collected at each location, the maximum value observed, and the annual average concentration. Validated samples are those not rejected due to equipment malfunction or other factors (e.g., a battery failure in the sampler, frozen or super-saturated silica gel, or the loss of sample during laboratory preparation). Airborne tritium samples were collected from each sampling station over a one-week period during each calendar month. While one location (S6) showed the maximum and average values to be above the typical minimum detection limit range from 1 to $6 \mathrm{pCi} / \mathrm{m}^{3}$, the remaining sample results were below the MDL. The collected data demonstrate that there were no significant differences in ambient tritium concentrations on site or at the site boundary. All annual average concentrations were below the MDL, except at Station S6, which is adjacent to the former Hazardous Waste 
Management Facility. The maximum concentration recorded at Station $\mathrm{S} 6$ was $40.0 \mathrm{pCi} / \mathrm{m}^{3}$. The values observed at this station are most likely due to continuing emissions during remediation and decommissioning work at the former Hazardous Waste Management Facility.

To put Station S6's maximum value of 40 $\mathrm{pCi} / \mathrm{m}^{3}$ into perspective, the concentration guide for tritium in air is $100,000 \mathrm{pCi} / \mathrm{m}^{3}$ (DOE Order 5400.5). This is the amount of an airborne radionuclide which, if inhaled at that level for one year, would result in an effective dose equivalent of $100 \mathrm{mrem}(1 \mathrm{mSv})$ to the maximally exposed individual. Therefore, all BNL station measurements of ambient tritium are less than 0.1 percent of the DOE-derived concentration guide value. Observed concentrations of tritium at the sampling stations in 2001 are comparable to

Table 4-4. Ambient Airborne Tritium Measurements.

\begin{tabular}{|c|c|c|c|c|}
\hline $\begin{array}{l}\text { Sample } \\
\text { Station }\end{array}$ & $\begin{array}{l}\text { Wind } \\
\text { Sector }\end{array}$ & $\begin{array}{l}\text { Validated } \\
\text { Samples }\end{array}$ & $\begin{array}{l}\text { Maximum } \\
\left(\mathrm{pCi} / \mathrm{m}^{3}\right)\end{array}$ & $\begin{array}{l}\text { Average } \\
\left(\mathrm{pCi} / \mathrm{m}^{3}\right)\end{array}$ \\
\hline 9 & NE & 12 & $<3.4$ & $0.8 \pm 0.7$ \\
\hline 011 & NNE & 11 & $<6.5$ & $1.0 \pm 1.0$ \\
\hline 012 & NNE & 12 & $<6.8$ & $0.7 \pm 0.6$ \\
\hline P2 & NNW & 12 & $7.7 \pm 4.2$ & $1.3 \pm 1.2$ \\
\hline 030 & ENE & 12 & $<5.6$ & $0.9 \pm 0.9$ \\
\hline 034 & NNW & 12 & $<5.8$ & $0.5 \pm 1.0$ \\
\hline 049 & $E$ & 11 & $8.2 \pm 4.3$ & $1.7 \pm 1.4$ \\
\hline 53 & NW & 11 & $<4.0$ & $0.4 \pm 0.9$ \\
\hline 063 & W & 1 & $5.4 \pm 4.0$ & $1.4 \pm 1.1$ \\
\hline 075 & SW & 11 & $<4.3$ & $0.7 \pm 0.5$ \\
\hline 076-302 & ESE & 11 & $1.5 \pm 1.0$ & $1.0 \pm 0.9$ \\
\hline 080 & ESE & 7 & $4.3 \pm 2.2$ & $1.4 \pm 1.3$ \\
\hline 082 & W & 11 & $<6.5$ & $0.4 \pm 0.8$ \\
\hline S6 & SE & 12 & $40.0 \pm 2.4$ & $16.2 \pm 8.5$ \\
\hline P7 & ESE & 12 & $4.1 \pm 2.1$ & $0.7 \pm 0.7$ \\
\hline 105 & $S$ & 12 & $2.8 \pm 1.1$ & $0.7 \pm 0.7$ \\
\hline 108 & SE & 10 & $<6.4$ & $0.3 \pm 1.1$ \\
\hline P4 & WSW & 12 & $<4.9$ & $0.9 \pm 0.7$ \\
\hline 111 & SW & 9 & $<6.7$ & $0.3 \pm 1.4$ \\
\hline 122 & SSE & 9 & $<6.5$ & $0.4 \pm 0.9$ \\
\hline 126 & SSW & 9 & $<6.1$ & $0.3 \pm 0.8$ \\
\hline $\begin{array}{l}\text { Grand } \\
\text { Average }\end{array}$ & & & & $1.6 \pm 0.7$ \\
\hline \multicolumn{5}{|c|}{$\begin{array}{l}\text { Notes: } \\
\text { See Figure 4-4 for station locations. } \\
\text { Wind sector is the downwind direction of the sample station from the five BNL } \\
\text { facilities noted in Section } 4.1 \text { that are subject to NESHAPs SubpartH } \\
\text { continuous monitoring requirements. } \\
\text { All values reported with a } 95 \% \text { confidence interval. } \\
\text { Typical minimum detection limit for tritium is between } 1 \text { and } 6 \mathrm{pCi} / \mathrm{m}^{3} \text {. }\end{array}$} \\
\hline
\end{tabular}

concentrations observed in 2000 , and are considerably lower than measured station concentrations in 1996, when the HFBR released $48 \mathrm{Ci}$ of HTO to the atmosphere.

\subsubsection{Removal Action V Recharge Basin}

As described in the BNL Site Environmental Report for Calendar Year 1997 (BNL 1999), an interim pump-and-recharge system was constructed to control the leading edge of the plume of tritiated groundwater associated with the leaking spent-fuel storage pool at the HFBR. Discharge from this system was directed to the Removal Action (RA) V Recharge Basin that had already been established in the center of the site. This was done to allow natural decay of the tritium to levels below the drinking water standard of $20,000 \mathrm{pCi} / \mathrm{L}$ before the groundwater migrated off site.

The pump-and recharge system used three extraction wells to pump groundwater containing both tritium and volatile organic compounds from approximately 150 feet below ground surface to carbon filtration units, and ultimately to the RA V Recharge Basin, located 3,000 feet to the north of the plume edge. (The volatile organic compounds being treated by this system were from sources unrelated to the HFBR.)

Using assumptions that later proved to be very conservative, the recharge basin was evaluated, prior to the start of pumping operations, as a potential air emission source for NESHAPs compliance. In addition, three polemounted air samplers were located near the recharge basin to monitor ambient tritium concentrations. Two monitors were installed immediately adjacent to the basin at the northeast and southeast corners (Stations 076-300 and 076-301 on Figure 4-4), downwind of the predominant winds on site (see BNL wind rose in Chapter 1, Figure 1-10). The third monitoring station was located near the National Weather Service building (Station 077-300), approximately 0.2 mile east of the basin.

In September 2000, the pump-and-recharge system was placed on standby status after no detectable levels of tritium were found in nearby groundwater monitoring wells located southeast of the system. However, airborne HTO monitor- 
Table 4-5. Ambient Tritium Monitoring Results at RA V Recharge Basin.

\begin{tabular}{|c|c|c|c|c|}
\hline Location & $\begin{array}{l}\text { Validated } \\
\text { Samples }\end{array}$ & Detections & $\underset{\left(\mathrm{pCi} / \mathrm{m}^{3}\right)}{\text { Maximum }}$ & $\begin{array}{l}\text { Average } \\
\left(\mathrm{pCi} / \mathrm{m}^{3}\right)\end{array}$ \\
\hline Northeast corner of basin (076-300) & 9 & 2 & $5.1 \pm 3.4$ & $2.0 \pm 1.2$ \\
\hline Southeast corner of basin (076-301) & 8 & 0 & $<3.9$ & $0.9 \pm 0.7$ \\
\hline National Weather Service Building (077-300) & 9 & 0 & $<3.7$ & $0.8 \pm 0.9$ \\
\hline \multicolumn{5}{|c|}{$\begin{array}{l}\text { Notes: } \\
\text { See Figure 4-4 for sample station locations. } \\
\text { Typical minimum detection limit for tritium is between } 1 \text { and } 6 \mathrm{pCi} / \mathrm{m}^{3} . \\
\text { Sampling ended in October } 2001 \text { due to the shutdown of the tritium pump and recharge remediation system. }\end{array}$} \\
\hline
\end{tabular}

ing in the vicinity of the RA V Recharge Basin continued through October 2001. During 2001, two of the 26 validated samples were detectable (see Table 4-5). These results are consistent with prior findings, which show that the majority of tritium samples collected since the tritium surveillance began in 1997 have been below the MDL.

\subsection{NONRADIOLOGICAL AIRBORNE EMISSIONS}

Various state and federal regulations governing nonradiological releases require facilities to conduct periodic or continuous emissions monitoring to demonstrate compliance with emission limits. BNL has several emission sources subject to state and federal regulatory requirements that do not require emissions monitoring (see Chapter 3 for more details). The Central Steam Facility (CSF) is the only BNL emission source that is required to monitor nonradiological emissions.

The CSF supplies steam for heating and cooling to BNL major facilities through an underground steam distribution and condensate grid. The location of the CSF is shown in Figure 4-1. The combustion units at the CSF are designated as Boilers 1A, 5, 6, and 7. Boiler 1A, which was installed in 1962, has a heat input of 56.7

MMBtu/hr. Boiler 5 was installed in 1965 and has a heat input of $225 \mathrm{MMBtu} / \mathrm{hr}$. The newest units, Boilers 6 and 7, were installed in 1984 and 1996. Each of these boilers has a heat input of 147 MMBtu/hr. For perspective, Keyspan's Northport New York power station has four utility-sized turbine/generator boilers, each with a nominal heat input of 1,330 MMBtu/hr.

Because of their design, heat inputs, and dates of installation, Boilers 6 and 7 are subject to Title 6 of the New York Code, Rules, and Regulations (NYCRR) Part 227-2, and the federal New
Source Performance Standard, 40 CFR 60 Subpart Db. As such, these boilers are equipped with continuous emission monitors for nitrogen oxides $\left(\mathrm{NO}_{\mathbf{x}}\right)$. Boiler 7 emissions are also continuously monitored for opacity. To measure combustion efficiency, both boilers are also monitored for carbon dioxide $\left(\mathrm{CO}_{2}\right)$. Continuous emissions monitoring results from the two boilers are reported on a quarterly basis to EPA and the New York State Department of Environmental Conservation.

From May 1 to September 15 (the peak ozone period), compliance with the $0.30 \mathrm{lbs} /$ $\mathrm{MMBtu} / \mathrm{hrNO}_{\mathbf{x}}$ emissions standard is demonstrated by calculating the 24 -hour average emission rate from continuous emission monitoring system readings and comparing the value to the emission standard. The remainder of the year, the calculated 30-day rolling average emission rate is used to establish compliance. Boiler 7 opacity levels are recorded as 6-minute averages. Measured opacity levels cannot exceed 20 percent opacity, except for one 6-minute period per hour of not more than 27 percent opacity. In 2001, there were no measured exceedances of the $\mathrm{NO}_{\mathrm{x}}$ emission standard for either boiler, or excess opacity measurements on Boiler 7.

In the spring of 1997, the Long Island Lighting Company completed work extending a natural gas main into the CSF. To accommodate the combustion of natural gas, new gas rings were added to the burners of Boiler 5 and natural gas trains were installed to connect the gas main to Boilers 5 and 7. In 1998, existing steamatomized oil burners on Boiler No. 6 were replaced with two dual-fuel low $\mathrm{NO}_{\mathbf{x}}$ burners, and a natural gas train was added to connect the boiler to the gas main. 
Table 4-6. Central Steam Facility Fuel Use and Emissions (1996-2001).

\begin{tabular}{|c|c|c|c|c|c|c|c|c|c|c|}
\hline \multirow[b]{2}{*}{ Year } & \multicolumn{6}{|c|}{ Annual Fuel Use and Fuel Heating Values } & \multicolumn{4}{|c|}{ Emissions } \\
\hline & $\begin{array}{c}\text { \# } 6 \text { Oil } \\
\left(10^{3} \text { gals }\right)\end{array}$ & $\begin{array}{l}\text { Heating } \\
\text { Value } \\
\text { (MMBtu) }\end{array}$ & $\begin{array}{c}\text { \# } 2 \text { Oil } \\
\left(10^{3} \text { gals }\right)\end{array}$ & $\begin{array}{l}\text { Heating } \\
\text { Value } \\
\text { (MMBtu) }\end{array}$ & $\begin{array}{c}\text { Natural Gas } \\
\qquad\left(10^{6} \mathrm{ft}^{3}\right)\end{array}$ & $\begin{array}{l}\text { Heating } \\
\text { Value } \\
\text { MMBtu }\end{array}$ & $\begin{array}{c}\text { TSP } \\
\text { (tons) }\end{array}$ & $\begin{array}{c}\mathrm{NO}_{\mathbf{x}} \\
\text { (tons) }\end{array}$ & $\begin{array}{c}\mathrm{SO}_{2} \\
\text { (tons) }\end{array}$ & $\begin{array}{l}\text { VOCs } \\
\text { (tons) }\end{array}$ \\
\hline 1996 & $4,782.55$ & 703,991 & 52.77 & 7,388 & 0.00 & 0 & 14.0 & 104.9 & 109.0 & 0.7 \\
\hline 1997 & $3,303.43$ & 484,613 & 10.23 & 1,432 & 190.65 & 26,691 & 13.7 & 83.5 & 75.1 & 1.0 \\
\hline 1998 & 354.28 & 52,283 & 9.44 & 1,322 & 596.17 & 608,093 & 2.7 & 75.1 & 8.9 & 1.7 \\
\hline 1999 & 682.76 & 78,335 & 2.77 & 388 & 614.98 & 627,280 & 5.1 & 53.5 & 16.7 & 1.8 \\
\hline 2000 & $2,097.32$ & 309,317 & 0.82 & 115 & 342.40 & 349,248 & 9.5 & 81.6 & 45.0 & 1.2 \\
\hline 2001 & $3,645.10$ & 538,847 & 3.40 & 476 & 103.96 & 106,039 & 17.5 & 80.4 & 77.8 & 0.8 \\
\hline SP & e Ora & $\begin{array}{l}\text { tes } \\
\text { unds }\end{array}$ & & & & & & & & \\
\hline
\end{tabular}

Through much of 2001, natural gas prices exceeded those for residual fuel (No. 6 oil). During these periods of higher natural gas prices, the CSF burned residual fuel. As a result, residual fuel supplied more than 83 percent of the heating and cooling needs of BNL's major facilities in 2001 (see Table 4-6). By comparison, in 1999, natural gas satisfied more than 88 percent of the major facility heating and cooling needs. Consequently, annual emissions of particulates, $\mathrm{NO}_{\mathbf{x}}$, and $\mathrm{SO}_{2}$,were 12.1 tons, 26.9 tons, and 61.1 tons higher than the respective totals for 1999 .

\section{REFERENCES}

BNL. 1999. BNL Site Environmental Report for Calendar Year 1997. BNL-52585. Brookhaven National Laboratory, Upton, NY. August 2000.

DOE Order 5400.1. 1990. General Environmental Protection Program. U.S. Department of Energy, Washington, D.C. Change 1: 6-29-90.

DOE Order 5400.5. 1993. Radiation Protection of the Public and the Environment. U.S. Department of Energy, Washington, D.C. Change 2: 1-7-93.

NYCRR Part 227-2. Title 6. 2001. Reasonably Available Control Technology for Oxides of Nitrogen, New York State Department of Environmental Conservation, Albany, N.Y. Change 7-3-01.

40 CFR 60 Subpart Db. (52 FR 47842, Dec. 16, 1987, as amended 66 FR 49834, Oct. 1, 2001)

40 CFR 61 Subpart H. (54 FR 51695, Dec. 15, 1989, as amended at 65 FR 62156, Oct. 17, 2000) 
Intentionally Left Blank 
BROOKHAVEN

NATIONAL

LABORATORY

2001 SITE ENVIRONMENTAL REPORT

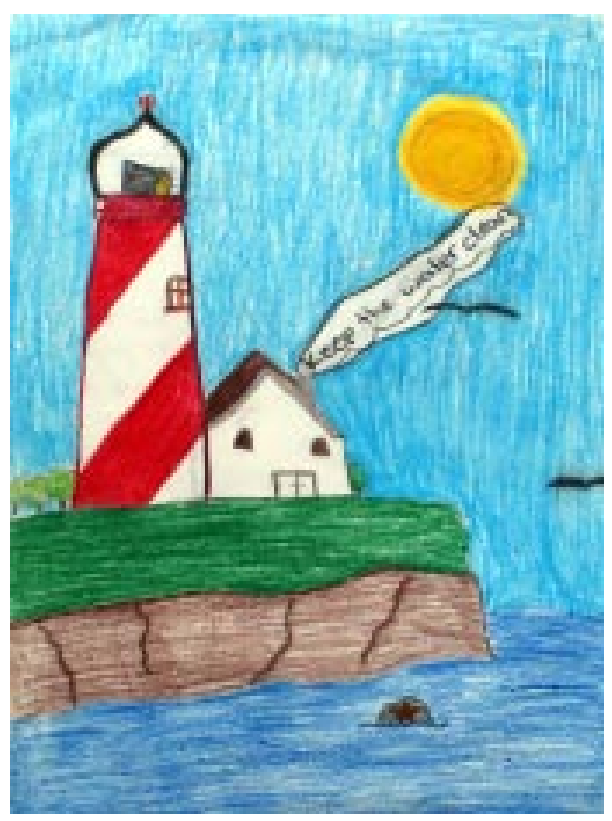

Chapter 5

\section{Water Quality}

Some BNL operations discharge, or have the potential to discharge, wastewater containing very low levels of radiological, organic, and/or inorganic contaminants to surface waters or to groundwater recharge basins. Monitoring, pollution prevention, and careful operation of treatment facilities helps ensure that these discharges comply with all applicable requirements and that the public, employees, and environment are protected.

Analytical data for 2001 showed that the average gross alpha and beta activity levels in the Sewage Treatment Plant discharge were within the range typical of background surface waters. Tritium releases to the Peconic River continued to drop and were the lowest since monitoring began in 1966. Cesium-137 and strontium-90 were detected infrequently in the effluent at levels significantly less than the drinking water standard. No other gamma-emitting nuclides in the effluent that were possibly attributable to BNL operations were detected throughout 2001. Nonradiological monitoring of the effluent showed that, with the exception of isolated incidents of noncompliance, organic and inorganic parameters were within New York State Pollutant Discharge Elimination System effluent limitations or other applicable standards. Inorganic data from the upstream, downstream, and control locations demonstrated that elevated amounts of aluminum, silver, iron, and zinc detected within the Peconic River are a result of natural geology. The low $\mathrm{pH}$ detected within several sections of the river was due to natural causes. Based upon the 2001 nonradiological and radiological data, the Peconic River water quality is comparable to other local freshwater rivers and is of consistent quality both upstream and downstream of BNL. Low concentrations of tritium were detected at the Sewage Treatment Plant outfall, but only sporadic detections were found at the first downstream monitoring station. The maximum tritium concentration downstream of the treatment plant discharge was approximately 4 percent of the drinking water standard. 


\subsection{SURFACE WATER MONITORING PROGRAM}

Treated wastewater from the BNL Sewage Treatment Plant (STP) is discharged into the headwaters of the Peconic River. This discharge is permitted by the New York State Department of Environmental Conservation (NYSDEC) point source discharge program. Effluent limits are based on the water quality standards established by NYSDEC, as well as historical operational data. To assess the impact of this discharge on the quality of the river, surface water monitoring is conducted at several locations upstream and downstream of the point of discharge. Monitoring Station HY, located on site but upstream of all BNL operations, provides information on the background water quality of the Peconic River. The Carmans River is monitored as a geographic control location for comparative purposes, as it is not affected by BNL operations.

On the BNL site, the Peconic River is an intermittent stream. Off-site flow only occurs during periods of sustained precipitation, typically in the spring. Due to heavier than average rain in March and June of 2001 (see Figure 1-11), off-site flow was recorded from February through August. Figure 5-1 shows an on-site portion of the Peconic River downstream of the STP discharge.

The following sections describe BNL's surface water monitoring and surveillance program.

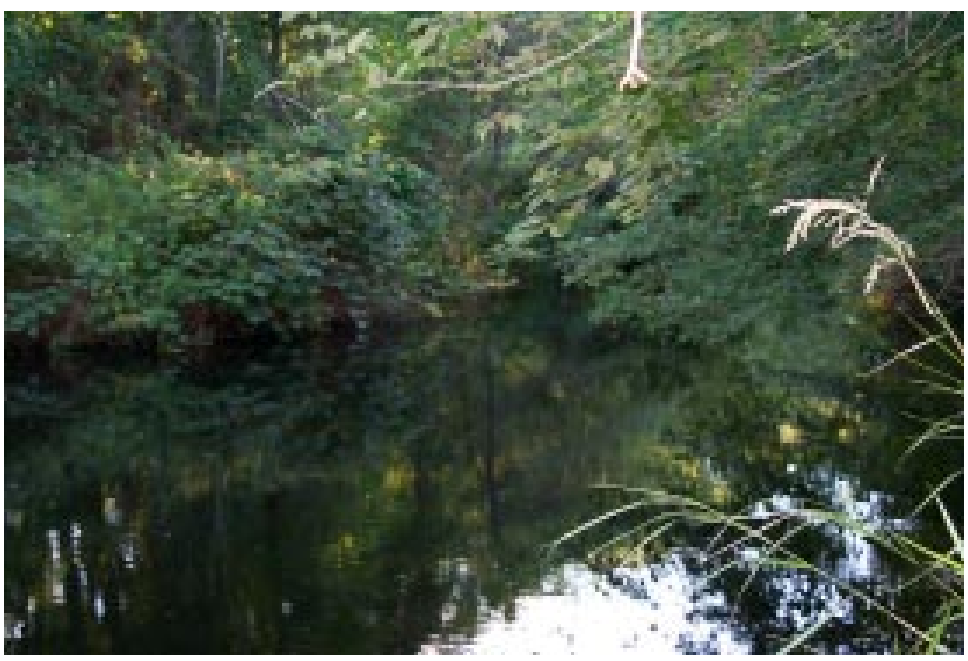

Figure 5-1. Peconic River West of Monitoring Station HMn.

\subsection{SANITARY SYSTEM EFFLUENTS}

The STP effluent (Outfall 001) is a discharge point operated under a State Pollutant Discharge Elimination System (SPDES) permit. Figure 5-2 shows a schematic of the STP and the STP sampling locations. The BNL STP treatment system includes: 1) primary clarification to remove settleable solids and floatable materials, 2) aerobic oxidation for secondary removal of biological matter and nitrification of ammonia, 3) secondary clarification, 4) intermittent sand filtration for final solids removal, and 5) ultraviolet disinfection for bacterial control prior to discharge to the Peconic River.

Tertiary treatment for nitrogen removal is also provided by controlling the oxygen levels in the aeration tanks. During the aeration process (i.e., Step 2), the oxygen levels are allowed to drop to the point where microorganisms use nitrate-bound oxygen for respiration, liberating nitrogen gas and consequently reducing the concentration of nitrogen in the STP discharge. Nitrogen is an essential nutrient in biological systems that, in high concentrations, can cause excessive aquatic vegetation growth. Since vegetation utilizes oxygen during nighttime hours, too much aquatic plant life can deprive a water system of oxygen needed by fish and other aquatic organisms for survival. Reducing the concentration of nitrogen in the STP discharge allows plant growth within the Peconic river to remain in balance with the nutrients provided by natural sources. During 2001, the STP discharge continuously met the nitrogen limit of $10 \mathrm{mg} / \mathrm{L}$ specified in the SPDES permit.

Real-time monitoring of the sanitary waste stream for radioactivity, $\mathrm{pH}$, and conductivity takes place at two locations. The first site is approximately 1.1 miles upstream of the STP, providing at least 30 minutes warning to the STP operator that wastewater is en route that may exceed SPDES limits or BNL effluent release criteria (which are much more stringent than DOE-specified levels). The second site is just before the point where the influent enters the primary clarifier. In addition to the two full monitoring stations, effluent leaving the primary clarifier is monitored a third time for radioactivity. 
Any influent to the clarifier that does not meet SPDES limits or BNL effluent release criteria is diverted to lined holding ponds. The total combined capacity of the two holding ponds exceeds 7,000,000 gallons, or approximately 12 days of flow. Diversion continues until the effluent's water quality meets the permit limits or release criteria. If wastewater is diverted to the holding ponds, it is tested and evaluated against the requirements for release. If necessary, the wastewater is treated, then reintroduced into the STP at a rate that ensures compliance with SPDES permit limits or BNL effluent release criteria. In 2001, a discharge of heat exchange fluid from the Building 902 cryogenic system cooling tower resulted in diversion of the STP influent for approximately one day. Although the discharge of heat exchange fluid did not violate SPDES permit requirements, the STP influent was diverted until the potential impact to aquatic organisms could be assessed. There were no other diversions of the STP influent in 2001.

Solids separated in the clarifiers are pumped to a digester, where they are reduced in volume by anaerobic bacteria. Periodically, a fraction of the sludge is emptied into a drying bed. The drying bed uses solar energy to dry the watery sludge to a semisolid cake. Since the dried sludge contains very low levels of radioactivity (e.g., Co- $60<0.1$ to $2 \mathrm{pCi} / \mathrm{g}$ ), it is containerized for off-site disposal at an authorized facility.

In 2001, BNL continued a third and final phase of STP upgrades. These upgrades include replacement of the anaerobic digester with a digester that uses aerobic organisms to degrade the sludge, upgrades to the pipe distribution system within the sand filters, relining of the holding ponds, and replacement, repair, or relining of approximately 16,000 linear feet of sewer collection and conveyance piping. By the

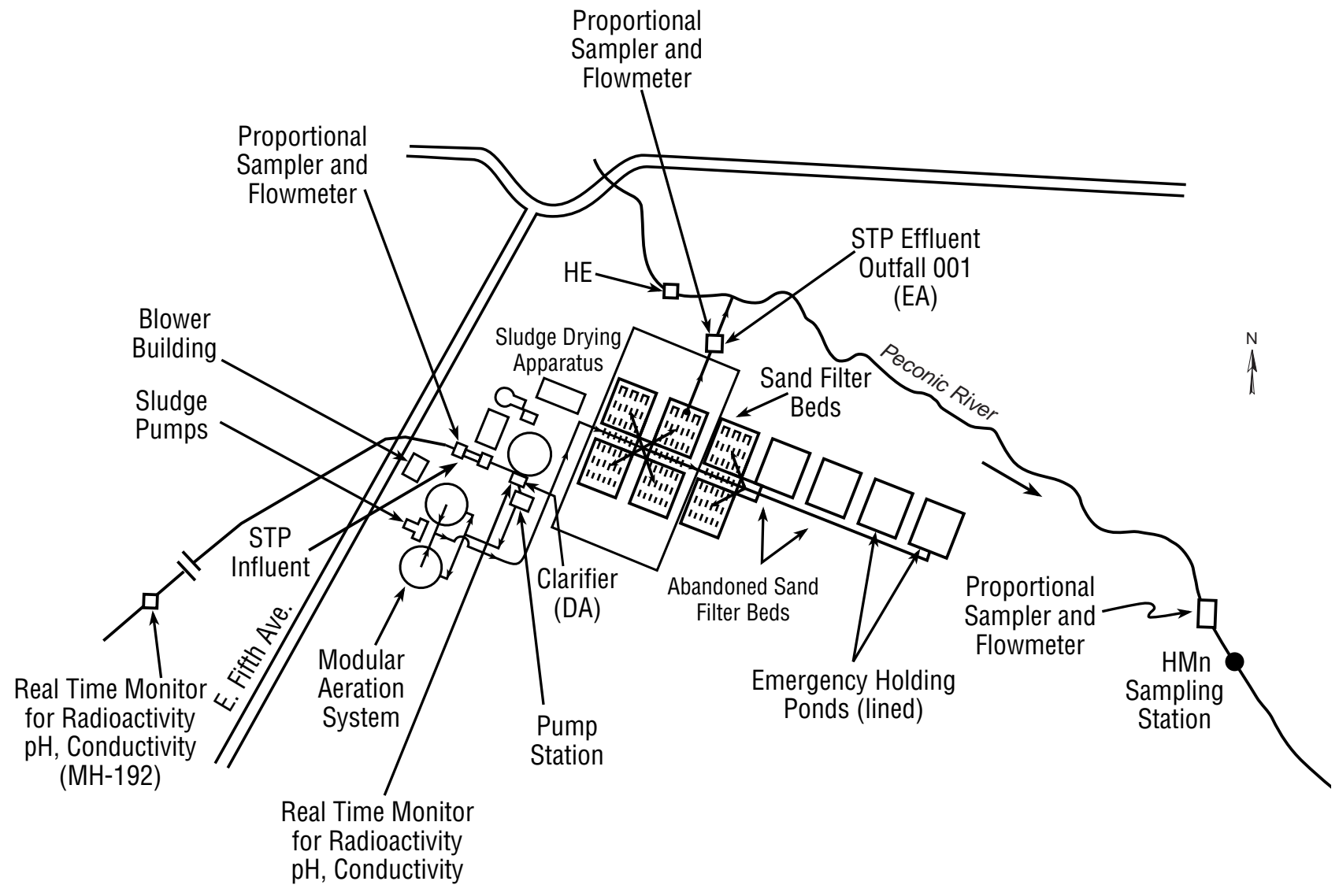

Figure 5-2. Schematic of BNL's Sewage Treatment Plant (STP). 
end of 2001, all piping repairs, holding pond relining, and filter work was completed. Construction of the aerobic digester will be completed in February 2002.

\subsubsection{Sanitary System Effluent - Radiological Analyses}

The STP effluent is sampled at the output of the primary clarifier (Station DA) and at the Peconic River Outfall (Station EA). At each location, samples are collected on a flowproportional basis; that is, for every 1,000 gallons of water treated, approximately 4 fluid ounces of sample are collected and composited into a 5gallon collection container. These samples are analyzed for gross alpha and gross beta activity and tritium concentrations. Samples collected from these locations are also analyzed monthly for gamma-emitting radionuclides and strontium90. During 2001, the frequency of sample collection was decreased from every 24 hours to every 48 hours. This decrease in sample collection frequency was based upon limited detection of contaminants in the STP discharge and the reduced potential for discharge resulting from the shutdown of the High Flux Beam Reactor (HFBR) and Brookhaven Medical Research Reactor (BMRR).

Although the Peconic River is not used as a direct source of potable water, BNL applies the stringent Safe Drinking Water Act (SDWA) standards for comparison purposes when monitoring effluent, in lieu of DOE wastewater criteria. The SDWA specifies that no individual may receive an annual dose greater than 4 mrem $(40 \mu \mathrm{Sv})$ per year from radionuclides present in drinking water. The SDWA annual average gross alpha activity limit is $15 \mathrm{pCi} / \mathrm{L}(0.6 \mathrm{~Bq} / \mathrm{L})$ (including radium-226, but excluding radon and uranium). The SDWA also stipulates a $50 \mathrm{pCi} / \mathrm{L}$ $(1.85 \mathrm{~Bq} / \mathrm{L})$ gross beta activity screening level, above which radionuclide-specific analysis is required. BNL goes beyond this basic screening requirement by performing radionuclide-specific gamma analysis, regardless of the gross beta activity. Other SDWA-specified drinking water limits are $20,000 \mathrm{pCi} / \mathrm{L}(740 \mathrm{~Bq} / \mathrm{L})$ for tritium and $8 \mathrm{pCi} / \mathrm{L}(0.3 \mathrm{~Bq} / \mathrm{L})$ for strontium-90. For all other radionuclides, Derived Concentration Guides (DCGs) found in DOE Order 5400.5
(DOE 1990) are used to determine the concentration of the nuclide, which, if continuously ingested over a calendar year, would produce an effective dose equivalent (EDE) of 4 mrem $(40 \mu \mathrm{Sv})$.

Gross activity (alpha and beta) measurements were used as a screening tool for detecting the presence of radioactivity. Table 5-1 shows the monthly gross alpha and beta activity data and tritium concentrations for the STP influent and effluent during 2001. Annual average gross alpha and beta activity in the STP effluent has remained consistent with, or lower than, levels at control locations for many years. This continued to be the case in 2001. Annual average gross alpha and beta activity of the STP effluent was $1.6 \pm 0.2 \mathrm{pCi} / \mathrm{L}(0.06 \pm 0.01 \mathrm{~Bq} / \mathrm{L})$ and $7.2 \pm 0.5$ $\mathrm{pCi} / \mathrm{L}(0.27 \pm 0.02 \mathrm{~Bq} / \mathrm{L})$, respectively. Control location data showed average gross alpha and beta levels of $5.75 \pm 9.59 \mathrm{pCi} / \mathrm{L}(0.21 \pm 0.36 \mathrm{~Bq} /$ $\mathrm{L})$ and $6.57 \pm 10.22 \mathrm{pCi} / \mathrm{L}(0.24 \pm 0.38 \mathrm{~Bq} / \mathrm{L})$, respectively.

Tritium detected at the STP originates from either HFBR sanitary system releases or small, infrequent batch releases that meet BNL discharge criteria from other facilities. Tritium continues to be released from the HFBR at very low concentrations, due to evaporative losses of residual tritium remaining in the reactor coolant and from off-gassing of the facility. Once tritium is in the air stream, it condenses as a component of water vapor in the air conditioning or air compressor units and is discharged in these wastewater streams. To minimize the quantity of tritium released to the STP, efforts have been made to capture air conditioning condensate generated at the HFBR. A plot of the 2001 tritium concentrations recorded in the STP effluent is presented in Figure 5-3. A 15-year trend plot of annual average tritium concentrations measured in the STP discharge is shown in Figure 5-4. Annual average concentrations have been declining since 1995 .

In 2001, the annual average tritium concentration measured in the STP effluent (EA, Outfall 001) was $136 \mathrm{pCi} / \mathrm{L}(4.1 \mathrm{~Bq} / \mathrm{L})$. This value is below the average minimum detection limit (MDL) for the BNL Analytical Services Laboratory of $329 \mathrm{pCi} / \mathrm{L}(13.0 \mathrm{~Bq} / \mathrm{L})$ and well below 
Table 5-1. Tritium and Gross Activity in Water at the Sewage Treatment Plant.

\begin{tabular}{|c|c|c|c|c|c|c|c|}
\hline & $\begin{array}{l}\text { Monthy } \\
\text { Flow } \\
\text { (L) }\end{array}$ & $\begin{array}{c}\text { Tritium } \\
\text { Maximum } \\
\text { (pCi/L) }\end{array}$ & $\begin{array}{l}\text { Tritium } \\
\text { Average } \\
\text { (pCi/L) }\end{array}$ & $\begin{array}{l}\text { Gross Alpha } \\
\text { Maximum } \\
(p \mathrm{Ci} / \mathrm{L})\end{array}$ & $\begin{array}{l}\text { Gross Alpha } \\
\text { Average } \\
\text { (pCi/L) }\end{array}$ & $\begin{array}{l}\text { Gross Beta } \\
\text { Maximum } \\
(p \mathrm{Ci} / \mathrm{L})\end{array}$ & $\begin{array}{c}\text { Gross Beta } \\
\text { Average } \\
\text { (pCi/L) }\end{array}$ \\
\hline \multicolumn{8}{|l|}{ STP Clarifier } \\
\hline January & $5.25 E+07$ & $<307$ & $69 \pm 50$ & $3.7 \pm 1.8$ & $1.0 \pm 0.4$ & $13.9 \pm 5.6$ & $5.9 \pm 1.2$ \\
\hline February & $3.57 E+07$ & $529 \pm 239$ & $113 \pm 62$ & $4.5 \pm 2.2$ & $1.0 \pm 0.5$ & $26.9 \pm 6.7$ & $10.1 \pm 3.3$ \\
\hline March & $4.59 E+07$ & $983 \pm 246$ & $366 \pm 106$ & $4.3 \pm 2.1$ & $1.3 \pm 0.6$ & $32.9 \pm 7.1$ & $12.9 \pm 4.1$ \\
\hline April & $5.12 E+07$ & $<341$ & $54 \pm 41$ & $4.7 \pm 2.2$ & $1.0 \pm 0.7$ & $32.2 \pm 6.8$ & $9.6 \pm 3.3$ \\
\hline May & $4.81 \mathrm{E}+07$ & $479 \pm 210$ & $111 \pm 52$ & $7.0 \pm 2.8$ & $1.2 \pm 0.7$ & $12.6 \pm 5.8$ & $7.6 \pm 1.1$ \\
\hline June & $6.04 \mathrm{E}+07$ & $<234$ & $26 \pm 45$ & $8.0 \pm 3.1$ & $2.2 \pm 1.0$ & $13.6 \pm 5.5$ & $8.2 \pm 1.2$ \\
\hline July & $6.91 E+07$ & $518 \pm 399$ & $127 \pm 58$ & $5.3 \pm 2.6$ & $2.4 \pm 0.7$ & $12.2 \pm 6.0$ & $6.7 \pm 1.1$ \\
\hline August & $7.17 \mathrm{E}+07$ & $<300$ & $95 \pm 43$ & $4.3 \pm 2.1$ & $2.2 \pm 0.5$ & $12.5 \pm 5.8$ & $6.4 \pm 1.2$ \\
\hline September & $4.68 \mathrm{E}+07$ & $<389$ & $61 \pm 51$ & $4.3 \pm 2.2$ & $1.5 \pm 0.7$ & $11.6 \pm 5.5$ & $6.9 \pm 1.2$ \\
\hline October & $6.97 \mathrm{E}+07$ & $<347$ & $25 \pm 56$ & $5.0 \pm 2.5$ & $1.5 \pm 0.5$ & $15.4 \pm 5.9$ & $7.1 \pm 1.3$ \\
\hline November & $5.93 E+07$ & $<295$ & $-25 \pm 60$ & $5.0 \pm 2.4$ & $2.6 \pm 0.7$ & $14.3 \pm 5.7$ & $8.4 \pm 1.7$ \\
\hline December & $4.81 E+07$ & $287 \pm 193$ & $89 \pm 69$ & $4.4 \pm 2.7$ & $1.2 \pm 0.8$ & $13.4 \pm 6.0$ & $8.0 \pm 1.2$ \\
\hline Annual Average & & & $97 \pm 21$ & & $1.6 \pm 0.2$ & & $8.1 \pm 0.7$ \\
\hline \multicolumn{8}{|l|}{ STP Outfall } \\
\hline January & $4.53 E+07$ & $317 \pm 208$ & $101 \pm 41$ & $2.3 \pm 1.6$ & $1.0 \pm 0.4$ & $11.4 \pm 5.7$ & $4.2 \pm 1.4$ \\
\hline February & $3.54 E+07$ & $570 \pm 227$ & $176 \pm 64$ & $7.0 \pm 2.7$ & $1.7 \pm 0.8$ & $16.0 \pm 6.2$ & $6.9 \pm 1.6$ \\
\hline March & $4.15 E+07$ & $940 \pm 241$ & $329 \pm 74$ & $4.5 \pm 2.2$ & $1.3 \pm 0.7$ & $29.2 \pm 6.9$ & $7.7 \pm 2.3$ \\
\hline April & $5.45 \mathrm{E}+07$ & $410 \pm 188$ & $120 \pm 43$ & $3.2 \pm 2.1$ & $1.0 \pm 0.5$ & $17.2 \pm 6.2$ & $7.1 \pm 1.3$ \\
\hline May & $4.28 \mathrm{E}+07$ & $407 \pm 195$ & $153 \pm 39$ & $3.5 \pm 2.4$ & $0.9 \pm 0.5$ & $16.4 \pm 6.2$ & $8.8 \pm 1.3$ \\
\hline June & $6.22 \mathrm{E}+07$ & $498 \pm 207$ & $82 \pm 58$ & $6.2 \pm 2.8$ & $1.4 \pm 0.6$ & $15.2 \pm 5.8$ & $7.2 \pm 1.4$ \\
\hline July & $5.17 \mathrm{E}+07$ & $425 \pm 255$ & $131 \pm 56$ & $3.1 \pm 2.0$ & $1.7 \pm 0.3$ & $15.8 \pm 5.9$ & $7.6 \pm 1.6$ \\
\hline August & $5.44 E+07$ & $401 \pm 225$ & $135 \pm 44$ & $4.9 \pm 2.4$ & $1.6 \pm 0.6$ & $13.4 \pm 5.8$ & $6.7 \pm 1.3$ \\
\hline September & $3.08 \mathrm{E}+07$ & $<389$ & $87 \pm 53$ & $5.5 \pm 2.4$ & $2.7 \pm 0.7$ & $10.6 \pm 5.4$ & $7.1 \pm 1.2$ \\
\hline October & $3.84 \mathrm{E}+07$ & $495 \pm 256$ & $70 \pm 62$ & $7.5 \pm 2.6$ & $2.4 \pm 0.9$ & $12.0 \pm 5.6$ & $7.0 \pm 1.2$ \\
\hline November & $2.81 E+07$ & $<295$ & $40 \pm 52$ & $4.3 \pm 2.3$ & $1.6 \pm 0.9$ & $14.6 \pm 5.7$ & $9.1 \pm 1.6$ \\
\hline December & $3.09 E+07$ & $426 \pm 239$ & $180 \pm 72$ & $5.0 \pm 2.8$ & $2.0 \pm 0.8$ & $13.7 \pm 5.7$ & $7.9 \pm 1.7$ \\
\hline Annual Average & & & $136 \pm 19$ & & $1.6 \pm 0.2$ & & $7.2 \pm 0.5$ \\
\hline Total Release & $5.16 \mathrm{E}+08$ & & $72.9 \mathrm{mCi}$ & & $0.8 \mathrm{mCi}$ & & $3.7 \mathrm{mCi}$ \\
\hline SDWA Limit & & & 20,000 (pCi/L) & & 15.0 (pCi/L) & & $50.0(\mathrm{pCi} / \mathrm{L})$ \\
\hline Average MDL & & & 329 (pCi/L) & & $3.2(\mathrm{pCi} / \mathrm{L})$ & & 8.7 (pCi/L) \\
\hline \multicolumn{8}{|c|}{$\begin{array}{l}\text { Notes: } \\
\text { All values shown with a } 95 \% \text { confidence interval. } \\
\text { To convert values from pCi to Bq, divide by } 27.03 \text {. } \\
\text { MDL = Minimum Detection Limit } \\
\text { SDWA = Safe Drinking WaterAct }\end{array}$} \\
\hline
\end{tabular}

the NYS drinking water standard of 20,000 $\mathrm{pCi} / \mathrm{L}$. A total of $0.073 \mathrm{Ci}$ (2.7 million $\mathrm{Bq})$ of tritium was released during the year. This level is almost 30 percent less than the discharge recorded for 2000 and is the lowest annual release of tritium to the Peconic River observed since routine measurements began in 1966, and is less than 2 percent of the peak values released in the late 1980s (see Figure 5-5). Tritium was detected in only 10 percent of the samples collected at the
STP discharge to the Peconic River. The maximum concentration of tritium was $940 \mathrm{pCi} / \mathrm{L}$ (35 $\mathrm{Bq} / \mathrm{L})$, detected in March. Reduced concentrations of tritium are primarily the result of operations readying the HFBR for permanent closure. In 2000, most of the primary coolant, which has very high concentrations of tritium, was drained from the reactor and shipped off site. The reactor was subsequently partially filled with tap water. This significantly reduced the inventory 
Figure 5-3. Tritium

Concentrations in Effluent from the Sewage Treatment Plant (CY 2001).
Figure 5-4. Average Tritium Concentrations at BNL's Sewage Treatment Plant, nearby Peconic River Locations (1987-2001).
Figure 5-5. Tritium Released to the Peconic River, 15-Year Trend (1987-2001).
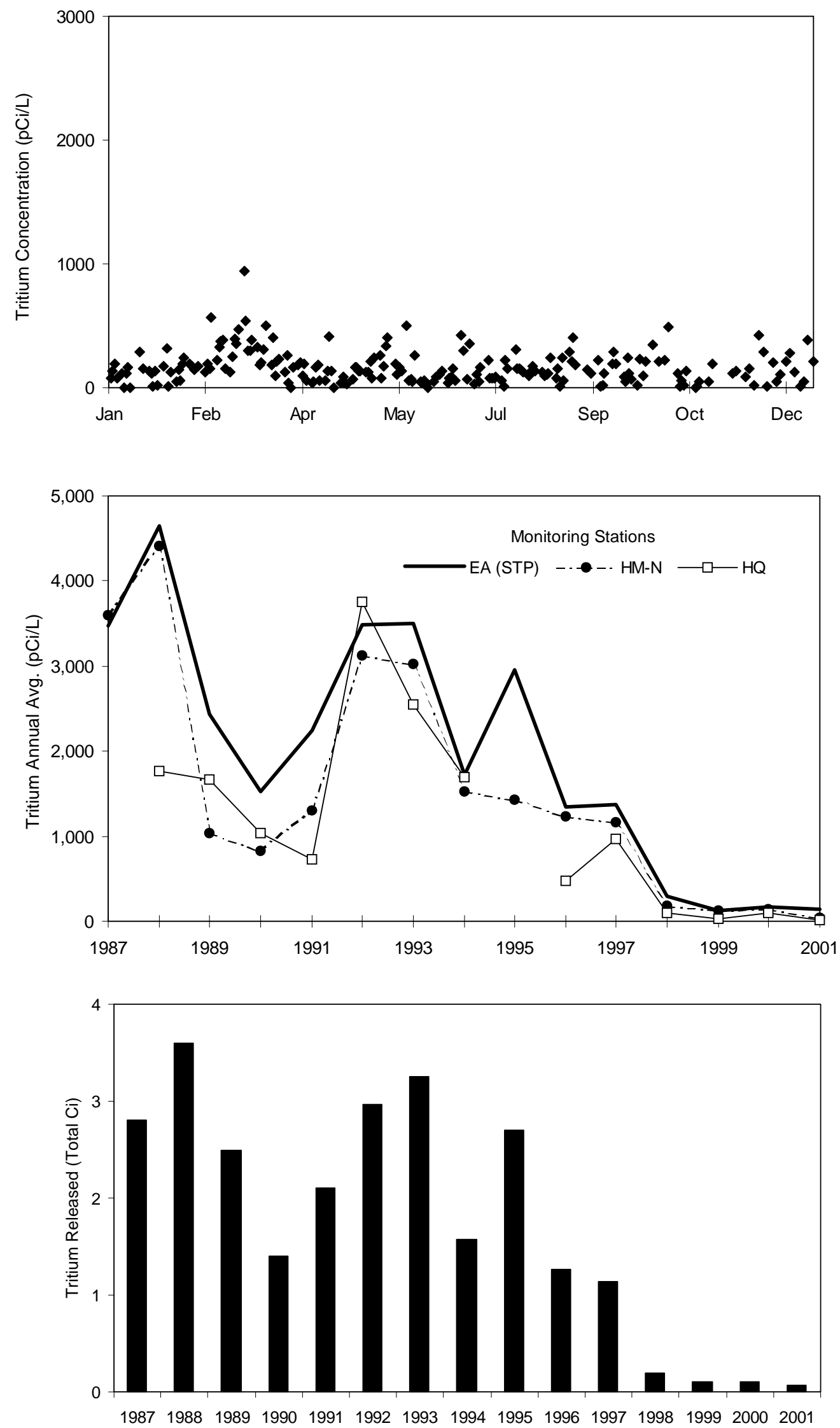
of tritium at the HFBR, resulting in declining levels from 2000 to 2001 . These levels will continue to decline as the HFBR moves into permanent decommissioning.

Table 5-2 presents the gamma spectroscopy analytical data of the monthly STP composite samples for radionuclides. During 2001, the samples showed the presence of cesium-137, once in the STP effluent and once in the influent. The concentration of cesium-137 detected in the effluent was approximately 1 percent of the SDWA drinking water standard. The presence of cesium-137 in the STP effluent is due to the continued leaching of very small amounts of cesium-137 from the STP sand filter beds and from sludge residuals in the piping systems. This radionuclide was deposited during pre-1990 releases to the site sanitary

Table 5-2. Gamma-Emitting Radionuclides and Strontium-90 in Water at the Sewage Treatment Plant.

\begin{tabular}{|c|c|c|c|c|c|c|}
\hline & $\begin{array}{c}\text { Flow } \\
\text { (Liters) }\end{array}$ & $\begin{array}{l}\text { Co-60 } \\
\text { (pCi/L) }\end{array}$ & $\begin{array}{l}\text { Cs-137 } \\
\text { (pCi/L) }\end{array}$ & $\begin{array}{c}\text { Be-7 } \\
(\mathrm{pCi} / \mathrm{L})\end{array}$ & $\begin{array}{l}\text { Na-22 } \\
\text { (pCi/L) }\end{array}$ & $\begin{array}{l}\text { Sr-90 } \\
(\mathrm{pCi} / \mathrm{L})\end{array}$ \\
\hline \multicolumn{7}{|l|}{ STP Clarifier } \\
\hline January & $5.25 E+07$ & ND & ND & ND & ND & $<0.18$ \\
\hline February & $3.57 \mathrm{E}+07$ & ND & ND & ND & ND & $<0.19$ \\
\hline March & $4.59 E+07$ & ND & ND & ND & ND & $<0.22$ \\
\hline April & $5.12 \mathrm{E}+07$ & ND & $1.72 \pm 1.41$ & ND & ND & $<0.27$ \\
\hline May & $4.81 \mathrm{E}+07$ & ND & ND & ND & ND & $<0.17$ \\
\hline June & $6.04 \mathrm{E}+07$ & ND & ND & ND & ND & $<0.16$ \\
\hline July & $6.91 \mathrm{E}+07$ & ND & ND & ND & ND & $<0.16$ \\
\hline August & $7.17 \mathrm{E}+07$ & ND & ND & ND & ND & $<0.17$ \\
\hline September & $4.68 \mathrm{E}+07$ & ND & ND & ND & ND & $<0.22$ \\
\hline October & $6.97 \mathrm{E}+07$ & ND & ND & ND & ND & $<0.25$ \\
\hline November & $5.93 E+07$ & ND & ND & ND & ND & $0.28 \pm 0.11$ \\
\hline December & $4.81 \mathrm{E}+07$ & ND & ND & ND & ND & $<0.21$ \\
\hline \multicolumn{7}{|l|}{ STP Outfall } \\
\hline January & $4.53 E+07$ & ND & ND & ND & ND & $0.26 \pm 0.10$ \\
\hline February & $3.54 \mathrm{E}+07$ & ND & ND & ND & ND & $<1.0$ \\
\hline March & $4.15 E+07$ & ND & ND & ND & ND & $<0.19$ \\
\hline April & $5.45 E+07$ & ND & ND & ND & ND & $<0.15$ \\
\hline May & $4.28 \mathrm{E}+07$ & ND & ND & ND & ND & $<0.22$ \\
\hline June & $6.22 E+07$ & ND & ND & ND & ND & $0.24 \pm 0.10$ \\
\hline July & $5.17 \mathrm{E}+07$ & ND & ND & ND & ND & $<0.21$ \\
\hline August & $5.44 \mathrm{E}+07$ & ND & ND & ND & ND & $<0.21$ \\
\hline September & $3.08 \mathrm{E}+07$ & ND & ND & ND & ND & $<0.18$ \\
\hline October & $3.84 \mathrm{E}+07$ & ND & ND & ND & ND & $<0.21$ \\
\hline November & $2.81 E+07$ & ND & $1.22 \pm 0.69$ & ND & ND & $<0.17$ \\
\hline December & $3.09 \mathrm{E}+07$ & ND & ND & ND & ND & $<0.16$ \\
\hline \multicolumn{2}{|l|}{ Total Release } & $0(\mathrm{mCi})$ & $0.03(\mathrm{mCi})$ & $0(\mathrm{mCi})$ & $0(\mathrm{mCi})$ & $0.03(\mathrm{mCi})$ \\
\hline \multicolumn{2}{|l|}{ DOE Order 5400.5 DCG } & $5,000(\mathrm{pCi} / \mathrm{L})$ & $3,000(\mathrm{pCi} / \mathrm{L})$ & $50,000(\mathrm{pCi} / \mathrm{L})$ & 10,000 (pCi/L) & $1,000(\mathrm{pCi} / \mathrm{L})$ \\
\hline \multicolumn{2}{|l|}{ Dose Limit of 4 mrem EDE } & 100 (pCi/L) & $200($ pCi/L) & $6,000(\mathrm{pCi} / \mathrm{L})$ & 400 (pCi/L) & $8(\mathrm{pCi} / \mathrm{L})$ \\
\hline \multicolumn{7}{|c|}{$\begin{array}{l}\text { Notes: } \\
\text { All values shown with a 95\% confidence interval. } \\
\text { DCG = Derived Concentration Guide } \\
\text { EDE = Effective Dose Equivalent } \\
\mathrm{ND}=\text { Not Detected }\end{array}$} \\
\hline
\end{tabular}


system. The cesium-137 concentrations in the STP influent and effluent have been steadily decreasing since 1990, as shown in Figure 5-6. Total releases for 2001 were approximately one-quarter of 2000 levels. Upgrades to the sewer system - specifically, cleaning and relining or repairing the piping systems-have most likely assisted in the decline in cesium137 releases.

Strontium-90 was detected at very low levels in both the STP influent and effluent monthly composite samples on three occasions in 2001 (once in the influent and twice in the effluent). The largest single value of strontium90 recorded for the STP influent was $0.28 \pm$ $0.1 \mathrm{pCi} / \mathrm{L}(0.01 \pm 0.004 \mathrm{~Bq} / \mathrm{L})$, which is 3.5 percent of the drinking water standard of 8 $\mathrm{pCi} / \mathrm{L}(0.3 \mathrm{~Bq} / \mathrm{L})$. The largest strontium-90 value for an STP effluent sample was $0.26 \pm$ $0.1 \mathrm{pCi} / \mathrm{L}(0.01 \pm 0.004 \mathrm{~Bq} / \mathrm{L})$, or 3.5 percent of the drinking water standard. The highest strontium-90 concentration detected in the STP effluent was approximately 20 percent of the highest level recorded in 2000. Effluent concentrations are significantly less than previous years. Strontium-90 was discharged from BNL facilities in the 1950s and 1960s and has remained in the sludge within the sanitary piping system. One goal of the sanitary sewer-cleaning project was to remove this residual activity, thus reducing concentrations in STP influent and effluent.

\subsubsection{Sanitary System Effluent - Nonradiological Analyses}

In addition to the compliance monitoring discussed in Chapter 3, effluent from the STP is also monitored for nonradiological contaminants under the BNL Environmental Surveillance Program. Data are collected for field-measured parameters, such as temperature, specific conductivity, $\mathrm{pH}$, and dissolved oxygen, as well as inorganic parameters such as chlorides, nitrates, sulfates, and metals measured in the analytical laboratory. Composite samples of the STP effluent are collected using a flow-proportional refrigerated sampling device (ISCO Model $\left.1600^{\mathrm{TM}}\right)$. The BNL Analytical Services Laboratory analyzes these composite samples for 21 inorganic elements. In addition, grab samples are collected monthly from the STP effluent and analyzed for 38 different volatile organic compounds (VOCs). Daily influent and effluent logs are maintained by the STP operators for flow, $\mathrm{pH}$, temperature, and settleable solids as part of routine monitoring of STP operations.

Table 5-3 summarizes the inorganic analytical results for the STP samples. Comparing the effluent data to the SPDES effluent limits (or other applicable standard) shows that the major-

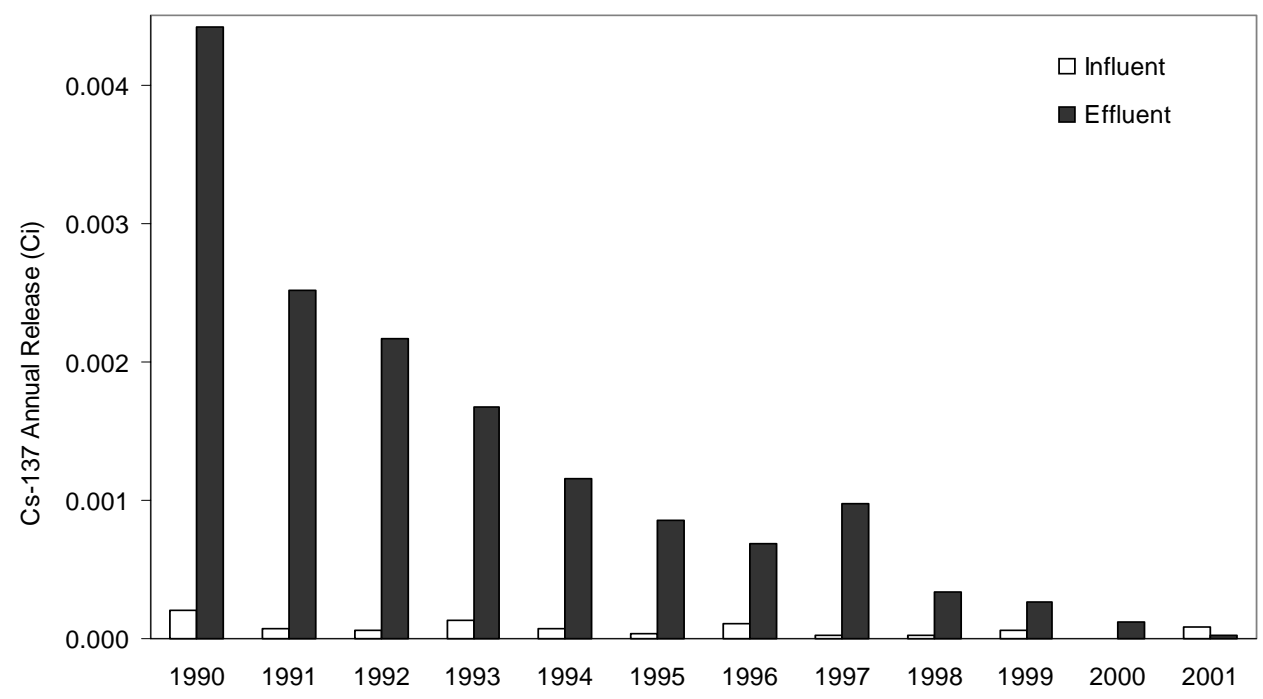

Figure 5-6. Cesium-137 in the Sewage Treatment Plant Influent and Effluent (1990-2001). 
Table 5-3. Average Water Quality and Analysis of Metals in Water at the Sewage Treatment Plant.

\begin{tabular}{|c|c|c|c|c|c|c|c|c|c|}
\hline & \multicolumn{4}{|c|}{ STP Influent } & \multicolumn{4}{|c|}{ STP Effluent } & \multirow{2}{*}{$\begin{array}{l}\text { SPDES Limit or } \\
\text { Ambient Water } \\
\text { Quality Standard }^{(1)}\end{array}$} \\
\hline & $\begin{array}{l}\text { No. of } \\
\text { Samples }\end{array}$ & Min. & Max. & Avg. & $\begin{array}{l}\text { No. of } \\
\text { Samples }\end{array}$ & Min. & Max. & Avg. & \\
\hline $\mathrm{pH}(\mathrm{SU})^{(2)}$ & 232 & 5.8 & 7.6 & NA & 261 & 5.4 & 7.8 & NA & $5.8-9.0$ \\
\hline Conductivity $(\mu \mathrm{mhos} / \mathrm{cm})^{(2)}$ & $\mathrm{NA}$ & NA & NA & NA & 261 & 153 & 404 & 280 & SNS \\
\hline Temperature $\left({ }^{\circ} \mathrm{C}\right)^{(2,3)}$ & NA & NA & $\mathrm{NA}$ & NA & 261 & 3.7 & 26.5 & 15.0 & SNS \\
\hline Dissolved Oxygen (mg/L) & NA & NA & NA & NA & 261 & 5.5 & 14.0 & 9.0 & SNS \\
\hline Chlorides (mg/L) & 12 & 26.5 & 75.0 & 42.3 & 12 & 29.8 & 51.8 & 36.8 & SNS \\
\hline Nitrate (as N) (mg/L) & 12 & $<1$ & 3.0 & 1.5 & 12 & 3.7 & 7.1 & 5.7 & 10 (Total N) \\
\hline Sulfates (mg/L) & 12 & 12.6 & 16.8 & 14.7 & 12 & 11.4 & 17.2 & 14.7 & $250(\mathrm{GA})$ \\
\hline Aluminum ( $\mu \mathrm{g} / \mathrm{L})$ & 13 & 37.6 & 1086.6 & 464.5 & 18 & 25.9 & 90.8 & 45.8 & 100 (Ionic) \\
\hline Antimony ( $\mu \mathrm{g} / \mathrm{L})$ & 13 & $<1.8$ & 3.7 & $<8.8$ & 18 & $<0.9$ & 5.9 & $<1.8$ & $3(\mathrm{GA})$ \\
\hline Arsenic ( $\mu \mathrm{g} / \mathrm{L})$ & 13 & $<3.0$ & 12.4 & $<6.0$ & 18 & $<3.0$ & 11.2 & $<6.0$ & 150 (Dissolved) \\
\hline Barium $(\mu \mathrm{g} / \mathrm{L})$ & 13 & 15 & 72.9 & 43.1 & 18 & 11.5 & 39.3 & 23.4 & 1000 (GA) \\
\hline Beryllium ( $\mu \mathrm{g} / \mathrm{L})$ & 13 & $<0.7$ & 1.1 & $<6.0$ & 18 & $<0.7$ & 3.9 & $<1.3$ & 11 (Acid Soluble) \\
\hline Cadmium ( $\mu \mathrm{g} / \mathrm{L})$ & 13 & $<2.2$ & $<11.0$ & $<11.0$ & 18 & $<1.1$ & 1.8 & $<2.2$ & 1.1 (Dissolved) \\
\hline Chromium ( $\mu \mathrm{g} / \mathrm{L})$ & 13 & $<1.0$ & 27.5 & 6.4 & 18 & $<1.0$ & 2.4 & 1.1 & 34.4 (Dissolved) \\
\hline Cobalt ( $\mu \mathrm{g} / \mathrm{L})$ & 13 & $<1.2$ & 1.9 & 0.9 & 18 & 0.3 & 4.6 & 0.6 & 5 (Acid Soluble) \\
\hline Copper ( $\mu \mathrm{g} / \mathrm{L})$ & 13 & 23.4 & 376.4 & 180.9 & 18 & 30.8 & 60.1 & 43.5 & 150 (SPDES) \\
\hline Iron (mg/L) & 13 & 0.4 & 2.6 & 1.27 & 14 & $<0.1$ & 0.77 & 0.19 & 0.37 (SPDES) \\
\hline Mercury ( $\mu \mathrm{g} / \mathrm{L})$ & 12 & $<0.1$ & 1.3 & 0.3 & 12 & $<0.1$ & 0.2 & $<0.1$ & 0.8 (SPDES) \\
\hline Manganese $(\mu \mathrm{g} / \mathrm{L})$ & 13 & 33.8 & 92.5 & 50.4 & 18 & $<2.0$ & 19.6 & 8.1 & 300 (GA) \\
\hline Molybdenum ( $\mu \mathrm{g} / \mathrm{L})$ & 13 & $<5.0$ & $<50.0$ & $<50.0$ & 18 & $<5.0$ & 8.9 & $<10.0$ & SNS \\
\hline Nickel ( $\mu \mathrm{g} / \mathrm{L})$ & 13 & $<2.2$ & 31.1 & 7.3 & 18 & 2.8 & 31.7 & 5.4 & 110 (SPDES) \\
\hline Lead ( $\mu \mathrm{g} / \mathrm{L})$ & 13 & 1.9 & 48.8 & 21.3 & 18 & $<1.3$ & 11.1 & $<2.6$ & 19 (SPDES) \\
\hline Selenium ( $\mu \mathrm{g} / \mathrm{L})$ & 13 & $<5.0$ & 18.0 & $<10.0$ & 18 & $<5.0$ & 16.7 & $<10.0$ & 4.6 (Dissolved) \\
\hline Silver ( $\mu \mathrm{g} / \mathrm{L})$ & 13 & $<1.0$ & 10.4 & 3.0 & 18 & $<1.0$ & 3.6 & 1.0 & 15 (SPDES) \\
\hline Sodium (mg/L) & 12 & 24 & 46.8 & 31.0 & 13 & 24.5 & 44.9 & 32.4 & SNS \\
\hline Thallium ( $\mu \mathrm{g} / \mathrm{L})$ & 13 & $<0.7$ & 2.3 & $<6.6$ & 18 & $<0.7$ & 7.8 & $<1.3$ & 8 (Acid Soluble) \\
\hline Vanadium ( $\mu \mathrm{g} / \mathrm{L})$ & 13 & $<5.5$ & $<55.0$ & $<55.0$ & 18 & $<5.5$ & 30.6 & $<11.0$ & 14 (Acid Soluble \\
\hline Zinc ( $\mu \mathrm{g} / \mathrm{L})$ & 13 & 18.3 & 160.5 & 77.3 & 18 & 19.0 & 147.0 & 73.8 & 100 (SPDES) \\
\hline \multicolumn{10}{|c|}{$\begin{array}{l}\text { Notes: } \\
\text { See Figure } 5-2 \text { for locations of the STP influent and effluent monitoring locations. } \\
\text { All analytical results were generated using total recoverable analytical techniques. } \\
\text { For Class C standards, the solubility state for the metal is provided. } \\
\text { SPDES = State PollutantDischarge Elimination System } \\
\text { NA = NotApplicable } \\
\text { SNS = Standard Not Specified } \\
\text { GA = Class GA (groundwater)Ambient Water Quality Standard } \\
\text { (1) Unless otherwise provided, the reference standard is Class C Surface Water. } \\
\text { (2) The pH and temperature values reported are based on analysis of daily grab samples. } \\
\text { (3) Continuously monitored by STP operators. }\end{array}$} \\
\hline
\end{tabular}

ity of the analytical parameters were within SPDES effluent permit limits (see also the compliance data in Chapter 3). Iron and zinc were detected on several occasions at concentrations exceeding SPDES limits. Between January and March 2001, zinc was detected at concentrations exceeding SPDES limits on five occasions. Concentrations ranged from 102 to $147 \mu \mathrm{g} / \mathrm{L}$; the
SPDES limit is $100 \mu \mathrm{g} / \mathrm{L}$. As discussed in Chapter 3, cleaning of residual sludge from the sewer lines was the most likely cause for increased levels of zinc in the STP effluent. Iron was detected in March and September at 0.49 and $0.77 \mathrm{mg} / \mathrm{L}$, respectively, which exceed the SPDES limit of $0.37 \mathrm{mg} / \mathrm{L}$. There were no violations of iron SPDES limits identified under 
the regulatory compliance sampling program. Review of influent data shows slightly higher levels of iron in the STP influent in March but typical levels in September. There were no sources defined which would explain these elevated levels.

Acetone, methylene chloride, and disinfection byproducts (e.g., chloroform) were detected at trace levels $(<2.0 \mu \mathrm{g} / \mathrm{L})$ sporadically throughout the year in grab samples collected from the STP effluent. Methylene chloride was also detected at elevated concentrations of 8.7 and $6.9 \mu \mathrm{g} / \mathrm{L}$ in grab samples collected on March 13 and August 9, 2001. The ambient water quality standard for methylene chloride in waters such as the Peconic is $200 \mu \mathrm{g} / \mathrm{L}$. However, as the BNL discharge also recharges the groundwater aquifer, $\mathrm{BNL}$ is held to a strict standard of $5 \mu \mathrm{g} / \mathrm{L}$.

Acetone was detected at a concentration of 3.8 $\mu \mathrm{g} / \mathrm{L}$ in a sample collected in November. The water quality standard for acetone is $50 \mu \mathrm{g} / \mathrm{L}$. Both acetone and methylene chloride are ubiquitous in the analytical laboratory and may be present due to cross-contamination of samples or sampling equipment. No other organic compounds were detected above minimum detection limits in the STP discharge during 2001.

\subsection{PROCESS-SPECIFIC WASTEWATER}

Wastewater that may contain constituents above SPDES permit limits or groundwater discharge standards is held by the generating facility and characterized to determine the appropriate means of disposal. The analytical results are compared with the appropriate discharge limit, and the wastewater is released to the sanitary system only if the volume and concentration of contaminants in the discharge would not jeopardize the quality of the STP effluent and subsequently the Peconic River.

The BNL SPDES permit includes requirements for quarterly sampling and analysis of process-specific wastewater discharged from the photographic developing operations in Building 197B, the printed-circuit-board fabrication operations conducted in Building 535B, the metal cleaning operations in Building 498, cooling tower discharges from Building 902, and boiler blowdown from satellite boilers located at
Buildings 244 and 423 . These operations were monitored for contaminants such as metals, cyanide, VOCs, and semiVOCs. Analyses of these waste streams showed that, although several operations contributed contaminants to the STP in concentrations exceeding SPDESpermitted levels, the concentration did not affect the quality of the STP effluent.

Process wastewaters that were not expected to be of consistent quality because they were not routinely generated were held for characterization before release to the site sewer system. The process wastewaters typically included ionexchange column regeneration wastes, primary closed-loop cooling water, and other industrial wastewaters. To determine the appropriate disposal method, samples were analyzed for contaminants specific to the process. The analyses were then reviewed, and the concentrations compared to the SPDES effluent limits and BNL effluent criteria. If the concentrations were within limits, authorization for sewer disposal was granted; if not, alternate means of disposal were pursued. Any waste that contained elevated levels of hazardous or radiological contaminants in concentrations that exceed BNL effluent criteria was sent to the BNL Waste Management Facility for proper disposal.

In 2001, as part of BNL's commitment to pollution prevention, the Laboratory continued to revise and finalize its administrative authorization criteria for wastewater containing low levels of radionuclides. This revision is based upon the Environmental As Low As Reasonably Achievable (also known as E-ALARA) concept, whereby BNL strives to minimize emissions and effluents to the lowest levels technically achievable and economically acceptable. The revised criteria are set at a fraction of the drinking water standards. Effluents that do not meet these stringent criteria are managed off site or reviewed by senior management for consideration of institutional risk. The authorization criteria were finalized and documented in Laboratorywide standard operating procedures in May 2001 (BNL 2001). This practice is much more stringent than industry standards and supports BNL's commitment to maintaining a clean environment. 


\subsection{RECHARGE BASINS}

Recharge basins are used for the disposal of "clean" wastewater streams, including oncethrough cooling water, stormwater runoff, and cooling tower blowdown. With the exception of elevated temperature and increased natural sediment content, these wastewaters are suitable for direct replenishment of the groundwater aquifer. Figure 5-7 shows the locations of BNL's discharges to recharge basins. An overall schematic of water use at BNL is presented in Figure 5-8. Nine recharge basins are used for managing once-through cooling water, cooling tower blowdown, and stormwater runoff, as described below.

- Basins HN, HT-W, and HT-E receive oncethrough cooling water discharges generated at the Alternating Gradient Synchrotron (AGS) and Relativistic Heavy Ion Collider (RHIC), as well as cooling tower blowdown and stormwater runoff.

- Basin HS receives predominantly stormwater runoff, once-through cooling water from Building 555 (Chemistry Department), and minimal cooling tower blowdown from the National Synchrotron Light Source.

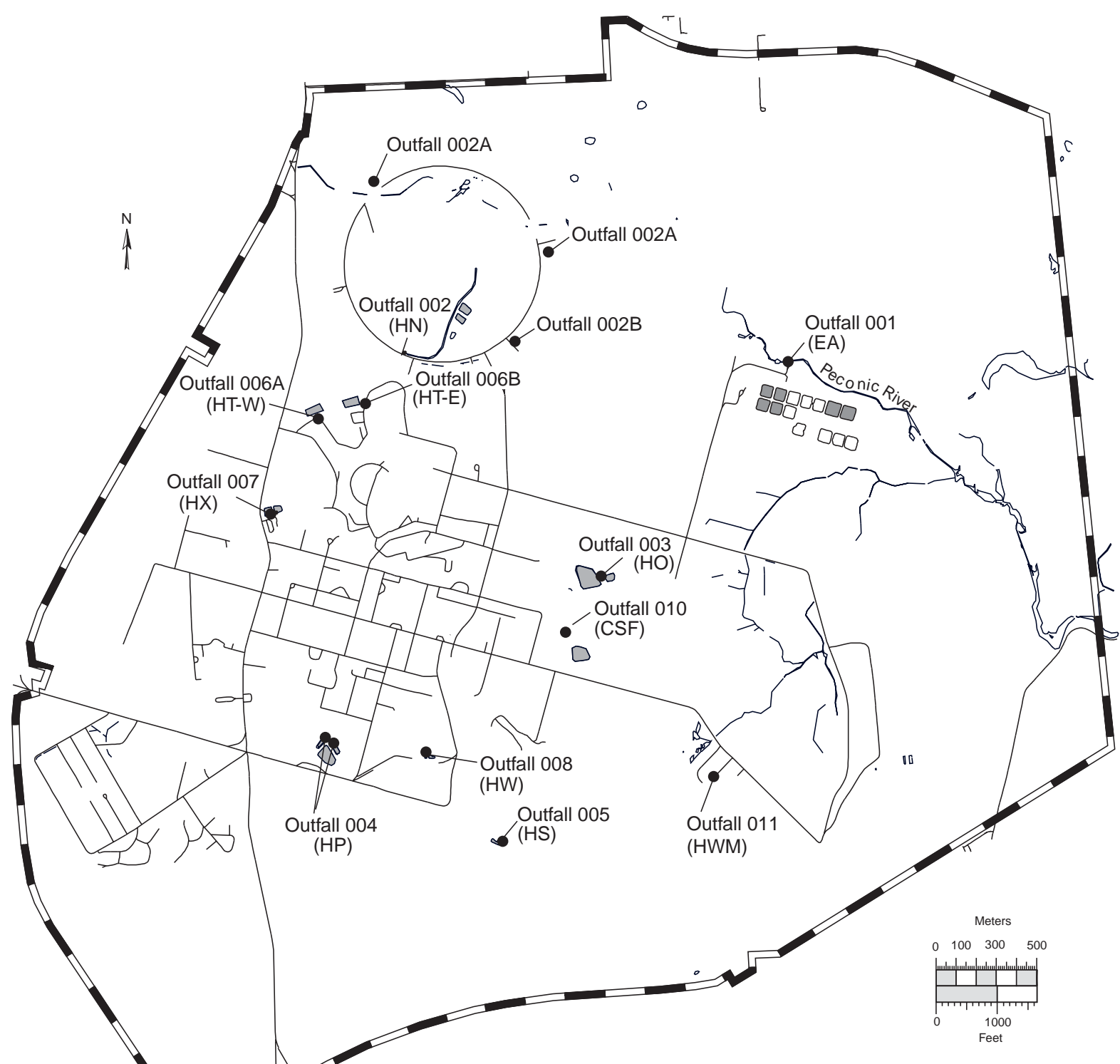

Figure 5-7. BNL Outfall/Recharge Basin Locations. 


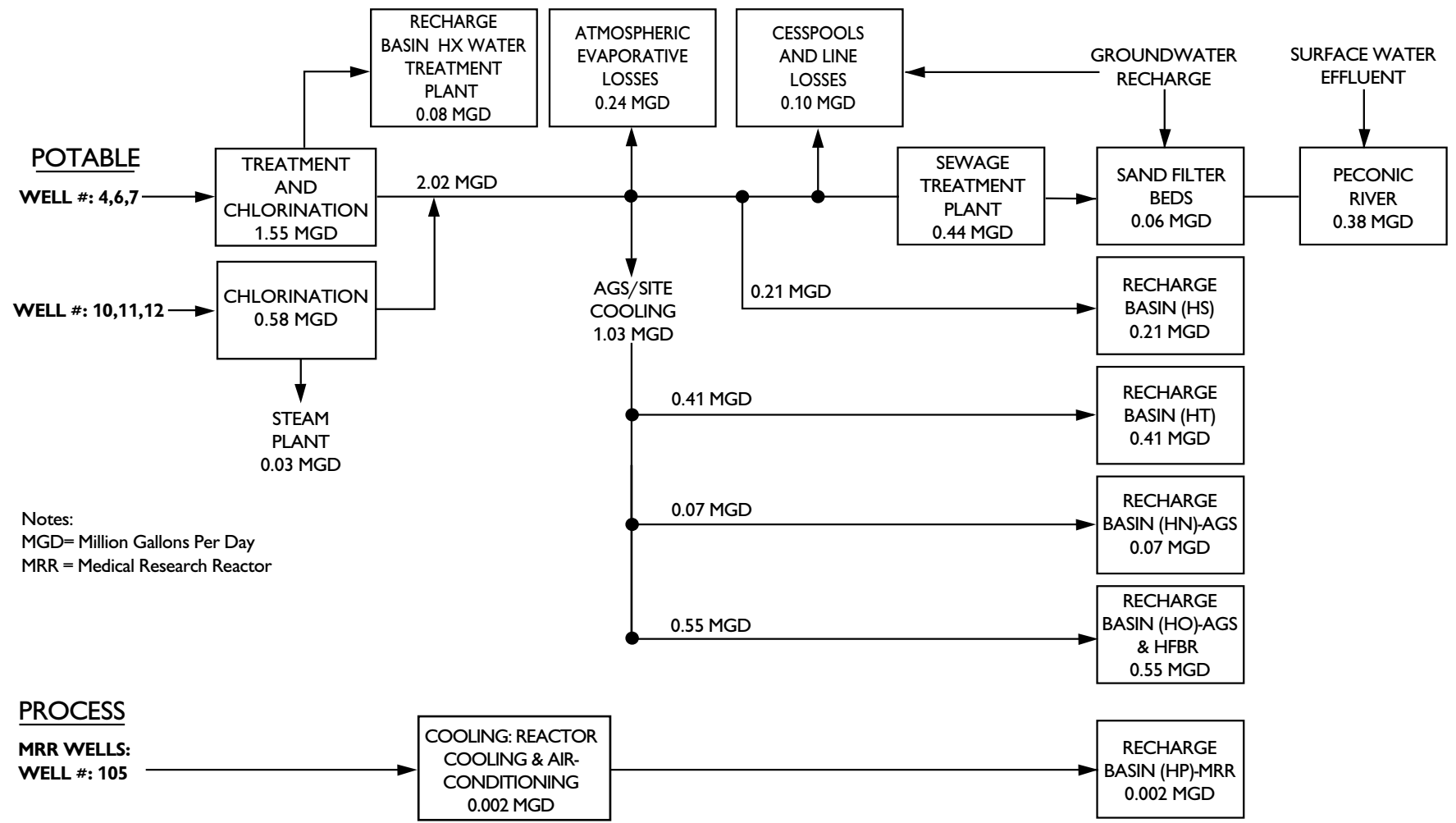

Figure 5-8. Schematic of Water Use and Flow at BNL.

- Basin HX receives Water Treatment Plant filter backwash water.

- Basin HP receives once-through cooling water from the Brookhaven Medical Research Reactor.

- Basin HO receives cooling water and cooling tower discharges from the AGS, and stormwater runoff from the area around the HFBR.

- Several other recharge areas are used exclusively for discharging stormwater runoff, including Basin HW in the warehouse area, Basin CSF at the Central Steam Facility, and Basin HWM at the former Hazardous Waste Management Facility. Each of the recharge basins is a permitted point source discharge under BNL's SPDES permit. Where required by the permit, the discharge to the basin is equipped with a flow monitoring station and weekly recordings of flow are collected, along with records of $\mathrm{pH}$. The specifics of the SPDES compliance monitoring program are provided in Chapter 3 . To supplement that monitoring program, samples also are routinely collected and analyzed under the Environmental Monitoring Program for radioactivity, VOCs, metals, and anions. During 2001, water samples were collected from Basins $\mathrm{HN}$, HO, HP, HS, HT-E, HT-W, HW, HX, and CSF.

\subsubsection{Recharge Basins - Radiological Analyses}

Discharges to the recharge basins were sampled throughout the year to measure concentrations of gross alpha and beta activity, gammaemitting radionuclides, and tritium. Radiological results for water samples collected at the recharge basins are presented in Table 5-4. Review of the data shows there were extremely low levels of beta activity detected in most of the basins, with Basin HW exhibiting higher concentrations than the others. The maximum concentration of beta activity detected in Basin HW was $18.5 \pm 1.8 \mathrm{pCi} / \mathrm{L}(0.7 \pm 0.07 \mathrm{~Bq} / \mathrm{L})$, which is less than 40 percent of the drinking water standard. The accompanying gamma analysis of water samples collected from all basins showed that only potassium- 40 , lead- 212 , and beryllium- 7 were detectable in these water samples. All 
Table 5-4. Radiological Analysis of Samples from On-Site Recharge Basins.

\begin{tabular}{|c|c|c|c|c|c|}
\hline \multicolumn{2}{|l|}{ Basin } & $\begin{array}{l}\text { Gross Alpha } \\
\qquad(\mathrm{pCi} / \mathrm{L})\end{array}$ & $\begin{array}{l}\text { Gross Beta } \\
\quad(\mathrm{pCi} / \mathrm{L})\end{array}$ & $\begin{array}{l}\text { Tritium } \\
\text { (pCi/L) }\end{array}$ & $\begin{array}{l}\text { Sr-90 } \\
\text { (pCi/L) }\end{array}$ \\
\hline \multirow[t]{3}{*}{$\mathrm{HN}$} & $\mathrm{N}$ & 4 & 4 & 4 & 1 \\
\hline & Max. & $<0.7$ & $3.2 \pm 1.4$ & $<374$ & $0.17 \pm 0.09$ \\
\hline & Avg. & $-0.1 \pm 0.2$ & $1.2 \pm 1.4$ & $79 \pm 89$ & NA \\
\hline \multirow[t]{3}{*}{$\mathrm{HO}$} & $\mathrm{N}$ & 4 & 4 & 4 & 1 \\
\hline & Max. & $<0.7$ & $<2.1$ & $<374$ & $<0.19$ \\
\hline & Avg. & $-0.1 \pm 0.3$ & $-0.1 \pm 1.1$ & $29 \pm 60$ & NA \\
\hline \multirow[t]{3}{*}{ HP } & $\mathrm{N}$ & 2 & 2 & 2 & NS \\
\hline & Max. & $<0.9$ & $3.3 \pm 1.4$ & $<317$ & \\
\hline & Avg. & $0.1 \pm 0.3$ & $2.1 \pm 1.6$ & $-4 \pm 51$ & \\
\hline \multirow[t]{3}{*}{ HS } & $\mathrm{N}$ & 4 & 4 & 4 & 1 \\
\hline & Max. & $<0.7$ & $<2.3$ & $<374$ & $<0.19$ \\
\hline & Avg. & $0.1 \pm 0.3$ & $1.1 \pm 0.8$ & $1 \pm 35$ & NA \\
\hline \multirow[t]{3}{*}{ HT-E } & $N$ & 4 & 4 & 4 & 1 \\
\hline & Max. & $4.2 \pm 2.3$ & $2.7 \pm 1.4$ & $<361$ & $<0.27$ \\
\hline & Avg. & $1.1 \pm 1.8$ & $0.9 \pm 1.1$ & $2 \pm 44$ & NA \\
\hline \multirow[t]{3}{*}{ HT-W } & $N$ & 4 & 4 & 4 & 1 \\
\hline & Max. & $<0.8$ & $3.4 \pm 1.4$ & $<374$ & $<0.19$ \\
\hline & Avg. & $0.4 \pm 0.1$ & $1.0 \pm 1.7$ & $39 \pm 92$ & $\mathrm{NA}$ \\
\hline \multirow[t]{3}{*}{ HW } & $\mathrm{N}$ & 4 & 4 & 4 & NS \\
\hline & Max. & $8.6 \pm 1.1$ & $18.5 \pm 1.8$ & $<364$ & \\
\hline & Avg. & $2.8 \pm 3.3$ & $7.0 \pm 7.4$ & $-77 \pm 52$ & \\
\hline \multicolumn{6}{|l|}{ SDWA } \\
\hline Limit & & 15 & 50 & 20,000 & 8 \\
\hline \multicolumn{6}{|c|}{$\begin{array}{l}\text { Figure 5-7 provides the locations of outfall/recharge basins. } \\
\text { No gamma-emitting anthropogenic radionuclides were detected in BNL } \\
\text { discharges to outfalls/recharge basins in } 2001 \text {. } \\
\text { All values reported with a } 95 \% \text { confidence interval. } \\
\text { Recharge basins HX and CSF were not sampled for radiological } \\
\text { parameters in } 2001 \text {. } \\
N=\text { Number of samples collected for analysis } \\
\text { NA= NotApplicable } \\
\text { NS = Samples not collected for this analysis } \\
\text { SDWA = Safe Drinking WaterAct }\end{array}$} \\
\hline
\end{tabular}

detected gamma-emitting nuclides are attributed to natural or cosmic sources. No gamma-emitting radionuclides attributable to $\mathrm{BNL}$ operations were detected in any of the recharge basins. Tritium was not detected in any basin above minimum detection limits during 2001.

\subsubsection{Recharge Basins - Nonradiological Analyses}

To determine the overall impact of the recharge basin discharges on the environment, the nonradiological analytical results were compared to groundwater discharge standards promulgated under Title 6 of the New York Codes, Rules, and Regulations Part 703.6. Samples were collected quarterly for water quality parameters, metals, and VOCs, and analyzed by the BNLAnalytical Services Laboratory. Field measured parameters ( $\mathrm{pH}$, conductivity, and temperature) were routinely monitored and recorded. The water quality and metals analytical results are summarized in Tables 5-5 and 5-6, respectively.

Low concentrations of disinfection byproducts were routinely detected in several discharges. These VOCs included bromoform, chloroform, dibromochloromethane, and dichlorobromomethane. Concentrations ranged from nondetectable to a maximum of $3.3 \mu \mathrm{g} / \mathrm{L}$. Sodium hypochlorite and bromine, used to control algae in cooling towers, are responsible for the formation of these compounds. Acetone was detected in a single sample collected from Recharge Basin HW in January at a concentration of $5.9 \mu \mathrm{g} / \mathrm{L}$. Acetone is commonly found as a contaminant in analytical laboratories and may be present due to its ability to evaporate in one area and then redissolve in water in another area of the laboratory.

The analytical data in Tables 5-5 and 5-6 show that most parameters, except for aluminum and iron, complied with the respective groundwater discharge or water quality standards. Aluminum and iron are natural components of soil and readily dissolve when water is acidified for sample preservation. Iron is present naturally in Long Island groundwater at concentrations that exceed the New York State groundwater effluent limit. The $\mathrm{pH}$ measured at several of the recharge basins was outside the groundwater effluent standard of 6.5 to 8.5 Standard Units. The $\mathrm{pH}$ of local groundwater and precipitation is lower than the standard, which contributed to the low $\mathrm{pH}$ observations. The high $\mathrm{pH}$ observations are attributed to sodium hydroxide or calcium hydroxide additions to the domestic water system. Periodically, the $\mathrm{pH}$ of the domestic water is greater than 8.5 , due to chemical over-addition.

Investigation of lead concentrations in soil samples collected at the CSF outfall continued in 
Table 5-5. Water Quality Data for Samples from On-Site Recharge Basins.

\begin{tabular}{|c|c|c|c|c|c|c|c|c|c|}
\hline \multicolumn{2}{|l|}{$\begin{array}{l}\text { Recharge } \\
\text { Basin }\end{array}$} & \multirow{2}{*}{$\begin{array}{c}\begin{array}{c}\text { pH } \\
(\mathrm{SU})\end{array} \\
19\end{array}$} & \multicolumn{2}{|c|}{$\begin{array}{l}\text { Conductivity } \\
(\mu \mathrm{S} / \mathrm{cm})\end{array}$} & \multirow{2}{*}{$\begin{array}{c}\text { Temperature } \\
\left({ }^{\circ} \mathrm{C}\right)\end{array}$} & \multirow{2}{*}{$\begin{array}{c}\begin{array}{c}\text { Dissolved Oxygen } \\
(\mathrm{mg} / \mathrm{L})\end{array} \\
6\end{array}$} & \multirow{2}{*}{$\begin{array}{c}\begin{array}{c}\text { Chlorides } \\
\text { (mg/L) }\end{array} \\
4\end{array}$} & \multirow{2}{*}{$\begin{array}{c}\begin{array}{c}\text { Sulfates } \\
(\mathrm{mg} / \mathrm{L})\end{array} \\
4\end{array}$} & \multirow{2}{*}{$\begin{array}{c}\begin{array}{c}\text { Nitrate as } \mathbf{N}^{*} \\
(\mathrm{mg} / \mathrm{L})\end{array} \\
4\end{array}$} \\
\hline $\mathrm{HN}$ & $\mathrm{N}$ & & & & & & & & \\
\hline \multirow{3}{*}{ (RHIC) } & Min. & 6.7 & 11 & & 8.0 & 6.9 & 21.1 & 7.5 & $<1$ \\
\hline & Max. & 8.1 & 67 & & 25.2 & 11.6 & 154.2 & 18.3 & $<1$ \\
\hline & Avg. & NA & 25 & & 17.3 & 9.3 & 60.7 & 13.0 & $<1$ \\
\hline & $\mathrm{N}$ & 17 & & + & 17 & 4 & 4 & 4 & 4 \\
\hline \multirow[t]{3}{*}{ (AGS/HFBR) } & Min. & 6.4 & 4 & & 7.8 & 8.2 & 20.7 & 9 & $<1$ \\
\hline & Max. & 7.8 & 15 & & 25.7 & 13.0 & 26.9 & 11.4 & $<1$ \\
\hline & Avg. & NA & 11 & & 18.4 & 9.8 & 23.5 & 10.1 & $<1$ \\
\hline $\mathrm{HP}$ & $\mathrm{N}$ & 3 & & & 3 & 3 & 2 & 2 & 2 \\
\hline \multirow[t]{3}{*}{ (BMRR) } & Min. & 5.8 & 15 & & 12.7 & 6.2 & 19.3 & 13.3 & 1 \\
\hline & Max. & 6.2 & 21 & & 13.0 & 6.2 & 33.0 & 18.6 & 1.1 \\
\hline & Avg. & NA & 18 & & 12.8 & 6.2 & 26.2 & 16.0 & 1 \\
\hline HS & $\mathrm{N}$ & 20 & & & 20 & 8 & 4 & 4 & 4 \\
\hline \multirow[t]{3}{*}{ (Stormwater) } & Min. & 6.9 & 17 & & 3.7 & 8.3 & 24.5 & 11.3 & $<1$ \\
\hline & Max. & 8.7 & 61 & & 31.1 & 16.1 & 138.9 & 14.7 & $<1$ \\
\hline & Avg. & $\mathrm{NA}$ & 30 & & 16.4 & 11.2 & 58.9 & 13.1 & $<1$ \\
\hline HT-E & $\mathrm{N}$ & 21 & & & 21 & 9 & 4 & 4 & 4 \\
\hline \multirow[t]{3}{*}{ (AGS) } & Min. & 6.7 & 7 & & 5.8 & 8.7 & 23.1 & 9.6 & $<1$ \\
\hline & Max. & 8.1 & 47 & & 19.7 & 12.9 & 281.0 & 18.6 & $<1$ \\
\hline & Avg. & NA & 19 & & 13.7 & 10.4 & 89.9 & 12.4 & $<1$ \\
\hline HT-W & $\mathrm{N}$ & 21 & & & 21 & 9 & 4 & 4 & 4 \\
\hline \multirow{3}{*}{ (LINAC) } & Min. & 6.9 & 13 & & 7.1 & 7.5 & $<4$ & $<4$ & $<1$ \\
\hline & Max. & 8.0 & 53 & & 23.3 & 12.4 & 117.9 & 11.3 & $<1$ \\
\hline & Avg. & $\mathrm{NA}$ & 23 & & 18.2 & 9.2 & 39.7 & 7.5 & $<1$ \\
\hline & $\mathrm{N}$ & 14 & & 4 & 14 & 4 & 4 & 4 & 4 \\
\hline \multirow[t]{3}{*}{ (Weaver Road) } & Min. & 6.0 & 5 & & 1.7 & 9.0 & $<4$ & $<4$ & $<1$ \\
\hline & Max. & 7.8 & 9 & & 21.9 & 13.3 & 11.2 & 5.6 & $<1$ \\
\hline & Avg. & NA & 7 & & 11.6 & 11.2 & 5.23 & 1.4 & $<1$ \\
\hline CSF & $\mathrm{N}$ & 11 & & 4 & 11 & 4 & 4 & 4 & 4 \\
\hline \multirow[t]{3}{*}{ (Stormwater) } & Min. & 6.1 & 5 & & 3.3 & 8.4 & $<4$ & $<4$ & $<1$ \\
\hline & Max. & 7.6 & 7 & & 22.4 & 13.6 & 33.2 & 6.4 & $<1$ \\
\hline & Avg. & $N A$ & 6 & & 13.3 & 10.7 & 9.6 & 1.6 & $<1$ \\
\hline & $\mathrm{N}$ & 9 & $\mathrm{~N}$ & & 9 & NS & NS & NS & NS \\
\hline \multirow{3}{*}{ (WTP Backwash) } & Min. & 6.5 & $\mathrm{~N}$ & & 9.2 & NS & NS & NS & NS \\
\hline & Max. & 7.3 & $\mathrm{~N}$ & & 17.1 & NS & NS & NS & NS \\
\hline & Avg. & NA & $\mathrm{N}$ & & 12.4 & NS & NS & NS & NS \\
\hline Outfall 002B & $\mathrm{N}$ & 4 & $\mathrm{~N}$ & & 4 & NS & NS & NS & NS \\
\hline \multirow[t]{3}{*}{$(\mathrm{RHIC})$} & Min. & 6.7 & $\mathrm{~N}$ & & 11.1 & NS & NS & NS & NS \\
\hline & Max. & 7.9 & $\mathrm{~N}$ & & 21.3 & NS & NS & NS & NS \\
\hline & Avg. & NA & $\mathrm{N}$ & & 18.0 & NS & NS & NS & NS \\
\hline \multirow{2}{*}{\multicolumn{3}{|c|}{$\begin{array}{l}\text { NYSDEC Effluent Standard } \\
\text { Typical MDL }\end{array}$}} & 6.5 to 8.5 & SNS & SNS & SNS & 500 & 500 & 10 \\
\hline & & & NA & 10 & NA & NA & 4 & 4 & 1 \\
\hline \multicolumn{10}{|l|}{ Notes: } \\
\hline${ }^{*}$ Holding times for nitr & ate analys & ses are rc & utinely exce & & & $\mathrm{N}=\mathrm{No}$. of samples & & & \\
\hline See Figure 5-7 for the & locations & of recha & ge basins. & & & $\mathrm{NA}=$ NotApplicable & & & \\
\hline AGS/HFBR = Alternat & ing Gradie & ent Syncl & rotron/High & Flux Beam & Reactor & NS $=$ Not Sampled & & & \\
\hline $\begin{array}{l}\text { BMRR = Brookhaven } \\
\text { CSF = Central Steam }\end{array}$ & $\begin{array}{l}\text { Medical R } \\
\text { Facility }\end{array}$ & Research & & & & NYSDEC = New York Sta & epartment of Er & onmental Con & envation \\
\hline $\mathrm{MDL}=$ Minimum Detec & tion Limit & & & & & SNS = Effluent Standard & Specified & & \\
\hline
\end{tabular}


= N

$>$ >

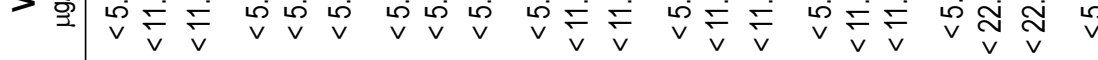

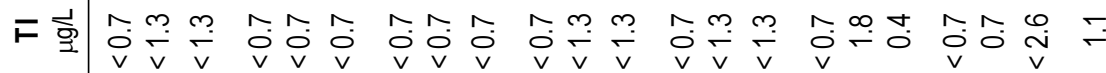

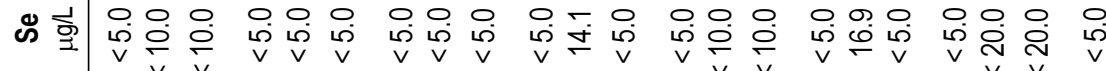
ம

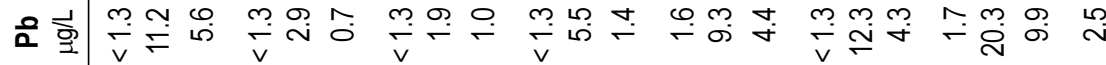

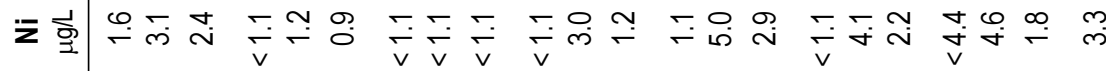

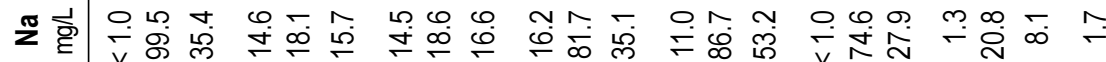

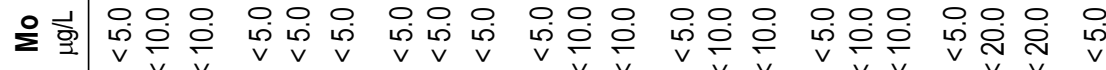

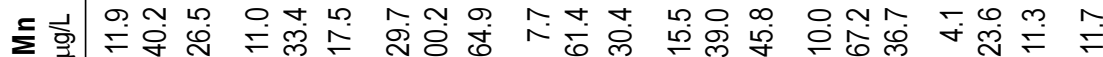
오 山 官 J

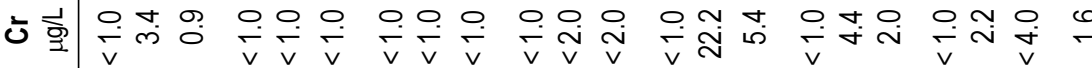
宁

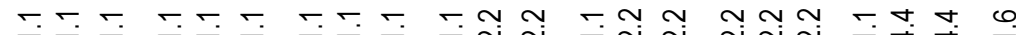

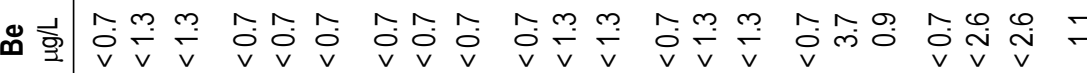

ஜ

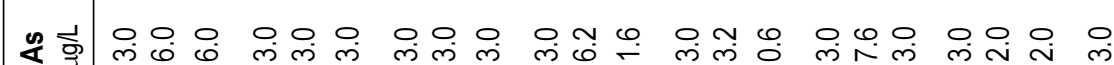

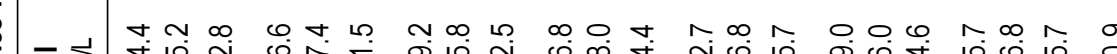

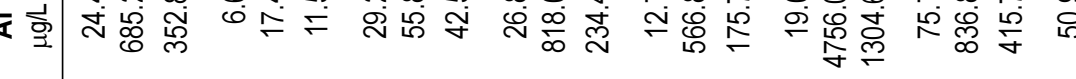

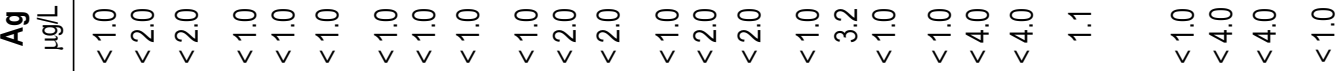

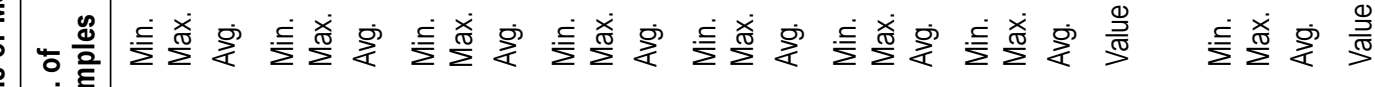
| 心

(n)

唯
竞

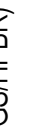

更

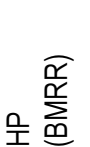

㐫<smiles>C=CC=C</smiles>
I

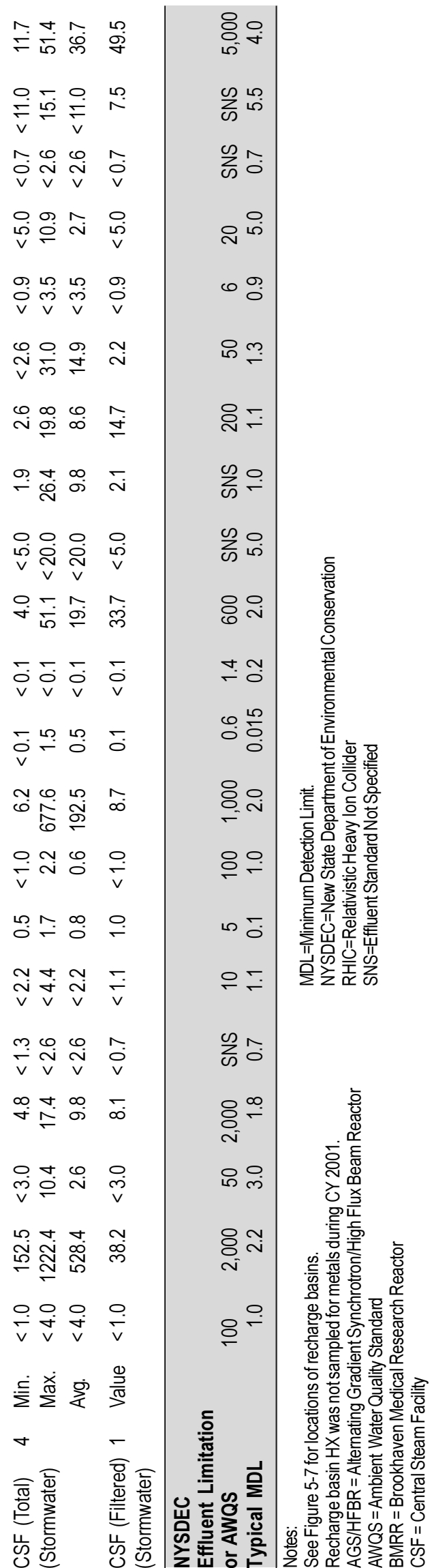


2001. A significant area of soils containing lead in concentrations greater than $10,000 \mathrm{mg} / \mathrm{Kg}$ is still under investigation. Historical operations of the Central Steam Facility, specifically the combustion of waste oils and the washing of boiler ash to this outfall, are the most likely cause. This investigation will continue in 2002. Monitoring this outfall for lead will most likely become a condition of the SPDES permit for this discharge; BNL will continue to monitor it under the surveillance program.

\subsubsection{Stormwater Assessment}

With the exception of Recharge Basins HP and $\mathrm{HX}$, all recharge basins receive stormwater runoff. At BNL, stormwater is managed by collecting runoff from paved surfaces, roofs, and other impermeable surfaces and directing it to the recharge basins via underground piping and abovegrade vegetated swales. Recharge Basin HS receives most of the stormwater runoff from the central, developed portion of the BNL site (all properties south of Cornell Avenue and west of Railroad Avenue). Basins HN and HT-E receive runoff from the $A G S$ and portions of the RHIC complex; Basin HO receives runoff from the BGRR and HFBR areas. As previously indicated, Basins HW, CSF, and HWM receive only stormwater runoff.

Stormwater runoff from the BNL site typically has elevated levels of inorganics and low $\mathrm{pH}$. The inorganics are attributable to high sediment content and the natural occurrence of these elements in native soils. In an effort to further protect the quality of stormwater runoff, BNL has drafted formal requirements for managing and maintaining outdoor work and storage areas. These requirements include covering areas to prevent contact with stormwater, an aggressive maintenance and inspection program, and formal restoration of these areas when operations cease. These requirements will become part of the revised Storage and Transfer of Hazardous and Nonhazardous Materials Subject Area, currently in draft.

\subsection{PECONIC RIVER SURVEILLANCE}

Several locations were monitored along the Peconic River to assess the overall water quality of the river and to assess any impact from BNL discharges. Sampling points along the Peconic River are identified in Figure 5-9. In total, ten stations are monitored: three upstream and seven downstream of the STP outfall. In addition, a sampling station along the Carmans River $(\mathrm{HH})$ is also monitored as a geographic control location that is not affected by BNL operations. All locations are monitored for radiological and nonradiological parameters on a routine basis.

The sampling stations are located as follows:

Downstream sampling stations

- HMn, on site and 0.5 miles downstream of the STP outfall

- HMs, on site (a typically dry tributary of the Peconic River)

- HQ, on site and 1.2 miles downstream of the STP outfall

- HA and HB, 3.1 miles downstream of the STP outfall

- HC, 4.3 miles downstream of the STP outfall

- HR, 13 miles downstream of the STP outfall (in Riverhead)

Upstream locations

- HE, on site, located approximately 20 feet upstream of the STP

- HV, on site, located just east of the 10 o'clock Experimental Hall in the RHIC ring

- HY, on site, located just east of the William Floyd Parkway

Control location

- HH, Carmans River

\subsubsection{Peconic River - Radiological Analyses}

Radionuclide measurements were performed on surface water samples collected from the Peconic River at all ten locations. Routine samples at Stations HMn and HQ were collected three times per week, as flow permitted. Station HE was collected quarterly in 2001 . Since February 1995, these three locations have been equipped with Parshall flumes that allow automated flow-proportional sampling and volume measurements. All other sites were sampled quarterly by collecting instantaneous grab samples, as flow allowed.

The radiological data from Peconic River surface water sampling in 2001 are summarized 


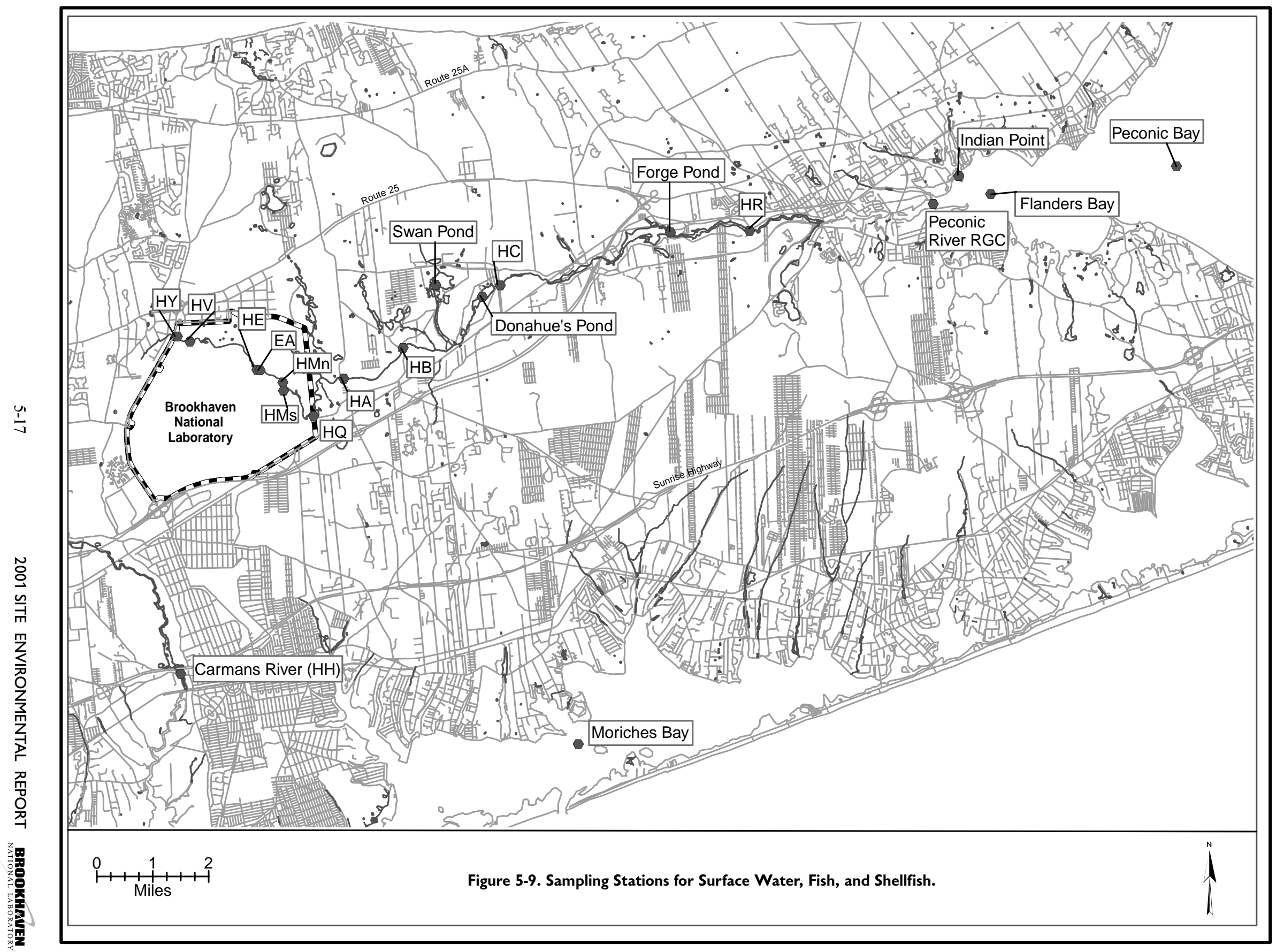


in Table 5-7. Radiological analysis of upstream water samples showed that gross alpha and beta activities were occasionally detected at low levels at all three upstream locations. Samples collected downstream of the BNL STP discharge showed higher concentrations than upstream values but were less than the samples collected at Station $\mathrm{HH}$, on the Carmans River. With the exception of a single detection of Cs-137 at Station HB, there were no gamma-emitting radionuclides attributable to BNL operations detected either upstream or downstream of the STP. Approximately $2.5 \mathrm{pCi} / \mathrm{L}$ of Cs-137 was detected in a grab sample collected in January from Station HB. Because Cs- 137 was not detected at other locations and because of the high turbidity of water samples associated with this sampling station, Cs-137 is being attributed to sediment entrained in the water sample. The concentration detected was only 1.3 percent of the drinking water standard.

Tritium analysis of water samples collected upstream and downstream from the STP discharge showed detectable levels only at Stations HMn and HQ. The maximum concentration (830 $\pm 278 \mathrm{pCi} / \mathrm{L}[30.7 \pm 10.3 \mathrm{~Bq} / \mathrm{L}])$, detected at Station HMn, was consistent with the levels discharged from the BNL STP. Tritium was detected only once at Station HQ, at a concentration of $397 \pm 241 \mathrm{pCi} / \mathrm{L}(14.7 \pm 8.9 \mathrm{~Bq} / \mathrm{L})$, which is much less than the drinking water standard of $20,000 \mathrm{pCi} / \mathrm{L}$.

Monitoring for strontium-90 was performed at Stations HE, HMn, and HQ. Trace levels were found at all locations, with the highest at Station HE. Strontium-90 was detected at Station HE at a maximum concentration of $0.31 \pm 0.1 \mathrm{pCi} / \mathrm{L}$ $(0.01 \pm 0.004 \mathrm{~Bq} / \mathrm{L})$, which is approximately 4 percent of the drinking water standard and equivalent to the levels detected in 2000.

\subsubsection{Peconic River - Nonradiological Analyses}

Samples collected in 2001 were analyzed for water quality parameters $(\mathrm{pH}$, temperature, conductivity, and dissolved oxygen), anions (chlorides, sulfates, and nitrates), metals, and VOCs. The inorganic analytical data for the Peconic River and Carmans River samples are summarized in Tables 5-8 (water quality) and 5-9 (metals).
No VOCs were routinely detected in river water samples above the minimum detection limits, although low concentrations were reported for acetone $(5.8 \mu \mathrm{g} / \mathrm{L}$ or less $)$ and methylene chloride ( $2 \mu \mathrm{g} / \mathrm{L}$ or less) at several locations. Due to the low level of detection and the ubiquitous nature of these compounds in the analytical laboratory, the presence of these compounds is questionable. Trace concentrations of 1,1,1trichloroethane and 1,1-dichloroethylene were detected in water samples collected at Station HR. Due to the location of this station (Riverhead) and the absence of these compounds at locations closer to BNL, these compounds are not expected to be the result of BNL operations, but may be the result of roadway runoff or other off-site sources. There were single detections of 1,2,3-trichlorobenzene $(2 \mu \mathrm{g} / \mathrm{L})$ and naphthalene $(7 \mu \mathrm{g} / \mathrm{L})$ at Station HM-N in May 2001. No other organic compounds were detected above the minimum detection limit upstream or downstream of the STP discharge.

Comparison of Peconic River water quality data collected upstream and downstream showed that water quality parameters were consistent throughout the river system. These data were also consistent with data from the Carmans River control location $(\mathrm{HH})$. Chlorides, sulfates, and nitrates tend to be slightly higher in samples collected immediately downstream of the STP discharge (Stations HMn and HQ) and were consistent with the concentrations in the STP discharge. Chlorides were, however, highest at upstream Station HY. The sample collected from Station HY in January measured $157 \mathrm{mg} / \mathrm{L}$, most probably due to road salting and surface run-off, due to its proximity to William Floyd Parkway.

The $\mathrm{pH}$ measured at several locations was very low due to the low $\mathrm{pH}$ of precipitation, groundwater, and the formation of humic acids from decaying organic matter. As the spring rains mix with the decaying matter, these acids decrease the already low $\mathrm{pH}$ of precipitation, resulting in a $\mathrm{pH}$ as low as 3.9 Standard Units. A discussion of precipitation monitoring is provided in Chapter 6 of this report.

Ambient water quality standards for metallic elements are based on their solubility state. Certain metals are only biologically available to 
Table 5-7. Radiological Results for Surface Water Samples Collected along the Peconic and Carmans Rivers.

\begin{tabular}{|c|c|c|c|c|c|c|}
\hline $\begin{array}{l}\text { Sample } \\
\text { Station }\end{array}$ & $\begin{array}{l}\text { Geographic } \\
\text { Location }\end{array}$ & & $\begin{array}{l}\text { Gross Alpha } \\
\qquad(\mathrm{pCi} / \mathrm{L})\end{array}$ & $\begin{array}{l}\text { Gross Beta } \\
\qquad(\mathrm{pCi} / \mathrm{L})\end{array}$ & $\begin{array}{l}\text { Tritium } \\
\text { (pCi/L) }\end{array}$ & $\begin{array}{l}\mathrm{Sr}-90 \\
(\mathrm{pCi} / \mathrm{L})\end{array}$ \\
\hline$\overline{H Y}$ & $\begin{array}{l}\text { Peconic River (headwaters), } \\
\text { on site, west of the RHIC ring }\end{array}$ & $\begin{array}{l}\mathrm{N} \\
\text { Max. } \\
\text { Avg. }\end{array}$ & $\begin{array}{c}4 \\
0.98 \pm 0.51 \\
0.50 \pm 0.36\end{array}$ & $\begin{array}{c}4 \\
3.47 \pm 1.44 \\
1.29 \pm 1.81\end{array}$ & $\begin{array}{c}4 \\
<375 \\
-135 \pm 132\end{array}$ & $\begin{array}{c}2 \\
<0.21 \\
<0.21\end{array}$ \\
\hline $\mathrm{HV}$ & $\begin{array}{l}\text { Peconic River (headwaters), } \\
\text { on site, inside the RHIC ring }\end{array}$ & $\begin{array}{l}\mathrm{N} \\
\text { Max. } \\
\text { Avg. }\end{array}$ & $\begin{array}{c}4 \\
1.13 \pm 0.57 \\
0.63 \pm 0.43\end{array}$ & $\begin{array}{c}4 \\
3.68 \pm 1.37 \\
1.90 \pm 1.16\end{array}$ & $\begin{array}{c}4 \\
<375 \\
-95 \pm 113\end{array}$ & NS \\
\hline $\mathrm{HE}$ & $\begin{array}{l}\text { Peconic River, } \\
\text { upstream of STP Outfall }\end{array}$ & $\begin{array}{l}\mathrm{N} \\
\text { Max. } \\
\text { Avg. }\end{array}$ & $\begin{array}{c}4 \\
1.45 \pm 0.59 \\
0.60 \pm 0.55\end{array}$ & $\begin{array}{c}4 \\
<2.10 \\
1.97 \pm 0.21\end{array}$ & $\begin{array}{c}4 \\
<329 \\
-5 \pm 124\end{array}$ & $\begin{array}{c}3 \\
0.31 \pm 0.10 \\
0.27 \pm 0.03\end{array}$ \\
\hline $\mathrm{HMn}$ & $\begin{array}{l}\text { Peconic River, } \\
0.4 \text { mi from STP, on site }\end{array}$ & $\begin{array}{l}\text { N } \\
\text { Max } \\
\text { Avg. }\end{array}$ & $\begin{array}{c}132 \\
5.58 \pm 3.17 \\
1.72 \pm 0.28\end{array}$ & $\begin{array}{c}132 \\
15.50 \pm 5.77 \\
5.46 \pm 0.48\end{array}$ & $\begin{array}{c}132 \\
830 \pm 278 \\
49 \pm 28\end{array}$ & $\begin{array}{c}3 \\
0.22 \pm 0.11 \\
0.06 \pm 0.16\end{array}$ \\
\hline $\mathrm{HMs}$ & $\begin{array}{l}\text { Peconic River } \\
\text { tributary, on site }\end{array}$ & $\begin{array}{l}\mathrm{N} \\
\text { Max. } \\
\text { Avg. }\end{array}$ & $\begin{array}{c}2 \\
1.03 \pm 0.55 \\
0.72 \pm 0.43\end{array}$ & $\begin{array}{c}2 \\
<2.29 \\
1.31 \pm 0.46\end{array}$ & $\begin{array}{c}2 \\
<321 \\
-199 \pm 10\end{array}$ & $\begin{array}{c}2 \\
0.30 \pm 0.11 \\
0.29 \pm 0.004\end{array}$ \\
\hline$H Q^{(1)}$ & $\begin{array}{l}\text { Peconic River, } \\
\text { BNL site boundary }\end{array}$ & $\begin{array}{l}\mathrm{N} \\
\text { Max. } \\
\text { Avg. }\end{array}$ & $\begin{array}{c}84 \\
4.84 \pm 2.87 \\
1.27 \pm 0.28\end{array}$ & $\begin{array}{c}84 \\
18.80 \pm 6.17 \\
6.37 \pm 0.91\end{array}$ & $\begin{array}{c}84 \\
397 \pm 241 \\
14 \pm 34\end{array}$ & $\begin{array}{c}3 \\
0.24 \pm 0.11 \\
0.14 \pm 0.09\end{array}$ \\
\hline $\mathrm{HA}$ & $\begin{array}{l}\text { Peconic River, } \\
\text { off site }\end{array}$ & $\begin{array}{l}\text { N } \\
\text { Max. } \\
\text { Avg. }\end{array}$ & $\begin{array}{c}4 \\
<0.71 \\
0.06 \pm 0.21\end{array}$ & $\begin{array}{c}4 \\
<2.10 \\
0.53 \pm 0.70\end{array}$ & $\begin{array}{c}4 \\
<374 \\
-33 \pm 1\end{array}$ & NS \\
\hline $\mathrm{HB}$ & $\begin{array}{l}\text { Peconic River, } \\
\text { off site }\end{array}$ & $\begin{array}{l}\mathrm{N} \\
\text { Max. } \\
\text { Avg. }\end{array}$ & $\begin{array}{c}4 \\
<0.76 \\
0.04 \pm 0.22\end{array}$ & $\begin{array}{c}4 \\
<2.10 \\
0.91 \pm 1.06\end{array}$ & $\begin{array}{c}4 \\
<375 \\
47 \pm 51\end{array}$ & NS \\
\hline $\mathrm{HC}$ & $\begin{array}{l}\text { Peconic River, } \\
\text { off site }\end{array}$ & $\begin{array}{l}\mathrm{N} \\
\text { Max. } \\
\text { Avg. }\end{array}$ & $\begin{array}{c}4 \\
<0.75 \\
0.06 \pm 0.16\end{array}$ & $\begin{array}{c}4 \\
2.35 \pm 1.32 \\
1.01 \pm 0.79\end{array}$ & $\begin{array}{c}4 \\
<375 \\
-25 \pm 61\end{array}$ & NS \\
\hline $\mathrm{HR}$ & $\begin{array}{l}\text { Peconic River, } \\
\text { Riverhead }\end{array}$ & $\begin{array}{l}\mathrm{N} \\
\text { Max. } \\
\text { Avg. }\end{array}$ & $\begin{array}{c}4 \\
<0.71 \\
0.10 \pm 0.18\end{array}$ & $\begin{array}{c}4 \\
2.31 \pm 1.43 \\
1.71 \pm 0.81\end{array}$ & $\begin{array}{c}4 \\
<329 \\
-10 \pm 68\end{array}$ & NS \\
\hline $\mathrm{HH}$ & $\begin{array}{l}\text { Carmans River, } \\
\text { (control location) }\end{array}$ & $\begin{array}{l}\mathrm{N} \\
\text { Max. } \\
\text { Avg. }\end{array}$ & $\begin{array}{r}4 \\
22.70 \pm 0.71 \\
5.75 \pm 9.59\end{array}$ & $\begin{array}{c}4 \\
24.60 \pm 2.06 \\
6.57 \pm 10.22\end{array}$ & $\begin{array}{c}4 \\
<329 \\
-17 \pm 53\end{array}$ & NS \\
\hline \multicolumn{3}{|c|}{ SDWA Limit } & 15 & 50 & 20,000 & 8 \\
\hline
\end{tabular}

Notes:

See Figure 5-9 for sample station locations.

All values shown with $95 \%$ confidence interval.

Negative numbers occur when the measured value is lower than background.

For Stations HM-N and HQ, Sr-90 analysis results are based on composite

$\mathrm{N}=$ Number of samples analyzed

NS $=$ Not Sampled for this analyte

SDWA = Safe Drinking WaterAct

samples; all others collected as grab samples.

aquatic organisms if they are in a dissolved or ionic state, whereas other metals are toxic in any form (i.e., dissolved and particulate combined). In 2001, the BNL monitoring program assessed water samples for both the dissolved and particulate forms. Dissolved 
Table 5-8. Water Quality Data for Surface Water Samples Collected along the Peconic and Carmans Rivers.

\begin{tabular}{|c|c|c|c|c|c|c|c|c|c|}
\hline $\begin{array}{l}\text { Sample } \\
\text { Station }\end{array}$ & $\begin{array}{l}\text { Geogrphic } \\
\text { Location }\end{array}$ & & $\begin{array}{c}\text { pH } \\
\text { (SU) }\end{array}$ & $\begin{array}{l}\text { Conductivity } \\
(\mu \mathrm{S} / \mathrm{cm})\end{array}$ & $\begin{array}{l}\text { Temp. } \\
\left({ }^{\circ} \mathrm{C}\right)\end{array}$ & $\begin{array}{l}\text { Dissolved } \\
\text { Oxygen } \\
\text { (mg/L) }\end{array}$ & $\begin{array}{l}\text { Chlorides } \\
\text { (mg/L) }\end{array}$ & $\begin{array}{l}\text { Sulfates } \\
(\mathrm{mg} / \mathrm{L})\end{array}$ & $\begin{array}{c}\text { Nitrates } \\
\text { as } \mathbf{N} \\
(\mathrm{mg} / \mathrm{L})\end{array}$ \\
\hline $\mathrm{HV}$ & $\begin{array}{l}\text { Peconic River (headwaters), } \\
\text { on site, inside the RHIC ring }\end{array}$ & $\begin{array}{l}\text { N } \\
\text { Min. } \\
\text { Max. } \\
\text { Avg. }\end{array}$ & $\begin{array}{c}4 \\
4.3 \\
7.0 \\
\mathrm{NA}\end{array}$ & $\begin{array}{r}4 \\
71 \\
310 \\
174\end{array}$ & \begin{tabular}{r}
\multicolumn{1}{c}{4} \\
1.0 \\
15.6 \\
9.9
\end{tabular} & \begin{tabular}{r}
\multicolumn{1}{c}{4} \\
1.6 \\
13.2 \\
7.8
\end{tabular} & $\begin{array}{l}\text { NS } \\
\text { NS } \\
\text { NS } \\
\text { NS }\end{array}$ & $\begin{array}{l}\text { NS } \\
\text { NS } \\
\text { NS } \\
\text { NS }\end{array}$ & $\begin{array}{l}\text { NS } \\
\text { NS } \\
\text { NS } \\
\text { NS }\end{array}$ \\
\hline \multirow[t]{2}{*}{$\mathrm{HY}$} & \multirow[t]{2}{*}{$\begin{array}{l}\text { Peconic River, } \\
\text { (headwaters), on site, } \\
\text { east of Wm. Floyd Pkwy. }\end{array}$} & $\begin{array}{l}\text { N } \\
\text { Min. } \\
\text { Max. }\end{array}$ & $\begin{array}{l}4 \\
4.3 \\
7.2\end{array}$ & $\begin{array}{r}4 \\
44 \\
587\end{array}$ & $\begin{array}{c}4 \\
1.6 \\
15.6\end{array}$ & $\begin{array}{c}4 \\
1.6 \\
12.6\end{array}$ & $\begin{array}{c} \\
4 \\
<4 \\
156.8\end{array}$ & $\begin{aligned} & 4 \\
< & 4 \\
& 5.6\end{aligned}$ & 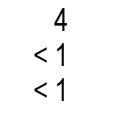 \\
\hline & & Avg. & $N A$ & 227 & 8.5 & 8.5 & 52.7 & 2.5 & $<1$ \\
\hline \multirow[t]{2}{*}{ HE } & \multirow[t]{2}{*}{$\begin{array}{l}\text { Peconic River, } \\
\text { upstream of STP Outfall }\end{array}$} & $\begin{array}{l}\text { N } \\
\text { Min. } \\
\text { Max. }\end{array}$ & $\begin{array}{l}8 \\
4.3 \\
7.3\end{array}$ & $\begin{array}{r}8 \\
38 \\
80\end{array}$ & $\begin{array}{c}8 \\
0.9 \\
21.3\end{array}$ & $\begin{array}{c}8 \\
3.7 \\
11.5\end{array}$ & $\begin{array}{c}4 \\
7.1 \\
12.3\end{array}$ & $\begin{aligned} & 4 \\
< & 4 \\
& 6.8\end{aligned}$ & $\begin{array}{r}4 \\
<1 \\
<1\end{array}$ \\
\hline & & Avg. & $\mathrm{NA}$ & 59 & 11.0 & 7.9 & 9.1 & 4.2 & $<1$ \\
\hline \multirow[t]{2}{*}{$\mathrm{HMn}$} & \multirow[t]{2}{*}{$\begin{array}{l}\text { Peconic River, } \\
0.4 \text { mi from STP, on site }\end{array}$} & $\begin{array}{l}\text { N } \\
\text { Min. } \\
\text { Max. }\end{array}$ & $\begin{array}{r}141 \\
4.6 \\
7.3\end{array}$ & $\begin{array}{r}141 \\
52 \\
343\end{array}$ & $\begin{array}{r}141 \\
0.2 \\
26.9\end{array}$ & $\begin{array}{r}141 \\
4.2 \\
16.8\end{array}$ & $\begin{array}{l}12 \\
10.8 \\
43.6\end{array}$ & $\begin{array}{c}12 \\
5.0 \\
15.5\end{array}$ & $\begin{array}{c}12 \\
1.0 \\
6.6\end{array}$ \\
\hline & & Avg. & $\mathrm{NA}$ & 195 & 12.8 & 8.5 & 29.2 & 12.2 & 4.0 \\
\hline \multirow[t]{2}{*}{ HMs } & \multirow[t]{2}{*}{$\begin{array}{l}\text { Peconic River, } \\
\text { tributary, on site }\end{array}$} & $\begin{array}{l}\text { N } \\
\text { Min. } \\
\text { Max. }\end{array}$ & $\begin{array}{l}2 \\
4.0 \\
4.3\end{array}$ & $\begin{array}{r}2 \\
43 \\
66\end{array}$ & $\begin{array}{l}2 \\
0.4 \\
5.3\end{array}$ & $\begin{array}{c}2 \\
7.5 \\
12.1\end{array}$ & $\begin{array}{l}2 \\
4.0 \\
5.3\end{array}$ & $\begin{array}{r}2 \\
<4 \\
4.6\end{array}$ & $\begin{array}{r}2 \\
<1 \\
<1\end{array}$ \\
\hline & & Avg. & $\mathrm{NA}$ & 55 & 2.8 & 9.8 & 4.7 & 2.3 & $<1$ \\
\hline$H Q$ & $\begin{array}{l}\text { Peconic River, } \\
\text { BNL site boundary }\end{array}$ & $\begin{array}{l}\text { N } \\
\text { Min. } \\
\text { Max. } \\
\text { Avg. }\end{array}$ & $\begin{array}{c}90 \\
4.9 \\
7.5 \\
\mathrm{NA}\end{array}$ & $\begin{array}{r}90 \\
58 \\
238 \\
143\end{array}$ & $\begin{array}{c}90 \\
1.4 \\
25.6 \\
14.7\end{array}$ & $\begin{array}{r}90 \\
0.3 \\
14.4 \\
5.7\end{array}$ & $\begin{array}{c}7 \\
10.2 \\
45.8 \\
26.5\end{array}$ & $\begin{array}{c}7 \\
5.0 \\
19.3 \\
10.0\end{array}$ & $\begin{array}{r}7 \\
<1 \\
5.9 \\
1.7\end{array}$ \\
\hline \multirow[t]{2}{*}{ HA } & \multirow[t]{2}{*}{$\begin{array}{l}\text { Peconic River, } \\
\text { off site }\end{array}$} & $\begin{array}{l}\mathrm{N} \\
\text { Min. } \\
\text { Max. }\end{array}$ & $\begin{array}{l}4 \\
3.9 \\
6.1\end{array}$ & $\begin{array}{r}4 \\
48 \\
65\end{array}$ & $\begin{array}{c}4 \\
1.4 \\
22.2\end{array}$ & $\begin{array}{c}4 \\
5.6 \\
15.6\end{array}$ & $\begin{array}{l}4 \\
7.0 \\
9.7\end{array}$ & $\begin{array}{r}4 \\
<4 \\
4.5\end{array}$ & $\begin{array}{r} \\
\quad 4 \\
< \\
<1 \\
<1\end{array}$ \\
\hline & & Avg. & NA & 54 & 11.8 & 9.4 & 7.8 & 1.1 & $<1$ \\
\hline \multirow[t]{2}{*}{$H B$} & \multirow[t]{2}{*}{$\begin{array}{l}\text { Peconic River, } \\
\text { off site }\end{array}$} & $\begin{array}{l}\mathrm{N} \\
\text { Min. } \\
\text { Max. }\end{array}$ & $\begin{array}{l}4 \\
5.2 \\
6.2\end{array}$ & $\begin{array}{r}4 \\
49 \\
66\end{array}$ & $\begin{array}{c}4 \\
0.3 \\
21.8\end{array}$ & $\begin{array}{c}4 \\
3.0 \\
16.4\end{array}$ & $\begin{array}{l}4 \\
7.7 \\
9.9\end{array}$ & $\begin{array}{c}4 \\
<4 \\
5.1\end{array}$ & $\begin{array}{r} \\
\quad 4 \\
< \\
<1 \\
<\end{array}$ \\
\hline & & Avg. & NA & 58 & 11.2 & 8.3 & 8.6 & 3.5 & $<1$ \\
\hline \multirow[t]{2}{*}{$\mathrm{HC}$} & \multirow[t]{2}{*}{$\begin{array}{l}\text { Peconic River, } \\
\text { off site }\end{array}$} & $\begin{array}{l}\text { N } \\
\text { Min. } \\
\text { Max. }\end{array}$ & $\begin{array}{l}4 \\
5.7 \\
6.4\end{array}$ & $\begin{array}{r}4 \\
56 \\
79\end{array}$ & $\begin{array}{c}4 \\
1.8 \\
23.9\end{array}$ & $\begin{array}{l}4 \\
7.8 \\
9.7\end{array}$ & $\begin{array}{c}4 \\
8.0 \\
10.8\end{array}$ & $\begin{array}{r} \\
<4 \\
<.6\end{array}$ & 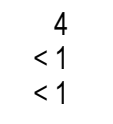 \\
\hline & & Avg. & $N A$ & 64 & 11.1 & 9.0 & 9.5 & 4.3 & $<1$ \\
\hline \multirow[t]{2}{*}{$H R$} & \multirow[t]{2}{*}{$\begin{array}{l}\text { Peconic River, } \\
\text { off site, Riverhead }\end{array}$} & $\begin{array}{l}\text { N } \\
\text { Min. } \\
\text { Max. }\end{array}$ & $\begin{array}{l}4 \\
6.3 \\
7.0\end{array}$ & $\begin{array}{r}4 \\
81 \\
131\end{array}$ & $\begin{array}{c}4 \\
4.2 \\
27.3\end{array}$ & $\begin{array}{c}4 \\
8.5 \\
12.6\end{array}$ & $\begin{array}{c}4 \\
11.5 \\
17.3\end{array}$ & $\begin{array}{c}4 \\
7.8 \\
10.8\end{array}$ & $\begin{array}{r} \\
4 \\
< \\
<1 \\
<\end{array}$ \\
\hline & & Avg. & $N A$ & 110 & 14.6 & 10.6 & 15.3 & 8.9 & $<1$ \\
\hline $\mathrm{HH}$ & $\begin{array}{l}\text { Carmans River, } \\
\text { (control location) }\end{array}$ & $\begin{array}{l}\text { N } \\
\text { Min. } \\
\text { Max. } \\
\text { Avg. }\end{array}$ & $\begin{array}{c}4 \\
6.4 \\
7.2 \\
\mathrm{NA}\end{array}$ & $\begin{array}{r}4 \\
149 \\
177 \\
161\end{array}$ & $\begin{array}{c}4 \\
4.8 \\
20.9 \\
12.3 \\
\end{array}$ & $\begin{array}{c}4 \\
8.6 \\
12.5 \\
10.2 \\
\end{array}$ & $\begin{array}{c}4 \\
23.1 \\
30.4 \\
26.7\end{array}$ & $\begin{array}{c}4 \\
9.6 \\
11.7 \\
10.7 \\
\end{array}$ & $\begin{array}{l}4 \\
1.1 \\
1.6 \\
1.3 \\
\end{array}$ \\
\hline \multicolumn{2}{|c|}{$\begin{array}{l}\text { NYS AWQS } \\
\text { Typical MDL }\end{array}$} & & $\begin{array}{c}6.5-8.5 \\
\text { NA }\end{array}$ & $\begin{array}{r}\text { SNS } \\
10\end{array}$ & $\begin{array}{r}\text { SNS } \\
\text { NA }\end{array}$ & $\begin{array}{l}<4.0 \\
\mathrm{NA}\end{array}$ & $\begin{array}{r}250 \text { (a) } \\
4.0\end{array}$ & $\begin{array}{r}250 \text { (a) } \\
4.0\end{array}$ & $\begin{array}{r}10^{(a)} \\
1.0 \\
\end{array}$ \\
\hline \multicolumn{3}{|c|}{$\begin{array}{l}\text { See Figure } 5-9 \text { for sample station locations. } \\
N=\text { No. of samples } \\
\text { NA = NotApplicable } \\
\text { NS = Not Sampled } \\
\text { MDL = Minimum Detection Limit }\end{array}$} & \multicolumn{7}{|c|}{$\begin{array}{l}\text { SNS = Standard Not Specified } \\
\text { (a) Since there are no Class C Surface Water Ambient Wa } \\
\text { Standards (AWQS) for these compounds, the AWQS for } \\
\text { groundwater is provided, if specified. }\end{array}$} \\
\hline
\end{tabular}




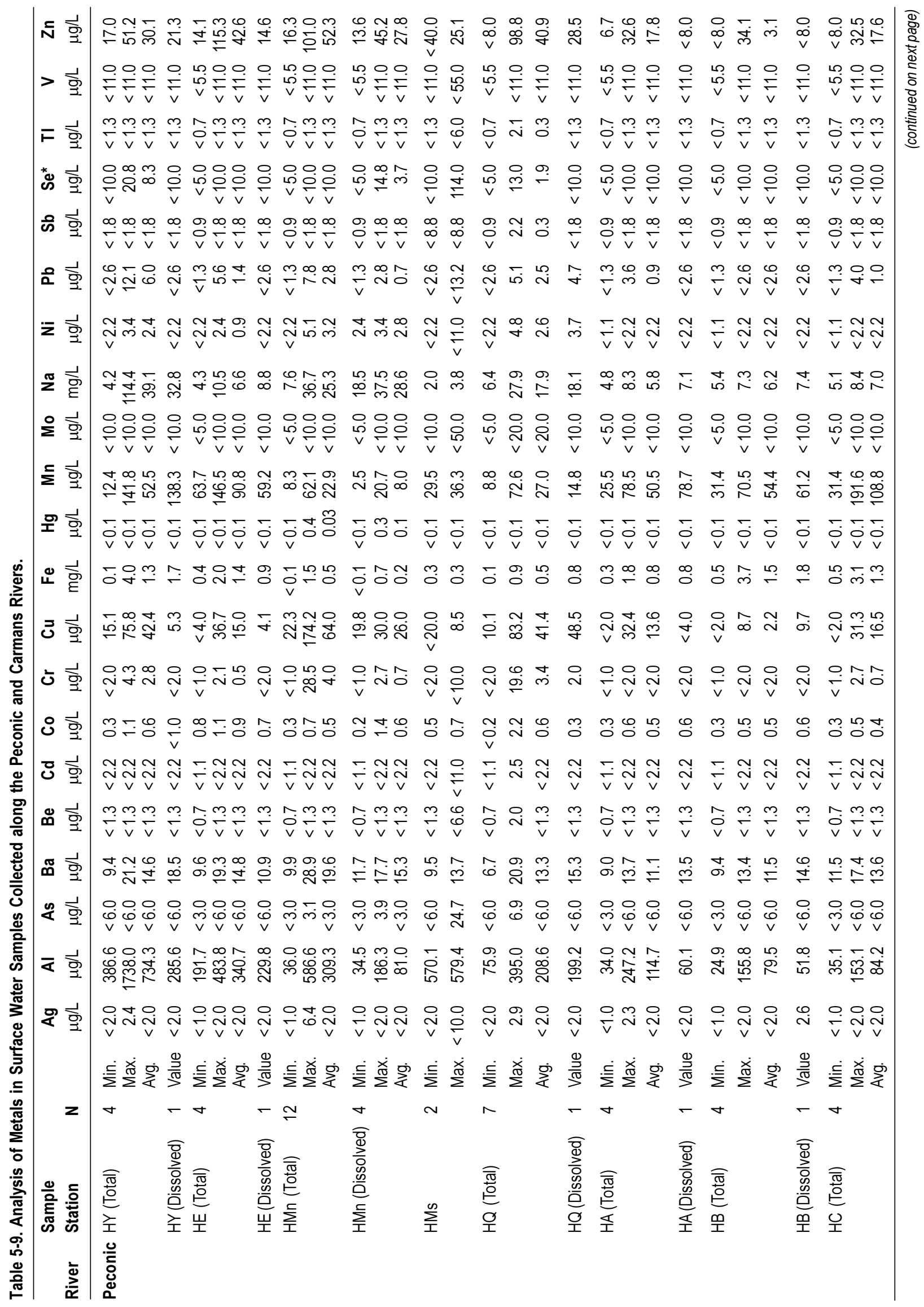




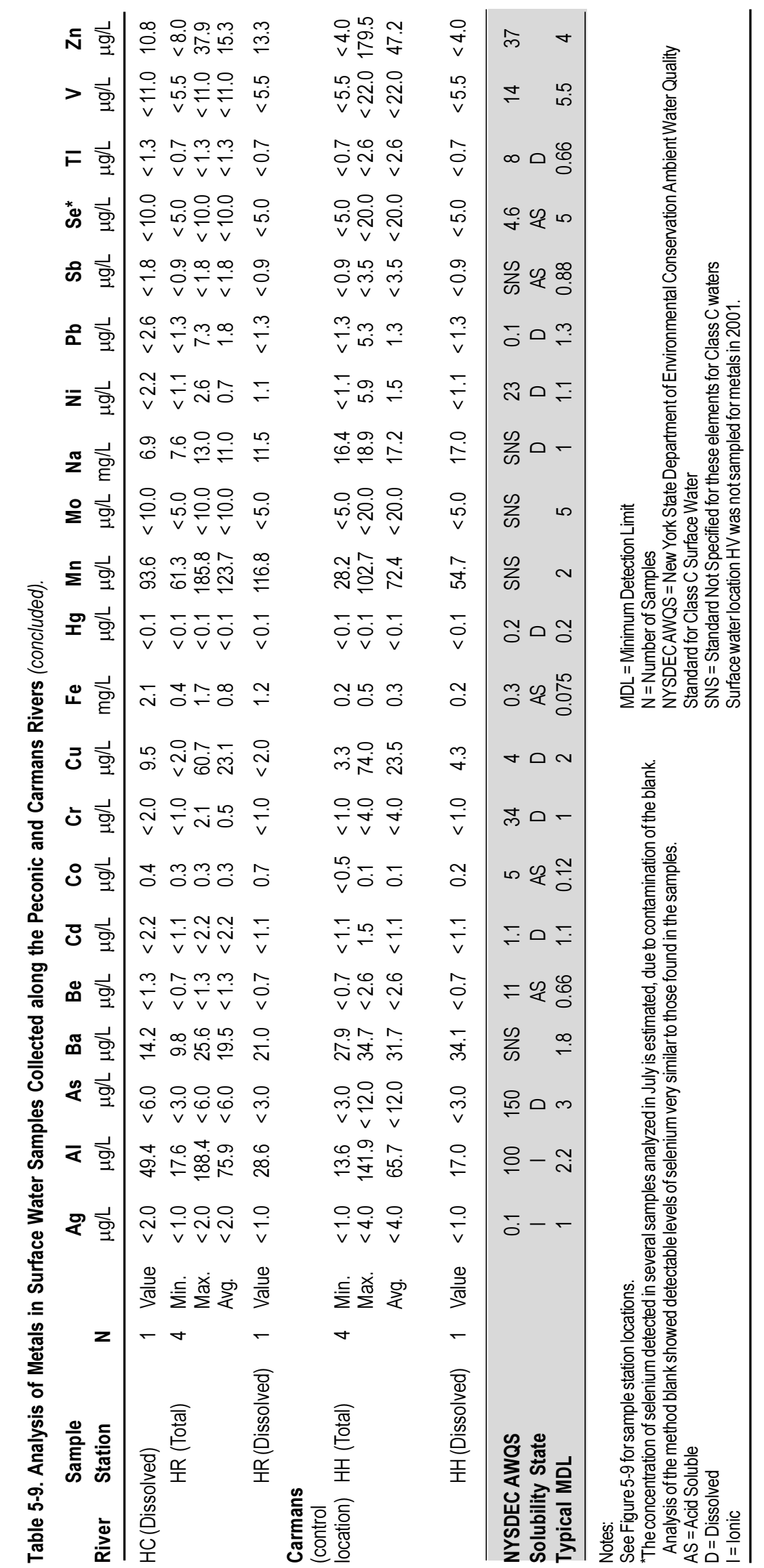


concentrations were determined by first filtering the samples prior to acid preservation and analysis. Examination of the metals data showed that aluminum, copper, lead, mercury, iron, selenium, silver, and zinc were present in concentrations that exceeded ambient water quality standards at upstream, downstream and, in some instances, the Carmans River stations. Aluminum, lead, iron, and zinc were at the highest concentrations in water samples collected upstream from the STP. The concentration of selenium was highest in a water sample collected at Station HMs, a tributary not impacted by STP operations. Copper, silver, and mercury were highest in water samples collected immediately downstream at Station HMn. These elements were routinely detected in the STP discharge and, with the exception of copper, were detected in the STP discharge in similar concentrations and were within SPDES permit limits. Copper exceeded SPDES permit limits in samples collected in November $(174 \mu \mathrm{g} / \mathrm{L})$ and December $(124 \mu \mathrm{g} / \mathrm{L})$. Filtration of samples had a drastic impact on the concentration of metals. In most instances, the concentration was significantly lower in the filtered sample than in the unfiltered (i.e., acid-digested) sample, indicating that sediments contained in the water were the likely contributor to the observed concentrations. The BNL STP effluent is routinely monitored for suspended solids. The concentration of solids in the STP discharge is typically nondetectable (see Table 3-3); consequently, the current BNL STP discharge is not the source of these contaminants. The most likely source is sediment scoured from the riverbed and entrained in the flowing stream. Contaminated sediments have been identified in the Operating Unit $V$ assessment, and remedial pilot studies have been initiated to determine the best method for removing the contaminated sediments. Further discussion of Operating Unit V activities for 2001 is provided in Chapter 2. BNL will continue to assess filtered samples to support this observation.

\section{REFERENCES}

BNL. 2001. Standards Based Management System Subject Area, Liquid Effluents. Brookhaven National Laboratory, Upton, NY. May 2001.

BNL. 2000. Brookhaven National Laboratory Environmental Monitoring Plan 2000. BNL-52584. Brookhaven National Laboratory, Upton, NY. March 2000.

DOE Order 5400.5. 1990. Radiation Protection of the Public and the Environment. U.S. Department of Energy, Washington, D.C. Change 2: 1-7-93. 
Intentionally Left Blank 
BROOKHAVEN

NATIONAL

LABORATORY

2001 SITE ENVIRONMENTAL REPORT

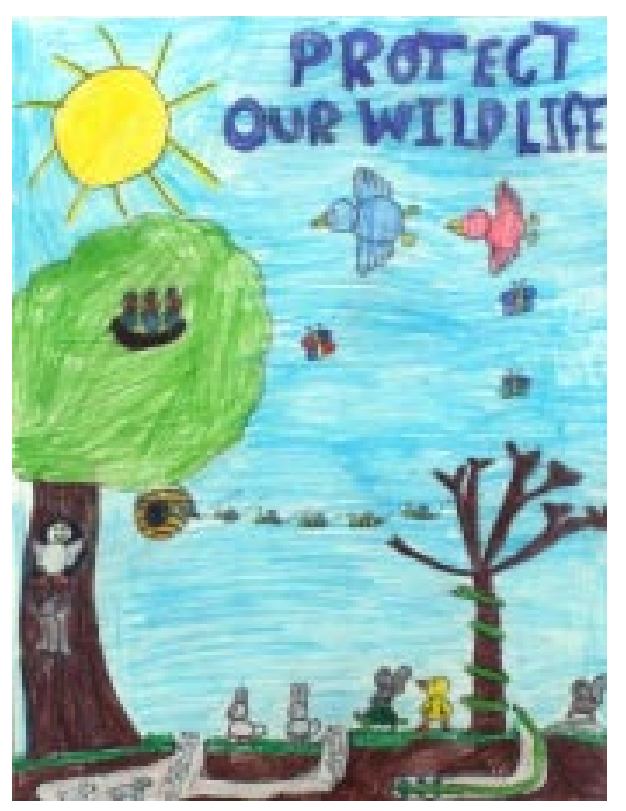

Chapter 6

Natural and

Cultural

Resources
The Brookhaven National Laboratory Wildlife Management Program is designed to protect and manage flora and fauna and their habitats. The Laboratory's wildlife management strategy is based on an understanding of the site's resources and on compliance with applicable regulations. The goals of the program include protecting and monitoring the ecosystem, conducting research, and communicating with staff and the public. Through this program, BNL focuses on protecting New York State threatened and endangered species, as well as on the Laboratory's role within the greater Long Island Central Pine Barrens ecosystem.

Monitoring to determine whether current or historical activities are affecting wildlife is also part of this program. In 2001, deer and fish sampling results were consistent with previous years. Local farm-grown produce, as well as vegetables grown in the BNL garden plot, continue to support historical analyses that there are no Laboratory-generated radionuclides in farm produce.

Completing the first full year of operation of the Upton Ecological and Research Reserve, its advisory group began research and preservation of the 530-acre area. Two research grants to investigate important local ecological issues were awarded.

In 2001, architectural and cultural resource inventories were completed. Work was completed on a survey to determine the potential historic value of BNL's buildings, in accordance with the National Historic Preservation Act. The High Flux Beam Reactor was determined to be eligible for listing on the National Register of Historic Places; the Brookhaven Graphite Research Reactor complex and Camp Upton's training trenches from World War I were previously determined to be eligible. 


\subsection{WILDLIFE MANAGEMENT PROGRAM}

The purpose of the Wildlife Management Program at BNL is to promote stewardship of the natural resources found at the Laboratory, as well as to integrate natural resource protection with BNL's mission. To meet this purpose, the Laboratory has a Wildlife Management Plan that describes the program strategy, elements, and planned activities (Naidu 1999). The plan and related information about natural resources at the Laboratory can be found at the Environmental Services Division website, $<$ http://www.bnl.gov/ esd/wildlife/>.

\subsubsection{Identification and Mapping}

An understanding of the environmental baseline is the foundation of wildlife management planning. Prior to 2001, BNL used a natural resource inventory of the site conducted by the Central Pine Barrens Commission, based on data collected from 1970 to 1990 . That inventory focused primarily on vegetation at a coarse scale, but was useful in identifying environmentally sensitive areas and significant wildlife communities. In 2001, through funding managed by the U.S. Fish \& Wildlife Service (FWS), the entire BNL property was surveyed using the National Vegetation

Standard; a new map was produced that clearly identifies the major vegetation complexes and their extents. An additional tool provided with the vegetation map allows the user to predict distributions of key animal species based on the presence of suitable habitat.

As noted in Chapter 1, a wide variety of vegetation, birds, reptiles, amphibians, and mammals reside at BNL. The only New York State endangered species known to inhabit BNL property is the tiger salamander (Ambystomat. tigrinum, Figure 6-1). Three New York State threatened species have been positively identified on site at BNL and a fourth species is considered likely. The banded sunfish (Enneacanthus obesus, Figure 6-2), the swamp darter (Etheostoma fusiforme, Figure 6-3), and the stiff goldenrod plant (Solidago rigida) have been previously reported (BNL 2000). A fourth species, the frosted elfin butterfly (Callophrys irus) has been identified as possibly being at BNL, based on historic documentation and the presence of its preferred habitat and host plant (wild lupine). In addition, several species that inhabit the BNL site or visit during migration are listed as "rare," "species of special concern," or "exploitably vulnerable" by New York State (Table 6-1).

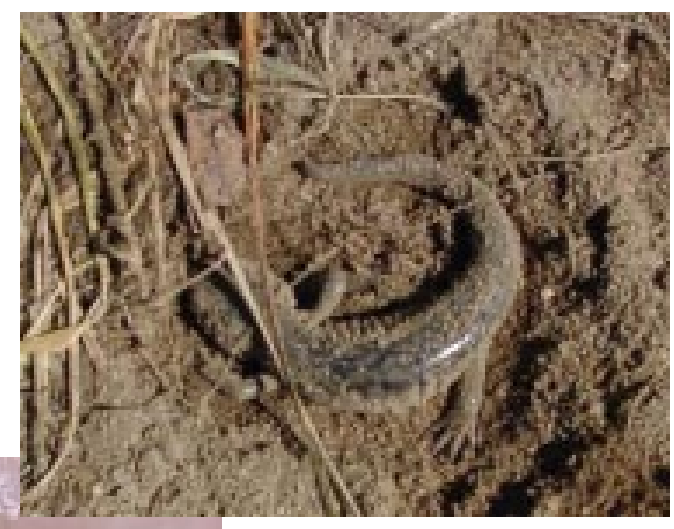

Figure 6-1. Tiger Salamander (Ambystoma t. tigrinum).

Figure 6-2. Banded Sunfish (Enneacanthus obesus). This fish was released immediately after the picture was taken.

\subsubsection{Habitat Protection and Enhancement}

BNL takes many precautions to protect onsite habitat and natural resources. Activities to eliminate or minimize negative effects on sensitive or critical species are either incorporated into BNL procedures or into specific program or project plans. Environmental restoration efforts 
Table 6-1. New York State Threatened, Endangered, and Species of Special Concern.

\begin{tabular}{llc}
\hline Common Name & Scientific Name & $\begin{array}{c}\text { State } \\
\text { Status }\end{array}$ \\
\hline Fish & & \\
Banded sunfish & Enneacanthus obesus & T \\
Swamp darter & Etheostoma fusiforme & T
\end{tabular}

Amphibians

Eastern tiger salamander

Ambystoma tigrinum tigrinum $\mathrm{E}$

Marbled salamander

Ambystoma opacum

SC

Reptiles

Spotted turtle

Clemmys guttata

SC

Eastern box turtle

Terrapene carolina

Heterodon platyrhinos

$\mathrm{SC}$

Eastern hognose snake

SC

Birds (nesting or common)

Horned lark

Eremophila alpestris

Whip-poor-will

Caprimulgus vociferus

Vesper sparrow

Pooecetes gramineus

Grasshopper sparrow

Ammodramus savannarum

Plants

Butterfly weed

Spotted wintergreen

Flowering dogwood

Pink lady's slipper

Winterberry

Sheep laurel

Narrow-leafed bush clover

Ground pine

Bayberry

Cinnamon fern

Clayton's fern

Royal fern

Swamp azalea

Stiff goldenrod

New York fern

Marsh fern

$\begin{array}{lc}\text { Asclepias tuberosa } & \mathrm{V} \\ \text { Chimaphila maculata } & \mathrm{V} \\ \text { Cornus florida } & \mathrm{V} \\ \text { Cypripedium acaule } & \mathrm{V} \\ \text { llex verticillata } & \mathrm{V} \\ \text { Kalmia angustifolia } & \mathrm{V} \\ \text { Lespedeza augustifolia } & \mathrm{R} \\ \text { Lycopodium obscurum } & \mathrm{V} \\ \text { Myrica pensylvanica } & \mathrm{V} \\ \text { Osmunda cinnamomera } & \mathrm{V} \\ \text { Osmunda claytoniana } & \mathrm{V} \\ \text { Osmunda regalis } & \mathrm{V} \\ \text { Rhododendron viscosum } & \mathrm{V} \\ \text { Solidago rigida } & \mathrm{T} \\ \text { Thelypteris novaboracensis } & \mathrm{V} \\ \text { Thelypteris palustris } & \mathrm{V} \\ \text { Woodwardia virginica } & \mathrm{V}\end{array}$

Notes:

Table information is based on 6 NYCRR Part 182, 6 NYCRR

Part 193, and BNL survey data.

No federally listed threatened or endangered species are

known to inhabit the BNL site.

$\mathrm{E}=$ Endangered

$\mathrm{R}=$ Rare

$\mathrm{SC}=$ Species of special concern

$T=$ Threatened

$V=$ Exploitably vulnerable remove pollutant sources that could contaminate habitats. Human access to critical habitats is restricted. In some cases, habitats are enhanced to improve survival or increase populations. After due consideration, routine activities that are not expected to affect habitat (such as road maintenance) are allowed to proceed.

\subsubsection{Tiger Salamander Efforts}

To safeguard tiger salamander breeding areas, a map of those locations is reviewed when new projects are proposed. Distribution of the map is limited, to protect the tiger salamander from exploitation by collectors and the pet trade. Other efforts to protect this state endangered species include determining when adult salamanders are migrating toward breeding locations, when metamorphosis has been completed, and when juveniles are migrating after metamorphosis. During these times, construction and maintenance activities near tiger salamander habitat are postponed. All projects planned near tiger salamander habitat must be reviewed by BNL environmental protection staff, and every effort is made to minimize impacts.

Water quality testing is conducted as part of the routine monitoring of water basins. In cooperation with the New York State Department of Conservation (NYSDEC), limited habitat surveys have been conducted annually since 1999. Biologists taking egg mass surveys have confirmed that 15 on-site ponds are used by tiger salamanders. All ponds that had egg masses during the spring surveys were surveyed again in June and July to check for the presence of larval salamanders; two ponds were surrounded by 4foot $\times 4$-foot plywood cover boards in order to study the dispersal patterns of metamorphic salamanders. Several hundred larvae were seen, captured, measured, and then released. Seven ponds with spring egg masses were thoroughly surveyed, while other ponds were visited but surveys were not completed due to high water levels. The results of surveys and cover board studies help determine the length of the breeding period and provide information that is needed to determine a window for any activities in and around the breeding areas. The information may also identify activities that could be affecting this 
species and changes in site use that may be needed. Information acquired from surveys is entered into a database and will eventually be linked to a geographic information system (GIS). The data will be used to visualize distributions, track reproductive success, and identify areas for focused management or study.

\subsubsection{Other Species}

As part of the tiger salamander surveys, incidental information is recorded on other amphibian species located in and around the tiger salamander habitat. Other species recorded include the northern redback salamander (Plethodon c. cinereus), marbled salamander (Ambystoma opacum), spring peeper (Pseudacris crucifer), wood frog (Rana sylvatica), gray tree frog (Hyla versicolor), bullfrog (Rana catesbiana), green frog (Rana clamitans), and Fowler's toad (Bufo fowleri). Banded sunfish protection efforts include ensuring that adequate flow of the river is maintained within areas currently identified as sunfish habitat, ensuring that existing vegetation in the sunfish habitat is not disturbed, and evaluating all river remediation efforts for potential impacts on these habitats. River surveys in 2001 indicated the continued presence of two small populations of banded sunfish, including one location that also contains a population of the swamp darter, another species that is threatened in New York.

BNL's Wildlife Management Plan also calls for habitat enhancement. A total of 216 species of birds have been identified at BNL since 1948, of which at least 85 are known to nest on site. Some of these nesting birds have shown declines in their populations nationwide over the past 30 years. In 2001, the Laboratory conducted its second year of routine monitoring of songbirds at five permanent bird survey routes in various habitats on site. Monthly surveys were conducted, starting at the end of March and extending to the end of October. The surveys in 2001 resulted in the identification of 73 species during the year -20 more species than the previous year. Seventeen species were counted only once and are likely to be migrants stopping briefly at BNL. The two most diverse observation transects pass near wetlands by the Biology
Fields and the Peconic River. The three transects passing through the various forest types (white pine, moist pine barrens, and dry pine barrens) showed a less diverse bird community. Data are stored in an electronic database, and there are plans to link the data to BNL's GIS.

The eastern bluebird (Sialia sialis) has been identified as one of the declining species of migratory birds in North America. This decline is due to loss of habitat and to nest site competition from European starlings (Sturnus vulgaris) and house sparrows (Passer domesticus). In 2001, BNL installed 10 new bluebird boxes, bringing the total to 36 boxes installed around open grassland areas of the site to enhance the bluebird population. Boxes were monitored approximately every three weeks during the breeding season to determine use and nesting success. Nineteen bluebird nests were observed. House wrens (Troglodytes aedon) produced seven nests, of which four were built over bluebird nests after the bluebirds had left. BNL presented bluebird boxes to the winners of BNL Environmental Awards and to winners of the annual Site Environmental Report art contest. The gift of nest boxes encourages habitat enhancement within the urban (and suburban) environment.

\subsubsection{Population Management}

BNL also monitors and manages other populations, including "species of interest," to ensure that they are sustained and to control invasive species.

\subsubsection{Wild Turkeys}

The wild turkeys (Meleagris gallopavo) on site are doing well. The forested areas of BNL provide good nesting and foraging habitat for this large bird. The on-site population was estimated at 60 to 80 birds in 1999 and had grown to around 250 birds by the end of 2001 . The large population of turkeys on site generated interest among the news media in 2001, resulting in a feature-length article in The New York Times (Nov. 25, 2001). Updated population reports are periodically sent to NYSDEC to assist with their population estimates. The turkey population will continue to be monitored to determine its reproductive success. 


\subsubsection{White-Tailed Deer}

BNL consistently updates information on the resident population of white-tailed deer (Odocoileus virginianus). As there are no natural predators on site and hunting is not permitted at BNL, there are no significant pressures on the population to migrate beyond their typical home range of approximately one square mile. A 1992 study indicated that the population of deer on site exceeded 700, or approximately 85 per square mile (Thomlinson 1993). Normally, a population density of 10 to 30 per square mile is considered an optimum sustainable level for a given area. This would equate to approximately 80 to 250 deer inhabiting the BNL property under normal circumstances. This was the approximate density in 1966, when the Laboratory reported an estimate of 267 deer on site (Dwyer 1966). The current estimate, based on surveys conducted late in 2001 , is 1,160 deer, or approximately 140 deer per square mile.

There were even more deer in late 2000, when the estimate was 1,942 animals (BNL 2000). The winter of 2000-2001 was wetter than normal, with significant snowfalls in late February through March. Snow covered the ground for significant periods during these two months, making it difficult for deer to forage. A lack of acorn production in 2000 compounded the problem. Between the lack of food and the difficult foraging conditions, the BNL deer population was reduced by approximately 50 percent during the winter of 2000-2001. Reproduction rates were also affected, rebuilding the population to only 60 percent of the 2000 level. The 2002 figures are expected to increase significantly, due to the mild winter.

Deer overpopulation can affect animal and human health (e.g., animal starvation, Lyme disease from deer ticks, collision injuries - both human and animal), species diversity (songbird species reduction due to selective grazing and destruction of habitat by deer), and property values (auto damage and browsing damage to ornamental plantings). In 2001, there were only 8 deer-related collisions reported on site, compared to 24 accidents documented in 2000 . This dramatic decrease in the number of on-site collisions is attributed to the large population reduction that occurred. Deer attempting to survive the winter of 2001 caused significant damage to ornamental plantings around BNL buildings. Virtually any edible plant was consumed. While damage to shrubbery was not a threat to human health, it may result in the need to replace shrubs at substantial cost.

BNL submitted National Environmental Policy Act (NEPA) documentation for deer management to DOE for review and approval in October 2001. A request for BNL to prepare an environmental assessment for deer management was made by year's end. BNL is developing the options for initiating the environmental assessment process in 2002 . BNL continues to work with state regulators to determine the best method for controlling the deer population.

\subsubsection{Compliance Assurance and Potential Impact Assessment}

The NEPA review process at BNL is one of the keys to ensuring that environmental impacts of a proposed action or activity are adequately evaluated and addressed. BNL will continue to use NEPA (or NEPA-like) values under the Comprehensive Environmental Response, Compensation and Liability Act (Environmental Restoration Program) when identifying potential environmental impacts associated with site activities - especially with physical alterations. As appropriate, stakeholders such as EPA,

NYSDEC, Suffolk County Department of Health Services, The Nature Conservancy, the Town of Brookhaven, the Community Advisory Council, and local environmental advocacy groups are involved in reviewing major projects that have potentially significant environmental impacts.

\subsection{UPTON ECOLOGICAL AND RESEARCH RESERVE}

On November 9, 2000, then-Secretary of Energy Bill Richardson, and Susan MacMahon, Acting Regional Director of Region 5 U.S. Fish \& Wildlife Service, dedicated 530 acres of Laboratory property as an ecological research reserve. The property was designated by DOE as the Upton Ecological and Research Reserve ("Upton Reserve") and is managed by FWS under an Interagency Agreement (DOE-FWS 2000). 
Additional information on the establishment of the Upton Reserve is on the Internet at $<\mathrm{http}$ :// www.bnl.gov/esd/reserve.htm>. The Upton Reserve, located on the eastern edge of BNL (Figure 6-4), is home to a wide variety of flora and fauna. It contains wetlands and is largely within the core preservation area of the Long Island Central Pine Barrens. Based on information from the 1994-1995 biological survey of $\mathrm{BNL}$, experts believe the reserve is home to more than 200 plant species and at least 162 species of mammals, birds, fish, reptiles, and amphibians (LMS 1995).

In establishing the Upton Reserve, DOE committed to provide FWS with $\$ 1,000,000$ over a five-year period to manage the reserve. In 2001 , the first full year of the reserve's existence,
FWS hired two biologists, formally established the boundary, and posted the area. The new staff began baseline biological survey work, initiated basic research, and funded educational programs in conjunction with BNL and Suffolk County Community College.

The Interagency Agreement that established the Upton Reserve specified the formation of a Technical Advisory Group (TAG), which includes the reserve's supervisory FWS biologist and representatives from NYSDEC, Suffolk County Parks Department, Central Pine Barrens Joint Policy and Planning Commission, DOE, Citizens Advisory Council, Brookhaven Executive Roundtable, Brookhaven Science Associates, and The Nature Conservancy. The TAG's primary responsibility is to provide technical

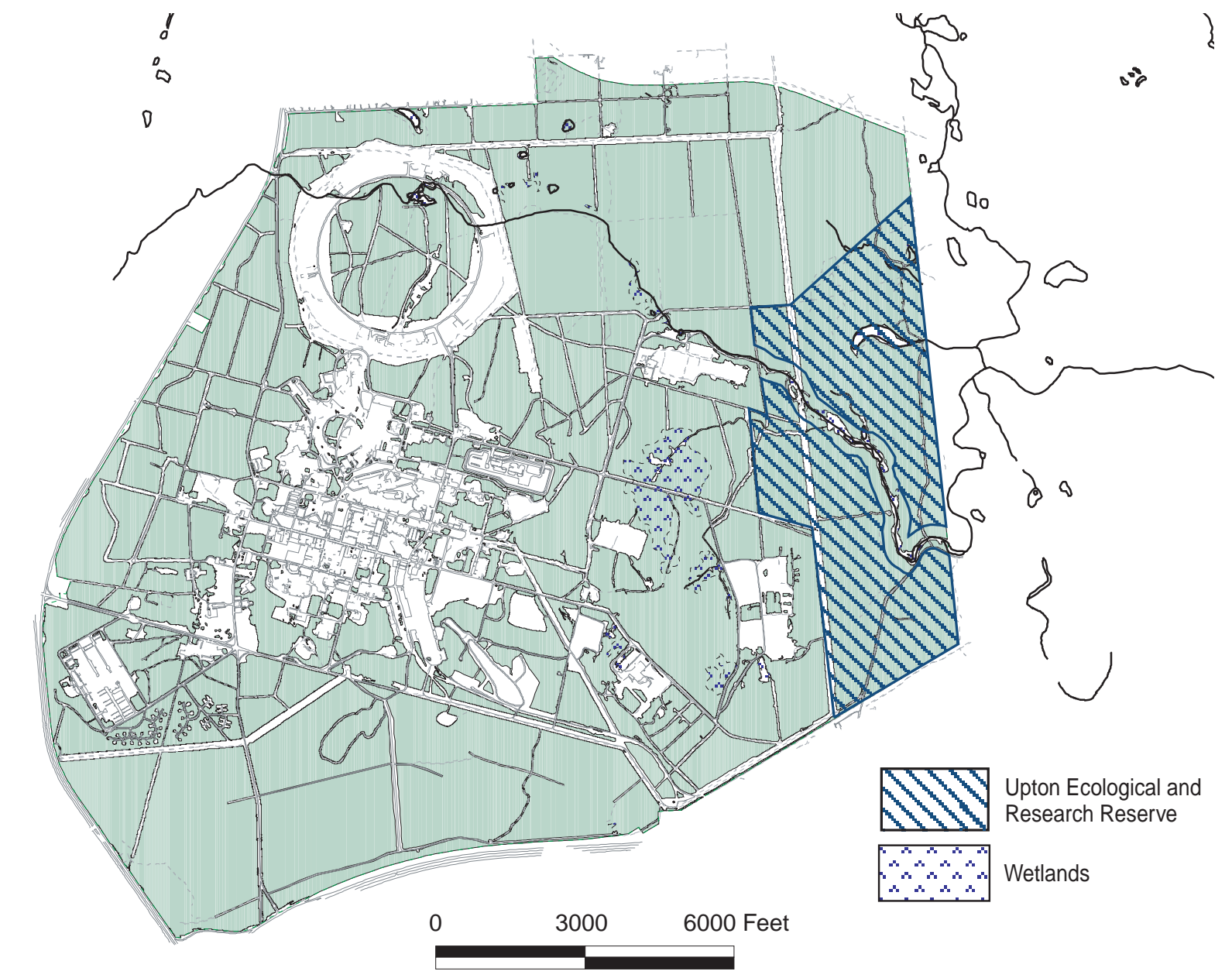

Figure 6-4. BNL Site Map Indicating the Boundary of the Upton Ecological and Research Reserve. 
input into the development of a comprehensive natural resource management plan for both BNL and the Upton Reserve. This plan will eventually replace the existing Wildlife Management Plan. The TAG also has developed criteria for soliciting and reviewing proposals and awarding funds for research to be conducted within the Upton Reserve. By the end of 2001, the TAG had approved two research proposals: one to investigate the physiological responses of oak trees to fall defoliation caused by the orange-striped oakmoth caterpillar (Anisota senatoria), and the second to investigate why some plants are more invasive than others.

\subsection{MONITORING FLORA AND FAUNA}

BNL conducts routine monitoring of flora and fauna to determine the impact of past and present Laboratory activities. Because soils contaminated with cesium-137 were used in some BNL landscaping projects at some point in the past, traces of contamination are found in deer and possibly in other animals and plants. Most tables of Laboratory radionuclide data list both potassium-40 and cesium-137 data.

Potassium- 40 occurs naturally in the environment and is not uncommon in flora and fauna. It is presented as a comparison to cesium-137, because cesium-137 competes with potassium at a cellular level. General trends indicate that cesium-137 will out-compete potassium when potassium salts are limited in the environment, which is the typical case on Long Island. In general, potassium- 40 values do not receive significant discussion in the scientific literature due to this relationship and the fact that potassium- 40 occurs naturally. The paragraphs below describe the results of the annual sampling conducted under the flora and fauna monitoring program.

\subsubsection{Deer Sampling}

Deer in New York State typically are large, with males weighing, on average, about 150 pounds; females typically weigh one-third less, about 100 pounds. However, deer on Long Island tend to be much smaller, with an average weight around 80 pounds. The available meat on local deer ranges from 20 to 40 pounds per deer. This fact has implications for calculations of possible human dose from eating BNL deer.

In 2001, as in recent years, an off-site deer sampling program was conducted with the NYSDEC Wildlife Branch and FWS. NYSDEC samples provide data on deer moving beyond BNL boundaries, where they can be legally hunted. NYSDEC also provides control data on deer living far from BNL. Also, FWS informed BNL staff of deer killed in or near the Wertheim National Wildlife Refuge and other FWS properties on Long Island. BNL sampling technicians then collected the samples and processed them for analysis. Samples were also obtained from road kill on and near BNL, and from BNL employees who hunt. The total number of samples obtained near the BNL site increased from past years, due to a large number of deervehicle accidents that occurred off site; hunter donations remained the same as in past years. In all, 8 deer samples were obtained on site and 36 were gathered from off-site locations, ranging from adjacent to BNL along the William Floyd Parkway, to as far away as Kingsfield, Maine.

\subsubsection{Cesium-137 in Deer Meat and Liver}

It has been previously established (BNL 1999) that deer taken on the BNL site contain higher concentrations of cesium-137 (half-life = 30 years) than deer taken off site. This is most likely the result of deer consuming contaminated soil and grazing on vegetation growing in soils where elevated cesium- 137 levels are known to exist. Cesium-137 in soil can be transferred to aboveground plant matter via root uptake, where it then becomes available to browsing animals.

Removal of contaminated soil areas at BNL has occurred under the site Environmental Restoration Program. All major areas of contamination in lawn soils were remediated in 2000 . Some soil contamination is still present in areas that are part of Operable Units (OU) I/VI and V. The cleanup of areas covered by the Record of Decision for Operable Units I and Radiologically Contaminated Soils (BNL 1999) is scheduled and will be completed as funds are available. A Record of Decision for the Sewage Treatment Plant (STP), a part of OU V, was signed in 2001; cleanup there is scheduled to begin in 2002 . 
In 2001, cesium- 137 concentrations in deer meat samples taken at BNL ranged from nondetectable to $4.31 \mathrm{pCi} / \mathrm{g}$ wet weight. (The "wet weight" concentration is before a sample is dried for analysis, and is the form most likely to be consumed. Dry weight concentrations are typically higher than wet weight values.) The maximum 2001 on-site concentration $(4.31 \mathrm{pCi} / \mathrm{g}$ wet weight) is significantly lower than the highest level reported in 2000 ( $7.31 \mathrm{pCi} / \mathrm{g}$ wet weight) and much lower than the highest level ever reported (11.74 $\mathrm{pCi} / \mathrm{g}$ wet weight, in 1996). In 2001 , the maximum off-site concentration of cesium-137 in deer meat samples was $6.19 \mathrm{pCi} / \mathrm{g}$ wet weight. The arithmetic average concentration in on-site meat samples was $1.44 \mathrm{pCi} / \mathrm{g}$. The average concentration in off-site meat samples was $1.23 \mathrm{pCi} / \mathrm{g}$ wet weight.

Cesium-137 concentrations in off-site deer meat samples were separated into two groups: samples taken within one mile of BNL and samples taken farther away (see Table 6-2). Concentrations in meat samples nearby range from 0.11 to $6.19 \mathrm{pCi} / \mathrm{g}$; concentrations in meat taken from farther away ranged from being nondetectable to $5.34 \mathrm{pCi} / \mathrm{g}$.

Figure 6-5 compares the ranges of cesium137 concentrations in meat samples from onsite and off-site deer collected since 1996. The majority of all samples taken both on and off site are at or below $1 \mathrm{pCi} / \mathrm{g}$ wet weight.

In liver samples collected on site, the maximum cesium- 137 concentration was 2.62 $\mathrm{pCi} / \mathrm{g}$ and the average was $0.50 \mathrm{pCi} / \mathrm{g}$. Concentrations in off-site deer liver samples ranged from nondetectable to $1.47 \mathrm{pCi} / \mathrm{g}$ wet weight, with the average for all off-site liver samples being $0.45 \mathrm{pCi} / \mathrm{g}$.

Figure 6-6 presents the five-year trend in arithmetic averages of both on- and off-site cesium- 137 concentrations in deer meat. The onsite trend was essentially level compared to 2000 , from 1.48 to $1.44 \mathrm{pCi} / \mathrm{g}$ wet weight. The level was maintained even with a lower number of samples, compared to 2000 . The trend for offsite samples indicates a decline from 1999 and 2000, where values had appeared to be leveling off. The off-site average declined from approximately 2.07 to $1.23 \mathrm{pCi} / \mathrm{g}$ wet weight.
The arithmetic average of cesium-137 in the 43 samples taken since 1996 from locations more than one mile from BNL is $0.78 \mathrm{pCi} / \mathrm{g}$. The onsite average concentration of $1.44 \mathrm{pCi} / \mathrm{g}$ is therefore 1.85 times greater than the average offsite concentration. This ratio is lower than that reported in 2000, which was 2.14.

The potential radiological dose resulting from deer meat consumption is discussed in Chapter 8 . The New York State Department of Health (NYSDOH) has formally considered the potential public health risk associated with elevated cesium-137 levels in on-site deer and determined that neither hunting restrictions nor formal health advisories are warranted (NYSDOH 1999). Their report can be accessed at $<\mathrm{http}: / / \mathrm{http}$ :// www.bnl.gov/esd/wildlife/deer_issues.htm $>$.

With respect to the health of the on-site deer based on their exposure to radionuclides, the International Atomic Energy Agency (IAEA) has concluded that chronic dose rates of 100 millirad per day to even the most radiosensitive species in terrestrial ecosystems are unlikely to cause detrimental effects in animal populations (IAEA 1992). A deer containing a uniform distribution of cesium-137 at the highest levels observed to date (11.74 pCi/g wet weight reported in 1996) would carry a total body burden of about $0.2 \mu \mathrm{Ci}$. Under these conditions, an animal would receive an absorbed dose of approximately 3 millirad per day, which is only 3 percent of the threshold established by IAEA. The deer observed and sampled on site appear to have no health effects from the level of cesium-137 found in their tissues, although the general health of the herd is not optimal because of overpopulation.

\subsubsection{Strontium-90 in Deer Bone}

BNL began testing bone (when available) for strontium-90 (Sr-90) content in 2000 and continued this analysis in 2001. Strontium-90 content ranged from 0.44 to $3.95 \mathrm{pCi} / \mathrm{g}$ dry weight in on-site samples, 0.92 to $5.88 \mathrm{pCi} / \mathrm{g}$ dry weight in samples taken within one mile of BNL, and 0.46 to $6.34 \mathrm{pCi} / \mathrm{g}$ dry weight in samples taken from locations greater than a mile from BNL. This overlap in values between all samples suggests that strontium-90 is present in the environment at background levels; it is likely a 
Table 6-2. Radiological Analysis Results of Deer Tissue.

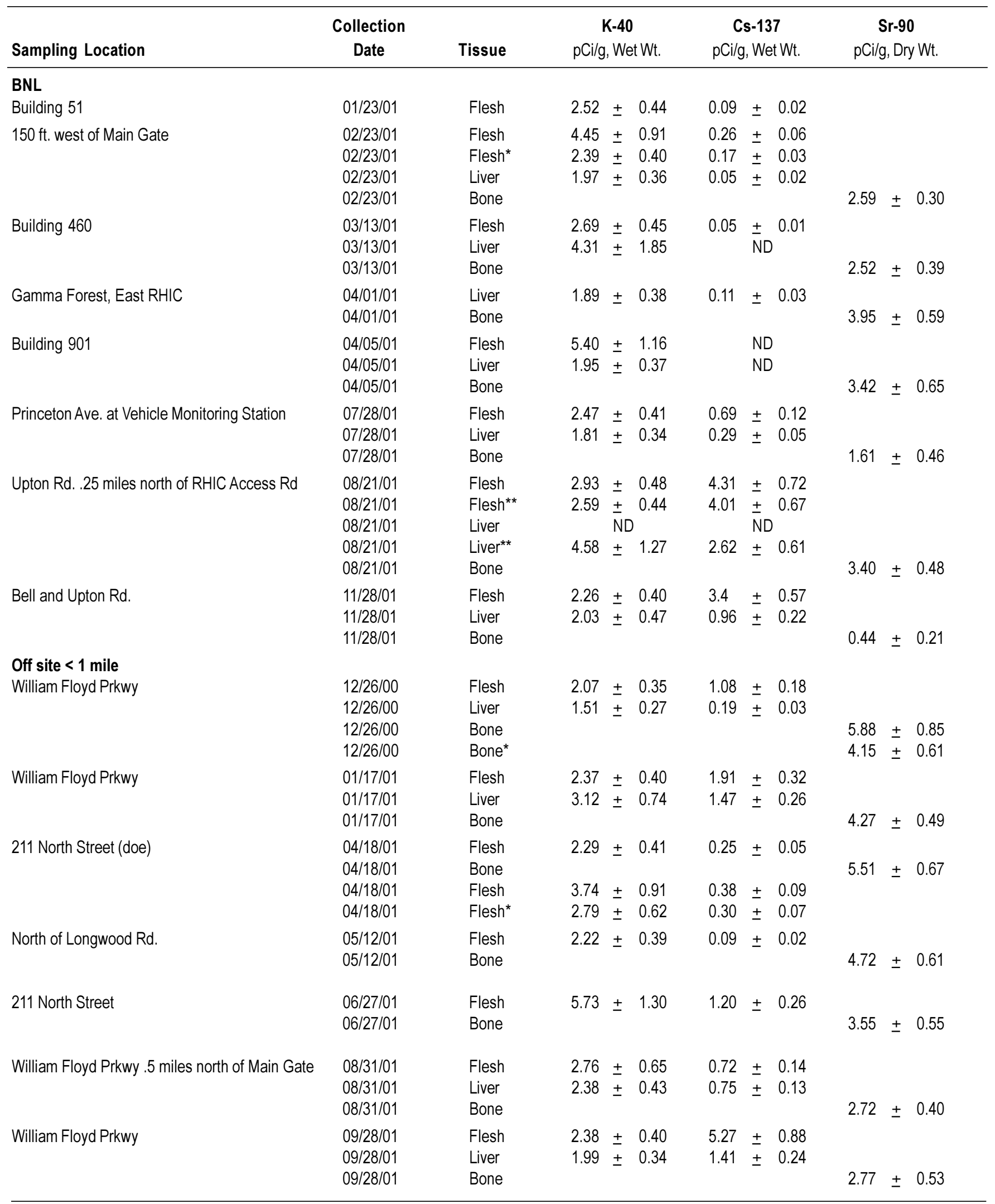


CHAPTER 6: NATURAL AND CULTURAL RESOURCES

Table 6-2. Radiological Analysis Results of Deer Tissue (continued).

\begin{tabular}{|c|c|c|c|c|c|c|c|c|c|c|c|}
\hline \multirow{2}{*}{$\frac{\text { Sampling Location }}{\text { North Street and Wading River Rd. }}$} & $\begin{array}{c}\begin{array}{c}\text { Collection } \\
\text { Date }\end{array} \\
10 / 03 / 01\end{array}$ & $\begin{array}{r}\text { Tissue } \\
\text { Flesh }\end{array}$ & \multicolumn{3}{|c|}{$\begin{array}{c}\mathbf{K}-\mathbf{4 0} \\
\mathrm{pCi} / \mathrm{g}, \text { Wet Wt. }\end{array}$} & \multicolumn{3}{|c|}{$\begin{array}{c}\text { Cs-137 } \\
\mathrm{pCi} / \mathrm{g}, \text { Wet Wt. }\end{array}$} & \multicolumn{3}{|c|}{$\begin{array}{c}\text { Sr-90 } \\
\text { pCi/g, Dry Wt. }\end{array}$} \\
\hline & $\begin{array}{l}10 / 03 / 01 \\
10 / 03 / 01 \\
10 / 03 / 01\end{array}$ & $\begin{array}{l}\text { Flesh } \\
\text { Liver } \\
\text { Bone }\end{array}$ & $\begin{array}{l}2.55 \\
2.23\end{array}$ & & $\begin{array}{l}0.43 \\
0.40\end{array}$ & $\begin{array}{l}0.99 \\
0.20\end{array}$ & $\begin{array}{l} \pm \\
\pm\end{array}$ & $\begin{array}{l}0.17 \\
0.04\end{array}$ & 2.48 & \pm & 0.45 \\
\hline William Floyd Prkwy & $\begin{array}{l}10 / 03 / 01 \\
10 / 03 / 01 \\
10 / 03 / 01\end{array}$ & $\begin{array}{l}\text { Flesh } \\
\text { Liver } \\
\text { Bone }\end{array}$ & $\begin{array}{l}2.29 \\
4.02\end{array}$ & $\begin{array}{l} \pm \\
\pm\end{array}$ & $\begin{array}{l}0.39 \\
0.91\end{array}$ & $\begin{array}{l}2.17 \\
1.21\end{array}$ & $\begin{array}{l} \pm \\
\pm\end{array}$ & $\begin{array}{l}0.37 \\
0.25\end{array}$ & 2.00 & \pm & 0.35 \\
\hline William Floyd Prkwy North of Rt. 25 & $\begin{array}{l}10 / 10 / 01 \\
10 / 10 / 01\end{array}$ & $\begin{array}{l}\text { Flesh } \\
\text { Bone }\end{array}$ & 2.17 & \pm & 0.38 & 1.56 & \pm & 0.26 & 2.21 & \pm & 0.45 \\
\hline William Floyd Prkwy .25 miles north of Main Gate & $\begin{array}{l}10 / 30 / 01 \\
10 / 30 / 01\end{array}$ & $\begin{array}{l}\text { Flesh } \\
\text { Bone }\end{array}$ & 2.92 & \pm & 0.76 & 2.79 & \pm & 0.52 & 0.92 & \pm & 0.29 \\
\hline William Floyd Prkwy .125 miles north of Main Gate & $\begin{array}{l}11 / 02 / 01 \\
11 / 02 / 01\end{array}$ & $\begin{array}{l}\text { Flesh } \\
\text { Bone }\end{array}$ & 1.91 & \pm & 0.35 & 2.62 & \pm & 0.45 & & $\mathrm{NL}$ & \\
\hline William Floyd Prkwy & $\begin{array}{l}12 / 05 / 01 \\
12 / 05 / 01\end{array}$ & $\begin{array}{l}\text { Flesh } \\
\text { Bone }\end{array}$ & 2.45 & \pm & 0.42 & 6.19 & \pm & 1.04 & 1.43 & \pm & 0.34 \\
\hline William Floyd Prkwy & $\begin{array}{l}12 / 06 / 01 \\
12 / 06 / 01 \\
12 / 06 / 01 \\
12 / 06 / 01\end{array}$ & $\begin{array}{l}\text { Flesh } \\
\text { Flesh* } \\
\text { Liver } \\
\text { Bone }\end{array}$ & $\begin{array}{l}2.20 \\
1.86 \\
2.85\end{array}$ & $\begin{array}{l} \pm \\
\pm \\
\pm\end{array}$ & $\begin{array}{l}0.38 \\
0.32 \\
0.48\end{array}$ & $\begin{array}{l}0.21 \\
0.11 \\
0.27\end{array}$ & $\begin{array}{l} \pm \\
\pm \\
\pm\end{array}$ & $\begin{array}{l}0.04 \\
0.02 \\
0.05\end{array}$ & 1.26 & \pm & 0.38 \\
\hline $\begin{array}{l}\text { Off site > } 1 \text { mile } \\
\text { Manorville, deer } 5\end{array}$ & $\begin{array}{l}12 / 03 / 00 \\
12 / 03 / 00\end{array}$ & $\begin{array}{l}\text { Heart } \\
\text { Liver }\end{array}$ & $\begin{array}{l}4.23 \\
2.65\end{array}$ & $\begin{array}{l} \pm \\
\pm\end{array}$ & $\begin{array}{l}1.57 \\
0.71\end{array}$ & $\begin{array}{l}1.67 \\
0.52\end{array}$ & $\begin{array}{l} \pm \\
\pm\end{array}$ & $\begin{array}{l}0.39 \\
0.11\end{array}$ & & & \\
\hline Manorville, deer 4 & $\begin{array}{l}12 / 07 / 00 \\
12 / 07 / 00 \\
12 / 07 / 00 \\
12 / 07 / 00\end{array}$ & $\begin{array}{l}\text { Flesh } \\
\text { Flesh* } \\
\text { Bone } \\
\text { Bone* }^{*}\end{array}$ & $\begin{array}{l}1.95 \\
1.84\end{array}$ & $\begin{array}{l} \pm \\
\pm\end{array}$ & $\begin{array}{l}0.35 \\
0.33\end{array}$ & $\begin{array}{l}0.60 \\
0.52\end{array}$ & $\begin{array}{l} \pm \\
\pm\end{array}$ & $\begin{array}{l}0.10 \\
0.09\end{array}$ & $\begin{array}{l}3.77 \\
3.31\end{array}$ & $\begin{array}{l} \pm \\
\pm\end{array}$ & $\begin{array}{l}0.52 \\
0.59\end{array}$ \\
\hline Manorville, deer 6 & $\begin{array}{l}12 / 07 / 00 \\
12 / 07 / 00 \\
12 / 07 / 00\end{array}$ & $\begin{array}{l}\text { Flesh } \\
\text { Bone } \\
\text { Bone }\end{array}$ & 3.59 & \pm & 0.64 & 1.24 & \pm & 0.21 & $\begin{array}{l}1.99 \\
6.34\end{array}$ & $\begin{array}{l} \pm \\
\pm\end{array}$ & $\begin{array}{l}0.48 \\
0.82\end{array}$ \\
\hline Manorville, deer 2 & $12 / 29 / 00$ & Liver & 1.48 & \pm & 0.30 & 0.07 & \pm & 0.02 & & & \\
\hline Smith Rd. N. of RR Tracks & $\begin{array}{l}01 / 02 / 01 \\
01 / 02 / 01\end{array}$ & $\begin{array}{l}\text { Flesh } \\
\text { Bone }\end{array}$ & 5.57 & \pm & 0.58 & 1.87 & \pm & 0.19 & 2.74 & \pm & 0.41 \\
\hline Seatuck Wildlife Preserve & $\begin{array}{l}01 / 12 / 01 \\
01 / 12 / 01\end{array}$ & $\begin{array}{l}\text { Flesh } \\
\text { Bone }\end{array}$ & 2.18 & \pm & 0.20 & 0.02 & \pm & 0.00 & 3.38 & \pm & 0.40 \\
\hline Seatuck Wildlife Preserve & $\begin{array}{l}01 / 17 / 01 \\
01 / 17 / 01 \\
01 / 17 / 01 \\
01 / 17 / 01\end{array}$ & $\begin{array}{l}\text { Flesh } \\
\text { Liver } \\
\text { Liver* } \\
\text { Bone }\end{array}$ & $\begin{array}{l}2.80 \\
1.69 \\
2.15\end{array}$ & $\begin{array}{l} \pm \\
\pm \\
\pm\end{array}$ & $\begin{array}{l}0.35 \\
0.16 \\
0.19\end{array}$ & 0.01 & $\begin{array}{l}\mathrm{ND} \\
\pm \\
\mathrm{ND}\end{array}$ & 0.00 & 3.14 & \pm & 0.46 \\
\hline Seatuck Wildlife Preserve deer 1 & $\begin{array}{l}02 / 06 / 01 \\
02 / 06 / 01\end{array}$ & $\begin{array}{l}\text { Flesh } \\
\text { Bone }\end{array}$ & 2.74 & \pm & 0.73 & & ND & & 2.24 & \pm & 0.32 \\
\hline Seatuck Wildlife Preserve deer 2 & $\begin{array}{l}02 / 06 / 01 \\
02 / 06 / 01 \\
02 / 06 / 01\end{array}$ & $\begin{array}{l}\text { Flesh } \\
\text { Bone } \\
\text { Bone* }^{*}\end{array}$ & 2.24 & \pm & 0.38 & 0.01 & \pm & 0.01 & $\begin{array}{l}1.32 \\
0.87\end{array}$ & $\begin{array}{l} \pm \\
\pm\end{array}$ & $\begin{array}{l}0.26 \\
0.17\end{array}$ \\
\hline Seatuck Wildlife Preserve deer 3 & $\begin{array}{l}02 / 06 / 01 \\
02 / 06 / 01\end{array}$ & $\begin{array}{l}\text { Flesh } \\
\text { Bone }\end{array}$ & 1.84 & \pm & 0.33 & 0.04 & \pm & 0.01 & 1.99 & \pm & 0.31 \\
\hline Montauk Hwy .25 miles west of Carmens River & 02/09/01 & Flesh & 2.34 & \pm & 0.41 & 0.05 & \pm & 0.01 & & & \\
\hline Montauk Hwy and Smith Rd & $\begin{array}{l}\text { 03/09/01 } \\
\text { 03/09/01 }\end{array}$ & $\begin{array}{l}\text { Flesh } \\
\text { Bone }\end{array}$ & 2.42 & \pm & 0.43 & 0.01 & \pm & 0.01 & 2.43 & \pm & 0.39 \\
\hline
\end{tabular}


Table 6-2. Radiological Analysis Results of Deer Tissue (concluded).

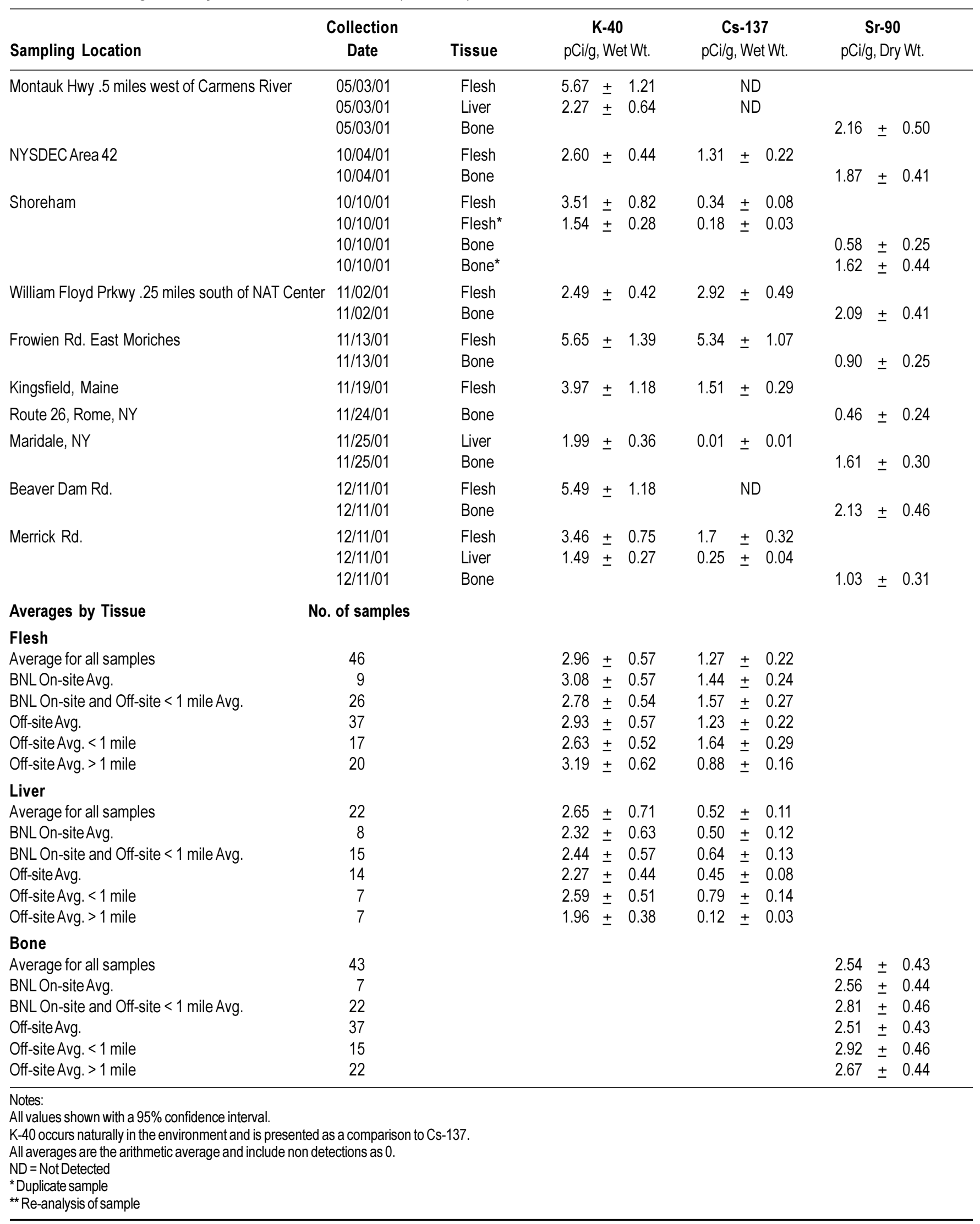




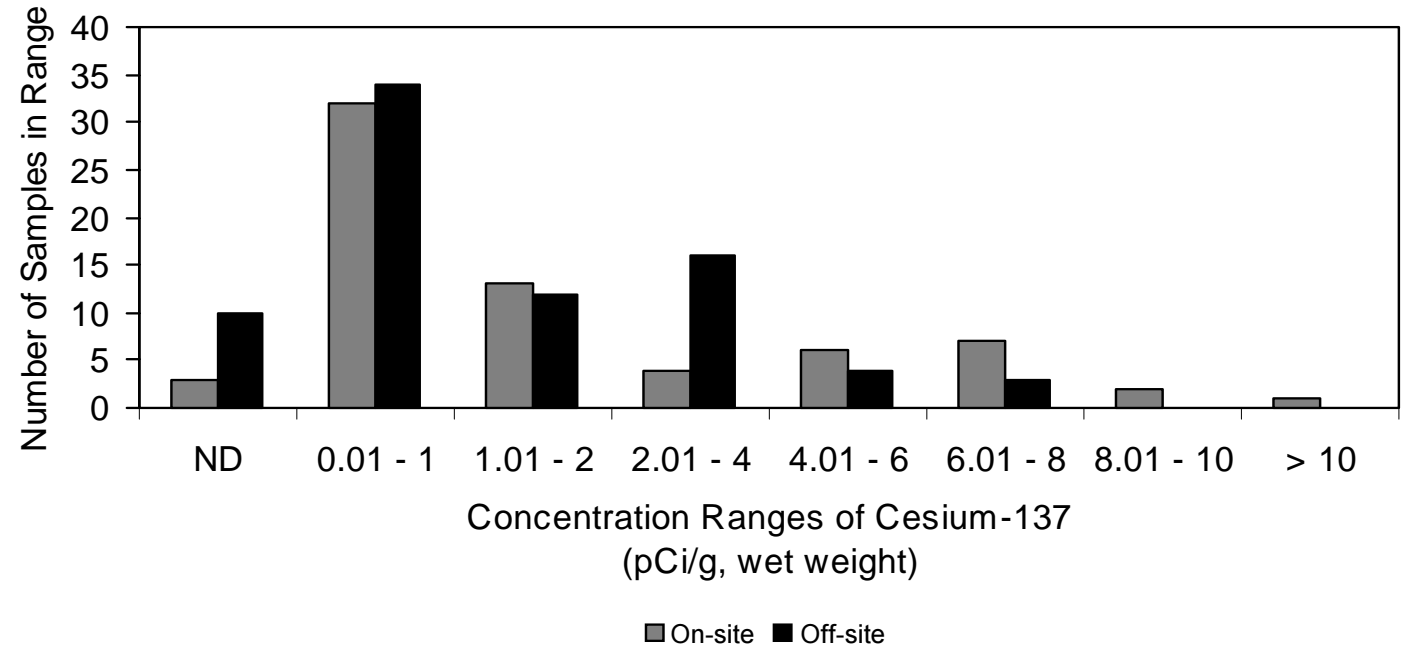

Figure 6-5. Distribution of Samples across Concentration Ranges of CS-137 in Deer Meat Samples Taken (1996-2001).

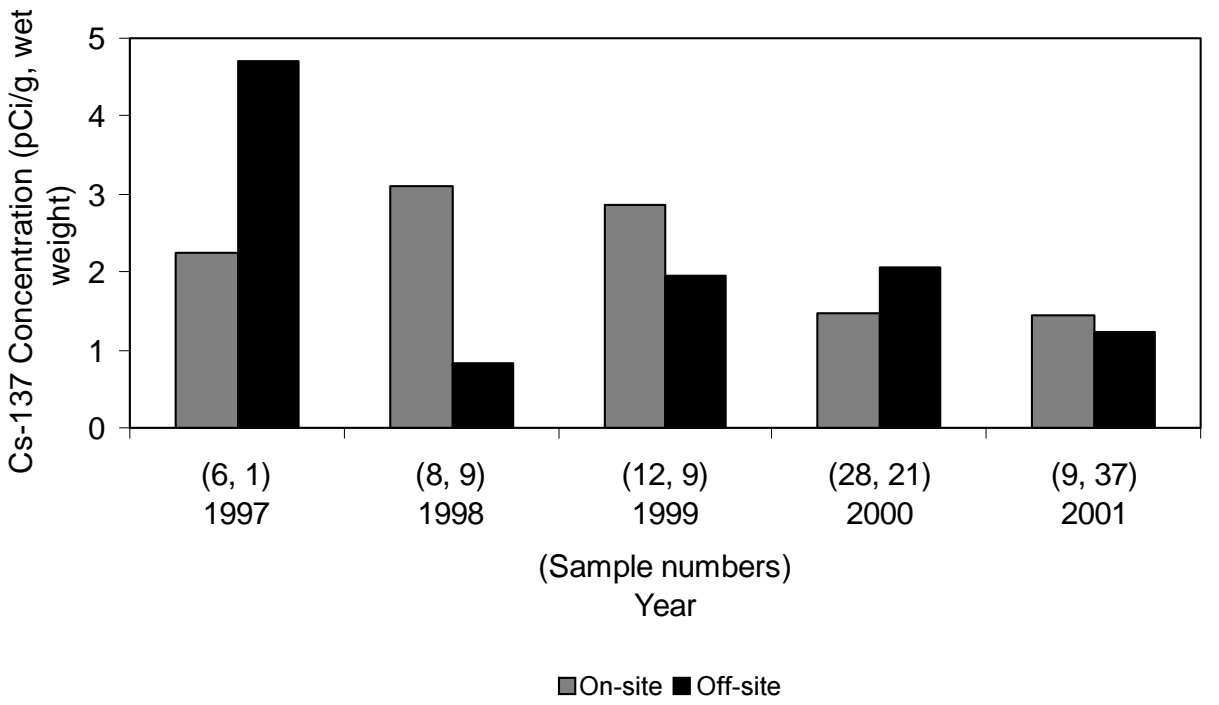

Figure 6-6. Five Year Trend of Cesium-137 Average Concentrations in Meat Taken from On-Site and Off-Site Deer (1997-2001).

result of worldwide fallout from nuclear weapons testing. Strontium-90 is present at very low levels in the environment, is readily incorporated into bone tissue, and may concentrate over time. BNL will continue to test for strontium-90 in bone to develop baseline information on this radionuclide and its presence in deer.

\subsubsection{Small Mammal Sampling}

BNL continued small mammal sampling in 2001 to determine the suitability of using small mammals, primarily squirrels, as a surrogate for deer sampling. Squirrels are readily trapped and tend to eat similar food as deer. Squirrels were sent to an off-site lab for dissection and analysis. The meat was tested for gamma-emitting radionuclides and the bone was tested for strontium90. Results of the analyses are presented in Table 6-3. Cesium-137 in off-site samples ranged from 0.05 to $1.53 \mathrm{pCi} / \mathrm{g}$ wet weight. On-site samples contained cesium-137 ranging from 0.07 to 16.60 $\mathrm{pCi} / \mathrm{g}$ wet weight. Strontium-90 was found in the bone samples of four squirrels, two on site and two off site.

Cesium-137 levels in one squirrel were high, $16.60 \mathrm{pCi} / \mathrm{g}$ wet weight, compared to all other 
Table 6-3. Radiological Analysis of Small Mammals (Squirrels).

\begin{tabular}{|c|c|c|c|c|}
\hline Location & Date & $\begin{array}{c}\text { K-40 } \\
\text { (pCi/g, wet weight) }\end{array}$ & $\begin{array}{c}\text { Cs-137 } \\
\text { (pCi/g, wet weight) }\end{array}$ & $\begin{array}{c}\text { Sr-90 } \\
\text { (pCi/g, dry weight) }\end{array}$ \\
\hline \multicolumn{5}{|l|}{ BNL } \\
\hline Trailer 533 & 01/17/01 & $7.12 \pm 0.90$ & $0.09 \pm 0.02$ & ND \\
\hline Bldg. 50 & 02/15/01 & $12.50 \pm 1.83$ & $0.32 \pm 0.06$ & ND \\
\hline Firehouse & 03/14/01 & $9.43 \pm 1.21$ & $0.39 \pm 0.05$ & $0.39 \pm 0.16$ \\
\hline Firehouse & 03/15/01 & $10.50 \pm 1.11$ & $1.06 \pm 0.08$ & $0.48 \pm 0.16$ \\
\hline BNL Rochester and Rowland & 04/20/01 & $8.23 \pm 1.59$ & $0.07 \pm 0.07$ & $\mathrm{ND}$ \\
\hline E.Fifth/ MH 192 & 08/23/01 & $12.40 \pm 0.37$ & $16.60 \pm 1.77$ & ND \\
\hline Bldg. 729 and Railroad Street & 08/30/01 & $16.40 \pm 2.46$ & $4.63 \pm 0.51$ & ND \\
\hline Railroad Street & 10/05/01 & $17.60 \pm 3.39$ & $5.42 \pm 0.64$ & ND \\
\hline T533 & 10/10/01 & $17.60 \pm 4.91$ & $0.99 \pm 0.49$ & ND \\
\hline Bldg. 120 & 10/11/01 & $15.40 \pm 2.41$ & $2.55 \pm 0.40$ & ND \\
\hline \multicolumn{5}{|l|}{ Off site } \\
\hline \multirow[t]{5}{*}{ Moriches } & 01/27/01 & $10.20 \pm 1.03$ & $0.10 \pm 0.04$ & $0.28 \pm 0.14$ \\
\hline & 03/15/01 & $10.90 \pm 1.48$ & $0.15 \pm 0.04$ & $0.66 \pm 0.19$ \\
\hline & 04/20/01 & $12.20 \pm 1.82$ & $0.05 \pm 0.04$ & ND \\
\hline & 07/29/01 & $12.20 \pm 2.12$ & $0.72 \pm 0.13$ & ND \\
\hline & 10/17/01 & $15.6 \pm 3.11$ & $1.53 \pm 0.25$ & ND \\
\hline \\
\hline
\end{tabular}

samples, including deer. The area in which this squirrel was taken is near old sewer lines that contain cesium- 137 contamination. Contaminated sewer lines in the area have been isolated from the sewer system. Cleanup of these lines or abandonment in place has been addressed in the Record of Decision for the STP portion of Operable Unit V. Small mammals will continue to be sampled to obtain added information about their usefulness in environmental surveillance and to better define where they may be acquiring cesium-137.

\subsubsection{Goose Fecal Material}

BNL has a resident population of Canada geese (Branta canadensis) that fluctuates between 80 and 120 birds. Canada geese tend to feed on green grasses and weedy plants and may ingest soil as they pull young plants out of the ground. In 2000, BNL initiated the sampling of goose fecal material and lawn grasses to determine if there is potential for the Canada goose population to pick up cesium-137 contamination from some of the landscape soils. Concurrent soil sampling was added to determine if cesium-137 was present in the areas where grass and goose fecal matter were collected. Table 6-4 displays the data from the radiological analysis of the goose fecal material, as well as grass and soil taken from the same areas. With the exception of one recharge basin, soil samples from all of the on-site locations showed very low levels of cesium-137 (soil range: nondetect to $0.62 \mathrm{pCi} / \mathrm{g}$ dry weight). None of the grass samples indicated the presence of cesium-137. However, goose fecal material collected near Buildings 438 and 490 and near the Sewage Treatment Plant showed levels of cesium-137 ranging from 0.02 to $0.14 \mathrm{pCi} / \mathrm{g}$ wet weight, with the highest value taken near the STP. There is known cesium-137 contamination at the treatment plant, which is scheduled for cleanup in 2002. It also was known that there had been cesium-137 contamination near Building 490; this was remediated in 2000 when contaminated landscape soils were removed sitewide. The levels of cesium-137 in goose fecal material indicate that geese do have the potential to acquire it. However, comparing the range of levels observed between years indicates that cesium-137 levels may be declining 
Table 6-4. Radiological Analysis of Goose Fecal Material, Associated Grass Clippings, and Soil.

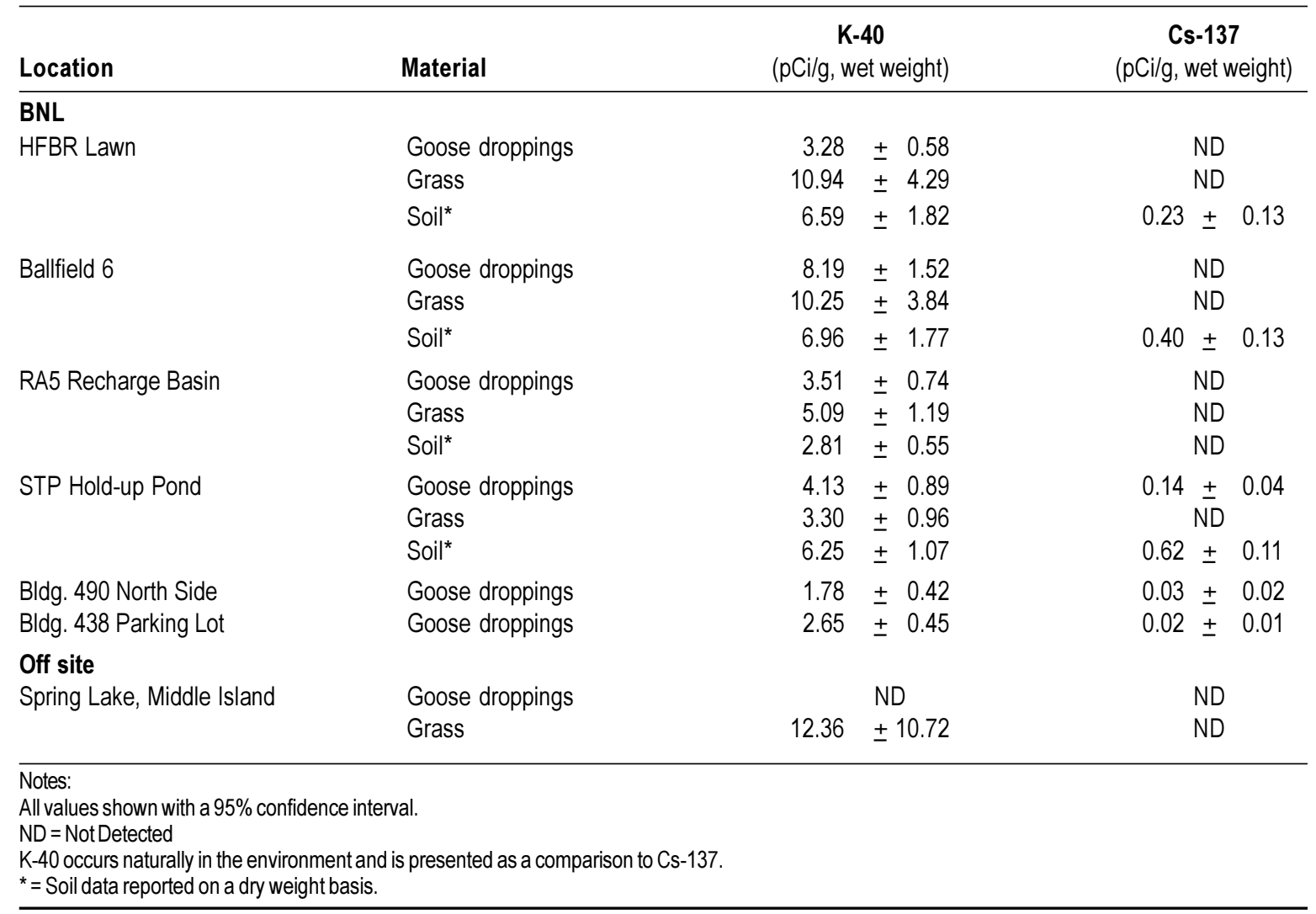

(just $0.14 \mathrm{pCi} / \mathrm{g}$ wet weight in 2001 , compared to a maximum of 0.64 in 2000). At present, there are no data about cesium-137 in the geese. If sampling of geese were warranted, BNL would acquire the necessary licenses before obtaining samples.

\subsubsection{Fish Sampling}

In collaboration with the NYSDEC Fisheries Division, BNL maintains an ongoing program for collecting and analyzing fish from the Peconic River and surrounding freshwater bodies. The annual sampling at BNL over the past several years has depleted the number of larger fish. As a result, it would be necessary to take more of the smaller fish to obtain a sample sufficiently large to complete all analyses desired. For this reason, BNL suspended most on-site sampling beginning in 2001 and will continue with the suspension for up to three years to allow the onsite fish populations to recover and mature. (The only on-site sampling in 2001 was performed by New York State in the stretch of river immedi- ately east of the last gauging station on BNL property to Schultz Road, and in Ice Pond just off the Peconic River east of BNL.)

Off-site sampling continued as in the past. All samples were analyzed for whole-body content of each of the analytes reported; in most instances, the samples were a composite of several fish to ensure adequate sample size for analysis. In 2001, various species of fish were collected off site from Swan Pond, Donahue's Pond, and Forge Pond (see Chapter 5, Figure 5-9 for locations). Swan Pond is a control location on the Peconic system, and Lower Lake on the Carmans River is the nonPeconic control site. Sampling is carried out through a contract with Cold Springs Harbor Fish Hatchery and Museum.

\subsubsection{Radiological Analysis of Fish}

The species collected in 2001 by BNL and NYSDEC for radiological analysis included Brown bullhead (Ictalurus nebulosus), chain pickerel (Esox niger), red-finned pickerel (Esox americanus), largemouth bass (Micropterus 
salmoides), black crappie (Pomoxis

nigromaculatus), bluegill (Lepomis macrochirus), pumpkinseed (Lepomis gibbosus), yellow perch (Perca flavescens), sunfish (Lepomis spp.), and golden shiner (Notemigonus crysoleucas). Gamma spectroscopy analysis was performed on all samples. Table 6-5 presents specific information on the sampling point, species collected, and analytical results. All sample results are presented as wet weight concentrations. NYSDEC results are based on analysis of fillets, whereas BNL results are based on whole-body analysis.

Cesium-137 was identified at low levels in all samples from the Peconic River system, ranging from $0.06 \mathrm{pCi} / \mathrm{g}$ wet weight in pumpkinseed fillets from Swan Pond, to $0.62 \mathrm{pCi} / \mathrm{g}$ wet weight in a whole-body analysis of a largemouth bass from Donahue's Pond. It is interesting to note that the highest value the previous year for the Peconic River system was also in a largemouth bass from Donahue's Pond ( $0.66 \mathrm{pCi} / \mathrm{g}$ wet weight). In 2001, fish taken from Lower Lake on the Carmans River (the non-Peconic control location) were either below the minimum detection limit for the analysis or had no detection of cesium-137, except for brown bullhead fillets, which had a level of $0.23 \mathrm{pCi} / \mathrm{g}$ wet weight.

In 2001, BNL continued the testing for strontium-90 that was initiated in 2000 . Strontium90 is readily deposited in bone. Values ranged from nondetect to $5.00 \mathrm{pCi} / \mathrm{g}$ dry weight in the same largemouth bass taken from Donahue's Pond that had the highest cesium-137 level. Because fish were analyzed for either whole-body content or as fillets, values for strontium-90 may vary widely, as seen in the data presented in Table 6-5. These variations result from random pieces of bone included in the aliquot of the sample used for analysis. The low levels detected in BNL on-site samples may also reflect the small size of the fish used to generate a composite sample. Younger fish have less bone mass than older fish. BNL will continue to test for strontium-90 in off-site samples in order to build baseline values for future comparisons.

Concentrations of naturally occurring potassium- 40 were observed to be very consistent in fish from the Peconic River and Carmans River, for both whole body and fillets, validating the comparability of the data. However, differences exist between sample types - whole-body versus fillets. Differences are likely due to laboratory preparation methods (wet analysis or dry analysis), methods for sample counting, and method detection limits. Data with low values are from the NYSDOH laboratory that typically runs wet analysis and long count times, whereas BNLreported data comes from dry analysis with conversion to wet weight values and shorter count times. Data from BNL's contract laboratory are consistent from year to year.

Some cesium-137 is detectable in the environment worldwide as a result of global fallout from past aboveground nuclear weapons testing. This is evident when examining the analytical results of fish from the control locations. To account for the different feeding habits and weights of various species, it is important to compare species with similar feeding habits (i.e., bottom feeders such as brown bullhead should be compared to other bottom feeders - in this case, other brown bullhead). Cesium- 137 concentrations in bullhead collected at all locations along the Peconic River had values less than $0.49 \mathrm{pCi} / \mathrm{g}$ wet weight, whereas values for bullhead at the control locations of Swan Pond and Lower Lake on the Carmans River had 0.33 and $0.23 \mathrm{pCi} / \mathrm{g}$ wet weight, respectively. Largemouth bass had levels below $0.62 \mathrm{pCi} / \mathrm{g}$ wet weight at all locations; a comparison between bass at Swan Pond and Lower Lake on the Carmans River shows respective values of $0.54 \mathrm{pCi} / \mathrm{g}$ wet weight and nondetect. Using data provided by NYSDEC for fish fillets of the various species (Table 6-5), the levels of cesium-137 decrease with increasing distance from the BNL boundary. Cesium-137 values in fish from both Donahue's Pond and Forge Pond are roughly equivalent to those seen at Swan Pond.

Though it is clear from discharge records and sediment sampling that past BNL operations have contributed to anthropogenic (human-caused) radionuclide levels in the Peconic River system, most of these radionuclides - with the exception of tritium - were released between the late 1950s and early 1970s, and concentrations continue to decline over time through natural decay (cesium137 has a half-life of 30 years). 
CHAPTER 6: NATURAL AND CULTURAL RESOURCES

Table 6-5. Radiological Analysis of Fish from the Peconic River System and Control Location.

\begin{tabular}{|c|c|c|c|c|c|c|}
\hline \multirow{2}{*}{$\begin{array}{l}\text { Location and } \\
\text { Fish/Sample Type } \\
\text { BNL HQ - Schultz Rd. }\end{array}$} & \multicolumn{3}{|c|}{ (pCi/g, wet weight) } & $\begin{array}{c}\text { Cs-137 } \\
\text { (pCi/g, wet weight) }\end{array}$ & \multicolumn{2}{|c|}{$\begin{array}{c}\text { Sr-90 } \\
\text { (pCi/g, dry weight) }\end{array}$} \\
\hline & & & & & & \\
\hline Largemouth Bass (fillet)* & 3.01 & \pm & 0.16 & $0.28 \pm 0.01$ & $0.18 \pm$ & 0.01 \\
\hline Largemouth Bass (fillet) ${ }^{*}$ & 2.94 & \pm & 0.13 & $0.30 \pm 0.01$ & $0.09 \pm$ & 0.01 \\
\hline Pumpkinseed (fillet) ${ }^{*}$ & 2.80 & \pm & 0.30 & $0.26 \pm 0.03$ & $0.19 \pm$ & 0.02 \\
\hline \multicolumn{7}{|l|}{ Ice Pond } \\
\hline Chain Pickerel (fillet) ${ }^{*}$ & 2.96 & \pm & 0.13 & $0.32 \pm 0.01$ & $0.05 \pm$ & 0.01 \\
\hline \multicolumn{7}{|l|}{ Swan Pond } \\
\hline Largemouth Bass (whole body) & 11.40 & \pm & 1.57 & $0.54 \pm 0.07$ & \multicolumn{2}{|c|}{$<M D L$} \\
\hline Bluegill (whole body) & 9.20 & \pm & 1.29 & $0.29 \pm 0.05$ & \multicolumn{2}{|c|}{$<M D L$} \\
\hline Brown Bullhead (whole body) & 12.70 & \pm & 1.69 & $0.33 \pm 0.06$ & \multicolumn{2}{|c|}{$<M D L$} \\
\hline Largemouth Bass (fillet)* & 2.72 & \pm & 0.18 & $0.18 \pm 0.01$ & $0.04 \pm$ & 0.01 \\
\hline Pumpkinseed (fillet) ${ }^{*}$ & 2.76 & \pm & 0.19 & $0.06 \pm 0.01$ & $0.06 \pm$ & 0.01 \\
\hline Brown Bullhead (fillet) ${ }^{*}$ & 2.89 & \pm & 0.17 & $0.07 \pm 0.01$ & \multicolumn{2}{|c|}{$<\overline{M D L}$} \\
\hline \multicolumn{7}{|l|}{ Donahue's Pond } \\
\hline Bluegill & 9.07 & \pm & 1.31 & $0.41 \pm 0.07$ & $1.56 \pm$ & 0.46 \\
\hline Brown Bullhead & 14.10 & \pm & 2.16 & $0.49 \pm 0.09$ & $1.32 \pm$ & 0.37 \\
\hline Largemouth Bass & 10.10 & \pm & 2.23 & $0.62 \pm 0.17$ & $5.00 \pm$ & 0.75 \\
\hline Sunfish (fillet) ${ }^{*}$ & 2.68 & \pm & 0.19 & $0.19 \pm 0.01$ & $0.01 \pm$ & 0.00 \\
\hline Chain Pickerel (fillet) ${ }^{*}$ & 2.90 & \pm & 0.16 & $0.28 \pm 0.02$ & $0.03 \pm$ & 0.00 \\
\hline \multicolumn{7}{|l|}{ Forge Pond } \\
\hline Bluegill (whole body) & 8.80 & \pm & 0.86 & $0.33 \pm 0.06$ & $0.90 \pm$ & 0.36 \\
\hline Largemouth Bass (whole body) & 10.10 & \pm & 1.48 & $0.56 \pm 0.11$ & $0.84 \pm$ & 0.37 \\
\hline Brown Bullhead (whole body) & 10.20 & \pm & 1.46 & $0.43 \pm 0.07$ & \multicolumn{2}{|c|}{$<\mathrm{MDL}$} \\
\hline Brown Bullhead (fillet)* & 2.66 & \pm & 0.18 & $0.11 \pm 0.01$ & $0.00 \pm$ & 0.00 \\
\hline Pumpkinseed (fillet) ${ }^{*}$ & 2.70 & \pm & 0.20 & $0.11 \pm 0.01$ & $0.03 \pm$ & 0.01 \\
\hline Chain Pickerel (fillet) ${ }^{*}$ & 2.88 & \pm & 0.19 & $0.15 \pm 0.01$ & $0.03 \pm$ & 0.01 \\
\hline \multicolumn{7}{|l|}{ Lower Lake, Carmans River } \\
\hline Bluegill & 10.20 & \pm & 1.28 & $<M D L$ & \multicolumn{2}{|l|}{ ND } \\
\hline Bluegill & 9.33 & \pm & 1.77 & $N D$ & \multicolumn{2}{|l|}{ ND } \\
\hline Pumpkinseed & 9.31 & \pm & 1.45 & $<M D L$ & \multicolumn{2}{|l|}{ ND } \\
\hline Pumpkinseed (fillet) ${ }^{*}$ & 2.50 & \pm & 0.30 & $<M D L$ & $0.03 \pm$ & 0.01 \\
\hline Black Crappie & 10.90 & \pm & 1.80 & $<M D L$ & ND & \\
\hline Bass & 11.90 & \pm & 2.62 & ND & ND & \\
\hline Golden Shiner & 8.94 & \pm & 1.82 & ND & ND & \\
\hline Golden Shiner & 11.20 & \pm & 2.12 & $<M D L$ & ND & \\
\hline Black Crappie & 13.80 & \pm & 3.50 & ND & ND & \\
\hline Yellow Perch & 12.20 & \pm & 2.91 & $<M D L$ & ND & \\
\hline Red-finned Pickerel & 19.00 & \pm & 4.67 & ND & ND & \\
\hline Brown Bullhead & 15.80 & \pm & 2.92 & $0.23 \pm 0.15$ & ND & \\
\hline
\end{tabular}




\subsubsection{Fish Population Assessment}

As was mentioned earlier, in $2001 \mathrm{BNL}$ suspended fish sampling on site because years of fish sampling had depleted the population and limited the remaining fish to smaller sizes. To document the number and size of fish in the onsite portions of the Peconic River, BNL conducted an electroshock survey (which does not harm the fish) from the STP to just beyond the east firebreak (Figure 6-7). The results of that survey are summarized in Table 6-6. A total of 106 fish and six species were found in this section of river. The average length of fish ranged from 2.81 inches to 7.06 inches. The largest fish was a 13-inch chain pickerel. The total number of fish is indicative of poor population numbers. One bright point to the surveys was the presence of the banded sunfish, a NYS threatened species, in shallow waters near the east firebreak. This small population appeared to be healthy. Brown bullhead and chain pickerel were the most abundant fish species; the largemouth bass was documented with a single individual. BNL will continue to monitor the population to determine when routine sampling may resume.

\subsubsection{Nonradiological Analysis of Fish and Shellfish}

In 1997, under the Operable Unit V remediation project, the BNL Environmental Restoration Program sampled and analyzed fish from the Peconic River for metals, pesticides, and

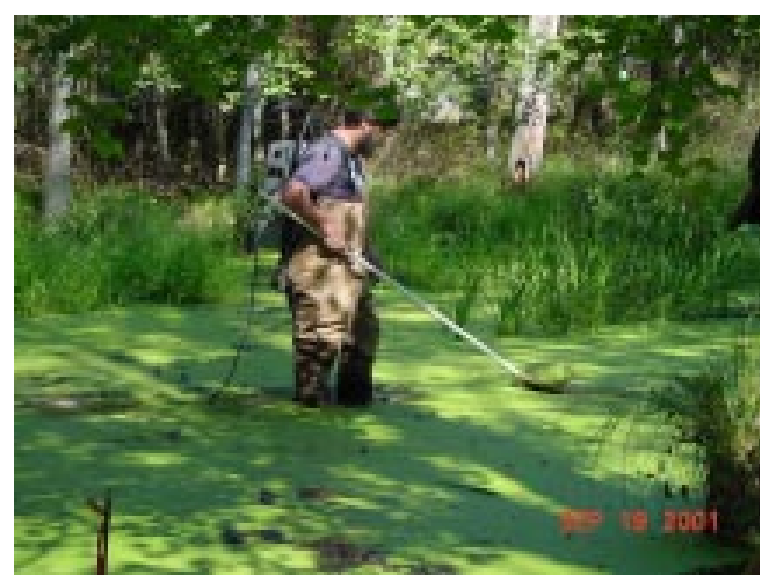

Figure 6-7. Electroshocking in the Peconic River.
Table 6-6. BNL Peconic River (STP to HMn) Population Survey Results.

\begin{tabular}{lcc}
\hline & No. Caught & $\begin{array}{c}\text { Avg. Size } \\
\text { (in.) }\end{array}$ \\
\hline Banded Sunfish & 18 & 2.8 \\
Brown Bullhead & 43 & 5.1 \\
Chain Pickerel & 20 & 7.1 \\
Golden Shiner & 9 & 4.4 \\
Largemouth Bass & 1 & 4.4 \\
Pumpkinseed & 15 & 3.9 \\
Total No. of Fish & 106 & \\
\hline
\end{tabular}

polychlorinated biphenyls (PCBs). The contaminant levels found were not considered to have a health impact on fish or humans, but DOE directed that sampling and analysis should be done annually. This analysis was conducted in 1999 and 2000; analysis in 2001 was limited to off-site fish. The timing of sampling has varied from year to year, as well as the sample preparation (wholebody, tissue separation, composite sampling). In 1997, sampling was performed during April through May; in 1999, sampling was performed during September through December. In 2000 and 2001, sampling occurred during July through August. Additionally, there were wide variations in fish size and samples had to be composite wholebody and fillet to obtain significant mass for analysis. These variables make the comparisons difficult, as there can be significant seasonal variations in feeding, energy consumption, and incorporation of nutrients in tissues.

Table 6-7 shows the concentration levels of metals in fish and shellfish (clams and mussels) for 2001. (Note: NYS only analyzed for mercury.) None of the metal concentrations were considered to be capable of affecting the health of the consumers of such fish or clams. Mercury was found in all fish at levels less than $1.0 \mathrm{mg} /$ $\mathrm{kg}$, which is the consumption standard set by the U.S. Food and Drug Administration. The highest levels of mercury detected were in pumpkinseed (a pan fish), taken from an area east of BNL known as the Ice Pond, at $0.925 \mathrm{mg} / \mathrm{kg}$. The area closest to the Laboratory (BNL-HQ Area) had a peak value for mercury of $0.66 \mathrm{mg} / \mathrm{kg}$, in brown bullhead. There is no fishing allowed on site at BNL, and, in general, fish on site are below legal size limits for retaining. 
CHAPTER 6: NATURAL AND CULTURAL RESOURCES

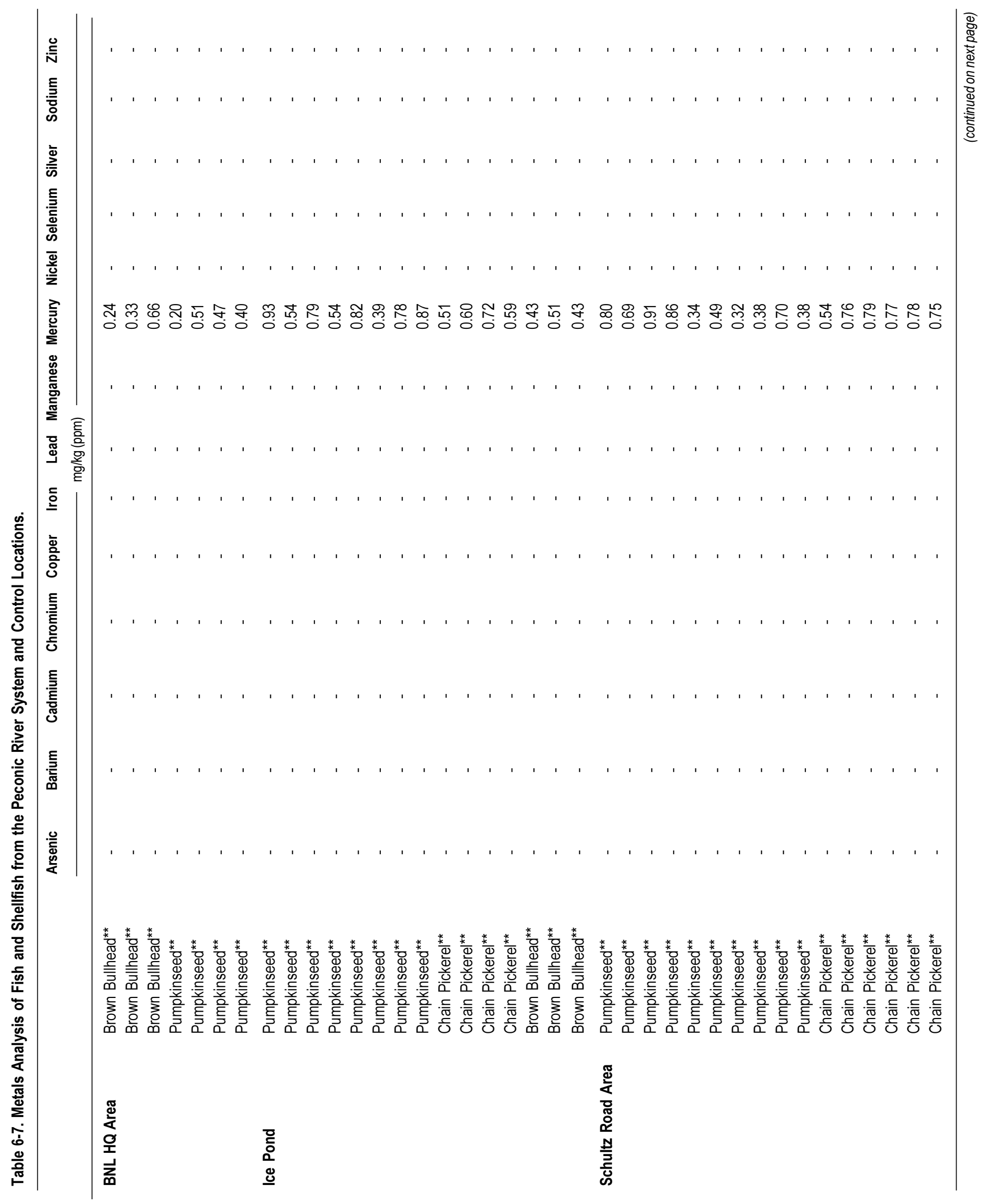




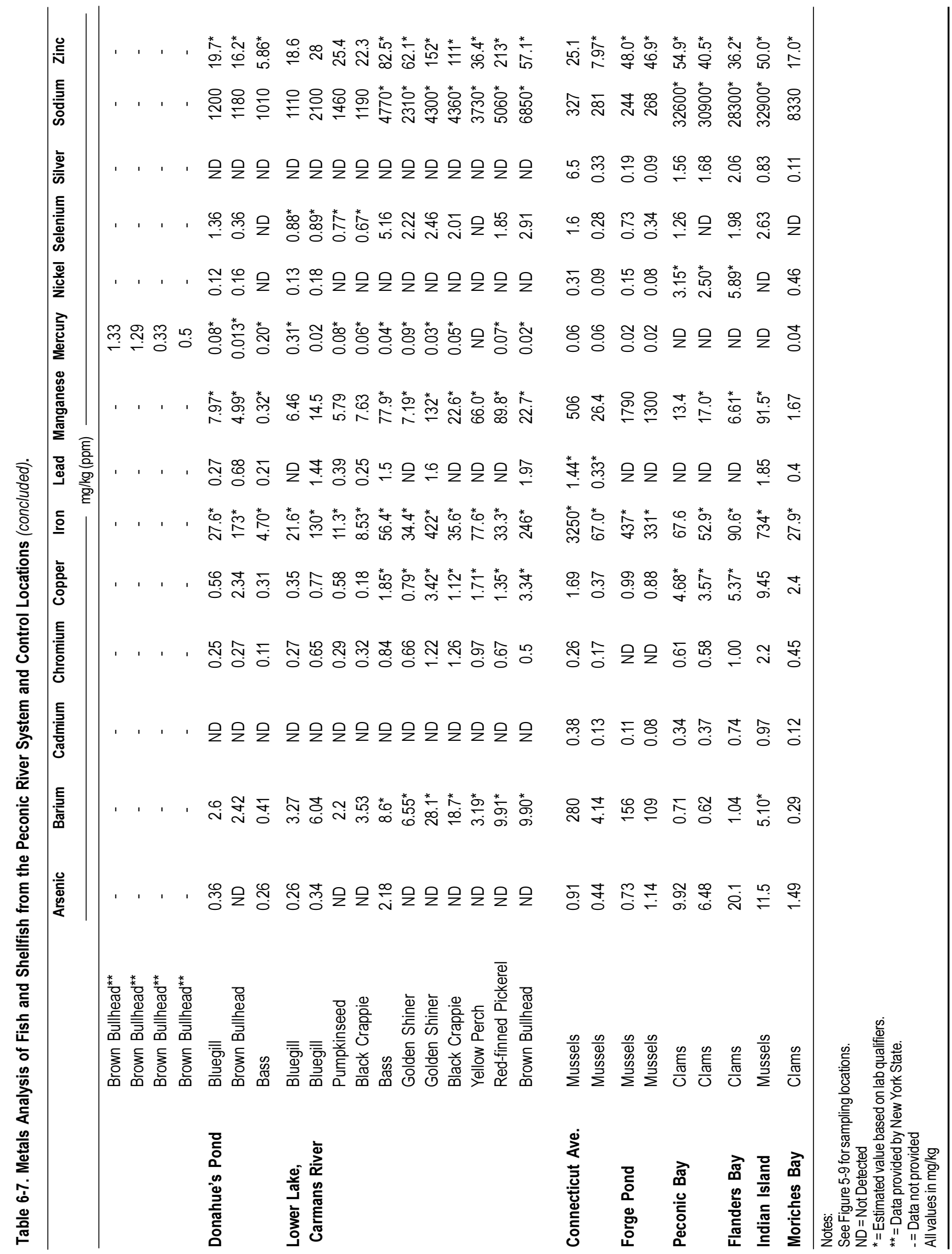


Table 6-8. Pesticide and PCB Analysis in Fish and Shellfish from the Peconic River System and Control Locations.

\begin{tabular}{|c|c|c|c|c|c|c|c|c|c|c|}
\hline & & $\begin{array}{c}\text { Heptachlor } \\
\text { epoxide }\end{array}$ & Dieldrin & 4,4'-DDE & 4,4'-DDD & 4,4'-DDT & $\begin{array}{l}\text { gamma- } \\
\text { Chlordane C }\end{array}$ & $\begin{array}{l}\text { alpha- } \\
\text { Chlordane }\end{array}$ & $\begin{array}{c}\text { Aroclor- } \\
1254\end{array}$ & $\begin{array}{c}\text { Aroclor- } \\
1260\end{array}$ \\
\hline \multirow[t]{7}{*}{ BNL HQ Area } & Brown Bullhead** & ND & ND & 10 & 6 & ND & ND & ND & ND & ND \\
\hline & Brown Bullhead** & ND & ND & 2 & ND & ND & ND & ND & ND & ND \\
\hline & Largemouth Bass** & ND & ND & 3 & ND & ND & ND & ND & ND & ND \\
\hline & Pumpkinseed ${ }^{* *}$ & ND & ND & 21 & 4 & 3 & ND & ND & 33 & 75 \\
\hline & Pumpkinseed ${ }^{* *}$ & ND & ND & 5 & ND & ND & ND & ND & ND & ND \\
\hline & Pumpkinseed ${ }^{* *}$ & ND & ND & 12 & 4 & ND & ND & ND & ND & 21 \\
\hline & Pumpkinseed ${ }^{* *}$ & ND & ND & 21 & 5 & 5 & ND & ND & 33 & 164 \\
\hline \multirow[t]{15}{*}{ Ice Pond } & Pumpkinseed ${ }^{* *}$ & ND & ND & 8 & 2 & ND & ND & ND & ND & 24 \\
\hline & Pumpkinseed ${ }^{* *}$ & ND & ND & 17 & 4 & ND & ND & ND & ND & 21 \\
\hline & Pumpkinseed ${ }^{* *}$ & ND & ND & 13 & 3 & 2 & ND & ND & ND & 21 \\
\hline & Pumpkinseed ${ }^{* *}$ & ND & ND & 12 & 2 & ND & ND & ND & ND & 21 \\
\hline & Pumpkinseed ${ }^{* *}$ & ND & ND & 13 & 3 & ND & ND & ND & 20 & 22 \\
\hline & Pumpkinseed ${ }^{* *}$ & ND & ND & 25 & 5 & ND & ND & ND & ND & 36 \\
\hline & Pumpkinseed ${ }^{* *}$ & ND & ND & 10 & 2 & ND & ND & ND & ND & 20 \\
\hline & Pumpkinseed ${ }^{* *}$ & ND & ND & 17 & 2 & ND & ND & ND & ND & 37 \\
\hline & Chain Pickerel** & ND & ND & 3 & ND & ND & ND & ND & ND & ND \\
\hline & Chain Pickerel** & ND & ND & 6 & 3 & ND & ND & ND & ND & ND \\
\hline & Chain Pickerel** & ND & ND & ND & ND & ND & ND & ND & ND & ND \\
\hline & Chain Pickerel** $^{* *}$ & ND & ND & ND & ND & ND & ND & ND & ND & ND \\
\hline & Brown Bullhead** & ND & ND & 16 & 4 & 2 & ND & ND & 23 & 49 \\
\hline & Brown Bullhead** & ND & ND & 14 & 2 & ND & ND & ND & ND & ND \\
\hline & Brown Bullhead** & ND & ND & 20 & 7 & 2 & ND & ND & 30 & 79 \\
\hline \multirow[t]{17}{*}{ Schultz Road Area } & Pumpkinseed ${ }^{* *}$ & ND & ND & 14 & 5 & ND & ND & ND & ND & 20 \\
\hline & Pumpkinseed ${ }^{* *}$ & ND & 13 & 17 & 2 & ND & ND & ND & ND & 22 \\
\hline & Pumpkinseed ${ }^{* *}$ & ND & ND & 13 & 4 & ND & ND & ND & ND & ND \\
\hline & Pumpkinseed ${ }^{* *}$ & ND & ND & 35 & 25 & 3 & ND & ND & ND & 20 \\
\hline & Pumpkinseed ${ }^{* *}$ & ND & ND & 13 & 7 & ND & ND & ND & 21 & ND \\
\hline & Pumpkinseed ${ }^{* *}$ & ND & ND & 19 & 6 & ND & ND & ND & ND & ND \\
\hline & Pumpkinseed ${ }^{* *}$ & ND & ND & 15 & 5 & ND & ND & ND & ND & ND \\
\hline & Pumpkinseed ${ }^{* *}$ & ND & ND & 21 & 10 & 2 & ND & ND & ND & 22 \\
\hline & Pumpkinseed** & ND & ND & 8 & 2 & ND & ND & ND & ND & ND \\
\hline & Chain Pickerel** & ND & ND & 2 & ND & ND & ND & ND & ND & ND \\
\hline & Chain Pickerel** & ND & ND & ND & ND & ND & ND & ND & ND & ND \\
\hline & Chain Pickerel** & ND & ND & 2 & ND & ND & ND & ND & ND & ND \\
\hline & Chain Pickerel** & ND & ND & ND & ND & ND & ND & ND & ND & ND \\
\hline & Chain Pickerel** & ND & ND & 2 & ND & ND & ND & ND & ND & ND \\
\hline & Brown Bullhead** & ND & ND & 3 & ND & ND & ND & ND & ND & ND \\
\hline & Brown Bullhead** & ND & ND & 13 & 6 & ND & ND & ND & ND & ND \\
\hline & Brown Bullhead** & ND & ND & 18 & 6 & ND & ND & ND & ND & 20 \\
\hline \multirow[t]{3}{*}{ Donahue's Pond } & Bluegill & ND & ND & 40 & 23 & $5^{*}$ & ND & ND & ND & ND \\
\hline & Brown Bullhead & ND & ND & 13 & 4 & ND & ND & ND & ND & ND \\
\hline & Bass & ND & ND & 21 & 9 & ND & ND & ND & ND & ND \\
\hline
\end{tabular}


Table 6-8. Pesticides Analysis in Fish and Shellfish from the Peconic River System and Control Locations (concluded).

\begin{tabular}{|c|c|c|c|c|c|c|c|c|c|c|}
\hline & & $\begin{array}{c}\text { Heptachlor } \\
\text { epoxide }\end{array}$ & Dieldrin & 4,4'-DDE & 4,4'-DDD & $\begin{array}{c}4,4^{\prime}-\mathrm{DDT} \\
-\mu \mathrm{g} / \mathrm{kg}\end{array}$ & $\begin{array}{l}\text { gamma- } \\
\text { Chlordane }\end{array}$ & $\begin{array}{l}\text { alpha- } \\
\text { Chlordane }\end{array}$ & $\begin{array}{c}\text { Aroclor- } \\
1254\end{array}$ & $\begin{array}{c}\text { Aroclor- } \\
1260\end{array}$ \\
\hline Lower Lake, & Bluegill & ND & $1^{*}$ & 31 & $10^{*}$ & $4^{*}$ & $1^{*}$ & $2^{*}$ & ND & ND \\
\hline \multirow[t]{10}{*}{ Carmans River } & Bluegill & $0.79^{*}$ & $2^{*}$ & 68 & $19^{*}$ & $7^{*}$ & $3^{*}$ & $1^{*}$ & ND & ND \\
\hline & Pumpkinseed & ND & $1^{*}$ & 47 & $11^{*}$ & $7^{*}$ & $1^{*}$ & $1^{*}$ & ND & ND \\
\hline & Black Crappie & ND & $1^{*}$ & 98 & $24^{*}$ & $11^{*}$ & $5^{*}$ & $10^{*}$ & ND & ND \\
\hline & Bass & ND & ND & 101 & 21 & ND & ND & ND & ND & ND \\
\hline & Golden Shiner & ND & ND & 119 & 36 & ND & ND & ND & ND & ND \\
\hline & Golden Shiner & ND & $5^{*}$ & 152 & 47 & ND & $10^{*}$ & $16^{*}$ & ND & ND \\
\hline & Black Crappie & ND & $7^{*}$ & 441 & 118 & 45 & $62^{*}$ & 18 & ND & ND \\
\hline & Yellow Perch & ND & $15^{*}$ & 305 & $68^{*}$ & ND & ND & ND & ND & ND \\
\hline & Red-finned Pickerel & ND & ND & 101 & 20 & ND & $6^{*}$ & $8^{*}$ & ND & ND \\
\hline & Brown Bullhead & ND & ND & 77 & $24^{*}$ & ND & $7^{*}$ & $12^{*}$ & ND & ND \\
\hline Moriches Bay & Clams & ND & ND & 17 & $2^{*}$ & $41^{*}$ & ND & ND & ND & ND \\
\hline \multicolumn{11}{|c|}{$\begin{array}{l}\text { Notes: } \\
\text { *= Estimated value based on lab qualifiers. } \\
\text { ** = Data provided by New York State. } \\
\text { ND = Not Detected }\end{array}$} \\
\hline
\end{tabular}

Metals in shellfish are also presented in Table 6-7. In most samples, metals appear to be consistent with or slightly above previous years' sampling efforts. One exception is the presence of manganese at high levels in freshwater mussels taken from Connecticut Avenue and Forge Pond. Also, arsenic in clams and mussels from Indian Island, Flanders Bay, and Peconic Bay appears higher compared to values reported in last year's report. Arsenic has historically been used in agricultural practices on Long Island. Run-off from farms is a likely source of this metal in the Peconic River.

Table 6-8 shows the concentrations of pesticides and PCBs in fish and shellfish for 2001. The table reflects only samples with detectable levels of pesticide in the tissues. Clams from Moriches Bay were the only shellfish to show measurable levels of pesticides. The levels detected in fish and shellfish do not exceed any standards that constitute health impacts on the consumers of such fish and are not considered harmful. No pesticides were detected in on-site samples. The pesticides DDT, DDD, and DDE were detected at low levels at several off-site locations. DDD and DDE pesticides are breakdown products of DDT, a pesticide commonly used before 1970. Chlordane and Dieldrin were also commonly used across Long Island and show up at off-site locations in low levels.

Barely detectable levels of PCBs (Aroclor1242 and Aroclor-1260) were found in fish taken from the Peconic River at the east boundary, as well as just off site at Ice Pond. All levels are below the FDA standard of $2 \mathrm{ppm}$ and should not pose a health hazard. Historically, Aroclor1260 was used in electrical equipment. The levels of PCBs detected were similar to levels seen in the past. The variation in the results may be due to differences in laboratory procedures, sample types (whole-body, composites, or tissues), and fish sizes.

\subsubsection{Marine/Estuarine Sampling}

Annual sampling for clams, sediment, and seawater in Peconic Bay, Flanders Bay, Indian Island, and Moriches Bay (control location) was conducted in 2001. (See Chapter 5, Figure 5-9, for locations.) Stakeholder concern that BNL's discharges and ongoing work with Operable Unit $\mathrm{V}$ may affect the clamming industry is the basis for continuing this sampling program. As in past years, the NYSDEC Marine Fisheries Branch assisted BNL in coordinating the sampling with local baymen. Table 6-9 summarizes the radiological data. Researchers tested estuarine vegeta- 
Table 6-9. Radiological Analysis Results for Shellfish, Aquatic Vegetation, Water, and Sediment.

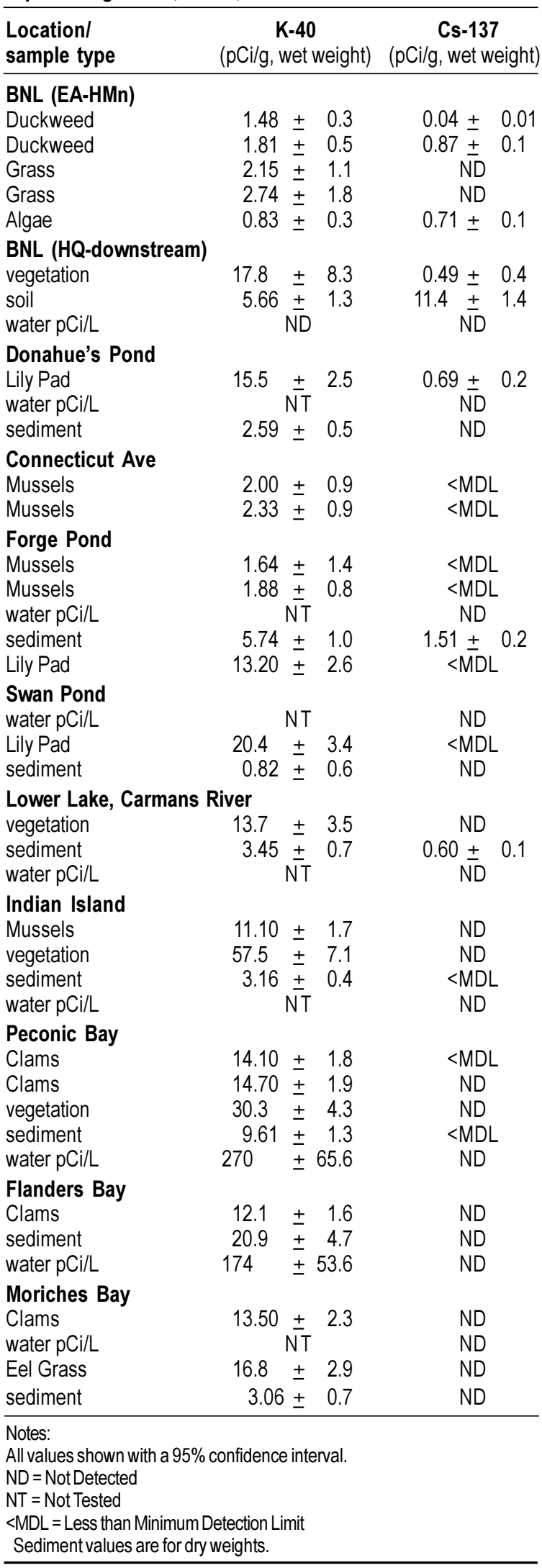

tion from Indian Island, Peconic Bay, and Moriches Bay. In addition, sediment and/or water samples from all four locations were tested. Naturally occurring potassium- 40 was the only radionuclide observed in any of the samples. No BNL-generated radionuclides have ever been detected in marine samples since 1992, when sampling began.

\subsubsection{Metals and Pesticides in Aquatic Samples}

Samples of freshwater mussels, vegetation, sediments, and water were taken at several locations within the Peconic River, bays, and estuaries, including on site at BNL and the Carmans River. Cesium-137 was detected at low levels in vegetation from on-site locations and Donahue's Pond. Sediments from BNL, Forge Pond, and Lower Lake on the Carmans River also showed low levels of cesium-137. None was detected in mussel samples. These levels were similar to past observations.

Metals analysis (Table 6-10) was conducted on aquatic vegetation, water, and sediments from the Peconic River, bays, and estuaries. Most of the data indicate metals at background levels. The standard used for comparison of sediments is the soil cleanup objectives for heavy metals supported by the Suffolk County Department of Health Services. Water sample results are compared to New York State Drinking Water Standards (see Chapter 3). Vegetation results are compared to both standards, because metals in vegetation may accumulate via uptake from sediment or water. Arsenic was found in vegetation taken from Peconic Bay and Indian Island at levels above cleanup objectives but below drinking water standards. Elevated levels of chromium, copper, mercury, nickel, and silver were found in vegetation taken on the BNL site from the Peconic River near the east firebreak. This area is scheduled to be included in a pilot study of cleanup options being considered for use in the Operable Unit $\mathrm{V}$ remediation activities. Chromium, copper, mercury, and silver were also seen in river sediments and water taken at the east boundary of the Laboratory. This area is also scheduled to be included in pilot studies. Off site, mercury was detected at levels just above Suffolk County cleanup objectives in sediments 


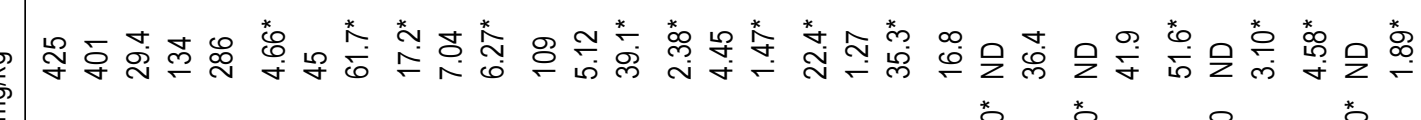

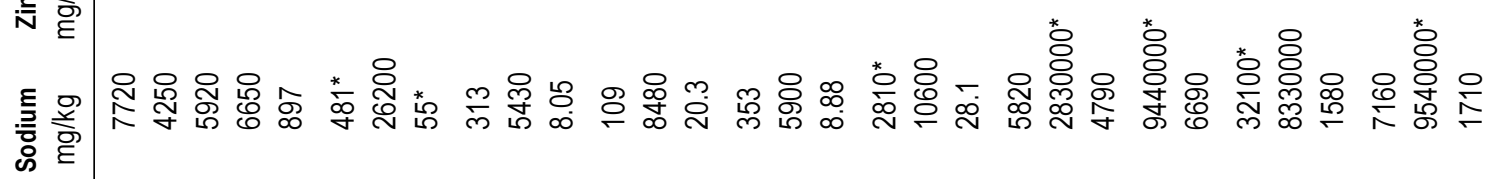

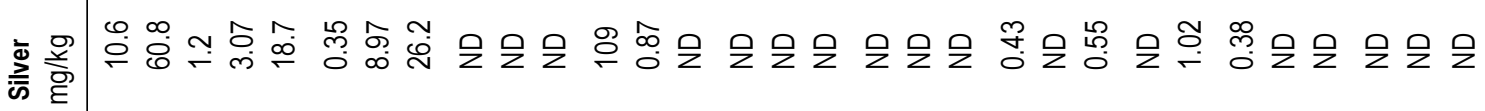

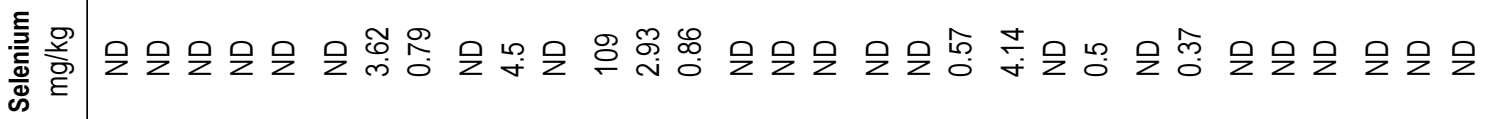

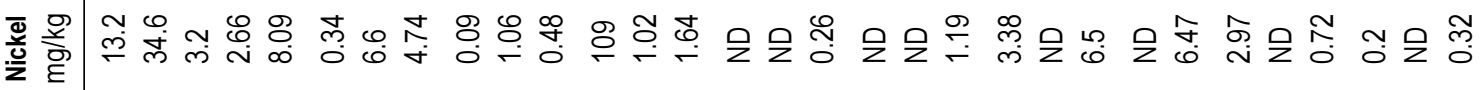
言岏 兽旁 ॠ ॠ

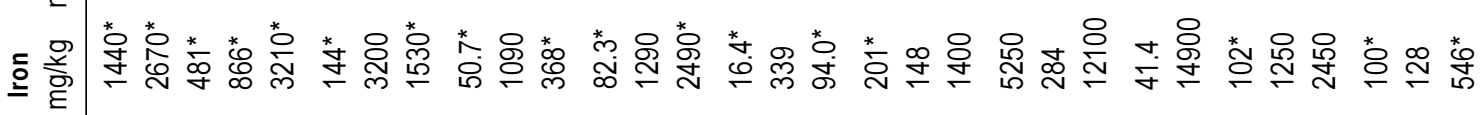

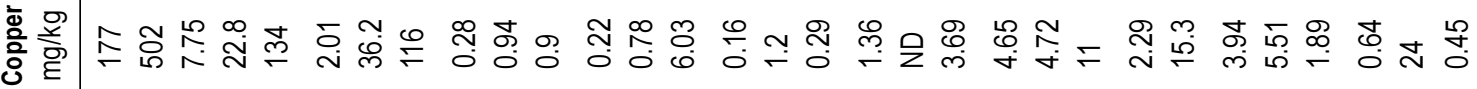

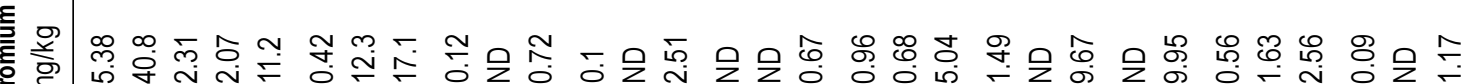
U

衰 旁

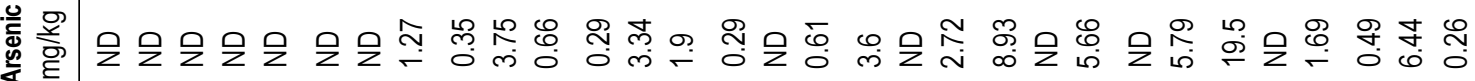

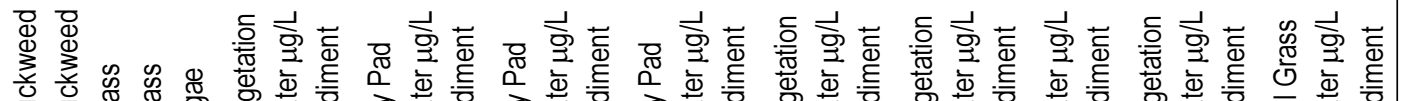

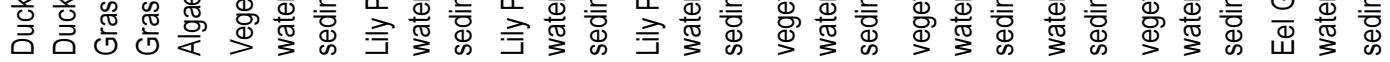

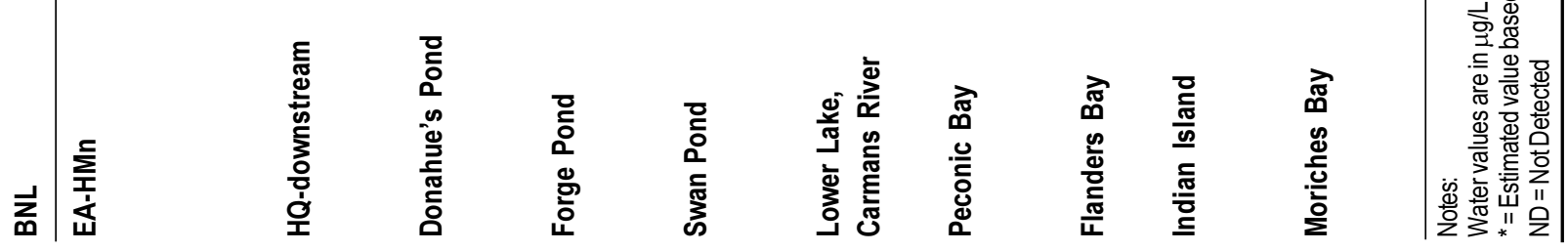


from Forge Pond and Swan Pond.

Pesticides and PCBs are reported in

Table 6-11 for only those samples with detectable limits. Aroclor- 1248 was the only PCB detected. A very low level of this PCB was detected in a water sample from Lower Lake on the Carmans River. DDT and its breakdown products, DDD and DDE, were detected in the Peconic River and Peconic Bay system, as well as in eel grass taken from Moriches Bay. All detections of DDT, DDD, and DDE were below the minimum detection limit. Chlordane was detected in duckweed taken on site. Both DDT and Chlordane were used historically across Long Island, including at BNL.

\subsubsection{Vegetation Sampling}

A variety of farm and garden vegetables were sampled in 2001. Samples were collected from farms near BNL as well as from an on-site garden (Figure 6-8). Samples were submitted for radiological analysis and the results are presented in Table 6-12. As in the past, no radionuclides attributable to BNL operations were observed in farm produce. Cesium-137 was absent from all on-site garden vegetables and apples. Potassium-40, which occurs naturally, was the only radionuclide detected in all of the produce sampled. BNL sampled grassy vegetation (Table 6-13) near air monitoring stations to support the surveillance monitoring associated with these points. Grassy vegetation was also sampled in lawn areas where geese tend to graze, for comparison with goose fecal sampling (see Section 6.3.3). Vegetation sampling is carried out to determine if depositional material is accumulating on plant surfaces and soils and whether there is uptake by the vegetation. In 2001, the only anthropogenic radionuclide found in grassy vegetation was cesium137. A single sample from air station $\mathrm{S}-5$ at the STP indicated a very low cesium-137 level ( $0.06 \mathrm{pCi} / \mathrm{g}$ wet weight). Cesium-137 was also detected at very low levels in grassy vegetation sampled from the NYSDEC Game Farm located in the nearby village of Ridge.

\subsection{BASIN SEDIMENT SAMPLING}

BNL samples basin sediments on a twoyear cycle. The next sampling is scheduled for 2002. However, in 2000, BNL reported levels of lead above Suffolk County cleanup action levels at the outfall for the Central Steam Facility and planned follow-up sampling to determine the extent of contamination. Details of this investigation are presented in Chapter 5.

Table 6-11. Pesticide and PCB Analysis of Aquatic Vegetation, Water, and Sediments from the Peconic River System, Bays, and Control Locations.

\begin{tabular}{|c|c|c|c|c|c|c|c|c|c|c|}
\hline & & $\begin{array}{l}\text { delta- } \\
\text { BHC }\end{array}$ & Dieldrin & 4,4'-DDE & 4,4'-DDD & $\begin{array}{l}\text { Endosulfan } \\
\text { sulfate }\end{array}$ & 4,4'-DDT & $\begin{array}{l}\text { gamma- } \\
\text { Chlordane }\end{array}$ & $\begin{array}{l}\text { alpha- } \\
\text { Chlordane }\end{array}$ & $\begin{array}{c}\text { Aroclor- } \\
1248\end{array}$ \\
\hline \multicolumn{11}{|l|}{ BNL } \\
\hline \multirow[t]{2}{*}{$\mathrm{EA}-\mathrm{HMn}$} & Duckweed & $<M D L$ & ND & $<M D L$ & ND & $<M D L$ & ND & $<M D L$ & $<M D L$ & ND \\
\hline & Duckweed & ND & $<\mathrm{MDL}$ & $<M D L$ & $<M D L$ & ND & ND & $<M D L$ & 45.4 & ND \\
\hline HQ-downstream & sediment & ND & ND & $<M D L$ & ND & ND & $<\mathrm{MDL}$ & ND & ND & ND \\
\hline Forge Pond & water $\mu \mathrm{g} / \mathrm{L}$ & ND & ND & ND & ND & ND & $<M D L$ & ND & ND & ND \\
\hline Swan Pond & water $\mu \mathrm{g} / \mathrm{L}$ & ND & ND & ND & ND & ND & $<M D L$ & ND & ND & ND \\
\hline Peconic Bay & sediment & ND & ND & $<M D L$ & $<M D L$ & ND & ND & ND & ND & ND \\
\hline Indian Island & water $\mu \mathrm{g} / \mathrm{L}$ & ND & ND & ND & ND & ND & $<\mathrm{MDL}$ & ND & ND & ND \\
\hline Moriches Bay & Eel Grass & ND & ND & $<M D L$ & ND & ND & $<M D L$ & ND & ND & ND \\
\hline $\begin{array}{l}\text { Lower Lake, } \\
\text { Carmans River }\end{array}$ & water $\mu \mathrm{g} / \mathrm{L}$ & ND & ND & ND & ND & ND & ND & ND & ND & 0.89 \\
\hline \multicolumn{11}{|c|}{$\begin{array}{l}\text { Notes: } \\
\text { Water values are in } \mu \mathrm{g} / \mathrm{L} \text {. } \\
<\mathrm{MDL}=\text { Less than Minimum Detection Limit } \\
\mathrm{ND}=\text { Not Detected }\end{array}$} \\
\hline
\end{tabular}




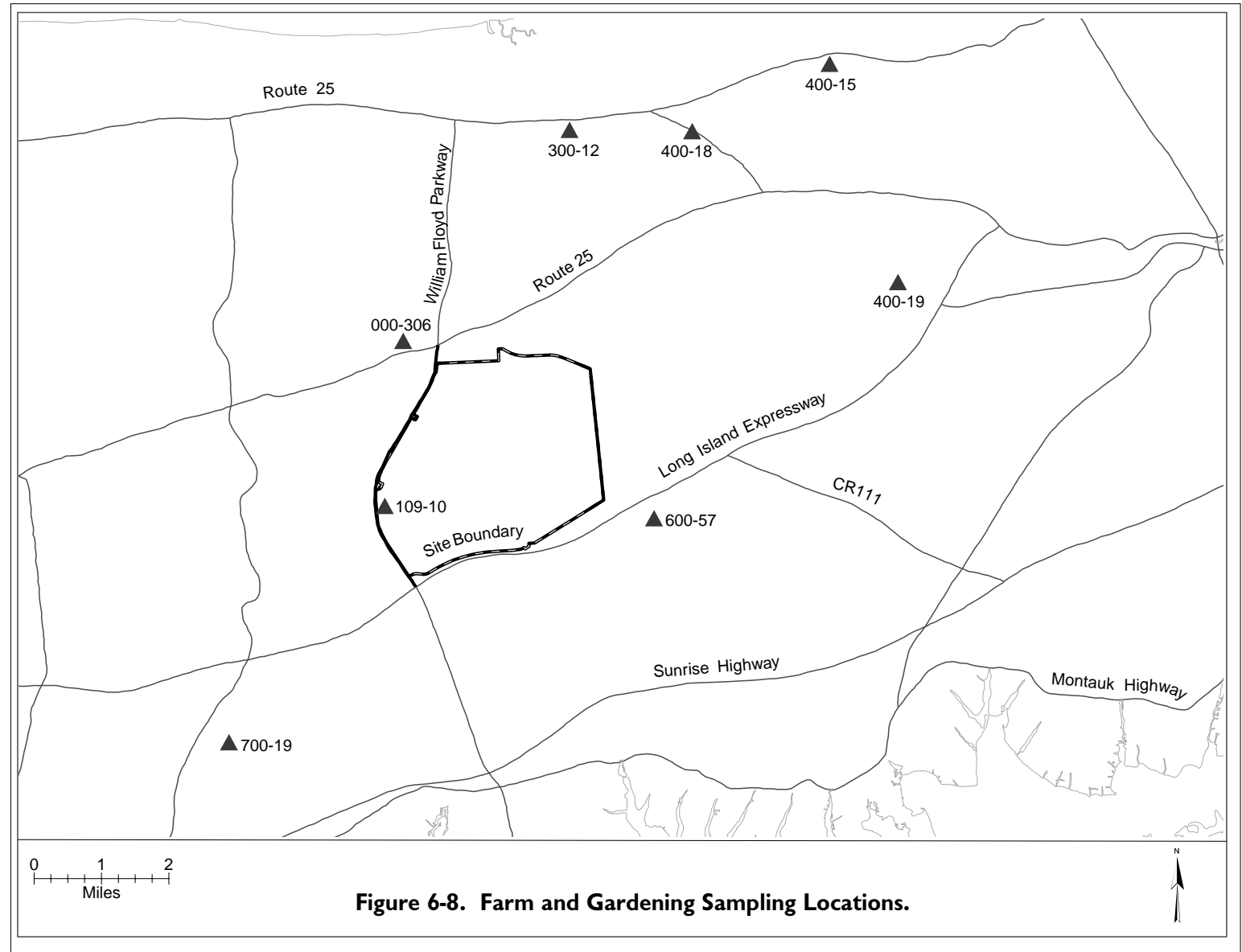

\subsection{SOIL SAMPLING}

Soil sampling was conducted to correspond with vegetation sampling near air stations, goose fecal matter collection points, the on-site garden, and local farms. Soil sampling is conducted as part of the surveillance program and is used to determine uptake in plants, as well as to determine long-term deposition or lack thereof. Soil samples were analyzed for gamma-emitting radionuclides. Table 6-14 shows the sampling results of the radiological analysis of soils. All radionuclides detected, with the exception of cesium-137, are found naturally in Long Island soils. Higher levels of some of the radionuclides, such as lead-212, lead-214, bismuth-214, and potassium-40 in some of the farm locations, are likely due to the addition of fertilizers to soils for growing crops. The maximum cesium-137 concentration was $0.62 \mathrm{pCi} / \mathrm{g}$ dry weight, except at station S-5 located at the Sewage Treatment Plant. The lower values are considered to be consistent with background levels resulting from worldwide fallout from historic aboveground nuclear weapons testing. The high elevation seen near the STP is likely due to known historic contamination in the area.

\subsection{TOXICITY TESTING, SEWAGE TREATMENT PLANT}

Under the State Pollutant Discharge Elimination System discharge permit, BNL conducted toxicity testing for the Sewage Treatment Plant effluent. Two species of fish were evaluatedthe fathead minnow (Pimephales promelas) and the water flea (Ceriodaphnia dubia). Results from this testing program are presented in Chapter 3.

\subsection{PRECIPITATION MONITORING}

As part of the Environmental Monitoring Program, precipitation samples were collected approximately quarterly at air monitoring Stations 
Table 6-12. Radiological Analysis of Farm and Garden Produce.

\begin{tabular}{|c|c|c|c|}
\hline Location & & $\begin{array}{c}\mathrm{K}-40 \\
\text { (pCi/g, } \\
\text { wet weight) }\end{array}$ & $\begin{array}{c}\text { Cs-137 } \\
\text { (pCi/g, } \\
\text { wet weight) }\end{array}$ \\
\hline \multirow[t]{8}{*}{ BNL Garden } & Lettuce & $1.94 \pm 0.43$ & ND \\
\hline & String Bean & ND & ND \\
\hline & Tomato & $1.50 \pm 0.24$ & ND \\
\hline & Tomato & $1.59 \pm 0.26$ & ND \\
\hline & Cucumber & $1.55 \pm 0.33$ & ND \\
\hline & Eggplant & $0.10 \pm 0.02$ & ND \\
\hline & Peppers & $1.27 \pm 0.21$ & ND \\
\hline & Corn & $2.05 \pm 0.36$ & ND \\
\hline \multicolumn{4}{|c|}{ BNL Vegetation } \\
\hline Bldg. 555 & Apple & $0.86 \pm 0.16$ & ND \\
\hline \multirow[t]{8}{*}{ Mays Farm } & Tomato & $4.26 \pm 0.79$ & ND \\
\hline & Corn & $2.16 \pm 0.52$ & ND \\
\hline & Corn* & $1.77 \pm 0.30$ & ND \\
\hline & String Bean & $1.91 \pm 0.31$ & ND \\
\hline & Cucumber & $1.28 \pm 0.21$ & ND \\
\hline & Pumpkin & $3.19 \pm 0.60$ & ND \\
\hline & Cauliflower & $3.16 \pm 0.60$ & ND \\
\hline & Eggplant & $1.85 \pm 0.30$ & ND \\
\hline \multirow[t]{10}{*}{ Lewins Farm } & Cucumber & $0.98 \pm 0.21$ & ND \\
\hline & Yellow Squash & $1.50 \pm 0.24$ & ND \\
\hline & Zuchini & $1.89 \pm 0.39$ & ND \\
\hline & Potato & $1.66 \pm 0.35$ & ND \\
\hline & Potato* & $1.42 \pm 0.23$ & ND \\
\hline & Corn & $2.42 \pm 0.44$ & ND \\
\hline & Apple & $1.02 \pm 0.17$ & ND \\
\hline & Peaches & ND & ND \\
\hline & Pumpkin & $1.89 \pm 0.31$ & ND \\
\hline & Apple & $7.76 \pm 1.33$ & ND \\
\hline Cornell Farm & Corn & $1.73 \pm 0.31$ & ND \\
\hline \multirow[t]{4}{*}{ Bruno Farm } & Cucumber & $3.48 \pm 0.68$ & ND \\
\hline & Zuchini & $2.12 \pm 0.41$ & ND \\
\hline & String Bean & $1.35 \pm 0.22$ & ND \\
\hline & Tomato & $1.92 \pm 0.30$ & ND \\
\hline Rt. 25 Farm & Strawberry & $1.25 \pm 0.21$ & ND \\
\hline \multirow[t]{2}{*}{ River Road } & Strawberry & $1.01 \pm 0.17$ & ND \\
\hline & Snap Peas & $1.63 \pm 0.40$ & ND \\
\hline
\end{tabular}

Notes:

See Figure 6-9 for sampling locations.

All values shown with a $95 \%$ confidence interval.

$\mathrm{K}-40$ occurs naturally in the environment and is presented as a comparison to $\mathrm{Cs}-137$.

$\mathrm{ND}=$ Not Detected

* = Duplicate sample
Table 6-13. Radiological Analysis of Grassy Vegetation.

\begin{tabular}{lrc}
\hline Location & $\begin{array}{c}\text { K-40 } \\
\text { (pCi/g, } \\
\text { wet weight) }\end{array}$ & $\begin{array}{c}\text { Cs-137 } \\
\text { (pCi/g, } \\
\text { wet weight) }\end{array}$ \\
\hline BNL & $4.13 \pm 0.76$ & $0.06 \pm 0.02$ \\
S-5 & $3.88 \pm 0.73$ & ND \\
P-7 & $3.70 \pm 0.66$ & ND \\
S-6 & $2.72 \pm 1.29$ & ND \\
P-2 & $2.24 \pm 0.55$ & ND \\
P-9 & $3.91 \pm 0.68$ & ND \\
P-4 & $10.94 \pm 4.29$ & ND \\
HFBR Lawn & $5.86 \pm 1.38$ & ND \\
NSLS Lawn & $10.25 \pm 3.84$ & ND \\
Ballfield 6 & $5.09 \pm 1.19$ & ND \\
RA5 Recharge Basin & $3.30 \pm 0.96$ & ND \\
STP Hold-up Pond & & \\
Offsite & & \\
NYSDEC Game Farm & $0.33 \pm 0.10$ & $0.01 \pm 0.00$ \\
Spring Lake, Middle Island & $12.36 \pm 10.72$ & ND \\
\hline Notes: & & \\
All values shown with a 95\% confidence interval. & \\
Table contains information also reported in Table6-4. & \\
K-40 occurs naturally in the environment and is presented as a comparison \\
to Cs-137. \\
ND = NotDetected & & \\
\hline
\end{tabular}

P4 and S5 (see Chapter 4, Figure 4-4 for station locations) and analyzed for radiological content. Four samples were taken from each of these two stations in 2001. Gross alpha activity measurements above the minimum detection limit were found in samples taken in July and October. The samples from the $\mathrm{P} 4$ location showed a maximum of $4.86 \mathrm{pCi} / \mathrm{L}$ activity, whereas the samples from the $\mathrm{S} 5$ location had a maximum activity level of $19.40 \mathrm{pCi} / \mathrm{L}$. Both of these values are within the range of historic values reported for gross alpha activity. Gross beta activity was measured in four samples at each of the sampling locations. In general, radioactivity in precipitation comes from naturally occurring radionuclides in dust and activation products resulting from solar radiation. Location $\mathrm{P} 4$ had a maximum activity level of $11.50 \mathrm{pCi} / \mathrm{L}$, with an average of 5.55 $\mathrm{pCi} / \mathrm{L}$. Location $\mathrm{S} 5$ had a maximum of 17.20 $\mathrm{pCi} / \mathrm{L}$, with the average activity of $6.88 \mathrm{pCi} / \mathrm{L}$. Gross beta activity values were within the range of values historically observed at these two locations. Tritium was not detected in any of the 


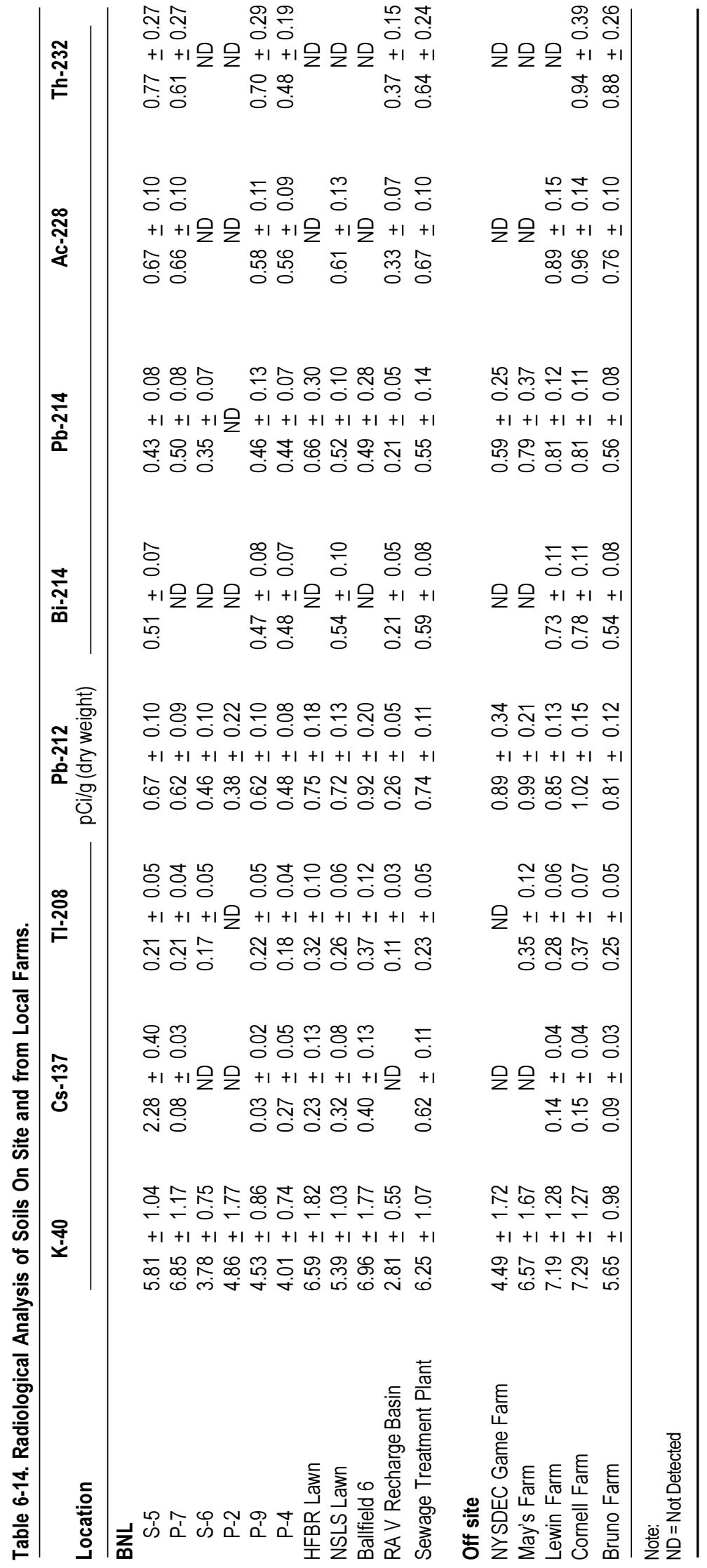

samples from either location. Gamma analysis of samples taken in February, April, and July showed the presence of beryllium-7 at a maximum of $67.5 \mathrm{pCi} / \mathrm{L}$ at Station $\mathrm{P} 4$ in April and $60.9 \mathrm{pCi} / \mathrm{L}$ in April at Station S5. Beryllium-7 is a naturally occurring radionuclide resulting from solar flare activity.

\subsection{WILDLIFE OUTREACH}

BNL sponsors a variety of educational and outreach activities on natural resources. These programs are designed to help participants understand the ecosystem and to foster interest in science. Wildlife programs are conducted at BNL in collaboration with DOE, local agencies, colleges, and high schools. Ecological research is also conducted on site to update the current natural resources inventory, gain a better understanding of the ecosystem, and guide management planning.

In 2001, the Environmental Services Division (ESD) hosted two student fellowships during the summer. One student was from the University of Puerto Rico and worked with Suffolk County Community College and the U.S. Fish \& Wildlife Service on plant distributions, fire ecology, and ecological education programs. The second student was from the University of Georgia and conducted research on the tiger salamander (Figure 6-9). The data gained from their studies have furthered BNL's understanding of pine barrens and tiger salamander ecology on BNL property.

In addition to hosting student fellowships, members of ESD and other departments volunteer as speakers and give guest lectures at schools, civic groups, and provide on-site ecology tours. ESD also hosted activities in association with Earth Day 2001 and provided activities to educate Laboratory employees and the general public on the environment and conservation. BNL hosted the Sixth Annual Pine Barrens Research Forum in October, providing a venue for researchers who are conducting work on pine barrens ecosystems to share and discuss their results. BNL also hosted the annual 


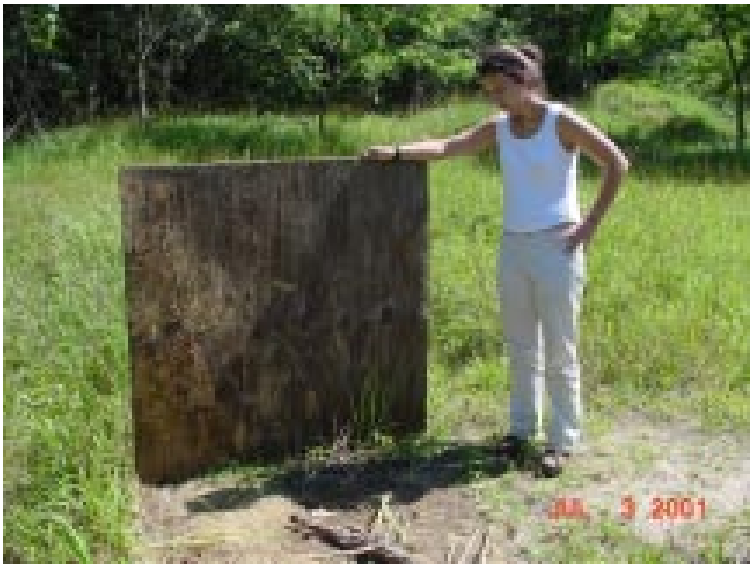

Figure 6-9. Summer Intern Working on Tiger Salamander Ecology.

Wildland Fire Academy offered by NYSDEC and the Central Pine Barrens Commission. This academy trains fire fighters in the methods of wildland fire suppression, prescribed fire, and fire analysis, all using the Incident Command System of wildfire management.

\subsection{CULTURAL RESOURCE ACTIVITIES}

The cultural resource management program is being developed to ensure that the Laboratory fully complies with the numerous cultural resource requirements. In October 2001, BNL submitted to the Department of Energy an accelerated schedule for developing the BNL Cultural Resources Management Plan, with a target completion date of December 2003. Development of a formal plan will guide the management of all of BNL's cultural resources. These resources include World War I trenches, Civilian Conservation Corps features such as the white pine groves, World War II buildings, and historic structures associated with high-energy physics and other science conducted at the Laboratory.

Section 110 of the National Historic Preservation Act requires that government agencies conduct surveys of their properties to identify buildings, structures, and features that may be eligible for inclusion in the National Register of Historic Places. In February 2001, BNL accepted receipt of The Architectural Inventory of the Brookhaven National Laboratory (Bernstein 2001a). The Institute for Long Island Archaeology, located at the State University of New York at Stony Brook, developed this document by conducting a building-by-building survey of all 440 buildings located at BNL.

In October 2001, BNL accepted receipt of the Cultural Resources Inventory of the Brookhaven National Laboratory (Bernstein 2001b), also prepared by the Institute for Long Island Archaeology. This document includes historic period contexts and an archeological sensitivity assessment of the BNL site. Information provided in this document will be used in developing the BNL Cultural Resource Management Plan.

With the permanent shutdown of the High Flux Beam Reactor in November 1999, BNL began placing the reactor into a safe and secure shutdown configuration. As part of this process, discussions began about the HFBR's significant contributions to science, its unique design, and its place in the BNL landscape. In October 2001, the New York State Historic Preservation Officer concurred with BNL's determination that the HFBR complex was eligible for listing on the National Register of Historic Places. The Laboratory has two additional structures or sites that have been determined to be eligible for listing: the World War I training trenches associated with Camp Upton and the BGRR complex.

BNL continued developing the mitigation packages associated with the Memorandum of Agreement (MOA) for the Mitigation of the Decommissioning of the Brookhaven Graphite Research Reactor (BGRR) (Desmarais 2000). Production of a BGRR history video documentary was in progress throughout 2001 . The contract, which used the services of a professional archivist to inventory and appraise BGRRrelated records and develop a researcher's guide, was completed in December 2001. Records relating to the design, construction, operations, and maintenance of the BGRR were evaluated as part of this effort. The BGRR Researcher's Guide includes an Excel database of all records, along with key-word descriptors and lists of all records and photographs. 


\section{REFERENCES}

Bernstein, D. 2001a. The Architectural Inventory of the Brookhaven National Laboratory. The Institute for Long Island Archaeology, Department of Anthropology, State University of New York at Stony Brook. February 2001.

Bernstein, D. 2001b. Cultural Resources Inventory of the Brookhaven National Laboratory. The Institute for Long Island Archaeology, Department of Anthropology, State University of New York at Stony Brook. October 2001.

BNL. 1999. Record of Decision: Operable Unit I and Radiologically Contaminated Soils. BNL/OU1/12.1/1-57 05-OCT-99. Brookhaven National Laboratory, Upton, NY. October 1999.

BNL. 2000. 1999 Site Environmental Report. BNL-52553. Brookhaven National Laboratory, Upton, NY. August 2000.

BNL. 2001. Site Environmental Report 2000. BNL-52626. Brookhaven National Laboratory, Upton, NY. September 2001.

Desmarais, R. 2000. "MOA Between BHG and New York State Historic Preservation Office Concerning Decommissioning Project." DOE Letter to E.A. Zimmerman, BNL. May 3, 2000. DOE-FWS. 2000. Interagency Agreement Number Al02-01 CH1107 Between the U.S. Department of Interior, U.S. Fish \& Wildlife Service, Long Island National Wildlife Refuge Complex, and the U.S. Department of Energy Chicago Operations Office - Brookhaven Group. November 2000.
Dwyer, Norval. 1966. Brookhaven National Laboratory. Long Island Forum (reprint), West Islip, NY.

IAEA. 1992. Effects of lonizing Radiation on Plants and Animals at Levels Implied by Current Radiation Protection Standards. Technical Report Series No. 332. International Atomic Energy Agency, Vienna.

LMS. 1995. Phase II Sitewide Biological Inventory Report, Final. Lawler, Matusky \& Skelly Engineers. Pearl River, NY. September 1995.

Naidu, J.R. 1999. Brookhaven National Laboratory Wildlife Management Plan. BNL-52556. Brookhaven National Laboratory, Upton, NY. September 22, 1999.

NYSDOH. 1996. Radioactive Contamination in the Peconic River. Bureau of Environmental Radiation Protection, New York State Department of Health, Albany, NY.

NYSDOH. 1999. Deer Meat Contaminated with Cesium-137 at Brookhaven National Laboratory. Bureau of Environmental Radiation Protection, New York State Department of Health, Albany, NY. March 1999.

Thomlinson, W. 1993. Deer Population Estimate for BNL Site. Summer Project Report. Brookhaven National Laboratory, Upton, NY. March 1993. 
Intentionally Left Blank 
BROOKHAVEN

NATIONAL

LABORATORY

2001 SITE ENVIRONMENTAL REPORT

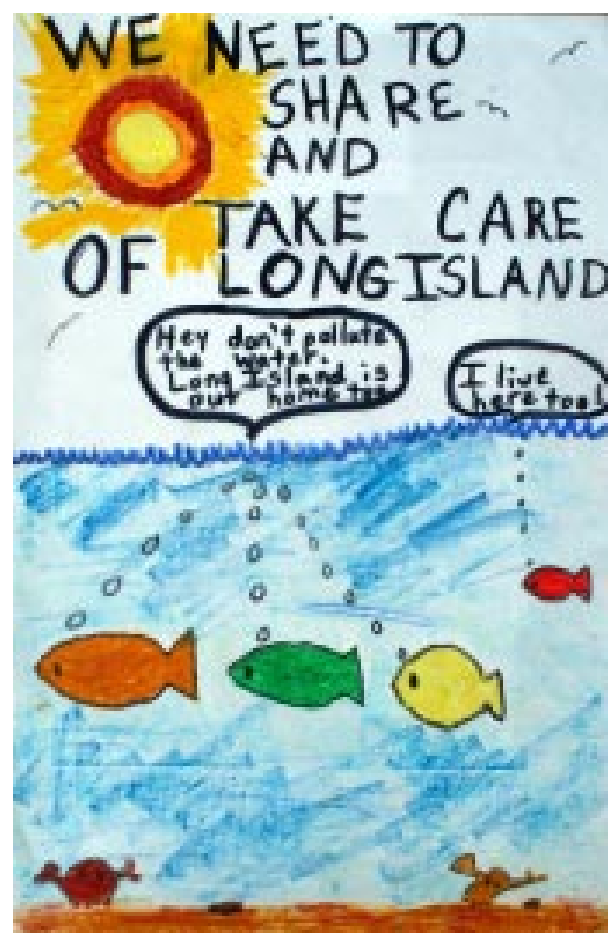

Chapter 7

\section{Groundwater Protection}

The Groundwater Protection Management Program is made up of four elements: prevention, monitoring, restoration, and communication. BNL is implementing aggressive pollution prevention measures to protect groundwater resources. An extensive groundwater monitoring well network is used to verify that prevention and restoration activities are effective. In 2001, BNL collected groundwater samples from 714 monitoring wells during 2,739 individual sampling events. Six volatile organic compound plumes and eight radionuclide plumes were tracked. Recent characterization work at the Brookhaven Graphite Research Reactor detected higher than expected strontium-90 contamination in the shallow groundwater beneath the reactor's belowground ducts. This legacy contamination is being addressed as part of the cleanup program. During 2001, six groundwater remediation systems removed approximately 609 pounds of volatile organic compounds and returned more than one billion gallons of treated water to the Upper Glacial aquifer. 


\subsection{THE BNL GROUNDWATER PROTECTION MANAGEMENT PROGRAM}

U.S. Department of Energy Order 5400.1 (DOE 1988), General Environmental Protection Program, requires development and implementation of a groundwater protection program. The primary goal of the BNL Groundwater Protection Management Program is to ensure that plans for groundwater protection, management, monitoring, and restoration are fully defined, integrated, and managed in a cost-effective manner that is consistent with federal, state, and local regulations. This program is described in the $B N L$ Groundwater Protection Management Program Description document (Paquette et al. 1998). The BNL Groundwater Protec-

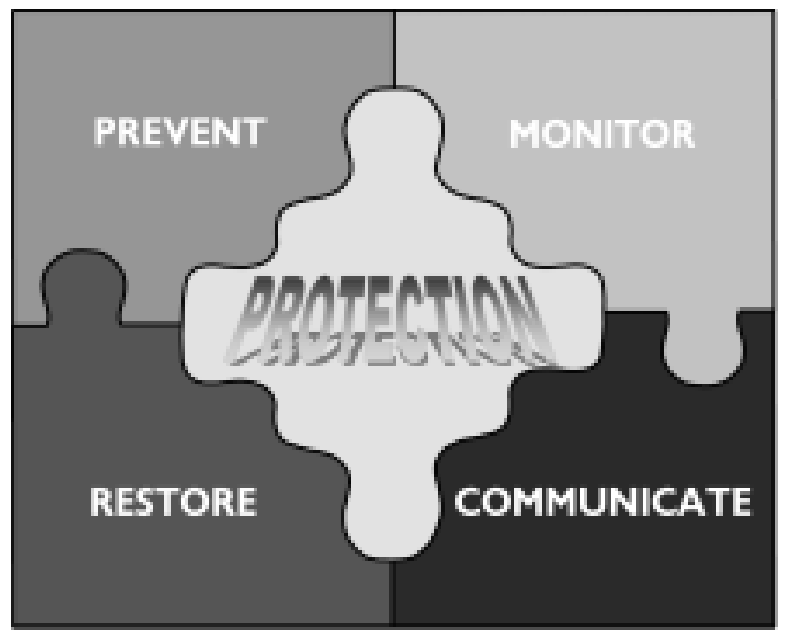

Figure 7-1. BNL's Groundwater Protection Program. these controls are working. The second phase resulted in a Laboratory-wide review of all experiments and industrial-type operations to determine the potential impacts of those activities on the environment and to integrate Pollution Prevention/Waste Minimization, Resource Conservation, and Compliance into planning, decision making, and implementation. Finally, phase three was to develop and implement an

Environmental Management System (EMS), which was finalized when BNL received ISO 14001 certification in 2001. The continuous improvement aspects of the EMS and ongoing reviews are designed to prevent further pollution of the sole source aquifer underlying the BNL site and are described in Chapter 2. In addition, as described in Chapter 3, efforts are being made to achieve or maintain compliance with regulatory requirements and to implement best management practices designed to protect groundwater. Examples include upgrading underground storage tanks (USTs), closing cesspools, adding engineered controls (e.g., barriers to prevent rainwater infiltration that could move contaminants out of the soil and into groundwater), and administrative controls (e.g., reducing the toxicity and volume of chemicals in use or storage).

\subsubsection{Monitoring}

BNL's groundwater monitoring network is designed to evaluate the impacts of groundwater contamination from historical and current operations and to track cleanup progress. Groundwater monitoring is a means of verifying that protection and restoration efforts are working. Groundwater monitoring is focused in two general areas: 1) Environmental Surveillance (ES), designed to satisfy DOE and New York 
State monitoring requirements for active research and support facilities, and 2) Environmental Restoration (ER) monitoring related to BNL's obligations under the Comprehensive Environmental Response, Compensation, and Liability Act (CERCLA). This monitoring is coordinated to ensure completeness and to prevent any duplication of effort in the installation, monitoring, and abandonment of wells. Furthermore, the monitoring program elements have been integrated, including the data quality objectives, plans and procedures, sampling and analysis, quality assurance, data management, and installation, maintenance, and abandonment of wells. This integration was done in order to create a cost-effective monitoring system and to ensure that water quality data are available for review and interpretation in a timely manner.

\subsubsection{Restoration}

BNL was added to the National Priorities List in 1989 (see Chapter 2 for a discussion of BNL's ER Program). The restoration effort was organized into 30 Areas of Concern (AOC), which were grouped into six Operable Units (OU); see Figure 2-11. Remedial Investigation/ Feasibility Studies have been conducted for each $\mathrm{OU}$, and the focus is now on designing and implementing cleanup systems. Contaminant sources (e.g., contaminated soil, underground storage tanks, and decommissioned reactor facilities) are being removed or remediated to prevent further contamination of groundwater. All remediation work is carried out under the Interagency Agreement involving EPA, the New York State Department of Environmental Conservation (NYSDEC), and DOE.

\subsubsection{Communication}

BNL's Community Education, Government and Public Affairs Program ensures that BNL communicates with the community in a consistent, timely, and accurate manner. A number of communication mechanisms are in place, such as web pages, mailings, public meetings, briefings, and roundtable discussions. Specific examples include the Community Advisory Council and the Brookhaven Executive Roundtable. Technical reports summarizing data, evaluations, and program indices are prepared annually. In addition, BNL has developed a Groundwater Protection Contingency Plan (BNL 2000b) that provides a formal process to communicate offnormal or unusual monitoring results to BNL's management, DOE, regulatory agencies, and other stakeholders in a timely manner.

\subsection{GROUNDWATER PROTECTION PERFORMANCE}

Since 1998, the BNL Groundwater Protection Management Program has been tracking progress toward eliminating new contamination of the aquifer system. The Laboratory has made significant investments in environmental and groundwater protection since 1998 and is making real progress in achieving its goal of preventing any new groundwater impacts. A "new" groundwater impact is defined as the detection of unusual or off-normal groundwater monitoring results. BNL is currently in a transition period, and it is expected to take several more years before the recent investments in environmental and groundwater protection allow BNL to reach its "zero" groundwater impact goal. The Groundwater Protection Contingency Plan (BNL $2000 \mathrm{~b}$ ) is designed to ensure that appropriate and timely actions are taken if unusual or off-normal results are observed. The contingency plan provides guidelines for evaluating the source of the problem, notifying stakeholders, and implementing appropriate corrective actions.

From 1998 through 2001, BNL installed several hundred permanent and temporary monitoring wells as a result of a comprehensive evaluation of known or potential contaminant source areas. Using this enhanced monitoring system, BNL has identified ten new groundwater impacts (Figure 7-2). It is important to note, however, that five of the ten identified impacts were determined to be from historical (or "legacy") contaminant releases. These newly discovered legacy issues include low-level petroleum hydrocarbon contamination in groundwater near the BNL Service Station, tritium near the former U-Line target area at the AGS, 1,1,1-trichloroethane (TCA) near Building 830 and the BNL Motor Pool, and higher than expected strontium- 90 contamination at the BGRR beneath the belowground ducts. 


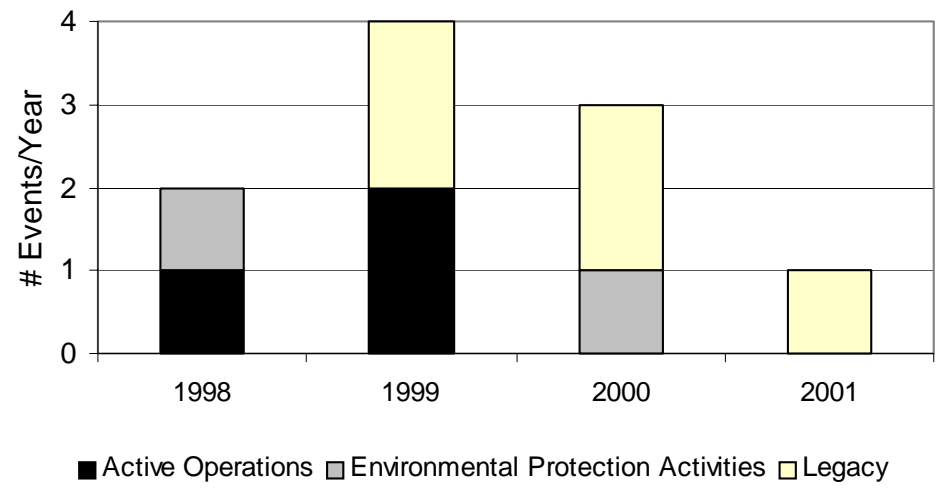

Figure 7-2. Groundwater Protection Performance during 2001.

The five remaining cases are related to active science operations and environmental protection activities. Three small tritium plumes that originated from active experimental areas at the AGS (the g-2 and E-20 Catcher areas) and the BLIP facility were discovered in 1998 and 1999. Activities associated with the Laboratory's environmental protection programs resulted in two new groundwater impacts. One was the inadvertent release of carbon tetrachloride during the removal of an underground storage tank, and the second was caused by an unexpected displacement of tritium during an innovative grout injection process designed to protect groundwater quality by stabilizing activated soils at the BLIP facility. In all ten cases, BNL thoroughly investigated the cause of the contamination and took corrective actions as necessary to eliminate or limit the scale of these impacts.

BNL will continue efforts to prevent new groundwater impacts, and is vigilant in measuring and communicating its performance.

\subsection{GROUNDWATER MONITORING}

Groundwater Monitoring Program elements include installing monitoring wells; planning and scheduling; developing and following quality assurance measures; collecting (see Figure 7-3) and analyzing samples; verifying, validating, and interpreting data; and reporting. Monitoring wells

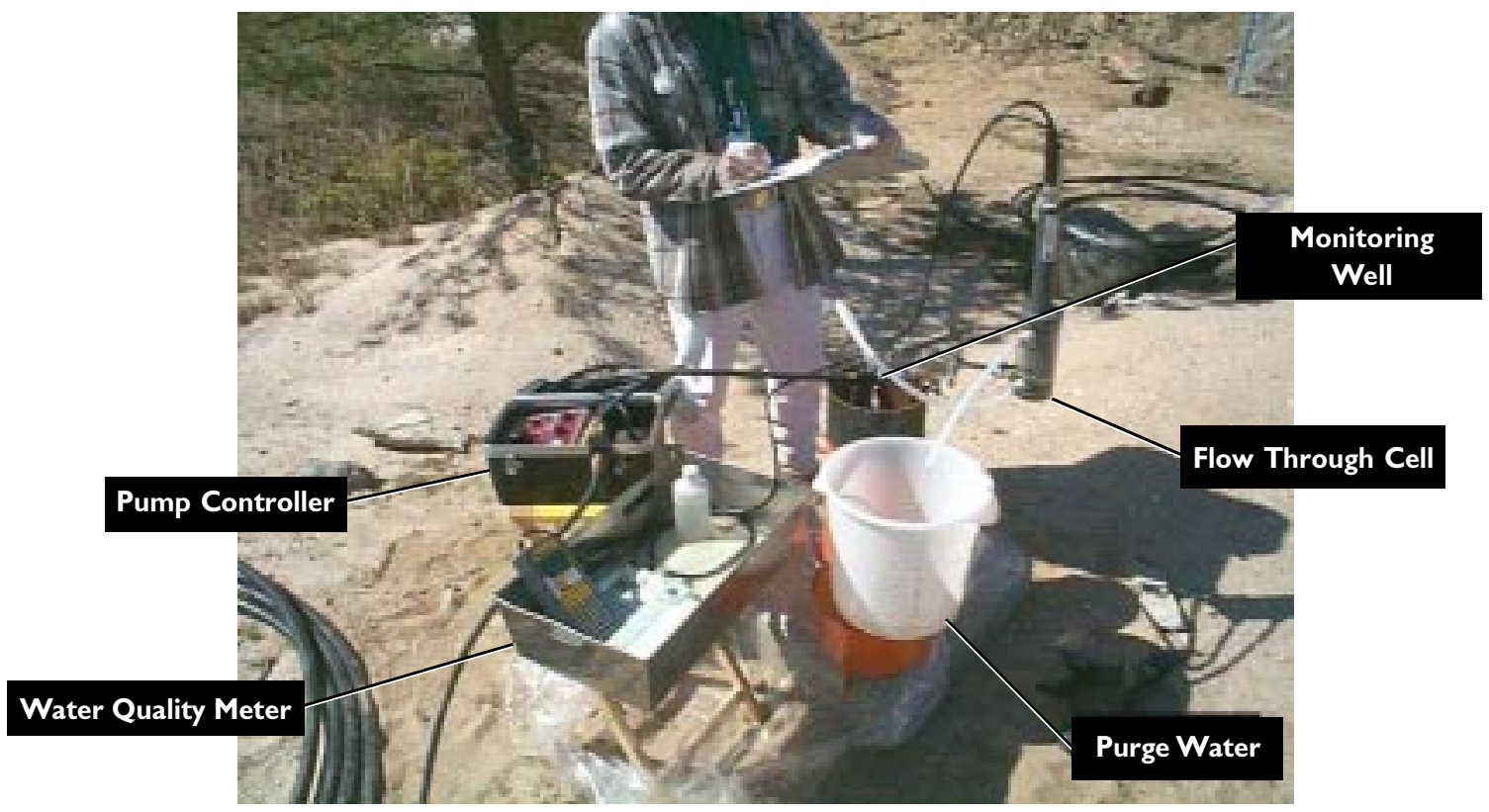

Figure 7-3. Sampling a Groundwater Monitoring Well. 
(which are not used for the drinking water supply) are used to evaluate BNL's progress in restoring groundwater quality, to comply with regulatory permit requirements, to monitor active research and support facilities, to assess the quality of groundwater entering and leaving the BNL site, and to ensure that corrective measures designed to protect and restore groundwater are, in fact, working as planned.

BNL monitors research and support facilities where there is a potential for environmental impact and in areas where past waste handling practices or accidental spills have already degraded groundwater quality. The groundwater beneath the BNL site is classified by New York State as Class GA groundwater, defined as a source of potable water supply and suitable for drinking. Federal drinking water standards, New York State Drinking Water Standards (NYS DWS), and New York State Ambient Water Quality Standards (NYS AWQS) for Class GA groundwater are used as groundwater protection and remediation goals. BNL evaluates the potential impact of radiological and nonradiological levels of contamination by comparing analytical results to New York State and DOE reference levels and background water quality levels. Nonradiological analytical results from groundwater samples collected from surveillance wells are usually compared to NYS AWQS. Radiological data are compared to NYS DWS (for tritium, gross beta, and strontium-90), NYS AWQS (for gross alpha and radium-226/ 228), and Safe Drinking Water Act (SDWA)/ DOE Derived Concentration Guides (for determining the $4 \mathrm{mrem}$ dose for other beta/ gamma-emitting radionuclides). Contaminant concentrations that are below these standards are also compared to background values to evaluate the potential effects from facility operations. The detection of low concentrations of facility-specific volatile organic compounds (VOCs) or radionuclides may provide important early indications of a contaminant release and allow for timely identification and remediation of the source.

Groundwater quality at BNL is routinely monitored through a network of approximately 714 on-site and off-site surveillance wells (see Figure 7-4). In addition to water quality assessments, water levels are routinely measured in more than 875 on-site and off-site wells to assess variations in directions and velocities of groundwater flow. Groundwater flow directions in the vicinity of BNL are shown on Figure 7-5.

Active and inactive facilities that have groundwater monitoring programs include the Sewage Treatment Plant/Peconic River area, Biology Agricultural Fields, Former Hazardous Waste Management Facility (HWMF), new Waste Management Facility (WMF), two former landfill areas, Central Steam Facility/Major Petroleum Facility (CSF/MPF), Alternating Gradient Synchrotron (AGS), Waste Concentration Facility (WCF), Supply and Material, and several other smaller facilities. As the result of detailed groundwater investigations conducted over the past fifteen years, six significant VOC plumes and eight radionuclide plumes have been identified (Figures 7-6 and 7-7).

\subsection{SUPPLEMENTAL MONITORING OF POTABLE AND PROCESS SUPPLY WELLS}

As discussed in Chapter 3, BNL is a public water purveyor and maintains water supply wells and associated treatment facilities for the distribution of potable water on the site. The BNL potable and cooling water supply well network consists of six supply wells (wells 4, 6, 7, 10, 11, and 12). Supply well 9 supplies process water to a facility where biological research on fish is conducted. Supply well 105 supplied cooling water to the Brookhaven Medical Research Reactor (BMRR) facility for the first six months of 2001. Because the BMRR is permanently shutdown, well 105 will be sealed in 2002 . The locations of the supply wells are shown on Figure 7-5.

The quality of the BNL potable water supply is monitored as required by the Safe Drinking Water Act (SDWA), and the analytical results are reported to the Suffolk County Department of Health Services. As required by the SDWA, BNL also prepares an annual Water Quality Consumer Confidence Report (BNL 2002a) that is distributed to all employees and guests.

Groundwater quality is routinely monitored at all active water supply wells. All supply wells are screened within the Upper Glacial aquifer. Because of the proximity of BNL's potable 


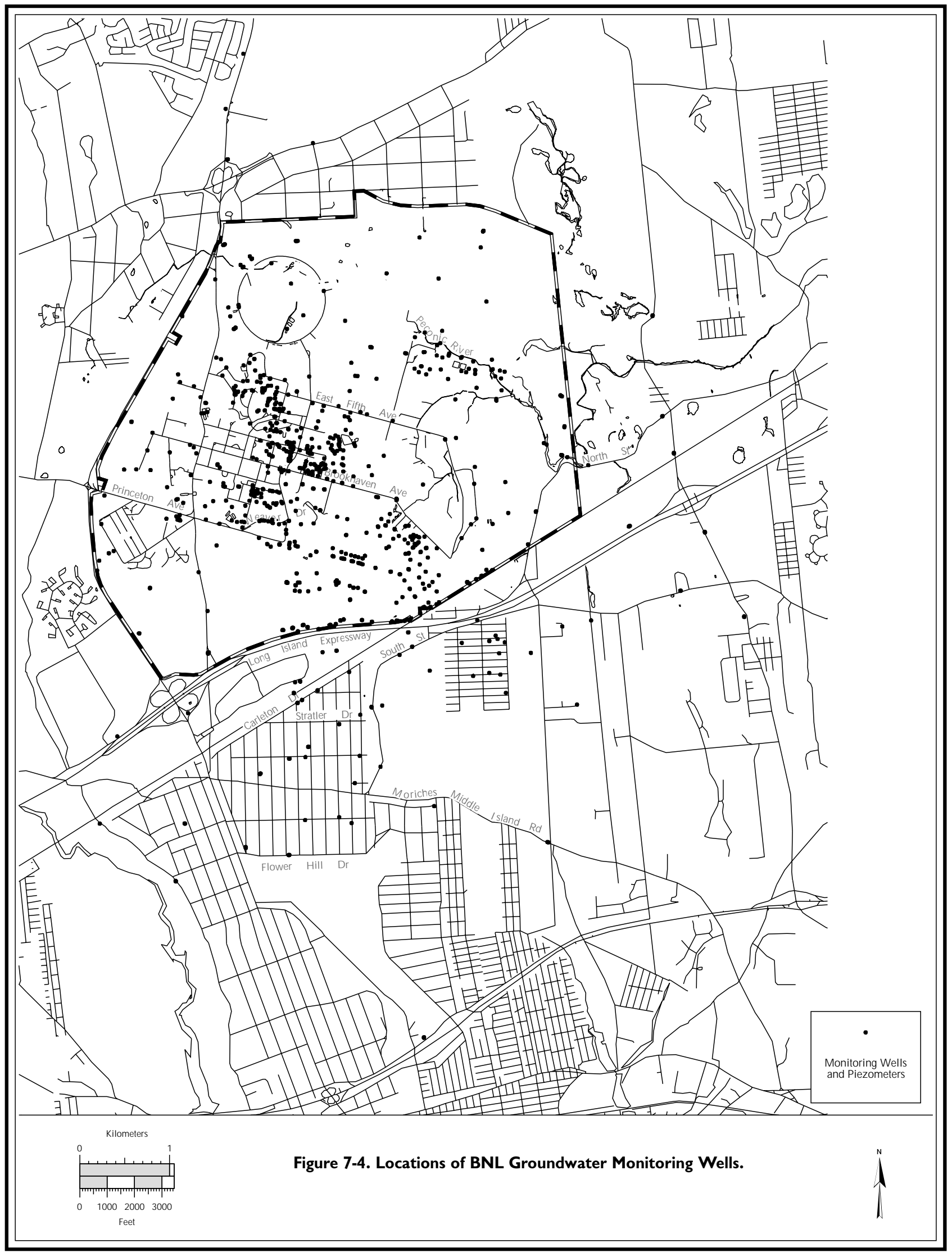




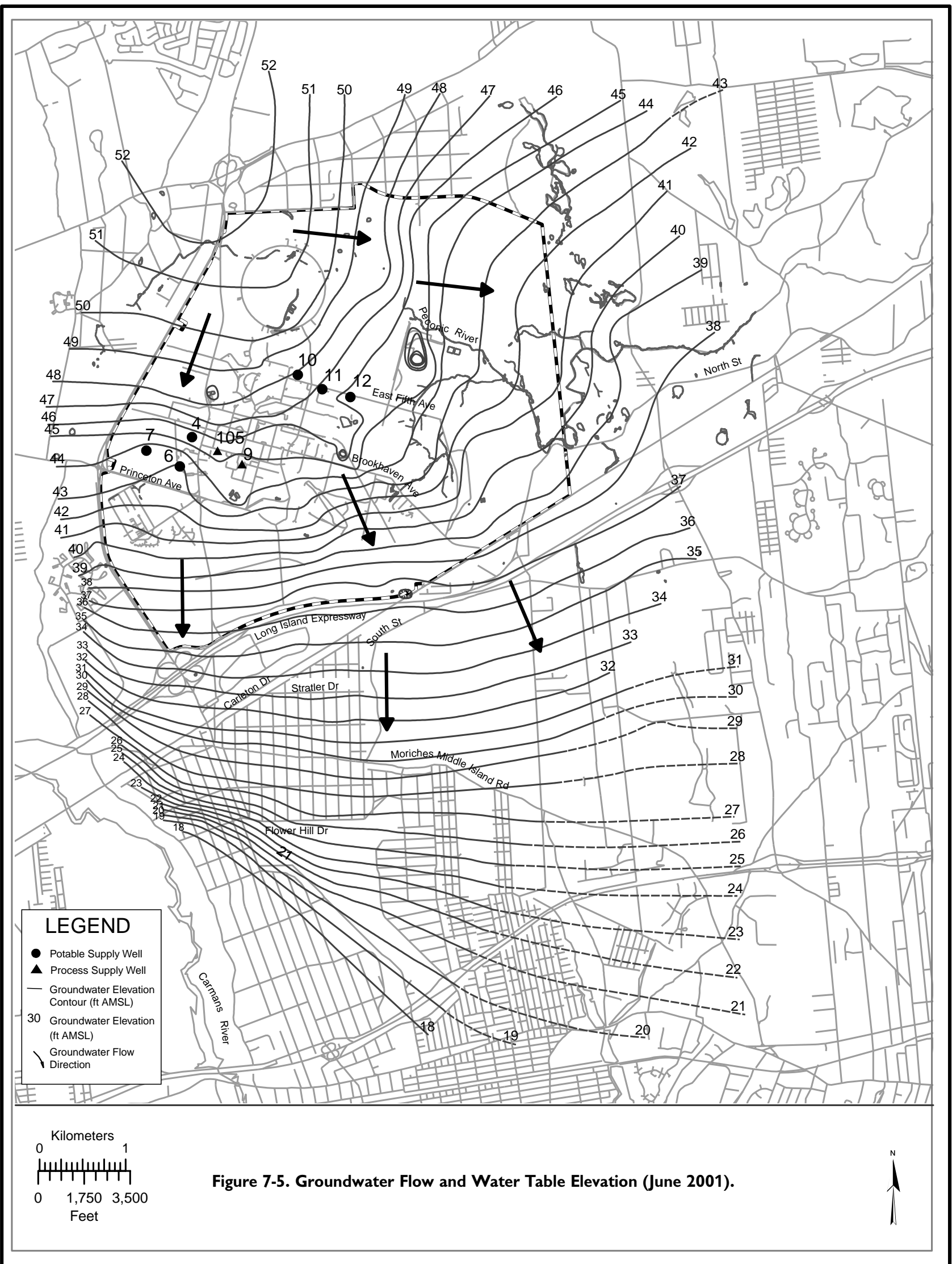




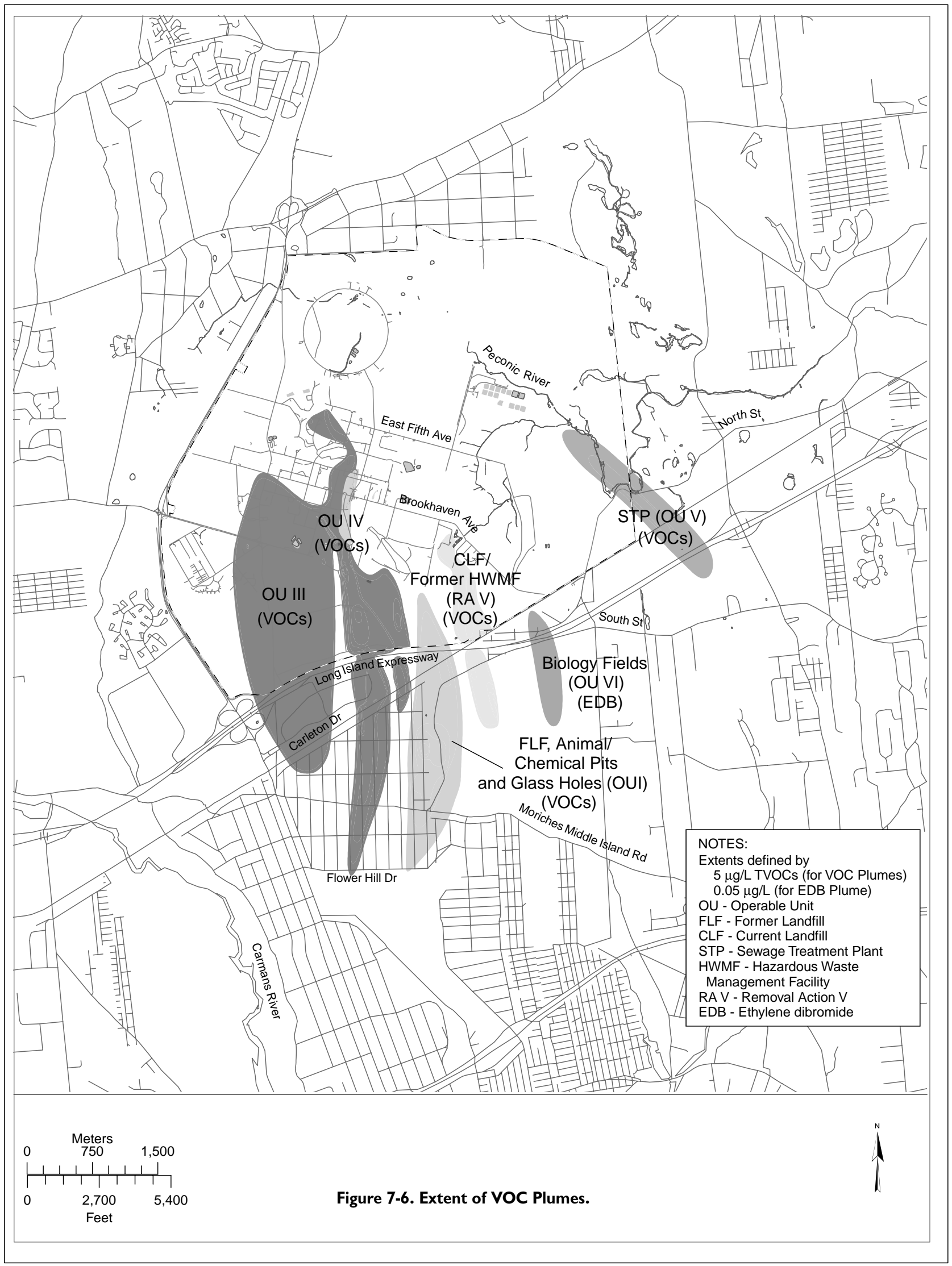




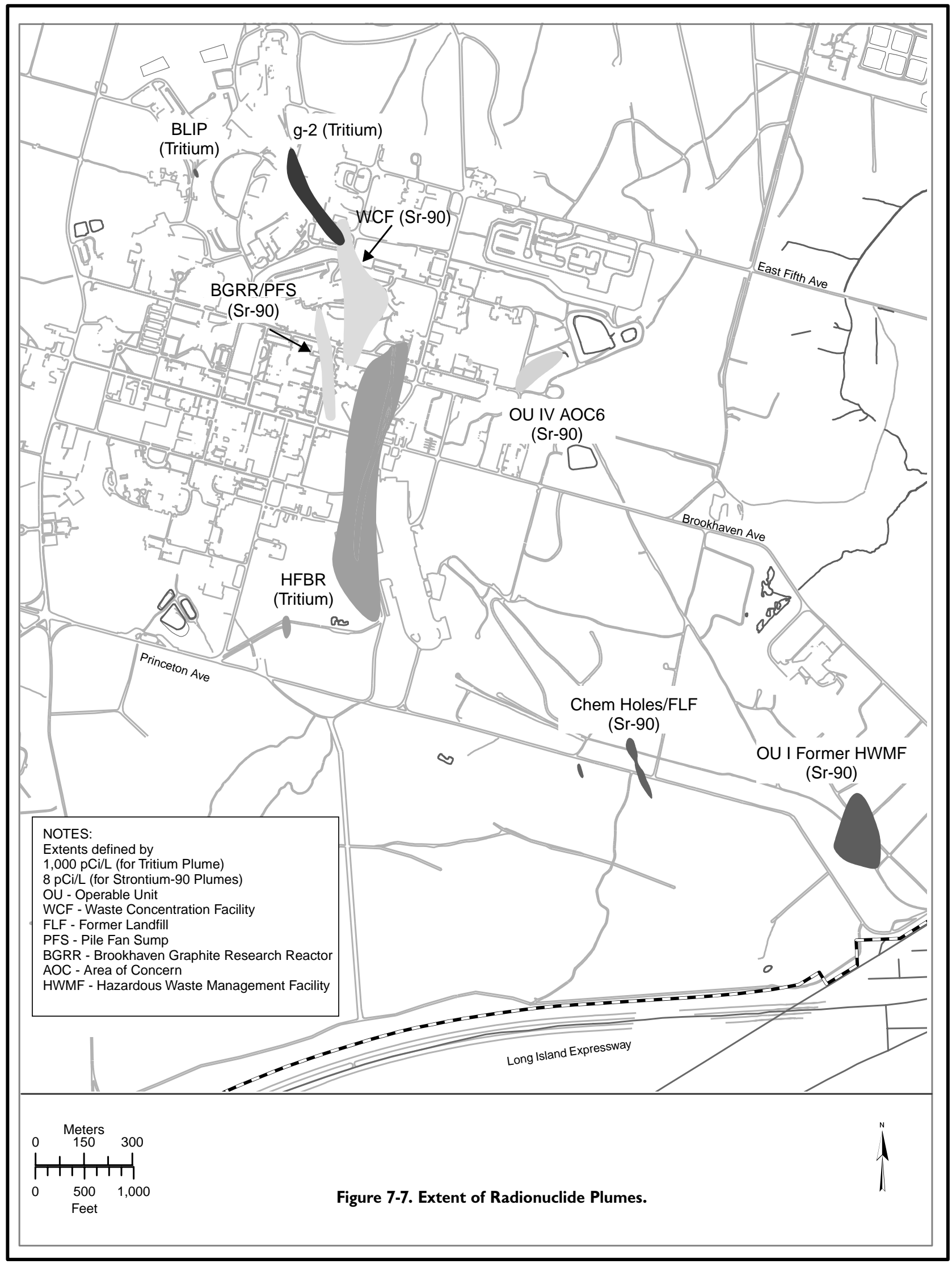


supply wells to known or suspected groundwater contamination plumes and source areas, BNL conducts a supplemental potable supply well monitoring program. Results of the SWDArequired monitoring are described in Chapter 3. Supplemental monitoring of the potable and process supply wells in 2001 included VOCs and radiological parameters. During 2001, the BNL potable water system fully complied with all drinking water requirements. To better understand the geographical source of BNL's drinking water and to identify potential sources of contamination within these geographical areas, BNL prepared the report titled Source Water Assessment for Drinking Water Supply Wells (Bennett et al. 2000). The source water assessment is designed to serve as a management tool in further protecting the sole source aquifer system underlying the BNL site.

\subsubsection{Radiological Results}

Potable well water was sampled and analyzed for gross alpha and gross beta activity, tritium, and strontium-90; the results are listed in Table 7-1. In addition, tap water samples were collected daily from Building 490 (the Analytical Services Laboratory) and analyzed for gross alpha and beta activity and tritium. Nuclidespecific gamma spectroscopy was also performed for potable well samples, supplementing the requirements of the SDWA, which does not require this analysis unless gross beta activity exceeds $50 \mathrm{pCi} / \mathrm{L}$. Average gross activity and tritium levels in the potable water wells were

Table 7-1. Potable and Process Well Radiological Analytical Results.

\begin{tabular}{|c|c|c|c|c|c|}
\hline $\begin{array}{l}\text { Potable } \\
\text { Well ID(a) }\end{array}$ & & $\begin{array}{l}\text { Gross Alpha } \\
\quad(\mathrm{pCi} / \mathrm{L})\end{array}$ & $\begin{array}{l}\text { Gross Beta } \\
\qquad(\mathrm{pCi} / \mathrm{L})\end{array}$ & $\begin{array}{l}\text { Tritium } \\
(\mathrm{pCi} / \mathrm{L})\end{array}$ & $\begin{array}{l}\text { Sr-90 } \\
(\mathrm{pCi} / \mathrm{L})\end{array}$ \\
\hline 4 (FD) & Value & $<0.8$ & $<2.2$ & $<315$ & $<0.8$ \\
\hline \multirow[t]{3}{*}{$6(\mathrm{FF})$} & $\mathrm{N}$ & 4 & 4 & 4 & 4 \\
\hline & Max. & $1.7 \pm 0.6$ & $3.0 \pm 1.4$ & $<306$ & $<0.8$ \\
\hline & Avg. & $0.6 \pm 0.6$ & $0.8 \pm 1.5$ & $-17 \pm 27$ & $<0.8$ \\
\hline \multirow[t]{3}{*}{$7(\mathrm{FG})$} & $\mathrm{N}$ & 5 & 5 & 5 & 5 \\
\hline & Max. & $1.4 \pm 0.6$ & $1.8 \pm 1.2$ & $<315$ & $<0.8$ \\
\hline & Avg. & $0.8 \pm 0.5$ & $1.2 \pm 0.4$ & $-62 \pm 83$ & $<0.8$ \\
\hline \multirow[t]{3}{*}{$11(\mathrm{FP})$} & $\mathrm{N}$ & 4 & 4 & 4 & 4 \\
\hline & Max. & $<0.8$ & $<2.2$ & $<300$ & $<0.8$ \\
\hline & Avg. & $0.1 \pm 0.3$ & $0.8 \pm 0.6$ & $54 \pm 38$ & $<0.8$ \\
\hline \multirow[t]{3}{*}{$12(F Q)$} & $\mathrm{N}$ & 7 & 7 & 7 & 7 \\
\hline & Max. & $2.5 \pm 0.7$ & $3.1 \pm 1.5$ & $<315$ & $<0.8$ \\
\hline & Avg. & $0.4 \pm 0.8$ & $1.9 \pm 0.5$ & $69 \pm 65$ & $<0.8$ \\
\hline Tap Water ${ }^{(b)}$ & $\mathrm{N}$ & 243 & 243 & 243 & NS \\
\hline Bldg 490 & Max. & $8.4 \pm 3.1$ & $13.0 \pm 5.5$ & $394 \pm 230$ & \\
\hline$(\mathrm{FN})$ & Avg. & $2.4 \pm 0.2$ & $3.6 \pm 0.4$ & $-5 \pm 15$ & \\
\hline \multicolumn{2}{|l|}{ SDWA Limit } & $15^{\text {(c) }}$ & $50^{(d)}$ & 20,000 & 8 \\
\hline \multicolumn{6}{|l|}{ Notes: } \\
\hline \multicolumn{6}{|c|}{ See Figure 7-5 for well locations. } \\
\hline \multicolumn{6}{|c|}{ No anthropogenic gamma-emitting radionuclides were detected in samples collected from these wells in 2001} \\
\hline \multicolumn{6}{|c|}{$\mathrm{N}=$ Number of samples collected. } \\
\hline \multicolumn{6}{|c|}{ NS = Not sampled for this analyte. } \\
\hline \multicolumn{6}{|c|}{$\begin{array}{l}\text { (b)The gross activity values for FN are elevated compared with the other potable wells due to differences in the analytical procedure (smaller sample } \\
\text { volumes and shorter counting times) used to obtain the activity values. }\end{array}$} \\
\hline \multicolumn{6}{|c|}{ (c)Excluding radon and uranium. } \\
\hline \multicolumn{6}{|c|}{ (d)Screening level above which analysis for individual radionuclides is required. } \\
\hline Potable Well\#1 & ut down & atomolod d ring & ihlog & (a) & \\
\hline
\end{tabular}


consistent with those of typical background water samples. Neither strontium-90 nor any manmade gamma-emitting radionuclides were observed above the minimum detection limit (MDL) in any of the potable water samples.

\subsubsection{Nonradiological Results}

Samples collected from supply wells $6,7,11$, and 12 were analyzed for VOCs following EPA Standard Method 624. (Note: Well 4 was out of service during 2001. Well 10 was used infrequently during 2001, and was only sampled under the compliance monitoring program described in Chapter 3.) This method tests for 38 organic compounds, including halogenated and aromatic hydrocarbons. The only parameter detected above the MDL was chloroform, found once during the year in both wells 7 and 12 at trace levels $(<2 \mu \mathrm{g} / \mathrm{L})$. The chloroform concentrations were below the ambient water quality standard of $7 \mu \mathrm{g} / \mathrm{L}$ and well below the drinking water standard of $80 \mu \mathrm{g} / \mathrm{L}$.

\subsection{ENVIRONMENTAL SURVEILLANCE PROGRAM}

BNL's Environmental Surveillance Program includes groundwater monitoring at active research facilities (e.g., research reactor areas, accelerator beam stop and target areas, greenhouse areas) and support facilities (e.g., fuel storage facilities and water treatment facilities). During 2001, 120 groundwater surveillance wells were monitored during 350 individual sampling events. All wells sampled during 2001 are listed in Appendix E. Results for these programs are summarized below. For detailed descriptions and maps related to groundwater monitoring in the Environmental Surveillance Monitoring Program, refer to the 2001 BNL Groundwater Status Report (BNL 2002b).

\subsubsection{Research Facilities}

\subsubsection{Alternating Gradient Synchrotron Complex}

Activated soils have been created near a number of Alternating Gradient Synchrotron experimental areas as the result of secondary particles (primarily neutrons) produced at beam targets and beam stops. Radionuclides, such as tritium and sodium-22, have been produced by the interaction of these secondary particles with the soils that surround the experimental areas. Furthermore, historical surface spills and discharges of solvents to cesspools and recharge basins near the AGS have contaminated soils and groundwater with VOCs. VOC contamination is monitored under the ER Program's OU III Central Areas Project (see Section 7.6.3).

During 2001, 44 groundwater wells were monitored to evaluate groundwater quality near potential soil activation areas within the AGS Complex (e.g., Building 912, AGS Booster Beam Stop, 914 Transfer Tunnel, g-2 experimental area, E-20 Catcher, former U-Line Target, and the new J-10 Beam Stop). Following the installation of thirty-nine new wells in the AGS area during 1999-2000, BNL detected three tritium plumes (i.e., groundwater with tritium concentrations greater than the drinking water standard of $20,000 \mathrm{pCi} / \mathrm{L}$ ). These plumes originated from activated soil shielding at the g- 2 experimental area, the former U-Line area, and the Former E-20 Catcher region of the AGS Complex (see Figure 7-8). Following these discoveries, BNL installed impermeable caps over the soil activation areas to prevent rainwater from infiltrating the soil and leaching tritium into the groundwater. Monitoring conducted during 2001 showed that these caps have effectively reduced tritium concentrations to below the drinking water standard at the former U-Line and former E-20 Catcher areas. However, tritium continues to be detected at concentrations above the drinking water standard downgradient of the $\mathrm{g}-2$ and BLIP facilities (Figure 7-8).

g-2 Experimental Area. In November 1999 , monitoring wells approximately 250 feet downgradient of the g- 2 experimental area detected the presence of tritium and sodium-22 in groundwater. A sample from well 054-67 collected in October 1999 had a tritium concentration of 41,700 pCi/L. A groundwater investigation conducted during November and December 1999 revealed a narrow tritium plume of approximately 20 to 30 feet wide and 250 to 300 feet long (see plume map presented 


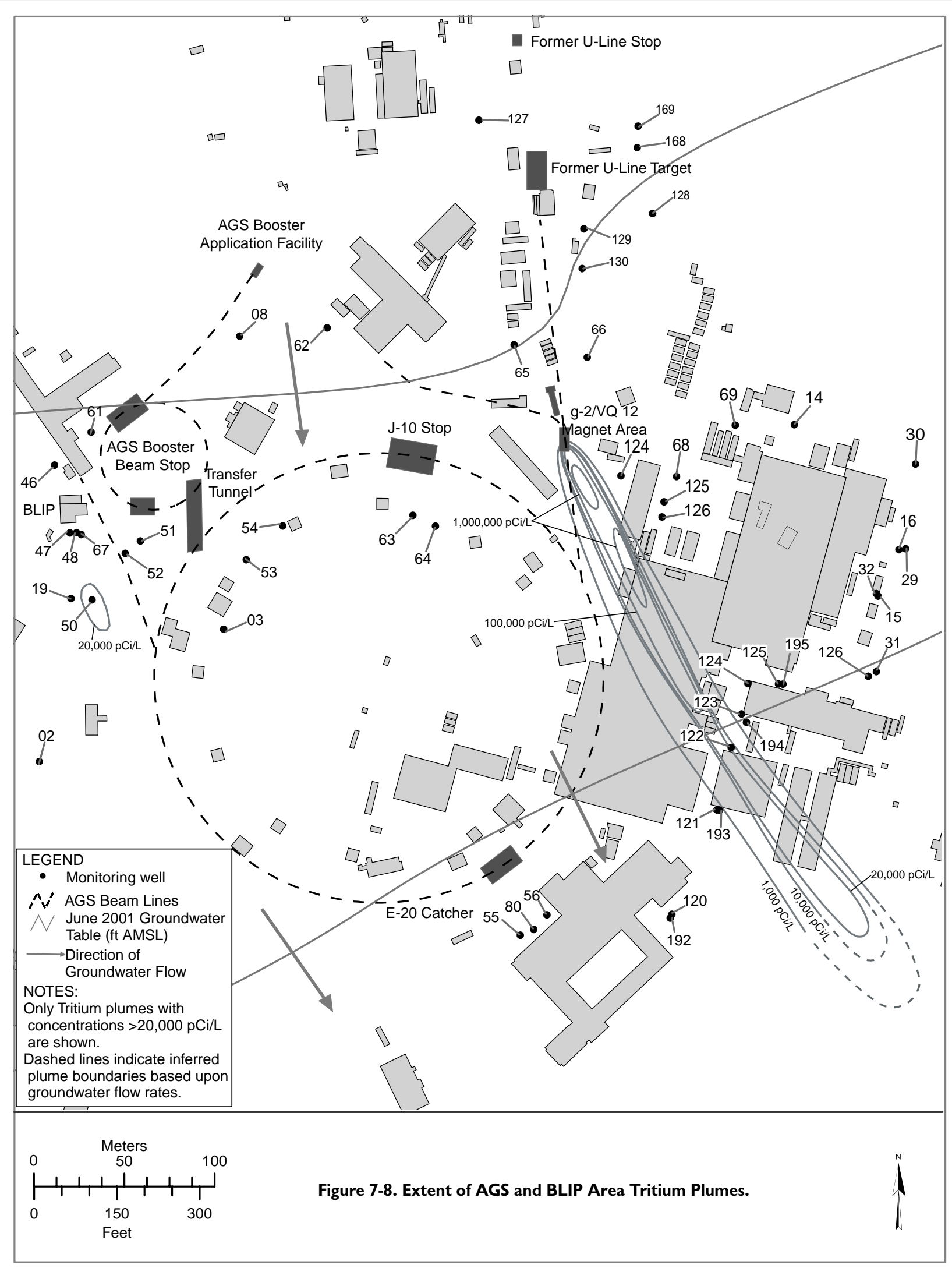


in BNL 2000a). The maximum radionuclide concentrations were detected in temporary well 054-116, approximately 70 feet downgradient of the $\mathrm{g}-2$ beam line, with a tritium concentration of $1,800,000 \mathrm{pCi} / \mathrm{L}$ and sodium-22 concentration of $60 \mathrm{pCi} / \mathrm{L}$. (Note: The drinking water standard for sodium-22 is $400 \mathrm{pCi} / \mathrm{L}$.)

Following this discovery, an investigation into the source of the contamination revealed that the tritium originated from activated soil shielding adjacent to the g-2 experiment's VQ12 Magnet. In December 1999, an impermeable Gunite $^{\mathrm{TM}}$ cap was installed over the soil activation area to prevent rainwater infiltration and the continued leaching of radionuclides out of the soil and into the groundwater. In September 2000 , the activated soil shielding and the associated tritium plume were designated as "Sub-Area of Concern 16T." Following this designation, DOE agreed to prepare an Engineering Evaluation/Cost Analysis (EE/CA) to evaluate the adequacy of the corrective actions taken to date, and the need for further actions. During 2001, BNL conducted additional characterization work designed to obtain the necessary plume concentration and position data required to prepare the $\mathrm{EE} / \mathrm{CA}$.

In February 2001, BNL installed eight temporary wells to monitor this plume. The effort focused on two main areas, the area just west of Building $912 \mathrm{~A}$ and the area just east of Building 912. The results from the temporary well samples taken west of Building 912A indicated tritium concentrations up to 170,000 $\mathrm{pCi} / \mathrm{L}$. The results from the temporary well samples collected east of Building 912 indicated tritium concentrations up to $67,500 \mathrm{pCi} / \mathrm{L}$. Based on these results, the leading edge of the g-2 tritium plume was found to be situated east of Building 912, positioned entirely within the shallow portion of the Upper Glacial aquifer. Anticipating that higher levels of tritium would eventually migrate to the east of Building 912 , BNL obtained regulatory agency concurrence that an additional year of monitoring was required before the EE/CA can be finalized. In November 2001, BNL installed nine additional temporary wells. The effort again focused on the same areas west of Building
912A and east of Building 912. The results from the temporary well samples taken west of Building 912A indicated tritium concentrations up to $1,820,000 \mathrm{pCi} / \mathrm{L}$. The results from the temporary well samples collected east of Building 912 indicated that the leading edge of the $\mathrm{g}-2$ tritium plume was now approximately 100 feet southwest of the WCF, a distance of approximately 1,000 feet from the VQ-12 source area (Figure 7-8). Tritium concentrations up to $79,500 \mathrm{pCi} / \mathrm{L}$ were observed in a temporary well installed directly east of Building 912, and tritium concentrations up to 25,500 $\mathrm{pCi} / \mathrm{L}$ were detected in a temporary well approximately 100 feet southwest of the WCF. Based on these findings, BNL installed three additional permanent monitoring wells near Building 912A to allow for improved long-term monitoring of the source area. The evaluation of various control/cleanup options for this plume will be completed by early 2003 .

Former E-20 Catcher. During 1999-2000, tritium and sodium-22 were detected at concentrations above their applicable drinking water standards in wells approximately 100 feet downgradient of the former E-20 Catcher. The location of the E-20 Catcher is shown in Figure $7-8$. The highest levels of tritium $(40,400 \mathrm{pCi} /$ $\mathrm{L})$ and sodium-22 $(704 \mathrm{pCi} / \mathrm{L})$ were found in temporary well 064-65. In April 2000, a temporary impermeable cap was installed over the E-20 Catcher soil activation area to prevent rainwater infiltration and the continued leaching of radionuclides out of the soils and into groundwater. A permanent cap was constructed by October 2000 .

During 2001, all tritium and sodium-22 concentrations were found to be well below drinking water standards, with a maximum tritium concentration of $2,070 \mathrm{pCi} / \mathrm{L}$ and a maximum sodium-22 concentration of $163 \mathrm{pCi} / \mathrm{L}$. The reduction in tritium and sodium-22 concentrations since the impermeable cap was constructed indicates that the cap has been effective in preventing additional rainwater infiltration into the activated soils that surround that portion of the AGS tunnel.

Former U-Line Target and Stop Areas. In 1999, BNL installed new monitoring wells 
downgradient of the former U-Line target area to evaluate whether residual activated soil shielding was affecting groundwater quality. The locations of the former U-Line target and beam stop areas are shown on Figure 7-8. Subsequent monitoring found low levels of tritium and sodium-22, but at concentrations well below the applicable drinking water standards. In early 2000, BNL installed four Geoprobe ${ }^{\mathrm{TM}}$ wells downgradient of the former U-Line beam stop, which is approximately 200 feet north of the target area. Tritium was detected at concentrations up to $71,600 \mathrm{pCi} / \mathrm{L}$. Sodium-22 was not detected in any of the samples. In May 2000, a temporary impermeable cap was installed over the U-Line stop soil activation area. By October 2000 , a permanent cap was constructed and two additional permanent wells were installed to provide improved long-term monitoring of this source area.

During 2001, low levels of tritium and sodium-22 continued to be detected in wells downgradient of the former U-Line target and stop areas, but at concentrations below drinking water standards. The highest tritium concentration during 2001 was detected approximately 400 feet downgradient of the stop area, in well 054-128 (6,330 pCi/L). The highest sodium-22 concentration was detected approximately 550 feet downgradient of the target area, in well 054-69 (26.6 pCi/L). Low-level contamination from the former U-Line area reaches to well 055-32, approximately 1,000 feet downgradient of the target area. There, the maximum tritium and sodium-22 concentrations were $3,820 \mathrm{pCi} / \mathrm{L}$ and $7.5 \mathrm{pCi} / \mathrm{L}$, respectively. As noted earlier, the low levels of tritium and sodium-22 detected in two of the nearby g-2 beam stop monitoring wells (054-67 and 054-68) are likely to have originated from the former U-Line target area.

Although low levels of tritium and sodium22 continue to be detected in groundwater downgradient of the former U-Line target, these concentrations are well below drinking water standards. Furthermore, the significant decrease in tritium concentrations since 2000 indicates that the impermeable cap has been effective in stopping rainwater infiltration into the residual activated soils surrounding the beam stop.

\subsubsection{Brookhaven Linac Isotope Producer} (BLIP)

The BLIP facility is at the southern end of the Linac (Figure 7-8). When the BLIP is operating, the Linac delivers a beam of protons that impinges on a series of eight targets within the BLIP target vessel. During irradiation, activation of the soils immediately outside of the vessel occurs, due to the creation of secondary particles produced at the target.

In February 1998, elevated levels of tritium $(52,000 \mathrm{pCi} / \mathrm{L})$ and sodium-22 (151 pCi/L) were detected in wells downgradient of the BLIP. To prevent rainwater from infiltrating the activated soils below the building, the BLIP building's roof drains were redirected away from the building, paved areas were resealed, and an extensive Gunite $^{\mathrm{TM}}$ cap was installed on three sides of the building. Groundwater monitoring data collected from January 1999 to July 2000 indicated that these corrective actions were highly effective in preventing the release of tritium and sodium-22 from the activated soils surrounding the BLIP target vessel. Tritium and sodium-22 were not detected in samples collected in April 2000.

In June 2000, BNL took an additional protective measure by using an innovative silica grouting technique to reduce the permeability of the activated soils. Soon after the activated soils were treated with the silica grout injection process, significant increases in tritium and sodium-22 concentrations were observed in groundwater samples. In early July 2000 , samples collected from wells within 40 feet of the target area, downgradient of the BLIP, contained tritium up to $5,700 \mathrm{pCi} / \mathrm{L}$. By October 2000 , tritium concentrations increased to 56,500 $\mathrm{pCi} / \mathrm{L}$. In accordance with the BNL Groundwater Protection Contingency Plan (BNL 2000b), $\mathrm{BNL}$ and DOE notified the regulatory agencies of this situation and increased the sampling frequency for the wells. The maximum sodium22 concentration was $299 \mathrm{pCi} / \mathrm{L}$, detected in well 064-67 on December 1, 2000. By December 21, 2000 , tritium concentrations dropped to below the $20,000 \mathrm{pCi} / \mathrm{L}$ drinking water standard in the wells immediately downgradient of the BLIP. Concurrently, as the slug of tritium continued to migrate downgradient of the BLIP, concentra- 
tions in well $064-50$ increased to $20,000 \mathrm{pCi} / \mathrm{L}$ by December 28,2000 . This well is approximately 150 feet downgradient of the BLIP.

During 2001, tritium concentrations in wells located 40 feet downgradient of the BLIP did not exceed $7,000 \mathrm{pCi} / \mathrm{L}$. Tritium concentrations in well $064-50$ reached a maximum of $60,800 \mathrm{pCi} / \mathrm{L}$ in July 2001, then declined to less than $20,000 \mathrm{pCi} / \mathrm{L}$ by November 2001. The pattern of decreasing tritium concentrations in wells directly downgradient of the BLIP indicates a short-term (pulsed) tritium release and that the plume has dissipated quickly in the aquifer. There was good correlation between modeled and observed tritium concentrations in well 064-50 during 2001, and it is expected that peak tritium concentrations in the plume will drop below the drinking water standard at all locations by September 2002.

Although the grouting process had a shortterm impact on groundwater quality, it is believed that the process will provide long-term benefits in reducing the permeability of the contaminated soil shielding. Information on the potential for displacing residual pore water will be used to improve this innovative grouting technology.

\subsubsection{Relativistic Heavy Ion Collider}

Within the RHIC facility, there are three areas where low levels of radionuclides could be produced in the soils outside of the collider tunnel. The first area contains two beam stops that are located at the 10 o'clock position of the ring, the second contains two collimators that are located at the 8 o'clock region, and the third is a beam stop located at the 6 o'clock position. Secondary particles created at the internal beam stop and collimator areas have the potential to activate the soils immediately surrounding those areas. Even though the predicted soil activation is expected to be very small, BNL installed impermeable caps over these areas as a precautionary measure. Thirteen monitoring wells are used to provide a means of verifying that the engineered (i.e., impermeable caps) and operational controls designed into the RHIC beam stops and collimators are effective in protecting groundwater quality.

Groundwater samples were collected from the thirteen RHIC monitoring wells on a semi- annual schedule during 2001. Surface water samples were also collected from the Peconic River both upstream and downstream of the beam stop area. As in previous years, no tritium or sodium-22 was detected in any of the groundwater or surface water samples.

\subsubsection{Brookhaven Medical Research Reactor}

During a 1997 evaluation of groundwater quality near the BMRR, low levels of tritium (up to $11,800 \mathrm{pCi} / \mathrm{L}$ ) were detected in the groundwater downgradient of the reactor building. After inspecting the facility and reviewing historical records, BNL concluded that the tritium might have originated from past discharges of small amounts of BMRR primary cooling water to a basement floor drain and sump system that leaked. Although the last discharge of primary cooling water to the floor drain system occurred in 1987, the floor drains continued to be used for secondary (nonradioactive) cooling water until 1997. The infiltration of this water may have promoted the movement of residual tritium from the soils surrounding the floor drain piping system to the groundwater. The floor drains were permanently sealed in 1998 to prevent any future accidental releases to underlying soils.

During 2001, tritium concentrations continued to be well below the drinking water standard of $20,000 \mathrm{pCi} / \mathrm{L}$. Detectable levels of tritium were observed in all three downgradient wells, with the maximum value of $1,550 \mathrm{pCi} / \mathrm{L}$ in well $084-27$. As in past years, no other reactor-related radionuclides were detected in the groundwater. Compared to the initial monitoring results from 1997, tritium concentrations in groundwater have shown a steady decline. Discontinuing the use of the BMRR's floor drains has apparently helped to reduce the movement of residual tritium from the soils surrounding the floor drain piping system to the groundwater.

\subsubsection{Surveillance Monitoring of Support Facilities}

\subsubsection{Sewage Treatment Plant Area}

As described in Chapters 1 and 3, the Sewage Treatment Plant processes sanitary sewage from BNL facilities. Approximately 15 percent of the treated effluent released to the 
STP's sand filter beds either evaporates or directly recharges to groundwater; the remaining water is discharged to the Peconic River.

The STP ground water surveillance program is designed to evaluate whether current operations are affecting groundwater quality. During 2001, six wells were used to monitor groundwater quality in the filter bed area and three wells were monitored in the holding pond area. Groundwater quality impacts resulting from historical STP discharges are currently being monitored as part of the OU V monitoring program, using wells that are at the site boundary and off-site areas (see Section 7.6.5).

Groundwater monitoring results for 2001 indicate that STP operations are not significantly affecting groundwater quality and that BNL's administrative and engineered controls designed to prevent the discharge of chemicals and radionuclides to the sanitary system have been highly effective.

Radionuclides. Radioactivity levels in samples collected from the STP wells were generally typical of ambient (background) levels, with the exception of low levels of tritium detected in several wells during 2001. In the filter bed area, one sample from well 039-08 had a tritium concentration of $392 \mathrm{pCi} / \mathrm{L}$. The drinking water standard for tritium is $20,000 \mathrm{pCi} / \mathrm{L}$. Slightly higher levels of tritium (up to $1,420 \mathrm{pCi} /$ L) were detected in well 039-89, downgradient of the holding ponds. Because the ponds have not been used recently to hold tritiated waste water and the wells are also downgradient of the filter bed area, it is likely that the tritium originated from past water releases to the filter beds. An elevated gross alpha concentration of $23.8 \mathrm{pCi} / \mathrm{L}$ was detected in the June 2001 sample from well 039-86. This value exceeds the 15 $\mathrm{pCi} / \mathrm{L}$ standard. This value was inconsistent with previous results, and the well was re-sampled in July to confirm the June sample result. Analysis of the July sample indicated a gross alpha value of less than the minimum detectable level of 0.7 $\mathrm{pCi} / \mathrm{L}$. It is likely that the elevated gross alpha concentration in the June sample was due to an erroneous measurement or cross-contamination of the sample. If the July groundwater sample had confirmed the elevated gross alpha result,
BNL would have conducted radionuclide-specific analyses to identify possible alpha-emitting radionuclides.

Volatile Organic Compounds, Metals, and Anions. During 2001, all water quality readings and most metal concentrations were below the applicable New York State Ambient Water Quality Standards (NYS AWQS). Sodium was detected at concentrations slightly above the NYS AWQS of $20 \mathrm{mg} / \mathrm{L}$ in three filter bed area wells. Wells 039-07, 039-08, and 039-86 had maximum sodium concentrations of $28.5 \mathrm{mg} / \mathrm{L}$, $29.3 \mathrm{mg} / \mathrm{L}$, and $30.5 \mathrm{mg} / \mathrm{L}$, respectively. One sample from well 039-87 had an aluminum concentration of $0.11 \mathrm{mg} / \mathrm{L}$, which is slightly above the $0.1 \mathrm{mg} / \mathrm{L}$ standard. Although low-level nitrates were detected in most STP area wells, with a maximum concentration of $6.5 \mathrm{mg} / \mathrm{L}$ detected in monitoring well 039-08 (in the filter bed area), these concentrations were below the NYS AWQS of $10 \mathrm{mg} / \mathrm{L}$. No VOCs were detected in any of the monitoring wells.

\subsubsection{Water Treatment Plant}

At the direction of the New York State Department of Environmental Conservation, five shallow Upper Glacial aquifer surveillance wells were installed at the Water Treatment Plant (WTP) in 1993 to assess potential leaching of iron from the plant's recharge basin (Basin HX) into the groundwater. Naturally high levels of iron in the groundwater pumped for potable and process supply is removed at the WTP, and the precipitated iron is discharged to the recharge basin during filter backflushing operations.

The groundwater monitoring wells in the WTP's recharge basin area were sampled in June 2001. Analytical results indicate that anion and metal concentrations (including iron) were below the applicable NYS AWQS. Since the beginning of the WTP groundwater monitoring program in 1992, iron has rarely been detected above the typical detection limit of $0.075 \mathrm{mg} / \mathrm{L}$ in groundwater near Basin HX, and has never exceeded the $0.3 \mathrm{mg} / \mathrm{L}$ water quality standard. Following anticipated 2002 changes to BNL's SPDES permit, the Laboratory will discontinue monitoring iron levels in WTP discharges to Basin HX. Concurrent with this change in 
SPDES permit requirements, BNL will discontinue the collection of groundwater samples from wells near the basin. BNL will maintain the wells for the collection of water level measurements and for potential future collection of water samples to periodically verify water quality.

\subsubsection{Motor Pool Facility}

Building 423 serves as the site Motor Pool, where BNL's fleet vehicles are repaired and refueled. Gasoline is stored in two 8,000-gallon capacity underground storage tanks (USTs), and waste oil is stored in one 500-gallon capacity underground storage tank. Although the USTs and associated distribution lines meet Suffolk County Article 12 requirements for secondary containment, leak detection, and high-level alarms, BNL initiated a groundwater monitoring program in 1996 as a means of verifying that groundwater quality is not being affected by current Motor Pool operations.

Groundwater surveillance at the Motor Pool facility during 2001 continued to indicate that releases from historical operations have impacted groundwater quality. Several activities were conducted and determined that the groundwater contamination came from historical, not current, operations. Monitoring of the leak detection systems and the wells downgradient of the Motor Pool's UST area indicates that the tanks and their associated distribution lines are not leaking. Furthermore, evaluation of current vehicle maintenance operations indicates that all waste oils and used solvents are being properly stored and recycled. Therefore, it is believed that the solvents detected in groundwater originate from historical vehicle maintenance activities at the Motor Pool, and are not related to current operations.

Underground Storage Tank Area. During 2001, no chemicals related to gasoline products benzene, ethylbenzene, toluene, xylenes, or methyl tertiary butyl ether (MTBE) — were detected in groundwater downgradient of the gasoline UST area. The solvent 1,1,1trichloroethane (TCA) was detected in both downgradient wells, but at concentrations below the NYS AWQS of $5 \mu \mathrm{g} / \mathrm{L}$. The TCA contamination is probably due to historical parts degreasing operations at the Motor Pool facility. Wells 102-05 and 102-06 were also tested for the presence of floating petroleum hydrocarbons. As in previous years, no floating product was observed.

Motor Pool Building. During 2001, TCA was detected in all four downgradient wells at concentrations ranging from $6.0 \mu \mathrm{g} / \mathrm{L}$ to $77.3 \mu \mathrm{g} /$ L. In well 102-12, 1,1-dichloroethane (DCA) was detected at concentrations up to $14.5 \mu \mathrm{g} / \mathrm{L}$. The NYS AWQS for TCA and DCA is $5 \mu \mathrm{g} / \mathrm{L}$. The gasoline additive MTBE was detected in all four wells, with a maximum observed concentration of $73.8 \mu \mathrm{g} / \mathrm{L}$. The NYS standard for MTBE is $10 \mu \mathrm{g} / \mathrm{L}$. It is believed that the TCA and DCA originate from historical vehicle maintenance/part degreasing operations. MTBE has been used as a gasoline additive since 1977. This compound has been detected at low levels (generally $<10 \mu \mathrm{g} / \mathrm{L}$ ) in the Motor Pool wells since the monitoring program began in 1996.

\subsubsection{Upton Service Station}

Building 630 is a commercial automobile repair and gasoline station for the BNL site. Gasoline is stored in two 8,000-gallon capacity and one 6,000-gallon capacity USTs, and waste oil is stored in one 500-gallon capacity UST. Although the storage tanks and associated distribution lines meet Suffolk County Article 12 requirements for secondary containment, leak detection, and high-level alarms, BNL initiated a groundwater monitoring program in 1996 as a means of verifying that groundwater quality is not being affected by current operations.

Groundwater quality in the Service Station area has been impacted by historical small-scale spills of oils, gasoline, and solvents, and by carbon tetrachloride contamination associated with a nearby underground storage tank that was used as part of an experiment conducted in the $1950 \mathrm{~s}$. The carbon tetrachloride contamination is being remediated as part of the Laboratory's Environmental Restoration Program (see Section 7.6.3.1). During 2001, carbon tetrachloride continued to be observed in Service Station monitoring wells. The maximum carbon tetrachloride concentration was $1,621 \mu \mathrm{g} / \mathrm{L}$, observed in well 085-16. These concentrations are less than those observed in 2000, when carbon tetrachloride concentrations in wells near 
the Service Station approached 4,400 $\mu \mathrm{g} / \mathrm{L}$. The NYS AWQS for carbon tetrachloride is $5 \mu \mathrm{g} / \mathrm{L}$.

Compared to monitoring results for 2000 (when high levels of petroleum hydrocarbonrelated compounds were detected in several downgradient wells), only low levels of xylenes $(8.3 \mu \mathrm{g} / \mathrm{L}$ total xylenes) were detected during 2001. Low levels of the solvent tetrachloroethylene (up to $9.8 \mu \mathrm{g} / \mathrm{L}$ ) were also detected. (The NYSAWQS for these compounds is $5 \mu \mathrm{g} / \mathrm{L}$.) The gasoline additive MTBE continued to be detected in wells 085-236 and 085-237. MTBE levels increased from approximately $5 \mu \mathrm{g} / \mathrm{L}$ in 2000 , to a maximum concentration of $64 \mu \mathrm{g} / \mathrm{L}$ in 2001. MTBE has been in use as a gasoline additive since 1977, and it is likely that the MTBE detected in the Service Station wells is related to historical small-scale spillage during vehicle refueling or maintenance operations. The NYS AWQS for MTBE is $10 \mu \mathrm{g} / \mathrm{L}$.

\subsubsection{Major Petroleum Facility}

The Central Steam Facility (CFS) supplies steam for heating to all major facilities of the Laboratory through an underground distribution system. The Major Petroleum Facility (MPF) is the storage area for most fuels used at the Central Steam Facility. Five shallow Upper Glacial aquifer wells monitoring the MPF were initially installed as part of the licensing requirements for this facility, and are screened across the water table so that potential free product (oil floating on top of the groundwater) can be detected. Three additional surveillance wells were installed in early 2000 to improve monitoring of the MPF area. Additional surveillance wells are in the CSF area. The CSF area wells are used to monitor groundwater contamination resulting from a 1977 leak of approximately 25,000 gallons of Alternative Liquid Fuel (a mixture of fuel oil and spent solvent). Contaminated soils and groundwater near the 1977 spill site have been undergoing active remediation since 1997 (see Section 7.6.4.1).

Semivolatile Organic Compounds. In accordance with the special license conditions for the MPF, groundwater samples are analyzed semi-annually for the polynuclear aromatic and base neutral compounds covered by EPA Test Method 625. During 2001, none of the target compounds were detected. The MPF wells were tested monthly for the presence of floating petroleum hydrocarbons. As in previous years, no floating petroleum product was observed.

\subsubsection{Waste Management Facility}

In 1997, BNL began operating its new Waste Management Facility (WMF), designed and operated in a manner that meets all applicable federal, state, and local environmental protection requirements. Nevertheless, BNL established a voluntary groundwater monitoring program as a secondary means of verifying the effectiveness of the facility's administrative and engineered controls. The WMF is monitored by eight shallow Upper Glacial aquifer wells. Groundwater monitoring results for 2001 are consistent with previous monitoring, and continue to show that WMF operations are not impacting groundwater quality.

Volatile Organic Compounds, Metals, and Anions. In 2001, all water quality and most metals concentrations were below the applicable NYS AWQS. As in past years, sodium was detected at concentrations above the NYS AWQS of $20 \mathrm{mg} / \mathrm{L}$ in upgradient well 055-03 (at a maximum concentration of $59.1 \mathrm{mg} / \mathrm{L}$ ). Low levels of 1,1,1-trichloroethane (TCA) and chloroform continue to be detected in several wells, but at concentrations below NYS AWQS. The gasoline additive MTBE was detected in well 056-22 at concentrations up to $6.2 \mu \mathrm{g} / \mathrm{L}$. The NYS water quality standard for MTBE is 10 $\mu \mathrm{g} / \mathrm{L}$. There are no reports of gasoline spillage at the WMF or nearby areas; therefore, a source for the MTBE has not been identified.

In 2000 , TCA $(153 \mu \mathrm{g} / \mathrm{L})$ and DCE $(35 \mu \mathrm{g} /$ L) had been detected in upgradient well 066-07. During 2001, TCA concentrations in this well dropped to a maximum of $2.6 \mu \mathrm{g} / \mathrm{L}$, and DCE was not detected in any of the samples. It is believed that the TCA and DCE contamination originated from historical releases from Building 830. In late 2000 and early 2001, BNL conducted an investigation into current and historical operations at Building 830 (see Section 
7.5.2.10). Although TCA had been used during metal cleaning operations at Building 830, BNL could not identify a continuing source for the contamination. It is unlikely that contamination from this facility will significantly affect groundwater quality in the WMF area.

Radionuclides. Radioactivity levels in samples collected from the WMF wells were generally typical of ambient (background) levels. No Laboratory-related radionuclides were detected in the WMF wells during 2001.

\subsubsection{Biology Department Greenhouse Area}

The Biology Department facility includes 11 greenhouses where various types of plants are grown for biological research. Eight of the greenhouses have dirt floors and three have concrete floors. Pesticides and fertilizers have been routinely used in the greenhouses. Records indicate that copper sulfate was applied to the dirt floors on an annual basis until the mid-1980s. The pesticide Endosulphan II was detected in soil samples collected from a dry well within Greenhouse 10. Analysis of groundwater samples collected to date does not indicate that greenhouse operations have affected groundwater quality.

In September 2001, the greenhouse area wells were sampled and tested for pesticides, metals, and anions. Pesticides were not detected, and all water quality concentrations were below the applicable NYS AWQS. Sodium was the only metal detected at a concentration above the NYS AWQS of $20 \mathrm{mg} / \mathrm{L}$, with a maximum concentration of $24.3 \mathrm{mg} / \mathrm{L}$ in well 084-36. The detection of low levels of sodium is not uncommon in wells within the developed area of the site, and could be related to road salting operations.

\subsubsection{Shotgun Range}

The BNL Shotgun Range, established in 1974, is used for trap and skeet target shooting by the Brookhaven Employees Recreation Association. The range is in an isolated, wooded area north of the new Waste Management Facility. Clay targets are thrown south from the trap house into an open field that is approximately 200 feet east-west by 400 feet north-south. Although most of the shot falls within the cleared range, shooting from several of the trap line positions deposits some shot in nearby wooded areas.

From 1974 until 2000, the shotgun shells used at the facility typically contained lead pellets. It is estimated that as many as 30,000 shotgun rounds per year have been used at the range. At an average of $1.125 \mathrm{oz}$. per round, as much as 2,100 pounds of lead may have been deposited on the surface of the range annually. To prevent additional deposition of lead, in early 2000 , BNL implemented a rule that allows only steel shot to be used at the range.

Groundwater monitoring data continue to indicate that Shotgun Range operations have not affected groundwater quality. In March of 2001, the groundwater monitoring wells at the Shotgun Range were sampled. All metal concentrations were below the applicable NYS AWQS and were consistent with established background levels. Lead was not detected in any of the groundwater samples.

\subsubsection{Live Fire Range}

The BNL Live-Fire Range consists of a sixposition, 100-yard, bermed, outdoor small arms range. The Live-Fire Range was constructed in 1986 and is immediately north of the BNL Sewage Treatment Plant's filter bed area. The eastern half of the range extends to within 200 feet of the Peconic River. The bullet stop at the range is an earthen berm, and bullets are known to have a typical penetration depth of approximately two to three inches into the berm. The soil of the berm is periodically screened to a depth of approximately one foot. The lead shot recovered during the screening process and the spent brass cartridges are disposed of, off site, by a commercial scrap metal waste handler.

Groundwater monitoring conducted to date does not indicate that range operations are affecting groundwater quality. During 2001, all metal concentrations were below the applicable NYS AWQS and were consistent with established background levels. Lead was not detected in any of the samples.

\subsubsection{Building 830}

In 2000, BNL's groundwater monitoring program for the Waste Management Facility 
detected the presence of the volatile organic compounds TCA and DCE at concentrations that exceed NYS AWQS in background well 066-07, which is near Building 830. TCA and DCE were detected at concentrations as high as $154 \mu \mathrm{g} / \mathrm{L}$ and $34 \mu \mathrm{g} / \mathrm{L}$, respectively. These findings were considered unusual, and resulted in the implementation of the BNL Groundwater Protection Contingency Plan (BNL 2000b). As required by that plan, $\mathrm{BNL}$ and $\mathrm{DOE}$ notified the regulatory agency stakeholders.

Operations within Building 830 started in 1963, when the High Intensity Radiation Development Laboratory was opened. The hot cells and associated laboratories were used to fabricate high-intensity cobalt-60 sources for food irradiation and other programs. In 1970, the Low Dosimetry Facility (currently known as the Gamma Irradiation Facility) was added to the northeast end of the building. This facility included a gamma irradiation pool and a machine shop. Building 830 is currently used by the Environmental Research and Technology Division, and provides analytical and electron microscopy labs and office and administrative space.

Based on an evaluation of current and historical operations in the Building 830 area, the TCA and DCE appear to have originated from historical metal cleaning activities at Building 830. Previous analysis of liquids that were contained in two former underground radioactive liquid waste storage tanks near Building 830 indicated the presence of high levels of both TCA and DCE. The waste lines that lead from Building 830 to the tanks are known to have leaked. While the tanks, exterior piping, and contaminated soils were removed, portions of the piping still remain beneath the building.

During 2001, TCA and DCE concentrations were $<5 \mu \mathrm{g} / \mathrm{L}$ in samples collected from wells 066-07 and 066-08. In February 2001, TCA and DCE concentrations in well 066-09 increased to nearly $80 \mu \mathrm{g} / \mathrm{L}$ and $25 \mu \mathrm{g} / \mathrm{L}$, respectively. All VOC concentrations dropped to $<5 \mu \mathrm{g} / \mathrm{L}$ for the remainder of 2001. To further characterize groundwater quality near Building $830, \mathrm{BNL}$ installed six temporary wells during July 2001. No VOCs were detected in temporary well samples at concentrations greater than the NYS AWQS of $5 \mu \mathrm{g} / \mathrm{L}$ (see BNL 2001c).

The groundwater investigation conducted during 2000-2001 concluded that Building 830 is not a significant or a continuing source of groundwater contamination. This conclusion is consistent with the earlier findings of the OU III Remedial Investigation. It is probable that historic, low-level VOCs releases from Building 830 have been contaminating the groundwater for many years. Very low levels of TCA have been detected in untreated water from nearby potable water supply wells 11 and 12 since the late 1980s. (Note: Water from potable wells 11 and 12 is treated using granular activated carbon filters before it is distributed for use.) Because the Building 830 area lies within the capture zones (or zones of contribution) for these supply wells, it is likely that TCA released from this facility was a contributing source of this contamination. One scenario for the source of the contamination is that some soil contamination went undetected during the exterior pipeline and D-tank removal projects. In 1998, pavement near the leaking D-waste pipes was removed, exposing the underlying soils to several heavy rain events. This may have caused leaching of residual soil contamination.

\subsection{ENVIRONMENTAL RESTORATION GROUND- WATER MONITORING PROGRAM}

The mission of the Environmental Restoration (ER) Groundwater Monitoring Program is to monitor the various contaminant plumes on site and off site, as well as to monitor the progress that the groundwater treatment systems are making toward plume remediation. The information below provides an overview of ER groundwater monitoring and remediation activities for 2001. In this period, a total of 594 groundwater surveillance wells were monitored during 2,389 individual sampling events. All wells sampled during 2001 are listed in Appendix E. Well-specific information on analytical parameters, as well as detailed analytical results for the ER Program, are provided in the 2001 BNL Groundwater Status Report (BNL 2002b).

Maps showing the main VOC and radionuclide plumes are provided as Figures 7-6 and 7-7. 
For each significant contaminant source area and plume described below, specific groundwater contaminant distribution maps are provided. Associated cross-sections showing the vertical distribution or extent of contamination, as well as the hydrogeology for the BNL site and surrounding areas, are also described in the 2001 BNL Groundwater Status Report (BNL 2002b).

\subsubsection{Background Monitoring}

Background groundwater quality for the BNL site is monitored through a network of 13 wells in the northern portion of the site and in off-site areas to the north. The off-site background wells provide information on the chemical and radiological composition of groundwater that has not been affected by activities at BNL. These background data are a valuable reference for comparison with groundwater quality data from areas that have been affected. This well network can also provide warning of any contaminants originating from potential sources located upgradient of the BNL site.

There were no significant detections of VOCs in background wells. Historically, low concentrations of VOCs have been detected in some background wells. All radionuclide concentrations were consistent with natural levels.

\subsubsection{Operable Unit I}

\subsubsection{Former Landfill, Animal/Chemical Pits, and Glass Holes}

The Former Landfill area was initially used by the U.S. Army as a landfill area during World Wars I and II. BNL used the southeast corner of the landfill from 1947 through 1966 for disposal of construction and demolition debris, sewage sludge, chemical and low-level radioactive waste, used equipment, and animal carcasses. From 1960 through 1966, BNL waste, glassware containing chemical and radioactive waste, and animal carcasses containing radioactive tracers were disposed of in shallow pits in an area directly east of the Former Landfill. From 1966 through 1981, BNL disposed of used glassware in shallow pits directly north of these chemical/animal pits. The Former Landfill was capped in 1996 and the Animal/Chemical Pits and Glass Holes were excavated in 1997.

A network of eight monitoring wells monitors the Former Landfill area. This monitoring program is designed in accordance with post-closure operation and maintenance requirements specified in 6 NYCRR Part 360, "Solid Waste Management Facilities." The objective of this program is to verify that the cap effectively prevents the continued leaching of contaminants from the landfill, and to document anticipated long-term improvements to groundwater quality. In addition to these wells, BNL established a separate network of 24 wells to monitor the Animal/Chemical Pits and Glass Holes areas and the downgradient portions of the Former Landfill plume. The downgradient portions of these VOC plumes are currently being monitored as part of the OU III North Street Monitoring Program.

Former Landfill Monitoring Results. The areal extent of VOC contamination from the Former Landfill-Animal/Chemical Pits and Glass Holes area is shown in Figure 7-9. The primary VOCs that are consistently detected in the Former Landfill Monitoring Program wells are TCA, 1,1-DCA, and chloroform. A detailed evaluation of VOCs, radionuclides, leachate parameters, metals, and pesticides/PCBs is provided in the Former Landfill Five-Year Evaluation Report (P.W. Grosser 2002). The contaminants of concern for the Former Landfill wells are VOCs and strontium-90.

VOC concentrations have been low in all of the Former Landfill wells over the past five years with minimal exceedances of the NYS AWQS. Few or no VOCs have been detected in upgradient wells 87-22, 87-72, and 86-42. TCE and 1,1-DCA consistently were detected in the downgradient wells (97-17, 97-64, 106-02, and 106-30), though NYS AWQS for these compounds were not exceeded in 2001, nor have they been since 1998 (in well 106-30).

Historically, strontium-90 has been detected in shallow well 97-64, less than 100 feet downgradient of the landfill footprint. Strontium- 90 concentrations in this well have been steadily declining since 1998 , when it was last detected at a concentration of $12 \mathrm{pCi} / \mathrm{L}$, above 


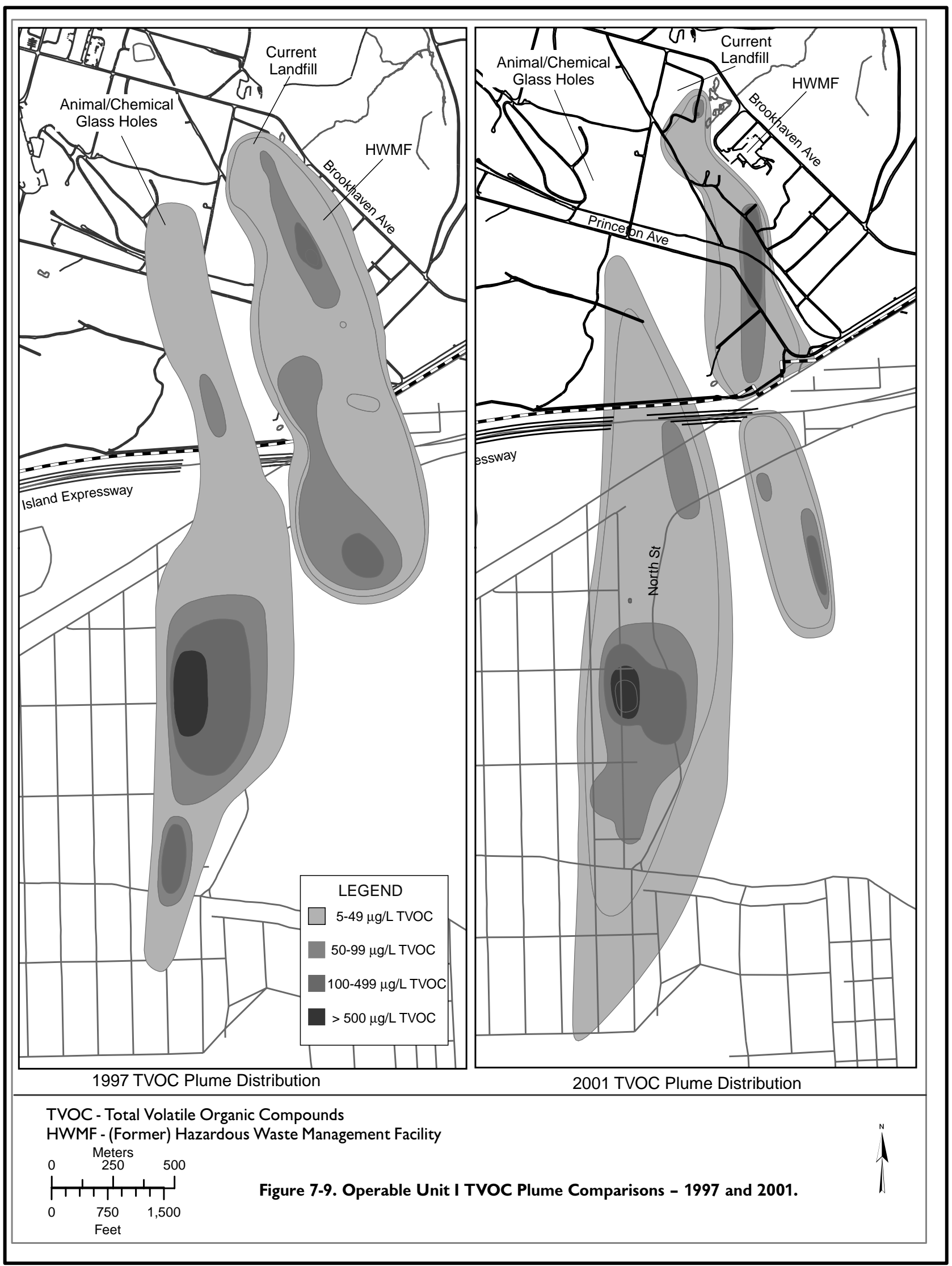


the NYS AWQS of $8 \mathrm{pCi} / \mathrm{L}$. The highest concentration in this well during 2001 was $3 \mathrm{pCi} / \mathrm{L}$, in January.

The declining VOC and strontium-90 concentration trends in downgradient wells suggest that the landfill cap is performing as planned. VOC concentrations in nearby wells remain below NYS AWQS. The trailing edge of the VOC plume emanating from the Former Landfill has migrated south of the monitoring well network (Figure 7-9). The strontium-90 plume has also shifted south of well 97-64 and the Former Landfill network, as shown in Figure $7-10$. The capping of the landfill and the passage of time since the landfill was last in use (1966) are contributing factors to the reduction in plume concentrations in the vicinity of the landfill.

Animal/Chemical Pits and Glass Holes Monitoring Results. This plume was extensively characterized in 2001 in anticipation of a pilot study to remediate strontium-90 in groundwater from this source. Groundwater samples were obtained from 30 temporary and 24 permanent monitoring well locations around and downgradient of the source areas during 2001. An active groundwater treatment system for this area has been designed, based on information gathered during the characterization effort.

Construction of the pilot study treatment system will take place in 2002. Detailed results of the 2001 groundwater characterization can be found in the Strontium-90 Pilot Study Work Plan/ 90 Percent Design Report (IT Corporation 2001).

Figure 7-10 shows the strontium-90 plume distribution. The highest strontium- 90 concentration observed during 2001 was $1,770 \mathrm{pCi} / \mathrm{L}$ in well 106-16, which is immediately south of the Animal Pits. This well has historically shown the highest strontium-90 concentrations in this area (see trend plot on Figure 7-10). The sharp increase in strontium-90 in this well appears to be correlated with the excavation of the Animal Pits area in 1997. The excavation process is believed to have released additional strontium-90 to the groundwater.

A strontium-90 plume with concentrations greater than $100 \mathrm{pCi} / \mathrm{L}$ extends from approximately 75 feet northwest of well 106-16 to approximately 125 feet south of the Princeton
Avenue firebreak road (Figure 7-10). The leading edge of the plume, as defined by the NYS AWQS of $8 \mathrm{pCi} / \mathrm{L}$, is approximately 275 feet south of this firebreak road. A second, smaller plume occurs south of the Former Landfill (and the Princeton Avenue firebreak road). A concentration of $17 \mathrm{pCi} / \mathrm{L}$ was detected in a temporary well installed south of the firebreak road.

\subsubsection{Current Landfill}

The Current Landfill operated from 1967 through 1990. (Note: This landfill is called the Current Landfill to distinguish it from the older [Former] landfill that closed in 1966.) It was used for disposal of putrescible waste, sludge containing precipitated iron from the Water Treatment Plant, and anaerobic digester sludge from the Sewage Treatment Plant. The latter contained low concentrations of radionuclides, and possibly metals and organic compounds. BNL also disposed of limited quantities of laboratory wastes containing radioactive and chemical material at the landfill. As a result, the Current Landfill is a source of groundwater contamination. Permanent closure (capping) of this landfill was completed in November 1995 as part of the ER Program.

The Current Landfill post-closure groundwater monitoring program consists of a network of 11 monitoring wells adjacent to the landfill in both upgradient and downgradient locations. These wells are monitored quarterly to determine the cap's effectiveness in preventing the continued leaching of contaminants from the landfill, and to document the anticipated longterm improvements to groundwater quality. The monitoring well network was designed in accordance with New York State-specified landfill post-closure Operation and Maintenance requirements. Data collected to date show that, in general, contaminant concentrations have been decreasing following the capping of the landfill in 1995, as described below.

Volatile Organic Compounds. The primary VOCs that have been consistently detected in wells at the Current Landfill are chloroethane and benzene. The highest total volatile organic compound (TVOC) value (primarily consisting of chloroethane) was $87 \mu \mathrm{g} / \mathrm{L}$ in well $88-109$, which 


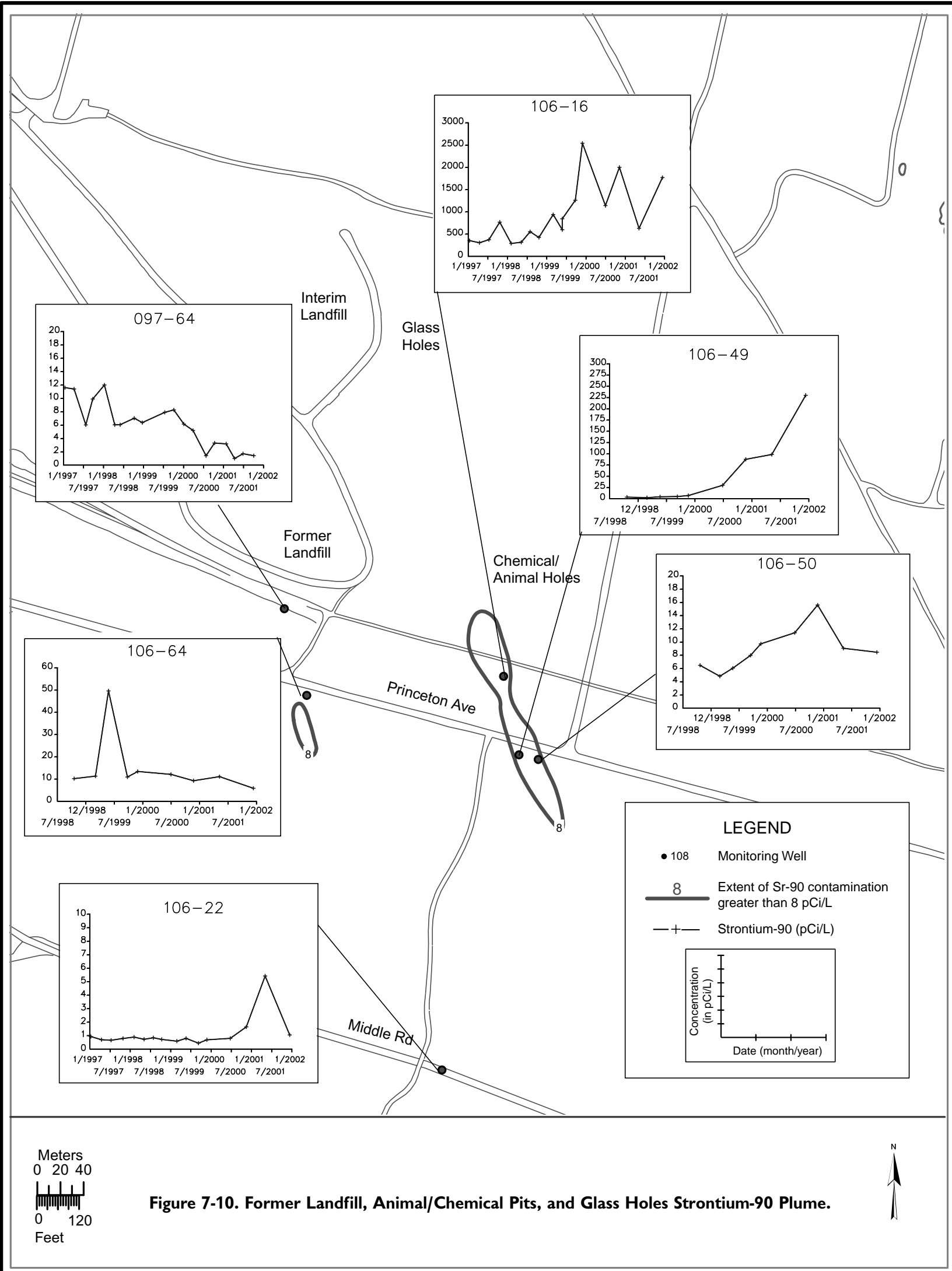


is adjacent to the southeast side of the landfill. (Note: TVOC is a summation of all individual VOC concentrations for a particular well sample.) This concentration was observed in the fourth quarter, following three previous quarters of levels below $10 \mu \mathrm{g} / \mathrm{L}$. VOC trends in other Current Landfill wells were stable or slightly decreased in 2001. The extent of the Current Landfill VOC plume is shown in Figure 7-9.

Radionuclides. As in previous years, low levels of tritium and strontium-90 were detected in Current Landfill monitoring wells during 2001, but at concentrations well below their applicable drinking water standards of $20,000 \mathrm{pCi} / \mathrm{L}$ and 8 $\mathrm{pCi} / \mathrm{L}$, respectively. The highest tritium value was $2,360 \mathrm{pCi} / \mathrm{L}$, detected in well $087-11$, and the highest strontium- 90 value was $4.67 \mathrm{pCi} / \mathrm{L}$, in well 088-21.

\section{Leachate Parameters and Metals. Most} conventional landfill leachate parameters (e.g., alkalinity, sulfates, chlorides, total nitrogen, nitrates, nitrites, TKN, total dissolved solids, and total suspended solids) were below applicable NYS AWQS, except for ammonia. Ammonia concentrations exceeded the NYS AWQS of 2 $\mathrm{mg} / \mathrm{L}$, with the highest concentrations detected in well 88-109, at $7 \mathrm{mg} / \mathrm{L}$. Ammonia is a common landfill contaminant and is generated by the degradation of organic material. As in past years, the metals iron and magnesium were also detected above NYS AWQS in many of the Current Landfill wells in 2001.

\subsubsection{Current Landfill/HWMF Plume}

Groundwater contamination originating from the downgradient section of the Current Landfill plume and the former Hazardous Waste Management Facility (HWMF) is being monitored under the OU I South Boundary program. That program uses a network of 62 monitoring wells ( 15 of which also are used for the Current Landfill and the OU III North Street monitoring programs), downgradient of the Current Landfill and former HWMF. Until 1997, the former HWMF was BNL's central facility for processing, neutralizing, and storing hazardous and radioactive wastes before off-site disposal. As a result of past waste handling and storage practices, groundwater at the former HWMF is contaminated with both chemicals and radionuclides at concentrations that exceed NYS AWQS or DWS.

The Current Landfill and former HWMF plumes become commingled south of the HWMF. The Current Landfill/HWMF plume is being remediated using a groundwater extraction and treatment system consisting of two wells screened in the deep portion of the Upper Glacial aquifer at the site boundary. This system provides hydraulic containment of those on-site portions of the plume that have TVOC concentrations greater than $50 \mu \mathrm{g} / \mathrm{L}$.

Volatile Organic Compounds. Total volatile organic compound concentration distributions for the Current Landfill/HWMF plume are shown in Figure 7-9. The primary VOCs found on site include chloroethane and DCA (the signature contaminants for the Current Landfill), whereas TCA, 1,1-dichloroethene (DCE), trichloroethene (TCE), and chloroethane are prevalent in the offsite segment of the plume. DCA and chloroethane are primarily detected in the Shallow Glacial aquifer near the source areas, and in the deep Upper Glacial aquifer at the site's boundary and off site. TCA, DCE, TCE, chloroethane, and chloroform are found in the mid to deep Upper Glacial aquifer off site south of North Street.

The Current Landfill/HWMF plume (defined by TVOC concentrations greater than $5 \mu \mathrm{g} / \mathrm{L}$ ) extends south from the Current Landfill to an area approximately 2,250 feet south of North Street (approximately 7,300 feet long, as measured from the Current Landfill). Its maximum width is about 1,300 feet at the southern site boundary. The areas of the plume displaying the highest VOC concentrations (greater than 100 $\mu \mathrm{g} / \mathrm{L}$ ) are approximately 500 feet downgradient of the former HWMF (at well 98-59), and off site, south of well 000-124. Eleven vertical profile wells were installed during 2001 to delineate the extent of the TVOC plume in the area south of North Street, near well 000-124. The maximum TVOC concentration detected was $165 \mu \mathrm{g} / \mathrm{L}$ in a temporary well approximately 600 feet south of well 000-124. Additional characterization studies planned for 2002 will define the leading edge of the plume, defined by concentrations greater than $5 \mu \mathrm{g} / \mathrm{L}$. Complete 
groundwater characterization data will be given in the OU III North Street East Groundwater Treatment System 90\% Design Report, which is scheduled for completion in November 2002.

There have been several changes in the distribution of the plume from 1997 through 2001, shown in its current configuration on Figure 7-9. Groundwater characterization work performed in 2001 indicates that the core of the high concentration slug of contamination previously observed at well $000-124$ continues to migrate south and generally to decrease in concentration. The south boundary pump-andtreat system appears to have created a break in the plume, characterized by a region of lowlevel TVOCs from south of the extraction wells to just south of the Long Island Expressway (LIE). A new groundwater treatment system (North Street East) is scheduled to be constructed in 2003. This treatment system is designed to remediate the high concentration portion of the VOC plume located off site (see Figure 7-18).

Radionuclides. Tritium has historically been detected in Current Landfill/HWMF plume wells below the NYS AWQS of $20,000 \mathrm{pCi} / \mathrm{L}$. The maximum detection during 2001 was $11,400 \mathrm{pCi} / \mathrm{L}$ in well $98-30$, which is 800 feet south of the former HWMF. Low levels of tritium continue to be detected off site in this plume. The maximum off-site tritium concentration observed in 2001 was $4,370 \mathrm{pCi} / \mathrm{L}$, in well 000-138.

Strontium-90 has historically been detected on site at concentrations above the drinking water standard of $8 \mathrm{pCi} / \mathrm{L}$ in two wells within and downgradient of the former HWMF (wells 88-26 and 98-21). In 2001, additional groundwater characterization work was performed using thirteen temporary wells downgradient of the former HWMF. The highest strontium-90 detection was observed in temporary well $108-30$, at $65.4 \mathrm{pCi} / \mathrm{L}$. The extent of strontium- 90 concentrations that are greater than the $8 \mathrm{pCi} / \mathrm{L}$ drinking water standard is shown in Figure 7-11. The leading edge of this plume was defined as being north of temporary well locations 108-38 and 108-42. Sentinel monitoring wells are planned for installation in 2002, downgradient of the leading edge of the plume. Historical strontium-90 trends for key monitoring wells in this area are provided in Figure 7-11.

\subsubsection{Operable Unit III}

The monitoring well network established to monitor the OU III VOC and radionuclide source areas and associated contaminant plumes is composed of approximately 180 monitoring wells positioned from the north-central portion of the site to the southern site boundary and off site. The OU III groundwater monitoring program is specifically designed to address the following groundwater contamination and plume remediation issues:

- Monitor VOC plumes with identified or suspected sources in the AGS Complex, Paint Shop, former carbon tetrachloride underground storage tank area, former Building 96 area, and the Supply and Material area.

- Monitor the tritium plume associated with the High Flux Beam Reactor (HFBR) and strontium-90 plumes associated with the Waste Concentration Facility and the formerly operated Brookhaven Graphite Research Reactor (BGRR).

- Evaluate the effectiveness of the OU III South Boundary, Middle Road, Carbon Tetrachloride, Industrial Park, and Building 96 groundwater treatment systems. These monitoring programs characterize the effects of the pumping on the contaminant plumes and provide the data necessary for making decisions on the future operations of the remediation systems.

- Monitor the off-site segment of the OU III plume and "sentinel" wells to the south (downgradient) of the defined extent of the off-site VOC plume, to provide data on future downgradient migration of the plume. Outpost wells are also situated in the southwestern portion of BNL, directly upgradient of the Suffolk County Water Authority's Parr Village Well Field near the William Floyd Parkway. These sentinel wells would provide an early warning if contaminants from BNL were to migrate toward the Suffolk County Water Authority wells. 


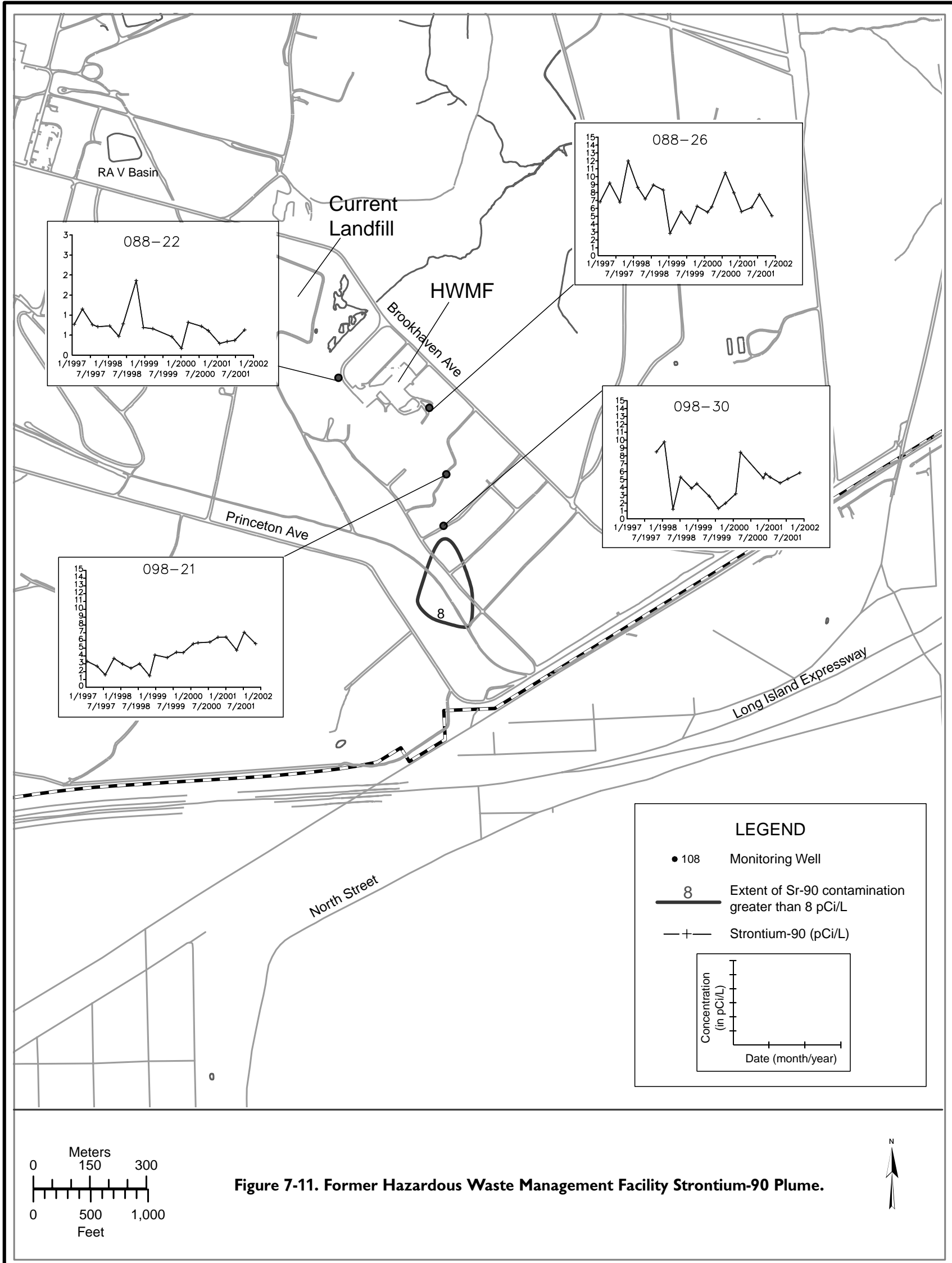




\subsubsection{OU III Volatile Organic Compound Plumes}

Figure 7-12 shows the areal extent of the OU III VOC plume, which extends from the AGS Complex area in the central part of the site south to the vicinity of Flower Hill Drive in North Shirley, a distance of approximately 18,000 feet.

The OU III VOC plume consists of multiple commingled plumes originating from a number of source areas located in the central areas of the BNL site. The primary VOCs detected in on-site monitoring wells include TCA, PCE, and carbon tetrachloride. Carbon tetrachloride and PCE are the primary VOCs detected in off-site groundwater monitoring wells.

On-site portions of the plume displaying the highest VOC concentrations during 2001 were the former carbon tetrachloride UST area (with carbon tetrachloride values up to $2,800 \mu \mathrm{g} / \mathrm{L}$ ) and the former Building 96 area (primarily PCE and lower concentrations of TCA, with TVOC values of up to $1,794 \mu \mathrm{g} / \mathrm{L}$ ). From the former Building 96 area, high levels of VOCs continue south to Princeton Avenue, where TVOC concentrations greater than $500 \mu \mathrm{g} / \mathrm{L}$ were observed. High levels of VOCs were also observed in wells from the Industrial Park to Carleton Drive, where TVOC levels range up to $9,780 \mu \mathrm{g} / \mathrm{L}$ (composed primarily of carbon tetrachloride and PCE).

In general, PCE, TCA, and carbon tetrachloride occur in the shallow Upper Glacial aquifer in the central portion of OU III, and in the deep Upper Glacial aquifer at the southern site boundary and off site. Monitoring results from wells 000-249 and 000-130 suggest that there is significant carbon tetrachloride and PCE contamination off site in the Upper Magothy aquifer. Characterization of the Magothy aquifer in this area began in 2000 and will be completed in 2002. Vertical profiles have been completed at 16 locations and monitoring wells have been installed in six locations. Data obtained from these vertical profiles have been used to help draw the various OU III contaminant plume maps. The highest carbon tetrachloride and PCE concentrations occurred in wells 000-253 and $000-130$, with maximum TVOC concentra- tions of $2,161 \mu \mathrm{g} / \mathrm{L}$ and $1,142 \mu \mathrm{g} / \mathrm{L}$, respectively. A comparison of the OU III plumes between 1997 and 2001 is provided in Figure 7-12. A summary of significant source areas and groundwater treatment areas is provided below.

OU III Central Area. The OU III Remedial Investigation identified several low-level (less than $100 \mu \mathrm{g} / \mathrm{L}$ ) source areas and nonpoint source contamination within the developed central areas of the BNL site. These areas are monitored under the OU III Central project.

The monitoring well network established for the central area of the site consists of 21 wells. This network also is supplemented with Environmental Surveillance program wells that are used to monitor active research and support facilities. During 2001, VOC concentrations in most of the OU III Central wells were near or below the NYS AWQS. Significant observations for 2001 are described below.

- TVOCs in shallow well 65-05 (in the AGS area) peaked at a concentration of $123 \mu \mathrm{g} / \mathrm{L}$ in September 2000, then decreased to 17 $\mu \mathrm{g} / \mathrm{L}$ during the fourth quarter of 2001 . The VOCs are likely to have originated from historical discharges to cesspools near Building 914.

- VOC concentrations (primarily TCA) in shallow well 066-09 (southeast of Building 830 ) significantly increased during late 2000 and early 2001, peaking at $112 \mu \mathrm{g} / \mathrm{L}$ TVOC in February 2001. VOC concentrations during the final three quarters of 2001 dropped to below NYS AWQS. A preliminary investigation identified several potential sources in Building 830; however, a subsequent geoprobe investigation during the summer of 2001 revealed little or no VOC contamination near the building (see Section 7.5.2.10).

- Well 83-02 is near the intersection of Brookhaven Avenue and Upton Road and is screened in the mid to deep Upper Glacial aquifer. Since 1997, this well consistently has contained 10 to $25 \mu \mathrm{g} / \mathrm{L}$ of chloroform. Potential sources of this contamination may be in the AGS area of the site.

- SCDHS wells 109-03 and 109-04 serve as 


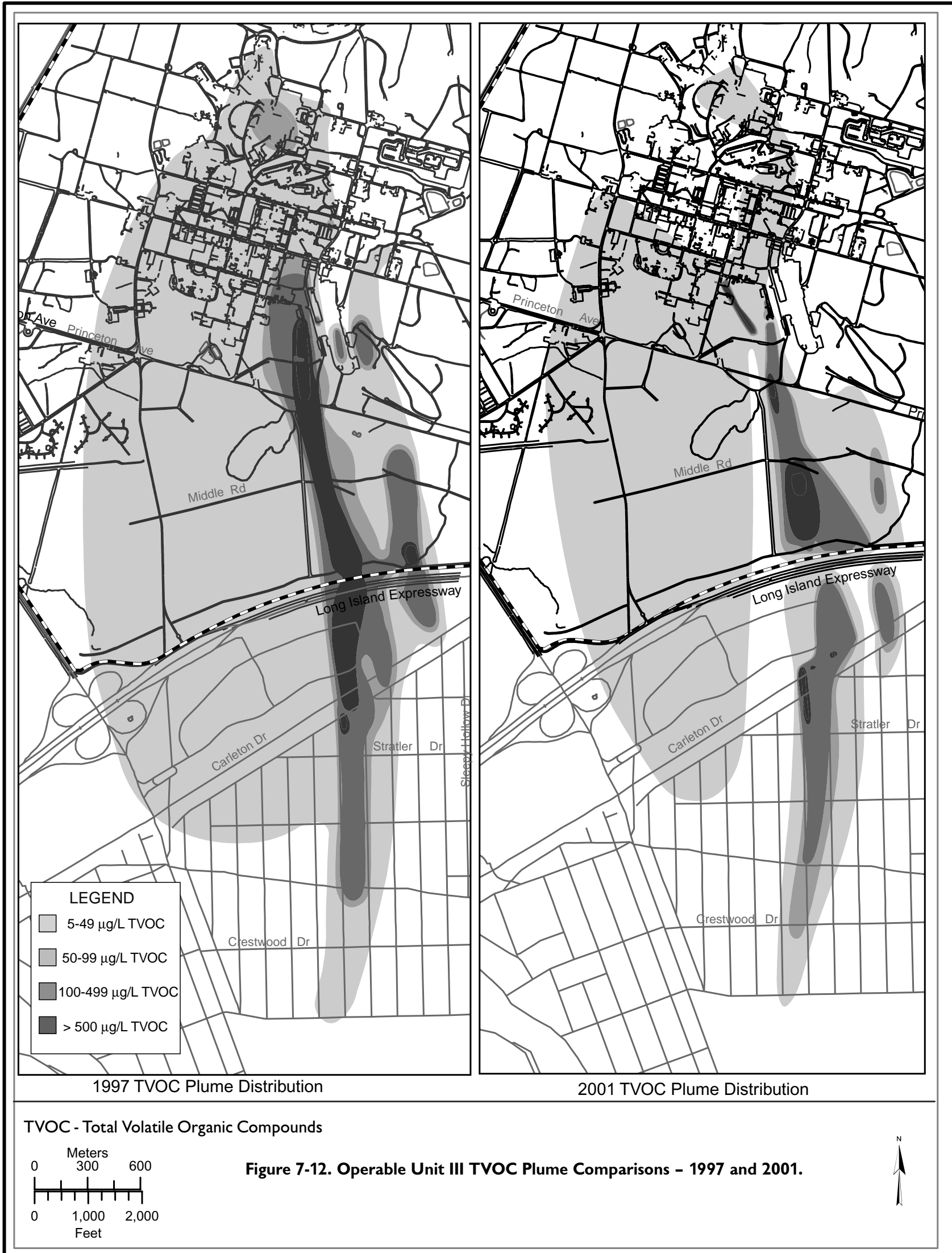


sentinel wells for the SCWA William Floyd Well Field and are near the eastern BNL site property boundary. There were no detections of either VOCs or radionuclides in these wells during 2001.

Former Building 96 Area. The OU III RI/ FS identified the Building 96 area as a significant source of the PCE detected in the OU III plume. The Building 96 area encompasses four distinct areas: Building 96 and associated leaching structures, Building 96 Scrapyard, Former Building T-239 and associated leaching structures, and the former truck wash area.

An in-well air sparging system to remediate the Building 96 VOC source area began in February 2001 (see Figure 7-18). The VOC plume consists primarily of PCE and lower concentrations of TCA. The maximum observed TVOC concentration during 2001 was $4,870 \mu \mathrm{g} / \mathrm{L}$ in temporary well $095-263$. The NYS AWQS for PCE and TCA was $5 \mu \mathrm{g} / \mathrm{L}$. The Building 96 groundwater treatment system consists of four recirculation treatment wells. During 2001, the Building 96 area VOC plume was monitored using 17 permanent wells and seven temporary wells. Monitoring data collected during 2001 indicate the size of the plume has decreased in response to the groundwater treatment system.

Carbon Tetrachloride UST Area. In April 1998, an inactive underground storage tank used for the storage of carbon tetrachloride was excavated and removed. This tank was approximately 200 feet northeast of the Upton Service Station (at the corner of Rowland Street and Rochester Street). Although groundwater samples collected from a nearby well had shown low-level concentrations of carbon tetrachloride since 1995, samples collected in June 1998 revealed levels approaching 100,000 $\mu \mathrm{g} / \mathrm{L}$. The NYS AWQS for carbon tetrachloride is $5 \mu \mathrm{g} / \mathrm{L}$. It is now apparent that the increase in contaminant concentration was probably due to the spillage of residual carbon tetrachloride during removal of the underground storage tank. A groundwater remediation system consisting of two extraction wells screened in the shallow Upper Glacial aquifer began operation in October 1999. A third extraction well began operation in December 2001. The effects of the pump-and-treat system on the source area are apparent in the sharp decline in carbon tetrachloride concentrations in wells near the former UST area.

The carbon tetrachloride contamination extends from the former UST southeast to the vicinity of the Weaver Road recharge basin, a distance of approximately 1,300 feet (Figure 712). The width of the plume, as defined by the $50 \mu \mathrm{g} / \mathrm{L}$ isocontour, is approximately 120 feet. In 1999, carbon tetrachloride concentrations in groundwater immediately downgradient of the former UST were greater than $150,000 \mu \mathrm{g} / \mathrm{L}$ (in well 85-98). Carbon tetrachloride concentrations in this area steadily decreased following the start of groundwater treatment system pumping, and were only $7 \mu \mathrm{g} / \mathrm{L}$ during the fourth quarter of 2001. Carbon tetrachloride concentrations were also observed to decrease in wells near the Service Station. For example, carbon tetrachloride concentrations in well 85-17 dropped from 3,760 $\mu \mathrm{g} / \mathrm{L}$ in February 2001 to $602 \mu \mathrm{g} / \mathrm{L}$ by November 2001.

Although the groundwater treatment system was highly effective in these areas, high carbon tetrachloride concentrations continued to be detected in downgradient wells that were beyond the capture zone of the extraction wells. To further define the downgradient extent of the carbon tetrachloride plume, six temporary vertical profiles were installed from April through July 2001 (see BNL 2001b). The leading edge of the shallow, high concentration portion of the carbon tetrachloride plume was delineated for purposes of locating an additional groundwater extraction well. The southernmost vertical profile installed along the plume centerline, well 095-248, contained carbon tetrachloride at $106 \mu \mathrm{g} / \mathrm{L}$ in the deepest sample interval ( 79 to 83 feet below land surface). Concentrations greater than $200 \mu \mathrm{g} / \mathrm{L}$ were detected in well 095-88. Using these data, a third extraction well was constructed in the vicinity of the Weaver Drive recharge basin. Start-up of this well took place in December 2001. A work plan will be developed for additional characterization of the deep carbon tetrachloride contamination in 2002. 
Middle Road Treatment Area. Six

groundwater extraction wells are used to hydraulically control the OU III VOC plume located near the Middle Road (Figure 7-18). This system began operating in October 2001. The Middle Road Monitoring Program consists of a network of 26 monitoring wells, eleven of which were installed during 2001 .

The highest TVOC concentrations are found immediately south of extraction wells RW-2 and RW-3, in monitoring wells 113-11 (823 $\mu \mathrm{g} / \mathrm{L})$ and $113-17(1,466 \mu \mathrm{g} / \mathrm{L})$. The contamination was present before the Middle Road treatment system was installed and will ultimately be captured by the OU III South Boundary system. TVOC concentrations in monitoring wells east of RW-3 are below $100 \mu \mathrm{g} / \mathrm{L}$.

TVOC concentrations in plume core well 105-23, approximately 2,000 feet upgradient of RW-1 near Princeton Avenue, were as high as $1,794 \mu \mathrm{g} / \mathrm{L}$ during 2001. VOC concentrations in this well declined during operation of the HFBR remediation system in 1997 through 2000, then rapidly increased after the HFBR system was put on standby in September 2000.

Southern Boundary Treatment Area. Hydraulic control of the OU III plume at the site boundary has been attained using seven extraction wells, which pump water from the deep portions of the Upper Glacial aquifer to an air stripper for treatment. This system began operation June 1997. VOC concentrations in groundwater along the site's southern property line are stratified vertically and horizontally. The seven recovery wells are screened at the depths showing the highest VOC concentrations. The effectiveness of the Southern Boundary treatment system is monitored using a network of 40 wells. During 2001, TVOC concentrations in monitoring wells near the extraction well system were generally less than $200 \mu \mathrm{g} / \mathrm{L}$.

Western South Boundary Treatment Area. The Western South Boundary pump-and-treat system will be in operation in 2002 . The system will have two extraction wells and is designed to capture the western portion of the OU III VOC plume, which contains VOC concentrations generally less than $50 \mu \mathrm{g} / \mathrm{L}$. Left untreated, these VOCs could potentially discharge into the
Carmans River. In 2001, the OU III Western South Boundary area was monitored using four wells. During 2001, the maximum VOC concentration was $28 \mu \mathrm{g} / \mathrm{L}$, in well 130-02. In late 2001 and early 2002, BNL installed an additional 12 wells to enhance the monitoring program near the extraction wells and provide for monitoring of the newly constructed recharge basin.

Industrial Park Area. The OU III Industrial Park Treatment system was designed to contain and remediate the portion of the OU III plume existing between BNL's southern boundary and the Parr Industrial Park (Figure 7-18). This portion of the plume consists primarily of carbon tetrachloride that is in the deep portions of the Upper Glacial aquifer and upper portion of the Magothy aquifer. A groundwater treatment system, consisting of seven in-well air stripping treatment wells, was initiated in the Industrial Park in wells installed in 1999, to treat VOC contamination in the deep Upper Glacial aquifer.

The monitoring well network for this area consists of 39 wells that extend from the Industrial Park to Carleton Drive. These wells are used to monitor the effectiveness of the inwell air stripping groundwater treatment system. The highest VOC concentrations in the Industrial Park area were observed between remediation wells UVB-1 and UVB-3, with the maximum concentration of $3,853 \mu \mathrm{g} / \mathrm{L}$ observed in monitoring well 000-256 during the first quarter of 2001. There has been a steady decline in VOC concentrations in plume core well 000-112 (immediately upgradient of UVB-1 and UVB-2) since 1999. Concentrations have decreased from a historical high of $1,898 \mu \mathrm{g} / \mathrm{L}$ in 1997 , to $24 \mu \mathrm{g} /$ $\mathrm{L}$ in October of 2001. Monitoring wells downgradient of the treatment system, along Carleton Avenue, showed stable or decreasing VOC concentrations during 2001.

Two new groundwater remediation systems are being planned to clean up the southern extent of the OU III plume not remediated by the Industrial Park treatment system. The treatment systems will be located along the northern edge of the Town of Brookhaven Airport and along the Long Island Power Authority (LIPA) right-ofway south of Carleton Drive (see Figure 7-18). These systems will be constructed by 2004 . 
North Street Monitoring. The North Street monitoring program (formerly known as OU I/IV monitoring program) addresses both a VOC plume that is primarily south of the site boundary and the issue of radiological contaminants that may have been introduced to groundwater in the OU IV portion of the site (particularly the Building 650 and 650 Sump Outfall areas).

Volatile Organic Compounds. A network of 25 monitoring wells monitors the downgradient portion of the OU IV, Former Landfill, Animal/ Chemical Pits, and Glass Holes VOC plumes. Wells sampled under the OU III South Boundary and Industrial Park Programs are also utilized for mapping this plume. The VOC plume extends from just south of the Chemical/Animal Hole area southward to the vicinity of the Brookhaven Airport (Figure 7-12). The primary VOCs associated with this plume are carbon tetrachloride, PCE, and TCA. Monitoring well 000-154 has historically shown the highest VOC concentrations (primarily carbon tetrachloride) in the North Street area. TVOC concentrations greater than $1,000 \mu \mathrm{g} / \mathrm{L}$ were observed in 1997 and 1998 but have steadily declined since that time. This high concentration area has migrated south of monitoring well $000-154$, as evidenced by the $2,020 \mu \mathrm{g} / \mathrm{L}$ of TVOC detected in vertical profile well 000-381, which was installed in the deep Upper Glacial aquifer approximately 700 feet to the south. The leading edge of the North Street VOC plume is near the northern boundary of the Brookhaven Airport near Flower Hill Drive, where TVOC concentrations up to $7 \mu \mathrm{g} / \mathrm{L}$ were detected in well 800-76, which is screened in the deep Upper Glacial aquifer. Detailed groundwater characterization data can be found in the North Street Groundwater Remediation System 90\% Design Report (Arcadis G\&M 2002) and the OU III Airport Groundwater Treatment System 90\% Design Documents (Holzmacher 2002a).

The North Street VOC plume will be remediated using two groundwater treatment systems. The first system will be located near Stratler Drive in North Shirley and is currently planned to consist of a two-well extraction and four-well recharge system (Figure 7-18). This system will capture the higher concentration portion of the VOC plume within the Upper Glacial aquifer that contains concentrations greater than $50 \mu \mathrm{g} / \mathrm{L}$. This system will help to minimize the potential for VOC migration to the Magothy aquifer. Details on the pre-design groundwater characterization and the planned groundwater treatment system can be found in the North Street Groundwater Remediation System 90\% Design Report (Arcadis G\&M 2002). This treatment system is scheduled to start operations in November 2003. The second groundwater remediation system is to be located at the Brookhaven Airport. This system is being designed to remediate the leading edge of this plume, as well as the leading edge of the OU III VOC plume to the west (Figure 7-18). Details on the proposed remediation system and pre-design characterization activities can be found in the $O U$ III Airport Groundwater Treatment System 90\% Design Documents (Holzmacher, 2002a).

Construction of the system is scheduled to begin in January 2003.

Radionuclides. Low levels of tritium have been detected off site in localized areas of the deep Upper Glacial aquifer at concentrations well below the $20,000 \mathrm{pCi} / \mathrm{L}$ drinking water standard. Tritium has been detected in this area since the monitoring program started in 1998 . The maximum tritium concentration observed in 2001 was $2,560 \mathrm{pCi} / \mathrm{L}$, in well $000-153$. Tritium was also detected in seven of the fifteen temporary vertical profile wells installed in 2001 and 2002. In six of the seven vertical profiles, tritium was detected at concentrations less than $1,000 \mathrm{pCi} / \mathrm{L}$. The highest tritium concentration was detected in temporary well $000-337$, at $9,130 \mathrm{pCi} / \mathrm{L}$, located approximately 300 feet north of well 000-153. Potential sources for this tritium, as well as other radionuclides, are located in the Former Landfill/ Chemical/Animal Holes and OU IV Building 650 areas of the site.

\subsubsection{OU III Radionuclide Plumes}

HFBR Tritium Plume. In late 1996, tritium was detected in wells near the High Flux Beam Reactor. The source of the release was traced to the HFBR spent fuel pool. In response, the fuel rods were removed from the pool for off-site disposal, the spent fuel pool was drained, and the 
HFBR was removed from service in 1997. Also, numerous monitoring wells were constructed to characterize the tritium plume downgradient of the HFBR. In May 1997, operation of a threewell groundwater extraction system began. This system was constructed on Princeton Avenue approximately 3,500 feet downgradient of the HFBR to capture the leading edge of the tritium plume. Extracted water was recharged at the RA $\mathrm{V}$ recharge basin. Groundwater modeling predicts that the tritium plume will naturally attenuate to below drinking water standards before reaching the site boundary. Three years of monitoring data showed that the plume had reached a relative steady-state due to natural attenuation and that it was not growing significantly. As a result, the extraction system was turned off and placed on standby status in September 2000.

The selected remedy for the HFBR tritium plume includes monitoring and low-flow extraction programs to prevent or minimize the plume's growth. During 2000 and 2001, low-flow extraction was applied to the highest concentration area of the plume. The low-flow extraction removed a total of 95,000 gallons of tritiated water that was sent off site for disposal. Low-flow pumping reduced the high concentrations from about $1,180,000 \mathrm{pCi} / \mathrm{L}$ to less than $750,000 \mathrm{pCi} / \mathrm{L}$.

A monitoring well network of 157 wells (including 22 wells installed in 2001) was designed to follow the extent of the plume, the source area, and the effectiveness of the groundwater remediation system. Due to the closeness of the HFBR to artificial pumping and recharge locations, the plume is subjected to changing hydraulic stresses, which have warranted an extensive monitoring network. BNL's Regional Groundwater Model was utilized to assist with the placement of the wells. The extent of the tritium plume, determined from data collected during the fourth quarter of 2001, is shown on Figure 7-13. By the end of 2001, the highest concentration of tritium detected was $447,000 \mathrm{pCi} / \mathrm{L}$, in well 75-418. This well is just east of the BNL National Synchrotron Light Source (NSLS) facility, a distance of about 750 feet from the HFBR. The leading edge of the $>20,000 \mathrm{pCi} / \mathrm{L}$ portion of the tritium plume is just north of temporary well $095-262$, which is screened in the mid to deep Upper Glacial aquifer. The highest concentration in this temporary well was $18,500 \mathrm{pCi} / \mathrm{L}$. The outer edge of the main body of the plume (as defined by concentrations $>1,000 \mathrm{pCi} / \mathrm{L}$ ) is just north of Weaver Drive. There were no detections of tritium in excess of $1,000 \mathrm{pCi} / \mathrm{L}$ during 2001 south of Weaver Drive.

\section{WCF and BGRR Area Sr-90 Plumes.}

Historical waste handling operations at the Waste Concentration Facility and operations at the former BGRR and associated Pile Fan Sump and Stack resulted in the release of strontium-90 to the groundwater below these facilities. The strontium90 plumes from these facilities are monitored using 57 wells. During 2001, additional groundwater characterization work was conducted near the BGRR Below Ground Ducts area using 24 temporary wells, and in the vicinity of the HFBR stack using three temporary wells.

Analytical results from monitoring wells and temporary wells show two separate areas of elevated strontium-90, one emanating from the WCF and extending south approximately 1,500 feet, and the other beginning south of the BGRR and extending south approximately 600 feet toward Brookhaven Avenue (Figure 7-14). Variability in groundwater flow directions, due to changes in pumping and recharge patterns in the plume vicinity over time, has caused some lateral spreading of the contamination.

There are three areas of strontium- 90 concentration greater than $50 \mathrm{pCi} / \mathrm{L}$ within the plumes. The first is in the vicinity of the Below Ground Ducts, where an August 2001 groundwater sample from a temporary well contained strontium- 90 levels at $540 \mathrm{pCi} / \mathrm{L}$. Concentrations greater than $50 \mathrm{pCi} / \mathrm{L}$ extend south of this area to well 75-190, which is just south of Cornell Avenue.

In the WCF area, high strontium-90 levels were detected immediately south of the former "D" tanks area. The highest strontium-90 concentration observed in this well during 2001 was $760 \mathrm{pCi} / \mathrm{L}$, in December; strontium-90 concentrations have exceeded $800 \mathrm{pCi} / \mathrm{L}$ since this well was installed in 1997.

A third area of high strontium-90 concentrations was discovered in 2001 in the vicinity of 


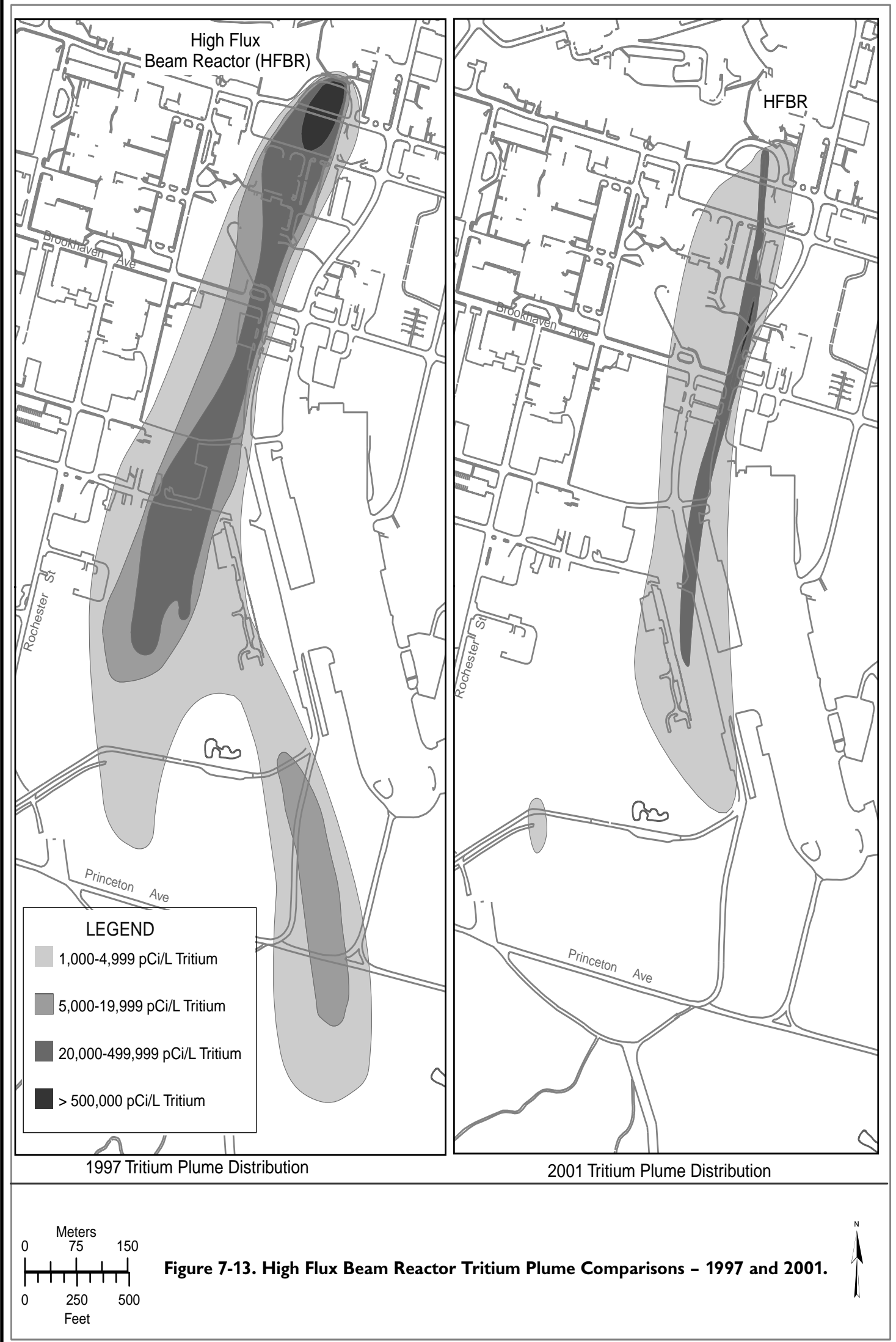




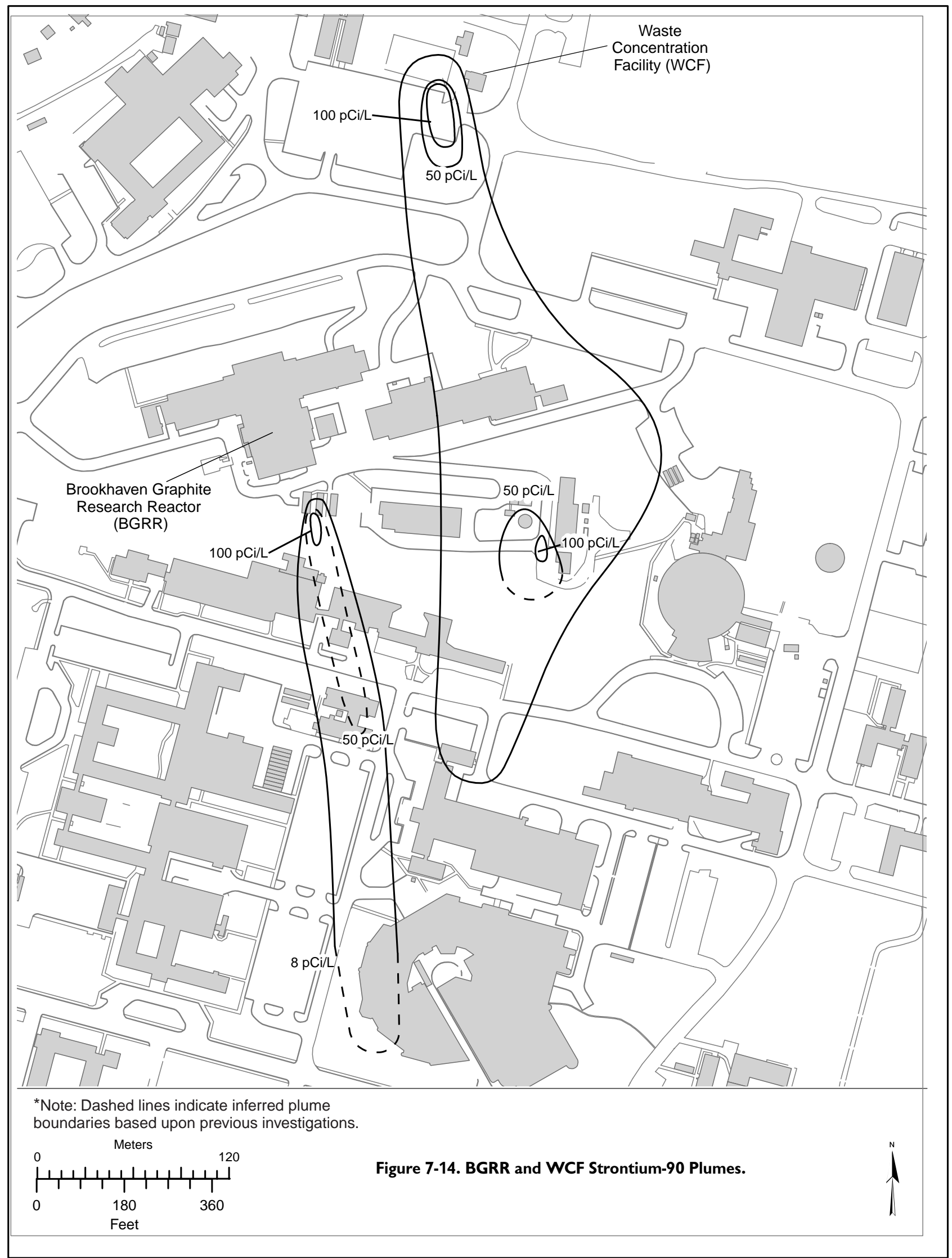


the HFBR stack. Strontium-90 was detected in a temporary well downgradient of the stack in 2001 , at a concentration of $392 \mathrm{pCi} / \mathrm{L}$.

\subsubsection{Operable Unit IV}

The Operable Unit IV area contains two significant source areas: the 1977 fuel oil/solvent spill site (Area if Concern 5), and the Building 650 Sump and Sump Outfall area (AOC 6).

\subsubsection{1977 Oil-Solvent Spill Site}

In 1977, between 23,000 and 25,000 gallons of a mixture of Number 6 fuel oil and mineral spirits were released when a pipe ruptured as the contents of an underground storage tank were being transferred to aboveground storage tanks at the Central Steam Facility. The primary chemical contaminants that were found in the OU IV plume near this 1977 spill site were TCA, PCE, DCE, TCE, toluene, ethylbenzene, and xylenes. In addition, several small spills of Number 6 fuel oil from the CSF fuel unloading area were documented between 1988 and 1993; it also is suspected that small volumes of solvents such as PCE were released to the ground near the CSF.

Since November 1997, BNL has operated an air sparging/soil vapor extraction (AS/SVE) system to remediate soil and groundwater contamination associated with the 1977 spill. The performance goals for soil cleanup were achieved in 1998, and the goals for groundwater cleanup were met in August 2000. A formal petition for shutdown was submitted to EPA and NYSDEC, and approval was received in January 2001. The system was shut down on January 10, 2001. However, following the shutdown, groundwater monitoring results for well 076-04 showed a rebound in concentrations for several VOC parameters (indicative of fuel oil). This well is in the area where the original fuel oil/solvent spill occurred and it had shown VOC levels below MDLs for nearly two years prior to system shutdown. As a result of this finding, portions of the AS/SVE system near well 076-04 were pulsed on and off on a weekly basis starting in February 2001. During the following months, analytical results from the monthly sampling showed a decreasing trend in VOC concentrations. In addition to pulsing the AS/SVE system, BNL used an enhanced biodegradation process with an oxygenreleasing compound (ORC) during July 29 to July 31,2001 . The objective of this action was to further reduce any residual VOCs (primarily ethylbenzene, xylenes, and trimethylbenzenes). During this process, a slurry of a mixture of magnesium peroxide powder and water was injected under pressure at seven locations around well 076-04 into the water table. The system was shut down in August 2001 and further monitoring was continued as per OU IV Remediation Area 1 Proposed Supplemental Remedial Effort - Work Plan, May 2001 (BNL 2001a).

Low levels of VOCs were detected in several wells (076-23 and 076-06) that are outside the area of influence of the AS/SVE system. Well 076-23 is west of the AS/SVE system and south of the CSF, and had a maximum TVOC concentration (consisting primarily cis-1,2dichloroethylene) of $45 \mu \mathrm{g} / \mathrm{L}$. It is likely that the cis-1,2-dichloroethylene, which is a breakdown product of the solvent tetrachloroethylene, originates from an historical spill that occurred near the CSF. Well 76-06 is east of the AS/SVE system. TVOC concentrations (primarily BTEX compounds) were greater than $10 \mu \mathrm{g} / \mathrm{L}$ during the first and fourth quarters of 2001.

\subsubsection{Building 650 and 650 Sump Outfall Areas} (AOC 6)

Building 650 was used as a decontamination facility for radioactively contaminated clothing and equipment. Drainage from an exterior heavy equipment decontamination pad was piped to a natural depression approximately 800 feet to the northeast, near recharge basin HO. As a result of these operations, soils and groundwater were contaminated at the decontamination pad and the sump outfall. Remediation of the soils associated with the Building 650 sump outfall and the pipe leading to the outfall will be excavated and disposed of off site during the spring and summer of 2002.

The overall extent of the strontium-90 plume originating from the Building 650 sump outfall did not change significantly from 2000 to 2001 (Figure $7-15)$. The highest strontium- 90 concentrations were detected in well $76-13(28 \mathrm{pCi} / \mathrm{L})$ in February 2001. Low levels of strontium-90 (14 
$\mathrm{pCi} / \mathrm{L})$ were also detected in well 076-28, immediately north of Building 650 adjacent to a former decontamination pad.

\subsubsection{Operable Unit V}

Historically, Brookhaven's Sewage Treatment Plant received discharges of contaminants from routine operations. Releases of VOCs, metals, and radionuclides to groundwater occurred via the STP sand filter beds and discharges to the Peconic River. In addition, trace levels of pesticides were detected in some wells. The OU V monitoring program uses 34 monitoring wells downgradient of the STP. These wells monitor VOC and tritium contamination resulting from historical releases at the STP. Surveillance of groundwater quality near the STP filter beds and emergency holding pond areas is performed as part of the BNL Environmental Surveillance Program for the STP (see Section 7.5.2.1).

Volatile Organic Compounds, Metals, and Pesticides. The extent of the OU V VOC plume is shown on Figure 7-16. The highest TVOC concentration observed during 2001 was 28 $\mu \mathrm{g} / \mathrm{L}$ in well 61-05, which is near the eastern site boundary.

Three pesticides were detected during 2001: 4,4'-dichlorodiphenyltrichloroethane (4,4'-DDT), aldrin, and dieldrin. 4,4'-DDT was detected in five wells at a maximum estimated concentration of $0.12 \mu \mathrm{g} / \mathrm{L}$. Aldrin and dieldrin were detected in well 000-123, at estimated concentrations of $0.016 \mu \mathrm{g} / \mathrm{L}$ and $0.011 \mu \mathrm{g} / \mathrm{L}$, respectively, during the March sampling event; they were not detected during the August sampling event.

Aluminum, antimony, iron, manganese, sodium, and thallium were detected at concentrations above applicable NYS AWQS levels. Aluminum was detected in 11 wells above the NYS AWQS of $0.2 \mathrm{mg} / \mathrm{L}$, with the highest concentration $(2.76 \mathrm{mg} / \mathrm{L})$ detected in well 061 03 . Antimony was detected above the NYS AWQS of $0.003 \mathrm{mg} / \mathrm{L}$ in well 037-04 at a concentration of $0.0058 \mathrm{mg} / \mathrm{L}$. Iron was detected in 18 wells above the NYS AWQS of $0.3 \mathrm{mg} / \mathrm{L}$, with the highest concentration of $25.9 \mathrm{mg} / \mathrm{L}$ detected in well 050-02. Manganese was detected in nine wells above the NYS AWQS of
$0.3 \mathrm{mg} / \mathrm{L}$, with the highest concentration (1.27 $\mathrm{mg} / \mathrm{L}$ ) detected in well 061-04. Sodium was detected above the NYS AWQS of $20 \mathrm{mg} / \mathrm{L}$ in five wells, with the highest concentration in well $600-21(107 \mathrm{mg} / \mathrm{L})$. Thallium was detected in well $049-05$ at a concentration of $0.0048 \mathrm{mg} / \mathrm{L}$, which exceeds the NYS AWQS of $0.0005 \mathrm{mg} / \mathrm{L}$.

Radionuclides. Detectable levels of tritium were found in a number of wells near BNL's southeastern site boundary, but the concentrations were well below the drinking water standard of $20,000 \mathrm{pCi} / \mathrm{L}$. In wells near the southeastern site boundary, a maximum tritium concentration of $1,710 \mathrm{pCi} / \mathrm{L}$ was detected in well 50-02. Tritium was not detected in any of the off-site monitoring wells. A detailed discussion on the distribution of tritium within the $\mathrm{OU}$ $\mathrm{V}$ plume is provided in the $2001 \mathrm{BNL}$ Groundwater Status Report (BNL 2002b).

\subsubsection{Operable Unit VI, Biology Fields}

Ethylene dibromide (EDB) was used as a fumigant in the BNL Biology Department's agricultural fields in the southeast portion of the site. Available records indicate that the application of EDB in this area took place in the 1970s. As a result of these historical releases of EDB, a contaminant plume (as defined by concentrations greater than the $0.05 \mu \mathrm{g} / \mathrm{L}$ drinking water standard for EDB) extends approximately 3,900 feet, from near BNL's southeastern site boundary to an area south of the Long Island Expressway (see Figure 7-17). EDB is the only contaminant of concern for the Biology Fields plume. The leading edge of the plume appears to be in the vicinity of temporary wells $000-383$ and 000 385. The plume is located in the deep Upper Glacial aquifer. The highest EDB concentration observed during 2001 was $7.6 \mu \mathrm{g} / \mathrm{L}$, in well 000 283. The federal drinking water standard for EDB is $0.05 \mu \mathrm{g} / \mathrm{L}$. The wells were also sampled for radionuclides and, as in past years, no radionuclides were detected.

A groundwater remediation system to address the off-site EDB plume is being designed, and system construction is planned for November 2002. Pre-design groundwater characterization work was performed in 2001 and consisted of installing five temporary wells. 


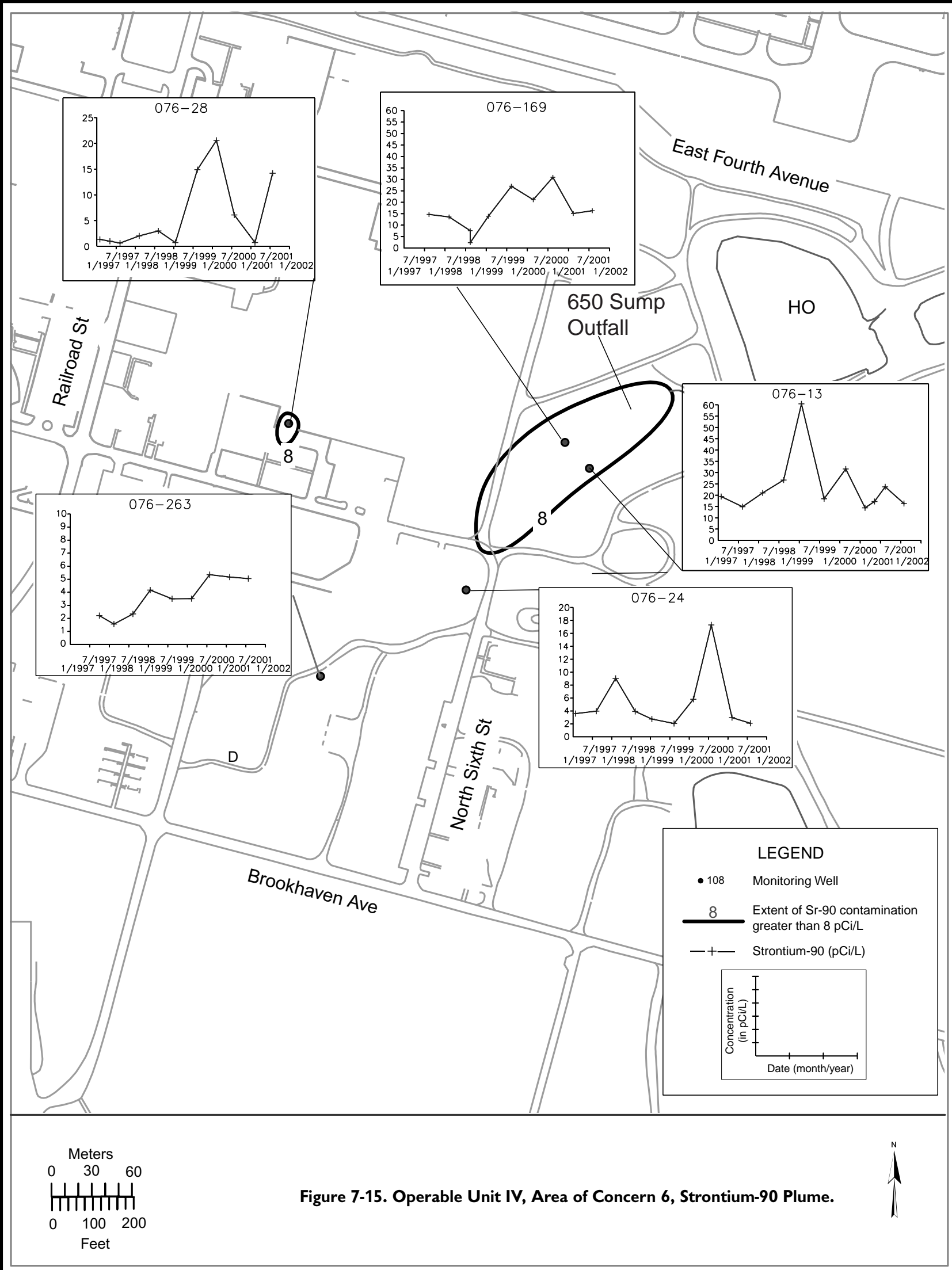




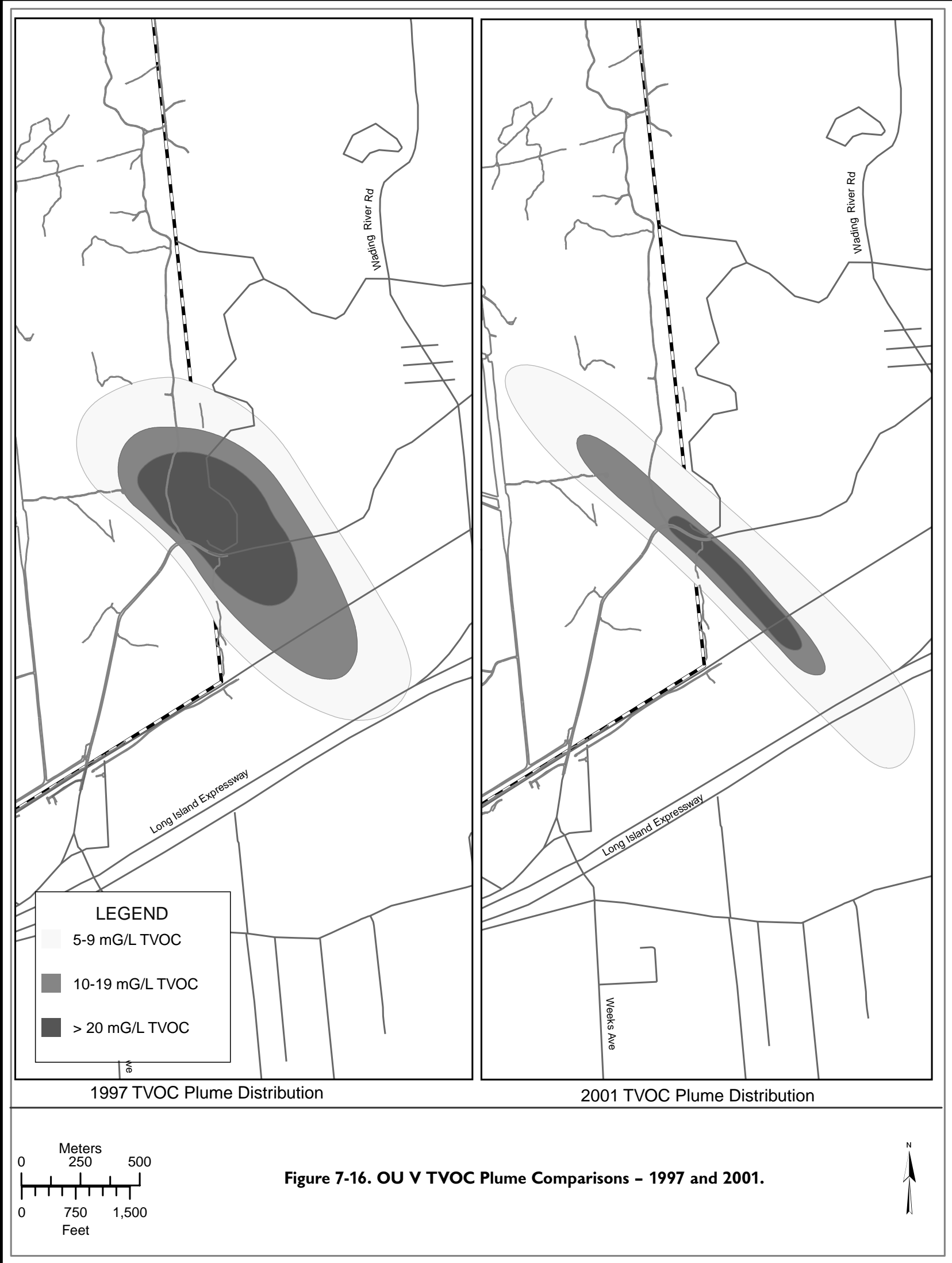




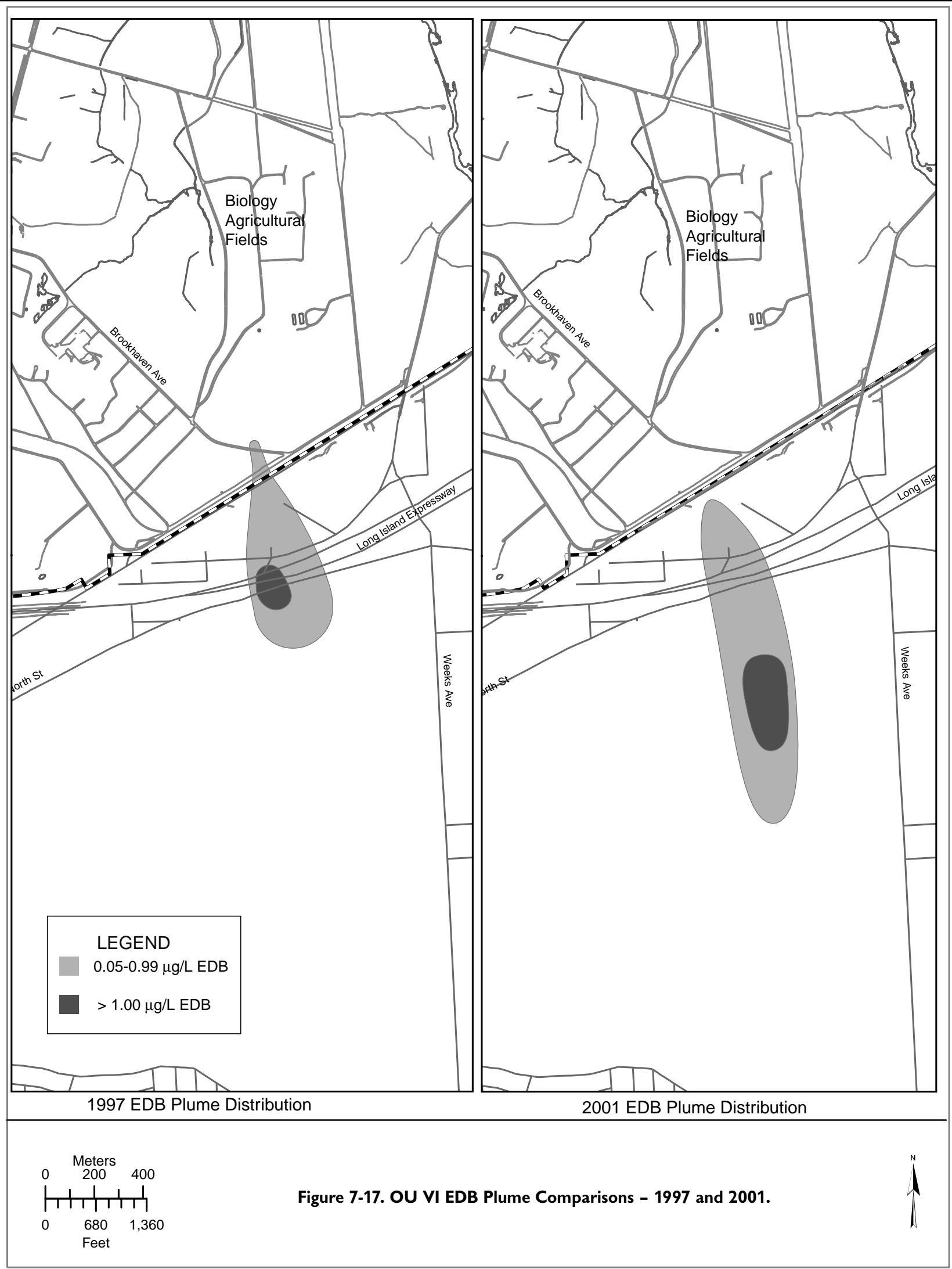




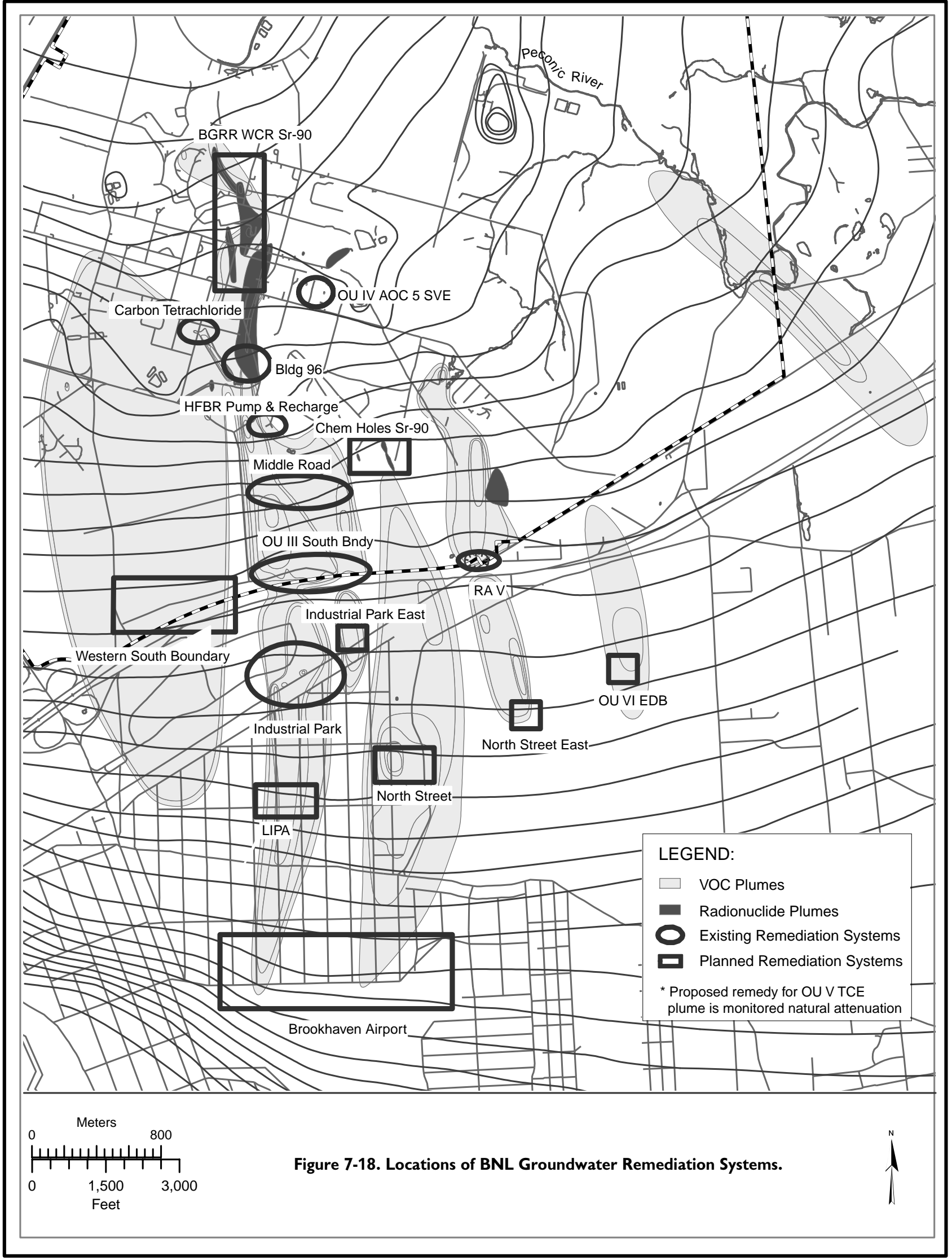


Table 7-2. Groundwater Remediation Systems Treatment Summary for 1997 - 2001.

\begin{tabular}{|c|c|c|c|c|}
\hline \multirow[b]{2}{*}{ Remediation System } & \multicolumn{2}{|c|}{$1997-2000$} & \multicolumn{2}{|c|}{2001} \\
\hline & $\begin{array}{l}\text { Water Treated } \\
\text { (Gallons) }\end{array}$ & $\begin{array}{l}\text { VOCs Removed } \\
\text { (Pounds) }\end{array}$ & $\begin{array}{l}\text { Water Treated } \\
\text { (Gallons) }\end{array}$ & $\begin{array}{l}\text { VOCs Removed } \\
\text { (Pounds) }^{(d)}\end{array}$ \\
\hline OU III South Boundary & $1,219,028,400$ & 1,424 & $339,408,450$ & 285 \\
\hline OU III Industrial Park (a) & $227,573,000$ & 240 & $163,120,000$ & 208 \\
\hline Carbon Tetrachloride (a) & $49,173,000$ & 219 & $39,164,300$ & 17 \\
\hline OU I South Boundary & $1,329,540,000$ & 229 & $411,399,000$ & 25 \\
\hline HFBR Tritium Plume & $241,528,000^{(b)}$ & 180 & 0 & 0 \\
\hline OUIVAS/SVE ${ }^{(c)}$ & - & 47 & - & 0 \\
\hline Building 96 & 0 & 0 & $24,238,416$ & 35 \\
\hline Middle Road & 0 & 0 & $55,353,550$ & 39 \\
\hline Total & $3,066,842,400$ & 2339 & $1,032,683,716$ & 609 \\
\hline \multicolumn{5}{|c|}{$\begin{array}{l}\text { Notes: } \\
\text { (a) Treatment system not installed/operational until } 1999 . \\
\text { (b) System was shut down and placed in standby mode on September } 29,2000 . \\
\text { (c) Air Sparging/Soil Vapor Extraction system performance measured by pounds of VOC removed per cubic feet of air treated. } \\
\text { (d) Values rounded to the nearest whole number. }\end{array}$} \\
\hline
\end{tabular}

Detailed information and data obtained during this investigation are presented in the $O U V I$ EDB Plume Groundwater Remediation System 90 Percent Design Documents (J.R. Holzmacher, Inc. 2002b).

\subsection{GROUNDWATER TREATMENT SYSTEMS}

The primary mission of BNL's

Environmental Restoration Program is remediating soil and groundwater contamination and preventing additional contamination from migrating off the BNL site. The cleanup goals are to: 1) prevent or minimize plume growth, and 2) reduce contaminant concentrations in the Upper Glacial aquifer to below regulatory standards within 30 years. In 2001, BNL continued to make significant progress in characterizing and restoring groundwater quality at the site. Six groundwater remediation systems were in operation by the end of 2001 with the addition of the OU III Middle Road system. Eight of the seventeen planned groundwater treatment plants have been constructed. Two systems remained in standby mode in 2001, as they substantially met their cleanup goals: the OU IV Air Sparging/Soil Vapor Extraction system, and the HFBR Pump $\&$ Recharge System. An additional extraction well was constructed for the OU III Carbon
Tetrachloride pump-and-treat system and was operational in December 2001. Compared to 2000 , the total groundwater cleanup treatment capacity was increased from $1,945 \mathrm{gpm}$ to 2,575 gpm. Ultimately, the total groundwater cleanup capacity will be approximately 4,500 gpm. Figure 7-18 shows the locations of the current and planned groundwater treatment systems.

Table 7-2 provides a summary of pounds of VOCs removed and gallons of water treated since the first treatment system became operational in 1997. During 2001, 609 pounds of VOCs were removed from the groundwater and more than one billion gallons of treated groundwater were returned to the aquifer. Detailed information on these treatment systems can be found in the 2001 BNL Groundwater Status Report (BNL 2002b).

Groundwater remediation is expected to take up to ten years of aquifer treatment before widespread improvements in groundwater quality at BNL are achieved. Even so, some noticeable improvements in groundwater quality are evident in OU IV, the OU III South Boundary area, and the OU I South Boundary area. Groundwater remediation activities are expected to continue until approximately 2025 to meet the ultimate cleanup objective. 


\section{REFERENCES}

Arcadis-Geraghty and Miller, Inc. 2002. North Street Groundwater Remediation System 90 Percent Design Report. Brookhaven National Laboratory, Upton, NY. March 2002.

Bennett, D., D. Paquette, K. Klaus, and W. Dorsch. 2000. Brookhaven National Laboratory, Source Water Assessment for Drinking Water Supply Wells. BNL-52608. Brookhaven National Laboratory, Upton, NY. December 27, 2000.

BNL 2000a. 1999 Site Environmental Report. Brookhaven National Laboratory, Upton, NY. August 2000. BNL Report 52585.

BNL 2000b. Groundwater Protection Contingency Plan. Brookhaven National Laboratory, Upton, NY. Standards Based Management System Subject Area. September 2000.

BNL. 2001a. OU IV Remediation Area 1 Proposed Supplemental Remedial Effort Work Plan. Brookhaven National Laboratory, Upton, NY. May 2001.

BNL 2001b. OU III Carbon Tetrachloride Plume Pre-Design Characterization Report. Brookhaven National Laboratory, Upton, NY. August 2001.

BNL 2001c. Building 830 Groundwater Investigation Report. Brookhaven National Laboratory, Upton, NY. September 2001.

BNL 2002a. 2002 BNL Water Quality Consumer Confidence Report. Brookhaven National Laboratory Bulletin - Special Supplement. Upton, NY. May 31, 2002.
BNL 2002b. 2001 BNL Groundwater Status Report. Brookhaven National Laboratory, Upton, NY. June 13, 2002.

DOE Order 5400.1. 1988. General Environmental Protection Program. U.S. Department of Energy, Washington, D.C. Change 1: June 29, 1990.

J.R. Holzmacher, Inc. 2002a. OU III Airport Groundwater Treatment System 90 Percent Design Documents. Brookhaven National Laboratory, Upton, NY. March 2002.

J.R. Holzmacher, Inc. 2002b. OU VI EDB Plume Groundwater Remediation System 90 Percent Design Documents. Brookhaven National Laboratory, Upton, NY. March 2002.

IT Corporation. 2001. Strontium-90 Pilot Study Work Plan/90 Percent Design Report. Brookhaven National Laboratory, Upton, NY. November 2001.

Paquette, D.E., T.G. Naymik, and E.A. Flores. 1998. Brookhaven National Laboratory, Groundwater Protection Management Program Description. Brookhaven National Laboratory, Upton, NY. BNL Report 52555.

P.W. Grosser, Inc. 2002. Former Landfill Five-Year Evaluation Report. Brookhaven National Laboratory, Upton, NY. March 2002. 
Intentionally Left Blank 
BROOKHAVEN

NATIONAL

LABORATORY

2001 SITE ENVIRONMENTAL REPORT

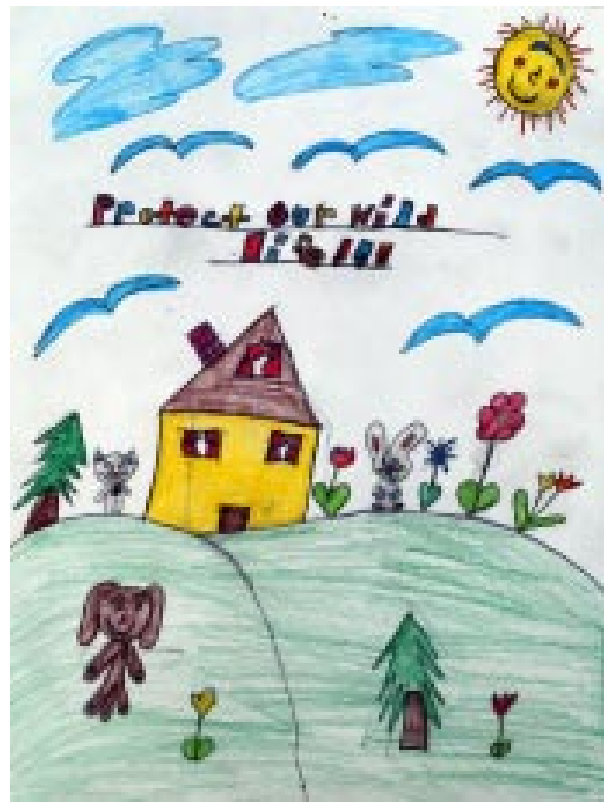

Chapter 8

\section{Radiological Dose}

During 2001, the radiological dose to members of the public and the environment from the many research facilities and scientific activities conducted at Brookhaven National Laboratory was minimal and well below regulatory limits. The radiological dose was calculated for inhalation, ingestion, and skin absorption pathways to show compliance with National Emissions Standard for Hazardous Air Pollutants, and Department of Energy regulatory dose limits.

The ambient on-site external dose was $75.5 \pm 10$ mrem (755 $\pm 100 \mu \mathrm{Sv})$ per year and the off-site ambient external dose was $71.5 \pm 7.9$ mrem $(715 \pm 79 \mu \mathrm{Sv})$ per year, both of which include natural background. A statistical comparison of the on-site and off-site average dose values indicated that there was no additional dose contributed by BNL operations above the natural background. The effective dose to the maximally exposed individual from the air pathway was estimated at 0.14 mrem $(1.4 \mu \mathrm{Sv})$ per year. The annual effective dose equivalent to an individual from consuming venison and fish (ingestion pathway) was estimated at $2.4 \mathrm{mrem}(24 \mu \mathrm{Sv})$. The total dose impact to an individual from all pathways was estimated to be 2.5 mrem $(25 \mu \mathrm{Sv})$. In comparison, the EPA regulatory limit for the air pathway is $10 \mathrm{mrem}(100 \mu \mathrm{Sv})$ and the DOE limit from all pathways is $100 \mathrm{mrem}(1,000 \mu \mathrm{Sv})$.

Additionally, 16 on-site remediation projects were evaluated for radiological air emissions; the dose impact from all of them was determined to be insignificant. The dose from BNL operations to aquatic and terrestrial biota was also found to be insignificant and comparable to natural background levels. 


\subsection{DIRECT RADIATION MONITORING}

In addition to monitoring effluents and performing pathway analysis, BNL measures direct penetrating radiation exposures to determine possible external doses of radiation that may be received by the public. The primary purpose of this monitoring is to measure the background level of radiation and the maximum radiation doses, if any, received by members of the public from direct gamma radiation that originates with BNL operations.

Direct penetrating gamma radiation cannot be collected by filters or chemically trapped in any media, but is directly measured using thermoluminescent dosimeters (TLDs). The principle of TLD operation is that when crystals are exposed to penetrating gamma radiation, impurities are excited to higher energy states and remain in that state at normal ambient tempera- ture. When the TLDs are heated, electrons are released and the crystal returns to the lower state of energy. The released electrons are in the form of photon energy, which is measured with a photomultiplier tube; the light intensity is proportional to the absorbed dose of radiation.

The environmental TLDs at BNL are composed of calcium fluoride $\left(\mathrm{CaF}_{2}\right.$ : Dy) and lithium fluoride (LiF: Mg, Ti). The accuracy of the TLDs is tested with known sources of radiation exposure and using inter-comparison participation programs. The device that reads the dosimeter is calibrated to read absorbed dose, the quantity of energy deposited by radiation in the given material.

To evaluate the potential impact of BNL operations, TLDs are deployed at BNL and off site, where members of the public reside. On-site locations are selected based on the potential for exposure to gaseous plumes, atmospheric particulates, and radiation-generating facilities. The BNL site is divided into grids and the TLDs are assigned numbers based on these grids. The off-site $\because$ TLDs do not have the grid numbers; instead, each is assigned a unique numerical identifier. The on-site and offsite TLDs are collected and read quarterly to determine the direct external radiation dose to members of the public and the environment.

Forty-one TLDs were posted on the BNL site and 17 were deployed off site in 2001, as shown in Figures 8-1 and 8-2, respectively. An additional 30 control TLDs were stored in a leadshielded container in the Instrumentation Building, Bldg.

535. Note that it is not possible to completely shield the control devices

from all natural and cosmic radiation.

Table 8-1 shows the quarterly on-site radiation measurements registered by the TLDs. The average on-site external doses for the first, second, third, and fourth quarters were

Figure 8-1. On-Site TLD Locations. 


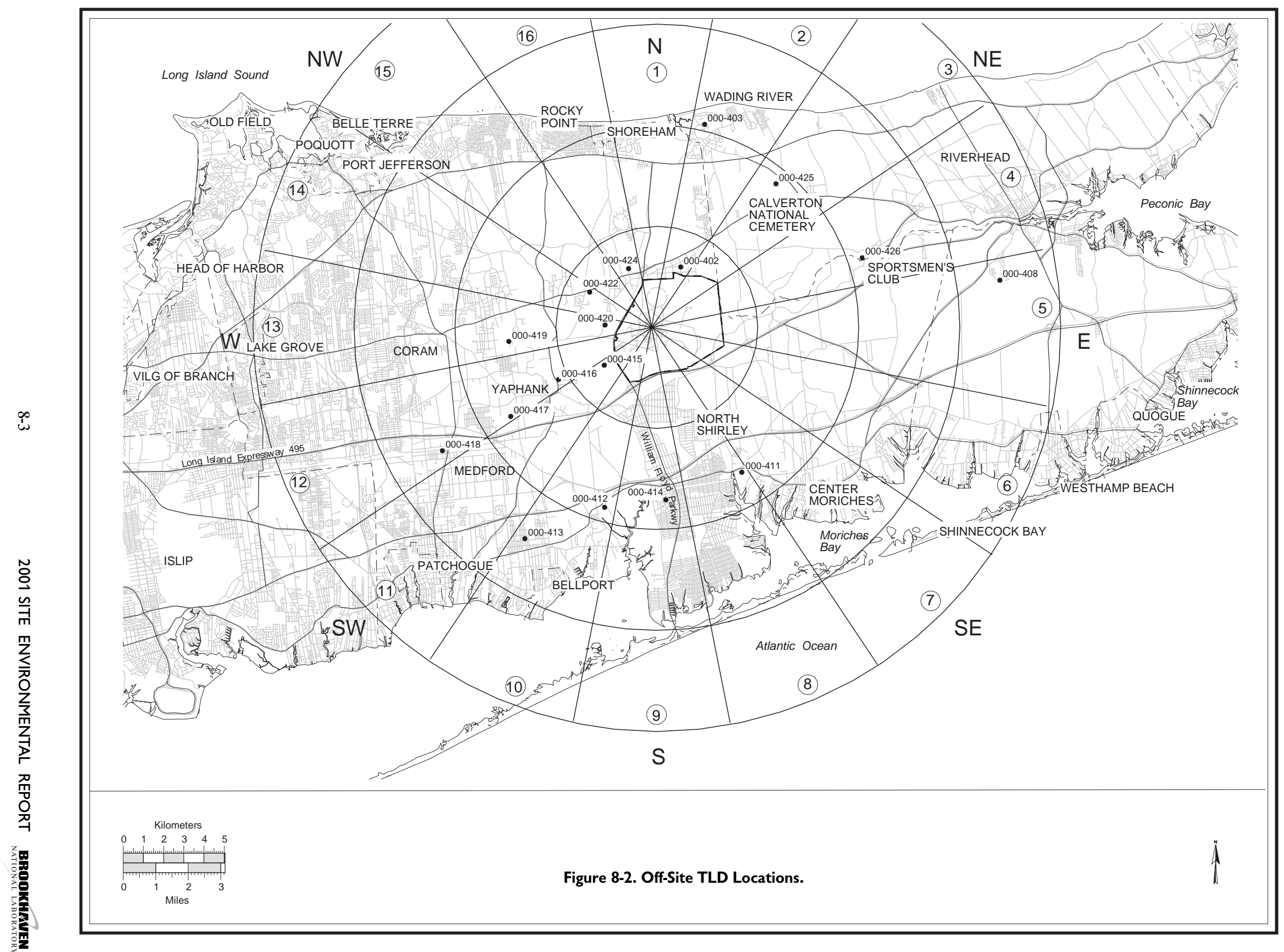


Table 8-1. On-Site Direct Radiation Measurements.

\begin{tabular}{|c|c|c|c|c|c|c|c|}
\hline \multirow{2}{*}{$\frac{\text { TLD\# }}{011-400}$} & \multirow{2}{*}{$\begin{array}{l}\text { Location } \\
\text { North Firebreak }\end{array}$} & \multirow{2}{*}{$\begin{array}{c}\begin{array}{c}1^{\text {st }} \\
\text { Quarter } \\
\text { (mrem) }\end{array} \\
17.0\end{array}$} & \multirow{2}{*}{$\begin{array}{c}\begin{array}{c}2^{\text {nd }} \\
\text { Quarter } \\
\text { (mrem) }\end{array} \\
16.9\end{array}$} & \multirow{2}{*}{$\begin{array}{l}\begin{array}{c}3^{\text {rd }} \\
\text { Quarter } \\
\text { (mrem) }\end{array} \\
18.7\end{array}$} & \multirow{2}{*}{$\begin{array}{c}\begin{array}{c}\mathbf{4}^{\text {th }} \\
\text { Quarter } \\
\text { (mrem) }\end{array} \\
18.9\end{array}$} & $\begin{array}{c}\text { Average } \\
2 \sigma(95 \%)\end{array}$ & $\begin{array}{c}\text { Annual Dos } \\
2 \sigma(95 \%) \\
\text { (mrem) }\end{array}$ \\
\hline & & & & & & $17.9 \pm 2.1$ & $71.5 \pm 8.4$ \\
\hline $013-400$ & North Firebreak & 17.6 & 19.3 & 17.7 & 18.0 & $18.2 \pm 1.5$ & $72.6 \pm 6.1$ \\
\hline $017-400$ & P-2 & 16.5 & 15.9 & 15.2 & 17.2 & $16.2 \pm 1.7$ & $64.8 \pm 6.6$ \\
\hline $025-400$ & Bldg.1010 beam-stop 1 & 20.2 & 18.5 & 16.7 & 18.3 & $18.4 \pm 2.8$ & $73.7 \pm 11.2$ \\
\hline $025-403$ & Bldg.1010 beam-stop 4 & 20.5 & 20.3 & 17.3 & 20.1 & $19.6 \pm 2.9$ & $78.2 \pm 11.8$ \\
\hline $030-400$ & NE Firebreak & 16.9 & 15.7 & 14.7 & 17.8 & $16.3 \pm 2.6$ & $65.1 \pm 10.6$ \\
\hline $034-400$ & North Access Rd & 19.9 & 19.5 & 17.9 & 20.1 & $19.4 \pm 1.9$ & $77.4 \pm 7.8$ \\
\hline 034-401 & North Met. & 19.9 & 18.7 & 20.1 & 20.7 & $19.9 \pm 1.6$ & $79.4 \pm 6.5$ \\
\hline $034-403$ & Bldg.1008 collimator 2 & 19.7 & 20.1 & 17.8 & 18.9 & $19.1 \pm 2.0$ & $76.5 \pm 7.9$ \\
\hline $034-405$ & Bldg.1008 collimator 4 & 22.5 & 20.0 & $N R$ & 22.9 & $21.8 \pm 3.1$ & $87.2 \pm 12.3$ \\
\hline $037-400$ & S-13 & 19.7 & 16.9 & 16.2 & 18.4 & $17.8 \pm 3.1$ & $71.2 \pm 12.2$ \\
\hline $038-450$ & S-5 & 17.6 & 15.6 & 16.3 & 18.2 & $16.9 \pm 2.3$ & $67.7 \pm 9.3$ \\
\hline $044-400$ & Bldg. 1006 & 35.4 & 23.7 & 18.7 & 20.7 & $24.6 \pm 14.6$ & $98.5 \pm 58.3$ \\
\hline $045-400$ & Bldg.1005S & 27.1 & 24.4 & 18.8 & 20.7 & $22.8 \pm 7.2$ & $91 \pm 29.0$ \\
\hline $049-400$ & East Firebreak & 16.8 & 14.7 & 14.6 & 17.8 & $16.0 \pm 3.1$ & $63.9 \pm 12.4$ \\
\hline $053-400$ & West Firebreak & 21.4 & 18.2 & 17.7 & 19.9 & $19.3 \pm 3.3$ & $77.2 \pm 13.2$ \\
\hline $063-400$ & West Firebreak & 19.4 & 17.2 & 17.7 & 21.3 & $18.9 \pm 3.6$ & $75.6 \pm 14.5$ \\
\hline $066-400$ & Sump H-O & 16.7 & 15.4 & 13.8 & 16.4 & $15.6 \pm 2.5$ & $62.3 \pm 10.2$ \\
\hline $073-400$ & West Met/Bldg. 51 & 19.5 & 19.3 & 20.6 & 20.5 & $20.0 \pm 1.3$ & $79.9 \pm 5.2$ \\
\hline $074-450$ & Bldg. 197 & 21.2 & 19.9 & 25.5 & 21.2 & $22.0 \pm 4.8$ & $87.8 \pm 19.1$ \\
\hline $074-451$ & Bldg. 907 & 23.6 & 17.5 & 18.2 & 18.9 & $19.6 \pm 5.4$ & $78.2 \pm 21.5$ \\
\hline $075-402$ & Bldg. 356 & 26.0 & 19.6 & 21.7 & 30.1 & $24.4 \pm 9.1$ & $97.4 \pm 36.4$ \\
\hline $080-400$ & East Firebreak & 18.7 & 16.6 & 17.1 & 22.5 & $18.7 \pm 5.2$ & $74.9 \pm 20.8$ \\
\hline $082-400$ & West Firebreak & 20.6 & 20.1 & 19.2 & 21.8 & $20.4 \pm 2.1$ & $81.7 \pm 8.5$ \\
\hline $084-400$ & Tennis Courts & 19.2 & 17.6 & 18.8 & 20.1 & $18.9 \pm 2.0$ & $75.7 \pm 8.1$ \\
\hline $085-400$ & TFCU (Credit Union) & 21.1 & 19.1 & 21.3 & 19.1 & $20.2 \pm 2.4$ & $80.6 \pm 9.5$ \\
\hline $085-401$ & Upton gas station & 20.0 & 17.5 & 17.1 & 20.0 & $18.7 \pm 3.1$ & $74.6 \pm 12.2$ \\
\hline $086-400$ & BERA ball fields & 20.2 & 18.4 & 18.8 & 21.5 & $19.7 \pm 2.8$ & $78.9 \pm 11.0$ \\
\hline $090-400$ & P-7 & 17.8 & 17.8 & 16.8 & 17.5 & $17.5 \pm 0.9$ & $69.9 \pm 3.7$ \\
\hline $105-400$ & South Firebreak & 18.1 & 18.1 & 18.0 & 23.9 & $19.5 \pm 5.7$ & $78.1 \pm 22.8$ \\
\hline $108-450$ & Water Tower & 17.8 & 19.0 & 18.5 & 18.2 & $18.4 \pm 1.0$ & $73.5 \pm 3.9$ \\
\hline $109-400$ & P-4 & 17.9 & 17.5 & 16.5 & 17.7 & $17.4 \pm 1.2$ & $69.6 \pm 4.9$ \\
\hline $111-400$ & Trailer Park & 17.5 & 16.8 & 17.4 & 18.4 & $17.5 \pm 1.3$ & $70.1 \pm 5.1$ \\
\hline $122-400$ & South Firebreak & 17.2 & 15.1 & 16.6 & 18.2 & $16.8 \pm 2.5$ & $67.1 \pm 10.1$ \\
\hline $126-400$ & South Gate & 19.0 & 17.4 & 16.8 & 20.0 & $18.3 \pm 2.9$ & $73.2 \pm 11.4$ \\
\hline \multicolumn{2}{|c|}{$\begin{array}{l}\text { On-Site Average } \\
2 \text { sigma }(95 \%)\end{array}$} & $\begin{array}{r}20.0 \\
\pm 7.1\end{array}$ & $\begin{array}{r}18.2 \\
\pm 4.1\end{array}$ & $\begin{array}{r}17.4 \\
\pm 4.3\end{array}$ & $\begin{array}{r}19.9 \\
\pm 4.8\end{array}$ & $18.9 \pm 2.5$ & $75.5 \pm 10.0$ \\
\hline $075-000$ & Control TLD average & 9.2 & 9.9 & 9.3 & 10.3 & $9.7 \pm 1.0$ & $38.7 \pm 4.0$ \\
\hline
\end{tabular}

$20.0 \pm 7.1,18.2 \pm 4.1,17.4 \pm 4.3,19.9 \pm 4.8$ mrem, respectively. The yearly on-site external dose was $75.5 \pm 10$ mrem from all potential sources, which includes the contribution from natural radiation sources.

Table 8-2 shows off-site TLD readings, for comparison. The on-site and off-site external dose averages were $75.5 \pm 10$ and $71.5 \pm 7.9$ mrem, respectively. A statistical t-test result showed no variability in the two averages; therefore, it can be concluded that there was no dose contribution from BNL operations.

\subsubsection{Facility Area Monitoring}

Six of the 41 on-site TLDs were posted near facilities that had greater probability to 
Table 8-2. Off-Site Direct Radiation Measurements.

\begin{tabular}{|c|c|c|c|c|c|c|c|}
\hline \multirow{3}{*}{$\frac{\text { TLD\# }}{000-402}$} & \multirow{3}{*}{$\begin{array}{l}\text { Location } \\
\text { Private Property }\end{array}$} & \multirow{3}{*}{$\begin{array}{c}\begin{array}{c}1^{\text {st }} \\
\text { Quarter } \\
\text { (mrem) }\end{array} \\
20.1\end{array}$} & \multirow{3}{*}{$\begin{array}{c}\begin{array}{c}2^{\text {nd }} \\
\text { Quarter } \\
\text { (mrem) }\end{array} \\
20.8\end{array}$} & \multirow{3}{*}{$\begin{array}{c}\begin{array}{c}3^{\text {rd }} \\
\text { Quarter } \\
\text { (mrem) }\end{array} \\
16.9\end{array}$} & \multirow{3}{*}{$\begin{array}{c}\begin{array}{c}\mathbf{4}^{\text {th }} \\
\text { Quarter } \\
\text { (mrem) }\end{array} \\
\text { N.P }\end{array}$} & \multirow{2}{*}{$\begin{array}{c}\text { Average } \\
2 \sigma(95 \%) \\
\text { (mrem) }\end{array}$} & \multirow{2}{*}{$\begin{array}{c}\text { Annual Dose } \\
2 \sigma(95 \%) \\
\text { (mrem) }\end{array}$} \\
\hline & & & & & & & \\
\hline & & & & & & $19.3 \pm 4.1$ & $77.1 \pm 16.2$ \\
\hline $000-403$ & Private Property & NP & 18.0 & 19.1 & 20.9 & $19.3 \pm 2.9$ & $77.4 \pm 11.5$ \\
\hline $000-408$ & Private Property & NP & 17.9 & 15.8 & 17.7 & $17.2 \pm 2.2$ & $68.6 \pm 9.0$ \\
\hline $000-411$ & Private Property & 20.0 & 17.1 & 17.6 & 18.5 & $18.3 \pm 2.5$ & $73.1 \pm 10.0$ \\
\hline $000-412$ & Private Property & NP & 19.4 & 19.8 & 21.5 & $20.2 \pm 2.2$ & $80.9 \pm 8.9$ \\
\hline $000-413$ & Private Property & 19.8 & 15.7 & 14.9 & NP & $16.8 \pm 5.1$ & $67.2 \pm 20.3$ \\
\hline $000-414$ & Suffolk County CD & 17.9 & 17.7 & 18.6 & 19.4 & $18.4 \pm 1.5$ & $73.7 \pm 6.0$ \\
\hline $000-415$ & Private Property & 16.5 & 15.6 & 17.1 & 17.0 & $16.5 \pm 1.4$ & $66.2 \pm 5.4$ \\
\hline $000-416$ & Private Property & 14.9 & 14.6 & 15.0 & 16.8 & $15.3 \pm 1.9$ & $61.3 \pm 7.8$ \\
\hline $000-417$ & Private Property & 17.0 & 17.0 & 17.1 & 19.7 & $17.7 \pm 2.5$ & $70.8 \pm 10.2$ \\
\hline $000-418$ & Private Property & 17.4 & 16.8 & 17.4 & 18.6 & $17.6 \pm 1.5$ & $70.2 \pm 5.9$ \\
\hline $000-419$ & Private Property & 15.8 & 15.7 & 15.2 & 19.1 & $16.5 \pm 3.5$ & $65.8 \pm 14.1$ \\
\hline $000-420$ & Smith Estate & 16.8 & 16.7 & 16.3 & 20.3 & $17.5 \pm 3.6$ & $70.1 \pm 14.4$ \\
\hline $000-422$ & Private Property & 14.7 & 19.8 & 16.4 & 19.5 & $17.6 \pm 4.8$ & $70.5 \pm 19.4$ \\
\hline $000-424$ & Mid-Isl. Game Farm & 18.2 & 17.7 & 17.5 & 20.1 & $18.4 \pm 2.3$ & $73.5 \pm 9.2$ \\
\hline $000-425$ & Calverton Nat. Cem. & 19.1 & 19.0 & 18.5 & 21.8 & $19.6 \pm 2.9$ & $78.4 \pm 11.6$ \\
\hline $000-426$ & Sportsmen's Club & 17.3 & 19.0 & 16.4 & 19.3 & $18.0 \pm 2.7$ & $72.1 \pm 10.9$ \\
\hline \multicolumn{2}{|c|}{$\begin{array}{l}\text { Off-Site Average } \\
2 \text { sigma }(95 \%)\end{array}$} & $\begin{array}{r}17.5 \\
\pm 3.4\end{array}$ & $\begin{array}{r}17.6 \\
\pm 3.3\end{array}$ & $\begin{array}{r}17.0 \\
\pm 2.8\end{array}$ & $\begin{array}{r}19.4 \\
\pm 2.9\end{array}$ & $17.9 \pm 2.0$ & $71.5 \pm 7.9$ \\
\hline \multicolumn{8}{|c|}{$\begin{array}{l}\text { Notes: } \\
\text { NP = TLD not posted at the location. } \\
\text { See Figure 8-2 for TLD locations. }\end{array}$} \\
\hline
\end{tabular}

contribute to the external dose. Table $8-3$ shows the external TLD dose measurements from facility area monitoring. The TLDs posted at the S-6 location adjacent to the old Waste Management Facility, and on the fence there, showed higher external dose than normal background. This can be attributed to the presence of radioactive materials, contaminated soils, and radioactive sources being repackaged for shipment to an off-site disposal site. The old
Waste Management facility is posted as a radiological area; only appropriately trained personnel with dosimeters are allowed inside the facility. The TLD near Building 914 (device 054-400) showed 237 mrem external dose for the first quarter and within the natural background for the third and fourth quarters. The higher reading was attributable to sky-shine phenomenon that occurs during the operation of the $\mathrm{g}-2$ experiment.

Table 8-3. Facility Area Monitoring.

\begin{tabular}{|c|c|c|c|c|c|c|c|}
\hline & & $\begin{array}{c}1^{\text {st }} \\
\text { Quarter }\end{array}$ & $\begin{array}{c}2^{\text {nd }} \\
\text { Quarter }\end{array}$ & $\begin{array}{c}3^{\text {rd }} \\
\text { Quarter }\end{array}$ & $\begin{array}{c}4^{\text {th }} \\
\text { Quarter }\end{array}$ & $\begin{array}{c}\text { Average } \\
2 \sigma(95 \%) \\
\end{array}$ & $\begin{array}{c}\text { Annual Dose } \\
2 \sigma(95 \%) \\
\end{array}$ \\
\hline TLD\# & Location & (mrem) & (mrem) & (mrem) & (mrem) & (mrem) & (mrem) \\
\hline $088-400$ & S-6 & 47.6 & 41.9 & 42.4 & 47.9 & $45.0 \pm 6.3$ & $179.8 \pm 25.3$ \\
\hline 088-401 & S-6 Fence & 67.8 & 52.8 & 60.8 & 212.4 & $98.5 \pm 148.6$ & $393.8 \pm 594.5$ \\
\hline 088-402 & S-6 Fence & 82.8 & 68.4 & 73.1 & 60.6 & $71.2 \pm 18.1$ & $284.9 \pm 72.4$ \\
\hline 088-403 & S-6 Fence & 64.3 & 51.0 & 79.7 & 81.1 & $69.0 \pm 27.7$ & $276.1 \pm 110.9$ \\
\hline 088-404 & S-6 Fence & 85.0 & $N R$ & 55.2 & 53.5 & $64.6 \pm 34.5$ & $258.3 \pm 138.2$ \\
\hline $054-400$ & Bldg. \# 914 & 237.4 & NR & 34.7 & 34.7 & $102.3 \pm 228.2$ & $409.1 \pm 912.8$ \\
\hline
\end{tabular}

Notes:

See Figure 8-1 for TLD locations.

$\mathrm{NR}=\mathrm{TLD}$ dose not reported from the device. 


\subsubsection{Building 650 Sump Outfall Monitoring}

The Building 650 sump outfall is a localized area of radiologically contaminated soils approximately 800 feet northeast of Building 650 . This contamination area is being addressed under the Environmental Restoration Program as Operable Unit (OU) IV, Area of Concern (AOC) 6. Radionuclides identified in the AOC 6 soil include strontium-90, cesium-137, and isotopes of europium and plutonium. The area around the sump is fenced and posted as a radiological area to prevent unauthorized entry. Twenty-one TLDs are located within the sump area; an additional four TLDs are located on the fence, one at each compass direction (north, south, east, and west) (see Figure 8-3). Additionally, two control TLDs are kept in a lead-shielded container to provide background readings for comparison.

The TLD dose was measured for the first, second, and third quarters of 2001, as shown in Table 8-4. The fourth-quarter TLDs were not

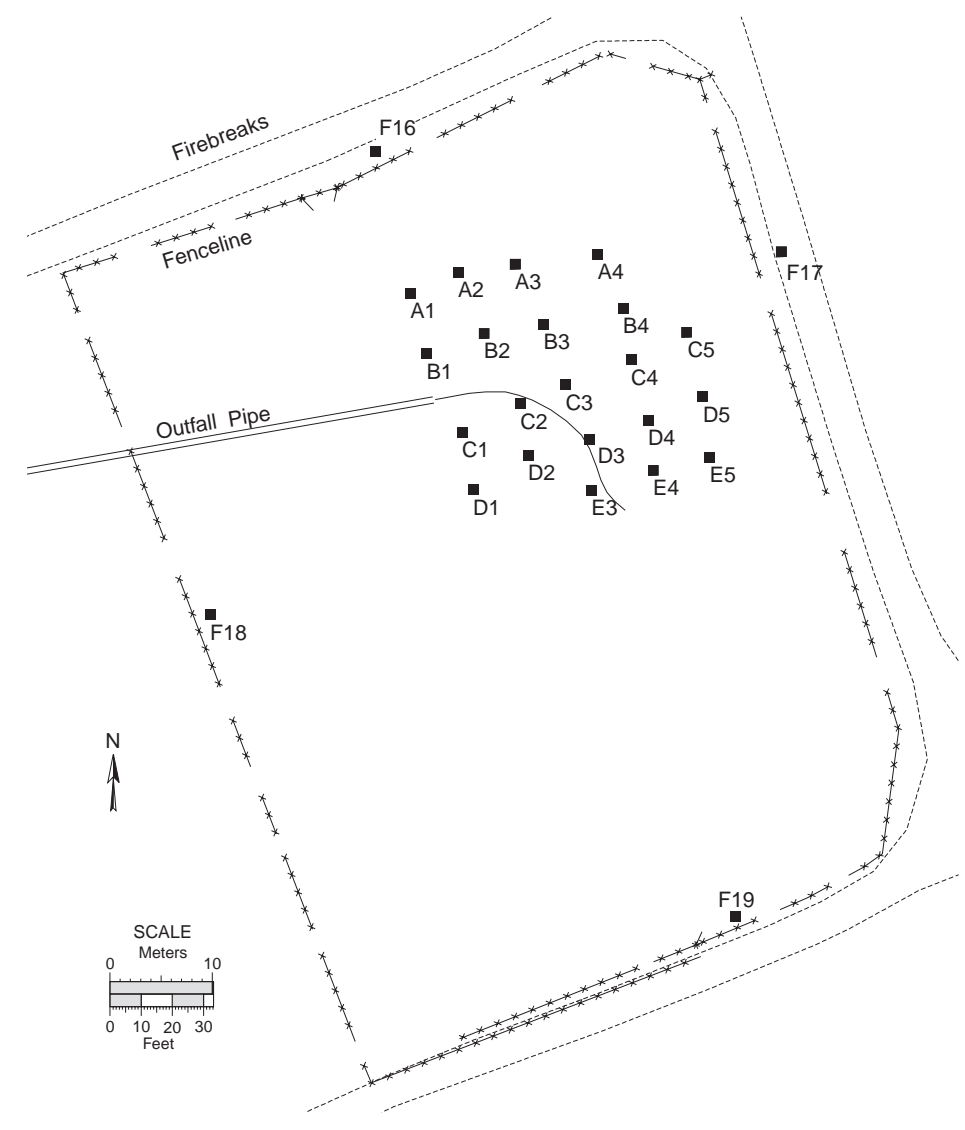

Figure 8-3. Building 650 Sump Outfall TLD Network. posted, as soil remediation work started during this period. Consistent with previous years, the data show that the highest concentration of radionuclides was at the $\mathrm{C} 4$ location. The annual dose measured at $\mathrm{C} 4$ was $1.18 \mathrm{rem}(11.8 \mathrm{mSv})$. The external dose was highest along the grid line C4, D4, and E4. The second highest dose was along the C3, D3, and E3 grid lines. The third highest dose was measured along the $\mathrm{C} 5, \mathrm{D} 5$, and E5 grid lines. The monitoring data and soil characterization data suggest that the soil contamination was mostly spread from B4 to D2 and from $\mathrm{B} 2$ to $\mathrm{E} 5$ grid locations. The contamination reduces to normal background levels toward the fence line.

The dose measurements in all four directions at the fence line of the Building 650 sump area were similar to those of the control background TLDs, demonstrating that the radiation field was localized to the immediate area mentioned above. Entry into the sump outfall area is restricted to authorized personnel, and therefore, there was no exposure hazard to members of the public. Radiological dose to authorized personnel is monitored to ensure that their dose stays below BNL administrative control levels, and is As Low As Reasonably Achievable (ALARA).

\subsection{AIR EMISSIONS}

The U.S. Environmental Protection Agency (EPA) regulates the airborne emissions from DOE facilities under the 40 CFR 61, Subpart H, National Emissions Standard for Hazardous Air Pollutants (NESHAPs) requirements. This regulation specifies the compliance monitoring and requirements for reporting radiation doses received by members of the public from airborne radionuclide emissions. The regulations mandate that no member of the public shall receive a dose from air emissions greater than 10 mrem (100 $\mu \mathrm{Sv}$ ) per year from DOE operations. The emissions monitoring requirements set forth in Subpart H of 40 CFR Section 61.93(b) include the use of a reference method for continuous monitoring at major release points (those with a potential to exceed 1 percent of the $10-\mathrm{mrem} / \mathrm{yr}$ standard), and a periodic confirmatory measurement program for all other release points. The regulations also require DOE facilities to submit 
Table 8-4. Building 650 Sump Outfall TLD Network (2001).

\begin{tabular}{|c|c|c|c|c|c|}
\hline TLD\# Location & $\begin{array}{c}1^{\text {st }} \\
\text { Quarter } \\
\text { (mrem) }\end{array}$ & $\begin{array}{c}2^{\text {nd }} \\
\text { Quarter } \\
\text { (mrem) }\end{array}$ & $\begin{array}{c}3^{\text {rd }} \\
\text { Quarter } \\
\text { (mrem) }\end{array}$ & $\begin{array}{c}\text { Average } \\
2 \sigma(95 \%) \\
\text { (mrem) }\end{array}$ & $\begin{array}{c}\text { Annual Dose } \\
2 \sigma(95 \%) \\
\text { (rem) }\end{array}$ \\
\hline $\mathrm{A} 1$ & 19.5 & 20.3 & 18.5 & $19.4 \pm 1.8$ & $0.08 \pm 0.01$ \\
\hline A2 & 60.2 & 70.5 & 62.7 & $64.5 \pm 10.5$ & $0.26 \pm 0.04$ \\
\hline A3 & 23.6 & 23.7 & 23.8 & $23.7 \pm 0.2$ & $0.09 \pm 0$ \\
\hline A4 & 18.4 & 19.9 & 18.5 & $18.9 \pm 1.6$ & $0.08 \pm 0.01$ \\
\hline B1 & 17.6 & 16.9 & 16.0 & $16.8 \pm 1.5$ & $0.07 \pm 0.01$ \\
\hline B2 & 30.3 & 36.2 & 31.0 & $32.5 \pm 6.3$ & $0.13 \pm 0.03$ \\
\hline B3 & 60.3 & 76.3 & 68.3 & $68.3 \pm 15.6$ & $0.27 \pm 0.06$ \\
\hline B4 & 29.9 & 37.4 & 26.6 & $31.3 \pm 10.8$ & $0.13 \pm 0.04$ \\
\hline C1 & 18.8 & 20.7 & 20.6 & $20.0 \pm 2.1$ & $0.08 \pm 0.01$ \\
\hline $\mathrm{C} 2$ & 36.0 & 45.8 & 44.7 & $42.2 \pm 10.5$ & $0.17 \pm 0.04$ \\
\hline $\mathrm{C} 3$ & 118.4 & 153.6 & 159.7 & $143.9 \pm 43.5$ & $0.58 \pm 0.17$ \\
\hline C4 & 249.7 & 317.2 & 316.1 & $294.3 \pm 75.4$ & $1.18 \pm 0.30$ \\
\hline C5 & 24.6 & 31.5 & 29.5 & $28.5 \pm 6.9$ & $0.11 \pm 0.03$ \\
\hline D1 & 18.3 & 19.2 & 21.5 & $19.7 \pm 3.2$ & $0.08 \pm 0.01$ \\
\hline D2 & 24.0 & 29.6 & 28.0 & $27.2 \pm 5.6$ & $0.11 \pm 0.02$ \\
\hline D3 & 95.1 & 119.4 & 118.8 & $111.1 \pm 27.1$ & $0.44 \pm 0.11$ \\
\hline D4 & 159.7 & 171.3 & 179.9 & $170.3 \pm 19.8$ & $0.68 \pm 0.08$ \\
\hline D5 & 46.4 & 56.5 & 54.7 & $52.5 \pm 10.5$ & $0.21 \pm 0.04$ \\
\hline E3 & 83.5 & 94.5 & 90.8 & $89.6 \pm 10.9$ & $0.36 \pm 0.04$ \\
\hline E4 & 115.9 & 132.9 & 128.8 & $125.9 \pm 17.3$ & $0.5 \pm 0.07$ \\
\hline E5 & 90.5 & 92.8 & ND & $91.6 \pm 3.2$ & $0.37 \pm 0.01$ \\
\hline Fence N & 13.6 & 13.7 & 12.7 & $13.3 \pm 1.1$ & $0.05 \pm 0$ \\
\hline Fence S & 13.2 & 12.5 & 12.2 & $12.6 \pm 1.0$ & $0.05 \pm 0$ \\
\hline Fence $\mathrm{E}$ & 15.8 & 14.1 & 16.7 & $15.5 \pm 2.6$ & $0.06 \pm 0.01$ \\
\hline Fence W & 16.3 & 14.2 & 15.1 & $15.2 \pm 2.1$ & $0.06 \pm 0.01$ \\
\hline BKGD1 & 15.4 & 15.5 & 15.9 & $15.6 \pm 0.2$ & $0.06 \pm 0$ \\
\hline BKGD2 & 13.2 & 14.6 & 14.8 & $14.2 \pm 0.7$ & $0.06 \pm 0.01$ \\
\hline \multicolumn{6}{|c|}{$\begin{array}{l}\text { Notes: } \\
\text { ND = No dose (TLD lost in the field). } \\
\text { See Figure 8-3 for TLD locations. }\end{array}$} \\
\hline
\end{tabular}

an annual NESHAPs report to EPA that describes the air emissions from all sources.

As part of the NESHAPs review process, all BNL programs and diffuse sources that have any potential to produce radioactive airborne emissions were evaluated. Although activities conducted by the Environmental Restoration Division (ERD) that generate airborne emissions are exempt under the Comprehensive Environmental Response, Compensation, and Liability Act (CERCLA), all activities with any potential to emit radioactive emissions were assessed for potential dose to the members of the public. Using the above criteria, a number of ERD and waste management operations were evaluated in 2001 using a computer modeling program (see Section 8.2.1 for details). The program that is used is explicitly designed to model continuous airborne radioactive emissions that occur over the course of a year. It is not well-suited for estimating short-term or acute releases. Given this limitation, the evaluations conservatively treated potential emission sources as if they were continuous annual sources that do not end with the cessation of ERD activities. Since these were diffuse sources with short-term activities, their potential dose impact was not included in the BNL summary of point sources, discussed in Section 8.2.4. Dose from air emissions sources at $\mathrm{BNL}$ is presented in Table 8.5.

\subsubsection{Dose Modeling Program}

Compliance with NESHAPs regulations is demonstrated through the use of EPA's CAP88- 
PC (Clean Air Act Assessment Package-1988), version 2 . This computer code uses a Gaussian plume model equation to estimate the average dispersion of radionuclides released from elevated stacks or diffuse sources (EPA 1992). The program computes radionuclide concentrations in air, rates of deposition on ground surfaces, and concentrations in food (where applicable) to calculate a final value for projected dose at the specified distance from the release point. The program supplies both the calculated effective dose equivalent (EDE) to the maximally exposed individual (MEI) and the collective population dose within a 50-mile radius of the emission source. This model provides very conservative dose estimates in most cases. For purposes of modeling the dose to the MEI, all emission points are located at the center of the developed portion of the BNL site. The modeling programs are based on lowlevel environmental releases and chronic intakes. Model input parameters include radionuclide type, emission rate in curies per year, stack parameters such as height and diameter, and emission exhaust velocity. Site-specific weather and population data were factored into the assessments. Weather data from BNL's meteorological tower included wind speed, direction, frequency, and temperature (details in Climatic data section of Chapter 1). Population data used in the model were based on the Long Island Power Authority population survey (LIPA 1999). Since visiting researchers and their families may reside at the BNL on-site apartment area for extended periods of time, these residents were also included in the population file used for dose assessment.

\subsubsection{Maximally Exposed Individual}

The MEI is defined as a hypothetical person with residence and lifestyle such that no other member of the public can receive a higher dose than this individual. This person is assumed to live 24 hours a day, 365 days a year at the BNL boundary in the downwind direction, and consume contaminated fish and deer during the year. In reality, it is a highly unlikely worst-case scenario that such a combination of maximized dose to any single individual would occur.

\subsubsection{Dose from Diffuse and Nonpoint Sources}

Diffuse sources are sources of radioactive contaminants (emissions) released into the atmosphere that do not have a defined point. Such sources are also known as nonpoint sources or area sources. In 2001, 16 nonpoint sources were evaluated for potential dosage.

\subsubsection{Insulating Gas in the TVDG Accelerator}

The Tandem Van de Graaff Generator (TVDG) Accelerator contains an insulating gas composed of $\mathrm{SF}_{6}$ (50 percent), $\mathrm{N}_{2}$ (35 percent), $\mathrm{CO}_{2}$ (10 percent) and $\mathrm{O}_{2}(5$ percent $)$ by volume. Due to the deuteron beam loss/interaction at the charge-exchange region, thermal neutrons are produced that activate the insulating gas in the accelerator. The total volume of the insulating gas was estimated at 11,250 cubic feet, with a 3 percent loss of insulating gas over the course of one year. A NESHAPs evaluation was completed to assess dose impact to members of the public and the environment. The neutron activation of the insulating gas and air emissions were based on calculations in Appendix 3, Table 6, of Unreviewed Safety Issues (USI) memo dated September 14, 2001 (BNL 2001). A conservative estimate of the effective dose equivalent was $1.9 \mathrm{E}-08 \mathrm{mrem} / \mathrm{year}$ to the MEI at 100 meters northwest of the source.

\subsubsection{Brookhaven Graphite Research Reactor - Below Ground Duct Filters/Coolers Removal}

During 2001, the BGRR work package included removing the primary exhaust filters and exhaust air-cooling coils, then removing and remediating dust and debris left behind. In the Safety Evaluation (BGRR-SE-01-03), a NESHAPs evaluation was completed on the potential reasonable inventory of radionuclides that could be released to the environment. The potential source term was based on 50 percent of the entire maximum inventory listed in the safety scenario as "potentially" released into the environment for the purpose of dose calculations. The remediation project was initiated on November 19, 2001, and was completed on January 15, 2002. The work was performed under a temporary portable tent with HEPA filtration. The potential radiological dose impact from the 
removal of belowground ducts and a cooler was evaluated for NESHAPs compliance, and the potential effective dose equivalent was estimated as $8.7 \mathrm{E}-02 \mathrm{mrem} /$ year to the MEI at the westsouthwest location.

\subsubsection{Brookhaven Graphite Research Reactor - Water Treatment House, Building 709A}

The purpose of this phase of the BGRR decommissioning project was to remove the aboveground Canal House (Building 709) and Water Treatment House (Building 709A). The first part of the activity was to de-energize and remove abandoned equipment from the Canal and Water Treatment Houses; the second part was to demolish the houses to grade elevation. Building 709 had a canal that was connected into the deep pit area of Building 701. Building 709 was metal framed and sided with "cemestos," a mixture of cement and asbetos. It was approximately 39 feet long, 15 feet wide, and 19 feet high, with a layered, builtup roof. When the reactor was refueled, spent fuel was placed into the deep pit and moved underwater to the Canal House, where it was prepared and loaded into casks for shipment. Attached to Building 709 was Building 709A, a concrete block structure approximately 39 feet long, 14 feet wide, and 12 feet high, with a layered builtup roof. It had cells, separated by walls, that contained the water filtering and purification equipment used to maintain the canal's water chemistry and clarity.

The interior surface of both buildings had loose surface contamination that was handled in accordance with the radiological control procedures. The cemestos siding was handled with asbestos abatement procedures. The project was initiated on July 09,2001 and continued into 2002. When a NESHAPs evaluation was completed for potential radioactive airborne emissions, the calculation for potential EDE yielded a conservative estimate of $1.9 \mathrm{E}-03 \mathrm{mrem} / \mathrm{year}$ to the MEI at the northeast location.

\subsubsection{Brookhaven Graphite Research Reactor - Lower Canal and Water Treatment House Removal}

The purpose of this project (BGRR-SE-0102) was to remove the pad area that surrounds the canal and water treatment house, the lower canal-piping system, and the east yard sump, and to remediate surface soil to meet cleanup criteria. The surface soils extended about 120 feet east of Building 701 and 160 feet south of Building 703 . The project was carried out with proper safety and health procedures and in accordance with the radiological control procedures. The potential for radioactive emissions during the removal of this structure was evaluated for NESHAPs compliance. The synopsis report from CAP88-PC, version 2.0, provided a conservative EDE estimate of $1.7 \mathrm{mrem} /$ year to the MEI at the southwest location. Therefore, continuous air sampling and analysis was implemented. The project was started on March 26, 2001 and completed on July 10, 2001. Continuous air sampling of air emissions from the remediation project showed no measurable radioactivity above background on the filters; therefore, there was minimal impact from the project.

\subsubsection{Brookhaven Graphite Research Reactor - Temporary HEPA Filtered Hood}

During the Geoprobe ${ }^{\mathrm{TM}}$ soil boring beneath the belowground ducts at the BGRR, contaminated soil was encountered with readings greater than $140 \mu \mathrm{R} / \mathrm{hr}$. Therefore, it was decided to perform the work under a temporary portable hood with HEPA filtration. The project lasted for a few weeks in August 2001. When the potential effective dose equivalent was evaluated for NESHAPs compliance, the potential effective dose equivalent was estimated as 1.1E-04 mrem/ year to the MEI at the northwest location.

\subsubsection{Building 830 Vault, B-25s, and Drums}

The scope of this project was to characterize and develop a radiological waste profile for the Building 830 vault, ten B- 25 containers, and three 55-gallon drums. The waste content consisted of process pipes, tanks, and sludge and/or tree branches. Characterization and a waste stream profile were necessary, in accordance with waste acceptance criteria (WAC) of the disposal site, before proper shipping and disposal could be accomplished. The waste was repackaged and shipped in accordance with the WAC outlined by Envirocare of Utah. The 
waste characterization process, carried out in August 2001, included a combination of process knowledge, sampling and analysis of the waste, and the In-Situ Object Counting System (ISOCS). When the potential dose from radioactive air emissions was evaluated for NESHAPs compliance, a conservative estimate of the effective dose equivalent was 1.7E-04 $\mathrm{mrem} /$ year to the MEI at the north-northwest location.

\subsubsection{Building 650 Sump Outfall}

Radiological contamination is present in soils at Building 650 (the reclamation facility) and in the sump outfall east of the facility. This facility was used from the late 1950s through late 1960 s to clean radioactive contaminants from clothing and equipment. Radiologically contaminated heavy equipment was decontaminated on a concrete pad adjacent to Building 650 . The liquid drained from this pad was contained in underground storage tanks. In 1969 , it was determined that under certain valve conditions, liquid from the underground tanks was inadvertently being routed to a depression in a wooded area approximately 800 feet northeast of Building 650 . This depression is referred to as the Building 650 Sump Outfall. The sump outfall is a source of localized radiological soil and groundwater contamination that will be remediated under the Environmental Restoration Program (Operable Unit IV, Area of Concern 6). Radionuclides identified in the soil include americium-241, strontium-90, cesium137, cobalt-60, and isotopes of europium and plutonium. The potential for radioactive emissions from the Building 650 Sump Outfall were evaluated for NESHAPs compliance. The potential effective dose equivalent was estimated as $4.0 \mathrm{E}-02 \mathrm{mrem} / \mathrm{year}$ to the MEI at the southwest location.

\subsubsection{Building 811, Underground Storage Tanks}

The remedial action plan for $\mathrm{AOC} 10 \mathrm{C}$ (the Building 811 Waste Concentration Facility) includes removal of six 8,000-gallon stainless steel underground storage tanks (USTs) located about 23 feet below the existing grade. These
USTs were used to store Class A and B radioactive liquid wastes. The radioactive sludge and liquids from the six USTs were removed and stabilized. The USTs were rinsed and an absorbent material was placed at the bottom of the tanks. Small amounts of radioactive materials, as removable and nonremovable contamination, may be present in these tanks. During the dismantling and size reduction process, there was a potential for airborne particulates, so a NESHAPs evaluation was performed in January 2001. The potential effective dose equivalent from radioactive emissions during the dismantling and size reduction phase of the remediation activity was $6.0 \mathrm{E}-03 \mathrm{mrem} / \mathrm{year}$ to the MEI at the southwest location.

\subsubsection{Building 811 Soil Removal}

This remedial action involved the removal of approximately 700 cubic yards of soil in the vicinity of Building 811 . The soil was sprayed with water mist to reduce or eliminate chance that particulates would become airborne during the soil disturbance. Safety standards called for work to be halted if the sustained wind speed reached greater than 25 miles per hour. The immediate area of excavation was monitored and the potential for radioactive emissions from soil excavation activity in the vicinity was evaluated for NESHAPs compliance in May 2001. The effective dose equivalent was estimated to be $8.5 \mathrm{E}-3 \mathrm{mrem} / \mathrm{year}$ to the MEI at the northeast location.

\subsubsection{Tritium Bottles}

Two lecture bottles containing tritium gas were evaluated for release through the High Flux Beam Reactor (HFBR) stack. The total volume of tritium expected to be released from the two lecture bottles was 6.25 cubic feet. The tritium activity in the first lecture bottle, as of 1996, was $20 \mathrm{mCi}$; the second bottle had 0.5 $\mu \mathrm{Ci}$, as of 1998. After decay correction, the quantity of tritium vented was much lower, but the potential airborne source term was based on the information provided on the 1996 and 1998 inventories. The potential effective dose equivalent was estimated to be $8.7 \mathrm{E}-08 \mathrm{mrem} /$ year to the MEI at the northwest location. 


\subsubsection{Plasma Torch Cutting Project}

This project at the former Hazardous Waste Management Facility entailed using a plasma torch to cut up a stainless steel frame (\#35-114 on Radiation Waste Control Form 28098), a half -circle metal plate (\# 65 on RWCF 28061), and a carbon steel plate (\#04-038 on RWCF 38053). The plasma torch cutting method was chosen as it creates less splatter and contamination than other methods of cutting. The WAC specified that the dimensions of the cut pieces would not exceed 10 inches wide and 10 feet long. Approximately 20 cuts were made to the frame and plates to meet the proper acceptance criteria for packaging, transport, and disposal at the waste site. These materials were activated with possible volumetric contamination but had minimal surface contamination. The potential airborne source term was based on the information provided and on previous sampling results. The EDE was calculated to be $5.3 \mathrm{E}-1 \mathrm{mrem} /$ year to the MEI at a distance of 105 meters from the cutting operation. The project was completed between September 10, 2001 and December 21, 2001. The emissions from the operation were monitored and there was insignificant dose impact to the members of the public and the environment.

\subsubsection{Tritium Ball}

The tritium ball was a functional part of the Tandem Van de Graaff Generator in the past but was removed from service and placed in storage at the former HWFM awaiting off-site disposal. The ball was a steel sphere mounted on steel supports. The purpose of the tritium ball project was to reduce the size of the ball and then dispose of the pieces. However, before this project could commence, a small residual inventory of tritium in the ball required evaluation as a potential diffuse source for air emissions. The NESHAPs evaluation was completed and the effective dose equivalent was estimated to be $1.5 \mathrm{E}-6 \mathrm{mrem} / \mathrm{year}$ to the MEI at the southwest location.

\subsubsection{Proposed Booster Applications Facility}

The Department of Energy, the National Aeronautical and Space Administration, and the
Department of Defense have identified a need for a research facility that could conduct space radiation research. The Booster Applications Facility (BAF) would be such a facility, with a new beam tunnel branching from the AGS Booster ring, a target room, and beam stop. A proton or heavy ion beam from the AGS Booster will travel through a 27-meter beam line tunnel, at which point it will be diverted 20 degrees and travel through an 80-meter long beam tunnel, where it will enter the BAF target room. The radiation fields in the target room have the potential to generate air activation products that could be released to the atmosphere. A

NESHAPs evaluation was completed based on the air activation source term and the potential radiological dose impact was estimated to be 9.7E-06 mrem/year at the northeast boundary.

\subsubsection{The V-Target Area, Building 919}

The V-Target project had an expansion tank and vents into an enclosed room. The air was vented through an exterior door. Evaporation of the cooling water from these expansion tanks could potentially generate airborne emissions. Therefore, the project was evaluated for fugitive source emissions. An effective dose equivalent of 5.3E-6 mrem/year to the MEI was estimated at the southwest location.

\subsubsection{Special Experimental Magnets System Cooling Towers}

The Special Experimental Magnets System cooling towers had 200 liters of residual water that was contaminated with tritium, manganese- 54 , and cobalt-60. It was anticipated that a substantial portion of the liquid would evaporate and could be a potential fugitive source for radiological airborne emissions. Therefore, a NESHAPs evaluation was conducted to assess dose impact to the members of the public and the environment. A conservative estimate of the potential effective dose equivalent was $1.7 \mathrm{E}-7 \mathrm{mrem} / \mathrm{year}$ to the MEI at the westsouthwest location.

\subsubsection{Liquid Effluent Storage Tankers}

The Collider-Accelerator Department uses three tankers, each with a capacity of 7,000 gallons, to store radiologically contaminated 
aqueous waste from the Special Experimental Magnets. The tankers are heated and the lid of the tankers has an open vent. It is anticipated that a substantial amount of the liquid will evaporate during the heating and venting of the tankers, and could be a potential diffuse source for radiological airborne emissions. Since the liquid waste has known quantities of tritium, manganese-54, and cobalt-60, a worst-case scenario with maximum concentrations was assumed. A NESHAPs evaluation provided a conservative estimate of effective dose equivalent of $8.6 \mathrm{E}-5 \mathrm{mrem} / \mathrm{year}$ to the MEI at the southwest location.

\subsubsection{Dose from Point Sources}

\subsubsection{Building 931: The Brookhaven Linac Isotope Producer}

As stated in last year's Site Environmental Report, the Brookhaven Linac Isotope Producer (BLIP) tank experienced corrosion due to an accumulation of moisture at the tank base. To mitigate the problem, a dehumidifier system was installed; the system became operational on February 20, 2001. Heated air from this unit is forced down the 16-inch outer diameter shaft, past shielding plugs and into the airspace below the tank. The entry of the dried air into the hot cell exhaust system is on the upstream side of the HEPA filter.

In the past, the BLIP facility was considered a "minor source" that required only periodic confirmatory sampling to show compliance with NESHAPs regulations. In 2000, the BLIP facility operated for just 63 days, from January 02, 2000 to March 16,2000. The facility is continuously monitored for particulates and tritium, but the air emissions of both are insignificant. Short- lived gases are the dominant air emissions and were periodically estimated using the conversion factor of $0.30 \mathrm{mCi} / \mu \mathrm{A}$-hours of operation for oxygen15. However, a unit conversion error was discovered in March 2001 after the stack emissions were sampled in February 2001. The 2000 air emissions were reported based on a corrected conversion factor of $10.8 \mathrm{mCi} / \mu \mathrm{A}$-hours. The total air emissions for the BLIP facility were reported in the 2000 SER at 1,070 curies of oxygen-15 and 2.46E-04 curies of tritium, and the effective dose equivalent was estimated to be 2.2E-03 mrem/year.

The BLIP facility was operational throughout calendar year 2001 except for May through July. In August, the short-lived gaseous characterization project was undertaken to: 1) measure and confirm flow rates; 2) sample, analyze, and quantify the short-lived gases; 3 ) calculate the effective dose equivalent to the MEI; and 4) confirm compliance with NESHAPs regulations. The sampling and analysis were completed in accordance with 40 CFR 61, Appendix B, Method 114. The radioactive gaseous emissions were measured directly with an in-line sampling system from the air exhaust by using a low-level $\mathrm{NaI}$ gamma spectrometer.

The BLIP facility emissions in 2001 were evaluated as contributing an EDE of 0.14 mrem $(1.4 \mu \mathrm{Sv})$ from short-lived gases $\mathrm{O}-15$ and $\mathrm{C}-11$. This dose exceeded 1 percent of the NESHAPs standard, with large uncertainty associated with sampling and characterization of the short-lived gaseous emissions. This dose estimate requires continuous sampling of the source. Historically, BLIP emissions had been characterized as a "minor emissions" source, but during 2001, the emissions exceeded 1 percent of the standard due to extra beam irradiation time. Discussions with EPA were initiated to determine cost effective and acceptable methods to control and/or monitor air emissions from the BLIP facility.

\subsection{INGESTION PATHWAY}

As discussed in Chapter 6, fish from Peconic River and deer that could have grazed on the BNL site were analyzed to assess the potential dose estimates to an MEI. To evaluate the dose impact, it was assumed that the MEI consumed 15 pounds of fish and about 64 pounds of venison per year (NYSDOH 1999).

Twenty-six samples of meat and 15 samples of liver were analyzed from the deer that were involved in car accidents on and off site within a 1-mile radius of BNL. Potassium- 40 and cesium137 were the two radionuclides detected in these samples. The average potassium- 40 concentrations were $2.8 \pm 0.5 \mathrm{pCi} / \mathrm{g}$ in the flesh and $2.4 \pm$ $0.6 \mathrm{pCi} / \mathrm{g}$ (wet weight) in the liver. The average 
Table 8-5. Effective Dose Equivalent from Airborne Emissions.

\begin{tabular}{|c|c|c|c|c|}
\hline Building & Facility or Process & $\begin{array}{l}\text { Construction } \\
\text { Permit No. }\end{array}$ & $\begin{array}{l}\text { MEI Dose } \\
\text { (mrem) }\end{array}$ & $\begin{array}{l}\text { Notes } \\
\text { (a) }\end{array}$ \\
\hline 463 & Biology Facility & None & $2.00 \mathrm{E}-16$ & (b) \\
\hline 490 & Radiation Therapy Facility & BNL-489-01 & $2.00 \mathrm{E}-05$ & (b) \\
\hline $490 D$ & Environmental Biology\& Instrumentation & None & ND & \\
\hline 491 & Brookhaven Medical Research Reactor & None & ND & \\
\hline 510 & Calorimeter Enclosure & BNL-689-01 & $6.00 \mathrm{E}-14$ & (b) \\
\hline 535 & Instrumentation & None & 1.40E-09 & (b) \\
\hline 555 & Chemistry Facility & None & $1.20 \mathrm{E}-14$ & (b) \\
\hline 703 & Analytical Laboratory & None & ND & \\
\hline 725 & National Synchrotron Light Source & None & 8.00E-09 & (b) \\
\hline 750 & High Flux Beam Reactor & None & $2.30 \mathrm{E}-05$ & \\
\hline 801 & Target Processing Lab & None & $3.00 \mathrm{E}-05$ & \\
\hline $802 B$ & Evaporator Facility & BNL-288-01 & ND & \\
\hline 820 & Accelerator Test Facility & BNL-589-01 & ND & (c) \\
\hline 830 & Environmental and Waste Mgmt. & None & ND & \\
\hline 919 & Liquid Effluent Storage Tankers & None & $9.00 \mathrm{E}-05$ & \\
\hline 931 & Brookhaven Linac Isotope Producer & None & 1.40E-01 & \\
\hline 938 & Radiation Effects Facility & BNL-789-01 & ND & (d) \\
\hline 942 & Alternating Gradient Synchrotron Booster & BNL-188-01 & ND & (e) \\
\hline 二 & Relativistic Heavy Ion Collider & BNL-389-01 & ND & \\
\hline \multicolumn{3}{|c|}{ Total from BNL Operations } & 0.14 mrem & \\
\hline \multicolumn{3}{|l|}{ EPA Limit } & 10.0 mrem & \\
\hline \multicolumn{5}{|c|}{$\begin{array}{l}\text { Notes: } \\
\text { (a) "Dose" as used in this table means effective dose equivalent. } \\
\text { (b) Calculations are based on } 40 \text { CFR } 61 \text {, Appendix D methodology. } \\
\text { ND = No-dose facility: Not operational or no air emissions in } 2001 . \\
\text { (c) This has become a zero facility since the original permit. } \\
\text { (d) This facility is no longer in use. } \\
\text { (e) Booster ventilation system prevents air release through continuous air recirculation. }\end{array}$} \\
\hline
\end{tabular}

cesium- 137 concentrations were $1.6 \pm 0.3 \mathrm{pCi} / \mathrm{g}$ in the flesh and $0.6 \pm 0.1 \mathrm{pCi} / \mathrm{g}$ (wet weight) in the liver. Potassium- 40 occurs naturally and is not related to BNL operations. The potential dose from eating deer meat with the average cesium137 concentration was estimated as $2.3 \mathrm{mrem}$ ( 23 $\mu \mathrm{Sv}$ ) per year, about 23 percent of the advisory limit of 10 mrem $(100 \mu \mathrm{Sv})$ set by the New York State Department of Health.
Three fish samples, two largemouth bass and a pumpkinseed fillet, were analyzed for beta/ gamma emitters; again, potassium- 40 and cesium-137 were detected in these samples. These fish samples were collected from Peconic River at Schulz Road just outside the BNL site boundary. The average potassium- 40 concentration was $2.9 \pm 0.1 \mathrm{pCi} / \mathrm{g}$ and the average cesium137 concentration was $0.3 \pm 0.0 \mathrm{pCi} / \mathrm{g}$ wet

Table 8-6. BNL Site Dose Summary.

\begin{tabular}{lccc}
\hline Pathway & $\begin{array}{c}\text { Dose to Maximally } \\
\text { Exposed Individual }\end{array}$ & $\begin{array}{c}\text { Percent of DOE } \\
\mathbf{1 0 0} \text { mrem/year Limit }\end{array}$ & $\begin{array}{c}\text { Estimated } \\
\text { Population Dose }\end{array}$ \\
\hline Air & $0.14 \mathrm{mrem}(1.4 \mu \mathrm{Sv})$ & $0.14 \%$ & 0.57 person-rem \\
Water & None & None & None \\
Ingestion & $2.4 \mathrm{mrem}(24 \mu \mathrm{Sv})$ & $2.40 \%$ & Not tracked \\
All Pathways & $2.5 \mathrm{mrem}(25 \mu \mathrm{Sv})$ & $2.50 \%$ & 0.57 person-rem \\
\hline
\end{tabular}


weight. The potential dose was estimated to be $0.1 \mathrm{mrem}(1 \mu \mathrm{Sv})$ per year from eating 15 pounds of fish.

\subsection{CUMULATIVE DOSE}

The cumulative dose impact to the MEI from the air and ingestion pathways was 2.52 mrem $(25 \mu \mathrm{Sv})$, as shown in Table 8-6. This dose is well below the DOE regulatory limits, $100 \mathrm{mrem}(1,000 \mu \mathrm{Sv})$ and within nominal background levels. The potential dose from drinking water was not estimated, as the residents adjacent to the BNL site get their drinking water from the Suffolk County Water Authority. Table 8-6 summarizes the cumulative dose from the BNL site.

To put the potential dose impact into perspective, a comparison was made with other sources of radiation. The annual dose from all natural background sources and radon is about $360 \mathrm{mrem}(3.6 \mathrm{mSv})$ per year. A chest x-ray would result in 5 to 20 mrem per exposure. Using natural gas in homes yields about 9 mrem per year, cosmic radiation gives $26 \mathrm{mrem}$ per year dose to humans, and natural potassium in the body gives about 39 mrem per year internal dose. Furthermore, the dose estimates from deer and fish consumption are overly conservative.

\subsection{DOSE TO AQUATIC AND TERRESTRIAL BIOTA}

DOE has developed draft screening methods to estimate radiological doses to aquatic animals, terrestrial plants, and terrestrial animals using the environmental surveillance data. These methods can be used to evaluate compliance with the requirements for protection of biota specified in DOE Order 5400.1 (1988), General Environmental Protection Program, DOE Order 5400.5 (1990), Radiation Protection of the Public and the Environment, and proposed Rule 10 CFR 834, Subpart F (66 FR 25380). The absorbed dose to aquatic animals and terrestrial plants should not exceed $1 \mathrm{rad} /$ day ( $10 \mathrm{mGy} /$ day $)$.
Terrestrial animals should not be exposed to more than $0.1 \mathrm{rad} /$ day ( $1 \mathrm{mGy} /$ day $)$. Based on the biota screening methods and very low concentrations detected in the samples, it was concluded that there was insignificant radiological dose to aquatic animals, terrestrial plants, and terrestrial animals from BNL operations.

REFERENCES

BNL. 2001. Appendix 3, Table 6, of Unreviewed Safety Issues (USI) memo dated September 14, 2001.

66 FR 25380. May 14, 2001. U.S. Department of Energy. "10 CFR 834, Radiation Protection of the public and the Environment." Federal Register.

DOE. 2000. A Graded Approach for Evaluation of Radiation Doses to Aquatic and Terrestrial Biota. Proposed Technical Standard. Project No. ENVR-0011. U.S. Department of Energy, Washington, DC. June 2000.

DOE Order 5400.1. 1988. General Environmental Protection Program. U.S. Department of Energy, Washington, D.C. Change 1: 6-29-90

DOE Order 5400.5. 1990. Radiation Protection of the Public and the Environment. U.S. Department Of Energy, Washington, D.C. Change 2: 1-7-93

EML-DOE. 2000. 12th International Intercomparison of Environmental Dosimeters. New York, NY

EPA. 1992. User's Guide for CAP88-PC, Version 2. EPA402B92001. U.S. Environmental Protection Agency. Washington, D.C.

EPA. 1996. Food Ingestion Factors, Exposure Factors HandbookVolume II. EPA600P95002FB. U.S. Environmental Protection Agency. Washington, D.C.

LIPA. 1999. Population Survey 1999: Current Population Estimates for Nassau and Suffolk Counties and the Rockaway Peninsula. Long Island Power Authority. Uniondale, NY. October 1999.

NCRP. 1987. Exposure of the Population of the United States and Canada from Natural Background Radiation. NCRP Report No. 94. National Council on Radiation Protection and Measurements, Bethesda, Maryland.

NYSDOH. 1993. Environmental Radiation in New York State. Bureau of Environmental Radiation Protection, New York State Department of Health, Albany, NY.

NYSDOH. 1996. Radioactive Contamination in the Peconic River. Bureau of Environmental Radiation Protection, New York State Department of Health, Albany, NY.

NYSDOH. 1999. Deer Meat Contaminated With Cs-137 at Brookhaven National Laboratory. Bureau of Environmental Radiation Protection, New York State Department of Health, Albany, NY. 
BROOKHAVEN

NATIONAL

LABORATORY

2001 SITE ENVIRONMENTAL REPORT

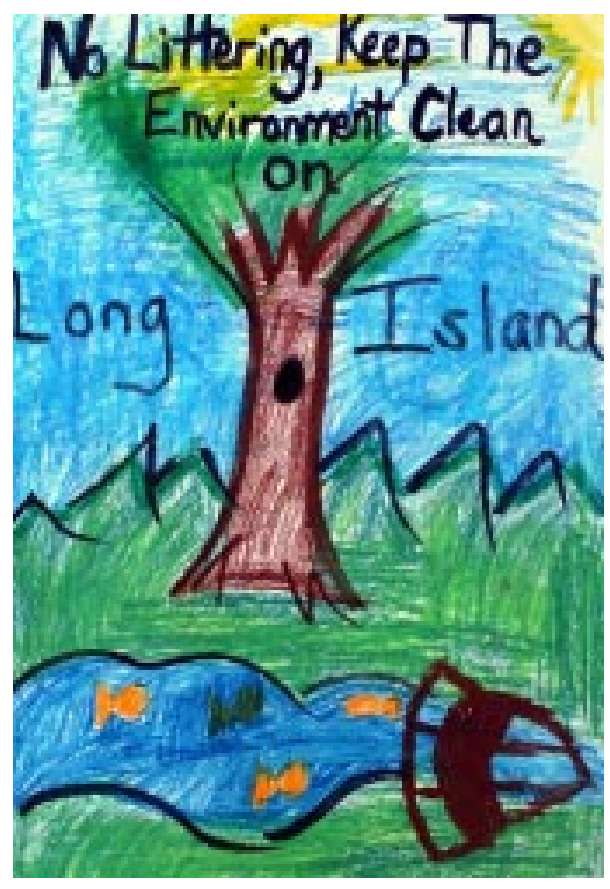

Chapter 9

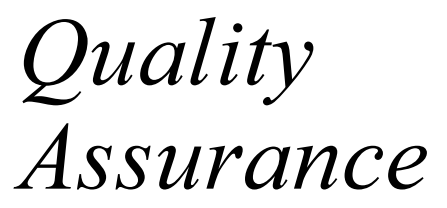

Quality assurance is an integral part of every activity at Brookhaven National Laboratory. A comprehensive program is in place to ensure that all environmental monitoring data meet quality assurance and quality control requirements. Samples are collected and analyzed in accordance with standard operating procedures that are designed to ensure that samples are representative and data are reliable and defensible. Quality control in the analytical laboratories is maintained through daily instrument calibration, efficiency and background checks, and testing for precision and accuracy. Data are verified and validated as required by project-specific quality objectives before they are used to support decision making.

BNL uses the on-site Analytical Services Laboratory and four off-site contractor laboratories to analyze environmental samples. All analytical laboratories are certified by New York State for the tests they perform for BNL and are subject to oversight that includes state and national performance evaluation testing, review of quality assurance programs, and audits.

The two primary laboratories reporting radiological analytical data (BNL and one off-site laboratory) scored 92 percent and 100 percent satisfactory results, respectively, in state and federal performance evaluation programs. This is an improvement from last year's overall score of 89 percent and 95 percent, respectively. In nonradiological performance evaluation testing under the New York State Environmental Laboratory Approval Program (potable and nonpotable water), BNL received a satisfactory rating of 96.8 percent; the three off-site contractor laboratories scored between 93.3 percent and 94.8 percent. BNL's combined score of 96 percent "overall satisfactory" for the 593 radiological and nonradiological performance evaluation tests carried out in 2001 is considered excellent. The multilayered components of Quality Assurance monitored at BNL ensure that all analytical data reported for the 2001 Site Environmental Report are reliable and of high quality. 


\subsection{QUALITY PROGRAM ELEMENTS}

As required by DOE Order 5400.1 (1988), General Environmental Protection Program, BNL has established a Quality Assurance/Quality Control (QA/QC) Program to ensure that the accuracy, precision, and reliability of environmental monitoring data are consistent with the requirements of 10 CFR 830 Subpart A, "Quality Assurance Requirements" and DOE Order 414.1A (2001), Quality Assurance. Responsibility for quality at BNL starts with the Laboratory Director and extends throughout the entire organization. The purpose of the BNL Quality Management (QM) System is to implement QM methodology throughout the various BNL management systems and associated processes to:

- Plan and perform BNL operations in a reliable and effective manner to minimize the impact on the environment, safety, and health of the staff and public

- Standardize processes and support continual improvement in all aspects of BNL operations

- Enable the delivery of products and services that meet or exceed our stakeholders' requirements and expectations.

For environmental monitoring, QA is defined as an integrated system of management activities that includes planning, implementation, control, reporting, assessment, and continual improvement. Quality Control activities measure each process or service against the QA standards. QA/QC practices and procedures are documented in detail in manuals, plans, and a comprehensive set of environmental monitoring standard operating procedures, or "EM-SOPs" (BNL 1999a). Staff who must follow these procedures and plans are required to sign off on the SOPs or receive training.

The ultimate goal of the environmental monitoring and analysis QA/QC program is to ensure that results are representative and defensible and that data are of the type and quality needed to verify protection of the Laboratory and community environment, as well as BNL employees and the public. Figure 9-1 depicts the flow of the QA/QC elements of BNL's Environmental Monitoring Program and indicates the sections of this chapter that discuss each element in more detail.

First, BNL environmental scientists and engineers determine sampling requirements using the U.S. Environmental Protection Agency Data Quality Objective (or equivalent) process. During this process, the team project manager determines the type, amount, and quality of data needed to support decision making, legal requirements, stakeholder concerns, and technical information. Next, the team prepares an environmental monitoring plan or project-specific sampling plan that specifies the location, frequency, type of sample, analytical methods to be used, and a sampling schedule. These plans or the standard operating procedures also specify data acceptance criteria. Contracts with off-site analytical laboratories are established as necessary. Detailed SOPs direct sampling technicians on proper sample collection, preservation, and handling requirements. Field quality control samples are prepared as necessary. Samples are analyzed in the field or at certified laboratories in accordance with SOPs. The results are then validated or verified in accordance with published procedures. Finally, data are reviewed and evaluated by environmental professionals and management in the context of expected results, related monitoring results, historical data, and applicable regulatory requirements (e.g., drinking water standards, permit limits, etc.). Data are then used to support decision making. Data are also reported as required, and summarized annually in the Site Environmental Report. Tables and figures on QA/QC results for calendar year 2001 are presented in this chapter and in Appendix F. Most of the data contained in this report are condensed and summarized from a separate document, Year 2001 ASL Quality Assurance Report (Scarpitta and Heotis 2002).

\subsection{SAMPLE COLLECTION AND HANDLING}

In 2001, environmental monitoring samples were collected as specified by procedures, the BNL Environmental Monitoring Plan (BNL 2000), and project-specific work plans, as applicable. For example, the BNL Groundwater Monitoring Program Quality Assurance Project 


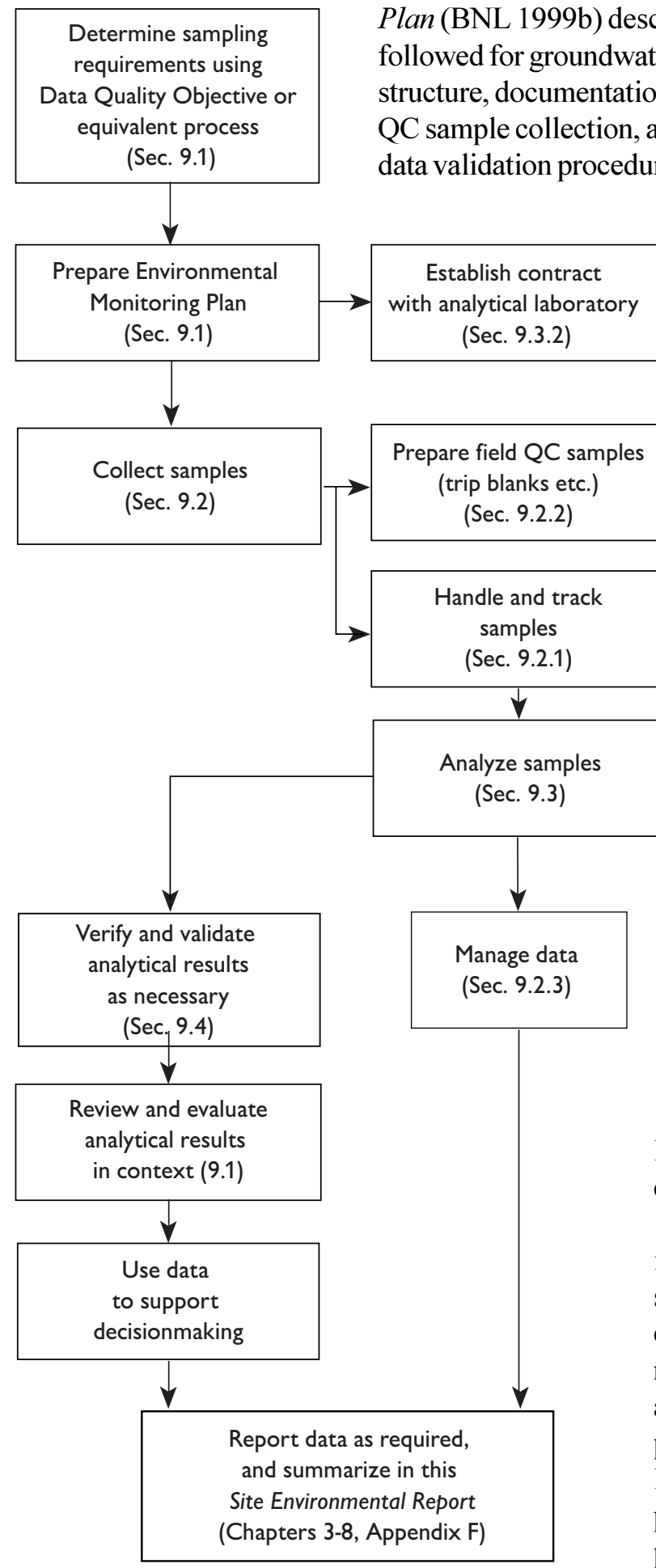

Figure 9-1. Flow of Environmental Monitoring QA/QC Program Elements

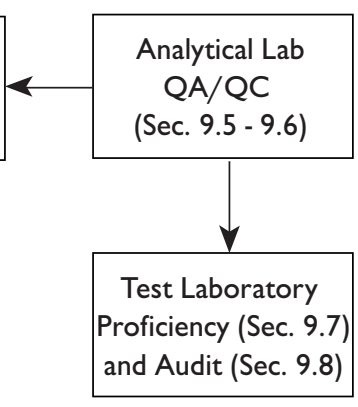

properly collect, handle, and preserve samples; and how to manage any wastes generated during sampling. The procedures ensure consistency between samples collected by BNL employees or outside contractors, whether those samples are col-

lected under the environmental restoration or environmental surveillance programs.

Quality control checks of sampling processes include the collection of field duplicates, matrix spike samples, field blanks, trip blanks, and equipment blanks. In addition, specific sampling methodologies include QC checks, such as field analysis of stability parameters, so that all parameters are within expected or acceptable limits. As another example, the low-flow sampling technique includes checks to ensure proper purging of the monitoring wells.

All wastes generated during sampling (contaminated equipment, purge water from wells, etc.) are managed in accordance with applicable requirements. One factor considered during sample collection is minimizing the amount of waste generated, consistent with the 
Pollution Prevention Program described in Chapter 2. In 1999, BNL implemented new procedures that dramatically reduced the volume of wastewater that is generated when groundwater wells are sampled. These new procedures were EM-SOP-302, Groundwater Sampling Procedure - Low Flow Purging and Sampling Using Dedicated Bladder Pumps, and EM-SOP307, Groundwater Sampling Procedure - Low Flow Purging and Sampling Using NonDedicated Electrical Pumps (BNL 1999a).

\subsubsection{Field Sample Handling}

To ensure the integrity of samples, chain-ofcustody (COC) was maintained and documented for all samples collected. A sample or evidence file is considered to be in the custody of a person if any of the following rules of custody are met: a) the person has physical possession of the sample or file, b) the sample or file remains in view of the person after being in possession, c) the sample or file is placed in a secure location by the custody holder, or d) the sample or file is in a designated secure area. These procedures are outlined in EMSOP-109, Chain-of-Custody Procedure (BNL 1999a). All environmental monitoring samples maintained a valid COC from the time of sample collection through sample disposal.

\subsubsection{Custody and Documentation}

The field sampling team leader was responsible for the care and custody of samples until they were transferred to a receiving group or analytical laboratory. Samples requiring refrigeration were placed immediately into a refrigerator or a cooler with cooling media, and kept under custody rules. The team member who maintained custody of the samples signed the $\mathrm{COC}$ form when relinquishing custody of them. The laboratory or group receiving the samples signed the COC form when accepting custody.

The sampling team is also required to maintain a bound, weatherproof logbook. When samples are collected, the logbook is used to record sample designation, collection time, description, and collection method, as well as notes on daily weather conditions, field measurements, and other appropriate sitespecific observations.

\subsubsection{Preservation and Shipment}

Samples shipped to off-site laboratories were managed as follows. Before sample collection, the team prepared all bottle labels and put them on the appropriate containers, as defined in the QA Program Plan and/or applicable EM-SOPs. Appropriate preservatives were added to the containers before or immediately after collection; in appropriate cases, samples were refrigerated.

Sample preservation was maintained as required throughout shipping. If samples were sent via commercial carrier, a bill-of-lading was used. COC seals were placed on the shipping containers; their intact status indicated that custody was maintained during shipment.

\subsubsection{Field Quality Control Samples}

Field QC samples collected for the Environmental Monitoring Program include equipment blanks, trip blanks, field blanks, field duplicate samples, and matrix spike/matrix spike duplicate samples. The rationale for selecting specific field QC samples and minimum requirements for their use in the Environmental Monitoring Program are provided in EM-SOP200, Collection and Frequency of Field Quality Control Samples (BNL 1999a). Equipment (rinsate) blanks and trip blanks were generally collected for all media except air and flora and fauna.

An equipment blank is a volume of solution (in this case, laboratory-grade water) that is used to rinse a sampling tool before sample collection. The rinsate is collected to demonstrate that the sampling tool was not contaminated. Equipment blank samples were collected, as needed, to verify the effectiveness of the decontamination procedures on nondedicated or reusable sampling equipment. For the groundwater monitoring program, equipment blanks were collected from the final rinse water that was generated during decontamination.

A trip blank is provided with each shipping container of samples to be analyzed for volatile organic compounds (VOCs). Analysis of trip blanks shows whether a sample bottle was contaminated during shipment from the manufacturer, while in bottle storage, in shipment to the laboratory, or during analysis at a lab. For 
the Groundwater Monitoring Program, trip blanks consist of an aliquot of distilled water sealed in a sample bottle, prepared either by the analytical laboratory prior to shipping the sample bottles to BNL or by field sampling personnel. Under the Groundwater Monitoring Program, trip blanks were included with all shipments of aqueous samples for VOC analysis.

Field blanks were collected to check for cross-contamination that might occur during sample collection. For the Groundwater Monitoring Program, one field blank was collected for every twenty samples, or one per sampling round, whichever was more frequent. On any given day, the field blanks were analyzed for the same parameters as the groundwater samples.

Contaminants in trip, field, and equipment blanks included methylene chloride, acetone, toluene, and phthalate esters. When these contaminants were detected, validation and/or verification procedures were used, where applicable, to qualify the associated data as nondetects, as described in procedures EM-SOP203 through 211 (see Section 9.4). The results from blank samples collected during 2001 did not indicate any significant impact to the quality of groundwater results. Typically, the only compounds detected in the blanks were toluene, chloroform, methylene chloride, and acetone. These compounds are commonly detected in blanks and do not pose significant problems with the interpretation of the analytical results.

Field duplicate samples were analyzed to check the reproducibility of sampling and analytical results. For the Groundwater Monitoring Program, duplicates were collected for 5 percent of the total number of samples collected for a project per sampling round. Table F-1 in Appendix F summarizes the number of field duplicate samples collected during 2001 that were acceptable for input into the Environmental Information Management System (EIMS) database. Field duplicate acceptability was based on EPA Region II guidelines (EPA 1996).

The relative percent difference for concentrations above the contract reporting limits is required to be less than 20 percent between the sample and the duplicate (see Section 9.6.3 for more information on the relative percent difference statistic). Although there were several instances where individual compounds did not meet the 20 percent relative percent difference limit, the overall list of parameters analyzed for those samples did meet the 20 percent requirement. This indicated that the field sampling personnel and the laboratories were performing the sampling analyses at a consistently high level of quality.

Matrix spike and matrix spike duplicates for organic analyses were performed to determine whether the sample matrix adversely affected the sample analysis. Matrix spikes are used to evaluate the effect of the sample matrix on the accuracy of a specific analysis and to evaluate the precision of a specific analysis. They were performed at a rate of approximately one per twenty samples collected per project. For groundwater samples, no significant matrix effects were observed.

Several results for media other than groundwater were considered suspect after field quality control sample results were evaluated. These specific instances are discussed in detail in Chapters 3 through 8 .

\subsubsection{Tracking and Data Management}

\subsubsection{Sample Tracking}

Most Environmental Monitoring Program samples and analytical results were tracked in the Environmental Information Management System. Tracking was initiated when a sample was recorded on a COC. Copies of the COC form and supplemental forms were provided to the project manager or the sample coordinator and forwarded to the data coordinator to be entered into the EIMS. Each analytical laboratory also maintains its own internal sample tracking system.

\subsubsection{Data Management}

Data management procedures are in place to govern tracking, validation, verification, and distribution of the analytical data. When samples were shipped to an analytical laboratory, COC information was entered into the EIMS. Following sample analysis, the laboratory 
provided the results to the project manager or designee and, when applicable, to the validation subcontractor in accordance with their contract.

\subsubsection{Distribution of Analytical Data}

Once data were entered into the Environmental Information Management System, reports were generated by one of two means. Project personnel and DOE-Brookhaven Area Office staff have a data query tool that allows access to all analytical sample results and printed reports. If a project required a special report format, the data management group was contacted to design and print it.

\subsection{SAMPLE ANALYSIS}

Environmental samples were analyzed either by the on-site BNL Analytical Services Lab (ASL) or by one of four contractor laboratories, whose selection is discussed in Section 9.3.2.

All samples were analyzed according to EPA-approved methods, where such methods exist. Where no EPA-approved methods exist, standard industry methods were approved by BNL personnel. In addition, sampling technicians performed field analyses of certain wastewaters for residual chlorine and $\mathrm{pH}$.

Samples sent off site for radiological analyses were those requiring methods (either EPA or DOE) that ALS does not perform, such as actinide analyses in soil, vegetation, animal tissue, and water. Most samples used to verify compliance with permitting requirements were sent off site, as were samples requiring semivolatile organic analysis or the toxicity characteristic leachate procedure (TCLP). In addition, when demand exceeded ASL capacity, some samples to be tested for strontium-90, metals, and polychlorinated byphenyls (PCBs) were sent to a contractor laboratory.

\subsubsection{ASL Qualifications}

BNL's ASL performs approximately 5,000 radiological and nonradiological (chemical) analyses per year on environmental samples to support both environmental monitoring and facility operations. The ASL is certified by the New York State Department of Health (NYSDOH) for tritium, gross alpha/beta, and gamma in potable and nonpotable water analysis in several matrices, all of which are approved EPA methods.

\subsubsection{Contractor Lab Qualifications}

BNL procured and maintained contracts with the following off-site laboratoriess:

- General Engineering Lab (GEL) in Charleston, South Carolina, for radiological and nonradiological analytes

- H2M Lab in Melville, New York, for nonradiological analytes

- Severn-Trent Lab (STL) in Monroe, Connecticut and St. Louis, Missouri, for radiological and nonradiological analytes

- Chemtex Lab in Port Arthur, Texas, for select nonradiological analytes.

The process of selecting contractor laboratories involves a number of factors: 1) their record on proficiency evaluation (PE) tests, 2) preselection bidding, 3) post-selection auditing, and 4) their adherence to their own QA/QC programs. Once a contract has been awarded, the laboratory must follow the QA requirements and analytical and QC requirements in the BNL Statement of Work. Routine QC procedures that labs must follow, as discussed in Section 9.5, include daily instrument calibrations, efficiency and background checks, and standard tests for precision and accuracy. All the analytical labs that BNL uses are certified by NYSDOH for the relevant analytes. The laboratories also are subject to PE testing (Section 9.7) and audits (Section 9.8).

\subsection{VERIFICATION AND VALIDATION OF ANALYTICAL RESULTS}

Environmental monitoring data are subject either to data verification or data validation performed in accordance with established procedures, when the data quality objectives of the project require this step. The data verification process involves checking for common errors associated with analytical data. The following criteria cause data to be rejected during the data verification process:

- Holding time missed - The analysis was not initiated or the sample was not extracted within the time frame required by EPA or by the contract. 
- Incorrect test method - The analysis was not performed according to a method required by the contract.

- Poor recovery - The compounds or radioisotopes added to the sample prior to laboratory processing were not recovered at the recovery ratio required by the contract.

- Insufficient $Q A / Q C$ data - Supporting data received from the analytical laboratory were insufficient to allow validation of results.

- Incorrect minimum detection limit (MDL) The laboratory reported extremely low levels of analytes as "less than minimum detectable," but the contractually required limit was not used.

- Invalid chain-of-custody - There was a failure to maintain proper custody of samples, as documented on chain-ofcustody forms.

- Instrument failure - The instrument did not perform correctly or was broken.

- Preservation requirements not met - The requirements identified by the specific analytical method were not met or properly documented.

- Contamination of samples from outside sources.

- Matrix interfaces.

- Incomplete data package or report.

Data validation is a more exhaustive process that includes all the verification checks as well as checks for less common errors, including calibration that was not conducted as required, internal standard errors, transcription errors, and calculation errors.

The amount of data that is checked varies, depending on the environmental media and on the data quality objectives for each project. Data for some projects, such as long-term groundwater monitoring, may be verified only. Data from initial investigations receive the more rigorous validation testing, performed on 20 percent to 100 percent of the analytical results. The results of the verification or validation process are entered into the EIMS.

\subsubsection{Verifying and Validating ASL Results}

For samples analyzed by Brookhaven's Analytical Services Lab in 2001, the QA officer or group leader verified that all analytical batches fulfilled internal QA/QC acceptance criteria. These criteria, which include precision, accuracy, recovery, instrument background checks, and stable instrument efficiency performance, are fully described in ASL's QA Program Plan (BNL 1999c). All QA/QC data were reviewed before ASL results were reported.

\subsubsection{Verifying and Validating Off-Site Results}

A subject matter expert in either radiological analyses or analytical chemistry reviewed a percentage of the 2001 results from off-site labs. Nonradiological data analyzed off site were verified and validated using EPA Contract Laboratory Program guidelines (EPA 1992, 1996). Radiological packages were verified and validated using BNL and DOE guidance documents (BNL 1997, DOE 1994).

\subsection{ANALYTICAL LABORATORY QA/QC}

Sample results for environmental restoration and environmental surveillance were analyzed by the on-site BNL lab ASL, or by one of the offsite contract labs: STL, GEL, or H2M.

For ASL analyses, procedures for calibrating instruments, analyzing samples, and assessing quality control (Appendix D) are consistent with EPA methodology. QC checks that were performed include analyzing blanks and instrument background; using Amersham Radiopharmaceutical Company or National Institute for Standards and Technology (NIST) traceable standards; and analyzing reference standards, spiked samples, and duplicate samples. The ASL supervisor, QA officer, or group leaders reviewed all ASL analytical and QA results before data were reported. More details of the ASL QA program are in Section 9.6.

Off-site contractor laboratories that perform radiological and chemical analyses for BNL also are required to maintain stringent $\mathrm{QA}$ programs. Their contracts specify analytes, methods, required detection limits, and deliverableswhich include standard batch QA/QC performance checks. As part of the contract lab selection process, contract labs were required to provide BNL with copies of their QA/QC manuals, as well as their QA program plans. 
A nonconformance report was generated when discrepancies were found in field sampling designs, documented procedures, chain-ofcustody forms, data analyses, data processing systems, QA software, or when failures in PE testing occurred. Following an investigation into the root cause, corrective actions were made and tracked to closure.

\subsection{ASL INTERNAL QUALITY ASSURANCE PROGRAM}

This section further describes the QA requirements for analytical activities conducted as part of the 2001 BNL Environmental Monitoring Program, and the results of QA checks. ASL's nonradiological chemical group is certified by the NYSDOH Environmental Laboratory Approval Program (ELAP) to perform analyses utilizing EPA Methods 524 and 624 for volatile organic analytes, in potable and wastewaters, respectively. Thirty-seven VOCs are currently provided for analysis with Method 624 (for ground and wastewaters), an additional 26 new analytes since 1998. EPA Method 524 (for potable water) includes 63 organic analytes and was a new addition to ASL's capabilities. Metals are analyzed utilizing both atomic absorption spectroscopy and inductively coupled plasma/mass spectroscopy by EPA methods. ASL is certified for analyses of 17 metals (the entire ELAP list) in potable water as well as 21 metals in wastewater. Certification for three anions has been established for potable and wastewaters using EPA Method 300.

In May 1999, ASL issued its own $Q A$ Program Plan (BNL 1999c) following EPA Region II guidelines (EPA 1998). Twenty-five internal operating procedures maintained by ASL were also revised in 2000 and into 2001. The QA procedures followed at ASL include daily instrument calibrations, efficiency and background checks, and routine tests for precision and accuracy. A detailed description of these activities can be found in the document titled Year 2001 Quality Assurance Report of the Analytical Services Laboratory (Scarpitta and Heotis 2002). A brief summary of that report follows.

\subsubsection{Radiological Instrument Calibrations}

ASL operates eight high-purity germanium gamma detectors. Each detector was calibrated daily for energy and instrument efficiency using a NIST-traceable cesium-137 standard. Geometry efficiency calibrations are performed annually. Efficiency is the measure by which radiological decaying events are converted into observable counts (counts per minute). During 2001, all eight gamma detectors performed well within the EPA acceptance limit of $1 \mathrm{keV}$ of the $662 \mathrm{keV}$ centroid peak.

ASL operates two gross alpha/beta (GAB) detectors and two liquid scintillation spectrometers for tritium. Instrument background and count-time are used to determine the "minimum detection limit" (MDL) of a radiological analyte. In 2001, there was no unusual drift or variability in instrument background for alpha, beta, and tritium, based on the mean background count-rates (and one standard deviation) values. Instrument efficiencies were determined daily, using a calibration standard, and averaged for the calendar year.

\subsubsection{Upgrades}

The following upgrades, improvements, or repairs were made within the ASL in 2001. In February 2001, the gamma spectroscopy system was shut down for backup and the computer disk drive was replaced. The system was reconfigured and calibrated using a mixed gamma radionuclide particulate standard. Two sigma uncertainties were reported for gamma results, where previously, one sigma uncertainty was reported. In July, one of eight gamma detectors was sent to the manufacturer for repairs and returned to service in August.

In June, one of the alpha/beta units was taken out of service for approximately two weeks due to a sensor that needed replacement.

A new liquid scintillation counter (LSC) was purchased, replacing an older unit. New quench curves were generated for both units after a new tritium standard was acquired and a QSMART Upgrade Kit was installed on one of the two LSC units. The computer, monitor, and printer were also replaced. A tritium adjustment factor was 
applied to all tritium data in 2001, resolving the bias problem described in Section 9.6.3.2.

\subsubsection{Accuracy and Precision}

Accuracy is the percent difference between a measured value and its known (expected) value. Precision is the percent difference between two measured values. The measure of batch precision is the "relative percent difference" statistic. This is defined as the absolute difference between two results, divided by the average of both results, multiplied by 100 . Typically, a radioactive tracer solution (i.e., "spike") is added to either a routine sample or tap water sample as a means of determining both precision and accuracy. In the case of nonradiological analyses, the spike is a known amount of a given analyte added to a sample and the accuracy is stated as "percent recovery": the ratio of the measured amount, divided by the known (spiked) amount, multiplied by 100 .

\subsubsection{Gross Alpha/Beta}

For gross alpha/beta, the relative percent difference was determined for each batch of analyses performed. Tap water was spiked with known amounts of americium-241 (for alpha) and strontium/yttrium-90 (for beta) in order to determine batch precision. The acceptance criterion for batch precision is a relative percent difference less than 20 percent (for activity concentrations that are five times greater than the method MDL). During 2001, gross alpha/beta batch precision for all 268 batches tested was within the acceptable range; there were no rejected batches.

\subsubsection{Tritium}

Tritium precision was determined for 334 batches processed in 2001. ASL utilizes three sampling protocols for differing sample volumes (i.e., $7 \mathrm{~mL}$ distilled, $7 \mathrm{~mL}$ undistilled, and $1 \mathrm{~mL}$ undistilled). A negative 20 percent tritium bias was observed beginning in the last quarter of CY2000 and into part of CY2001 for the distilled $7 \mathrm{~mL}$ tritium using EPA Method 906.0. This bias was not evident in the $1-\mathrm{mL}$ tritium analyses. All internal QA/QC records and logs were reviewed and the primary cause of the problem was eventually isolated. The six-month investigation revealed that differences in scintillation reagent accounted, in part, for most, but not all, of the observed bias. After a new tritium standard was purchased and new quench curves prepared, a negative 10 percent bias still persisted into CY2001. A new LSC was purchased in the spring of 2001 and the bias was still about negative 11 percent.

Since no root cause of the negative 11 percent bias was discovered, the ASL adjusted all 7-mL tritium results for the bias of the day, regardless of instrument. Blind proficiency evaluation test scores for tritium were satisfactory. There were no rejected batches for tritium in 2001.

\subsubsection{Strontium-90}

The eight batches of strontium-90 processed in 2001 all met standard precision and accuracy requirements. There were no rejected batches.

\subsubsection{Nonradiological Organic and Inorganic Analyses}

Method precision was determined for 14 volatile organic compounds, 3 anions (discussed below), and 21 metals processed by ASL in 2001. With the exception of 3 metals, all analytes had relative percent differences within ASL's internal acceptance limit of \pm 20 percent. The three standard deviation uncertainties were also within the EPA acceptance criteria.

ASL has an internal QC program for the ion chromatography, ICP/MS, and atomic absorption methods used for inorganic analyses. Several QC checks were performed for each batch of metals and anions. For the 21 certified metals analyzed by ASL, beryllium, zinc, and aluminum exceeded the three standard deviation EPA acceptance criteria for recovery. For these three metals, this was attributable to a single daily excursion that resulted in an overall three-sigma standard deviation value that was higher than acceptable. For this reason, analytical data for aluminum, zinc, and beryllium for the months in question were "qualified" but still usable.

ASL has an internal QC program for the gas chromatography/mass spectroscopy method used for 14 primary VOCs. Recoveries and 99 percent confidence intervals were determined for 69 independent VOC batches. Average recoveries for 
all of the 14 analytes were within their target ranges of \pm 25 percent for both EPA 524.0 and EPA 624.0 methods.

The 99 percent confidence intervals for surrogate recoveries were also determined for four analytes in 2001 . The recovery for 4bromofluorobenzene, toluene, and dibromofluoromethane were within three-sigma acceptance criteria. All surrogate recoveries were within EPA acceptance limits.

\subsection{PROFICIENCY EVALUATION TESTING}

As in prior years, ASL and three contractor laboratories (GEL, STL, and H2M) participated in several national and state proficiency evaluation testing programs. Results of those PE tests provide information on the quality of a laboratory's analytical capabilities.

During 2001, ASL, GEL, STL, and H2M participated in either the NYSDOH ELAP (for radiological and nonradiological proficiency evaluation testing) or the DOE Environmental Measurements Laboratory (EML) Quality Assessment Program (for radiological PE testing only). These laboratories participated in at least one proficiency evaluation program, although several labs participated in multiple programs. The results from these blind, independent tests are discussed in Section 9.7.1.

Effective December 21, 1998, EPA terminated its PE programs for both radiological and nonradiological analytes. To replace that program, ASL chose Environmental Resource Associates (ERA), a private, independent PE program.

PE test data are not presented in this report for the fourth contractor, Chemtex Laboratory, because there are no ERA or NYSDOH PE testing programs for the specific analytes analyzed by this laboratory. Chemtex performed four chemical analyses for BNL on the following analytes: dibromo-nitrilopropionamide, tolytriazole, polypropyleneglycol-monobutyl-ether, and 1,1hydroxyethylidene-diphosphonic acid.

\subsubsection{Summary of Test Results}

During 2001, ASL's (BNL's) scores on radiological PE tests in the NYSDOH ELAP and
DOE EML program were 100 percent and 95.3 percent “Overall Satisfactory," respectively. BNL's off-site contractor laboratory for radiological work, GEL, scored 100 percent in both programs. In the voluntary ERA radiological program, BNL and GEL achieved scores of 91.3 percent and 96 percent, respectively.

For nonradiological results, the Overall Satisfactory results ranged from 86 percent to 99 percent for BNL, H2M, GEL, and STL in both the ERA and NYSDOH testing programs.

BNL's combined score of 96 percent Overall Satisfactory on the 593 radiological and nonradiological PE tests performed in 2001 is considered excellent.

Figures 9-2 and 9-3 summarize the 2001 scores of BNL's ASL and the three contractor laboratories that participated in the mandatory DOE EML program (for radiological analytes only) and the NYSDOH ELAP, as well as the voluntary ERA program. The bar graphs of Figures 9-2 and 9-3 summarize all tabulated radiological and nonradiological results (as percentage scores) that were "Acceptable," "Warning (But Acceptable)," or "Not Acceptable," for each analytical laboratory, by PE test program. A Warning is considered "Satisfactory," being within two and three standard deviations of the target value. (An "Overall Satisfactory" score is the sum of results rated as Acceptable and those rated as Warning, divided by the total number of results reported.) A "Not Acceptable" rating reflects a result that is greater than three standard deviations of the target value. Tabulated results are presented in Appendix $\mathrm{F}$ and described in detail in Sections 9.7.2 and 9.7.3.

\subsubsection{Radiological Assessments}

Both ASL and GEL participated in the DOE EML Quality Assessment Program, the NYSDOH ELAP, and the ERA program. Results are detailed in Appendix F, Tables F-2 through F-4, and discussed below.

\subsubsection{Table F-2: EML Radiological Results}

Overall, ASL's performance in the EML program was satisfactory in 95.3 percent of the analyses performed on four matrices (air, vegetation, water, and soil). Thirty-six of 43 


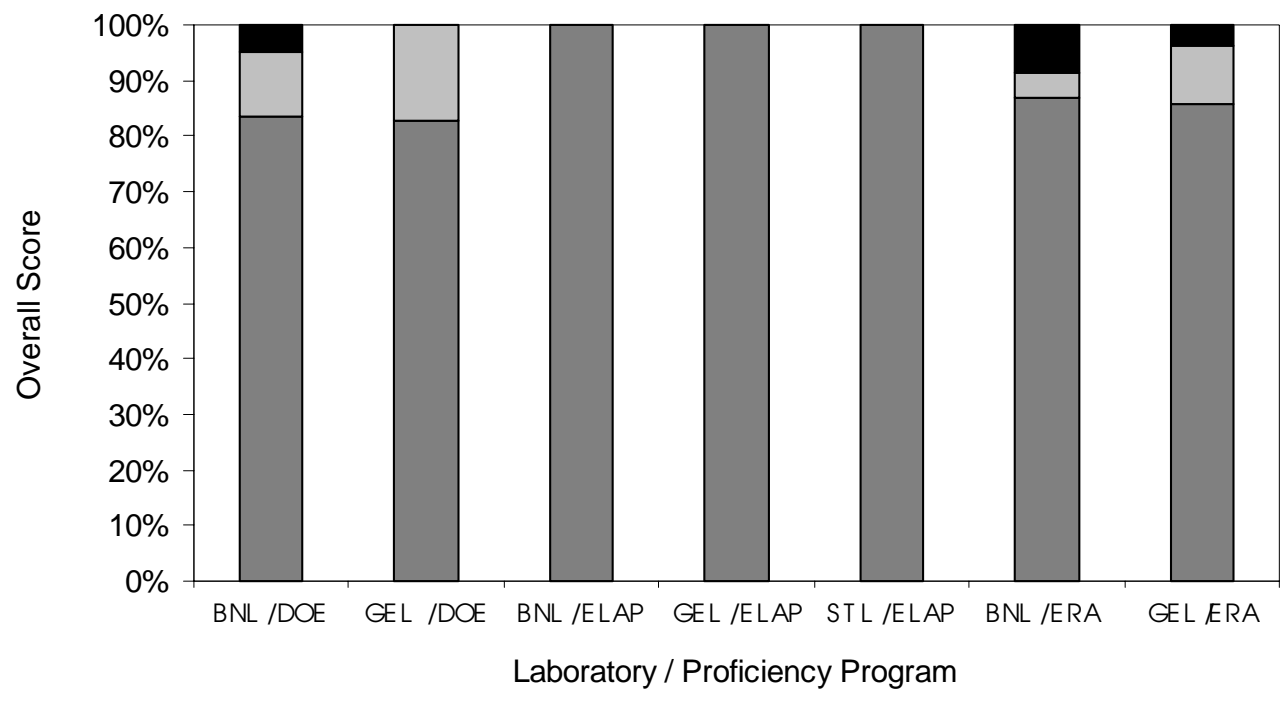

$\square$ Acceptable $\square$ Warning (But Acceptable) $\square$ Not Acceptable

Figure 9-2. Radiological Results Summarized: Labs' Scores in US DOE/EML, NYSDOH ELAP, and ERA PE Programs for 2001.

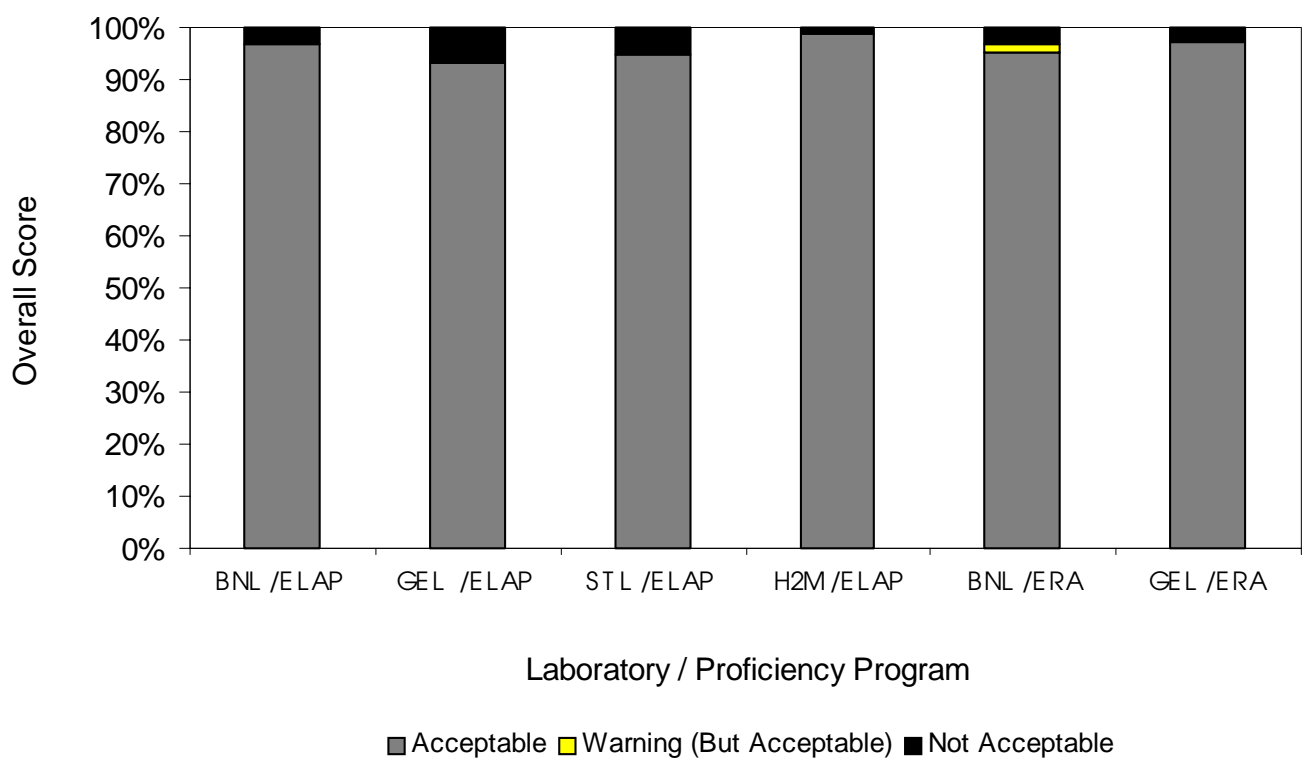

Figure 9-3. Nonradiological Results Summarized: Labs' Scores in NYSDOH ELAP and ERA PE Programs for 2001.

analyses (83.7 percent) were within established DOE EML limits, showing "Acceptable" agreement with the known value. Five results (11.6 percent) were within "Warning" limits, also earning satisfactory status. Two analyses
(4.7 percent) fell outside the acceptance limits. The two results that were unacceptable (gross alpha only) occurred in different rounds of testing. The ASL passed gross alpha and beta testing in both the ELAP and the ERA 
programs and maintained state certification. An investigation is ongoing as to the reason for the two isolated EML failures.

Table F-2 also presents GEL's performance, which was satisfactory (Acceptable or within Warning limits) in 100 percent of the analyses performed on the four matrices (air, vegetation, water, and soil). Seventy-two of 87 analyses (82.8 percent) were within EML's acceptance limit; 15 of 87 analyses (17.2 percent) were within upper and lower warning limits, demonstrating satisfactory agreement; no analyses fell outside the acceptance limits.

\subsubsection{Table F-3: ELAP Radiological Results}

ASL's radiological results for the NYSDOH ELAP program were in 100 percent agreement for the four analyses. STL and GEL also had Overall Satisfactory scores of 100 percent on the eight analytes shown in Table F-3.

\subsubsection{Table F-4: ERA Radiological Results}

ASL and GEL participated in the ERA radiological performance evaluation studies, shown in Table F-4. ASL's overall score for the 23 results reported in 2001 was 91.3 percent, with two unacceptable gamma results (Co-60 and Cs-137). These failures occurred while the ASL gamma system was undergoing upgrades, as described in Section 9.6.2. GEL's overall score in the ERA radiological PE studies was 96.4 percent for 28 analytes.

\subsubsection{Nonradiological Assessments}

During 2001, ASL, GEL, STL, and H2M participated in the NYSDOH ELAP, which certifies laboratories that test for nonpotable water, potable water, and solid wastes. The results of this evaluation are summarized in Tables F-5 through F-7 for each of the four laboratories (note that STL has two labs: one in Missouri and one in Connecticut). Although participation in the ERA water supply and water pollution studies is not required for New York State certification, ASL and GEL also participated in the ERA evaluation; results are presented in Table F-8.
9.7.3.1 Table F-5: ELAP Nonpotable Water Results

Table F-5 shows results for the NYSDOH ELAP for nonpotable water. Of the 139 results reported for ASL, there were four cases of "Unsatisfactory," earning ASL an Overall Satisfactory score of 97.1 percent. GEL's results for 499 analytes included 22 instances of "Unsatisfactory," leading to a score of 95.6 percent. H2M reported 531 results with eight Unsatifactory results, scoring 98.5 percent. STL's Missouri lab reported 520 results and scored 93.5 percent; the Connecticut lab reported 354 results and scored 97.1 percent.

\subsubsection{Table F-6: ELAP Solid and Hazardous Waste Chemistry}

Table F-6 shows results for the NYSDOH ELAP Solid and Hazardous Waste Chemistry Proficiency Program for BNL's ASL only. ASL scored 100 percent in this category for the 13 results reported.

\subsubsection{Table F-7: ELAP Potable Water Results}

Table F-7 summarizes results of the potable water category of the NYSDOH ELAP. Brookhaven's ASL reported 146 results with five Unsatisfactorys, earning an Overall Satisfactory score of 96.6 percent. GEL reported 176 results with 23 Unsatisfactorys, scoring 86.9 percent. H2M reported 211 results with seven Unsatisfactorys, generating a score of 96.7 percent. STL (Missouri) reported 219 results with 12 Unsatisfactorys, scoring 94.5 percent.

\subsubsection{Table F-8: Voluntary ERA PE Studies}

GEL and Brookhaven's ASL participated in the voluntary ERA water pollution and water supply performance evaluation studies, as shown in Table F-8. For these studies combined, ASL reported 233 results: 223 Acceptables, two within warning limits ("Check for Error"), and eight "Not Acceptables." The Overall Satisfactory score for ASL in ERA's water supply and water pollution studies was 96.6 percent. GEL reported 320 results, with 311 Acceptables, two Check for Errors, and seven Not Acceptables. GEL's score in these voluntary PE studies was 97.8 percent. 


\subsection{LABORATORY AUDITS}

In addition to $\mathrm{PE}$ testing, $\mathrm{BNL}$ conducts a program of internal and external audits to verify the effectiveness of the environmental sampling, analysis, and database activities. Contractor laboratories were subject to audits by BNL personnel at the time of contract renewal. To verify competence in analytical methodology and implementation of a comprehensive QA program, the contractor laboratories are also audited periodically by ASL, the Quality Programs and Services Office, or the Environmental Restoration Program staff.

ASL audited GEL and $\mathrm{H} 2 \mathrm{M}$ during contract renewal and bid processes in the spring of 2000; there were no significant findings. An audit of Chemtex is planned for late 2002 when the existing contract expires.

A three-day audit of Brookhaven's ASL was conducted in the spring of 2001 by NYSDOH using the U.S. EPA National Environmental Laboratory Accreditation Program (NELAP) guidelines. The NELAP audit follows a checklist of more than 250 items that can be viewed at http://www.epa.gov/ttnnela1/checklst.html. Analytical labs performing environmental measurements must be certified by the state to this EPA program or risk losing state certification.

Prior to the audit, ASL was required to prepare a Quality Manual using the NELAP guidelines. The ASL passed the NELAP audit without qualifications. There were four recommendations for corrective action. Two recommendations related to record-keeping issues (i.e., maintaining logbooks), one recommendation was for an update on the ASL tritium SOP, and one recommendation was for improvement in uniquely identifying sample bottles listed on the BNL Chain-of-Custody Form. The first three items were rectified within two months of the audit and a revision was made to the BNL COC Form to satisfy the last item.

The Quality Programs and Services Office, DOE Brookhaven Group, DOE Chicago Operations, regulatory agencies, and other independent parties also periodically audit BNL environmental programs, as discussed in Chapters 2 and 3.

\subsection{CONCLUSIONS}

Detailed data on quality control results for all analyses conducted at BNL's ASL are presented in ASL's Year 2001 QA Report (Scarpitta and Heotis 2002). The report presents tables and figures depicting instrument calibration, efficiency, background checks, precision, and accuracy testing. Overall, QC checks were consistently within the EPA guidelines of \pm 20 percent.

Detailed data on external performance evaluation testing for the ASL and the three BNL contractor laboratories are also presented in the Year 2001 QA Report. Overall, the three laboratories reporting radiological analytical data in the Site Environmental Report 2001 (ASL, STL, and GEL) had combined satisfactory results of 94 percent, 100 percent, and 100 percent, respectively, in both state and federal performance evaluation programs. For nonradiological performance evaluation testing, ASL and the three BNL contractor laboratories (H2M, GEL, and STL) all scored better than 92 percent in the NYSDOH ELAP evaluations. BNL's combined Overall Satisfactory score of 96 percent on the 593 radiological and nonradiological PE tests performed in 2001 is considered excellent.

Based on implementation and evaluation of the QA/QC program, it can be concluded that the analytical data reported in the 2001 Site Environmental Report are reliable and of high quality.

\footnotetext{
REFERENCES

10 CFR 830 Subpart A. U.S. Department of Energy. "Quality Assurance Requirements." U.S. Code of Federal Regulations. 2000.

BNL. 1997. Radiochemical Data Validation Standard Operating Procedure. Brookhaven National Laboratory, Upton, NY.

BNL. 1998. Natural Attenuation Monitoring Work Plan for the HFBR Tritium Plume. Brookhaven National Laboratory, Upton, NY. December 1998.

BNL. 1999a. Environmental Monitoring Standard Operating Procedures. Brookhaven National Laboratory, Upton, NY.

BNL. 1999b. BNL Groundwater Monitoring Program Quality Assurance Project Plan (QAPP). Brookhaven National Laboratory, Upton, NY. August 31, 1999.
} 
BNL. 1999c. Quality Assurance Program Plan: Analysis of Radionuclides and Hazardous Chemicals at Brookhaven National Laboratory. BNL-RCD/ASL-99-01. Radiological Control Division/Analytical Services Laboratory, Brookhaven National Laboratory, Upton, NY.

BNL. 2000. Brookhaven National Laboratory Environmental Monitoring Plan 2000. BNL-52584. Brookhaven National Laboratory, Upton, NY.

DOE. 1994. RD-4 Guidance for Radiochemical Data Validation. Draft. Report EM-73. U.S. Department of Energy, Washington, D.C.

DOE Order 414.1A. 2001. Quality Assurance. U.S. Department of Energy, Washington, D.C. November 24, 1998.

DOE Order 5400.1. 1988. General Environmental Protection Program. U.S. Department of Energy, Washington, D.C. Change 1: $6-29-90$
EPA. 1992. Evaluation of Metals Data for the Contract Laboratory Program. EPA Region-II SOP HW-2. U.S. Environmental Protection Agency, Washington, D.C.

EPA. 1996. CLP Organic Data Review and Preliminary Review. EPA Region II, SOP HW-6. U.S. Environmental Protection Agency, Washington, D.C.

EPA. 1998. EPA Requirements for Quality Assurance Project Plans for Environmental Data Operations. Report QA/R-5. U.S. Environmental Protection Agency, Washington, D.C.

Scarpitta, S., and Heotis, P. 2002. Year 2001 Quality Assurance Report of the Analytical Services Laboratory, RCD-ASL-QA Report 2001, Rev-O, Radiation Control Division, Brookhaven National Laboratory, Upton, NY. May 2002. 


\section{Acronyms and Abbreviations}

These acronyms and abbreviations reflect the typical manner in which terms are used for this specific document and may not apply to all situations.

\begin{tabular}{|c|c|c|c|}
\hline AGS & Alternating Gradient Synchrotron & DWS & drinking water standards \\
\hline ALARA & as low as reasonably achievable & EA & environmental assessment \\
\hline AMSL & above mean sea level & EDB & ethylene dibromide \\
\hline $\mathrm{AOC}$ & area of concern & EDE & effective dose equivalent \\
\hline ARPA & Acheological Resource Protection Act & EDTA & ethylenediaminetetraacetic acid \\
\hline AS/SVE & air sparging/soil vapor extraction & $\mathrm{EE} / \mathrm{CA}$ & Engineering Evaluation/Cost Analysis \\
\hline ASL & Analytical Services Laboratory (BNL) & EIMS & Environmental Information Management \\
\hline AUI & Associated Universities, Incorporated & & System \\
\hline BAF & Booster Applications Facility & ELAP & Environmental Laboratory Approval Program \\
\hline BAO & Brookhaven Area Office & EML & Environmental Measurements Laboratory \\
\hline BGRR & Brookhaven Graphite Research Reactor & EMS & Environmental Management System \\
\hline BLIP & Brookhaven Linac Isotope Producer & EPA & U.S. Environmental Protection Agency \\
\hline BMRR & Brookhaven Medical Research Reactor & EPCRA & Emergency Planning and \\
\hline BNL & Brookhaven National Laboratory & & Community Right-to-Know Act \\
\hline BOD & biochemical oxygen demand & ER & environmental restoration \\
\hline $\mathrm{Bq}$ & becquerel & ERA & Environmental Resource Associates \\
\hline $\mathrm{Bq} / \mathrm{g}$ & becquerel per gram & ERD & Environmental Restoration Division \\
\hline $\mathrm{Bq} / \mathrm{L}$ & becquerel per liter & ES & environmental surveillance \\
\hline BSA & Brookhaven Science Associates & ES\&H & environment, safety, and health \\
\hline Btu & British thermal units & ESD & Environmental Services Division \\
\hline CAA & Clean Air Act & $\mathrm{ESH} \& \mathrm{Q}$ & Environment, Safety, Health, and \\
\hline CAP & Clean Air Act Assessment Package & & Quality Directorate \\
\hline CERCLA & Comprehensive Environmental Response, & FFCA & Federal Facilities Compliance Act \\
\hline & Compensation and Liability Act & FIFRA & $\begin{array}{l}\text { Federal Insecticide Fungicide and } \\
\text { Rodenticide Act }\end{array}$ \\
\hline $\mathrm{CFR}$ & U.S. Code of Federal Regulations & FY & fiscal year \\
\hline CO & $\begin{array}{l}\text { curie } \\
\text { certificate to operate }\end{array}$ & FWS & U.S. Fish and Wildlife Service \\
\hline $\mathrm{COC}$ & Chain of custody & GAB & gross alpha beta \\
\hline Cs & cesium & GC/ECD & $\begin{array}{l}\text { gas chromatography/electron capture } \\
\text { detector }\end{array}$ \\
\hline CSF & Central Steam Facility & GC/MS & gas chromatography/mass spectrometry \\
\hline CT & carbon tetrachloride & GEL & General Engineering Laboratory \\
\hline CWA & Clean Water Act & GWh & gigawatt hour \\
\hline CY & calendar year & $\mathrm{H} 2 \mathrm{M}$ & one of the contract labs \\
\hline DCA & 1,1-dichloroethane & HEPA & high efficiency particulate air \\
\hline DCE & 1,1-dichloroethylene & HFBR & High Flux Beam Reactor \\
\hline $\begin{array}{l}\text { DCG } \\
\text { DDD }\end{array}$ & $\begin{array}{l}\text { derived concentration guide } \\
\text { dichlorodiphenyldichloroethat }\end{array}$ & НTO & tritiated water (liquid or vapor) \\
\hline DDT & henyltrichloroethane & HWMF & Hazardous Waste Management Facility (former) \\
\hline DMR & Discharge Monitoring Report & IAEA & International Atomic Energy Agency \\
\hline DOE & U.S. Department of Energy & IAG & Interagency Agreement \\
\hline DOE BAO & U.S. Department of Energy, & IC & ion chromatography \\
\hline & Brookhaven Area Office & $\mathrm{ICP} / \mathrm{MS}$ & inductively coupled plasma/mass spectrometry \\
\hline $\mathrm{DOE} \mathrm{CH}$ & U.S. Department of Energy, & ISO & International Organization for Standardization \\
\hline & Chicago Operations $C$ & ISOCS & In-Situ Object Counting System \\
\hline DQO & data quality objective & $\mathrm{K}$ & potassium \\
\hline
\end{tabular}




\begin{tabular}{|c|c|c|c|}
\hline $\mathrm{kBg}$ & kilobecquerels & $\mathrm{P} 2$ & pollution prevention \\
\hline $\mathrm{kwH}$ & kilowatt hours & $\mathrm{Pb}$ & lead \\
\hline LED & light emitting diode & PCB & polychlorinated biphenyl \\
\hline LIE & Long Island Expressway & PCE & tetrachloroethylene (or perchloroethylene) \\
\hline LINAC & Linear Accelerator & $\mathrm{pCi} / \mathrm{g}$ & picocuries per gram \\
\hline MBtu & thousand British thermal units & PE & performance evaluation \\
\hline MMBtu & million British thermal units & PET & positron emission tomography \\
\hline MDL & minimum detection limit & $\mathrm{ppb}$ & parts per billion \\
\hline MEI & maximally exposed individual & Ppm & parts per million \\
\hline MGD & million gallons per day & QA & quality assurance \\
\hline MOA & Memorandum of Agreement & QAPP & quality assurance program plan \\
\hline MPF & Major Petroleum Facility & QC & quality control \\
\hline MPN & most probable number & RA & removal action \\
\hline MRC & Medical Research Center & RACT & Reasonable Available Control Technology \\
\hline $\mathrm{mSv}$ & millisievert & RCRA & Resource Conservation and Recovery Act \\
\hline MTBE & methyl tertiary butyl ether & $\mathrm{RHIC}$ & Relativistic Heavy lon Collider \\
\hline MW & megawatt & ROD & record of decision \\
\hline$\mu g / L$ & micrograms per liter & RPD & relative percent difference \\
\hline $\mathrm{mg} / \mathrm{L}$ & milligrams per liter & SARA & Superfund Amendments and Reauthorization Act \\
\hline $\mathrm{mmhos} / \mathrm{cm}$ & micro ohm/centimeters & SBMS & Standards Based Management System \\
\hline NA & not analyzed & SCDHS & Suffolk County Department of Health Services \\
\hline NCRP & $\begin{array}{l}\text { National Council on Radiation Protection and } \\
\text { Measurements }\end{array}$ & $\begin{array}{l}\text { SDWA } \\
\text { SER }\end{array}$ & $\begin{array}{l}\text { Safe Drinking Water Act } \\
\text { Site Environmental Report }\end{array}$ \\
\hline ND & not detected or no dose & SNS & standard not specified \\
\hline NEPA & National Environmental Policy Act & $\mathrm{SO}_{2}$ & sulfur dioxide \\
\hline NESHAPs & $\begin{array}{l}\text { National Emission Standards for Hazardous Air } \\
\text { Pollutants }\end{array}$ & $\begin{array}{l}\text { SOP } \\
\text { SPCC }\end{array}$ & $\begin{array}{l}\text { standard operating procedure } \\
\text { spill prevention control and countermeasures }\end{array}$ \\
\hline NHPA & National Historic Preservation Act & SPDES & State Pollutant Discharge Elimination System \\
\hline NIST & National Institute for Standards and Technology & STL & Severn Trent Laboratories \\
\hline $\mathrm{NO}_{2}$ & nitrogen dioxide & STP & Sewage Treatment Plant \\
\hline $\mathrm{NO}_{x}$ & nitrogen oxides & SU & standard unit \\
\hline NOEC & no observable effect concentration & Sv & sievert \\
\hline NPDES & $\begin{array}{l}\text { National Pollutant Discharge Elimination } \\
\text { System }\end{array}$ & SVOC & semivolatile organic compound \\
\hline NR & not required & $\mathrm{t}_{1 / 2}$ & half-life \\
\hline NS & not sampled & TBq & trillion Becquerels \\
\hline NSLS & National Synchrotron Light Source & TCA & 1,1,1-trichloroethane \\
\hline NT & not tested & TCE & trichloroethylene \\
\hline NYCRR & New York Codes, Rules, and Regulations & TCLP & toxicity characteristic leaching procedure \\
\hline NYS & New York State & TLD & thermoluminescent dosimeter \\
\hline NYS AWQS & New York State ambient water quality standard & TSCA & Toxic Substances Control Act \\
\hline & New rork state amblent water quality stancara & TVDG & Tandem Van de Graaff \\
\hline NYS DWS & New York State drinking water standard & TVOC & total volatile organic compounds \\
\hline NYSDEC & $\begin{array}{l}\text { New York State Department of Environmental } \\
\text { Conservation }\end{array}$ & $\begin{array}{l}\text { UIC } \\
\text { USI }\end{array}$ & $\begin{array}{l}\text { underground injection control } \\
\text { unreviewed safety issues }\end{array}$ \\
\hline NYSDOH & New York State Department of Health & UST & underground storage tank \\
\hline NYSHPO & New York State Historic Preservation Office & VOC & volatile organic compound \\
\hline $\mathrm{O}_{3}$ & ozone & WAC & waste acceptance criteria \\
\hline ORC & oxygen-releasing compound & WCF & Waste Concentration Facility \\
\hline ORPS & Occurrence Reporting and Processing System & WMF & Waste Management Facility \\
\hline OU & operable unit & WTP & Water Treatment Plant \\
\hline
\end{tabular}

PAAA Price Anderson Acts Amendment 


\section{Technical Terms}

These definitions reflect the typical manner in which the terms are used for this specific document and may not apply to all situations. For definitions and descriptions of the various environmental regulations see Chapter 3 .

\section{A}

accuracy - The degree of agreement of a measurement with an accepted reference or true value. It is expressed as the difference between two values, as a percentage of the reference or true value, or as a ratio of the measured value and the reference or true value.

activation - The process of making a material radioactive by bombardment with neutrons, protons, or other high energy particles.

activation products - A material that has become radioactive through the process of activation.

activity - Synonym for radioactivity.

Administrative Record - A collection of documents established in compliance with Comprehensive Environmental Response, Compensation, and Liability Act (CERCLA) program. Consists of information upon which the CERCLA lead agency bases its decision on the selection of response actions. The Administrative Record file should be established at or near the facility and made available to the public. An Administrative Record can also be the record for any enforcement case.

aerosol - A gaseous suspension of very small particles of liquid or solid.

air sparging - A method of extracting volatile organic compounds from the groundwater in situ (i.e., in place) using compressed air. The vapors are typically collected using a soil vapor extraction system.

air stripping - A process whereby volatile organic chemicals are removed from contaminated water by forcing a stream of air through the water in a vessel. The contaminants are evaporated into the air stream. The air may be further treated before it is released into the atmosphere.

ALARA - As Low As Reasonably Achievable, a phrase that describes an approach to minimize exposures to individuals and minimize releases of radioactive or other harmful material to the environment to levels as low as social, technical, economic, practical, and public policy considerations will permit. ALARA is not a dose limit, but a process with a goal to keep dose levels as far below applicable limits as is practicable.

alpha radiation - The emission of alpha particles during radioactive decay. Alpha particles are identical in makeup to the nucleus of a helium atom and have a positive charge. Alpha radiation is easily stopped by materials as thin as a sheet of paper and has a range in air of only an inch or so. Despite its low penetration ability, alpha radiation is densely ionizing and therefore very damaging when ingested or inhaled. Naturally occurring radioactive elements such as radon emit alpha radiation.

ambient air - The surrounding atmosphere, usually the outside air, as it exists around people, animals, plants, and structures. It does not include the air immediately adjacent to emission sources.

analyte - A constituent that is being analyzed.

anion - A negatively charged ion, often written as a negative sign after an element symbol, such as Cl-.

anthropogenic radionuclides - Radionuclides produced as a result of human activity (i.e., human-made).

aquifer - A water saturated layer of rock or soil below the ground surface that can supply usable quantities of groundwater to wells and springs. Aquifers can be a source of water for domestic, agricultural, and industrial uses.

area of concern (AOC) - Under the Comprehensive Environmental Response, Compensation and Liability Act (CERCLA), this term refers to an area where releases of hazardous substances may have occurred or a location where there has been a release or threat of a release into the environment of a hazardous substance, pollutant, or contaminant (including radionuclides). AOCs may include, but need not be limited to, former spill areas, landfills, surface impoundments, waste piles, land treatment units, transfer stations, wastewater treatment units, incinerators, container storage areas, scrap yards, cesspools, tanks, and associated piping that are known to have caused a release into the environment or whose integrity has not been verified.

atomic absorption (AA) - A method used to determine the elemental spectroscopy composition of a sample. In this method, the sample is vaporized and the amount of light it absorbs is measured.

\section{B}

background - A sample or location used as reference or control to compare BNL analytical results to those in areas that could not have been impacted by BNL operations. 
background radiation - Radiation present in the environment as a result of naturally occurring radioactive materials, cosmic radiation, or human-made radiation sources, including fallout.

becquerel (Bq) - A quantitative measure of radioactivity. This is an alternate measure of activity used internationally and with increasing frequency in the United States. One Bq of activity is equal to one nuclear decay per second. All references to quantities of radioactive material in this report are made in curies, followed in parentheses by the equivalent in Bq.

beta radiation - Beta radiation is composed of charged particles emitted from a nucleus during radioactive decay, with a mass equal to $1 / 1837$ that of a proton. A negatively charged beta particle is identical to an electron. A positively charged beta particle is called a positron. Beta radiation is slightly more penetrating than alpha, but may be stopped by materials such as aluminum or Lucite panels. Naturally occurring radioactive elements such as potassium- 40 emit beta radiation.

biochemical oxygen demand (BOD) - A measure of the amount of oxygen in biological processes that breaks down organic matter in water; a measure of the organic pollutant load. It is used as an indicator of water quality.

blank - A sample (usually reagent grade water) in the same type of container used for quality control of field sampling methods, to demonstrate that cross contamination has not occurred.

blowdown - Water discharged from either a boiler or cooling tower in order to prevent the build-up of inorganic matter within the boiler or tower and to prevent scale formation (i.e., corrosion).

\section{C}

cap - A layer of material, such as clay or a synthetic material (like Gunite ${ }^{\mathrm{TM}}$ ), used to prevent rainwater from penetrating and spreading contaminated materials. The surface of the cap is generally mounded or sloped so water will drain off.

carbon adsorption/carbon treatment - $A$ treatment system in which contaminants are removed from groundwater, surface water, and air by forcing water or air through tanks containing activated carbon (a specially treated material that attracts and holds or retains contaminants).

carbon tetrachloride -A poisonous, nonflammable, colorless liquid, $\mathrm{CCl}_{4}$.

chain-of-custody - A method for documenting the history and possession of a sample from the time of collection, through analysis and data reporting, to its final disposition.

characterization - Facility or site sampling, monitoring and analysis activities to determine the extent and nature of contamination. Characterization provides the basis of necessary technical information to select an appropriate cleanup alternative.
Class GA groundwater - New York State Department of Environmental Conservation classification for high quality groundwater, where the best intended use is as a source of potable water.

closure - Under the Resource Conservation and Recovery Act (RCRA) regulations, this term refers to a hazardous or solid waste management unit that is no longer operating and where potential hazards that it posed have been addressed (through clean up, immobilization, capping, etc.) to the satisfaction of the regulatory agency.

Code of Federal Regulations (CFR) - A codification of all regulations developed and finalized by federal agencies in the Federal Register.

collective effective dose equivalent - A measure of health risk to a population exposed to radiation. It is the sum of the effective dose equivalents of all individuals within an exposed population, frequently considered to be within 50 miles ( 80 kilometers) of an environmental release point. It is expressed in person-rem or person-sievert.

committed effective dose equivalent - The total Effective Dose Equivalent received over a 50-year period following the internal deposition of a radionuclide. It is expressed in rem or sieverts.

composite sample - A sample of an environmental media that contains a certain number of sample portions collected over a period of time. The samples may be collected from the same location or different locations. They may or may not be collected at equal time intervals over a predefined period of time (e.g., 24 hours).

confidence interval - A numerical range within which the true value of a measurement or calculated value lies. In this report, radiological values are shown with a $95 \%$ confidence interval, i.e., there is a $95 \%$ probability that the true value of a measurement or calculated value lies within the specified range.

contamination - Unwanted radioactive and/or hazardous material that is dispersed on or in equipment, structures, objects, air, soil, or water.

control - See background.

cooling water - Water that is used to cool machinery and equipment. Contact cooling water is any wastewater that contacts machinery or equipment to remove heat from the metal. Non-contact cooling water is water used for cooling purposes but has no direct contact with any process material or final product. Process wastewater cooling water is water used for cooling purposes that may have become contaminated through contact with process raw materials or final products.

curie (Ci) - A quantitative measure of radioactivity. One $\mathrm{Ci}$ of activity is equal to $3.7 \times 10^{10}$ decays per second. 


\section{$\mathrm{D}$}

decay product - A nuclide resulting from the radioactive disintegration of a radionuclide, being formed either directly or as a result of successive transformations in a radioactive series. A decay product may be either radioactive or stable.

decontamination - The removal or reduction of radioactive or hazardous contamination from facilities, equipment, or soils by washing, heating, chemical or electrochemical action, mechanical cleaning, or other techniques to achieve a stated objective or end condition.

Department of Energy (DOE) - The federal agency that sponsors energy research and regulates nuclear materials used for weapons production. DOE has responsibility for the national laboratories and the science and research conducted at these laboratories, including BNL.

derived concentration guide (DCG) - The concentration of a radionuclide in air or water that, under conditions of continuous exposure for one year by a single pathway (e.g., air inhalation/immersion, water ingestion), would result in an effective dose equivalent of $100 \mathrm{mrem}(1 \mathrm{mSv})$. The values have been established by DOE in Order 5400.5, Radiation Protection of the Public and the Environment. (1990, change 2, 1/7/93).

disposal - Final placement or destruction of waste.

dosimeter - A portable detection device for measuring the total accumulated exposure to ionizing radiation.

downgradient - In the direction of groundwater flow from a designated area; analogous to "downstream."

$\mathrm{E}$

effective dose equivalent (EDE) - A value used to express the health risk from radiation exposure to a tissue or tissues in terms of an equivalent whole body exposure. It is a normalized value that allows the risk from radiation exposure received by a specific organ or part of the body to be compared with the risk due to whole body exposure. It is equal to the sum of the doses to different organs of the body multiplied by their respective weighting factors. It includes the sum of the effective dose equivalent due to radiation from sources external to the body and the committed effective dose equivalent due to the internal deposition of radionuclides. EDE is expressed in units of rem or sieverts.

effluent - Any liquid discharged to the environment, including stormwater runoff at a site or facility.

emission - Any gaseous or particulate matter discharged to the atmosphere.

environment - Surroundings in which an organization operates (including air, water, land, natural resources, flora, fauna, and humans) and their interrelation.

environmental aspect - Elements of an organization's activities, products, or services that can interact with the environment. environmental assessment (EA) - A report that identifies potentially significant environmental impacts from any federally approved or funded project that may change the physical environment. If an EA identifies a "significant" impact (as defined by the National Environmental Policy Act [NEPA]), an Environmental Impact Statement is required.

environmental impact - Any change to the environment, whether adverse or beneficial, wholly or partially resulting from an organization's activities, products, or services.

environmental media - Includes air, groundwater, surface water, soil, flora and fauna.

environmental monitoring or surveillance - Sampling for contaminants in air, water, sediments, soils, food stuffs, plants, and animals, either by directly measuring or by collecting and analyzing samples.

Environmental Protection Agency (EPA) - The federal agency responsible for developing and enforcing environmental laws. Although state regulatory agencies may be authorized to administer environmental regulatory programs, EPA generally retains oversight authority.

ethylene dibromide (EDB) - A colorless, nonflammable, heavy liquid with a sweet odor; slightly soluble in water, soluble in ethanol, ether, and most organic solvents. It was used as an additive in leaded gasoline, as a soil and grain fumigant, and in waterproofing preparations. It is still used to treat felled logs for bark beetles; to control wax moths in beehives; as a chemical intermediary for dyes, resins, waxes, and gums; to spot-treat milling machinery; and to control Japanese beetles in ornamental plants. The U.S. Department of Health and Human Services has determined that ethylene dibromide may reasonably be anticipated to be a carcinogen.

evapotranspiration - A process by which water is transferred from the soil to the air by plants that take the water up through their roots and release it through their leaves and other aboveground tissue.

exposure - A measure of the amount of ionization produced by $\mathrm{x}$-rays or gamma rays as they travel through air. The unit of radiation exposure is the roentgen $(R)$.

\section{$\mathrm{F}$}

fallout - Radioactive material made airborne as a result of aboveground nuclear weapons testing that has been deposited on the Earth's surface.

feasibility study (FS) - A process for developing and evaluating remedial actions using data gathered during the remedial investigation. The FS defines the objectives of the remedial program for the site and broadly develops remedial action alternatives, performs an initial screening of these alternatives, and performs a detailed analysis of a limited number of alternatives that remain after the initial screening stage. 


\section{G}

gamma radiation - Gamma radiation is a form of electromagnetic radiation, like radio waves or visible light, but with a much shorter wavelength. It is more penetrating than alpha or beta radiation, capable of passing through dense materials such as concrete.

gamma spectroscopy - This analysis technique identifies specific radionuclides. It measures the particular energy of a radionuclide's gamma radiation emissions. The energy of these emissions is unique for each nuclide, acting as a "fingerprint" to identify a specific nuclide.

grab sample - A single sample collected at one time and place.

groundwater - Water found beneath the surface of the ground (subsurface water). Groundwater usually refers to a zone of complete water saturation containing no air.

Gunite $^{\mathrm{TM}}$ - A mixture of cement, sand, and water sprayed on a metal mold.

\section{$\mathrm{H}$}

half-life $\left(\mathbf{t}_{1 / 2}\right)$ - The time required for one half of the atoms of any given amount of a radioactive substance to disintegrate; the time required for the activity of a radioactive sample to be reduced by one half.

hazardous waste - Toxic, corrosive, reactive, or ignitable materials that can negatively affect human health or damage the environment. It can be liquid, solid, or sludge, and include heavy metals, organic solvents, reactive compounds, and corrosive materials. It is defined and regulated by the Resource Conservation and Recovery Act (RCRA), Subtitle C.

heat input - The heat derived from combustion of fuel in a steam generating unit. It does not include the heat from preheated combustion air, recirculated flue gases, or the exhaust from other sources.

heavy water $\left(\mathbf{D}_{2} \mathbf{O}\right)$ - A form of water containing deuterium, a nonradioactive isotope of hydrogen.

hot cell - Shielded and air controlled facility for the remote handling of radioactive material.

hydrology - The science dealing with the properties, distribution, and circulation of natural water systems.

\section{I}

inert - Lacking chemical or biological action.

influent - Liquid (e.g., wastewater) flowing into a reservoir, basin, or treatment plant.

intermittent river - A stream that dries up on occasion, usually as a result of seasonal factors or decreased contribution from other sources (e.g., a sewage treatment plant). ionizing radiation - Any radiation capable of displacing electrons from atoms or molecules, thereby producing ions. Some examples are alpha, beta, gamma, x-rays, neutrons, and light. High doses of ionizing radiation may produce severe skin or tissue damage.

isotope - Two or more forms of a chemical element having the same number of protons in the nucleus (or the same atomic number), but having different numbers of neutrons in the nucleus (or different atomic weights). Isotopes of a single element possess almost identical chemical properties.

\section{$\mathrm{L}$}

leaching - The process by which soluble chemical components are dissolved and carried through soil by water or some other percolating liquid.

light water - Tap water (as used in this document).

liquid scintillation counter - An analytical instrument used to quantify tritium, carbon-14, and other beta-emitting radionuclides.

\section{$\mathrm{M}$}

maximally exposed individual (MEI) - The hypothetical individual whose location and habits tend to maximize his/her radiation dose, resulting in a dose higher than that received by other individuals in the general population.

mean sea level (MSL) - The average height of the sea for all stages of the tide. Used as a benchmark for establishing groundwater and other elevations.

minimum detection limit (MDL) - The lowest level to which an analytical parameter can be measured with certainty by the analytical laboratory performing the measurement. While results below the MDL are sometimes measurable, they represent values that have a reduced statistical confidence associated with them (less than $95 \%$ confidence).

mixed waste - Waste that contains both a hazardous waste component regulated under Subtitle $C$ of the Resource Conservation and Recovery Act (RCRA) and a radioactive component.

monitoring - The collection and analysis of samples or measurements of effluents and emissions for the purpose of characterizing and quantifying contaminants, and demonstrating compliance with applicable standards.

monitoring well - A well that collects groundwater for the purposes of evaluating water quality, establishing groundwater flow and elevation, determining the effectiveness of treatment systems, and determining whether administrative or engineered controls designed to protect groundwater are working as intended.

\section{$\mathrm{N}$}

nuclide - A species of atom characterized by the number of protons and neutrons in the nucleus. 


\section{$\mathrm{O}$}

onsite - The area within the boundaries of a site that is controlled with respect to access by the general public.

opacity - Under the Clean Air Act (CAA), a measurement of the degree to which emissions (e.g., smoke) other than water reduce the transmission of light and obscure the view of an object in the background.

operable unit (OU) - Division of a contaminated site into separate areas based on the complexity of the problems associated with it. Operable units may address geographical portions of a site, specific site problems, or initial phases of an action. They may also consist of any set of actions performed over time, or actions that are concurrent, but located in different parts of a site. An operable unit can receive specific investigation and a particular remedy may be proposed. A record of decision (ROD) is prepared for each operable unit (see Record of Decision).

outfall - The place where wastewater is discharged.

oxides of nitrogen $\left(\mathrm{NO}_{\mathrm{x}}\right.$ ) - All oxides of nitrogen, except nitrous oxide, which is expressed as nitrogen dioxide $\left(\mathrm{NO}_{2}\right)$.

ozone $\left(\mathbf{O}_{3}\right)$ - A very reactive form of oxygen formed naturally in the upper atmosphere and providing a shield for the earth from the sun's ultraviolet rays. At ground level or in the lower atmosphere, it is pollution that forms when oxides of nitrogen and hydrocarbons react with oxygen in the presence of strong sunlight. Ozone at ground level can lead to health effects and cause damage to trees and crops.

\section{P}

percent recovery - For analytical results, the ratio of the measured amount, divided by the known (spiked) amount, multiplied by 100 .

permit - An authorization issued by a federal, state or local regulatory agency. Permits are issued under a number of environmental regulatory programs, including the Resource Conservation and Recovery Act (RCRA), Clean Air Act (CAA), Clean Water Act (CWA), and Toxic Substances Control Act (TSCA). They grant permission to operate, to discharge, to construct, etc. Permit provisions may include emission/effluent limits and other requirements such as the use of pollution control devices, monitoring, record keeping and reporting. Also called a "license" or "certificate" under some regulatory programs.

pH - A measure of hydrogen ion concentration in an aqueous solution. Acidic solutions have a $\mathrm{pH}$ less than 7 , neutral solutions have a $\mathrm{pH}$ of 7 , and basic solutions have a $\mathrm{pH}$ greater than 7 and up to 14 .

plume - A body of contaminated groundwater or polluted air flowing from a specific source. The movement of a groundwater plume is influenced by such factors as local groundwater flow patterns, the character of the aquifer in which groundwater is contained, and the density of contami- nants. The movement of an air contaminant plume is influenced by the ambient air motion, the temperatures of the ambient air and of the plume, and the density of the contaminants.

point source - Any confined and discrete conveyance (e.g., pipe, ditch, well, or stack) of a discharge.

pollutant - Any hazardous or radioactive material naturally occurring or added to an environmental media, such as air, soil, water, or vegetation.

pollution prevention (P2) - Preventing or reducing the generation of pollutants, contaminants, hazardous substances, or wastes at the source, or reducing the amount for treatment, storage, and disposal through recycling. Pollution prevention can be achieved through reduction of waste at the source, segregation, recycle/reuse, and the efficient use of resources and material substitution. The potential benefits of pollution prevention include the reduction of adverse environmental impacts, improved efficiency, and reduced costs.

polychlorinated biphenyls (PCBs) - A family of organic compounds used from 1926 to 1979 (when they were banned by EPA) in electrical transformers, lubricants, carbonless copy paper, adhesives, and caulking compounds. PCBs are extremely persistent in the environment because they do not break down into different and less harmful chemicals. PCBs are stored in the fatty tissues of humans and animals through the bioaccumulation process.

potable water - Water of sufficient quality for use as drinking water without endangering the health of people, plants, or animals.

precision - The dispersion around a central value, usually represented as a variance, standard deviation, standard error, or confidence interval.

putrescible waste - Garbage that contains food and other organic biodegradable materials. There are special management requirements for this waste in 6 NYCRR Part 360.

\section{Q}

qualifier - A letter or series of letter codes indicating that the associated value is estimated. A qualified value is an estimated value.

quality assurance (QA) - In environmental monitoring, any action to ensure the reliability of monitoring and measurement data. Aspects of QA include procedures, interlaboratory comparison studies, evaluations, and documentation.

quality control (QC) - In environmental monitoring, the routine application of procedures to obtain the required standards of performance in monitoring and measurement processes. QC procedures include calibration of instruments, control charts, and analysis of replicate and duplicate samples. 


\section{$\mathrm{R}$}

radioactive series - A succession of nuclides, each of which transforms by radioactive disintegration into the next until a stable nuclide results. The first member of the series is called the parent and the intermediate members are called daughters or progeny.

radioactivity - The spontaneous transition of an atomic nucleus from a higher energy to a lower energy state. This transition is accompanied by the release of a charged particle or electromagnetic waves from the atom. Also known as "activity."

radionuclide - A radioactive element characterized by the number of protons and neutrons in the nucleus. There are several hundred known radionuclides, both artificially produced and naturally occurring.

recharge - The process by which water is added to a zone of saturation (aquifer) from surface infiltration typically when rainwater soaks through the earth to reach an aquifer.

recharge basin - A basin (natural or artificial) that collects water. The water will infiltrate to the aquifer.

Record of Decision (ROD) - A document that records a regulator agency's decision for the selected remedial action. The ROD also includes a responsiveness summary and a bibliography of documents that were used to reach the remedial decision. When the ROD is finalized, remedial design and implementation can begin.

relative percent difference $-A$ measure of precision, expressed by the formula: $\mathrm{RPD}=[(\mathrm{A}-\mathrm{B}) /(\mathrm{A}+\mathrm{B})] \times 200$, where A equals the concentration of the first replicate: and $\mathrm{B}$ equals the concentration of the second replicate.

release - Spilling, leaking, pumping, pouring, emitting, emptying, discharging, injecting, escaping, leaching, dumping, or disposing of a hazardous substance, pollutant, or contaminant into the environment. The National Contingency Plan also defines the term to include a threat of release.

rem - Stands for "roentgen equivalent man," a unit by which human radiation dose is assessed. This is a risk-based value used to estimate the potential health effects to an exposed individual or population.

remedial (or remediation) alternatives - Options considered under the Comprehensive Environmental Response, Compensation and Liability Act (CERCLA) for cleaning up contamination at a site, such as an operable unit (OU) or area of concern (AOC). Remedial actions are long-term activities that stop or substantially reduce releases, or prevent possible releases, of hazardous substances that are serious but not immediately life-threatening. See also feasibility study (FS) and record of decision (ROD).

remedial investigation (RI) - An investigation that includes extensive sampling and laboratory analyses to characterize the nature and extent of contamination, define the pathways of migration, and measure the degree of contamination in surface water, groundwater, soils, air, plants, and animals. Information gathered during the RI attempts to fully describe the contamination problem at the site so that the appropriate remedial action can be developed.

removal actions (RA) or removals - Interim actions that are undertaken to prevent, minimize, or mitigate damage to the public health or environment that may otherwise result from a release or threatened release of hazardous substances, pollutants, or contaminants pursuant to Comprehensive Environmental Response, Compensation, and LiabilityAct (CERCLA), and that are not inconsistent with the final remedial action. Under CERCLA or Superfund, the U.S. Environmental Protection Agency may respond to releases or threats of releases of hazardous substances by starting a removal action. The purpose of the removal action is to stabilize or clean up an incident or site that poses an immediate threat to public health or welfare. Removal actions differ from remedial actions. However, removal actions must contribute to the efficiency of future remedial actions.

residual fuel - Crude oil, Nos. 1 and 2 fuel oil that have a nitrogen content greater than 0.05 weight percent, and all fuel oil Nos. 4, 5, and 6, as defined by the American Society of Testing and Materials in ASTM D396-78, Standard Specifications for Fuel Oils, (c. 2001).

runoff - The movement of water over land. Runoff can carry pollutants from the land into surface waters or uncontaminated land.

\section{S}

sampling - The extraction of a prescribed portion of an effluent stream or environmental media for purposes of inspection or analysis

sediment - The layer of soil and minerals at the bottom of surface waters, such as streams, lakes, and rivers.

sensitivity - The minimum amount of an analyte that can be repeatedly detected by an instrument.

sievert (Sv) - A unit for assessing the risk of human radiation dose, used internationally and with increasing frequency in the United States. One sievert is equal to 100 rem.

skyshine - Radiation emitted over an open-topped shielded enclosure and reflected by air so as to radiate people on the outside.

sludge - Semisolid residue from industrial or water treatment processes.

soil vapor extraction - An in situ (in place) method of extracting volatile organic chemicals from soil. The chemicals are extracted by applying a vacuum to the soil and collecting the air, which can be further treated to remove the chemicals or discharged to the atmosphere. 
sole source aquifer - An area defined by the U.S. Environmental Protection Agency as being the primary source of drinking water for a particular region. Includes the surface area above the sole source aquifer and its recharge area.

spallation - The process by which a high energy particle striking a nucleus causes fragments to be ejected from the nucleus. The resulting atom is usually radioactive.

stable - Nonradioactive.

stakeholder - People or organizations with vested interests in BNL and its environment and operations. Stakeholders include federal, state, and local regulators; the public; the U.S. Department of Energy; and BNL staff.

State Pollution Discharge Elimination System (SPDES) - A program under which permits are issued by the state to regulate wastewater discharges. The permit specifies the maximum discharge limits for the parameters present in the particular discharge.

stripping - A process used to remove volatile contaminants from a substance (see also Air Stripping).

sump - A pit or tank that catches liquid runoff for drainage or disposal.

\section{$\mathrm{T}$}

thermoluminescent dosimeter (TLD) - A device used to measure radiation dose to occupational workers or radiation levels in the environment.

total volatile organic compounds (TVOC) - A sum of all individual VOC concentrations detected in a given sample.

trichloroethylene (TCE) (also, trichloroethene) - A stable, colorless liquid with a low boiling point. TCE has many industrial applications, including use as a solvent and as a metal degreasing agent. TCE may be toxic to people when inhaled or ingested, or through skin contact, and can damage vital organs, especially the liver (see also volatile organic compounds).

tritium - The heaviest and only radioactive nuclide of hydrogen, with a half-life of 12.3 years and a very low energy radioactive decay (beta emitter).

\section{$\mathrm{U}$}

underground injection control (UIC) - Any hole whose vertical dimensions are larger than its largest horizontal dimensions and used for disposal of waste water. underground storage tank (UST) - A stationary device, constructed primarily of nonearthen material, designed to contain petroleum products or hazardous materials. In a UST, $10 \%$ or more of the volume of the tank system is below the surface of the ground.

upgradient/upslope - A location of higher groundwater elevation; analogous to "upstream."

\section{V}

vernal pool - A small, isolated, and contained basin that holds water on a temporary basis, most commonly during winter and spring. It has no aboveground outlet for water and is extremely important to the life cycle of many amphibians (such as the spotted salamander), as it is too shallow to support fish, a major predator of amphibian larvae.

volatile organic compounds (VOCs) - Secondary petrochemicals, including light alcohols, acetone, trichlorethylene, perchloroethylene, dichloroethylene, benzene, vinyl chloride, toluene, and methylene chloride. These potentially toxic chemicals are used as solvents, degreasers, paints, thinners, and fuels. Because of their volatile nature, they readily evaporate into the air, increasing the potential for human exposure. Due to their widespread industrial use, they are commonly found in soil and groundwater.

\section{W}

waste minimization - An action that avoids or reduces the generation of waste by source reduction, reduces the toxicity of hazardous waste, improves energy usage, or recycling. This action is consistent with the general goal of minimizing present and future threats to human health, safety, and the environment. Associated with pollution prevention, but more likely to occur after the waste has already been generated.

water table - The water-level surface below the ground at which the unsaturated zone ends and the saturated zone begins. It is the level to which a well that is screened in the unconfined aquifer would fill with water.

watershed - The region draining into a river, a river system, or a body of water.

weighting factor - A factor which, when multiplied by the dose equivalent delivered to a body organ or tissue, yields the equivalent risk due to a uniform radiation exposure of the whole body.

wind rose - A diagram that shows the frequency of wind from different directions at a specific location. 
Intentionally Left Blank 


\section{Concepts of Radioactivity}

This section introduces some of the basic concepts of radioactivity. It is designed to provide the general reader with an overall understanding of the radiological sections of this report. A discussion of the analyses used to qualitatively quantify radioactive material, the common sources of radioactivity in the environment, and how they contribute to an individual's radiation dose are provided. Some general statistical concepts are also presented, along with a discussion of radionuclides of environmental interest at BNL.

\section{RADIOACTIVITY}

The atom is the basic constituent of all matter and is one of the smallest units into which matter can be divided. Each atom is composed of a tiny central core of particles, or nucleus, surrounded by a cloud of negatively charged particles called electrons. Most atoms in the physical world are stable, meaning that they are not radioactive. However, some atoms possess excess energy, which causes them to be physically unstable. In order to become stable, an atom rids itself of this extra energy by casting it off in the form of charged particles or electromagnetic waves, known as radiation.

\section{COMMON TYPES OF RADIATION}

The three most important types of radiation are described below:

ALPHA

An alpha particle is identical in makeup to the nucleus of a helium atom, consisting of two neutrons and two protons. Alpha particles have a positive charge and have little or no penetrating power in matter. They are easily stopped by materials such as paper and have a range in air of only an inch or so. Naturally occurring radioactive elements such as uranium and radon daughters emit alpha radiation.

BETA

Beta radiation is composed of particles that are identical to electrons. As a result, beta particles have a negative charge. Beta radiation is slightly more penetrating than alpha but may be stopped by materials such as aluminum foil and Lucite ${ }^{\mathrm{TM}}$ panels. They have a range in air of several feet. Naturally occurring radioactive elements such as potassium- $40(\mathrm{~K}-40)$ emit beta radiation.

GAMMA

Gamma radiation is a form of electromagnetic radiation, like radio waves or visible light, but with a much shorter wavelength. It is more penetrating than alpha or beta radiation, capable of passing through dense materials such as concrete. X-rays are similar to gamma radiation.

\section{NOMENCLATURE}

Throughout this report, radioactive elements (also called radionuclides) are referred to by a name followed by a number, e.g., cesium-137. The number following the name of the element is called the mass of the element and is equal to the total number of particles contained in the nucleus of the atom. Another way to specify the identity of cesium-137 is by writing it as Cs-137, where 'Cs' is the chemical symbol for cesium as it appears in the standard Periodic Table of the Elements. This type of abbreviation is used in the text and many of the data tables in this report. 


\section{SOURCES OF RADIATION}

Radioactivity and radiation are part of the earth's natural environment. Human beings are exposed to radiation from a variety of common sources, the most significant of which are listed below.

COSMIC

Cosmic radiation primarily consists of charged particles that originate in space, beyond the Earth's atmosphere. This includes radiation from the sun and secondary radiation generated by the entry of charged particles into the Earth's atmosphere at high speeds and energies. Radioactive elements such as hydrogen-3 (tritium), beryllium-7, carbon14 , and sodium-22 are produced in the atmosphere by cosmic radiation. The average dose from cosmic radiation to a person living in the United States is about 26 mrem per year.

TERRESTRIAL

Terrestrial radiation is released by radioactive elements present in the soil since the formation of the Earth about five billion years ago. Common radioactive elements contributing to terrestrial exposure include isotopes of potassium, thorium, actinium, and uranium. The average dose from terrestrial radiation to a person living in the United States is about 28 mrem per year.

INTERNAL

Internal exposure occurs when radionuclides are ingested, inhaled, or absorbed through the skin. Radioactive material may be incorporated into food through the uptake of terrestrial radionuclides by plant roots. Human ingestion of radionuclides can occur when contaminated plant matter or animals that consume contaminated plant matter are eaten. Most exposure to inhaled radioactive material results from breathing the decay products of naturally occurring radon gas. The average dose from eating foods to a person living in the United States is about 40 mrem per year; the average dose from radon product inhalation is about 200 mrem per year.

MEDICAL

Millions of people every year undergo medical procedures that utilize radiation. Such procedures include chest and dental x-rays, mammography, thallium heart stress tests, and tumor irradiation therapies. The average dose from nuclear medicine and x-ray examination procedures in the United States is about 14 and 39 mrem per year, respectively.

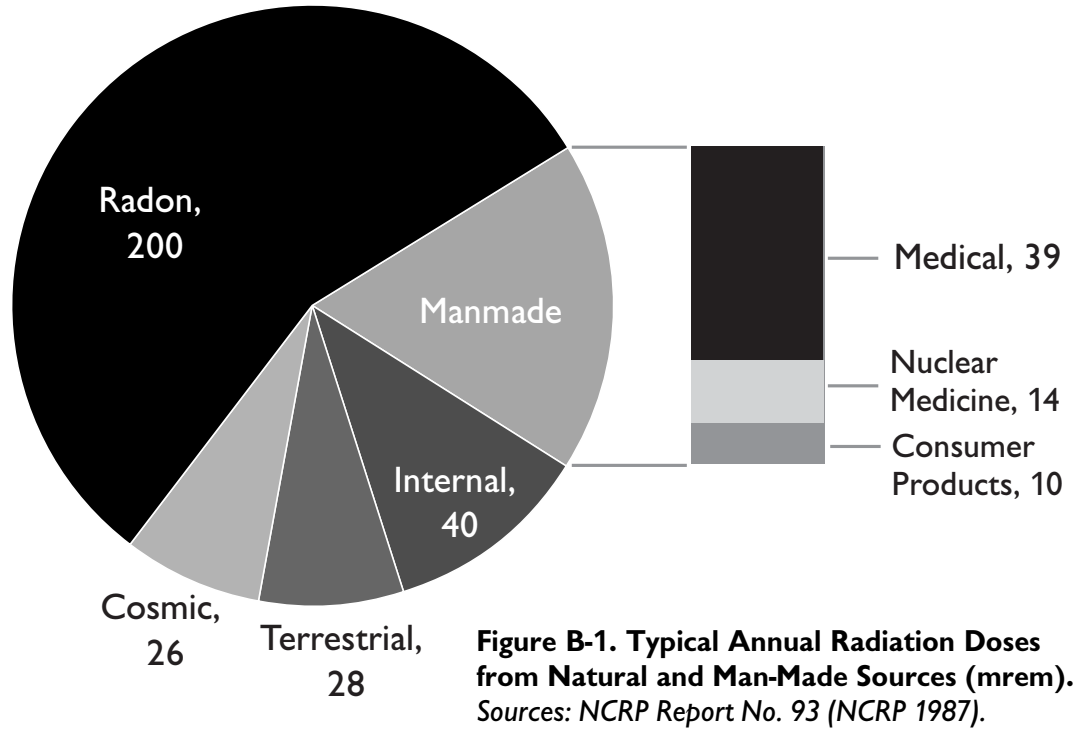

ANTHROPOGENIC

Sources of anthropogenic (manmade) radiation include consumer products such as static eliminators (containing polonium-210), smoke detectors (containing americium241), cardiac pacemakers (containing plutonium-238), fertilizers (containing isotopes of the uranium and thorium decay series), and tobacco products (containing polonium-210 and lead-210). The average dose from consumer products to a person living in the United States is 10 mrem per year (excluding tobacco contributions). 
DOSE UNITS

The amount of energy that radiation deposits in body tissues or organs, when corrected for human risk factors, is referred to as dose equivalent or, more generally, as dose. Radiation doses are measured in units of rem. Since the rem is a fairly large unit, it is convenient to express most doses in terms of millirem $(1,000 \mathrm{mrem}=1 \mathrm{rem})$. To give a sense of the size and importance of a 1 mrem dose, Figure B-1 indicates the number of mrem received by an individual in one year from natural and background sources. These values represent typical values for residents of the United States. Note that the alternate unit of dose measurement commonly used internationally and increasingly in the United States is the sievert, abbreviated $\mathrm{Sv}$. One $\mathrm{Sv}$ is equivalent to 100 rem. Likewise, 1 millisievert $(\mathrm{mSv})$ is equivalent to $100 \mathrm{mrem}$.

The unit used to express the quantity of radioactive material in a sample is the curie $(\mathrm{Ci})$. This is a measure of the rate at which radioactive atoms are transformed to stable atoms. Since the curie is a relatively large unit for measuring environmental samples, the picocurie (pCi) is often used. This unit is equal to one trillionth of a $\mathrm{Ci}$, or 0.037 decays per second. The alternate unit for quantifying radioactivity is the becquerel, abbreviated Bq. One becquerel is equal to 1 decay per second. Additional units of measure and their conversion factors can be found on the inside of the back cover of this report.

\section{TYPES OF RADIOLOGICAL ANALYSIS}

The quality of environmental air, water, and soil with respect to radioactive material can be assessed using several types of analysis. The most common analyses are described below.

GROSS ALPHA

Alpha particles are emitted in a range of different energies. An analysis that measures all alpha particles simultaneously, without regard to their particular energy, is known as a gross alpha activity measurement. This type of measurement is valuable as a screening tool to indicate the magnitude of alpha-emitting radionuclides that may be present in a sample.

GROSS BETA

This is the same concept as described above, except that it applies to the measurement of beta particle activity.

TRITIUM

Due to the nature of the radiation, a low energy beta particle, emitted from the tritium atom, it is detected and quantified by liquid scintillation counting method. (More information on tritium is presented in the next section.)

Due to the nature of the radiation emitted by strontium-90, a special analysis is required. Samples are chemically processed to separate and collect any strontium atoms that may be present. The collected atoms are then analyzed separately. (More information on strontium-90 is presented in the next section.)

This analysis technique identifies specific radionuclides. It measures the particular energy of a radionuclide's gamma radiation emissions. The energy of these emissions is unique for each nuclide, acting as a "fingerprint" to identify a specific nuclide. 


\section{STATISTICS}

Two important statistical aspects of measuring radioactivity are uncertainty in results and negative values.

UNCERTAINTY

Because the emission of radiation from an atom is a random process, a sample counted several times will yield a slightly different result each time; a single measurement is, therefore, not definitive. To account for this phenomenon, the concept of uncertainty is applied to radiological data. In this report analysis results are displayed with $\mathrm{x} \pm \mathrm{y}$ format, where $\mathrm{x}$ is the result and $\pm y$ is the 95 percent confidence interval of the result. That is, there is a 95 percent probability that the true value of $x$ lies between $x+y$ and $\mathrm{x}-\mathrm{y}$. Conversely, there is a 5 percent probability that the true value of $x$ lies outside of this range.

Negative values

There is always a small amount of natural radiation in the environment. The instruments used in the laboratory to measure radioactivity in BNL site environmental media are sensitive enough to measure the natural, or background, radiation along with any contaminant radiation in a sample. To obtain a true measure of the contaminant level in a sample, the natural (or background) radiation level must be subtracted from the total amount of radioactivity measured by an instrument. Due to the randomness of radioactive emissions and the very low concentrations of some contaminants, it is possible to obtain a background measurement that is larger than the actual contaminant measurement. When the larger background measurement is subtracted from the smaller contaminant, a negative result is generated. The negative results are reported because they are essential when conducting statistical evaluations of data.

\section{RADIONUCLIDES OF ENVIRONMENTAL INTEREST}

Several types of radionuclides are found in the environment at BNL due to historical operations and include the following:

STRONTIUM-90

Strontium- 90 is a beta-emitting radionuclide with a half-life of 28 years (i.e., after 28 years only one half of the activity from the original remains). It is found in the environment principally as a result of fallout from aboveground nuclear weapons testing. (Fallout refers to the deposition of radionuclides on soils and water bodies as a result of being dispersed high into the Earth's atmosphere during nuclear explosions.) Strontium90 released in the 1950s and early 1960s is still present in the environment today due to its long half-life. Additionally, nations that were not signatories of the Nuclear Test Ban Treaty of 1963 have conducted tests that have contributed to the global strontium-90 inventory. This radionuclide was also released as a result of the 1986 Chernobyl accident in the former Soviet Union.

The data in this environmental report are reported by method of analysis. Because strontium- 90 requires a unique method of analysis, it is reported as a separate parameter in the data tables. The level of sensitivity for detecting strontium-90 using state-of-the-art analysis methods is quite low (less than $1 \mathrm{pCi} / \mathrm{L}$ ), which makes it possible to detect strontium-90 at levels that are indicative of the environmental sources described above.

TRITIUM

Among the radioactive materials that are used or produced at BNL, tritium has received the most public attention. Tritium exists in nature and is formed when cosmic radiation from space interacts with the gaseous nitrogen in the Earth's upper atmosphere. Approximately 4 million $\mathrm{Ci}(1.5 \mathrm{E} 5 \mathrm{TBq})$ per year are produced in the atmosphere in this way, with the total global quantity being about 70 million $\mathrm{Ci}$ (2.6E6 $\mathrm{TBq}$ ) at any given time (NCRP 1979). As a result of the 1950s and early 1960s aboveground weapons testing program, the global atmospheric tritium inventory was increased by a factor of about 200 . Other human activities such as consumer product manufacturing and nuclear power reactor operations have also released tritium into the environment. Commercially, tritium is used in products such as self-illuminating exit signs and wrist watches (exit signs may contain as much as $25 \mathrm{Ci}$ [925 GBq] of tritium). It also has many uses in medical and biological research as a 
labeling agent in chemical compounds and is frequently used in universities and other research settings.

Of the sources mentioned above, the most significant contributor to tritium in the environment has been aboveground nuclear weapons testing. In the early 1960 s, the average tritium concentration in surface streams in the United States reached a value of $4,000 \mathrm{pCi} / \mathrm{L}$ (148 $\mathrm{kBq} / \mathrm{L}$ ) (NCRP 1979). Approximately the same concentration was measurable in precipitation. Today, the level of tritium in surface waters in New York State is below $200 \mathrm{pCi} / \mathrm{L}(7.4 \mathrm{kBq} / \mathrm{L})$ (NYSDOH 1993), less than the detection limit of most analytical laboratories.

Tritium has a half-life of 12.3 years. When an atom of tritium decays, it releases a beta particle, causing transformation of the tritium atom into stable (nonradioactive) helium. This beta radiation has a very low energy when compared to the emissions of most other radioactive elements. The body's outer layer of dead skin cells easily stops tritium beta radiation and therefore, only when taken into the body, can tritium cause an exposure. Because of its low energy radiation and short residence time in the body, the health threat posed by tritium is very small for most credible exposures.

Environmental tritium is found in two forms: (1) gaseous elemental tritium and (2) tritiated water (or water vapor), in which at least one of the hydrogen atoms in the $\mathrm{H}_{2} \mathrm{O}$ water molecule has been replaced by a tritium atom (hence, its shorthand notation HTO). All tritium released from BNL sources is in the form of HTO.

CESIUM-137

Cesium-137 is a man-made, fission-produced radionuclide with a half-life of 30 years. It is found in the environment as a result of past aboveground nuclear weapons testing and can be observed in the upper levels of environmental soils at very low concentrations, usually less than $1 \mathrm{pCi} / \mathrm{g}(0.04 \mathrm{~Bq} / \mathrm{g})$. It is a beta-emitting radionuclide, but can be detected by gamma spectroscopy by the gamma emissions of its decay product, barium $-137 \mathrm{~m}$.

\section{SCIENTIFIC NOTATION}

Since many of the numbers used in measurement and quantification in this report are either very large or very small, many zeroes would be required to express their value. Because this is inconvenient, scientific notation is used as a kind of numerical shorthand. Scientific notation is based on the principle of representing numbers in multiples of ten. For example, the number one million could be written as $1,000,000$. Alternatively, this number could be written in scientific notation as $1 \times 10^{6}$. That is, "one times ten raised to the sixth power." Since even this shorthand can be cumbersome, it can be reduced even further by using the capital letter $\mathrm{E}$ to stand for $10^{\mathrm{x}}$, or "ten raised to the power of some value x." Using this notation, 1,000,000 would be represented as $1 \mathrm{E}+06$. Scientific notation is also used to represent very small numbers like 0.0001 , which can be written as $1 \times 10^{-4}$ or $1 \mathrm{E}$ 04 . This notation is used in the text and some tables in this report.

\section{PREFIXES}

Another method of representing very large or very small numbers without the use of many zeroes is to use prefixes to represent multiples of ten. For example, the prefix "milli" means that the value being represented is one thousandth of a whole unit, so that one-milligram is equal to one thousandth of a gram.

\section{DEFINITION OF RADIOLOGICAL TERMS}

Radiological terms are used throughout this report where radiation and radioactive material are discussed. The definitions of commonly used radiological terms are found in Appendix A.

\footnotetext{
REFERENCES

NCRP. 1979. Tritium in the Environment. NCRP Report No. 62. National Council on Radiation Protection and Measurements. Bethesda, Maryland.

NCRP. 1987. Ionizing Radiation Exposure of the Population of the United States. NCRP Report No. 93. National Council on Radiation Protection and Measurements. Bethesda, Maryland.

NYSDOH. 1993. Environmental Radiation in New York State. Bureau of Environmental Radiation Protection, New York State Department of Health, Albany, New York.
} 
Intentionally Left Blank 
APPENDIX C

\section{Radiological Data Methodologies}

\section{DOSE CALCULATION - ATMOSPHERIC RELEASE PATHWAY}

The effective dose equivalent for low levels of airborne radioactive materials dispersed into the environment was calculated for each of the 16 compass sectors using the CAP88-PC, version 2.0 dose model program (EPA 1992). Site meteorology data were used to calculate annual dispersions for the midpoint of a given sector and distance. Facility-specific radionuclide release rates (in curies per year $[\mathrm{Ci} / \mathrm{yr}]$ ) were also used. All annual site boundary and collective dose values were generated using the CAP88-PC computer code, which calculates the total dose due to contributions from the immersion, inhalation, and ingestion pathways. The dose and risk estimates were based on low levels of chronic intake of radionuclides.

\section{DOSE CALCULATION - FISH INGESTION PATHWAY}

To estimate the effective dose equivalent from the fish consumption pathway, the following procedure was used:

Intake.

The average fish consumption for an individual engaged in recreational fishing in the Peconic River was based on a study done by the New York State Department of Health (NYSDOH 1996), which estimates the consumption rate at approximately 15 pounds $(7 \mathrm{~kg})$ per year.

Activity in Flesh.

Radionuclide data for fish samples were all converted to picocuries per gram ( $\mathrm{pCi} / \mathrm{g}$ ) wet weight, since this is the form in which the fish are caught and consumed.

\section{Dose Factor.}

DOE Order 5400.5 (1990) 50-year committed dose equivalent factors (in rem per microcurie $[\mathrm{rem} / \mu \mathrm{Ci}]$ intake) were applied. The committed dose equivalent factor for Cs-137 is $5.0 \mathrm{E}-$ $02 \mathrm{rem} / \mu \mathrm{Ci}$.

\section{Calculation:}

$$
\begin{aligned}
\text { Dose }(\mathrm{rem} / \mathrm{yr}) & =\text { Intake }(\mathrm{kg} / \mathrm{year}) \\
& \times \text { Activity in Flesh }(\mu \mathrm{Ci} / \mathrm{kg}) \\
& \times \text { Dose Factor }(\mathrm{rem} / \mu \mathrm{Ci})
\end{aligned}
$$

\section{DOSE CALCULATION - DEER MEAT CONSUMPTION}

This calculation is performed in exactly the same way as shown in the previous section. The same DOE Order 5400.5 dose conversion factors are used. The only change is the estimate of total pounds ingested during the course of a year. For deer meat, the consumption rate of 64 pounds $(29 \mathrm{~kg})$ per year is based on the Environmental Protection Agency Exposure Factors Handbook (EPA 1996).

\section{RADIOLOGICAL DATA PROCESSING}

Radiation events occur in a random fashion such that if a radioactive sample is counted multiple times, a distribution of results will be obtained. This spread, known as a Poisson distribution, will be centered about a mean value. If counted multiple times, the background activity of the instrument (the number of radiation events observed when no sample is present) will also be seen to have a distribution of values centered about a mean. The goal of a radiological analysis is to determine whether the sample in question contains activity in excess of the instrument or method blank background. Since the activity of the sample and the background are both Poisson distributed, subtraction of background activity from the measured sample activity results in a value that may vary slightly from one analysis to the next. Therefore, the concept of a minimum detection limit (MDL) was established to determine the statistical likelihood that the sample contains activity that is truly greater than the instrument background.

Identifying a sample as containing activity greater than background, when it actually does not have activity present, is known as a Type I error. As with most laboratories, the BNL Analytical Services Laboratory sets its acceptance of a Type I error at 5 percent when calculating the MDL for a given analysis. That is, for any value that is greater than or equal to the MDL, there is 95 percent confidence that it represents the detection of true activity. Values 
that are less than the MDL may be valid, but they have a reduced confidence associated with them. Therefore, all validated or verified radiological data are reported, regardless of their value.

At very low sample activity levels that are close to the instrument background, it is possible to obtain a sample result that is less than the zero. This occurs when the background activity is subtracted from the sample activity to obtain a net value, and a negative value results. Due to

Table C-1. Typical Minimum Detection Limits for Gross Activity and Tritium Concentrations in Water.

\begin{tabular}{lcc}
\hline Analysis & Aliquot $(\mathrm{mL})$ & MDL $(\mathrm{pCi} / \mathrm{L})$ \\
\hline Gross alpha & 100 & 4 \\
& 200 & 1 \\
Gross beta & 100 & 9 \\
& 200 & 2 \\
Tritium & 1 & 3,900 \\
& 7 & 350 \\
\hline
\end{tabular}

Table C-2. Typical Minimum Detection Limits for Gamma Spectroscopy Analysis.

\begin{tabular}{|c|c|c|c|}
\hline Nuclide & $\begin{array}{c}300 \mathbf{g} \\
\text { Soil } \\
(\mu \mathrm{Ci} / \mathrm{mL})\end{array}$ & $\begin{array}{l}300 \mathrm{~mL} \\
\text { Water } \\
(\mu \mathrm{Ci} / \mathrm{mL})\end{array}$ & $\begin{array}{c}3 \mathrm{~L} \\
\text { Maranelli } \\
(\mu \mathrm{Ci} / \mathrm{mL})\end{array}$ \\
\hline $\mathrm{Be}-7$ & 7E-08 & $1 \mathrm{E}-07$ & 1E-08 \\
\hline $\mathrm{Na}-22$ & 9E-09 & $1 \mathrm{E}-08$ & 1E-09 \\
\hline$K-40$ & $2 \mathrm{E}-07$ & $2 \mathrm{E}-07$ & $2 \mathrm{E}-08$ \\
\hline Sc-48 & 1E-08 & $1 \mathrm{E}-08$ & $3 \mathrm{E}-08$ \\
\hline Cr-51 & 8E-08 & $1 \mathrm{E}-07$ & 1E-08 \\
\hline$M n-54$ & 8E-09 & $1 \mathrm{E}-08$ & 1E-09 \\
\hline$M n-56$ & $2 \mathrm{E}-07$ & $3 \mathrm{E}-07$ & $2 \mathrm{E}-08$ \\
\hline Co-57 & 7E-09 & 9E-09 & $1 \mathrm{E}-09$ \\
\hline Co-60 & 1E-08 & $1 \mathrm{E}-08$ & 1E-09 \\
\hline Zn-65 & $2 \mathrm{E}-08$ & $2 \mathrm{E}-08$ & 2E-09 \\
\hline Cs-134 & 1E-08 & $1 \mathrm{E}-08$ & 1E-09 \\
\hline Cs-137 & 9E-09 & $1 \mathrm{E}-08$ & 1E-09 \\
\hline Ra-226 & $3 \mathrm{E}-08$ & $3 \mathrm{E}-08$ & $4 \mathrm{E}-08$ \\
\hline Th-228 & $2 \mathrm{E}-08$ & $3 \mathrm{E}-08$ & $1 \mathrm{E}-07$ \\
\hline $\mathrm{Br}-82$ & 1E-08 & $2 \mathrm{E}-08$ & $8 \mathrm{E}-08$ \\
\hline |-131 & 9E-09 & $1 \mathrm{E}-08$ & 3E-09 \\
\hline |-133 & $1 \mathrm{E}-08$ & $2 \mathrm{E}-08$ & 3E-09 \\
\hline \multicolumn{4}{|c|}{$\begin{array}{l}\text { Note: All MDLs shown above are approximate. For gamma spectroscopy } \\
\text { the MDL of the analysis is dependent upon several variables, such as the } \\
\text { efficiency of the particular detector and the activity of the sample. These } \\
\text { factors will vary between analyses and instrumentation. }\end{array}$} \\
\hline
\end{tabular}

this situation, a single radiation event observed during a counting period could have a significant effect on the average (mean) value result. Subsequent analysis may produce a sample net result that is positive. All results must be averaged; therefore, all negative values are retained for reporting as well. This data handling practice is consistent with the guidance provided in the Handbook of Radioactivity Measurements Procedure, NCRP Report No. 58 (NCRP 1985), and the Environmental Regulatory Guide for Radiological Effluent Monitoring and Environmental Surveillance, DOE/EH-0173T (1991). Typical MDLs for the various analyses performed on environmental and effluent samples are shown in Tables C-1, C-2, and C-3.

Table C-3. Typical Minimum Detection Limits for Chemical Analyses by BNL Analytical Services Lab and Off-site Analytical Laboratories.

\begin{tabular}{|c|c|c|}
\hline Constituent & BNL Laboratory & Offsite Laboratories \\
\hline $\mathrm{Ag}$ & 0.025 & 0.010 \\
\hline $\mathrm{Cd}$ & 0.0005 & 0.005 \\
\hline $\mathrm{Cr}$ & 0.005 & 0.010 \\
\hline $\mathrm{Cu}$ & 0.050 & 0.025 \\
\hline $\mathrm{Fe}$ & 0.075 & 0.100 \\
\hline $\mathrm{Hg}$ & 0.0002 & 0.0002 \\
\hline $\mathrm{Mn}$ & 0.050 & 0.015 \\
\hline $\mathrm{Na}$ & 1.0 & 5.0 \\
\hline $\mathrm{Pb}$ & 0.005 & 0.003 \\
\hline $\mathrm{Zn}$ & 0.02 & 0.020 \\
\hline Ammonia-N & NA & 0.02 \\
\hline Nitrite-N & NA & 0.01 \\
\hline Nitrate-N & 1.0 & NA \\
\hline Specific Conductance & $10 \mu \mathrm{mhos} / \mathrm{cm}$ & NA \\
\hline Chlorides & 4.0 & NA \\
\hline Sulfates & 4.0 & $N A$ \\
\hline 1,1,1-trichloroethane & 0.002 & 0.005 \\
\hline trichloroethylene & 0.002 & 0.005 \\
\hline tetrachloroethylene & 0.002 & 0.005 \\
\hline chloroform & 0.002 & 0.005 \\
\hline chlorodibromomethane & 0.002 & 0.005 \\
\hline bromodichloromethane & 0.002 & 0.005 \\
\hline bromoform & 0.002 & 0.005 \\
\hline benzene & 0.002 & 0.005 \\
\hline toluene & 0.002 & 0.005 \\
\hline xylene & 0.002 & 0.005 \\
\hline \multicolumn{3}{|c|}{$\begin{array}{l}\text { Notes: } \\
\text { All concentrations in } \mathrm{mg} / \mathrm{L} \text { except where noted. } \\
\mathrm{NA}=\text { NotApplicable (Laboratory does not perforr }\end{array}$} \\
\hline
\end{tabular}


Average values are calculated using actual analytical results, regardless of whether they are above or below the MDL, or even equal to zero. The uncertainty of the mean, or the 95 percent confidence interval, is determined by multiplying the population standard deviation of the mean by the $t_{(0.05)}$ statistic.

\section{REFERENCES}

DOE Order 5400.5. 1990. Radiation Protection of the Public and the Environment. U.S. Department of Energy, Washington, D.C. Change 2: 1-7-93.
DOE/EH-0173T. 1991. Environmental Regulatory Guide for Radiological Effluent Monitoring and Environmental Surveillance. U.S. Department of Energy, Washington, D.C.

EPA. 1992. User's Guide for CAP-88-PC, Version 2. EPA402b92001. U.S. Environmental Protection Agency. Washington, D.C.

EPA. 1996. Food Ingestion Factors, Exposure Factors HandbookVolume II. EPA600P95002FB. U.S. Environmental Protection Agency. Washington, D.C.

NCRP. 1985. Handbook of Radioactivity Measurements Procedures, NCRP Report No. 58. National Council on Radiation Protection and Measurements, Bethesda, Maryland. NYSDOH. 1996. Radioactive Contamination in the Peconic River. Bureau of Environmental Radiation Protection, New York State Department of Health, Albany, New York. 
Intentionally Left Blank 


\section{Instrumentation and Analytical Methods}

The Analytical Services Laboratory (ASL) is divided into radiological and nonradiological sections to facilitate analysis of specific parameters in each category. The methods and instrumentation for each category are briefly described below. Only validated and regulatory referenced methods were used during the analysis. All samples were collected and preserved by trained technicians according to appropriate referenced methods. Qualified and trained analysts performed each of the different analyses.

\section{RADIOLOGICAL ANALYTICAL METHODS}

The ASL is certified by the New York State Department of Health (NYSDOH) for gross alpha, gross beta, gamma, tritium, and strontium-90 (nonpotable water). The following is a description of the radiological analytical methods.

\section{GROSS ALPHA AND GROSS BETA ANALYSIS - WATER MATRIX - EPA 900.0}

Water samples are collected in four-liter polyethylene containers by BNL sampling teams and preserved at the time of collection by acidification to $\mathrm{pH} 2$ using nitric acid. Effluent or surface stream samples of $100 \mathrm{ml}$ are extracted for analysis. Groundwater samples are typically analyzed using a 200-mL aliquot. The aliquot is evaporated to neardryness in a glass beaker. Two drops of concentrated nitric acid are added, after which the solids are policed down the side of the beaker. The sample is transferred to a stainless steel planchet. Four drops of 10 percent Triton- $X$ are added to the sample before it completely evaporates on a hot plate. The planchets are placed in a drying oven at $105^{\circ} \mathrm{C}$ for a minimum of 2 hours; removed to a desiccator and allowed to cool; and weighed and counted in a gas-flow proportional counter for 50 minutes. Groundwater samples are counted for 200 minutes. Samples are normally processed in batch mode. The first sample of each batch is a background, for which the count rate is subtracted from the raw data before computing net activity concentration. System performance is checked daily with NIST-traceable standards: americium-241 for alpha, and strontium-90 for beta. Spiked duplicates are performed within each batch of samples to determine precision and accuracy.

\section{GROSS ALPHA AND GROSS BETA ANALYSIS - AIR PARTICULATE MATRIX}

Air particulate samples are collected on $50-\mathrm{mm}$ glass fiber filters at a nominal flow rate of 15 liters per minute. At the end of the collection, the filters are returned to the analytical laboratory for assay. After a one week holding time, filters are counted once in a gas flow proportional counter for 50 minutes. This delay permits the short-lived radon/ thoron daughters to decay. The first sample of each batch is a blank filter whose count rate is subtracted from the raw data before calculating net activity concentration. The system's performance is checked daily with National Institute for Standards and Technology (NIST) traceable standards: americium241 for alpha and strontium-90 for beta.

\section{TRITIUM ANALYSIS - WATER MATRIX - EPA 906.0}

Water samples are collected in glass containers. No preservatives are added before collecting the sample. Effluent and surface stream samples, as well as groundwater samples, are analyzed using a 7$\mathrm{mL}$ aliquot. Potable-water samples (as well as other samples requiring a low minimum detection limit) are distilled following the method outlined in EPA Method 906.0 (EPA 1980), and a 7-mL aliquot is analyzed. Liquid scintillation cocktail is added to the aliquot so that the final volume in the liquidscintillation-counting vial is $7 \mathrm{~mL}$ of sample plus 10 $\mathrm{ml}$ of cocktail. Samples then are counted in a lowbackground liquid-scintillation counter for 50 minutes. Samples are normally processed in batch mode. The first sample of each batch is a steamdistilled water background that is subtracted from the raw data before calculating the net activity concentration. The second sample in each batch is a NIST-traceable tritium standard, which is used to verify the system's performance and efficiency. Each sample is also monitored for quenching. Corrections for background, quenching, and efficiency of the sample matrix are factored into the final net concentrations for each sample. Spiked duplicates are performed within each batch of samples to determine precision and accuracy.

\section{TRITIUM ANALYSIS - AIR MATRIX}

Concentration of tritium in ambient and facility air is measured by drawing the air through a 
desiccant at a rate of approximately $200 \mathrm{cc} / \mathrm{min}$. At the end of each collection period, typically one week, the desiccant is brought to the analytical laboratory for processing. It is heated in a glass manifold system. Dedicated glassware are used for environmental samples. The desiccant, containing moisture from the sampled air, is heated using an electric mantle, and the evaporated moisture is condensed by a water-cooled glass condenser. The total volume of water collected is determined gravimetrically. A 7-mL aliquot of this water is then assayed for tritium content. If the desiccant contains less than 7-mL of condensed liquid, a 1-ml aliquot is used. Liquid scintillation cocktail is then added to the aliquot so that the final volume in the counting vial is $17-\mathrm{mL}$. Samples are then counted in a low-background liquid-scintillation counter for 50 minutes. If a 1-mL aliquot was used, liquid scintillation cocktail is added to the vial so that the final volume is $11-\mathrm{mL}$. These samples are counted for 100 minutes. Samples are normally processed in batch mode. The first sample of each batch is a steam-distilled water background whose count rate is subtracted from the raw data before computing net activity concentration. The second sample in each batch is a NIST-traceable tritium standard, which is used to verify the system's performance and efficiency. Each sample is also monitored for quenching. Corrections for background, water recovery, air sample volume, quenching and efficiency for the sample matrix are factored into the final net concentrations for each sample. Spiked duplicates are performed within each batch of samples to determine precision and accuracy, respectively.

\section{STRONTIUM-90 ANALYSIS}

Strontium-90 analyses are currently performed on water. Groundwater samples are processed inhouse using either DOE Method RP500, which utilizes a crown ether to selectively separate strontium from the acidified sample matrix or an ion exchange resin method. The strontium is eluted from the resin or filtration disk using dilute nitric acid. The resulting eluent is evaporated on a $5 \mathrm{~cm}$ stainless steel planchet and the sample counted in a gas-flow proportional counter. Samples are prepared in batches, including a standard and a method blank in each batch. Chemical recovery is determined for each sample by the recovery of strontium carbonate. NIST-traceable strontium-90 standards are used to calibrate and verify the performance of the counting instrument. Samples are counted once after a two-week radiological ingrowth time.

Potable water samples, as well as samples of solids, are shipped to a contractor laboratory, which is certified to perform the EPA (1980), 905.0 method for strontium-90 in drinking water. This method employs time-consuming and costly wetchemistry techniques to isolate strontium from the sample. Samples are counted twice to verify strontium-90 and yttrium-90 in-growth. Samples are typically processed in a batch. Backgrounds and system performance are verified with each batch. Chemical recoveries are determined by either gravimetric or gamma-emitting strontium-85 standard addition techniques.

\section{GAMMA SPECTROSCOPY ANALYSIS - EPA 901.1}

Surface, potable, and groundwater surveillance samples are typically of 4 liters and are placed in polyethylene bottles acidified to $\mathrm{pH} 2$ with nitric acid. Samples are then measured into a $4-\mathrm{L}$ Marinelli ${ }^{\mathrm{TM}}$ beaker and counted on a calibrated gamma spectroscopy detector for 50,000 seconds. Air-particulate filters and air-charcoal canisters are counted directly on the calibrated gamma spectroscopy detector for 10,000 seconds. Soil, vegetation, and aquatic biota are all processed following collection. Typically, a 100-, 200-, or 300 -gram aliquot is taken, placed in a Teflon-lined aluminum can, and directly counted. For gamma spectroscopy analyses, overnight backgrounds are counted once per week, with calibration and background checked daily. Analytical results reflect net activity that has been corrected for background and efficiency for each counting geometry used.

\section{NONRADIOLOGICAL ANALYTICAL METHODS}

The ASL is certified by NYSDOH ELAP for purgeable aromatics, purgeable halocarbons, PCBs, anions, and metal compounds, in both potable and wastewater matrices, using EPA 524, EPA 624, EPA 200.8, EPA 245.2, EPA 236.1, EPA 273.1, and EPA 300.0 methods. Tables D-1 and D-2 list the nonradiological organic and inorganic NYSDOH ELAP certified analytes, respectively.

\section{PURGEABLE AROMATICS AND PURGEABLE HALOCARBONS}

Water samples are collected in $40 \mathrm{~mL}$ glass vials with removable teflon-lined caps without any headspace, and acidified 1:1 $\mathrm{HCl}$ to $\mathrm{pH}<2.0$. Samples are stored at $4^{\circ} \mathrm{C}$ and analyzed within 14 days. Thirty eight purgeable compounds (including: benzene, toluene, ethyl benzene, total xylenes, chloroform, 1,1-dichloroethane, 1,1dichloroethylene, tetrachloroethylene, 1,1,1trichloroethane, trichloroethylene, chlorobenzene, carbon tetrachloride, methyl chloride and acetone) are analyzed under this category following EPA Method 624 protocols using Gas Chromatography/ Mass Spectrometry (GC/MS). There are currently two Hewlett-Packard ${ }^{\mathrm{TM}}$ GC/MS instruments used to 
Table D-1. ASL Certified Organic Analytes.

\begin{tabular}{|c|c|c|c|}
\hline \multicolumn{4}{|l|}{ EPA 624 Analytes } \\
\hline $\begin{array}{l}\text { Bromoform } \\
\text { Chloromethane } \\
\text { Vinyl Chloride } \\
\text { Bromomethane } \\
\text { Chloroethane } \\
\text { Trichlorofluoromethane } \\
\text { 1,1-Dichloroethene } \\
\text { Acetone } \\
\text { Methylene Chloride } \\
\text { trans-1,2-Dichloroethene }\end{array}$ & $\begin{array}{l}\text { 1,1-Dichloroethane } \\
\text { 2-Butanone } \\
\text { Chloroform } \\
\text { 1,1,1-Trichloroethane } \\
\text { Dibromofluoromethane } \\
\text { Carbon Tetrachloride } \\
\text { Benzene } \\
\text { 1,2-Dichloroethane } \\
\text { All Dichlorobenzenes }\end{array}$ & $\begin{array}{l}\text { Trichloroethene } \\
\text { 1,2-Dichloropropane } \\
\text { Bromodichloromethane } \\
\text { 1,1,2,2-Tetrachloroethane } \\
\text { 4-Methyl-2-pentanone } \\
\text { cis-1,3-Dichloropropene } \\
\text { p-Bromofluorobenzene } \\
\text { Toluene } \\
\text { trans-1,3-Dichloropropene }\end{array}$ & $\begin{array}{l}\text { 1,1,2-Trichloroethane } \\
\text { Tetrachloroethene } \\
\text { 2-Hexanone } \\
\text { Dibromochloromethane } \\
\text { MTBE } \\
\text { Chlorobenzene } \\
\text { Ethylbenzene } \\
\text { mlp-xylene } \\
\text { o-Xylene }\end{array}$ \\
\hline \multicolumn{4}{|l|}{ EPA 524.2 Analytes } \\
\hline $\begin{array}{l}\text { Dichlorodifuoromethane } \\
\text { Chloromethane } \\
\text { Vinyl Chloride } \\
\text { Bromomethane } \\
\text { Chloroethane } \\
\text { Trichlorofluoromethane } \\
\text { 1,1-Dichloroethene } \\
\text { Chlorobenzene } \\
\text { Methylene Chloride } \\
\text { trans-1,2-Dichloroethene } \\
\text { 1,1-Dichloroethane } \\
\text { 2,2-Dichloropropane } \\
\text { cis-1,2-Dichloroethene } \\
\text { Bromochloromethane } \\
\text { Ethylbenzene }\end{array}$ & $\begin{array}{l}\text { Chloroform } \\
\text { 1,1,1-Trichloroethane } \\
\text { Carbon Tetrachloride } \\
\text { 1,1-Dichloropropene } \\
\text { Benzene } \\
\text { 1,2-Dichloroethane } \\
\text { o-Xylene } \\
\text { Trichloroethene } \\
\text { 1,2-Dichloropropane } \\
\text { Dibromomethane } \\
\text { Bromodichloromethane } \\
\text { cis-1,3-Dichloropropene } \\
\text { Styrene } \\
\text { Toluene } \\
\text { Trans-1,3-Dichloropropene }\end{array}$ & $\begin{array}{l}\text { 1,1,2-Trichloroethane } \\
\text { Tetrachloroethene } \\
\text { m,p-xylene } \\
\text { 1,3-dichloropropane } \\
\text { Dibromochloromethane } \\
\text { 1,2-dibromoethane } \\
\text { 1,1,1,2-Tetrachloroethane } \\
\text { Bromoform } \\
\text { Isopropylbenzene } \\
\text { Bromobenzene } \\
\text { 1,1,2,2-Tetrachloroethane } \\
\text { n-Propylbenzene } \\
\text { 1,2,3-Trichloropropane } \\
\text { 2-Chlorotoluene } \\
\text { 1,3,5-trimethylbenzene }\end{array}$ & $\begin{array}{l}\text { 4-Chlorotoluene } \\
\text { Tertbutylbenzene } \\
\text { 1,2,4-trimethylbenzene } \\
\text { sec-Butylbenzene } \\
\text { p-lsopropyltoluene } \\
\text { n-Butylbenzene } \\
\text { 1,3-Dichlorobenzene } \\
\text { 1,4-Dichlorobenzene } \\
\text { 1,2-Dichlorobenzene } \\
\text { 1,2-Dibromo-3-Cl-propane } \\
\text { 1,2,4-Trichlorobenzene } \\
\text { Hexachlorobutadiene } \\
\text { Naphthalene } \\
\text { 1,2,3-trichlorobenzene }\end{array}$ \\
\hline
\end{tabular}

analyze purgeable organic compounds. Since groundwater under BNL is classified as a sole source aquifer under the Safe Drinking Water Act and Class GA groundwater by the New York State Department of Environmental Conservation (NYSDEC), the detection limits reported for the compounds are close to NYS drinking water standards and the ambient water quality standard. EPA drinking water Methods 524.2 and 624 are used to analyze water, based on the project manager's data quality requirements.

The method involves purging a $25-\mathrm{mL}$ aliquot of the sample with ultra pure helium in a specially designed sparger using the Purge and Trap technique. Each sample is spiked with a known concentration of internal standards and surrogates before purging to facilitate identifying, quantifying, and determining the extraction efficiency of analytes from the matrix. The purged analytes are trapped onto a specially designed trap and thermally desorbed onto the capillary chromatographic column by back flushing the trap with helium. Individual compounds are separated with a temperature program of the GC and enter the mass spectrometer where they undergo fragmentation to give characteristic mass spectra. The unknown compounds are identified by comparing their mass spectra and retention times with reference compounds and quantified by internal standard method. The quantitation data is supported by
Table D-2. ASL Certified Metals and Anions.

\begin{tabular}{lcc}
\hline Metals & Instrument & Method \\
\hline Aluminum & ICP/MS & EPA200.8 \\
Antimony & ICP/MS & EPA200.8 \\
Arsenic & ICP/MS & EPA200.8 \\
Barium & ICP/MS & EPA200.8 \\
Beryllium & ICP/MS & EPA200.8 \\
Cadmium & ICP/MS & EPA200.8 \\
Chromium & ICP/MS & EPA200.8 \\
Cobalt & ICP/MS & EPA200.8 \\
Copper & ICP/MS & EPA200.8 \\
Iron & AAS & EPA236.1 \\
Lead & ICP/MS & EPA200.8 \\
Manganese & ICP/MS & EPA200.8 \\
Mercury & AAS & EPA245.2 \\
Molybdenum & ICP/MS & EPA200.8 \\
Nickel & ICP/MS & EPA200.8 \\
Selenium & ICP/MS & EPA200.8 \\
Silver & ICP/MS & EPA200.8 \\
Sodium & AAS & EPA273.1 \\
Thallium & ICP/MS & EPA200.8 \\
Vanadium & ICP/MS & EPA200.8 \\
Zinc & ICP/MS & EPA200.8 \\
\hline Anions & Instrument & Method \\
\hline Chloride & IC & EPA300.0 \\
Nitrate & IC & EPA300.0 \\
Sulfate & IC & EPA300.0 \\
\hline Notes: & & \\
ICP/MS = Inductively Coupled/Mass Spectrometry & \\
AAS =AtomicAbsorption Spectrometry & \\
IC = lon Chromatography & & \\
\hline
\end{tabular}


extensive Quality Assurance/Quality Control, such as tuning the mass spectrometer to meet bromofluorobenzene criteria, initial and continuing calibrations verifying daily response factors, method blanks, surrogate recoveries, duplicate analysis, matrix spike and matrix spike duplicate analysis, and reference standard analysis to verify the daily working standard.

\section{PCB ANALYSIS}

The ASL is NYSDOH Certified for PCB Aroclors 1016, 1221, 1232, 1242, 1248, 1254 and 1260. Samples are collected in $50-100 \mathrm{~mL}$ glass containers with Teflon ${ }^{\mathrm{TM}}$-lined lids and stored at $4^{\circ} \mathrm{C}$ and analyzed within 30 days. Transformer oil, mineral oil, hydraulic fluid, waste oil and spill wipesamples are analyzed for PCBs using gas chromatography-dual electron capture detector (GC-ECD) method. This method is similar to EPA SW-846 Method 8082 and is targeted to identify and quantify seven different mixtures of PCB congeners in samples.

The method consists of diluting a known weight of the sample with isooctane and removing the interfering compounds with one or more aliquots of concentrated sulfuric acid until the acid layer is almost colorless. The entire oil matrix, along with other interfering polar compounds, is selectively removed from the sample, leaving the PCBs in isooctane solvent.

There is currently a single GC-ECD instrument for analyzing PCB. The PCBs found in the samples are identified and quantified by comparing the retention times and chromatographic patterns with the standards. Methods blanks, duplicates, spikes, calibration, and reference check standards are run as part of Quality Assurance/Quality Control.

\section{ANIONS}

Chloride, nitrate- $\mathrm{N}$, and sulfate are analyzed using Dionex Ion-chromatography (IC) with ion suppression and conductivity detection technique. Samples from monitoring wells are collected in 100 -mL polyethylene bottles, cooled to $4^{\circ} \mathrm{C}$, and analyzed within 28 days. For nitrate in drinking water analysis, samples are analyzed within $48 \mathrm{hrs}$. Holding times were exceeded for nitrate analysis of some nonpotable monitoring well samples, but the depletion of nitrate is expected to be negligible.

The anions are passed through an anionexchange polymer column and eluted with carbonate/bicarbonate solution. Then the eluent passes through a membrane suppressor, where the background contribution from the eluent is suppressed, improving signal to noise ratio (and detection limits). The target anions are then detected by conductivity meter.

Initially, the system is calibrated with standards to define its working range. The target anions in the samples are identified and quantified by comparing the retention times and areas with the standards. Method blanks, duplicates, replicates, spikes, and reference standards are routinely analyzed as part of Quality Assurance/Quality Control.

\section{METALS}

Samples are collected in $500-\mathrm{mL}$ glass bottles and stabilized with ultra-pure nitric acid to a pH of $<2$. The samples are analyzed within 6 months, except for mercury, which is analyzed within 26 days.

Iron and sodium are analyzed with a PerkinElmer atomic absorption spectrometer. Using the flame technique, the sample containing the target element is nebulized and atomized in an oxyacetylene flame. At the same time, a beam of light from an element-specific hollow cathode lamp corresponding to the absorption frequency of target element is passed through the flame. The atomized element absorbs the energy specific to that element from the cathode lamp and the intensity of absorption is proportional to the concentration of the element in the sample. Calibration curves establish the linearity of the system and samples are quantified by comparing with standards.

Fourteen of the seventeen elements offered for certification in potable water by NYSDOH ELAP are analyzed by Inductively Coupled Plasma/Mass Spectrometry (ICP/MS). Iron and sodium are detailed in the preceding paragraph, and mercury in the following. Including aluminum, cobalt, molybdenum and vanadium, for which only wastewater certification is available, there are eighteen elements analyzed by the ICP/ MS technique. Aqueous samples are nebulized, and introduced into a radio frequency argon plasma, at temperatures reaching $8000^{\circ} \mathrm{K}$. The de-solvated, atomized analytes are ionized to predominantly singly-charged cations, which are identified and quantified by the use of a quadrupole mass spectrometer. Isobaric and polyatomic ion interferences are corrected using elemental interference equations based on natural isotopic abundances. Internal standardization eliminates or minimizes instrument drift and matrix-induced signal suppressions and enhancements. Using this technique, sub-part per billion sample detection limits are achievable.

Using a cold-vapor technique for mercury, a $100-\mathrm{mL}$ aliquot of the sample is digested with potassium permanganate/persulfate oxidizing solution at $95^{\circ} \mathrm{C}$ for two hours to oxidize any organically bound and/or monovalent mercury to mercury (II) oxidation state. Excess oxidizing agent is destroyed with hydroxylamine 
hydrochloride. The mercuric ion later is reduced to elemental mercury with excess stannous chloride, which is purged with argon into the absorption cell. The absorption is directly proportional to the concentration of mercury in the sample. All the atomic absorption techniques involve initial calibrations to define the calibration range, continuing calibrations, method blanks, duplicates, replicates, matrix spikes, and reference standard analysis as a part of Quality Assurance/Quality Control.

In the fall of 2000, a Leeman PS 200 II automated mercury analyzer was added. This unit enables improved detection limits $(<0.1 \mu \mathrm{g} / \mathrm{L})$, and a more stable baseline than previous instrumentation. This has resulted in improved data quality.

\section{REFERENCES}

DOE. 1995. Methods for Evaluating Environmental and Waste Management Samples. DOE/EM 0089T. U.S. Department of Energy. Washington, D.C.

EPA. 1980. Prescribed Procedures for the Measurement of Radioactivity in Water. EPA600480032. U.S. Environmental Protection Agency. Washington, D.C. August 1980.

NYSDEC. 1995. Analytical Services Protocols. Bureau of Technical Services and Research, New York State Department of Environmental Conservation. Albany, New York. October 1995. 
Intentionally Left Blank 
APPENDIX E

\section{Groundwater Monitoring Wells List for 2001}

ER = Environmental Restoration Program

ES = Environmental Surveillance

OU I - HWMF/Current Landfill (RA-V)

077-02 ER

098-21 ER 098-62 ER

087-21 ER

098-22 ER

098-63 ER

107-26 ER

108-30 ER

115-29 ER

116-06 ER

088-13 ER

099-04 ER

108-08 ER

115-03 ER

115-30 ER

000-124 ER

098-30 ER

108-12 ER

115-13 ER

115-31 ER

000-137 ER

088-20 ER

115-14 ER

115-36 ER

108-14 ER

115-15 ER

000-138 ER

088-26 ER

098-59 ER

107-24 ER

108-17 ER

115-41 ER

800-54 ER

098-19 ER

098-61 ER

1017-25 ER

115-16 ER

115-42 ER

116-05 ER

Total

47

OU I Current Landfill Post-Closure

087-09 ER 087-23 ER 087-26 ER

087-27 ER

088-21 ER

088-23 ER

088-109 ER

088-110 ER

087-11 ER

087-24 ER

088-22 ER

Total

OU I Former Landfill Post-Closure

$\begin{array}{lllllll}\text { 086-42 ER } & 087-22 \text { ER } & 097-17 \text { ER } & 097-64 \text { ER } & 097-277 \text { ER } & 106-02 \text { ER } & 106-30 \text { ER } \\ \text { 086-72 ER } & & & \text { Total } & \mathbf{8}\end{array}$

Chemical/Animal Holes Area

\begin{tabular}{|c|c|c|c|c|c|c|c|}
\hline 106-04 ER & 106-16 ER & 106-22 ER & 106-43 ER & $106-46 \mathrm{ER}$ & $106-49 \mathrm{ER}$ & 106-63 ER & \\
\hline 106-13 ER & 106-17 ER & 106-23 ER & 106-44 ER & 106-47 ER & $106-50 \mathrm{ER}$ & 106-64 ER & \\
\hline 106-14 ER & $106-20 \mathrm{ER}$ & 106-24 ER & $106-45$ ER & $106-48$ ER & $106-62 \mathrm{ER}$ & 114-01 ER & \\
\hline \multirow[t]{2}{*}{ 106-15 ER } & 106-21 ER & 106-25 ER & & & & & \\
\hline & & & & & & Total & 24 \\
\hline \multicolumn{8}{|c|}{ Alternating Gradient Synchrotron Facility } \\
\hline 054-07 ES & 054-67 ES & 054-128 ES & 055-14 ES & 064-03 ES/ER & 064-52 ES & $065-126 \mathrm{ES}$ & \\
\hline 054-08 ES & $054-68 \mathrm{ES}$ & 054-129 ES & 055-15 ES & 064-51 ES & $065-120$ ES & 065-192 ES & \\
\hline 054-62 ES & 054-69 ES & 054-130 ES & 055-16 ES & $065-52$ ES & 065-121 ES & 065-193 ES & \\
\hline 054-63 ES & 054-124 ES & 054-168 ES & 055-29 ES & 064-53 ES & $065-122$ ES & 065-194 ES & \\
\hline 054-64 ES & 054-125 ES & $054-169$ ES & $055-30$ ES & 064-54 ES & 065-123 ES & 065-195 ES & \\
\hline 054-65 ES & $054-126$ ES & 054-184 ES & 055-31 ES & 064-55 ES & 065-124 ES & & \\
\hline 054-66 ES & 054-127 ES & 054-185 ES & 055-32 ES & $064-56$ ES & $065-125$ ES & Total & 47 \\
\hline \multicolumn{8}{|c|}{ Relativistic Heavy Ion Collider Facility } \\
\hline 025-01 ES & 025-04 ES & 025-07 ES & 034-05 ES & 043-01 ES & 044-13 ES & $044-29$ ES & \\
\hline 025-02 ES & 025-05 ES & 025-08 ES & 034-06 ES & 043-02 ES & 044-14 ES & & \\
\hline 025-03 ES & 025-06 ES & & & & & Total & 14 \\
\hline \multicolumn{8}{|c|}{ Brookhaven LINAC Isotope Producer } \\
\hline \multirow{2}{*}{$\begin{array}{l}054-61 \text { ES } \\
064-02 \text { ES }\end{array}$} & $064-46$ ES & 064-47 ES & $064-48$ ES & $064-49 \mathrm{ES}$ & $064-50 \mathrm{ES}$ & 064-67 ES & \\
\hline & & & & & & Total & 8 \\
\hline \multicolumn{8}{|c|}{ Waste Management Facility } \\
\hline \multirow{3}{*}{$\begin{array}{l}055-03 \text { ES } \\
055-10 \text { ES }\end{array}$} & 056-21 ES & 056-22 ES & 056-23 ES & 066-07 ES & 066-83 ES & 066-84 ES & \\
\hline & & & & & & & \\
\hline & & & & & & Total & 8 \\
\hline
\end{tabular}




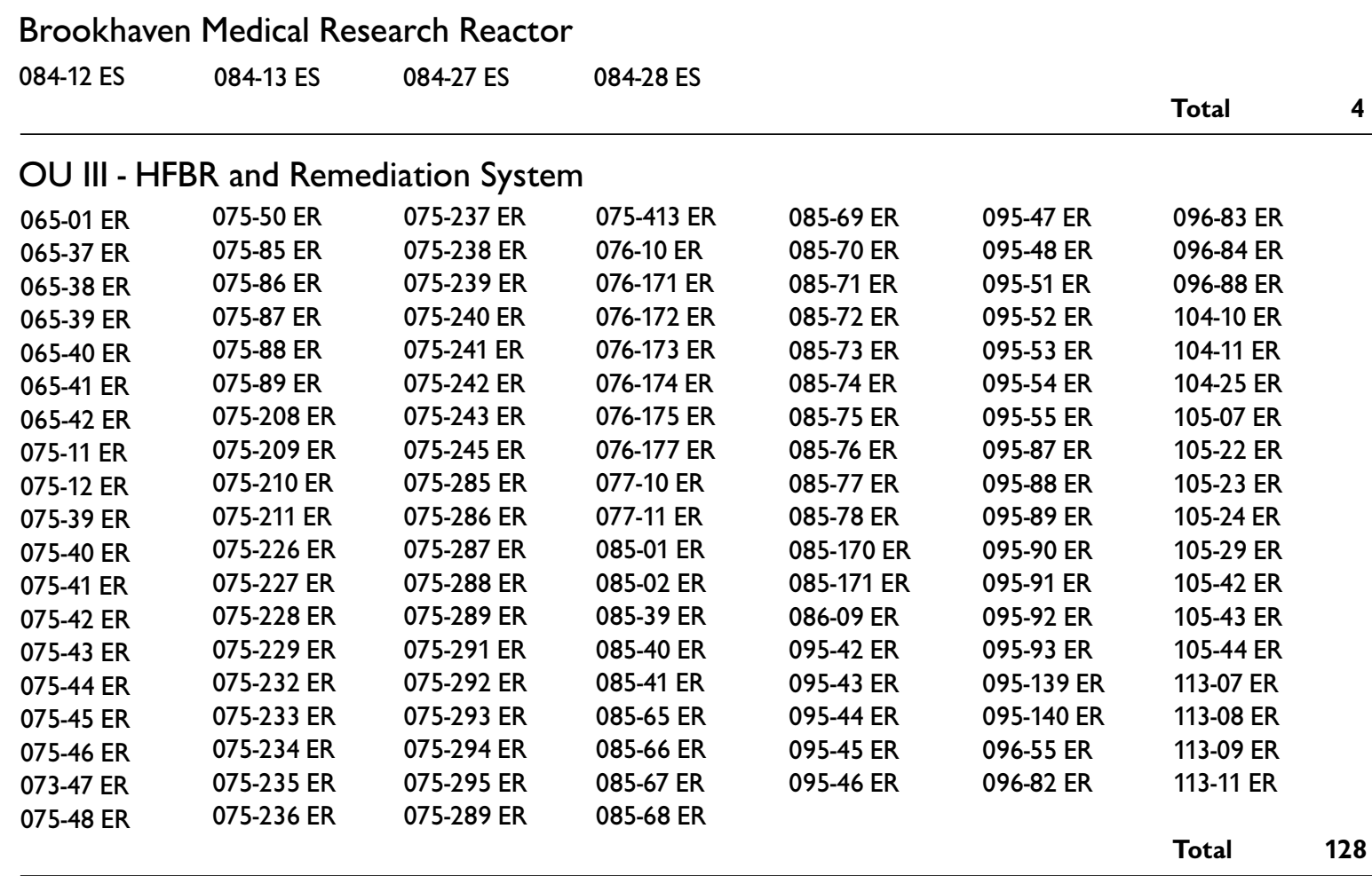

Live Fire Range

039-91 ES 039-92 ES

Total

2

Shotgun Range

046-01 ES 046-02 ES 046-03 ES

Total

Water Treatment Plant

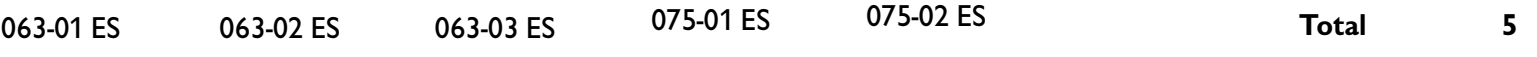

BNL Gasoline Station

085-16 ES 085-17 ES 085-235 ES/ER 085-236 ES/ER 085-237 ES/ER

BNL Motor Pool

102-05 ES 102-08 ES 102-09 ES 102-10 ES $102-11 \mathrm{ES} \quad 102-12 \mathrm{ES} \quad 102-13 \mathrm{ES}$ 102-06 ES

Total

Biology Greenhouse Area

084-36 ES 084-37 ES

\begin{tabular}{|c|c|c|c|c|c|c|c|}
\hline & & & & & & Total & 2 \\
\hline OU III - & tral Secto & & & & & & \\
\hline 064-03 ER & 066-08 ER & 075-01 ER & 084-04 ER & 105-06 ER & 109-03 ER & 113-07 ER & \\
\hline 064-08 ER & 066-09 ER & 075-02 ER & 084-05 ER & $105-25$ ER & 109-04 ER & & \\
\hline 065-02 ER & 072-03 ER & 083-01 ER & 096-07 ER & 106-19 ER & & & \\
\hline 065-05 ER & 072-04 ER & 083-02 ER & $105-05$ ER & & & Total & 22 \\
\hline
\end{tabular}




\section{OU III - Southern Boundary}

\begin{tabular}{|c|c|c|c|c|c|c|c|}
\hline 114-06 ER & $121-10$ ER & 121-19 ER & 122-04 ER & 122-17 ER & 122-31 ER & 126-01 ER & \\
\hline 114-07 ER & 121-11 ER & $121-20$ ER & $122-05$ ER & $122-18$ ER & $122-32$ ER & $130-02$ ER & \\
\hline 121-06 ER & $121-12$ ER & 121-21 ER & $122-09 \mathrm{ER}$ & $122-19$ ER & $122-33$ ER & 130-03 ER & \\
\hline 121-07 ER & $121-13$ ER & $121-22$ ER & $122-10$ ER & $122-20$ ER & $122-34$ ER & 130-04 ER & \\
\hline 121-08 ER & 121-14 ER & $121-23$ ER & 122-15 ER & 122-21 ER & $122-35$ ER & & \\
\hline \multirow{2}{*}{ 121-09 ER } & 121-18 ER & $122-02$ ER & $122-16$ ER & $122-22$ ER & $124-02$ ER & & \\
\hline & & & & & & Total & 40 \\
\hline \multicolumn{8}{|c|}{ OU III - Carbon Tetrachloride Plume } \\
\hline 085-07 ER & 085-98 ER & 085-163 ER & 086-114 ER & 095-47 ER & 095-183 ER & 104-11 ER & \\
\hline 085-13 ER & 085-161 ER & $085-238$ ER & 098-43 ER & 095-88 ER & 095-185 ER & $105-42$ ER & \\
\hline 085-16 ER/ES & 085-160 ER & 086-113 ER & 095-45 ER & 095-89 ER & 095-186 ER & & \\
\hline 085-17 ER/ES & 085-162 ER & & & & & Total & 22 \\
\hline \multicolumn{8}{|c|}{ OU III - Building 96} \\
\hline 085-97 ER & 095-85 ER & 095-162 ER & 095-165 ER & 095-168 ER & 095-170 ER & 095-172 ER & \\
\hline 085-293 ER & 095-159 ER & 095-163 ER & 095-166 ER & 095-169 ER & 095-171 ER & & \\
\hline 095-84 ER & 095-161 ER & 095-164 ER & 095-167 ER & & & Total & 17 \\
\hline
\end{tabular}

OU III - Middle Road

\begin{tabular}{|c|c|c|c|c|c|c|c|}
\hline 105-23 ER & 105-53 ER & 106-55 ER & $106-62$ ER & 113-09 ER & $113-18$ ER & 113-21 ER & \\
\hline 105-25 ER & 105-54 ER & $106-56$ ER & $113-06$ ER & 113-11 ER & 113-19 ER & $113-22$ ER & \\
\hline 105-44 ER & 106-53 ER & $106-58$ ER & 113-07 ER & 113-16 ER & $113-20$ ER & $114-12$ ER & \\
\hline $105-52$ ER & $106-54$ ER & 106-59 ER & $113-08$ ER & 113-17 ER & & Total & 26 \\
\hline \multicolumn{8}{|c|}{ OU III - Off-site } \\
\hline 000-97 ER & 000-101 ER & 000-105 ER & 800-21 ER & $800-40$ ER & $800-44$ ER & 800-52 ER & \\
\hline 000-98 ER & 000102 ER & 000-107 ER & $800-22$ ER & $800-41$ ER & $800-50$ ER & 800-53 ER & \\
\hline \multirow{2}{*}{ 000-99 ER } & 000-104 ER & 000-131 ER & $800-23$ ER & $800-43$ ER & 800-51 ER & & \\
\hline & & & & & & Total & 20 \\
\hline \multicolumn{8}{|c|}{ OU III - Industrial Park Area } \\
\hline 000-112 ER & $000-248$ ER & $000-254$ ER & $000-260$ ER & 000-266 ER & 000-271 ER & 000-276 ER & \\
\hline 000-114 ER & 000-249 ER & 000-255 ER & 000-261 ER & 000-267 ER & 000-272 ER & 000-277 ER & \\
\hline 000-130 ER & $000-250$ ER & $000-256$ ER & $000-262$ ER & 000-268 ER & 000-273 ER & 000-278 ER & \\
\hline 000-245 ER & $000-251$ ER & $000-257$ ER & $000-263$ ER & 000-269 ER & 000-274 ER & 000-279 ER & \\
\hline 000-246 ER & $000-252$ ER & $000-258$ ER & $000-264$ ER & $000-270$ ER & 000-275 ER & $000-280$ ER & \\
\hline \multirow[t]{2}{*}{ 000-247 ER } & $000-253$ ER & $000-259$ ER & $000-265$ ER & & & & \\
\hline & & & & & & Total & 39 \\
\hline \multicolumn{8}{|c|}{ OU III - BGRR/WCF Areas } \\
\hline 065-03 ER & 065-39 ER & 065-167 ER & 065-175 ER & 075-41 ER & 075-189 ER & 075-197 ER & \\
\hline 065-04 ER & 065-40 ER & 065-168 ER & 065-176 ER & $075-46$ ER & 075-190 ER & 075-198 ER & \\
\hline 065-06 ER & 065-160 ER & 065-169 ER & 065-177 ER & 075-47 ER & 075-191 ER & 075-199 ER & \\
\hline 065-11 ER & 065-161 ER & 065-170 ER & 065-178 ER & 075-48 ER & 075-192 ER & 075-200 ER & \\
\hline 065-18 ER & 065-162 ER & 065-171 ER & 075-09 ER & 075-85 ER & 075-193 ER & 075-201 ER & \\
\hline 065-19 ER & 065-163 ER & 065-172 ER & 075-10 ER & 075-86 ER & 075-194 ER & 075-202 ER & \\
\hline 065-20 ER & 065-164 ER & 065-173 ER & 075-39 ER & 075-87 ER & 075-195 ER & 075-203 ER & \\
\hline 065-37 ER & 065-165 ER & 065-174 ER & 075-40 ER & 075-188 ER & 075-196 ER & & \\
\hline 065-38 ER & 065-166 ER & & & & & Total & 7 \\
\hline
\end{tabular}

SCWA Onsite Sentinel Wells - Wm. Floyd Well Field 109-03 ER 109-04 ER 
APPENDIX F

\section{Quality Control Tables}

This appendix presents the tables for Chapter 9, Quality Assurance. The tables show performance evaluation (PE) results for the ASL as well as three BNL contractor laboratories (H2M, GEL, and STL) that participated in national and/or state PE testing programs during 2000 . Section 9.7 of the SER describes the data shown in the 8 tables. The detailed data contained in the tables were also used to determine the overall PE score of each participating laboratory, for both radiological and nonradiological programs. The combined overall PE test scores (i.e., acceptable, warning, and unacceptable) are summarized as bar graphs in Figures 9-2 and 9-3 of the text for each laboratory by PE testing program.

\section{TABLES}

Table F-1. Groundwater Blind Duplicate Results

Table F-2. DOE's Evaluation of BNL and GEL Performance on Quality Assessment Tests 54 and 55. F-2

Table F-3. NYSDOH's Evaluation of the Potable Water Radiochemistry Testing Done by BNL and Two Contract Labs.

Table F-4. Results for BNL and GEL on the InterLab RadCheM Proficiency Test Conducted by Environmental Resource Associates.

Table F-5. NYSDOH's Evaluation of the Nonpotable Water Testing Performed by BNL and Contract Labs.

Table F-6. NYSDOH's Evaluation of BNL Performance on Proficiency Tests 240 and 245 (Solid and Hazardous Waste Chemistry).

Table F-7. NYSDOH's Evaluation of the Potable Water Testing Performed by BNL and Contract Labs. F-12

Table F-8. Independent Company's Evaluation of Water Supply and Pollution Studies Performed by BNL and Contract Lab.

Table F-1.Groundwater Blind Duplicate Results (CY 2001).

\begin{tabular}{lccc}
\hline $\begin{array}{l}\text { Parameterl } \\
\text { Analytical Fraction }\end{array}$ & $\begin{array}{c}\text { Number } \\
\text { of Duplicate }\end{array}$ & $\begin{array}{c}\text { Percent } \\
\text { Acceptable }^{(a)}\end{array}$ & $\begin{array}{c}\text { Acceptable } \\
\text { Accilpha }\end{array}$ \\
\hline Gross Al & 26 & 96 \\
Gross Beta & 27 & 26 & 96 \\
Tritium & 74 & 72 & 97 \\
Strontium-90 & 43 & 42 & 97 \\
Gamma Spectroscopy & 25 & 25 & 100 \\
Volatile Organic Compounds & 56 & 55 & 98 \\
Ethylene Dibromide & 8 & 8 & 100 \\
Semivolatile Organic Compounds & 2 & 2 & 100 \\
Pesticides & 4 & 4 & 100 \\
Metals & 11 & 11 & 100 \\
Classical Chemistry & 11 & 7 & 63
\end{tabular}

Notes:

(a) Acceptability requirements are based on USEPA Region II duplicate guidelines. 


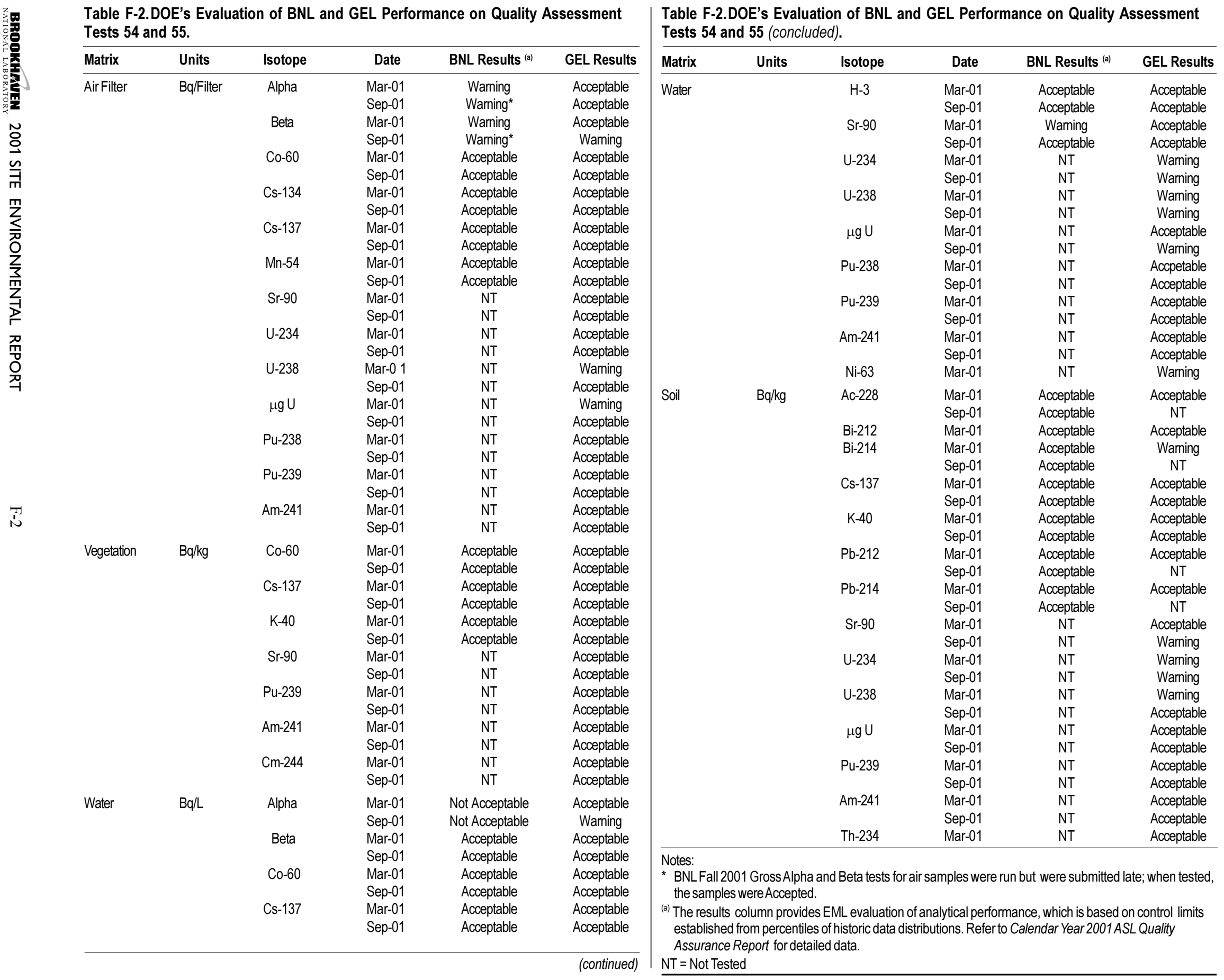


Table F-3.NYSDOH's Evaluation of the Potable Water Radiochemistry Testing Done by BNL and Two Contract Labs.

\begin{tabular}{lccc}
\hline Radionuclide & $\begin{array}{c}\text { BNL } \\
\text { Result }\end{array}$ & $\begin{array}{c}\text { GEL } \\
\text { Result }\end{array}$ & $\begin{array}{c}\text { STL-MO } \\
\text { Result }\end{array}$ \\
\hline Gross Alpha-Apr 2001 & Satisfactory & Satisfactory & Satisfactory \\
Gross Alpha-Oct 2001 & Satisfactory & Satisfactory & Satisfactory \\
Gross Beta-Apr 2001 & Satisfactory & Satisfactory & Satisfactory \\
Gross Beta-Oct 2001 & Satisfactory & Satisfactory & Satisfactory \\
Radium-226-Apr 2001 & NT & Satisfactory & Satisfactory \\
Radium-228-Apr 2001 & NT & Satisfactory & Satisfactory \\
Radium-226-Oct 2001 & NT & Satisfactory & Satisfactory \\
Radium-228-Oct 2001 & NT & Satisfactory & Satisfactory \\
\hline Notes: & & \\
Results for all labs are summarized as Satisfactory, Warning or Unsatisfactory. & \\
Refer to Calendar Year 2001 ASL Quality Assurance Report for detailed data. & \\
NT = Not Tested & & & \\
\hline
\end{tabular}

Table F-4.Results for BNL and GEL on the InterLab RadCheM Proficiency Test Conducted by Environmental Resource Associates.

\begin{tabular}{|c|c|c|c|}
\hline Analyte & Date & BNL Result(a) & GEL Result \\
\hline \multirow[t]{6}{*}{ Gross Alpha } & Mar-01 & Acceptable & NT \\
\hline & Apr-01 & NT & Acceptable \\
\hline & Jul-01 & Acceptable & Acceptable \\
\hline & Aug-01 & Acceptable & Acceptable \\
\hline & Oct-01 & Acceptable & NT \\
\hline & Dec-01 & Acceptable & NT \\
\hline \multirow[t]{6}{*}{ Gross Beta } & Mar-01 & Acceptable & NT \\
\hline & Apr-01 & NT & Acceptable \\
\hline & Jul-01 & Acceptable & Acceptable \\
\hline & Aug-01 & Acceptable & Acceptable \\
\hline & Oct-01 & Acceptable & NT \\
\hline & Dec-01 & Acceptable & NT \\
\hline Ba-133 & Aug-01 & Acceptable & NT \\
\hline \multirow[t]{3}{*}{ Co-60 } & Jul-01 & Acceptable & Acceptable \\
\hline & Aug-01 & Acceptable & Acceptable \\
\hline & Dec-01 & NotAcceptable & NT \\
\hline \multirow[t]{3}{*}{ Cs-134 } & Jul-01 & Acceptable & Acceptable \\
\hline & Aug-01 & Acceptable & Acceptable \\
\hline & Dec-01 & Acceptable & NT \\
\hline \multirow[t]{3}{*}{ Cs-137 } & Jul-01 & Acceptable & Acceptable \\
\hline & Aug-01 & NotAcceptable & Acceptable \\
\hline & Dec-01 & Check for Error & NT \\
\hline Zn-65 & Aug-01 & Accpetable & NT \\
\hline \multirow[t]{3}{*}{$\mathrm{H}-3$} & Mar-01 & Acceptable & NT \\
\hline & Aug-01 & NT & Acceptable \\
\hline & Sep-01 & Acceptable & NT \\
\hline \multirow[t]{3}{*}{ Ra-226 } & Jul-01 & NT & NotAcceptable \\
\hline & Aug-01 & NT & Acceptable \\
\hline & Nov-01 & NT & Acceptable \\
\hline \multirow[t]{3}{*}{ Ra-228 } & Jul-01 & NT & Check for Error \\
\hline & Aug-01 & NT & Acceptable \\
\hline & Nov-01 & NT & Acceptable \\
\hline \multirow[t]{3}{*}{ Sr-89 } & Apr-01 & NT & Acceptable \\
\hline & Jul-01 & NT & Check for Error \\
\hline & Sep-01 & NT & Acceptable \\
\hline \multirow{3}{*}{ Sr-90 } & Apr-01 & NT & Acceptable \\
\hline & Jul-01 & NT & Check for Error \\
\hline & Sep-01 & NT & Acceptable \\
\hline \multirow[t]{3}{*}{$\mathrm{U}(\mathrm{NAT})$} & Jul-01 & NT & Acceptable \\
\hline & Aug-01 & NT & Acceptable \\
\hline & Nov-01 & NT & Acceptable \\
\hline
\end{tabular}

Notes:

Refer to Calendar Year 2001 ASL Quality Assurance Report for detailed data.

(a) Result column provides ERA evaluation of analytical performance, which is based on 95 and $99 \%$ confidence interval about the target value.

NT = Not Tested. "Check for Error" is considered passing. 


\begin{tabular}{|c|c|c|c|c|c|c|c|c|c|c|c|}
\hline \multirow[b]{2}{*}{ Category } & \multirow[b]{2}{*}{ Analyte } & \multicolumn{5}{|c|}{ January 2001} & \multicolumn{5}{|c|}{ July 2001} \\
\hline & & BNL & GEL & STL-CT & STL-MO & $\mathrm{H} 2 \mathrm{M}$ & BNL & GEL & STL-CT & STL- MO & $\mathrm{H} 2 \mathrm{M}$ \\
\hline \multicolumn{12}{|l|}{$\begin{array}{l}\text { Change } \\
\text { Demand }\end{array}$} \\
\hline & Chemical Oxygen Demand & NT & Unsatisfactory & Satisfactory & Satisfactory & Satisfactory & NT & Satisfactory & NT & Unsatisfactory & Unsatisfactory \\
\hline \multirow{4}{*}{ Residue } & Organic Carbon, total & NT & Satisfactory & Satisfactory & Unsatisfactory & Satisfactory & NT & Satisfactory & NT & Satisfactory & Unsatisfactory \\
\hline & Total Dissolved Solids & NT & Satisfactory & Satisfactory & Satisfactory & Satisfactory & NT & Satisfactory & NT & Satisfactory & Satisfactory \\
\hline & Total Suspended Solids & NT & Satisfactory & Satisfactory & Satisfactory & Satisfactory & NT & Satisfactory & NT & Satisfactory & Satisfactory \\
\hline & Total Solids & NT & Satisfactory & Satisfactory & Satisfactory & Satisfactory & NT & Satisfactory & NT & Satisfactory & Satisfactory \\
\hline Hydrogen lon & $\mathrm{nH}$ & & & & & & & & & & \\
\hline \multirow{3}{*}{ Organic Nutrients } & $\mathrm{pH}$ & $\mathrm{NI}$ & Satisfactory & Satisfaciory & Saluslaciory & satistactory & $\mathrm{NI}$ & satisiactory & $\mathrm{NI}$ & Satisfactory & Satisfactory \\
\hline & Total Kjedahl Nitrogen & NT & Satisfactory & Satisfactory & Unsatisfactory & Satisfactory & NT & Satisfactory & NT & Unsatisfactory & Satisfactory \\
\hline & Phosphorus & NT & Satisfactory & Satisfactory & Satisfactory & Satisfactory & NT & Satisfactory & NT & NT & Satisfactory \\
\hline Alkalinity & Alkalinity & NT & Satisfactory & Satisfactory & Unsatisfactory & Satisfactory & NT & Satisfactory & NT & Satisfactory & Satisfactory \\
\hline \multirow[t]{3}{*}{ Inorganic Nutrients } & Ammonia & NT & Satisfactory & Satisfactory & Unsatisfactory & Satisfactory & NT & Satisfactory & NT & Satisfactory & Satisfactory \\
\hline & Nitrate & Satisfactory & Satisfactory & Satisfactory & Satisfactory & Satisfactory & Satisfactory & Satisfactory & NT & Satisfactory & Satisfactory \\
\hline & Orthophosphate & NT & Satisfactory & Satisfactory & Satisfactory & Satisfactory & NT & Satisfactory & NT & Unsatisfactory & Satisfactory \\
\hline \multirow[t]{3}{*}{ Minerals } & & & & & & & & & & & \\
\hline & Chloride & Satisfactory & Satisfactory & Unsatisfactory & Satisfactory & Satisfactory & Satisfactory & Satisfactory & NT & Satisfactory & Satisfactory \\
\hline & Sulfate & Satisfactory & Satisfactory & Satisfactory & NT & Satisfactory & Satisfactory & Satisfactory & NT & NT & Satisfactory \\
\hline \multirow[t]{2}{*}{ Phenols } & Dhongl & & & & & & & & & & \\
\hline & Phenols & NT & Satisfactory & Satisfactory & Satisfactory & Satisfactory & NT & Satisfactory & NT & Satisfactory & \\
\hline Oil and Grease & Oil and Grease & NT & Satisfactory & Unsatisfactory & Satisfactory & Satisfactory & NT & Satisfactory & NT & Satisfactory & Satisfactory \\
\hline \multirow{2}{*}{ Mercury } & & & & & & & & & & & \\
\hline & Mercury & Satisfactory & Satisfactory & Satisfactory & Satisfactory & Satisfactory & Satisfactory & Satisfactory & NT & Satisfactory & Satisfactory \\
\hline \multirow[t]{16}{*}{ Metals I and II } & Silver & Satisfactory & Satisfactory & Satisfactory & Satisfactory & Satisfactory & Satisfactory & Satisfactory & NT & Satisfactory & Satisfactory \\
\hline & Aluminum & Satisfactory & Satisfactory & Satisfactory & Satisfactory & Satisfactory & Satisfactory & Satisfactory & NT & Unsatisfactory & Satisfactory \\
\hline & Arsenic & Satisfactory & Satisfactory & Satisfactory & Satisfactory & Satisfactory & Unsatisfactory & Satisfactory & NT & Satisfactory & Satisfactory \\
\hline & Barium & Satisfactory & Satisfactory & Satisfactory & Satisfactory & Satisfactory & Satisfactory & Satisfactory & NT & Satisfactory & Satisfactory \\
\hline & Beryllium & Satisfactory & Satisfactory & Satisfactory & Satisfactory & Satisfactory & Satisfactory & Satisfactory & NT & Satisfactory & Satisfactory \\
\hline & Calcium & NT & Satisfactory & Satisfactory & Satisfactory & Satisfactory & Satisfactory & Satisfactory & NT & Satisfactory & Satisfactory \\
\hline & Cobalt & Satisfactory & Satisfactory & Satisfactory & Satisfactory & Satisfactory & Satisfactory & Satisfactory & NT & Satisfactory & Satisfactory \\
\hline & Cadmium & Satisfactory & Satisfactory & Satisfactory & Satisfactory & Satisfactory & Satisfactory & Satisfactory & NT & Satisfactory & Satisfactory \\
\hline & Chromium & Satisfactory & Satisfactory & Satisfactory & Satisfactory & Satisfactory & Satisfactory & Satisfactory & NT & Satisfactory & Satisfactory \\
\hline & Copper & Satisfactory & Satisfactory & Satisfactory & Satisfactory & Satisfactory & Satisfactory & Satisfactory & NT & Satisfactory & Satisfactory \\
\hline & Iron & Satisfactory & Satisfactory & Satisfactory & Satisfactory & Satisfactory & Satisfactory & Satisfactory & NT & Unsatisfactory & Satisfactory \\
\hline & Potassium & NT & Satisfactory & Satisfactory & Satisfactory & Satisfactory & Satisfactory & Satisfactory & NT & Unsatisfactory & Satisfactory \\
\hline & Magnesium & NT & Satisfactory & Satisfactory & Satisfactory & Satisfactory & Satisfactory & Satisfactory & NT & Satisfactory & Satisfactory \\
\hline & Manganese & Satisfactory & Satisfactory & Satisfactory & Satisfactory & Satisfactory & Satisfactory & Satisfactory & NT & Satisfactory & Satisfactory \\
\hline & Sodium & Satisfactory & Satisfactory & Satisfactory & Satisfactory & Satisfactory & Satisfactory & Satisfactory & NT & Satisfactory & Satisfactory \\
\hline & Nickel & Satisfactory & Satisfactory & Satisfactory & Satisfactory & Satisfactory & Satisfactory & Satisfactory & NT & Satisfactory & Satisfactory \\
\hline
\end{tabular}


Table F-5.NYSDOH's Evaluation of the Nonpotable Water Testing Performed by BNL and Contract Labs (continued).

\begin{tabular}{|c|c|c|c|c|c|c|c|c|c|c|c|}
\hline \multirow[b]{2}{*}{ Category } & \multirow[b]{2}{*}{ Analyte } & \multicolumn{5}{|c|}{ January 2001} & \multicolumn{5}{|c|}{ July 2001} \\
\hline & & BNL & GEL & STL-CT & STL-MO & H2M & BNL & GEL & STL-CT & STL- MO & H2M \\
\hline \multirow[t]{6}{*}{ Metals I and II } & Lead & Satisfactory & Satisfactory & Satisfactory & Satisfactory & Satisfactory & Satisfactory & Satisfactory & NT & Satisfactory & Satisfactory \\
\hline & Selenium & Satisfactory & Satisfactory & Satisfactory & Satisfactory & Satisfactory & Satisfactory & Satisfactory & NT & Satisfactory & Satisfactory \\
\hline & Antimony & Satisfactory & Satisfactory & Satisfactory & Satisfactory & Satisfactory & Satisfactory & Satisfactory & NT & Satisfactory & Satisfactory \\
\hline & Thallium & Satisfactory & Satisfactory & Satisfactory & Satisfactory & Satisfactory & Satisfactory & Satisfactory & NT & Satisfactory & Satisfactory \\
\hline & Vanadium & Satisfactory & Satisfactory & Satisfactory & Satisfactory & Satisfactory & Satisfactory & Satisfactory & NT & Satisfactory & Satisfactory \\
\hline & Zinc & Satisfactory & Satisfactory & Satisfactory & Satisfactory & Satisfactory & Satisfactory & Satisfactory & NT & Satisfactory & Satisfactory \\
\hline \multicolumn{12}{|l|}{ Metals III } \\
\hline & Molybdenum & Satisfactory & Satisfactory & Satisfactory & Satisfactory & Satisfactory & Satisfactory & Satisfactory & NT & Satisfactory & Satisfactory \\
\hline & \multicolumn{11}{|c|}{ Cyanide } \\
\hline \multicolumn{12}{|c|}{ PurgableAromatics } \\
\hline & 1,2-Dichlorobenzene & Satisfactory & Satisfactory & Satisfactory & Satisfactory & Satisfactory & Satisfactory & Satisfactory & Satisfactory & Satisfactory & Satisfactory \\
\hline & 1,3-Dichlorobenzene & Satisfactory & Unsatisfactory & Satisfactory & Satisfactory & Satisfactory & Satisfactory & Satisfactory & Satisfactory & Satisfactory & Satisfactory \\
\hline & 1,4-Dichlorobenzene & Satisfactory & Unsatisfactory & Satisfactory & Satisfactory & Satisfactory & Satisfactory & Satisfactory & Satisfactory & Satisfactory & Satisfactory \\
\hline & Benzene & Satisfactory & Satisfactory & Satisfactory & Satisfactory & Satisfactory & Satisfactory & Satisfactory & Satisfactory & Satisfactory & Satisfactory \\
\hline & Chlorobenzene & Satisfactory & Satisfactory & Satisfactory & Satisfactory & Satisfactory & Satisfactory & Satisfactory & Satisfactory & Satisfactory & Satisfactory \\
\hline & Ethyl benzene & Satisfactory & Satisfactory & Satisfactory & Satisfactory & Satisfactory & Satisfactory & Satisfactory & Satisfactory & NT & Satisfactory \\
\hline & Toluene & Satisfactory & Satisfactory & Satisfactory & Satisfactory & Satisfactory & Satisfactory & Satisfactory & Satisfactory & Satisfactory & Satisfactory \\
\hline & total Xylenes & Satisfactory & Satisfactory & Satisfactory & Satisfactory & Satisfactory & Satisfactory & Satisfactory & Satisfactory & Satisfactory & Satisfactory \\
\hline \multicolumn{12}{|c|}{ Purgable Halocarbons } \\
\hline & 1,1,1-Trichloroethane & Satisfactory & Satisfactory & Satisfactory & Satisfactory & Satisfactory & Satisfactory & Satisfactory & Satisfactory & Satisfactory & Satisfactory \\
\hline & 1,1,2,2-Tetrachloroethane & Satisfactory & Satisfactory & Satisfactory & Satisfactory & Satisfactory & Satisfactory & Satisfactory & Satisfactory & Satisfactory & Satisfactory \\
\hline & 1,1,2-Trichloroethane & NT & Satisfactory & Satisfactory & Satisfactory & Satisfactory & NT & Satisfactory & Satisfactory & Satisfactory & Satisfactory \\
\hline & 1,1-Dichloroethane & Satisfactory & Satisfactory & Satisfactory & Satisfactory & Satisfactory & Satisfactory & Satisfactory & Satisfactory & Satisfactory & Satisfactory \\
\hline & 1,1-Dichloroethene & Satisfactory & Satisfactory & Satisfactory & Satisfactory & Satisfactory & Satisfactory & Satisfactory & Satisfactory & Satisfactory & Satisfactory \\
\hline & 1,2-Dichloroethane & Satisfactory & Satisfactory & Satisfactory & Satisfactory & Satisfactory & Satisfactory & Satisfactory & Satisfactory & Satisfactory & Satisfactory \\
\hline & 1,2-Dichloropropane & Satisfactory & Satisfactory & Satisfactory & Satisfactory & Satisfactory & Satisfactory & Satisfactory & Satisfactory & Satisfactory & Satisfactory \\
\hline & 2-Chloroethylvinylether & NT & NT & Satisfactory & Satisfactory & Satisfactory & NT & Satisfactory & Satisfactory & Satisfactory & Satisfactory \\
\hline & Carbon tetrachloride & Satisfactory & Satisfactory & Unsatisfactory & Satisfactory & Satisfactory & Satisfactory & Satisfactory & Satisfactory & Satisfactory & Satisfactory \\
\hline & Bromomethane & Satisfactory & Satisfactory & Satisfactory & Satisfactory & Satisfactory & Satisfactory & Satisfactory & Satisfactory & Satisfactory & Satisfactory \\
\hline & Bromodichloromethane & Satisfactory & Satisfactory & Satisfactory & Satisfactory & Satisfactory & Satisfactory & Satisfactory & Satisfactory & Satisfactory & Satisfactory \\
\hline & Bromoform & Satisfactory & Satisfactory & Satisfactory & Satisfactory & Satisfactory & Satisfactory & Satisfactory & Satisfactory & Satisfactory & Satisfactory \\
\hline & Cis-1,3-Dichloropropene & Satisfactory & Satisfactory & Satisfactory & Satisfactory & Satisfactory & Satisfactory & Satisfactory & Satisfactory & Satisfactory & Satisfactory \\
\hline & Dibromomethane & NT & NT & Satisfactory & NT & NT & NT & NT & NT & NT & NT \\
\hline & Dibromochloromethane & Satisfactory & Satisfactory & Satisfactory & Satisfactory & Satisfactory & Satisfactory & Satisfactory & Satisfactory & Satisfactory & Satisfactory \\
\hline & Dichlorodifluoromethane & Satisfactory & Satisfactory & Satisfactory & Satisfactory & Satisfactory & Unsatisfactory & Satisfactory & Satisfactory & Satisfactory & Satisfactory \\
\hline & Chloroethane & Satisfactory & Satisfactory & Satisfactory & Satisfactory & Satisfactory & Satisfactory & Satisfactory & Satisfactory & Satisfactory & Satisfactory \\
\hline & Chloromethane & Satisfactory & Satisfactory & Satisfactory & Satisfactory & Satisfactory & Satisfactory & Satisfactory & Unsatisfactory & Satisfactory & Satisfactory \\
\hline & Chloroform & Satisfactory & Satisfactory & Satisfactory & Satisfactory & Satisfactory & Satisfactory & Satisfactory & Satisfactory & Satisfactory & Satisfactory \\
\hline & Methylene chloride & Satisfactory & Satisfactory & Satisfactory & Satisfactory & Satisfactory & Satisfactory & Satisfactory & Satisfactory & Satisfactory & Satisfactory \\
\hline & Trans-1,3-Dichloropropene & Satisfactory & Satisfactory & Satisfactory & Satisfactory & Satisfactory & Satisfactory & Satisfactory & Satisfactory & Satisfactory & Satisfactory \\
\hline & Tetrachloroethene & Satisfactory & Satisfactory & Satisfactory & Satisfactory & Satisfactory & Satisfactory & Satisfactory & Satisfactory & Satisfactory & Unsatisfactory \\
\hline & Trichloroethene & Satisfactory & Satisfactory & Satisfactory & Satisfactory & Satisfactory & Satisfactory & Satisfactory & Satisfactory & Satisfactory & Satisfactory \\
\hline & Trichlorofluoromethane & Satisfactory & Satisfactory & Satisfactory & Satisfactory & Satisfactory & Satisfactory & Satisfactory & Satisfactory & Satisfactory & Satisfactory \\
\hline & Vinyl chloride & Satisfactory & Satisfactory & Satisfactory & Satisfactory & Satisfactory & Satisfactory & Satisfactory & Satisfactory & Satisfactory & Satisfactory \\
\hline
\end{tabular}


Table F-5.NYSDOH's Evaluation of the Nonpotable Water Testing Performed by BNL and Contract Labs (continued).

\begin{tabular}{|c|c|c|c|c|c|c|c|c|c|c|c|}
\hline \multirow[b]{2}{*}{ Category } & \multirow[b]{2}{*}{ Analyte } & \multicolumn{5}{|c|}{ January 2001} & \multicolumn{5}{|c|}{ July 2001} \\
\hline & & BNL & GEL & STL-CT & STL-MO & H2M & BNL & GEL & STL-CT & STL- MO & H2M \\
\hline \multicolumn{12}{|c|}{ Nitrosamines } \\
\hline & N-Nitrosodimethylamine & NT & Satisfactory & Satisfactory & NT & Satisfactory & NT & Satisfactory & NT & Satisfactory & Satisfactory \\
\hline & N-Nitrosodiphenylamine & NT & Satisfactory & Satisfactory & NT & Satisfactory & NT & Satisfactory & NT & Satisfactory & Satisfactory \\
\hline & N-Nitrosodi-n-propylamine & NT & Satisfactory & Satisfactory & NT & Satisfactory & NT & Satisfactory & NT & Satisfactory & Satisfactory \\
\hline \multicolumn{12}{|l|}{ Benzidines } \\
\hline & 3,3'-Dichlorobenzidine & NT & Satisfactory & Satisfactory & Satisfactory & Satisfactory & NT & Satisfactory & NT & Satisfactory & Satisfactory \\
\hline & Benzidene & NT & Satisfactory & Satisfactory & Satisfactory & Satisfactory & NT & Satisfactory & NT & Satisfactory & Satisfactory \\
\hline \multicolumn{12}{|c|}{ Chlorinated Hydrocarbons } \\
\hline & 1,2,4-Trichlorobenzene & NT & Satisfactory & Satisfactory & Satisfactory & Satisfactory & NT & Satisfactory & Satisfactory & Satisfactory & Satisfactory \\
\hline & 2-Chloronaphthalene & NT & Satisfactory & Satisfactory & Satisfactory & Satisfactory & NT & Satisfactory & Satisfactory & Satisfactory & Satisfactory \\
\hline & Hexachlorobenzene & NT & Satisfactory & Satisfactory & Satisfactory & Satisfactory & NT & Satisfactory & Satisfactory & Satisfactory & Satisfactory \\
\hline & Hexachlorobutadiene & NT & Satisfactory & Satisfactory & Satisfactory & Satisfactory & NT & Satisfactory & Satisfactory & Satisfactory & Satisfactory \\
\hline & Hexachloroethane & NT & Satisfactory & Satisfactory & Satisfactory & Satisfactory & NT & Satisfactory & Satisfactory & Satisfactory & Satisfactory \\
\hline & Hexachlorocyclopentadiene & NT & Satisfactory & Satisfactory & Satisfactory & Satisfactory & NT & Satisfactory & Satisfactory & Satisfactory & Satisfactory \\
\hline \multicolumn{12}{|c|}{ Phthalate Esters } \\
\hline & bis(2-Ethylhexyl)phthalate & NT & Satisfactory & Satisfactory & Satisfactory & Satisfactory & NT & Satisfactory & NT & Satisfactory & Satisfactory \\
\hline & Benzyl butyl phthalate & NT & Satisfactory & Satisfactory & Satisfactory & Satisfactory & NT & Satisfactory & NT & Satisfactory & Satisfactory \\
\hline & Di-n-butyl phthalate & NT & Satisfactory & Satisfactory & Satisfactory & Satisfactory & NT & Satisfactory & NT & Satisfactory & Satisfactory \\
\hline & Diethyl phthalate & NT & Satisfactory & Satisfactory & Satisfactory & Satisfactory & NT & Satisfactory & NT & Satisfactory & Satisfactory \\
\hline & Dimethyl phthalate & NT & Satisfactory & Satisfactory & Satisfactory & Satisfactory & NT & Satisfactory & NT & Unsatisfactory & Satisfactory \\
\hline & Di-n-octyl phthalate & NT & Satisfactory & Satisfactory & Satisfactory & Satisfactory & NT & Satisfactory & NT & Satisfactory & Satisfactory \\
\hline \multicolumn{12}{|l|}{ Haloethers } \\
\hline & 4-Chlorophenylphenyl ether & NT & Satisfactory & Satisfactory & Satisfactory & Satisfactory & NT & Satisfactory & NT & Satisfactory & Satisfactory \\
\hline & 4-Bromophenylphenyl ether & NT & Satisfactory & Satisfactory & Satisfactory & Satisfactory & NT & Satisfactory & NT & Satisfactory & Satisfactory \\
\hline & Bis(2-chloroethyl)ether & NT & Satisfactory & Satisfactory & Satisfactory & Satisfactory & NT & Satisfactory & NT & Satisfactory & Satisfactory \\
\hline & Bis(2-chloroethoxy)methane & NT & Satisfactory & Satisfactory & Satisfactory & Satisfactory & NT & Satisfactory & NT & Satisfactory & Satisfactory \\
\hline & Bis(2-chloroisopropyl) ether & NT & Satisfactory & Satisfactory & Satisfactory & Satisfactory & NT & Satisfactory & NT & Satisfactory & Satisfactory \\
\hline \multicolumn{12}{|c|}{ Nitroaromatics and Isophorone } \\
\hline & 2,4-Dinitrotoluene & NT & Satisfactory & Satisfactory & Satisfactory & Satisfactory & NT & Satisfactory & NT & Satisfactory & Satisfactory \\
\hline & 2,6-Dinitrotoluene & NT & Satisfactory & Satisfactory & Satisfactory & Satisfactory & NT & Satisfactory & NT & Satisfactory & Satisfactory \\
\hline & Isophorone & NT & Satisfactory & Satisfactory & Satisfactory & Satisfactory & NT & Satisfactory & NT & Satisfactory & Unsatisfactory \\
\hline & Nitrobenzene & NT & Satisfactory & Satisfactory & Satisfactory & Satisfactory & NT & Satisfactory & NT & Satisfactory & Satisfactory \\
\hline \multicolumn{12}{|c|}{ Polynuclear Aromatic Hydrocarbons } \\
\hline & Acenaphthene & NT & Satisfactory & Satisfactory & Satisfactory & Satisfactory & NT & Satisfactory & NT & Satisfactory & Satisfactory \\
\hline & Anthracene & NT & Satisfactory & Satisfactory & Satisfactory & Satisfactory & NT & Satisfactory & NT & Satisfactory & Satisfactory \\
\hline & Acenaphthylene & NT & NT & Satisfactory & Satisfactory & Satisfactory & NT & Satisfactory & NT & Satisfactory & Satisfactory \\
\hline & Benzo(a)anthracene & NT & Satisfactory & Satisfactory & Satisfactory & Satisfactory & NT & Satisfactory & NT & Satisfactory & Satisfactory \\
\hline & Benzo(a)pyrene & NT & Satisfactory & Satisfactory & Satisfactory & Satisfactory & NT & Satisfactory & NT & Satisfactory & Satisfactory \\
\hline & Benzo(b)fluoranthene & NT & Satisfactory & Satisfactory & Satisfactory & Satisfactory & NT & Satisfactory & NT & Satisfactory & Satisfactory \\
\hline & Benzo(ghi)perylene & NT & Satisfactory & Satisfactory & Satisfactory & Satisfactory & NT & Satisfactory & NT & Satisfactory & Satisfactory \\
\hline & Benzo(k)flouranthene & NT & Satisfactory & Satisfactory & Satisfactory & Satisfactory & NT & Satisfactory & NT & Satisfactory & Satisfactory \\
\hline & Chrysene & NT & Satisfactory & Satisfactory & Satisfactory & Satisfactory & NT & Satisfactory & NT & Satisfactory & Satisfactory \\
\hline & Benzo(a,h)anthracene & NT & Satisfactory & Satisfactory & Satisfactory & Satisfactory & NT & Satisfactory & NT & Satisfactory & Unsatisfactory \\
\hline & Fluoranthene & NT & Satisfactory & Satisfactory & Satisfactory & Satisfactory & NT & Satisfactory & NT & Satisfactory & Satisfactory \\
\hline & Fluorene & NT & NT & Satisfactory & Satisfactory & Satisfactory & NT & Satisfactory & NT & Satisfactory & Satisfactory \\
\hline & Indeno(1,2,3-cd)pyrene & NT & Satisfactory & Satisfactory & Satisfactory & Satisfactory & NT & Satisfactory & NT & Satisfactory & Satisfactory \\
\hline & Naphthalene & NT & Satisfactory & Satisfactory & Satisfactory & Satisfactory & NT & Satisfactory & NT & Satisfactory & Satisfactory \\
\hline & Phenanthrene & NT & Satisfactory & Satisfactory & Satisfactory & Satisfactory & NT & Satisfactory & NT & Satisfactory & Satisfactory \\
\hline & Pyrene & NT & Satisfactory & Satisfactory & Satisfactory & Satisfactory & NT & Satisfactory & NT & Satisfactory & Satisfactory \\
\hline
\end{tabular}


Table F-5.NYSDOH's Evaluation of the Nonpotable Water Testing Performed by BNL and Contract Labs (continued).

\begin{tabular}{|c|c|c|c|c|c|c|c|c|c|c|c|}
\hline \multirow[b]{2}{*}{ Category } & \multirow[b]{2}{*}{ Analyte } & \multicolumn{5}{|c|}{ January 2001} & \multicolumn{5}{|c|}{ July 2001} \\
\hline & & BNL & GEL & STL-CT & STL-MO & H2M & BNL & GEL & STL-CT & STL- MO & H2M \\
\hline \multicolumn{12}{|c|}{ Priority Pollutant Phenols } \\
\hline & 2,4,5-Trichlorophenol & NT & Satisfactory & Satisfactory & Satisfactory & Satisfactory & NT & Satisfactory & NT & Satisfactory & Satisfactory \\
\hline & 2,4,6-Trichlorophenol & NT & Satisfactory & Satisfactory & Satisfactory & Satisfactory & NT & Satisfactory & NT & Satisfactory & Satisfactory \\
\hline & 2,4-Dichlorophenol & NT & Satisfactory & Satisfactory & Satisfactory & Satisfactory & NT & Satisfactory & NT & Satisfactory & Satisfactory \\
\hline & 2,4-Dimethylphenol & NT & Satisfactory & Satisfactory & Satisfactory & Satisfactory & NT & Satisfactory & NT & Satisfactory & Satisfactory \\
\hline & 2,4-Dinitrophenol & NT & Satisfactory & Unsatisfactory & Satisfactory & Satisfactory & NT & Satisfactory & NT & Satisfactory & Satisfactory \\
\hline & 2-Chlorophenol & NT & Satisfactory & Satisfactory & Satisfactory & Satisfactory & NT & Satisfactory & NT & Satisfactory & Satisfactory \\
\hline & 2-Methyl-4,6-dinitrophenol & NT & Satisfactory & Satisfactory & Satisfactory & Satisfactory & NT & Satisfactory & NT & Satisfactory & Satisfactory \\
\hline & 2-Nitrophenol & NT & Satisfactory & Satisfactory & Satisfactory & Satisfactory & NT & Satisfactory & NT & Satisfactory & Satisfactory \\
\hline & 4-Chloro-3-methyl phenol & NT & Satisfactory & Satisfactory & Satisfactory & Satisfactory & NT & Satisfactory & NT & Satisfactory & Satisfactory \\
\hline & 4-Nitrophenol & NT & Satisfactory & Satisfactory & Satisfactory & Satisfactory & NT & Satisfactory & NT & Satisfactory & Satisfactory \\
\hline & Phenol & NT & Satisfactory & Satisfactory & Satisfactory & Satisfactory & NT & Satisfactory & NT & Satisfactory & Satisfactory \\
\hline & Pentachlorophenol & NT & Satisfactory & Satisfactory & Satisfactory & Satisfactory & NT & Satisfactory & NT & Satisfactory & Satisfactory \\
\hline \multicolumn{12}{|l|}{ Chlordane } \\
\hline & Chlordane & NT & Satisfactory & Satisfactory & Satisfactory & Satisfactory & NT & Satisfactory & NT & Unsatisfactory & Satisfactory \\
\hline \multicolumn{12}{|c|}{ Polychlorinated Biphenyls } \\
\hline & PCB-1016 & Satisfactory & Unsatisfactory & Satisfactory & Satisfactory & Satisfactory & Satisfactory & NT & NT & Satisfactory & Satisfactory \\
\hline & PCB-1221 & Unsatisfactory & Satisfactory & Unsatisfactory & Satisfactory & Satisfactory & Satisfactory & NT & NT & Unsatisfactory & Satisfactory \\
\hline & PCB-1232 & Satisfactory & Unsatisfactory & Satisfactory & Satisfactory & Satisfactory & Satisfactory & NT & NT & Satisfactory & Satisfactory \\
\hline & PCB-1242 & Satisfactory & Unsatisfactory & Satisfactory & Satisfactory & Satisfactory & Satisfactory & NT & NT & Satisfactory & Satisfactory \\
\hline & PCB-1248 & Satisfactory & Unsatisfactory & Satisfactory & Satisfactory & Satisfactory & Satisfactory & NT & NT & Satisfactory & Satisfactory \\
\hline & PCB-1254 & Unsatisfactory & Satisfactory & Satisfactory & Satisfactory & Satisfactory & Satisfactory & NT & NT & Satisfactory & Satisfactory \\
\hline & PCB-1260 & Satisfactory & Unsatisfactory & Satisfactory & Satisfactory & Satisfactory & Satisfactory & NT & NT & Satisfactory & \\
\hline \multicolumn{12}{|c|}{ Chlorinated Hydrocarbon Pesticides } \\
\hline & 4,4-DDD & NT & Satisfactory & Satisfactory & Satisfactory & Satisfactory & NT & NT & NT & Satisfactory & Satisfactory \\
\hline & 4,4-DDE & NT & Satisfactory & Satisfactory & Satisfactory & Satisfactory & NT & NT & NT & Satisfactory & Satisfactory \\
\hline & 4,4-DDT & NT & Satisfactory & Satisfactory & Satisfactory & Satisfactory & NT & NT & NT & Satisfactory & Satisfactory \\
\hline & Aldrin & NT & Satisfactory & Satisfactory & Satisfactory & Satisfactory & NT & NT & NT & Satisfactory & Satisfactory \\
\hline & Alpha-BHC & NT & Satisfactory & Satisfactory & Satisfactory & Satisfactory & NT & NT & NT & Satisfactory & Satisfactory \\
\hline & Beta-BHC & NT & Satisfactory & Satisfactory & Satisfactory & Satisfactory & NT & NT & NT & Satisfactory & Satisfactory \\
\hline & delta-BHC & NT & Satisfactory & Satisfactory & Satisfactory & Satisfactory & NT & NT & NT & Satisfactory & Satisfactory \\
\hline & Dieldrin & NT & Satisfactory & Satisfactory & Satisfactory & Satisfactory & NT & NT & NT & Satisfactory & Satisfactory \\
\hline & Endrin Aldehyde & NT & Satisfactory & Satisfactory & Satisfactory & Satisfactory & NT & NT & NT & Satisfactory & Satisfactory \\
\hline & Endrin & NT & Satisfactory & Satisfactory & Satisfactory & Satisfactory & NT & NT & NT & Satisfactory & Satisfactory \\
\hline & Endosulfan I & NT & Satisfactory & Satisfactory & Satisfactory & Satisfactory & NT & NT & NT & Satisfactory & Satisfactory \\
\hline & Endosulfan II & NT & Satisfactory & Satisfactory & Satisfactory & Satisfactory & NT & NT & NT & Unsatisfactory & Satisfactory \\
\hline & Endosulfansulfate & NT & Satisfactory & Satisfactory & Unsatisfactory & Satisfactory & NT & NT & NT & Satisfactory & Satisfactory \\
\hline & Heptachlor & NT & Satisfactory & Satisfactory & Satisfactory & Satisfactory & NT & NT & NT & Satisfactory & Satisfactory \\
\hline & Heptachlor epoxide & NT & Satisfactory & Satisfactory & Satisfactory & Satisfactory & NT & NT & NT & Satisfactory & Satisfactory \\
\hline & Lindane & NT & Satisfactory & Satisfactory & Satisfactory & Satisfactory & NT & NT & NT & Satisfactory & Satisfactory \\
\hline & Methoxychlor & NT & Satisfactory & Satisfactory & Satisfactory & Satisfactory & NT & NT & NT & Satisfactory & Satisfactory \\
\hline \multicolumn{12}{|c|}{ Chlorophenoxy Acid Pesticides (Herbicides) } \\
\hline & $2,4,5-T$ & NT & Satisfactory & Satisfactory & Satisfactory & Satisfactory & NT & Satisfactory & NT & Satisfactory & Satisfactory \\
\hline & 2,4-D & NT & Satisfactory & Satisfactory & Satisfactory & Satisfactory & NT & Satisfactory & NT & Unsatisfactory & Satisfactory \\
\hline & 2,4,5-TP (Silvex) & NT & Satisfactory & Satisfactory & Satisfactory & Satisfactory & NT & Satisfactory & NT & Satisfactory & Satisfactory \\
\hline
\end{tabular}


Table F-5.NYSDOH's Evaluation of the Nonpotable Water Testing Performed by BNL and Contract Labs (continued).

\begin{tabular}{|c|c|c|c|c|c|c|c|c|c|c|c|}
\hline \multirow[b]{2}{*}{ Category } & \multirow[b]{2}{*}{ Analyte } & \multicolumn{5}{|c|}{ January 2001} & \multicolumn{5}{|c|}{ July 2001} \\
\hline & & $\mathrm{BNL}$ & GEL & STL-CT & STL-MO & $\mathrm{H} 2 \mathrm{M}$ & BNL & GEL & STL-CT & STL-MO & H2M \\
\hline \multicolumn{12}{|l|}{$\overline{\text { Metals }}$} \\
\hline & Arsenic & NT & Satisfactory & Satisfactory & Satisfactory & $\begin{array}{l}\text { Satistactory } \\
\text { Satisfactory }\end{array}$ & NT & Satisfactory & $\begin{array}{l}\text { NI } \\
\text { NT }\end{array}$ & $\begin{array}{l}\text { Satistactory } \\
\text { Satisfactory }\end{array}$ & $\begin{array}{c}\mathrm{NT} \\
\text { Satisfactory }\end{array}$ \\
\hline & Barium & NT & Satisfactory & Satisfactory & Satisfactory & Satisfactory & NT & Satisfactory & NT & Satisfactory & Satisfactory \\
\hline & Cadmium & NT & Satisfactory & Satisfactory & Satisfactory & Satisfactory & NT & Satisfactory & NT & Satisfactory & Satisfactory \\
\hline & Chromium & NT & Satisfactory & Unsatisfactory & Satisfactory & Satisfactory & NT & Satisfactory & NT & Satisfactory & Satisfactory \\
\hline & Nickel & NT & Satisfactory & Satisfactory & Satisfactory & Satisfactory & NT & Satisfactory & NT & Satisfactory & Satisfactory \\
\hline & Lead & NT & Satisfactory & Satisfactory & Satisfactory & Satisfactory & NT & Satisfactory & NT & Satisfactory & Satisfactory \\
\hline & Antimony & NT & Satisfactory & Satisfactory & Satisfactory & Satisfactory & NT & Satisfactory & NT & Satisfactory & Satisfactory \\
\hline & Selenium & NT & Satisfactory & Satisfactory & Satisfactory & Satisfactory & NT & Satisfactory & NT & Satisfactory & Satisfactory \\
\hline \multicolumn{12}{|l|}{ Chlorinated Hydrocarbons } \\
\hline & 1,2,4-Trichlorobenzene & NT & Satisfactory & Satisfactory & Satisfactory & Satisfactory & NT & Satisfactory & Satisfactory & Satisfactory & Satisfactory \\
\hline & 2-Chloronaphthalene & NT & Satisfactory & Satisfactory & Satisfactory & Satisfactory & NT & Satisfactory & Satisfactory & Satisfactory & Satisfactory \\
\hline & Hexachlorobenzene & NT & Satisfactory & Satisfactory & Satisfactory & Satisfactory & NT & Satisfactory & Satisfactory & Satisfactory & Satisfactory \\
\hline & Hexachlorobutadiene & NT & Satisfactory & Satisfactory & Satisfactory & Satisfactory & NT & Satisfactory & Satisfactory & Satisfactory & Satisfactory \\
\hline & Hexachloroethane & NT & Satisfactory & Satisfactory & Satisfactory & Satisfactory & NT & Satisfactory & Satisfactory & Satisfactory & Satisfactory \\
\hline & Hexachlorocyclopentadiene & NT & Unsatisfactory & Satisfactory & Unsatisfactory & Satisfactory & NT & Satisfactory & Satisfactory & Satisfactory & Satisfactory \\
\hline \multicolumn{12}{|l|}{ Phthalate Esters } \\
\hline & Bis(2-ethylhexyl)phthalate & NT & Satisfactory & Satisfactory & Satisfactory & Satisfactory & NT & Satisfactory & NT & Satisfactory & Satisfactory \\
\hline & Benzyl butyl phthalate & NT & Satisfactory & Satisfactory & Satisfactory & Satisfactory & NT & Satisfactory & NT & Satisfactory & Satisfactory \\
\hline & Di-n-butyl phthalate & NT & Satisfactory & Satisfactory & Satisfactory & Satisfactory & NT & Satisfactory & NT & Satisfactory & Satisfactory \\
\hline & Diethylphthalate & NT & Satisfactory & Satisfactory & Satisfactory & Satisfactory & NT & Satisfactory & NT & Satisfactory & Satisfactory \\
\hline & Dimethyl phthalate & NT & Satisfactory & Satisfactory & Satisfactory & Satisfactory & NT & Satisfactory & NT & Satisfactory & Satisfactory \\
\hline & Di-n-octyl phthalate & NT & Satisfactory & Satisfactory & Satisfactory & Satisfactory & NT & Satisfactory & NT & Satisfactory & Satisfactory \\
\hline \multicolumn{12}{|l|}{ Haloethers } \\
\hline & Bis(2-chloroisopropyl)ether & NT & Satisfactory & Satisfactory & Satisfactory & Satisfactory & NT & Satisfactory & NT & Satisfactory & Satisfactory \\
\hline & Bis(2-chloroethoxy)methane & NT & Satisfactory & Satisfactory & Satisfactory & Satisfactory & NT & Satisfactory & NT & Satisfactory & Satisfactory \\
\hline \multicolumn{12}{|c|}{ Nitroaromatics and Isophorone } \\
\hline & 2,4-Dinitrotoluene & NT & Satisfactory & Satisfactory & Satisfactory & Satisfactory & NT & Satisfactory & NT & Satisfactory & Satisfactory \\
\hline & 2,6-Dinitrotoluene & NT & Satisfactory & Satisfactory & Satisfactory & Satisfactory & NT & Satisfactory & NT & Satisfactory & Satisfactory \\
\hline & Isophorone & NT & Satisfactory & Satisfactory & Satisfactory & Satisfactory & NT & Satisfactory & NT & Satisfactory & Satisfactory \\
\hline & Nitrobenzene & NT & Satisfactory & Satisfactory & Satisfactory & Satisfactory & NT & Satisfactory & NT & Satisfactory & Satisfactory \\
\hline \multicolumn{12}{|c|}{ Polynuclear Aromatic Hydrocarbons } \\
\hline & Acenaphthylene & NT & Satisfactory & Satisfactory & Unsatisfactory & Satisfactory & NT & Satisfactory & Satisfactory & Satisfactory & Satisfactory \\
\hline & Acenaphthene & NT & Unsatisfactory & Satisfactory & Satisfactory & Satisfactory & NT & Satisfactory & Satisfactory & Satisfactory & Satisfactory \\
\hline & Anthracene & NT & Satisfactory & Satisfactory & Satisfactory & Satisfactory & NT & Satisfactory & Satisfactory & Satisfactory & Satisfactory \\
\hline & Benzo(a)anthracene & NT & Satisfactory & Satisfactory & Satisfactory & Satisfactory & NT & Satisfactory & Satisfactory & Satisfactory & Satisfactory \\
\hline & Benzo(a)pyrene & NT & NT & Satisfactory & Satisfactory & Satisfactory & NT & Satisfactory & Satisfactory & Satisfactory & Satisfactory \\
\hline & Benzo(b)fluoranthene & NT & Satisfactory & Satisfactory & Satisfactory & Satisfactory & NT & Satisfactory & Satisfactory & Satisfactory & Satisfactory \\
\hline & Benzo(ghi)perylene & NT & Satisfactory & Satisfactory & Satisfactory & Satisfactory & NT & Satisfactory & Satisfactory & Satisfactory & Satisfactory \\
\hline & Chrysene & NT & Satisfactory & Satisfactory & Satisfactory & Satisfactory & NT & Satisfactory & Satisfactory & Satisfactory & Satisfactory \\
\hline & Dibenzo(a,h)anthracene & NT & Satisfactory & Satisfactory & Satisfactory & Satisfactory & NT & Satisfactory & Satisfactory & Satisfactory & Satisfactory \\
\hline & Fluoranthene & NT & Satisfactory & Satisfactory & Satisfactory & Satisfactory & NT & Satisfactory & Satisfactory & Satisfactory & Satisfactory \\
\hline & Fluorene & NT & Satisfactory & Satisfactory & Satisfactory & Satisfactory & NT & Satisfactory & Satisfactory & Satisfactory & Satisfactory \\
\hline & Indeno(1,2,3-cd)pyrene & NT & Satisfactory & Satisfactory & Satisfactory & Satisfactory & NT & Satisfactory & Satisfactory & Satisfactory & Satisfactory \\
\hline & Naphthalene & NT & Satisfactory & Satisfactory & Satisfactory & Satisfactory & NT & Satisfactory & Satisfactory & Satisfactory & Satisfactory \\
\hline & Phenanthrene & NT & Satisfactory & Satisfactory & Satisfactory & Satisfactory & NT & Satisfactory & Satisfactory & Satisfactory & Satisfactory \\
\hline & Pyrene & NT & Satisfactory & Satisfactory & Satisfactory & Satisfactory & NT & Satisfactory & Satisfactory & Satisfactory & Satisfactory \\
\hline
\end{tabular}


Table F-5.NYSDOH's Evaluation of the Nonpotable Water Testing Performed by BNL and Contract Labs (continued).

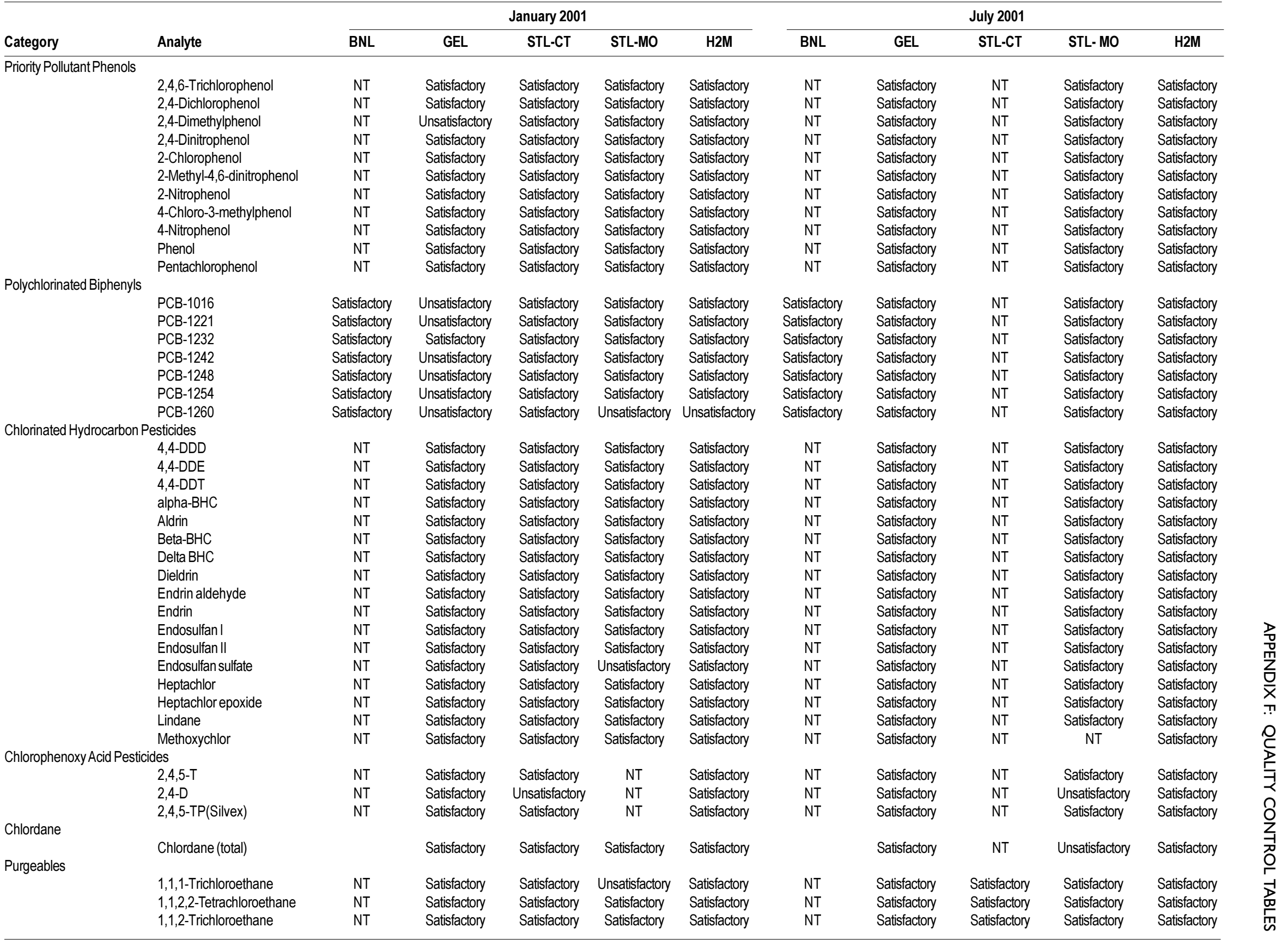


Table F-5.NYSDOH's Evaluation of the Nonpotable Water Testing Performed by BNL and Contract Labs (concluded).

\begin{tabular}{|c|c|c|c|c|c|c|c|c|c|c|c|}
\hline \multirow[b]{2}{*}{ Category } & \multirow[b]{2}{*}{ Analyte } & \multirow[b]{2}{*}{ BNL } & \multicolumn{4}{|c|}{ January 2001} & \multicolumn{5}{|c|}{ July 2001} \\
\hline & & & GEL & STL-CT & STL-MO & $\mathrm{H} 2 \mathrm{M}$ & BNL & GEL & STL-CT & STL- MO & H2M \\
\hline \multirow[t]{27}{*}{ Purgables } & 1,1-Dichloroethane & NT & Unsatisfactory & Satisfactory & Unsatisfactory & Satisfactory & NT & Satisfactory & Satisfactory & Satisfactory & Satisfactory \\
\hline & 1,1-Dichloroethene & NT & Unsatisfactory & Satisfactory & Unsatisfactory & Satisfactory & NT & Satisfactory & Satisfactory & Satisfactory & Satisfactory \\
\hline & 1,2-Dichloroethane & NT & Unsatisfactory & Satisfactory & Satisfactory & Satisfactory & NT & Satisfactory & Satisfactory & Satisfactory & Satisfactory \\
\hline & 1,2-Dichloropropane & NT & Satisfactory & Satisfactory & Unsatifactory & Satisfactory & NT & Satisfactory & Satisfactory & Satisfactory & Satisfactory \\
\hline & 2-Chloroethylvinyl ether & NT & Satisfactory & Satisfactory & Satisfactory & Satisfactory & NT & Satisfactory & Satisfactory & Satisfactory & Satisfactory \\
\hline & Benzene & NT & Unsatisfactory & Satisfactory & Unsatisfactory & Satisfactory & NT & Satisfactory & Satisfactory & Satisfactory & Satisfactory \\
\hline & Bromodichloromethane & NT & Satisfactory & Satisfactory & Satisfactory & Satisfactory & NT & Satisfactory & Satisfactory & Satisfactory & Satisfactory \\
\hline & Bromoform & NT & Satisfactory & Satisfactory & Unsatisfactory & Satisfactory & NT & Satisfactory & Satisfactory & Satisfactory & Satisfactory \\
\hline & CarbonTetrachloride & NT & Satisfactory & Satisfactory & Unsatisfactory & Satisfactory & NT & Satisfactory & Satisfactory & Satisfactory & Satisfactory \\
\hline & Bromomethane & NT & Satisfactory & Satisfactory & Satisfactory & Satisfactory & NT & Satisfactory & Satisfactory & Satisfactory & Satisfactory \\
\hline & Chloromethane & NT & Satisfactory & Satisfactory & Satisfactory & Satisfactory & NT & Satisfactory & Unsatisfactory & Unsatisfactory & Satisfactory \\
\hline & Trichlorofluoromethane & NT & Satisfactory & Satisfactory & Unsatisfactory & Satisfactory & NT & Satisfactory & Satisfactory & Satisfactory & Satisfactory \\
\hline & Chlorobenzene & NT & Satisfactory & Satisfactory & Unsatisfactory & Satisfactory & NT & Satisfactory & Satisfactory & Satisfactory & Satisfactory \\
\hline & Chloroethane & NT & Satisfactory & Satisfactory & Satisfactory & Satisfactory & NT & Satisfactory & Satisfactory & Satisfactory & Satisfactory \\
\hline & Chloroform & NTN & Satisfactory & Satisfactory & Unsatisfactory & Satisfactory & NT & Satisfactory & Satisfactory & Satisfactory & Satisfactory \\
\hline & Dichlorodifluoromethane & NT & Satisfactory & Satisfactory & Satisfactory & Satisfactory & NT & Satisfactory & Satisfactory & Satisfactory & Satisfactory \\
\hline & Ethylbenzene & NT & Satisfactory & Satisfactory & Unsatisfactory & Satisfactory & NT & Satisfactory & Satisfactory & Satisfactory & Satisfactory \\
\hline & Methylene chloride & NT & Satisfactory & Satisfactory & Satisfactory & Satisfactory & NT & Satisfactory & Satisfactory & Satisfactory & Satisfactory \\
\hline & Trans-1,3-Dichloropropene & NT & Satisfactory & Satisfactory & Satisfactory & Satisfactory & NT & Satisfactory & Satisfactory & Satisfactory & Satisfactory \\
\hline & Tetrachloroethene & NT & Satisfactory & Satisfactory & Satisfactory & Satisfactory & NT & Satisfactory & Satisfactory & Satisfactory & Satisfactory \\
\hline & Toluene & NT & Satisfactory & Satisfactory & Satisfactory & Satisfactory & NT & Satisfactory & Satisfactory & Satisfactory & Satisfactory \\
\hline & Trichloroethene & NT & Satisfactory & Satisfactory & Unsatisfactory & Satisfactory & NT & Satisfactory & Satisfactory & Satisfactory & Satisfactory \\
\hline & Total Xylenes & NT & Satisfactory & Satisfactory & Satisfactory & Satisfactory & NT & Satisfactory & Satisfactory & Satisfactory & Satisfactory \\
\hline & Vinyl chloride & NT & Satisfactory & Satisfactory & Satisfactory & Satisfactory & NT & Satisfactory & Satisfactory & Satisfactory & Satisfactory \\
\hline & 1,2-Dichlorobenzene & NT & NT & Satisfactory & Satisfactory & Satisfactory & NT & Satisfactory & Satisfactory & Satisfactory & Satisfactory \\
\hline & 1,3-Dichlorobenzene & NT & NT & Satisfactory & Satisfactory & Unsatisfactory & NT & Satisfactory & Satisfactory & Satisfactory & Satisfactory \\
\hline & 1.4-Dichlorobenzene & NT & NT & Satisfactory & Satisfactory & Satisfactory & NT & Satisfactory & Satisfactory & Satisfactory & Unsatisfactory \\
\hline
\end{tabular}

Notes:

Results for all off-site contractor labs are summarized as Satisfactory, Unsatisfactory, or NT.

NT = Not Tested; certification was not applicable for the work performed for BNL.

STL-Newburgh New York was only used to analyze Ethylene dibromide. The January and July results were both Satisfactory. 
Table F-6.NYSDOH's Evaluation of BNL Performance on Proficiency Tests 240 and 245 (Solid and Hazardous Waste Chemistry).

\begin{tabular}{lrl}
\hline Analyte & Date & Result (a) \\
\hline PCB-1016 & Jan-01 & Acceptable \\
PCB-1221 & Jul-01 & Acceptable \\
& Jan-01 & Acceptable \\
Jul-01 & Acceptable \\
PCB-1232 & Jan-01 & Acceptable \\
PCB-1242 & Jul-01 & Acceptable \\
& Jan-01 & Acceptable \\
PCB-1248 & Jul-01 & Acceptable \\
& Jan-01 & Acceptable \\
PCB-1260 & Jul-01 & Acceptable \\
PCB-1254 & Jan-01 & Acceptable \\
\hline
\end{tabular}

Notes:

Refer to Calendar Year 2001 ASL Quality Assurance Report for detailed data.

(a) Result column provides ELAP evaluation of analytical performance which is based on 95 and $99 \%$ confidence interval about the target value. 
Table F-7. NYSDOH's Evaluation of the Potable Water Testing Performed by BNL and Contract Labs.

\begin{tabular}{|c|c|c|c|c|c|c|c|c|c|}
\hline \multirow[b]{2}{*}{ Category } & \multirow[b]{2}{*}{ Analyte } & \multicolumn{4}{|c|}{ April 2001} & \multicolumn{4}{|c|}{ October 2001} \\
\hline & & BNL & GEL & $\mathrm{H} 2 \mathrm{M}$ & STL-MO & BNL & GEL & $\mathrm{H} 2 \mathrm{M}$ & STL- MO \\
\hline \multicolumn{10}{|l|}{ Alkalinity } \\
\hline & Alkalinity & NT & Satisfactory & Satisfactory & Unsatisfactory & NT & Satisfactory & Satisfactory & Satisfactory \\
\hline \multicolumn{10}{|c|}{ Calcium Hardness } \\
\hline & Calcium Hardness & NT & Satisfactory & Satisfactory & Unsatisfactory & NT & Satisfactory & Satisfactory & Unsatisfactory \\
\hline \multicolumn{10}{|l|}{ Minerals } \\
\hline & Chloride & Satisfactory & Unsatisfactory & Satisfactory & Satisfactory & Satisfactroy & Unsatisfactory & Satisfactory & Satisfactory \\
\hline & Nitrate & Unsatisfactory & Satisfactory & Satisfactory & Satisfactory & Satisfactory & Satisfactory & Satisfactory & Satisfactory \\
\hline & Total Dissolved Solids & NT & Satisfactory & Satisfactory & Satisfactory & NT & Satisfactory & Satisfactory & Satisfactory \\
\hline & Sulfate & Satisfactory & Unsatisfactory & Unsatisfactory & Satisfactory & Satisfactory & Satisfactory & Satisfactory & Satisfactory \\
\hline \multicolumn{10}{|l|}{ Nitrite } \\
\hline & Nitrite & NT & Satisfactory & Satisfactory & Satisfactory & NT & Unsatisfactory & Satisfactory & Satisfactory \\
\hline \multicolumn{10}{|c|}{ Hydrogen lon } \\
\hline & $\mathrm{pH}$ & NT & Satisfactory & Satisfactory & Satisfactory & NT & Satisfactory & Satisfactory & Satisfactory \\
\hline \multicolumn{10}{|l|}{ Cyanide } \\
\hline & Cyanide & NT & Satisfactory & Satisfactory & Satisfactory & NT & Satisfactory & Satisfactory & Unsatisfactory \\
\hline \multicolumn{10}{|l|}{ Metals } \\
\hline & Silver & Satisfactory & Satisfactory & Satisfactory & Unsatisfactory & Satisfactory & Satisfactory & Satisfactory & Satisfactory \\
\hline & Arsenic & Satisfactory & Satisfactory & Satisfactory & Satisfactory & Satisfactory & Satisfactory & Satisfactory & Satisfactory \\
\hline & Barium & Satisfactory & Satisfactory & Satisfactory & Satisfactory & Satisfactory & Satisfactory & Satisfactory & Satisfactory \\
\hline & Beryllium & Satisfactory & Satisfactory & Satisfactory & Satisfactory & Satisfactory & Satisfactory & Satisfactory & Satisfactory \\
\hline & Cadmium & Satisfactory & Satisfactory & Satisfactory & Satisfactory & Satisfactory & Satisfactory & Satisfactory & Satisfactory \\
\hline & Chromium & Satisfactory & Satisfactory & Satisfactory & Satisfactory & Satisfactory & Satisfactory & Satisfactory & Satisfactory \\
\hline & Copper & Satisfactory & Satisfactory & Satisfactory & Satisfactory & Satisfactory & Satisfactory & Satisfactory & Satisfactory \\
\hline & Iron & Satisfactory & Satisfactory & Satisfactory & Unsatisfactory & Satisfactory & Unsatisfactory & Satisfactory & Unsatisfactory \\
\hline & Mercury & Unsatisfactory & Satisfactory & Satisfactory & Satisfactory & Satisfactory & Satisfactory & Satisfactory & Satisfactory \\
\hline & Manganese & Unsatisfactory & Satisfactory & Satisfactory & Satisfactory & Satisfactory & Unsatisfactory & Satisfactory & Satisfactory \\
\hline & Sodium & Satisfactory & Satisfactory & Satisfactory & Satisfactory & Satisfactory & Satisfactory & Satisfactory & Satisfactory \\
\hline & Nickel & Satisfactory & Satisfactory & Satisfactory & Satisfactory & Satisfactory & Satisfactory & Satisfactory & Satisfactory \\
\hline & Lead & Satisfactory & Satisfactory & Satisfactory & Satisfactory & Satisfactory & Satisfactory & Satisfactory & Satisfactory \\
\hline & Antimony & Satisfactory & Satisfactory & Satisfactory & Satisfactory & Satisfactory & Satisfactory & Satisfactory & Satisfactory \\
\hline & Selenium & Satisfactory & Satisfactory & Satisfactory & Satisfactory & Satisfactory & Satisfactory & Satisfactory & Satisfactory \\
\hline & Thallium & Satisfactory & Satisfactory & Satisfactory & Satisfactory & Satisfactory & Satisfactory & Satisfactory & Unsatisfactory \\
\hline & Zinc & Satisfactory & Satisfactory & Satisfactory & Satisfactory & Satisfactory & Satisfactory & Satisfactory & Unsatisfactory \\
\hline \multicolumn{10}{|c|}{ Trihalomethanes } \\
\hline & Bromodichloromethane & NT & Satisfactory & Satisfactory & Satisfactory & NT & Satisfactory & Satisfactory & Satisfactory \\
\hline & Bromoform & NT & Satisfactory & Satisfactory & Satisfactory & NT & Satisfactory & Satisfactory & Satisfactory \\
\hline & Dibromochloromethane & NT & Satisfactory & Satisfactory & Satisfactory & NT & Satisfactory & Satisfactory & Satisfactory \\
\hline & Chloroform & NT & Satisfactory & Satisfactory & Satisfactory & NT & Satisfactory & Satisfactory & Satisfactory \\
\hline
\end{tabular}


Table F-7. NYSDOH's Evaluation of the Potable Water Testing Performed by BNL and Contract Labs (continued).

\begin{tabular}{|c|c|c|c|c|c|c|c|c|c|}
\hline \multirow[b]{2}{*}{ Category } & \multirow[b]{2}{*}{ Analyte } & \multicolumn{4}{|c|}{ April 2001} & \multicolumn{4}{|c|}{ October 2001} \\
\hline & & $\overline{\mathrm{BNL}}$ & GEL & H2M & STL- MO & BNL & GEL & H2M & STL- MO \\
\hline \multicolumn{10}{|c|}{ Gross Alpha and Gross Beta } \\
\hline & Gross Alpha & Satisfactory & Satisfactory & NT & Satisfactory & Satisfactory & Satisfactory & NT & Satisfactory \\
\hline & Gross Beta & Satisfactory & Satisfactory & NT & Satisfactory & Satisfactory & Satisfactory & NT & Satisfactory \\
\hline \multicolumn{10}{|l|}{ Radium } \\
\hline & Radium-226 & NT & Satisfactory & NT & Satisfactory & NT & Satisfactory & NT & Satisfactory \\
\hline & Radium-228 & NT & Satisfactory & NT & Satisfactory & NT & Satisfactory & NT & Satisfactory \\
\hline \multicolumn{10}{|c|}{ Volatile Halocarbons } \\
\hline & 1,1,1,2-Tetrachloroethane & Satisfactory & Satisfactory & Satisfactory & Satisfactory & Satisfactory & Unsatisfactory & Satisfactory & Satisfactory \\
\hline & 1,1,1-Trichloroethane & Satisfactory & Satisfactory & Satisfactory & Satisfactory & Satisfactory & Satisfactory & Satisfactory & Satisfactory \\
\hline & 1,1,2,2-Tetrachloroethane & Satisfactory & Satisfactory & Satisfactory & Satisfactory & Satisfactory & Unsatisfactory & Satisfactory & Satisfactory \\
\hline & 1,1,2-Trichloroethane & Satisfactory & Satisfactory & Satisfactory & Satisfactory & Satisfactory & Unsatisfactory & Satisfactory & Satisfactory \\
\hline & 1,1-Dichloroethane & Satisfactory & Satisfactory & Satisfactory & Satisfactory & Satisfactory & Unsatisfactory & Satisfactory & Satisfactory \\
\hline & 1,1-Dichloroethene & Satisfactory & Satisfactory & Satisfactory & Satisfactory & Satisfactory & Unsatisfactory & Satisfactory & Satisfactory \\
\hline & 1,1-Dichloropropene & Satisfactory & Satisfactory & Satisfactory & Satisfactory & Satisfactory & Unsatisfactory & Satisfactory & Satisfactory \\
\hline & 1,2,3-Trichloropropane & Satisfactory & Satisfactory & Satisfactory & Satisfactory & Satisfactory & Unsatisfactory & Satisfactory & Satisfactory \\
\hline & 1,2-Dichloroethane & Satisfactory & Satisfactory & Satisfactory & Satisfactory & Satisfactory & Unsatisfactory & Satisfactory & Satisfactory \\
\hline & cis-1,2-Dichloroethylene & NT & Satisfactory & Satisfactory & Satisfactory & NT & Unsatisfactory & Satisfactory & Unsatisfactory \\
\hline & 1,2-Dichloropropane & Unsatisfactory & Satisfactory & Satisfactory & Satisfactory & Satisfactory & Unsatisfactory & Satisfactory & Satisfactory \\
\hline & 1,3-Dichloropropane & NT & Satisfactory & Satisfactory & Satisfactory & Satisfactory & Satisfactory & Satisfactory & Satisfactory \\
\hline & 2,2-Dichloropropane & Satisfactory & Satisfactory & Satisfactory & Satisfactory & Satisfactory & Satisfactory & Satisfactory & Satisfactory \\
\hline & Bromochloromethane & Satisfactory & Satisfactory & Satisfactory & Satisfactory & Satisfactory & Unsatisfactory & Satisfactory & Satisfactory \\
\hline & cis-1,3-Dichloropropene & Satisfactory & Satisfactory & Satisfactory & Satisfactory & Satisfactory & Satisfactory & Satisfactory & Satisfactory \\
\hline & Carbon tetrachloride & Satisfactory & Satisfactory & Satisfactory & Satisfactory & Satisfactory & Unsatisfactory & Satisfactory & Satisfactory \\
\hline & Bromomethane & Satisfactory & NT & NT & NT & Satisfactory & Satisfactory & Satisfactory & Satisfactory \\
\hline & Chloromethane & Unsatisfactory & Satisfactory & Satisfactory & Satisfactory & Satisfactory & Satisfactory & Satisfactory & Satisfactory \\
\hline & Trichlorofluoromethane & Satisfactory & Satisfactory & Satisfactory & Satisfactory & Satisfactory & Unsatisfactory & Satisfactory & Satisfactory \\
\hline & Chloroethane & Satisfactory & Satisfactory & Satisfactory & Satisfactory & Satisfactory & Satisfactory & Satisfactory & Satisfactory \\
\hline & Dibromomethane & Satisfactory & Satisfactory & Satisfactory & Satisfactory & Satisfactory & Unsatisfactory & Satisfactory & Satisfactory \\
\hline & Dichlorodifluoromethane & Satisfactory & Satisfactory & Satisfactory & Satisfactory & Satisfactory & Satisfactory & Satisfactory & Satisfactory \\
\hline & Methylene chloride & Satisfactory & Satisfactory & Satisfactory & Satisfactory & Satisfactory & Unsatisfactory & Satisfactory & Satisfactory \\
\hline & trans-1,2-Dichloroethene & Satisfactory & Satisfactory & Satisfactory & Satisfactory & Satisfactory & Satisfactory & Satisfactory & Satisfactory \\
\hline & trans-1,3-Dichloropropene & Satisfactory & Satisfactory & Satisfactory & Satisfactory & Satisfactory & Satisfactory & Satisfactory & Satisfactory \\
\hline & Tetrachloroethene & Satisfactory & Satisfactory & Satisfactory & Satisfactory & Satisfactory & Unsatisfactory & Satisfactory & Satisfactory \\
\hline & Trichloroethene & Satisfactory & NT & Satisfactory & Satisfactory & Satisfactory & Satisfactory & Unsatisfactory & Satisfactory \\
\hline & Vinyl chloride & Satisfactory & Satisfactory & Satisfactory & Satisfactory & Satisfactory & Unsatisfactory & Satisfactory & Satisfactory \\
\hline \multicolumn{10}{|c|}{ Volatile Aromatics } \\
\hline & 1,2,3-Trichlorobenzene & Satisfactory & Satisfactory & Satisfactory & Satisfactory & Satisfactory & Satisfactory & Satisfactory & Satisfactory \\
\hline & 1,2,4-Trichlorobenzene & Satisfactory & Satisfactory & Satisfactory & Satisfactory & Satisfactory & Satisfactory & Satisfactory & Satisfactory \\
\hline & 1,2,4-Trimethylbenzene & Satisfactory & Satisfactory & Satisfactory & Satisfactory & Satisfactory & Satisfactory & Satisfactory & Satisfactory \\
\hline & 1,2-Dichlorobenzene & Satisfactory & Satisfactory & Satisfactory & Satisfactory & Satisfactory & Satisfactory & Satisfactory & Satisfactory \\
\hline & 1,3,5-Trimethylbenzene & Satisfactory & Satisfactory & Satisfactory & Satisfactory & Satisfactory & Satisfactory & Satisfactory & Satisfactory \\
\hline & 1,3-Dichlorobenzene & Satisfactory & Satisfactory & Satisfactory & Satisfactory & Satisfactory & Satisfactory & Satisfactory & Satisfactory \\
\hline
\end{tabular}


Table F-7. NYSDOH's Evaluation of the Potable Water Testing Performed by BNL and Contract Labs (continued).

\begin{tabular}{|c|c|c|c|c|c|c|c|c|c|}
\hline \multirow[b]{2}{*}{ Category } & \multirow[b]{2}{*}{ Analyte } & \multicolumn{4}{|c|}{ April 2001} & \multicolumn{4}{|c|}{ October 2001} \\
\hline & & BNL & GEL & $\mathrm{H} 2 \mathrm{M}$ & STL-MO & BNL & GEL & $\mathrm{H} 2 \mathrm{M}$ & STL- MO \\
\hline & 1,4-Dichlorobenzene & Satisfactory & Satisfactory & Satisfactory & Satisfactory & Satisfactory & Satisfactory & Satisfactory & Satisfactory \\
\hline & 2-Chlorotoluene & Satisfactory & Satisfactory & Satisfactory & Satisfactory & Satisfactory & Satisfactory & Satisfactory & Satisfactory \\
\hline & 4-Chlorotoluene & Satisfactory & Satisfactory & Satisfactory & Satisfactory & Satisfactory & Satisfactory & Satisfactory & Satisfactory \\
\hline & Bromobenzene & Satisfactory & Satisfactory & Unsatisfactory & Satisfactory & Satisfactory & Satisfactory & Satisfactory & Satisfactory \\
\hline & Benzene & Satisfactory & Satisfactory & Satisfactory & Satisfactory & Satisfactory & Satisfactory & Satisfactory & Satisfactory \\
\hline & Chlorobenzene & Satisfactory & Satisfactory & Satisfactory & Satisfactory & Satisfactory & Satisfactory & Satisfactory & Satisfactory \\
\hline & Ethyl benzene & Satisfactory & Satisfactory & Satisfactory & Satisfactory & Satisfactory & Satisfactory & Satisfactory & Satisfactory \\
\hline & Hexachlorobutadiene & Satisfactory & Satisfactory & Satisfactory & Satisfactory & Satisfactory & Satisfactory & Satisfactory & Satisfactory \\
\hline & Isopropylbenzene & Satisfactory & Satisfactory & Satisfactory & Satisfactory & Satisfactory & Satisfactory & Satisfactory & Satisfactory \\
\hline & n-Butylbenzene & Satisfactory & Satisfactory & Satisfactory & Satisfactory & Satisfactory & Satisfactory & Satisfactory & Satisfactory \\
\hline & n-Propylbenzene & Satisfactory & Satisfactory & Satisfactory & Satisfactory & Satisfactory & Satisfactory & Satisfactory & Satisfactory \\
\hline & o-Xylene & Satisfactory & Satisfactory & Satisfactory & Satisfactory & Satisfactory & Satisfactory & Satisfactory & Satisfactory \\
\hline & p-isopropyltoluene & Satisfactory & Satisfactory & Satisfactory & Satisfactory & Satisfactory & Satisfactory & Satisfactory & Satisfactory \\
\hline & sec-Butylbenzene & Satisfactory & Satisfactory & Satisfactory & Satisfactory & Satisfactory & Satisfactory & Satisfactory & Satisfactory \\
\hline & Toluene & Satisfactory & Satisfactory & Satisfactory & Satisfactory & Satisfactory & Satisfactory & Satisfactory & Satisfactory \\
\hline & Styrene & Satisfactory & Satisfactory & Satisfactory & Satisfactory & Satisfactory & Satisfactory & Satisfactory & Satisfactory \\
\hline & tert-Butylbenzene & Satisfactory & Satisfactory & Satisfactory & Satisfactory & Satisfactory & Satisfactory & Satisfactory & Satisfactory \\
\hline & m-Xylene & NT & Satisfactory & Satisfactory & Unsatisfactory & Satisfactory & Satisfactory & Satisfactory & Satisfactory \\
\hline & p-Xylene & Satisfactory & Satisfactory & Unsatisfactory & Unsatisfactory & Satisfactory & Satisfactory & Satisfactory & Satisfactory \\
\hline \multicolumn{10}{|c|}{ Microextractables } \\
\hline & 1,2-Dibromo-3-chloropropane & NT & Satisfactory & Satisfactory & NT & NT & Satisfactory & Satisfactory & NT \\
\hline & 1,2-Dibromoethane & NT & Satisfactory & Satisfactory & NT & NT & Satisfactory & Satisfactory & NT \\
\hline \multicolumn{10}{|l|}{ Chlordane } \\
\hline & Chlordane & NT & NT & Satisfactory & NT & NT & NT & Satisfactory & NT \\
\hline \multicolumn{10}{|c|}{ Mixed Pesticides } \\
\hline & Aldrin & NT & NT & Satisfactory & NT & NT & NT & Satisfactory & NT \\
\hline & Dieldrin & NT & NT & Satisfactory & NT & NT & NT & Satisfactory & NT \\
\hline & Endrin & NT & NT & Satisfactory & NT & NT & NT & Satisfactory & NT \\
\hline & Hexachlorobenzene & NT & NT & Satisfactory & NT & NT & NT & Satisfactory & NT \\
\hline & Hexachlorocyclopentadiene & NT & NT & Satisfactory & NT & NT & NT & Satisfactory & NT \\
\hline & Heptachlor & NT & NT & Satisfactory & NT & NT & NT & Satisfactory & NT \\
\hline & Heptachlor epoxide & NT & NT & Satisfactory & NT & NT & NT & Satisfactory & NT \\
\hline & Lindane & NT & NT & Satisfactory & NT & NT & NT & Satisfactory & NT \\
\hline & Methoxychlor & NT & NT & Satisfactory & NT & & NT & Satisfactory & NT \\
\hline \multicolumn{10}{|l|}{ Total PCBs } \\
\hline & Total PCBs as Decachlorobiph & enyl NT & NT & Satisfactory & NT & NT & NT & Satisfactory & NT \\
\hline \multicolumn{10}{|l|}{ Toxaphene } \\
\hline & Toxaphene & NT & NT & Satisfactory & NT & NT & NT & Satisfactory & NT \\
\hline \multicolumn{10}{|c|}{ Mixed Esters } \\
\hline & bis(2-Ethylhexyl)phthalate & NT & NT & Satisfactory & NT & NT & NT & Satisfactory & NT \\
\hline
\end{tabular}


Table F-7. NYSDOH's Evaluation of the Potable Water Testing Performed by BNL and Contract Labs (concluded).

\begin{tabular}{|c|c|c|c|c|c|c|c|c|c|}
\hline \multirow[b]{2}{*}{ Category } & \multirow[b]{2}{*}{ Analyte } & \multicolumn{4}{|c|}{ April 2001} & \multicolumn{4}{|c|}{ October 2001} \\
\hline & & $\overline{\mathrm{BNL}}$ & GEL & H2M & STL-MO & BNL & GEL & H2M & STL- MO \\
\hline \multicolumn{10}{|c|}{ Benzo(a)pyrene } \\
\hline & Benzo(a)pyrene & NT & NT & Satisfactory & NT & NT & NT & Satisfactory & NT \\
\hline \multicolumn{10}{|c|}{ Mixed Herbicides } \\
\hline & 2.4-D & NT & NT & Satisfactory & NT & NT & NT & Unsatisfactory & NT \\
\hline & Dalapon & NT & NT & Satisfactory & NT & NT & NT & Satisfactory & NT \\
\hline & Dicamba & NT & NT & Satisfactory & NT & NT & NT & Satisfactory & NT \\
\hline & Dinoseb & NT & NT & Satisfactory & NT & NT & NT & Satisfactory & NT \\
\hline & Pentachlorophenol & NT & NT & Satisfactory & NT & NT & NT & Unsatisfactory & NT \\
\hline & Pichloram & NT & NT & Satisfactory & NT & NT & NT & Satisfactory & NT \\
\hline & 2,4,5-TP (Silvex) & NT & NT & Satisfactory & NT & NT & NT & Unsatisfactory & NT \\
\hline \multicolumn{10}{|c|}{ Bacteriology } \\
\hline \multicolumn{10}{|c|}{ NWFecal Coliforms } \\
\hline & Fecal Coliform & NT & NT & NT & Satisfactory & NT & NT & NT & Satisfactory \\
\hline \multicolumn{10}{|c|}{ NW Total Coliforms } \\
\hline & Total coliforms & NT & NT & NT & Satisfactory & NT & NT & NT & Satisfactory \\
\hline \multicolumn{10}{|c|}{ Total Coliforms and E. Coli } \\
\hline & E. Coli & NT & NT & NT & Satisfactory & NT & NT & NT & Satisfactory \\
\hline & Total Coliforms & NT & NT & NT & Satisfactory & NT & NT & NT & Satisfactory \\
\hline & E. Coli & NT & NT & NT & Satisfactory & NT & NT & NT & Satisfactory \\
\hline & Total Coliforms & NT & NT & NT & Satisfactory & NT & NT & NT & Satisfactory \\
\hline & E. Coli & NT & NT & NT & Satisfactory & NT & NT & NT & Satisfactory \\
\hline & Total Coliforms & NT & NT & NT & Satisfactory & NT & NT & NT & Satisfactory \\
\hline & E. Coli & NT & NT & NT & Satisfactory & NT & NT & NT & Satisfactory \\
\hline & Total Coliforms & NT & NT & NT & Satisfactory & NT & NT & NT & Satisfactory \\
\hline & E. Coli & NT & NT & NT & Satisfactory & NT & NT & NT & Satisfactory \\
\hline & Total Coliforms & NT & NT & NT & Satisfactory & NT & NT & NT & Satisfactory \\
\hline & E. Coli & NT & NT & NT & Satisfactory & NT & NT & NT & Satisfactory \\
\hline & Total Coliforms & NT & NT & NT & Satisfactory & NT & NT & NT & Satisfactory \\
\hline & E. Coli & NT & NT & NT & Satisfactory & NT & NT & NT & Satisfactory \\
\hline & Total Coliforms & NT & NT & NT & Satisfactory & NT & NT & NT & Satisfactory \\
\hline & E. Coli & NT & NT & NT & Satisfactory & NT & NT & NT & Satisfactory \\
\hline & Total Coliforms & NT & NT & NT & Satisfactory & NT & NT & NT & Satisfactory \\
\hline & E. Coli & NT & NT & NT & Satisfactory & NT & NT & NT & Satisfactory \\
\hline & Total Coliforms & NT & NT & NT & Satisfactory & NT & NT & NT & Satisfactory \\
\hline & E. Coli & NT & NT & NT & Satisfactory & NT & NT & NT & Satisfactory \\
\hline & Total Coliforms & NT & NT & NT & Satisfactory & NT & NT & NT & Satisfactory \\
\hline \multicolumn{10}{|c|}{ Standard Plate Count } \\
\hline & Standard Plate Count & NT & NT & NT & Satisfactory & NT & NT & NT & Satisfactory \\
\hline
\end{tabular}

Refer to Calendar Year 2001 ASL Quality Assurance Report for detailed data.

Result column provides ELAP evaluation of analytical performance, which is based on 95 and $99 \%$ confidence interval about the target value.

NT = Not Tested; certification was not applicable for the work performed for BNL. 
Table F-8. Independent Company's Evaluation of Water Supply and Pollution Studies Performed by BNL and Contract Lab.

\begin{tabular}{|c|c|c|c|c|c|c|c|c|c|c|}
\hline \multirow[b]{2}{*}{ Category } & \multirow[b]{2}{*}{ Analyte } & \multicolumn{5}{|c|}{ GEL } & \multicolumn{4}{|c|}{ BNL } \\
\hline & & WP-80 & WP-81 & WS-54 & WS-57 & WP-72 & WP-73 & WP-78 & WS-57 & WS-63 \\
\hline \multicolumn{11}{|l|}{ Minerals } \\
\hline & Total Solids & Acceptable & NT & NT & NT & NT & NT & NT & NT & NT \\
\hline & Total Dissolved Solids & Acceptable & NT & Acceptable & NT & NT & NT & NT & NT & NT \\
\hline & Alkalinity & Acceptable & NT & NT & NT & NT & NT & NT & NT & NT \\
\hline & Chloride & NotAcceptable & NT & Acceptable & NT & Acceptable & NT & Acceptable & Acceptable & Acceptable \\
\hline & Potassium & Acceptable & Acceptable & Acceptable & NT & NT & NT & NT & NT & NT \\
\hline & Sodium & Acceptable & NT & Acceptable & NT & Acceptable & NT & Acceptable & NT & NT \\
\hline & Sulfate & Acceptable & NT & Acceptable & NT & Acceptable & NT & Acceptable & Acceptable & Acceptable \\
\hline Hydrogen Ion & $\mathrm{pH}$ & Acceptable & NT & Accpetable & NT & NT & NT & NT & NT & NT \\
\hline \multicolumn{11}{|l|}{ Hardness } \\
\hline & Total Suspended Solids & Acceptable & NT & NT & NT & NT & NT & NT & NT & NT \\
\hline & Calcium & Acceptable & NT & Acceptable & Acceptable & NT & NT & NT & NT & NT \\
\hline & Magnesium & Acceptable & NT & Acceptable & Acceptable & NT & NT & NT & NT & NT \\
\hline \multicolumn{11}{|l|}{ Demand } \\
\hline & Biological Oxygen Demand & dCheck for Error & NT & NT & NT & NT & NT & NT & NT & NT \\
\hline & Total Organic Carbon & Check for Error & NT & Acceptable & NT & NT & NT & NT & NT & NT \\
\hline \multicolumn{11}{|l|}{ Nutrients } \\
\hline & Ammonia & Acceptable & NT & NT & NT & NT & NT & NT & NT & NT \\
\hline & Nitrate & Acceptable & NT & Acceptable & NT & NT & NT & NT & Acceptable & Acceptable \\
\hline & Ortho-phosohate & Acceptable & NT & Acceptable & NT & NT & NT & NT & NT & NT \\
\hline \multicolumn{11}{|l|}{ Nititite } \\
\hline & Nitrite & NT & NT & Acceptable & NT & NT & NT & NT & NT & NT \\
\hline \multicolumn{11}{|l|}{ Bromide } \\
\hline & Bromide & NT & NT & NotAcceptable & Accpetable & NT & NT & NT & NT & NT \\
\hline \multicolumn{11}{|c|}{ Nutients-Complex } \\
\hline & Total Phosphorous & Acceptable & NT & NT & NT & NT & NT & NT & NT & NT \\
\hline & Total Kjeldahl Nitrogen & Acceptable & NT & NT & NT & NT & NT & NT & NT & NT \\
\hline & Cyanide, total & Acceptable & NT & Acceptable & NT & NT & NT & NT & NT & NT \\
\hline \multicolumn{11}{|l|}{ Phenolics } \\
\hline & Phenolics, total & Acceptable & NT & NT & NT & NT & NT & NT & NT & NT \\
\hline \multicolumn{11}{|l|}{ Grease \& Oil } \\
\hline & Grease \& Oil (Gravametric) & ) Acceptable & NT & NT & NT & NT & NT & NT & NT & NT \\
\hline \multicolumn{11}{|l|}{ Trace Metals } \\
\hline & Aluminum & Acceptable & NT & Acceptable & NT & Acceptable & NT & Acceptable & Acceptable & Acceptable \\
\hline & Antimony & Acceptable & NT & Acceptable & NT & NT & NT & Acceptable & Acceptable & Acceptable \\
\hline & Arsenic & Acceptable & NT & Acceptable & NT & Acceptable & NT & Acceptable & Acceptable & Acceptable \\
\hline & Barium & Acceptable & NT & Acceptable & NT & Acceptable & NT & Acceptable & Acceptable & Acceptable \\
\hline & Boron & Acceptable & NT & Acceptable & NT & & & & & \\
\hline
\end{tabular}


Table F-8. Independent Company's Evaluation of Water Supply and Pollution Studies Performed by BNL and Contract Lab (continued).

\begin{tabular}{|c|c|c|c|c|c|c|c|c|c|c|}
\hline \multirow[b]{2}{*}{ Category } & \multirow[b]{2}{*}{ Analyte } & \multicolumn{5}{|c|}{ GEL } & \multicolumn{4}{|c|}{ BNL } \\
\hline & & WP-80 & WP-81 & WS-54 & WS-57 & WP-72 & WP-73 & WP-78 & WS-57 & WS-63 \\
\hline & Beryllium & Acceptable & NT & Acceptable & NT & Acceptable & NT & Acceptable & NotAcceptable & Acceptable \\
\hline & Cadmium & Acceptable & NT & Acceptable & NT & Acceptable & NT & Acceptable & Acceptable & Acceptable \\
\hline & Chromium & Acceptable & NT & Acceptable & NT & Acceptable & NT & Acceptable & Acceptable & Acceptable \\
\hline & Cobalt & Acceptable & NT & NT & NT & Acceptable & NT & Acceptable & NT & NT \\
\hline & Copper & Acceptable & NT & Acceptable & NT & Acceptable & NT & Acceptable & Acceptable & Acceptable \\
\hline & Iron & Acceptable & NT & Acceptable & NT & Acceptable & NT & Acceptable & Acceptable & Acceptable \\
\hline & Lead & Acceptable & NT & Acceptable & NT & Acceptable & NT & Acceptable & Acceptable & Acceptable \\
\hline & Magnesium & NT & NT & NT & NT & NT & NT & NT & NT & NT \\
\hline & Manganese & Acceptable & NT & Acceptable & NT & Acceptable & NT & Acceptable & Acceptable & Acceptable \\
\hline & Molybdenum & Acceptable & NT & Acceptable & NT & Acceptable & NT & Acceptable & Acceptable & Acceptable \\
\hline & Nickel & Acceptable & NT & Acceptable & NT & Acceptable & NT & Acceptable & Acceptable & Acceptable \\
\hline & Selenium & Acceptable & NT & Acceptable & NT & Acceptable & NT & Acceptable & Acceptable & Acceptable \\
\hline & Silver & NotAcceptable & NT & Acceptable & NT & Acceptable & NT & Acceptable & Acceptable & Acceptable \\
\hline & Thallium & Acceptable & NT & NotAcceptable & Acceptable & Acceptable & NT & Acceptable & Acceptable & Acceptable \\
\hline & Vanadium & Acceptable & NT & Acceptable & NT & Acceptable & NT & Acceptable & Acceptable & Acceptable \\
\hline & Zinc & Acceptable & NT & NotAcceptable & Acceptable & Acceptable & NT & Acceptable & Acceptable & Acceptable \\
\hline & Mercury & Acceptable & NT & Acceptable & NT & Acceptable & NT & Acceptable & Acceptable & Acceptable \\
\hline \multicolumn{11}{|l|}{ Volatiles } \\
\hline & Acetone & Acceptable & NT & NT & NT & NT & Acceptable & Acceptable & NT & NT \\
\hline & Acrylonitrile & Acceptable & NT & NT & NT & NT & NT & NT & NT & NT \\
\hline & Acrloien & Acceptable & NT & NT & NT & NT & NT & NT & NT & NT \\
\hline & Benzene & Acceptable & NT & Acceptable & NT & NT & Acceptable & Acceptable & Acceptable & Acceptable \\
\hline & Bromodichloromethane & Acceptable & NT & Acceptable & NT & NT & Acceptable & Acceptable & Acceptable & Acceptable \\
\hline & Bromoform & Acceptable & NT & Acceptable & NT & NT & Acceptable & Acceptable & NotAcceptable & NotAcceptable \\
\hline & 2-Butanone & Acceptable & NT & NT & NT & NT & Acceptable & Acceptable & NT & NT \\
\hline & Bromomethane & Acceptable & NT & Acceptable & NT & NT & Acceptable & Acceptable & NT & NT \\
\hline & Carbon disulfide & Acceptable & NT & NT & NT & NT & NT & NT & NT & NT \\
\hline & Carbon tetrachloride & Acceptable & NT & Acceptable & NT & NT & Acceptable & Acceptable & Acceptable & Acceptable \\
\hline & Chlorobenzene & Acceptable & NT & Acceptable & NT & NT & Acceptable & Acceptable & Acceptable & Acceptable \\
\hline & Chlorodibromomethane & Acceptable & NT & Acceptable & NT & NT & Acceptable & Acceptable & Acceptable & Acceptable \\
\hline & Chloroethane & Acceptable & NT & Acceptable & NT & NT & Acceptable & Acceptable & NT & NT \\
\hline & EDB & Acceptable & NT & Acceptable & NT & NT & NT & NT & NT & NT \\
\hline & Dibromomethane & Acceptable & NT & Acceptable & NT & NT & NT & NT & NT & NT \\
\hline & 1,2-Dichlorobenzene & Acceptable & NT & Acceptable & NT & NT & Check for Error & NotAcceptable & Acceptable & Acceptable \\
\hline & 1,3-Dichlorobenzene & Acceptable & NT & Acceptable & NT & NT & Notacceptable & NotAcceptable & NT & NT \\
\hline & 1,4-Dichlorobenzene & Acceptable & NT & Acceptable & NT & NT & Check for Error & NotAcceptable & Acceptable & Acceptable \\
\hline & Dichlorodifluoromethane & Acceptable & NT & NotAcceptable & NT & NT & NT & NT & NT & NT \\
\hline & 1,1-Dichloroethane & Acceptable & NT & Acceptable & NT & NT & Acceptable & Acceptable & NT & NT \\
\hline & 1,2-Dichloroethane & Acceptable & NT & Acceptable & NT & NT & Acceptable & Acceptable & Acceptable & Acceptable \\
\hline & 1,1-Dichloroethylene & Acceptable & NT & Acceptable & NT & NT & Acceptable & Acceptable & Acceptable & Acceptable \\
\hline & cis-1,2-Dichloroethylene & Acceptable & NT & Acceptable & NT & NT & NT & NT & Acceptable & Acceptable \\
\hline & trans-1,2-Dichloroethylene & Acceptable & NT & Acceptable & NT & NT & Acceptable & Acceptable & Acceptable & Acceptable \\
\hline & 1,2-Dichloropropane & Acceptable & NT & Acceptable & NT & NT & Acceptable & Acceptable & Acceptable & Acceptable \\
\hline & cis-1,3-Dichloropropylene & Acceptable & NT & Acceptable & NT & NT & Acceptable & Acceptable & NT & NT \\
\hline
\end{tabular}


Table F-8. Independent Company's Evaluation of Water Supply and Pollution Studies Performed by BNL and Contract Lab (continued).

\begin{tabular}{|c|c|c|c|c|c|c|c|c|c|c|}
\hline \multirow[b]{2}{*}{ Category } & \multirow[b]{2}{*}{ Analyte } & \multicolumn{5}{|c|}{ GEL } & \multicolumn{4}{|c|}{ BNL } \\
\hline & & WP-80 & WP-81 & WS-54 & WS-57 & WP-72 & WP-73 & WP-78 & WS-57 & WS-63 \\
\hline & trans-1,3-Dichloropropylene & Acceptable & NT & Acceptable & NT & NT & Acceptable & Acceptable & NT & NT \\
\hline & Ethylbenzene & Acceptable & NT & Acceptable & NT & NT & Acceptable & Acceptable & Acceptable & Acceptable \\
\hline & 2-Hexanone & Acceptable & NT & NT & NT & NT & Acceptable & Acceptable & NT & NT \\
\hline & Methylene chloride & Acceptable & NT & Acceptable & NT & NT & Acceptable & Acceptable & Acceptable & Acceptable \\
\hline & Methyl iso butyl ketone & Acceptable & NT & NT & NT & NT & Acceptable & Acceptable & NT & NT \\
\hline & Styrene & Acceptable & NT & Acceptable & NT & NT & NT & NT & Acceptable & Acceptable \\
\hline & 1,1,1,2-Tetrachloroethane & Acceptable & NT & Acceptable & NT & NT & NT & NT & NT & NT \\
\hline & 1,1,2,2-Tetrachloroethane & Acceptable & NT & Acceptable & NT & NT & Acceptable & Acceptable & NT & NT \\
\hline & Tetrachloroethylene & Acceptable & NT & Acceptable & NT & NT & Acceptable & Acceptable & Acceptable & Acceptable \\
\hline & Toluene & Acceptable & NT & Acceptable & NT & NT & Acceptable & Acceptable & Acceptable & Acceptable \\
\hline & 1,1,1-Trichloroethane & Acceptable & NT & Acceptable & NT & NT & Acceptable & Acceptable & Acceptable & Acceptable \\
\hline & 1,1,2-Trichloroethane & Acceptable & NT & Acceptable & NT & NT & Acceptable & Acceptable & Acceptable & Acceptable \\
\hline & Trichloroethylene & Acceptable & NT & Acceptable & NT & NT & Acceptable & Acceptable & Acceptable & Acceptable \\
\hline & Trichlorofluoromethane & Acceptable & NT & NT & NT & NT & Acceptable & Acceptable & NT & NT \\
\hline & Vinyl chloride & Acceptable & NT & Acceptable & NT & NT & Acceptable & Acceptable & Acceptable & Acceptable \\
\hline & Xylenes, total & Acceptable & NT & Acceptable & NT & NT & Acceptable & Acceptable & Acceptable & Acceptable \\
\hline & 1,2,4-Trichlorobenzene & Acceptable & NT & Acceptable & NT & NT & NT & NT & Acceptable & Acceptable \\
\hline & Chloroform & Acceptable & NT & Acceptable & NT & NT & Acceptable & Acceptable & NotAcceptable & Acceptable \\
\hline & Total Trihalomethanes & NT & NT & Acceptable & NT & NT & NT & NT & Acceptable & Acceptable \\
\hline & Bromochloromethane & Acceptable & NT & Acceptable & NT & NT & NT & NT & NT & NT \\
\hline & n-Butylbenzene & NT & NT & Acceptable & NT & NT & NT & NT & NT & NT \\
\hline & sec-Butylbenzene & NT & NT & Acceptable & NT & NT & NT & NT & NT & NT \\
\hline & methyl-tert-Butyl Ether & NT & NT & NT & NT & NT & NT & NT & NT & NT \\
\hline & Chloromethane & Acceptable & NT & Acceptable & NT & NT & Acceptable & Acceptable & NT & NT \\
\hline & 2-Chlorotoluene & NT & NT & Acceptable & NT & NT & NT & NT & NT & NT \\
\hline & 4-Chlorotoluene & NT & NT & Acceptable & NT & NT & NT & NT & NT & NT \\
\hline & 1,3,-Dichloropropane & Acceptable & NT & Acceptable & NT & NT & NT & NT & NT & NT \\
\hline & 1,1-Dichloropropene & NT & NT & Acceptable & NT & NT & NT & NT & NT & NT \\
\hline & Hexachlorobutadiene & NT & NT & Acceptable & NT & NT & NT & NT & NT & NT \\
\hline & Isopropylbenzene & NT & NT & Acceptable & NT & NT & NT & NT & NT & NT \\
\hline & 4-Isopropyltoluene & NT & NT & Acceptable & NT & NT & NT & NT & NT & NT \\
\hline & n-Butylbenzene & NT & NT & Acceptable & NT & NT & NT & NT & NT & NT \\
\hline & n-Propylbenzene & NT & NT & Acceptable & NT & NT & NT & NT & NT & NT \\
\hline & 1,2,3-Trichlorobenzene & NT & NT & Acceptable & NT & NT & NT & NT & NT & NT \\
\hline & 1,2,3-Trichloropropane & NT & NT & Acceptable & NT & NT & NT & NT & NT & NT \\
\hline & 1,2,4-Trimethylbenzene & NT & NT & Acceptable & NT & NT & NT & NT & NT & NT \\
\hline \multicolumn{11}{|c|}{ PCBs in Water } \\
\hline & Aroclor 1016/1242 & Acceptable & NT & NT & NT & NT & NT & NT & NT & NT \\
\hline & Aroclor 1221 & Acceptable & NT & NT & NT & NT & NT & NT & NT & NT \\
\hline & Aroclor 1232 & Acceptable & NT & NT & NT & NT & NT & NT & NT & NT \\
\hline & Aroclor 1248 & Acceptable & NT & NT & NT & NT & NT & NT & NT & NT \\
\hline & Aroclor 1254 & Acceptable & NT & NT & NT & NT & NT & NT & NT & NT \\
\hline & Aroclor 1260 & Acceptable & NT & NT & NT & NT & NT & NT & NT & NT \\
\hline
\end{tabular}


Table F-8. Independent Company's Evaluation of Water Supply and Pollution Studies Performed by BNL and Contract Lab (continued).

\begin{tabular}{|c|c|c|c|c|c|c|c|c|c|c|}
\hline \multirow[b]{2}{*}{ Category } & \multirow[b]{2}{*}{ Analyte } & \multicolumn{5}{|c|}{ GEL } & \multicolumn{4}{|c|}{ BNL } \\
\hline & & WP-80 & WP-81 & WS-54 & WS-57 & WP-72 & WP-73 & WP-78 & WS-57 & WS-63 \\
\hline \multicolumn{11}{|l|}{ PCBs in Oil } \\
\hline & Aroclor 1254 (STD\#1) & Acceptable & NT & NT & NT & Acceptable & NT & Acceptable & NT & NT \\
\hline & Aroclor 1254 (STD \#2) & Acceptable & NT & NT & NT & Acceptable & NT & Acceptable & NT & NT \\
\hline & Aroclor Identification & NT & NT & NT & NT & NT & NT & NT & NT & NT \\
\hline & Aroclor Identification & NT & NT & NT & NT & NT & NT & NT & NT & NT \\
\hline & Aroclor 1016/1242 (STD \#1) & Acceptable & NT & NT & NT & Acceptable & NT & Acceptable & NT & NT \\
\hline & Aroclor 1016/1242 (STD \#2) & Acceptable & NT & NT & NT & Acceptable & NT & Acceptable & NT & NT \\
\hline & Aroclor 1260 (STD \#1) & Acceptable & NT & NT & NT & Acceptable & NT & Acceptable & NT & NT \\
\hline
\end{tabular}

Pesticides

\begin{tabular}{|c|c|c|c|c|c|c|c|c|c|}
\hline Aldrin & Acceptable & NT & Acceptable & Acceptable & NT & NT & NT & NT & NT \\
\hline Alpha-BHC & Acceptable & NT & NT & NT & NT & NT & NT & NT & NT \\
\hline beta-BHC & Acceptable & NT & NT & NT & NT & NT & NT & NT & NT \\
\hline delta-BHC & Acceptable & NT & NT & NT & NT & NT & NT & NT & NT \\
\hline gamma-BHC (Lindane) & Acceptable & NT & Acceptable & Acceptable & NT & NT & NT & NT & NT \\
\hline alpha-Chlordane & Acceptable & NT & NT & NT & NT & NT & NT & NT & NT \\
\hline gamma-Chlordane & Acceptable & NT & NT & NT & NT & NT & NT & NT & NT \\
\hline 4,4'-DDD & Acceptable & NT & NT & NT & NT & NT & NT & NT & NT \\
\hline 4,4'-DDE & Acceptable & NT & NT & NT & NT & NT & NT & NT & NT \\
\hline 4,4'-DDT & Acceptable & NT & NT & NT & NT & NT & NT & NT & NT \\
\hline Dieldrin & Acceptable & NT & NotAcceptable & Acceptable & NT & NT & NT & NT & NT \\
\hline Endrin & Acceptable & NT & Acceptable & Acceptable & NT & NT & NT & NT & NT \\
\hline Endrin Aldehyde & Acceptable & NT & NT & NT & NT & NT & NT & NT & NT \\
\hline Endrin ketone & Acceptable & NT & NT & NT & NT & NT & NT & NT & NT \\
\hline Endosulfan I & Acceptable & NT & NT & NT & NT & NT & NT & NT & NT \\
\hline Endosulfan II & Acceptable & NT & NT & NT & NT & NT & NT & NT & NT \\
\hline Endosulfan sulfate & Acceptable & NT & NT & NT & NT & NT & NT & NT & NT \\
\hline Heptachlor & Acceptable & NT & Acceptable & Acceptable & NT & NT & NT & NT & NT \\
\hline Heptachlo epoxide & Acceptable & NT & Acceptable & Acceptable & NT & NT & NT & NT & NT \\
\hline $\begin{array}{l}\text { Methoxychlor } \\
\text { Chlordane }\end{array}$ & Acceptable & NT & Acceptable & Acceptable & NT & NT & NT & NT & NT \\
\hline Chlordane, technical & Acceptable & NT & Acceptable & NT & NT & NT & NT & NT & NT \\
\hline Acenaphthene & Acceptable & Acceptable & Acceptable & NT & NT & NT & NT & NT & NT \\
\hline Acenaphthylene & Acceptable & Acceptable & NT & NT & NT & NT & NT & NT & NT \\
\hline Analine & Acceptable & Acceptable & NT & NT & NT & NT & NT & NT & NT \\
\hline Anthracene & Acceptable & Acceptable & Acceptalble & NT & NT & NT & NT & NT & NT \\
\hline Benzidine & Acceptable & NT & NT & NT & NT & NT & NT & NT & NT \\
\hline Benzo(b)fluoranthene & Acceptable & Acceptable & Acceptable & NT & NT & NT & NT & NT & NT \\
\hline Benzo(k)fluoranthene & Acceptable & Acceptable & Acceptable & NT & NT & NT & NT & NT & NT \\
\hline Benzo $(g, h, l)$ perylene & Acceptable & Acceptable & Acceptable & NT & NT & NT & NT & NT & NT \\
\hline Benzo(a)pyrene & Acceptable & Acceptable & Acceptable & NT & NT & NT & NT & NT & NT \\
\hline
\end{tabular}


Table F-8. Independent Company's Evaluation of Water Supply and Pollution Studies Performed by BNL and Contract Lab (continued).

\begin{tabular}{|c|c|c|c|c|c|c|c|c|c|c|}
\hline \multirow[b]{2}{*}{ Category } & \multirow[b]{2}{*}{ Analyte } & \multicolumn{5}{|c|}{ GEL } & \multicolumn{4}{|c|}{ BNL } \\
\hline & & WP-80 & WP-81 & WS-54 & WS-57 & WP-72 & WP-73 & WP-78 & WS-57 & WS-63 \\
\hline & Benzyl alcohol & Acceptable & NT & NT & NT & NT & NT & NT & NT & NT \\
\hline & 4-Bromophenyl-phenyl ether & r Acceptable & NT & NT & NT & NT & NT & NT & NT & NT \\
\hline & Butylbenzylphthalate & Acceptable & NT & Acceptable & NT & NT & NT & NT & NT & NT \\
\hline & 4-Chloroanaline & Acceptable & NT & NT & NT & NT & NT & NT & NT & NT \\
\hline & bis(2-Chloroethoxy)methane & Acceptable & NT & NT & NT & NT & NT & NT & NT & NT \\
\hline & bis(2-Chloroethyl)ether & Acceptable & NT & NT & NT & NT & NT & NT & NT & NT \\
\hline & bis(2-Chloroisopropyl)ether & Acceptable & NT & NT & NT & NT & NT & NT & NT & NT \\
\hline & 2-Chloronaphthalene & Acceptable & NT & NT & NT & NT & NT & NT & NT & NT \\
\hline & 4-Chlorophenyl-phenylether & Acceptable & NT & NT & NT & NT & NT & NT & NT & NT \\
\hline & Chrysene & Acceptable & Acceptable & Acceptable & NT & NT & NT & NT & NT & NT \\
\hline & Dibenz(a,h)anthracene & Acdeptable & Acceptable & Acceptable & NT & NT & NT & NT & NT & NT \\
\hline & Dibenzofuran & Acceptable & NT & NT & NT & NT & NT & NT & NT & NT \\
\hline & Di-n-butyl phthalate & Acceptable & NT & NT & NT & NT & NT & NT & NT & NT \\
\hline & 1,2-Dichlorobenzene & Acdeptable & NT & NT & NT & NT & NT & NT & NT & NT \\
\hline & 1,3-Dichlorobenzene & Acceptable & NT & NT & NT & NT & NT & NT & NT & NT \\
\hline & 1,4-Dichlorobenzene & Acceptable & NT & NT & NT & NT & NT & NT & NT & NT \\
\hline & Diethylphthalate & Acceptable & NT & Acceptable & NT & NT & NT & NT & NT & NT \\
\hline & Dimethylphthalate & Acceptable & NT & Acdeptable & NT & NT & NT & NT & NT & NT \\
\hline & 2,4-Dinitrotoluene & Acceptable & NT & NT & NT & NT & NT & NT & NT & NT \\
\hline & 2,6-Dinitrotoluene & Acceptable & NT & NT & NT & NT & NT & NT & NT & \\
\hline & bis(2-Ethylhexyl)phthalate & Acceptable & NT & Acceptable & NT & NT & NT & NT & NT & \\
\hline & Fluoranthene & Acceptable & Acceptable & Acceptable & NT & NT & NT & NT & NT & NT \\
\hline & Fluorene & Acceptable & Acceptable & Acceptable & NT & NT & NT & NT & NT & NT \\
\hline & Hexachlorobenzene & Acceptable & NT & NT & NT & NT & NT & NT & NT & NT \\
\hline & Hexachlorobutadiene & Acceptable & NT & Acceptable & NT & NT & NT & NT & NT & NT \\
\hline & Hexachlorocyclopentadiene & Acceptable & NT & NT & NT & NT & NT & NT & NT & NT \\
\hline & Hexachloroethane & NT & NT & NT & NT & NT & NT & NT & NT & NT \\
\hline & Indeno(1,2,3-cd)pyrene & NT & Acceptable & Acceptable & NT & NT & NT & NT & NT & NT \\
\hline & Isophorone & NT & NT & NT & NT & NT & NT & NT & NT & NT \\
\hline & 1-Methylnaphthalene & NT & NT & Acceptable & NT & NT & NT & NT & NT & NT \\
\hline & 2-Methylnaphthalene & NT & NT & Acceptable & NT & NT & NT & NT & NT & NT \\
\hline & Naphthalene & NT & Acceptable & Acceptable & NT & NT & NT & NT & NT & NT \\
\hline & 3-Nitroanaline & NT & NT & NT & NT & NT & NT & NT & NT & NT \\
\hline & 4-Nitroanaline & NT & NT & NT & NT & NT & NT & NT & NT & NT \\
\hline & Nitrobenzene & NT & NT & NT & NT & NT & NT & NT & NT & NT \\
\hline & N-Nitrosodimethylamine & NT & NT & NT & NT & NT & NT & NT & NT & NT \\
\hline & N-Nitrosodiphenylamine & NT & NT & NT & NT & NT & NT & NT & NT & NT \\
\hline & N-Nitroso-di-n-propylamine & NT & NT & NT & NT & NT & NT & NT & NT & NT \\
\hline & Phenanthrene & Acceptable & Acceptable & Acceptable & NT & NT & NT & NT & NT & NT \\
\hline & Pyrene & Acceptable & Acceptable & Acceptable & NT & NT & NT & NT & NT & NT \\
\hline & Pyridine & NT & NT & NT & NT & NT & NT & NT & NT & NT \\
\hline & 1,2,4-Trichlorobenzene & Acceptable & NT & NT & Acceptable & NT & NT & NT & NT & NT \\
\hline
\end{tabular}


Table F-8. Independent Company's Evaluation of Water Supply and Pollution Studies Performed by BNL and Contract Lab (concluded).

\begin{tabular}{|c|c|c|c|c|c|c|c|c|c|c|}
\hline \multirow[b]{2}{*}{ Category } & \multirow[b]{2}{*}{ Analyte } & \multicolumn{5}{|c|}{ GEL } & \multicolumn{4}{|c|}{ BNL } \\
\hline & & WP-80 & WP-81 & WS-54 & WS-57 & WP-72 & WP-73 & WP-78 & WS-57 & WS-63 \\
\hline \multicolumn{11}{|l|}{ Acids } \\
\hline & 2-Chlorophenol & Acceptable & NT & NT & NT & NT & NT & NT & NT & NT \\
\hline & 2,4-Dimethylphenol & Acceptable & NT & Acceptable & NT & NT & NT & NT & NT & NT \\
\hline & 2,4-Dinotrophenol & Acceptable & NT & Acceptable & NT & NT & NT & NT & NT & NT \\
\hline & 2-Methylphenol & Acceptable & NT & NT & NT & NT & NT & NT & NT & NT \\
\hline & 3-Methylphenol & Acceptable & NT & NT & NT & NT & NT & NT & NT & NT \\
\hline & 4-Methylphenol & Acceptable & NT & NT & NT & NT & NT & NT & NT & NT \\
\hline & 2-Nitrophenol & Acceptable & NT & NT & NT & NT & NT & NT & NT & NT \\
\hline & Pentachlorophenol & Acceptable & NT & Acceptable & NT & NT & NT & NT & NT & NT \\
\hline & Phenol & Acceptable & NT & NT & NT & NT & NT & NT & NT & NT \\
\hline & 2,4,5-Trichlorophenol & Acceptable & NT & Acceptable & NT & NT & NT & NT & NT & NT \\
\hline & 2,4,6-Trichlorophenol & Acceptable & NT & NT & NT & NT & NT & NT & NT & NT \\
\hline
\end{tabular}

Notes:

Refer to Calendar Year 2001 ASL Quality Assurance Report for detailed data.

Result column provides ERA evaluation of analytical performance, which is based on 95 and $99 \%$ confidence interval about the target value.

NT $=$ Not Tested 


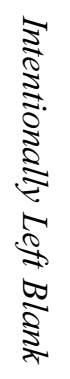




\section{We Would Like to Hear from You.}

The Site Environmental Report is an annual summary of Brookhaven National Laboratory's environmental programs and performance. It presents the steps the Laboratory is taking to protect the environment and the public from the possible effects of operations - both past and present —at the site.

Please use the space below to provide any comments, suggestions, or questions you may have. If you would like to add yourself to our environmental issues mailing list, check the box below and be sure to give us your name, address, and phone number. You can also contact us at (631) 344-3711 or by email at ratel@bnl.gov.

Some questions we are particularly interested in are:

- Does the Site Environmental Report have enough detail, or too little detail, on any specific issue?

- Is the report too technical or not technical enough?

- Do you have a suggestion for any changes that would make the report more readable and useful to you?

Add me to your mailing list for environmental issues.

Name:

Address:

Telephone:

Email Address: 


\section{Helpful Information on Units of Measure and Conversions}

UNITS OF RADIATION MEASUREMENT AND CONVERSIONS

\begin{tabular}{|l|c|c|}
\hline U.S. System & International System & Conversion \\
\hline curie $(\mathrm{Ci})$ & becquerel $(\mathrm{Bq})$ & $1 \mathrm{Ci}=3.7 \times 10^{10} \mathrm{~Bq}$ \\
\hline $\mathrm{rad}$ & gray (Gy) & $1 \mathrm{rad}=0.01 \mathrm{~Gy}$ \\
\hline rem & sievert (Sv) & $1 \mathrm{rem}=0.01 \mathrm{~Sv}$ \\
\hline
\end{tabular}

APPROXIMATE METRIC CONVERSIONS

\begin{tabular}{|c|c|c|c|c|c|}
\hline W hen you know & multiply by & to obtain & W hen you know & multiply by & to obtain \\
\hline centimeters (cm) & 0.39 & inches (in.) & in. & 2.54 & $\mathrm{~cm}$ \\
\hline meters (m) & 3.28 & feet $(\mathrm{ft})$ & $\mathrm{ft}$ & 0.305 & $\mathrm{~m}$ \\
\hline kilometers (km) & 0.62 & miles (mi) & mi & 1.61 & $\mathrm{~km}$ \\
\hline kilograms (kg) & 2.20 & pounds (Ib) & $\mathrm{lb}$ & 0.45 & $\mathrm{~kg}$ \\
\hline liters (L) & 0.264 & gallons (gal) & gal & 3.785 & $\mathrm{~L}$ \\
\hline cubic meters $\left(\mathrm{m}^{3}\right)$ & 35.32 & cubic feet $\left(\mathrm{ft}^{3}\right)$ & $\mathrm{ft}^{3}$ & 0.03 & $\mathrm{~m}^{3}$ \\
\hline hectares (ha) & 2.47 & acres & acres & 0.40 & ha \\
\hline square kilometers $\left(\mathrm{km}^{2}\right)$ & 0.39 & square miles $\left(\mathrm{mi}^{2}\right)$ & $\mathrm{mi}^{2}$ & 2.59 & $\mathrm{~km}^{2}$ \\
\hline degrees $\mathrm{C}$ elcius $\left({ }^{\circ} \mathrm{C}\right)$ & $1.8\left({ }^{\circ} \mathrm{C}\right)+32$ & degrees Fahrenheit ( ${ }^{\circ} \mathrm{F}$ ) & ${ }^{\circ} \mathrm{F}$ & $\left({ }^{\circ} \mathrm{F}-32\right) / 1.8$ & ${ }^{\circ} \mathrm{C}$ \\
\hline
\end{tabular}

SCIENTIFIC NOTATION USED FOR MEASUREMENTS

\begin{tabular}{|l|c|c|c|c|}
\hline Multiple & Decimal Equivalent & Notation & Prefix & Symbol \\
\hline $1 \times 10^{3}$ & 1,000 & $\mathrm{E}+03$ & kilo- & $\mathrm{k}$ \\
\hline $1 \times 10^{-2}$ & 0.01 & $\mathrm{E}-02$ & centi- & $\mathrm{m}$ \\
\hline $1 \times 10^{-3}$ & 0.001 & $\mathrm{E}-03$ & milli- & $\mu$ \\
\hline $1 \times 10^{-6}$ & 0.000001 & $\mathrm{E}-06$ & micro- & $\mathrm{n}$ \\
\hline $1 \times 10^{-9}$ & 0.000000001 & $\mathrm{E}-09$ & nano- & $\mathrm{p}$ \\
\hline $1 \times 10^{-12}$ & 0.000000000001 & $\mathrm{E}-12$ & pico- & \\
\hline
\end{tabular}

CONCEN TRATION CON VERSIONS

$1 \mathrm{ppm}=1,000 \mathrm{ppb}$
$1 \mathrm{ppb}=0.001 \mathrm{ppm}=1 \mu \mathrm{g} / \mathrm{L}^{*}$
$1 \mathrm{ppm}=1 \mathrm{mg} / \mathrm{L}=1000 \mu \mathrm{g} / \mathrm{L}^{*}$

* For aqueous fractions only. 


\section{BROOK TRTEN \\ NATIONAL LABORATORY}

